i

4 





\title{
COMPARATIVE ZOOLOGY
}

\author{
StruCTURAL AND Systematic
}

\section{FOR USE IN SCHOOLS AND COLLEGES}

\author{
By JAMES ORTON, A.M., Ph.D.
}

LATE PROFESSOR OF NATURAL HISTORY IN VASSAR COLLEGE; CORRESPONDING MEMBER OF THE ACADEMY OF NATURAL SCIENCES, PHILADELPHIA, AND OF THE LYCEUM OF NATURAL HISTORY, NEW YORK; AUTHOR OF "THE ANDES AND THE AMAZON," ETC.

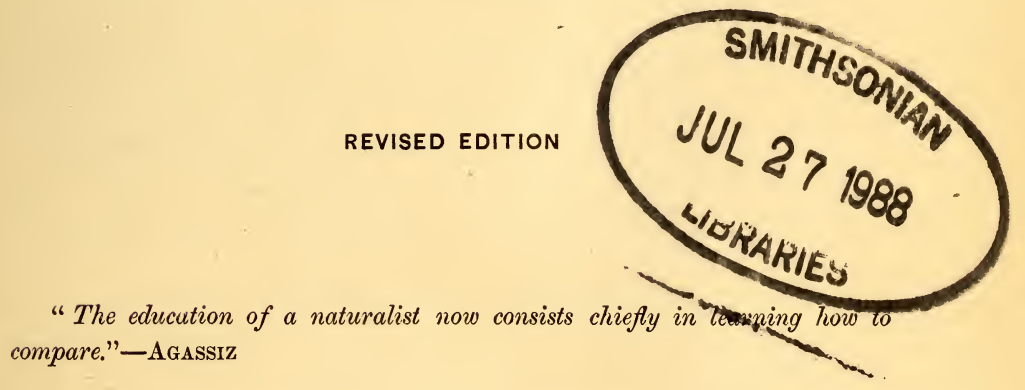

Reptites Amphthiane U. S. Nat1onal Museu

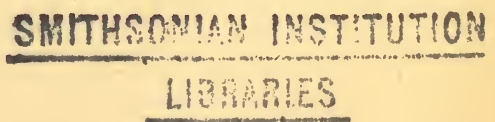

NEW YORK

HARPER \& BROTHERS, FRANKLIN SQUARE 
Entered according to Act of Congress, in the year 1876, by. HARPER \& BROTHERS,

In the Office of the Librarian of Congress, at Washington.

Copyright, 1883, by HARPER \& BRothers. 


\section{PREF A C E.}

THE distinctive character of this work consists in the treatment of the whole Animal Kingdom as a unit; in the comparative study of the development and variations of organs and their functions, from the simplest to the most complex state; in withholding Systematic Zoology until the student has mastered those structural affinities upon which true classification is founded; and in being fitted for High Schools and Mixed Schools by its language and illustrations, yet going far enough to constitute a complete grammar of the science for the undergraduate course of any College.

It is designed solely as a manual for instruction. It is not a work of reference, nor a treatise. So far as a book is encyclopedic, it is unfit for a text-book. This is prepared on the principle of "just enough, and no more." It aims to present clearly, and in a somewhat new form, the established facts and principles of Zoology. All theoretical and debatable points, and every fact or statement, however valuable, which is not absolutely necessary to a clear and adequate conception of the leading principles, are omitted. It is written in the light of the most recent phase of the science, but not in the interest of any particular theory. To have given an exhaustive survey of animal life would have been not only undesirable, but impossible. Even Cuvier's great work must be supple- 
mented by museums, monographs, and microscopes. Natural History has outgrown the limits of a single book. Trial has proved the folly of giving the student so many things to learn that he has no time to understand, and the error of condemning the student to expend his strength upon the details of classification, which may change in the coming decade, instead of upon structure, which is permanent. Of course, specialists will miss many things, and find abundant room for criticism in what they regard as deficiencies; but the work should be judged by what it does contain, rather than by what it does not.

What is claimed, in the language of inventors, is the selection and arrangement of essential principles and typical illustrations from the standpoint of the teacher. The synthetic method is employed, as being the most natural: to begin with complex Man, instead of the simplest forms, would give a false idea. Man is not a model, but a monstrusity, the most modified of Vertebrates. But these outlines must be filled up, on the part of the teacher, by lectures, and by the exhibition of specimens; and, on the part of the student, by observation (noting, above all, the characteristic habits of animals), and by personal work with the knife and microscope. No text-book can take the place of nature, or supersede oral instruction from a competent teacher.

Suggestions and corrections from naturalists and teachers will be thankfully received.

In a work of this character, which is but a compound of the labors of all naturalists, it would be superfluous to make acknowledgments. The works referred to on page 397 have been specially consulted. 


\section{A Friend's Book.}

THis book is his? the gorgeous dreams between These covers his, the friend's I used to know ?

Yet many a morn together have we seen The clouds refold their airy tents and go,

And many a silent evening, from the glen, The mountain blazing with their golden camp. Fool that I was not to have known him then ! I never guessed he owned Aladdin's lamp!

He seemed like other men whom one may meet, But, like the honey-bees, with skill untold, He gathered treasures even at my feet, And in the dark was building roofs of gold!

Samuel V. Cole, in The Critic. 



\section{REVISER'S NOTE.}

IN revising the work of Professor Orton, the writer has not attempted to rewrite the book nor to introduce new ideas. His plan has been to insert such changes as the author would have been likely to make if he had lived to revise his book. On only two points has the reviser departed from this plan of altering only minor details. The chapter on Development has been largely rewritten, and the classification of the Invertebrates has been changed so as to separate the worms from the Arthropoda and the sponges from the Protozoa. In both these cases the change seemed imperatively demanded by the progress of Zoology in those directions. It is hoped that the alterations in the book will increase its accuracy and usefulness.

EDw. A. Birge.

UNIVERSITY OF WISCONSIN. 

How Animals Eat................................ 49

1. The Prehension of Food $\ldots \ldots \ldots \ldots \ldots \ldots \ldots \ldots \ldots \ldots, 49$

2. The Mouths of Animals..................... 55

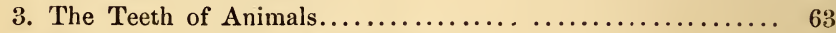

4. Deglutition, or How Animals Swallow.............. 72

CHAPTER IX.

The Alimentary Canal.............................. 74

CHAPTER $\mathrm{x}$.

How Animals Digest............................. 91

CHAPTER XI.

The Absorbent System.......................... 94

CHAPTER XII.

'The Blood of Animals............................. 97

CHAPTER XIII.

The Circulation of the Blood..................... 103

CHAPTER XIV.

How Animals Breathe.............................. 111

CHAPTER XV.

Secretion And Excretion.......................... 121

CHAP'TER XVI.

The Skin and Skeleton........................... 127

\section{CHAPTER XVII.}

How Animals Move............................... 154

1. Muscle.................................. 154

2. Locomotion............................ 157

\section{CHAP'TER XVIII.}

The Nervous System............................. 166

1. The Senses.................................... 176

2. Instinct and Intelligence........................ 184

3. The Voices of Animals......................... 18 \& 
CHAPTER XIX.

Reproduction.

CHAPTER XX.

Development

1. Metamorphosis .............................. 207

2. Alternate Generation ............................ 211

3. Growth and Repair............................ 214

4. Likeness and Variation........................ 215

5. Homology, Analogy, and Correlation............... 217

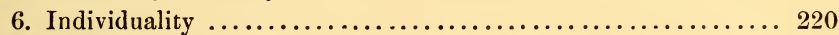

7. Relations of Number, Size, Form, and Rank........... 221

8. The Struggle for Life......................... 226

\section{PART II.-SYSTEMATIC ZOOLOGY.}

\section{CHAPTER XXI.}

The Classification of Animals....................... 231

Protozoa..................................... 238

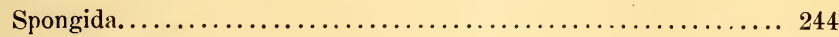

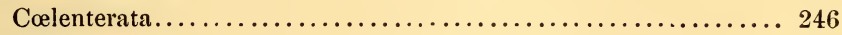

Echinodermata.................................. 257

Vermes....................................... 263

Mollusca..................................... 269

Arthropoda................................... 281

Tunicata........................................... 305

Vertebrata..................................... 306

CHAPTER XXII.

Systematic Arrangement of Representative Forms.......... 362

CHAPTER XXIII.

The Distribution of Animals......................... 371

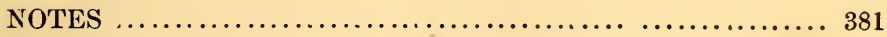

THE NATURALIST'S LIBRARY..................... 397

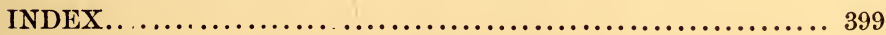





\section{N T R O D U C T I O N.}

1. Definition of Zoology, and its Place among the Sciences.-The province of Natural History is to describe, compare, and classify natural objects. These objects have been divided into the "organic" and the "inorganic," or those which are, and those which are not, the products of life. Biology is the science of the former, and Mineralogy the science of the latter. Biology again separates into Botany, or the Natural History of Plants, and Zoology, or the Natural History of Animals ; while Mineralogy divides into Mineralogy proper, the science of mineral species, and Lithology, the science of mineral aggregates or rocks. Geology is that comprehensive knowledge of the earth's structure and development which rests on the whole doctrine of Natural History.

If we examine a piece of chalk, and determine its physical and chemical characters, its mode of occurrence and its uses, so as to distinguish it from all other forms of matter, we have its Mineralogy. But chalk occurs in vast natural beds : the examination of these masses-their origin, structure, position, and relation to other rocks-is the work of the Lithologist. Further, we observe that while chalk and marble are chemically alike, they widely differ in another respect. Grinding a piece of chalk so thin that we can see through it, and putting it under a microscope, we find imbedded in it innumerable bodies, about the hundredth of an inch in diameter, having a well-defined, symmetrical shape, and chambered like a Nautilus. We cannot say these are accidental aggregations, nor are they crystals : if the oyster-shell is formed by an oyster, these also must be the products of life. Indeed, the dredge brings up similar microscopic skeletons from the bottom of the Atlantic. So we conclude that chalk is but the dried mud of an ancient sea, the cemetery of count- 
less animals that lived and died long ago. The consideration of their fossil remains belongs to Paleontology, or that part of Biology which describes the relics of extinct forms of life. To study the stratigraphical position of the chalkbed, and by the aid of its Paleontology to determine its age and part in the world's history, is the business of Geology.

Of all the sciences, Zoology is the most extensive. Its field is a world of varied forms-hundreds of thousands in number. To determine their origin and development, their structure, habits, distribution, and mutual relations, is the work of the Zoologist. But so many and far-reaching are the aspects under which the animal creation may be contemplated, that the general science is beyond the grasp of any single person. Special departments have, therefore, arisen; and Zoology, in its comprehensive sense, is the combined result of the labors of many workers, each in his own line of research.

Structural Zoology treats of the organization of animals. There are two main branches: Anatomy, which considers the constitution and construction of the animal frame ; and Physiology, which is the study of the apparatus in action. The former is separated into Embryology, or an account of the successive modifications through which an animal passes in its development from the egg to the adult state; and Morphology, which includes all inquiries concerning the form of mature animals, or the form and arrangement of their organs. The microscopical examination of any part, especially the tissues, belongs to Histology. Comparative Zoology is the comparison of the anatomy and physiology of all animals, existing and extinct, to discover the fundamental likeness underneath the superficial differences, and to trace the adaptation of organs to the habits and spheres of life. It is this comparative science which has led to such grand generalizations as the unity of structure amidst the diversity of form in the animal creation, and by revealing the degrees of affinity between species has enabled us to classify them in natural groups, and thus laid the foundation of Systematic Zoology. When the study of structure is limited to a particular class or species of animals, or to a particular organ or part, monographic sciences are created, as Ornithotomy, 
or anatomy of birds; Osteology, or the science of bones; and Odontography, or the natural history of teeth.

Systematic Zoology is the classification or grouping of animals according to their structural and developmental relations. The systematic knowledge of the several classes, as Insects, Reptiles, and Birds, has given rise to subordinate sciences, like Entomology, Herpetology, or Ornithology. ${ }^{1 *}$

Distributive Zoology is the knowledge of the successive appearance of animals in the order of time (Paleontology in part), and of the geographical and physical distribution of animals, living or extinct, over the surface of the earth.

Theoretical Zoology includes those provisional modes of grouping facts, and interpreting them, which still stand waiting at the gate of science. They may be true, but we cannot say that they are true. The evidence is incomplete. Such are the theories which attempt to explain the origin of life and the origin of species.

Suppose we wish to understand all about the Horse. Our first object is to study its structure. The whole body is enclosed within a hide, a skin covered with hair; and if this hide be taken off, we find a great mass of flesh or muscle, the substance which, by its power of contraction, enables the animal to move. On removing this, we have a series of bones, bound together with ligaments, and forming the skeleton. Pursuing our researches, we find within this framework two main cavities : one, beginning in the skull and running through the spine, containing the brain and spinal marrow; the other, commencing with the mouth, contains the gullet, stomach, intestines, and the rest of the apparatus for digestion, and also the heart and lungs. Examinations of this character would give us the Anatomy of the Horse, or, more precisely, Hippotomy. The study of the bones alone would be its Osteology; the knowledge of the nerves would belong to Neurotomy. If we examined, under the microscope, the minute structure of the hair, skin, flesh, blood, and bone, we would learn its Histology. The consideration of the manifold changes undergone in developing from the egg to the full-grown animal, would be the Embry-

* Numbers like this refer to the Notes at the end of the volume. 
ology of the Horse; and its Morphology, the special study of the form of the adult animal and of its internal organs.

Thus far we have been looking, as it were, at a steamengine, with the fires out, and nothing in the boiler ; but the body of the living Horse is a beautifully formed, active machine, and every part has its different work to do in the working of that machine, which is what we call its life. The science of such operations as the grinding of the food in the complex mill of the mouth; its digestion in the laboratory of the stomach; the pumping of the blood through a vast system of pipes over the whole body; its purification in the lungs ; the process of growth, waste, and repair ; and that wondrous telegraph, the brain, receiving impressions, sending messages to the muscles, by which the animal is endowed with voluntary locomotion-this is Physiology. But Horses are not the only living creatures in the world; and if we compare the structures of various animals, as the Horse, Zebra, Dog, Monkey, Eagle, and Codfish, we shall find more or less resemblances and differences, enough to enable us to classify them, and give to each a description which will distinguish it from all others. This is the work of Systematic Zoology. Moreover, the Horses now living are not the only kinds that have ever lived; for the examination of the earth's crust-the great burial-ground of past ages-reveals the bones of numerous horse-like animals : the study of this pre-adamite race belongs to Paleontology. The chronological and geographical distribution of species is the department of Distributive Zoology. Speculations about the origin of the modern Horse, whether by special creation, or by development from some allied form now extinct, are kept aloof from demonstrative science, under the head of Theoretical Zoology.

2. History.-The Greek philosopher Aristotle (в.c. 384322 ) is called the "Father of Zoology." Certainly, he is the only great representative in ancient times, though his frequent allusions to familiar works on anatomy show that something had been done before him. His "History of Animals," in nine books, displays a wonderful knowledge of external and internal structure, habits, instincts, and uses. His descriptions are incomplete, but generally exact, so far 
as they go. Alexander, it is said, gave him nine hundred talents to collect materials, and put at his disposal several thousand men, for hunting specimens and procuring information.

-The Romans accomplished little in natural science, though their military expeditions furnished unrivalled opportunities. Nearly three centuries and a half after Aristotle, Pliny (A.D. 23-79) wrote his "Natural History." He was a voluminous compiler, not an observer : he added hardly one new fact. He states that his work was extracted from over two thousand volumes, most of which are now lost.

During the Middle Ages, Natural History was studied in the books of the ancients; and at the close of the fifteenth century it was found where Pliny had left it, with the addition of many vague hypotheses and silly fancies. Albertus Magnus, of the thirteenth century, and Conrad Gesner and Aldrovandus, of the sixteenth, were voluminous writers, not naturalists. In the latter half of the sixteenth century, men began to observe nature for themselves. The earliest noteworthy researches were made on Fishes, by Rondelet (15071556) and Belon (1517-1564), of France, and Salviani (15141572), of Italy. They were followed by valuable observations upon Insects, by Redi (1626-1698), of Italy, and Swammerdam (1637-1680), of Holland; and towards the end of the same century, the Dutch naturalist, Leeuwenhoeck (1632-1723), opened a new world of life by the use of the microscope.

But there was no real advance of Systematic Zoology till the advent of the illustrious John Ray (1628-1705), of England. His "Synopsis," published in 1693, contained the first attempt to classify animals according to structure. Ray was the forerunner of "the immortal Swede," Linnæus (17071778), "the great framer of precise and definite ideas of natural objects, and terse teacher of the briefest and clearest expressions of their differences." His chief merit was in defining generic groups, and inventing specific names. ${ }^{2}$ Scarcely less important, however, was the impulse which he gave to the pursuit of Natural History. The spirit of inquiry, which his genius infused among the great, produced voyages of research, which led to the formation of national museums. 
The first expedition was sent forth by George III. of England, in 1765. Réaumur (1683-1757) made the earliest zoological collection in France; and the West Indian collections of Sir Hans Sloane (1660-1752) were the nucleus of the British Museum. The accumulation of specimens suggested comparisons, which eventually resulted in the highest advance of the science.

The brilliant style of Buffon (1707-1788) made Zoology popular not only in France, but throughout Europe. While the genius of Linnæus led to classification, that of Buffon lay in description. He was the first to call attention to the subject of Distribution. Lamarck (1745-1829), of Paris, was the next great light. The publication of his "Animaux sans Vertèbres," in 1801, was an epoch in the history of the lower animals. He was also the first prominent advocate of the transmutation of species.

But the brightest luminary in Zoology was George Cuvier (1769-1832), a German, born on French soil. Before his time, "there was no great principle of classification. Facts were accumulated, and more or less systematized, but they were not yet arranged according to law ; the principle was still wanting by which to generalize them and give meaning and vitality to the whole." It was Cuvier who found the key. He was the first so to interpret structure as to be able from the inspection of one bone to reconstruct the entire animal, and assign its position. His anatomical investigations revealed the natural affinities of animals, and led to the grand generalization, that the most comprehensive groups in the kingdom were based, not on special characters, but on different plans of structure. Palissy had long ago (1580) asserted that petrified shells were of animal origin ; but the publication of Cuvier's "Memoir on Fossil Elephants," in 1800 , was the beginning of those profound researches on the remains of ancient life which created Paleontology. The discovery of the true relation between all animals, living and extinct, opened a boundless field of inquiry ; and from that day the advance of Zoology has been unparalleled. Special studies of particular parts or clasises of animals have so rapidly developed, that the history of Zoology during the last fifty years is the history of many sciences. ${ }^{3}$ 


\section{PART I.}

STRUCTURAL ZOOLOGY. 
The first thing to be determined about a new specimen is not its name, but its most prominent character. Until you know an animal, care not for its name.-AGaSSIZ.

The great benefit which a scientific education bestows, whether as training or as knowledge, is dependent upon the extent to which the mind of the student is brought into immediate contact with facts-upon the degree to which he learns the habit of appealing directly to Nature.-HoxuEx. 


\section{COMPARATIVE ZOOLOGY.}

\section{CHAPTER I.}

MINERALS AND ORGANIZED BODIES DISTINGUISHED.

Nature may be separated into two great kingdomsthat of mere dead matter, and that of matter under the influence of life. ${ }^{4}$ These differ in the following points:

(1) Composition.-While most of the chemical elements are found in different living beings, by far the greater part of their substance is composed of three or four-carbon, oxygen, and hydrogen; or these three with the addition of nitrogen. Next to these elements, sulphur and phosphorus are most widely distributed, though always found in very small quantities. The organic compounds belong to the carbon series, and contain three, four, or five elements. The former class, comprising starch, sugar, fat, etc., are relatively stable. The latter, possessing the three elements named, with nitrogen and sulphur or phosphorus, are very complex, containing a very large number of atoms to the molecule, and are usually unstable. Here belong albumen, myosin, chondrin, etc., the constituents of the living tissues. The formula for albumen is said to be $\mathrm{C}_{72} \mathrm{H}_{112} \mathrm{~N}_{18} \mathrm{SO}_{22}$, or some multiple of this formula. These compounds also contain more or less water, and usually exist in a jelly-like condition, neither solid nor fluid. With these colloid substances alone is life associated. Only these can undergo the rapid decomposition 
and recomposition necessary to the manifestation of the vital phenomena.

(2) Structure.-Minerals are homogeneous, while organized bodies are usually heterogeneous; $i$. e., composed of different parts, called tissues and organs, having peculiar uses and definite relations to one another. The tissues and organs, again, are heterogeneous, consisting mainly of microscopic cells, structures developed only by vital action. All the parts of an organism are mutually dependent, and reciprocally means and ends, while each part of a mineral exists for itself. The smallest fragment of marble is as much marble as a mountain-mass; but the fragment of a plant or animal is not an individual.

(3) Size and Shape.-Living bodies gradually acquire determinate dimensions; so do minerals in their perfect or crystal condition. But uncrystallized, inorganic bodies have an indefinite bulk. Most minerals are amorphous; crystals have regular forms, bounded, as a rule, by plane surfaces and straight lines; plants and animals are circumscribed by curved surfaces, and rarely assume accurate geometrical forms.

(4) Phenomena.-Minerals remain internally at rest, and increase by external additions, if they grow at all. Living beings are constantly changing the matter of which they are composed, and grow by taking new matter into themselves and placing it among the particles already present. Organized bodies, moreover, pass through a cycle of changes-growth, development, reproduction, and death. These phenomena are characteristic of living as opposed to inorganic bodies. All living bodies grow from within, constantly give up old matter and replace it by new, reproduce their kind, and die; and no inorganic body shows any of these phenomena. 


\section{CHAPTER II.}

PLANTS AND ANIMALS DISTINGUISHED.

It may seem an easy matter to draw a line between plants and animals. Who cannot tell a Cow from a Cabbage? Who would confound a Coral with a Mushroom? Yet it is impossible to assign any absolute, distinctive character which will divide the one mode of life from the other. The difficulty of defining an animal increases with our knowledge of its nature. Linnæus defined it in three words; a century later, Owen declared that a definition of plants which would exclude all animals, or of animals which would not let in a single plant, was impossible. Each different character used in drawing the boundary will bisect the debatable ground in a different latitude of the organic world. Between the higher animals and higher plants the difference is apparent; but when we reflect how many characters the two have in common, . and especially when we descend to the lower and minuter forms, we discover that the two "kingdoms" touch, and even dissolve into, each other. This border-land has been as hotly contested ainong naturalists as many a disputed frontier between adjacent nations. Its inhabitants have been taken and retaken several times by botanists and zoologists; for they have characters that lead on the one side to plants, and on the other to animals. To solve the difficulty, some eminent naturalists, as Häckel and Owen, propose a fourth "kingdom," to receive those living beings which are organic, but not distinctly vegetable or animal. But a greater difficulty arises in attempting to fix its precise limits. 
The drift of modern research points to this: that there are but two kingdoms of nature, the mineral and the organized, and these closely linked together; that the latter must be taken as one whole, from which two great branches rise and diverge. "There is at bottom but one life, which is the whole life of some creatures, and the common basis of the life of all; a life of simplest moving and feeling, of feeding and breathing, of producing its kind and lasting its day: a life which, so far as we at present know, has no need of such parts as we call organs. Upon this general foundation are built up the manifold special characters of animal and vegetable existence; but the tendency, the endeavor, so to speak, of the plant is one, of the animal is another, and the unlikeness between them widens the higher the building is carried up. As we pass along the series of either [branch] from low to high, the plant becomes more vegetative, the animal more animal." ${ }^{6}$

Defining animals and plants by their prominent characteristics, we may say that a living being which has cellwalls of cellulose, and by deoxidation and synthesis of its simple food-stuffs produces the complicated organic substances, is a plant; while a living being which has albuminous tissues, and by oxidation and analysis reduces its complicated food-stuffs to a simpler form, is an animal. But both definitions are defective, including too many forms, and excluding forms that properly belong to the respective kingdoms. No definition is possible which shall include all animals and exclude all plants, or vice versâ.

(1) Origin.-Both branches of the tree of life start alike: the lowest of plants and animals, as Protococcus and Gregarina, consist of a single cell. In fact, the cycle of life in all living beings, high or low, begins in a small, round particle of matter-in plants called an ovule, in animals 
an ovum. This cell contains a semi-fluid, called protoplasm, similar in composition and in function. In the very simplest forms the protoplasm is not enclosed by a membrane, but generally there is a cell-wall. In plants, with few exceptions, this wall is of cellulose, a substance akin to starch; in animals, with few exceptions, the wall is a pellicle of firmer protoplasm, $i$. e., albuminous.

(2) Composition.-Modern research has broken down the partition between plants and animals, so far as chemical nature is concerned. The vegetable fabric and secretions may be ternary or binary compounds; but the essential living parts of plants, as of animals, are quaternary, consisting of four elements-carbon, hydrogen, oxygen, and nitrogen. Cellulose (woody fibre), starch, and chlorophyl (green coloring matter) are eminently vegetable products, but not distinctive; for cellulose is wanting in some plants, as some Fungi, and present in some animals, as Tunicates; starch, under the name of glycogen, is found in the liver and brains of Mammals, and chlorophyl gives color to the fresh - water Polyp. Still, it holds good, generally, that plants consist mainly of cellulose, dextrine, and starch; while animals are mainly made up of albumen, fibrine, and gelatine; that nitrogen is more abundant in animal tissues, while in plants carbon is predominant.

(3) Form.-No outline can be drawn which shall be common to all animals or all plants. The lowest members of both have no fixed shape. The spores of Confervæ can hardly be distinguished from animalcules; the compound and tixed animals, Sea-mat and Sea-moss (Polyzoa), and Corals, often resemble vegetable forms, although in structure widely removed from plants. Similar conditions of life are here accompanied by an external likeness. In free-living animals this resemblance is not found.

(4) Structure.-A plant is the multiplication of the unit - a cell with a cellulose wall. Some simple animals have 
a similar simple cellular structure; and all animal tissues, while forming, are cellular. But this character, which is permanent in plants, is generally transitory in animals. In the more highly organized tissues the cells are so united as partly or wholly to lose their individuality, and the characteristic part of the tissue is the intercellular substance, while the cells themselves are small and unimportant, or else the cells are melted together and lose their dividing walls, as in striped muscles and in nerves. Excepting the lowest forms, animals are more composite than plants, i.e., their organs are more complex and numerous, and more specially devoted to particular purposes. Repetition of similar parts is a characteristic of plants ; and when found in animals, as the Angle-worm, is called vegetative repetition. Differentiation and specialization are characteristic of animals. Most animals, moreover, have fore-and-aft polarity; in contrast, plants are up-and-down structures, though in this respect they are imitated by radiated animals, like the Star-fish. Plants are continually receiving additional members; most animals soon become perfect.

(5) Physiology.-In their modes of nutrition, plants and animals stand widest apart. A plant in the seed and an animal in the egg exist in similar conditions: in both cases a mass of organic matter accompanies the germ. When this supply of food is exhausted, both seek nourishment from without. But here analogy ends: the plant feeds on mineral matter, the animal on organic. Plants have the power to form chlorophyl, the green coloring matter of leaves, which uses the force of the sunlight to form starch out of the inorganic substances-carbon-dioxide and water. They are able also to form albuminoid matter out of inorganic substances. A very few animals which have a substance identical with or allied to chlorophyl have the same power, "but in general animals are de- 
pendent for their food on the compounds put together in plants. Colorless plants, possessing no chlorophyl, feed, like animals, on organic compounds. No living being is able to combine the simple elements-carbon, oxygen, hydrogen, and nitrogen-into organic compounds.

The food of plants is gaseous (carbon dioxide and ammonia) or liquid (water), that of animals usually more or less solid. The plant, then, absorbs these foods through its outer surface, while the animal takes its nourishment in larger or smaller masses, and digests it in a special cavity. A few exceptions, however, occur on both sides. Certain moulds seem to swallow their food, and certain animals, as the tape-worm, have no digestive tract.

Plants are ordinarily fixed, their food is brought to them, and a large share of their work, the formation of organic compounds, is done by the force of the sunlight; while animals are usually locomotive, must seek their food, and are unable to utilize the general forces of nature as the plant does. The plant is thus able to grow much more than the animal, as very little of the nourishment received is used to repair waste, while in most animals the time soon comes when waste and repair are approximately equal. But in both all work done is paid for by waste of substance already formed.

In combining carbon dioxide and water to form starch the plant sets oxygen free $\left(6\left(\mathrm{CO}_{2}\right)+5\left(\mathrm{H}_{2} \mathrm{O}\right)=\mathrm{C}_{6} \mathrm{H}_{10} \mathrm{O}_{5}+\right.$ $\left.6\left(\mathrm{O}_{2}\right)\right)$ : in oxidizing starch or other food the animal uses oxygen and sets carbon dioxide free. The green plant in the sunlight, then, gives off oxygen and uses carbon dioxide, while plants which have no chlorophyl, at all times, and all plants in the darkness, use oxygen and give off carbon dioxide, like an animal. Every plant begins life like an animal-a consumer, not a producer: not till the young shoot rises above the soil, and unfolds itself to the light of the sun, at the touch of whose mystic rays chlo- 
rophyl is created, does real, constructive vegetation begin; then its mode of life is reversed-carbon is retained and oxygen set free.

Most plants, and many animals, multiply by budding and division; on both we practise grafting; in both the cycle of life comes round again to the ovule or ovum. Do annuals flower but to die? Insects lay their eggs in their old age.

Both animals and plants have sensibility. This is one of the fundamental physiological properties of protoplasm. But in plants the protoplasm is scattered and buried in rigid structures: feeling is, therefore, dull. In animals, the protoplasm is concentrated into special organs, and so feeling, like electricity rammed into Leyden jars, goes off with a flash. ${ }^{\circ}$ Plants never possess consciousness or volition, as the higher animals do.

The self-motion of animals and the rooted state of plants is a very general distinction; but it fails where we need it most. It is a characteristic of living things to move. The protoplasm of all organisms is unceasingly active. ${ }^{9}$ Besides this internal movement, myriads of plants, as well as animals, are locomotive. Rambling Diatoms, writhing Oscillaria, and the agile spores of Cryptogams crowd our waters, their instruments of motion (cilia) being of the very same character as in microscopic animals; while Sponges, Corals, Oysters, and Barnacles are stationary. A contractile vesicle is not exclusively an animal property, for the fresh-water Volvox and Gonium have it. The act of muscular contraction in the highest animal is due to the same kind of change in the form of the cells of the ultimate fibrillæ as that which produces the sensible motions of plants. The ciliary movements of animals and of microscopic plants are precisely similar, and in neither case indicate consciousness or self-determining power. 
Plants, as well as animals, need a season of repose. Both have their epidemics. On both, narcotic and acrid poisons produce analogous results. Are some animals warm-blooded? In germination and flowering, plants evolve heat-the stamens of the Arum, e.g., showing a rise of $20^{\circ}$. In a sense, an Oak has just as much heat as an Elephant, only the miserly tree locks up the sunlight in solid carbon.

At present, any boundary of the Animal Kingdom is arbitrary. "Probably life is essentially the same in the two kingdoms; and to vegetable life, faculties are superadded in the lower animals, some of which are, here and there, not indistinctly foreshadowed in plants." "It must be said that there are organisms which at one period of their life exhibit an aggregate of phenomena such as to justify us in speaking of them as animals, while at another they appear to be as distinctly vegetable. ${ }^{10}$

\section{CHAPTER III.}

RELATION BETWEEN MINERALS, PLANTS, AND ANIMALS.

There are no independent members of creation: all things touch upon one another. The matter of the living world is identical with that of the inorganic. The plant, feeding on the minerals, carbon dioxide, water, and ammonia, builds them up into complex organic compounds, as starch, sugar, gum, cellulose, albumen, fibrine, caseine, and gluten. When the plant is eaten by the animal, these substances are used for building up tissnes, repairing waste, laid up in reserve as glycogen and fat, or oxidized in the blood to produce heat. The albuminoids are essential for the formation of tissues, like muscle, nerve, 
cartilage; but the ternary compounds help in repairing waste, while both produce heat. When oxidized, whether for work or warinth, these complex compounds break up into the simple compounds - water, carbon dioxide, and (ultimately) ammonia, and as such are returned to earth and air from the animal. Both plant and animal end their life by going back to the mineral world: and thus the circle is complete-from dust to dust. Carbonate of ammonia and water, a blade of grass and a horse, are but the same elements differently combined and arranged. Plants compress the forces of inorganic nature into chemical compounds; animals liberate them. Plants produce; animals consume. The work of plants is synthesis, a building-up; the work of animals is analysis, or destruction. The tendency in plants is deoxidation; the tendency in animals is oxidation. Withont plants, animals would perish; without animals, plants had no need to be. There is no plant which may not serve as food to some animal.

\section{CHAPTER IV.}

LIFE.

All forces are known by the phenomena which they cause. So long as the animal and plant were supposed to exist in opposition to ordinary physical forces or independently of them, a vital force or principle was postulated by which the work of the body was performed. It is now known that most, if not all, of the phenomena manifested by a living body are due to one or more of the ordinary physical forces - heat, chemical affinity, electricity, etc. There is no work done which demands a vital force.

The common modern view is that vitality is simply a 
collective name for the sum of the phenomena displayed by living beings. It is neither a force nor a thing at all, but is an abstraction, like goodness or sweetness; or, to use Huxley's expression, to speak of vitality is as if one should speak of the horologity of a clock, meaning its time-keeping properties.

A third theory is still possible. The combination of elements into organic cells, the arrangement of these cells into tissues, the grouping of these tissues into organs, and the marshalling of these organs into plans of structure, call for some further shaping, controlling power to effect such wonderful co-ordination. Moreover, the manifestation of feeling and consciousness is a mystery which no physical hypothesis has cleared up. The simplest vital phenomenon has in it something over and above the known forces of the laboratory. ${ }^{11}$ If the vital machine is given, it works by physical forces; but to produce it and keep it in order needs, so far as we now know, more than mere physical force. To this controlling power we may apply the name vitality.

Life is exhibited only under certain conditions. One condition is the presence of a physical basis called protoplasm. This substance is found in all living bodies, and, so far as we know, is similar in all - a viscid, transparent, homogeneous, or minutely granular, albuminoid matter. Life is inseparable from this protoplasm; but it is dormant unless excited by some external stimulants, such as heat, light, electricity, food, water, and oxygen. Thus, a certain temperature is essential to growth and motion; taste is induced by chemical action, and sight by luminous vibrations.

The essential manifestations of animal life may be reduced to three: contractility; sensibility, or the peculiar power of receiving and transmitting impressions; and the power of assimilating food. All these powers are pos- 
sessed by protoplasm, and so by all animals: all move, feel, and grow. But some of the lowest forms are without the slightest trace of organs; they seem to be as perfectly homogeneous and structureless as a drop of jelly. They could not be more simple. They are devoid of muscles, nerves, and stomach; yet they have all the fundamental attributes of life-moving, feeling, and eating. It has been supposed that the muscular and nervous matter is diffused in a molecular form; but all we can say is, that the highest power of the microscope reveals no organized structure whatever-i.e., there are no parts set apart for a particular purpose, but a fraginent is as good as the whole to perform all the functions of life. The animal series, therefore, begins with forms that feel without nerves, move without muscles, and digest without a stomach: in other words, life is the cause of organization, not the result of $i t$. Animals do not live because they are organized, but are organized because they are alive.

\section{CHAPTER V. \\ O R G A N I Z A T I O N.}

$\mathrm{W}_{\mathrm{E}}$ have seen that the simplest life is a formless speck of protoplasm, without distinctions of structure, and therefore without distinctions of function, all parts serving all purposes - mouth, stomach, limb, and lung - indiscriminately. There is no separate digestive cavity, no separate respiratory, muscular, or nervous systems. Every part will successively feed, feel, move, and breathe. Just as in the earliest state of society all do everything, each does all. Every man is his own tailor, architect, and lawyer. But in the progress of social development the principle of 
the division of labor emerges. First comes a distinction between the governing and governed classes; then follow and multiply the various civil, military, ecclesiastical, and industrial occupations.

In like manner, as we advance in the animal series, we find the body more and more heterogeneous and complex by a process of differentiation, i.e., setting apart certain portions of the body for special duty. In the lowest forms, the work of life is carried on by very simple apparatus. ${ }^{12}$ But in the higher organisms every function is performed by a special organ. For example, contractility, at first the property of the entire animal, becomes centred in muscular tissue; respiration, which in simple beings is effected by the whole surface, is specialized in lungs or gills; sensibility, from being common to the whole organism, is handed over to the nerves. An animal, then, whose body, instead of being uniform throughout, is made up of different parts for the performance of particular functions, is said to be organized. And the term is as applicable to the slightly differentiated cell as to complex Man. Organization is expressed by single cells, or by their combination into tissues and organs.

1. Cells.-A cell is the simplest form of organized life. In general, it is a microscopic globule, consisting of a delicate membrane enclosing a minute portion of protoplasm. The very simplest kinds are without granules or signs of circulation; but usually the protoplasm is granular, and contains a defined separate mass called the nucleus, within which are sometimes seen one or two, rarely more, dark, round specks, named nucleoli. The enveloping membrane is

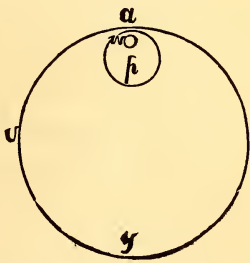

Fra. 1.-Parts of a Cell: $\alpha, v, y$, cell-wall ; $p$, nucleus; $w$, nncleolus. extremely thin and transparent, and structureless: it is only an excretion of dead matter acting as a boundary to 
the cell-contents. ${ }^{13}$ The nucleus is generally attached to the inside of the membrane, and is the centre of activity.

Cells vary greatly in size, but are generally invisible to the naked eye, ranging from $\frac{1}{500}$ to $\frac{1}{10000}$ of an inch in diameter. About 4000 of the smallest would be necessary to cover the dot of this letter $i$. The natural form of isolated cells is spherical; but when they crowd each other, as seen in bone, cartilage, and muscle, their outlines become angular, either hexagonal or irregular.

Within the narrow boundary of a simple sphere, the cell-membrane, are exhibited all the essential phenomena of life-growth, development, and reproduction. The physiology of these minute organisms is of peculiar interest, since all animal structure is but the multiplication of the cell as a unit, and the whole life of an animal is that of the cells which compose it: in them and by them all its vital processes are carried on. ${ }^{14}$

The structure of a cell can be seen in blood-corpuscles, by diluting with a weak ( $\frac{1}{2}$ per cent.) solution of salt a drop of blood from a Frog, and placing it under the microscope. (See Fig. 63.)

2. Tissues.-There are organisms of the lowest grade (as Gregarina) which consist of a single cell, living for and by itself. In this case, the animal and cell are identical: the Gregarina has as much individuality as the Elephant. But all animals, save these unicellular beings, are mainly aggregations of cells: for the various parts of a body are not only separable by the knife into bones, muscles, nerves, etc., but these are susceptible of a finer analysis by the microscope, which shows that they arise from the development and union of cells. These cellular fabrics, called tissues, differ from one another both chemically and structurally, but agree in being permeable to liquids ---a property which secures the flexibility of the organs so essential to animal life. Every part of the human body, for exam- 
ple, is moist: even the hairs, nails, and cuticle contain water. The contents as well as the shape of the cells are usually modified according to the tissue which they form: thus, we find cells containing earthy matter, iron, fat, mucus, etc.

In plants, the cell always retains the characters of the cell; but in animals (after the embryonic period) the cell usually undergoes such modifications that the cellular form disappears. The cells are connected together or enveloped by an intercellular substance (blastema), which may be watery, soft, and gelatinous, firmer and tenacious, still more solid and hyaline, or hard and opaque. In the fluids of the body, as the blood, the cells are separate; i.e., the blastema is fluid. But in the solid tissues the cells coalesce, being simply connected, as in the epidermis, or united into fibres and tubes.

In the lowest forms of life, and in all the higher animals in their embryonic state, the cells of which they are composed are not transformed into differentiated tissues: definite tissues make their first appearance in the Sponges, and they differ from one another more and more widely as we ascend the scale of being. In other words, the bodies of the lower and the immature animals are more uniform in composition than the higher or adult forms. In the Vertebrates only are all the following tissues found represented:

(1) Epithelial Tissue.-This is the simplest form of cellular structure. It covers all the free surfaces of the body, internal and external, so that an animal may be said to be contained between the walls of a double bag. That which is internal, lining the mouth, windpipe, lungs, blood-vessels, gullet, stomach, intestines-in fact, every cavity and canal - is called epithelium. It is a very delicate skin, formed of flat or cylindrical cells, and in some parts (as in the wind-pipe of air-breathing animals, and along the gills 
of the Oyster) is covered with cilia, or minute hairs, about $\frac{1}{6000}$ of an inch long, which are incessantly moving. Con-

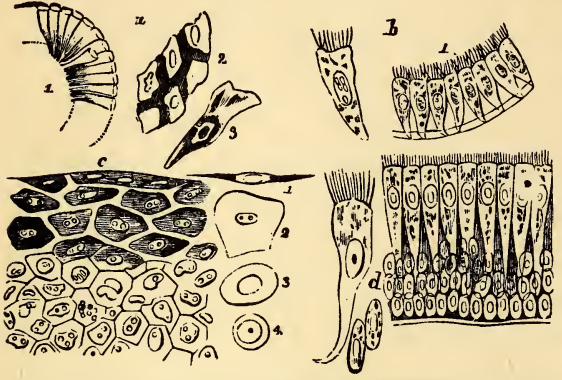

Fra. 2.-Various kinds of Epithelium Cells : $a$, columnar, from small intestine; 3 , a single cell, showing nucleus; $b$, ciliated, from one of the small airtubes; $d$, the same, from the windpipe, with single cell magnified about 200 times; $c$, squamons, from eyelid of a calf, showing changes of form, from the deep to superticial cells, 1 being the scurf. tinuous with this inner lining of the body (as seen on the lip), and covering the outside, is the epidermis, or cuticle. It is the outer layer of the "skin," which we can remove by a blister, and in Man varies in thickness from $\frac{1}{80} \overline{0}$ of an inch on the cheek to $\frac{1}{10}$ on the sole of the foot. It is constantly wearing off at the surface, and as constantly growing in the deeper portion; and in the process of growth and passage outward, the cells change from the spherical form to dead horny scales (seen in scurf and dandruff). In the lower layer of the cuticle we find the pigment cells, characteristic of colored races. Neither the epidermis nor the corresponding tissue within (epithelium) has any blood-vessels or nerves. The epithelial tissue, then, is simply a superficial covering, bloodless and insensible, protecting the more delicate parts underneath. Hairs, horns, hoofs, nails, claws, corns, beaks, scales, tortoise-shell, the wings of Insects, etc., are modifications of the epidermis.

The next three sorts of tissue are characterized by a great development of the intercellular substance, while the cells themselves are very slightly modified.

(2) Connective Tissue.-This is the most extensive tissue in animals, as it is the great connecting medium by which the different parts are held together. Could it be taken 
out entire, it would be a complete mould of all the organs. It surrounds the bones, muscles, blood-vessels, nerves, and glands, and is the substance of the ligaments, tendons, "true skin," mucous membrane, etc. It varies in character, being soft, tender, and elastic, or dense, tough, and generally unyielding. In the former state, it consists of innumerable fine white and yellow fibres, which interlace in all directions, leaving irregular spaces, and form-

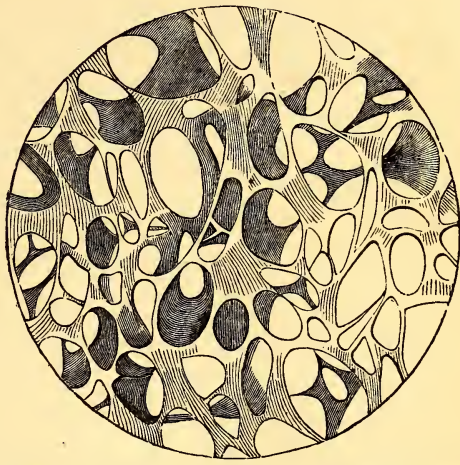

Frg. 3.-Connective Tissue, showing areolar structure, $\times 25$. ing a loose, spongy, moist web. In the latter, the fibres

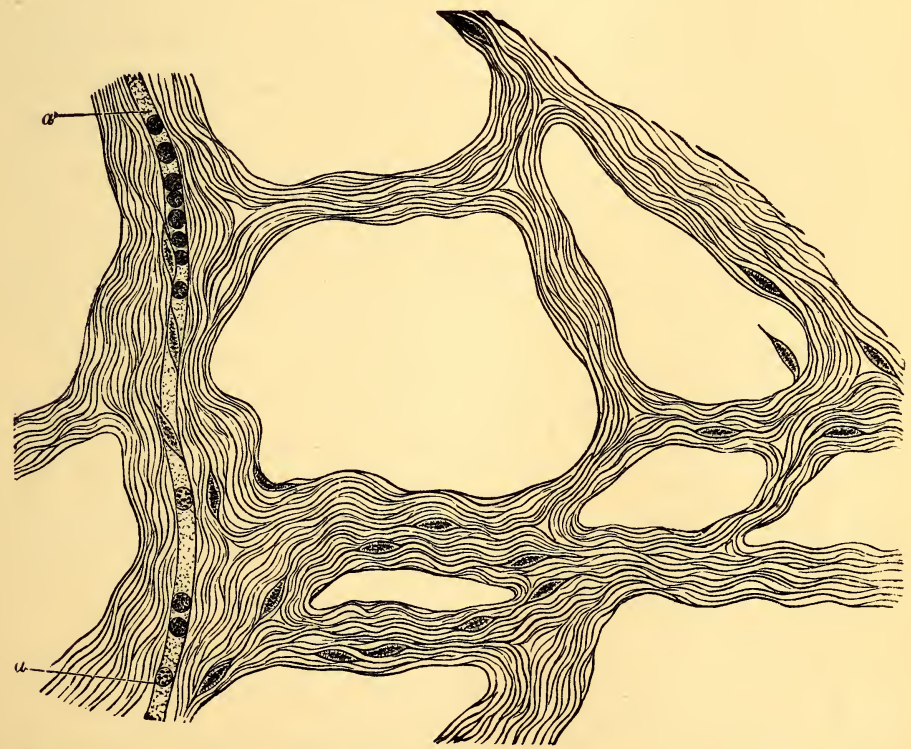

Fig. 4.-Connective Tissue from human peritoneum; highly magnified; $a$, bloodvessel. 
are condensed into sheets or parallel cords, having a wavy, glistening appearance. Such structures are the fasciæ and tendons. Connective tissue is not very sensitive. It contains gelatine - the matter which tans when hide is made into leather. In this tissue the intercellular substances take the form of fibres. The white fibres are inelastic, and from $\frac{1}{40000}$ to $\frac{1}{24000}$ of an inch in diameter. They are best seen in the tendons. The yellow fibres are

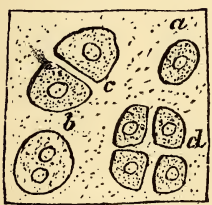

Fra. 5.-Hyaline Cartilage, Diagram : $\alpha$, cartilage cell; $b$, cell about to divide ; $c$, cell divided into two; $d$, into four parts. The space between the cells is filled with transparent intercellular substance; highly magnified.

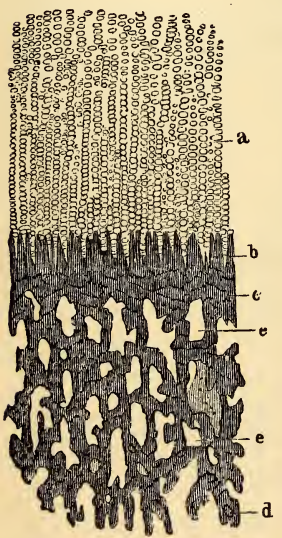

Fra. 6. - Ossifying Cartilage, $\times 10 ; a$, cartilage cells, passing into compact bone, $c$, and then spongy boue, $e$. elastic, curled at the ends, very. long, and from $\frac{1}{21000}$ to $\frac{1}{4000}$ of an inch in diameter. They are shown in the hinge-ligament of an Oyster. Connective tissue appears areolar, $i . e$., shows interspaces, only under the microscope.

(3) Cartilaginous Tissue.-This tissue, known also as "gristle," is composed of cells imbedded in a granular or hyaline substance, which is dense, elastic, bluish white, and translucent. It is found where strength, elasticity, and insensibility are wanted, as at the joints. It also takes the place of the long bones in the embryo. When cartilage is mixed with connective tissue, as in the ear, it is called fibro-cartilage.

(4) Osseous Tissue.-This hard, opaque tissue, called "bone," differs from the former two in having the intercellular spaces or meshes filled with phosphate of lime and other earths, instead of a hyaline or fibrous substance. It may be called petrified tissue-the quantity of earthy matter, and therefore the brittleness of the bone, increasing with the 
age of the animal. If a chicken-bone be left in dilute muriatic acid several days, it may be tied into a knot, since the acid has dissolved the lime, leaving nothing but cartilage and connective tissue. If a bone be burned, it becomes light, porous, and brittle, the lime alone remaining. ${ }^{15}$

Bone is a very vascular tissue; that is, it is traversed by minute blood-vessels and nerves, which pass through a Femur), $\times 50$, showing Haversian canals. net-work of tubes, called Haversian canals. The canals average $\frac{1}{1000}$ of an inch, being finest near the surface of the bone, and larger further in, where they form a cancellated or spongy structure, and finally merge (in the long

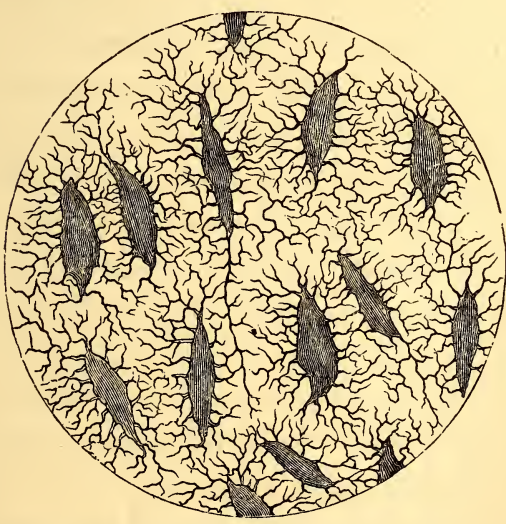
Fig. 8.-Frontal Bone of Human Skull under the pores, or canaliculi. microscope, showing lacuni and canaliculi. These represent the original cells of the bone, and differ in shape and size in different animals. cavity, containing the marrow, Under the microscope, each canal appears to be the centre of a multitude of lamince, or plates, arranged around it. Lying between these plates are little cavities, called lacunce, from which radiate exceedingly fine

bones) into the central

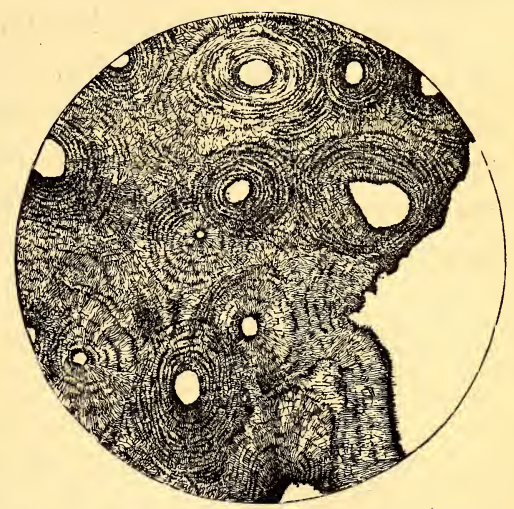


True bone is found only in Vertebrates, or back-boned animals.

(5) Dental Tissue.-Like bone, a tooth is a combination of earthy and animal matter. It may be called petrified skin. In the higher animals, it consists of three parts: dentine, forming the body of the tooth, and always present; enamel, capping the crown; and cement, covering the fangs (Fig. 31). The last is true bone, or osseous tissue.

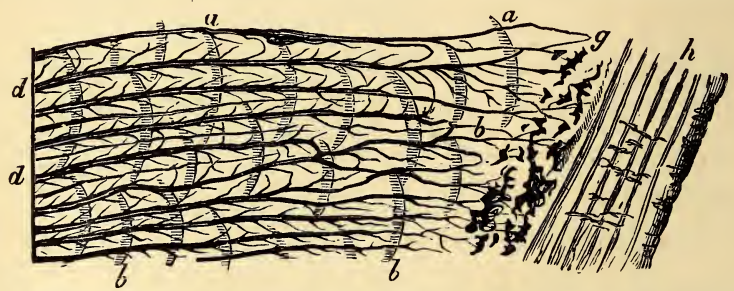

Fig. 9.-Highly magnified section of Dentine and Cement, from the fang of a Human Molar: $a, b$, marks of the original dentinal pulp; $d$, dentinal tubes, terminating in the very sensitive, modified layer, $g ; h$, cement.

Dentine resembles bone, but differs in having neither lacunæ nor (save in Shark's teeth) canaliculi. It shows, in place of the former, innumerable parallel tubes, reaching from the outside to the pulp-cavity within. The "ivory" of Elephants consists of dentine. Enamel is the hardest substance in the body, and is composed of minute six-sided

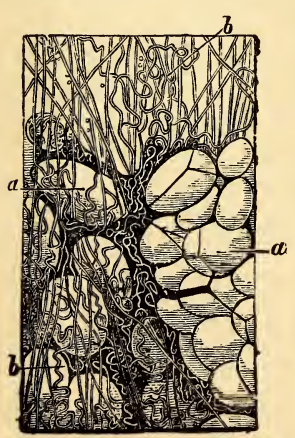

Frg. 10.-Adipose 'lissue, $a$; with fibres of connective tissue, $b$. fibres, set closely together. It is wanting in the teeth of most Fishes, Snakes, Sloths, Armadillos, Sperm-whales, etc. True dental tissue is confined to Vertebrates.

(6) Adipose Tissue.-Certain cells become greatly enlarged and filled with fat, so that the original protoplasm occupies a very sinall part of the space within the cell-membrane. These cells are united into masses by connective tissue, in the skin (as in the "blub- 
ber" of whales), between the muscles (as in "streaky" meat), or in the abdominal cavity, in the omentum, mesentery, or about the kidneys. The marrow of bones is an example. Globules of fat occur in many Molluscs and Insects; but true adipose tissue is found only in backboned animals, particularly the herbivorous. In the average Man, it constitutes about $\frac{1}{20}$ part of his weight, and a single Whale has yielded 120 tons of oil. The fat of animals has the different names of oil, lard, tallow, suet, spermaceti, etc. It is a reserve of nutriment in excess of consumption, serving also as a packing material, and as a protection against cold.

(7) Muscular Tissue.-If we examine a piece of lean meat, we find it is made up of a number of fasciculi, or bundles of fibres, placed side by side, and bound together by connective tissue. The microscope informs us that each fibre is itself a bundle of smaller fibres; and when one of these is more closely examined, it is found to be enclosed in a delicate, glossy tube, called the sarcolemma. This tube is filled with very minute, parallel fibrils, averaging $\frac{1}{10000}$

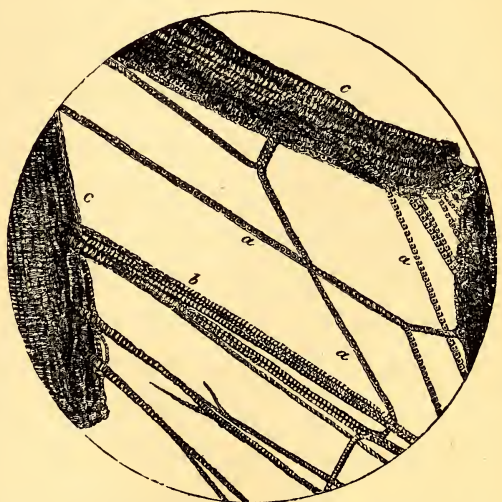

Fig. 11.-Striated Muscular Fibre (of the Pig), $\times 200$. The constituent fibres are seen at $a$; $c$ is a fasciculus, or bundle. of an inch in diameter, and having a striated aspect. Tissue of this description constitutes all ordinary muscle, or "lean meat," and is marked by regular cross-lines, or strice.

Besides this striated muscular tissue, there exist, in the coats of the stomach, intestines, blood-vessels, and some other parts of Vertebrates, smooth muscular fibres, or mem- 
branes, which show a nucleus under the microscope, and do not break up into fibrils (Fig. 122). The gizzards of

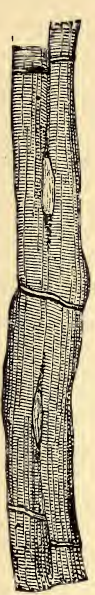

Fig. 12. - Striated

Muscular Fibres, from the heart of Man, divided by transverse septa into separate nucleated portions. fowls exhibit this form.

All muscle has the property of shortening itself when excited; but the contraction of the striated kind is under the control of the will, while the movement of the smooth fibres is involuntary. ${ }^{16}$ Muscles are well supplied with arteries, veins, and nerves; but the color is due to a peculiar pigment, not to the blood.

Muscular tissue is found in all animals from the Coral to Man.

(8) Nervous Tissue.-Nervous matter exists under three forms: First-the cellular, consisting of nucleated cells, varying from $\frac{1}{6000}$ to $\frac{1}{200}$ of an inch in diameter, and found in the nerve-centres (Fig. 132), the gray portion of the brain, spinal cord, and other ganglia. Second-the fibrous, consisting of pale, flat, extremely fine filaments. They abound in the sympathetic nerves, and are the only nerves found in the Invertebrates. Third-the tubular. These are much larger than the fibrous, the coarsest being $\frac{1}{120 \sigma}$ of an inch in diameter. They consist of tubes enclosing a transparent fibre and a fatty substance called the nerve-marrow. ${ }^{17}$ The delicate tube itself is called neurilem$m a$, analogous to the sarcolemma of muscular tissue. Nerve-tubes are found only in back-boned animals, in the white substance of the brain, spinal cord, and in the nerves.

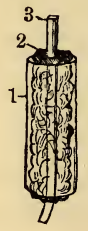

Frg. 13.-Structure of a Nerve: 1 , sheath, or neurilemma: 2, medullary substance of Schwann ; 3, axis cylinder, or primitive band.

A bundle of fibrous or tubular nervous matter, surrounded by connective tissue, constitutes a nerve. 


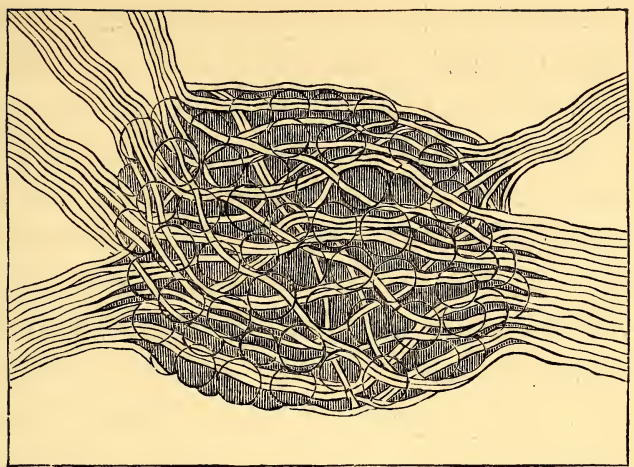

Fig. 14.-A Ganglion of the Sympathetic Nerve of a Mouse.

3. Organs, and their Functions.-Animals, like Plants, grow, feel, and move; these three are the capital facts of every organism. Besides these there may be some peculiar phenomena, as motion and will.

Life is manifested in certain special operations, called functions, performed by certain special parts, called organs. Thus, the stomach is an organ, whose function is digestion. A single organ may manifest vitality, but it does not (save in the very lowest forms) show forth the whole life of the animal. For, in being set apart for a special purpose, an organ takes upon itself, so to speak, to do something for the benefit of the whole animal, in return for which it is absolved from doing many things. The stomach is not called upon to circulate or purify the blood.

There may be functions without special organs, as the Amœba digests, respires, moves, and reproduces by its general mass. But, as we ascend the scale of animal life, we pass from the simple to the complex: groups of cells or tissues, instead of being repetitions of each other, take on a difference, and become distinguished as special parts with specific duties. The higher the rank of the animal, the more complicated the organs. The more complicated the structure, the more complicated the functions. But in 
all animals, the functions are performed under conditions essentially the same. Thus, respiration in the Sponge, the Fish, and in Man has one object and one means, though the methods differ. A function, therefore, is a group of similar phenomena effected by analogous structures.

The life of an animal consists in the accumulation and expenditure of force. The tissues are storehouses of power, which, as they waste, is given off in various forms. Thus, the nervous tissue generates nerve-force; the muscles, motion. If we contemplate the phenomena presented by a Dog, the most obvious fact is his power of moving from place to place, a power produced by the interplay of muscles and bones. We observe, also, that his motions are neither mechanical nor irregular; there is method in his movement. He has the power of willing, seeing, hearing, feeling, etc.; and these functions are accomplished by a delicate apparatus of nerves.

But the Dog does not exhibit perpetual motion. Sooner or later he becomes exhausted, and rest is necessary. Sleep gives only temporary relief. In every exercise of the muscles and nerves there is a consumption or waste of their substance. The blood restores the organs, but in time the blood itself needs renewal. If not renewed, the animal becomes emaciated, for the whole body is laid under contribution to furnish a supply. Hence the feelings of hunger and thirst, impelling the creature to seek food. Only this will maintain the balance between waste and repair. We notice, therefore, an entirely different set of functions, involving, however, the use of motion and will. The Dog seizes a piece of meat, grinds it between its teeth, sends it into the stomach, where it is digested, and then into the intestine, where it is further changed; there the nourishing part is absorbed, and carried to the heart, which propels it through tubes, called blood-vessels, all over the body. In this process of digestion, certain fluids 
are required, as saliva, gastric juice, and bile: these are secreted by special organs, called glands. Moreover, since not all the food eaten is fitted to make blood, and as the blood itself, in going around the body, acts like a scavenger, picking up worn-out particles, we have another function, that of excretion, or removal of useless matter from the system. The kidneys and lungs do much of this; but the lungs do something else. They expose the blood to the air, and introduce oxygen, which, we shall find, is essential to the life of every animal.

These centripetal and centrifugal movements in the body-throwing in and throwing out-are so related and involved, especially in the lower forms, that they cannot be sharply defined and classified. It has been said that every Dog has two lives - a vegetative and an animal. The former includes the processes of digestion, circulation, respiration, secretion, etc., which are common to all life; the functions of the other, as motion, sensation, and will, are peculiar to animals. The heart is the centre of the vegetative life, and the brain is the centre of the animal life. The aim of the vegetative organs is to nourish the individual, and reproduce its kind; the organs of locomotion and sense establish relations between the individual and the world without. The former maintain life; the others express it. The former develop, and afterwards sustain, the latter. The vegetative organs, however, are not independent of the animal; for without muscles and nerves we could not procure, masticate, and digest food. The closer the connection and dependence between these two sets of organs, the higher the rank. ${ }^{18}$

All the apparatus and phenomena of life may be included under the heads of

Nutrition,

Motion,

Sensation. 
These three are possessed by all animals, but in a variety of ways. No two species have exactly the same mechanism and method of life. We must learn to distinguish between what is vital and what is only accessory. That only is essential to life which is common to all forms of life. Our brains, stomachs, livers, hands, and feet are luxuries. They are necessary to make us human, but not living, beings. Half of our body is taken up with a complicated system of digestion; but the Amœba has neither mouth nor stomach. We have an elaborate apparatus of motion; the Oyster cannot stir an inch.

Nutrition, Motion, and Sensation indicate three steps up the grade of life. Thus, the first is the prominent function in the Coral, which simply "vegetates," the powers of moving and feeling being very feeble. In the higher Insect, as the Bee, there is great activity with simple organs of nutrition. In the still higher Mammal, as Man, there is less power of locomotion, though the most perfect nutritive system ; but both functions are subordinate to sensation, which is the crowning development.

In studying the comparative anatomy and physiology of the animal kingdom, our plan will be to trace the various organs and functions, from their simplest expression upward to the highest complexity. Thus Nutrition will begin with absorption, which is the simplest method of taking food; going higher, we find digestion, but in no particular spot in the body; next, we see it confined to a tube; then to a tube with a sac, or stomach; and, finally, we reach the complex arrangement of the higher animals. 


\section{CHAPTER VI.}

\section{NUTRITION.}

Nutrition is the earliest and most constant of vital operations. So prominent is the nutritive apparatus, that an animal has been likened to a moving sac, organized to convert foreign matter into its own likeness, to which the complex organs of animal life are but auxiliaries. Thus, the bones and muscles are levers and cords to carry the body about, while the nervous system directs its motions in quest of food.

The objects of nutrition are growth, repair, and propagation. The first object of life is to grow, for no animal is born finished. Some animals, like plants, grow as long as they live $;^{19}$ but the majority. soon attain a fixed size. In all animals, however, without exception, food is wanted for another purpose than growth, namely, to repair the waste which is constantly going on. For every exercise of the muscles and nerves involves the death and decay of those tissues, as shown by the excretions. The amount of matter expelled from the body, and the amount of nourishment needed to make good the loss, increase with the activity of the animal. The supply must equal the demand, in order to maintain the life of the individual; and as an organism can make nothing, it must seek it from without. Not only the muscles and nerves are wasted by use, but every organ in the body; so that the whole structure needs constant renewal. An animal begins to die the moment it begins to live. The function of nutrition, therefore, is constructive, while motion and sensation are destructive. 
Another source of demand for food is the production of germs, to propagate the race, and the nourishment of such offspring in the egg and infantile state. This reprodnction and development of parts which can maintain an independent existence is a vegetative phenomenon (for plants have it), and is a part of the general process of Nutrition. But it will be more convenient to consider it hereafter (chapters xix., xx.). Still another necessity for aliment among the higher animals is the maintenance of bodily heat. This will be treated under the head of Respiration.

For the present, we will study Nutrition, as manifested in maintaining the life of an adult individual.

In all animals, this process essentially consists in the introduction of food, its conversion into tissue, its oxidation, and the removal of worn-out material.

1. The food must be procured, and swallowed. (Ingestion.)

2. The food must be dissolved, and the nutritious parts separated into a fluid. (Digestion.)

3. The nutritive fluid must be carefully taken up, and then distributed all over the body. (Absorption and Circulation.)

4. The tissues must repair their parts wasted by use, by transforming particles of blood into living matter like themselves. (Assimilation.)

5. Certain matters must be strained from the blood, some to serve a purpose, others to be cast out of the system. (Secretion and Excretion.)

6. In order to produce work and heat, the food must be oxidized, either in the blood or in the tissues, after assimilation. The necessary oxygen is obtained through exposure of the blood to the air in the lungs. (Respiration in part.)

7. The waste products of this oxidation taken up by the blood must be got rid of; some from the lungs (car- 
bon dioxide, water), some from the kidneys (water, urea, mainly), some from the skin (water, salines). (Respiration in part, Excretion.)

The mechanism to accomplish all this in the lowest forms of life is exceedingly simple, a single cavity and surface performing all the functions. But in the majority of animals the apparatus is very complicated: there is a set of organs for the prehension of food; another, for digestion ; a third, for absorption ; a fourth, for distribution; and a fifth, for purification.

\section{CHAPTER VII.}

\section{THE FOOD OF ANIMALS.}

The term food includes all substances which contribute to nutrition, whether they simply assist in the process, or are actually appropriated, and become tissue. With the food is usually combined more or less indigestible matter, which is separated in digestion.

Food is derived from the mineral, vegetable, and animal kingdoms. Water and salt, for example, are inorganic. The former is the most abundant, and a very essential article of food. Most of the lower forms of aquatic life seem to live by drinking: their real nourishment, however, is present in the water in the state of solution. The Earthworm, some Beetles, and certain savage tribes of Men swallow earth; but this, likewise, is for the organic matter which the earth contains. As no animal is produced immediately from inorganic matter, so no animal can be sustained by it.

Nutritious or tissue-forming food comes from the organic world, and is albuminous, as the lean meat of ani- 
mals and the gluten of wheat; oleaginous, as animal fat and vegetable oil; or saccharine, as starch and sugar. The first is the essential food-stuff; no substance can serve permanently for food-that is, can permanently prevent loss of weight in the body-unless it contains albuminous matter. As stated before, all the living tissues are albuminous, and therefore albuminous food is required to supply their waste. Albumen contains nitrogen, which is necessary to the formation of tissue; fats and sugars are rich in carbon, and therefore serve to maintain the heat of the body, and to repair part of the waste of tissues. Warm-blooded animals feed largely on farinaceous or starchy substances, which in digestion are converted into sugar. But any animal, of the higher orders certainly, whether herbivorous or carnivorons, would starve, if fed on pure albumen, oil, or sugar. Nature insists upon a mixed diet; and so we find in all the staple articles of food, as milk, meat, and bread, at least two of these principles present. As a rule, the nutritive principles in vegetables are less abundant than in animal food, and the indigestible residue is consequently greater. The nutriment in flesh increases as we ascend the animal scale; thus, Oysters are less nourishing than Fish; Fish, less than Fowl; and Fowl, less than the flesh of Quadrupeds.

Many animals, as most Insects and Marnmals, live solely on vegetable food, and some species are restricted to particular plants, as the Silk-worm to the white mulberry. But the majority of animals feed on one another; such are hosts of the microscopic forms, and nearly all the radiated species, marine Mollusks, Crustaceans, Beetles, Flies, Spiders, Fishes, Amphibians, Reptiles, Birds, and clawed Quadrupeds.

A few, as Man himself, are omnivorous, i.e., are maintained on a mixture of animal and vegetable food. The use of fire in the preparation of food is peculiar to Man, 
who has been called "the cooking animal." A few of the strictly herbivorous and carnivorous animals have shown a capacity for changing their diet. Thus, the Horse and Cow may be brought to eat fish and flesh; the Sea-birds can be habituated to grain; Cats are fond of alligatorpears; and Dogs take naturally to the plantain. Certain animals, in passing from the young to the mature state, make a remarkable change of food. Thus, the Tadpole feeds upon vegetable matter; but when it becomes a Frog it lives on Insects.

Many tribes, especially of Reptiles and Insects, are able to go without food for months, or even years. Insects in the larval, or caterpillar, state are very voracious; but upon reaching the perfect, or winged, state, they eat little - some species taking no food at all, the mouth being actually closed. The males of some Rotifer's and other tribes take no food from the time of leaving the egg until death.

In general, the greater the facility with which an animal obtains its food, the more dependent is it upon a constant supply. Thus, carnivores endure abstinence better than herbivores, and wild animals than domesticated ones.

\section{CHAPTER VIII.}

H OW A IMALS EAT.

1. The Prehension of Food.- (1) Liquids.-The simplest method of taking nourishment is by absorption through the skin. The Tape-worm, for example, has neither month nor stomach, but imbibes the digested food of the animal it infests. Many other animals, especially Insects, live upon liquid food, but obtain it by suction through a special orifice or tube. Thus, we find a mouth, 
or sucker, furnished with teeth for lancing the skin of animals, as in the Leech; a bristle-like tube fitted for piercing, as in the Mosquito; a sharp sucker armed with barbs, to fix it securely during the act of sucking, as in the Louse; and a long, flexible proboscis, as in the Butterfly. Bees have a hairy, channelled tongue, and Flies have one terminating in a large fleshy knob, with or without little "knives" at the base for cutting the skin: both lap, rather than suck, their food.

Most animals drink by suction, as the $\mathrm{Ox}$; and a few by lapping, as the Dog; the Elephant pumps the water up with its trunk, and then pours it into its throat; and Birds (excepting Doves) till the beak, and then, raising the head, allow the water to run down.

Many aquatic animals, whose food consists of small particles diffused through the water, have an apparatus for creating currents, so as to bring such particles within their reach. This is particularly true of low, fixed forms, which are unable to go in search of their food. Thus, the Sponge draws nourishment from the water, which is made to circulate through the system of canals traversing its body by the vibration of minute hairs, or cilia, lining parts of the canals (Fig. 189). The microscopic Infusoria have cilia surrounding the mouth, with which they draw or drive into the body little currents containing nutritious particles. Bivalve mollusks, as the Oyster and Clam, are likewise dependent upon this method of procuring food, the gills being fringed with cilia. So the singular fish, Amphioxus (the only example among Vertebrates), employs ciliary action to obtain the minute organisms on which it feeds. The Greenland Whale has a mode of ingestion somewhat unique, gulping great volumes of water into its mouth, and then straining out, through its whalebone sieve, the small animals which the water may contain (Fig. 343). 
(2) Solids.-When the food is in solid masses, whether floating in water or not, the animal is usually provided with prehensile appendages for taking hold of it. The jellylike Amœba has neither mouth nor stomach, but extemporizes them, seizing its food by means of its soft body. The food then passes through the outer wall into the softer interior, where it is digested. The waste particles

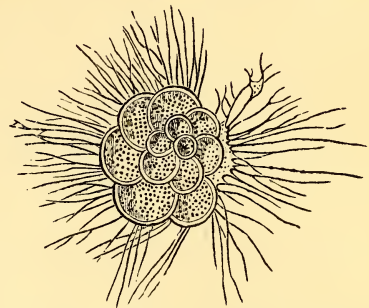
are passed out in a similar way. In the Foraminifers, thread-like projections of the body are thrown ont (pseudopodia) which adhere to the prey. The soft jelly-like substance of the body then flows down the pseudopodium, collects about the food, and digests it (Fig. 15).

A higher type is seen in Polyps and Jelly-fishes, which have hollow tentacles around the entrance to the stomach (Fig. 193). These tentacles are contractile, and, moreover, are covered with an immense number of minute sacs, in which a highly elastic filament is coiled up spirally (lassocells, nettle-cells). When the tentacles are touched by a passing animal, they seize it, and at the same moment throw out their myriad filaments, like so many lassos, which penetrate the skin of the victim, and probably also emit a fluid, which paralyzes it; the mouth, meanwhile, expands to an extraordinary size, and the creature is soon engulfed in the digestive bag.

In the next stage, we find no tentacles, but the food is brought to the mouth by the flexible lobes of the body, commonly called "arms," which are covered with hundreds of minute suckers; and if the prey, as an Oyster, is too large to be swallowed, the stomach protrudes, like a proboscis, and sucks it out of its shell. This is seen in the Star-fish (Fig. 126). 
A great advance is shown by the Sea - mrchin, whose mouth is provided with five sharp teeth, set in as many jaws, and capable of being projected so as to grasp, as well as to masticate, its food (Figs. 214, 28).

In Mollusks having a single shell, as the Snail, the chief organ of prehension is a strap-like tongue, covered with minute recurved teeth, or spines, with which the animal

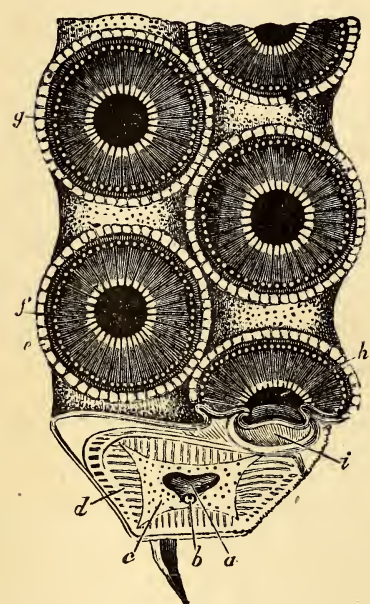

FIG. 16.-Suckers on the Tentacles of a Cuttle-fish : $a$, hollow axis of the arm, containing nerve and artery ; $c$, cellular tissue ; $d$, radiating fibres; $h$, raised margin of the disk around the aperture $f, g$, which contains a retractile membrane, or "piston," $i$. rasps its food, while the upper lip is armed with a sharp, horny plate (Fig. 29). In many marine species, as the Whelk, the tongue is situated at the end of a retractile proboscis, or muscular tube. In the Cuttle-fish, we see the sudden development of an elaborate system of prehensile organs. Besides a spinous tongue, it has a pair of hard mandibles, resembling the beak of a Parrot, and working vertically; and around the mouth are eight or ten powerful arms furnished with numerous cup-like suckers. So perfect is the adhesion of these suckers, that it is easier to tear away a limb than to detach it from its hold.

The Earth-worm swallows earthy matter and decaying leaves, which it secures with its lips, the upper one being prolonged. Other worms (as Nereis) are so constructed that the gullet, which is frequently armed with teeth and forceps, can be turned inside ont, to form a proboscis for seizing prey.

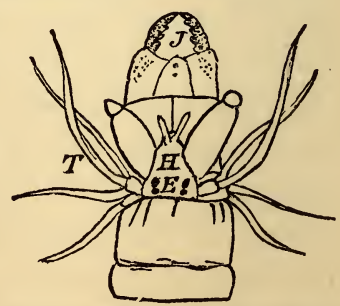

Fra. 17.-Nereis - head, with extended proboscis: $J$, jaws; $T$, tentacles; $H$, head; $E$, eyes. 
The Arthropoda exhibit a great variety of means for procuring nourishment, in addition to the suctorial contrivances already mentioned, the innumerable modifications of the mouth corresponding to the diversity of food. Millepedes, Caterpillars, and Grubs have a pair of horny jaws moving horizontally. The Centipede has a second pair of jaws, which are really modified feet, terminated by curved fangs containing a poison-duct. The Horseshoe Crab uses its feet for prehension, and the thighs, or basal joints, of its legs to masticate the food and force it into the stomach. The first six pair of legs in the Lobster and Crab are likewise appropriated to conveying food into the mouth, the sixth being enormously developed, and furnished with powerful pincers. Scorpions have a similar pair of claws for prehension, and also a pair of small forceps for holding the food in contact with the inouth. In their relatives, Fra. 18._One of the Fangs, or Perforated the Spiders, the claws are

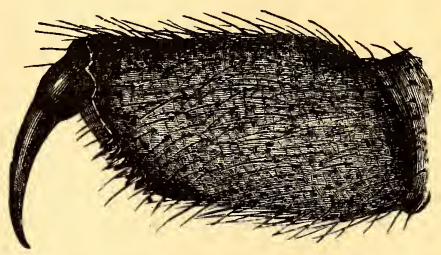
wanting, and the forceps end in a fang, or hook, which is perforated to convey venom. ${ }^{20}$

The biting Insects, as Beetles and Locusts, have two pairs of horny jaws, which open sidewise, one above and the other below the oral orifice. The upper pair are called mandibles; the lower, maxillæ. The former are armed with sharp teeth, or with cutting edges, and sometimes are fitted, like the molars of quadrupeds, to grind the food. The maxillæ are usually composed of several parts, some of which serve to hold the food, or to help in dividing it, while others (palpi) are sensory. There is generally present a third pair of jaws - the labium - which are united in the middle line, and serve as a lower lip. They also bear palpi. The Mantis seizes its prey with its long 
fore-legs, crushes it between its thighs, which are armed with spines, and then delivers it up to the jaws for mastication. All Arthropods move their jaws horizontally.

The back-boned animals generally apprehend food by means of their jaws, of which there are two, moving vertically. The toothless Sturgeon draws in its prey by powerful suction. The Hag-fish has a single tooth, which it plunges into the sides of its victim, and, thus securing a firm hold, bores its way into the flesh by means of its sawlike tongue. But Fishes are usually well provided with teeth, which, being sharp and curving inward, are strictly prehensile. The fins and tongue are not prehensile. A mouth with horny jaws, as in the Turtles, or bristling with teeth, as in the Crocodile, is the only means possessed by nearly all Amphibians and Reptiles for securing food. The Toad, Frog, and Chameleon capture insects by darting out the tongue, which is tipped with glutinous saliva. The constricting serpents (Boas) crush their prey in their coils before swallowing; and the venomous Snakes have a poison-fang. No reptile has prehensile lips. All Birds use their toothless beaks in procuring food, but birds of prey also seize with their talons, and Woodpeckers, Hummers, and Parrots with their tongues. The beak varies greatly in shape, being a hook in the Eagle, a probe in the Woodpecker, and a shovel in the Duck.

Among the Quadrupeds we find a few special contrivances, as the trunk of the Elephant, and the long tongues of the Giraffe and Ant-eater; but, as a rule, the teeth are the chief organs of prehension, always aided more or less by the lips. Ruminants, like the Ox, having hoofs on their feet, and no upper front teeth, employ the lips and tongue. Such as can stand erect on the hind-legs, as the Squirrel, Bear, and Kangaroo, use the front limbs for holding the food and bringing it to the mouth, but never one limb alone. The clawed animals, like the Cat and Lion, 
make use of their feet in securing prey, all four limbs being furnished with curved retractile claws; but the food is conveyed into the mouth by the movement of the head and jaws. Man and the Monkeys employ the hand in bringing food to the mouth, and the lips and tongue in taking it into the cavity. The thumb on the human hand is longer and more perfect than that of the Apes and Monkeys; but the foot of the latter is also prehensile.

2. The Mouths of Animals. -In the Parasites, as the Tapeworm, which absorb nourishment through the skin, and Insects, as the May-fly and Bot-fly, which do all their eating in the larval state,

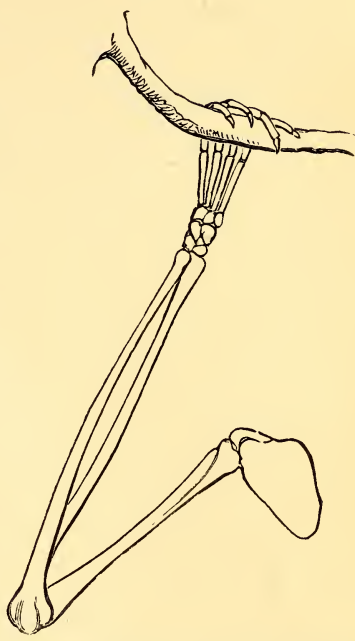

Fra. 19.-Arm of the Thumbless Monkey (Ateles). the mouth is either wanting or rudimentary. The Amœba, also, has no mouth proper, its food passing through the firmer outside part of the bit of protoplasm which constitutes its body. Mouth and anus are thus extemporized, the opening closing as soon as the food or excrement has passed through.

In the Infusoria the mouth is a round or oval opening leading through the cuticle and outer layer of protoplasm to the interior of the single cell which makes their body. It is usually bordered with cilia, and situated on the side or at one end of the animal.

An elliptical or quadrangular orifice, surrounded with tentacles, and leading directly to the stomach, is the ordinary mouth of the Polyps and Jelly-fishes. In those which are fixed, as the Actinia, Coral, and Hydra, the mouth looks upward: in those which freely move about, 
as the Jelly-fish, it is generally underneath, the position of the animal being reversed. In some, the margin, or lip, is protruded like a proboscis; and in all it is exceedingly dilatable.

The mouth of the Star-fish and Sea-urchin is a simple round aperture, followed by a very short throat. In the Star-fish, it is enclosed by a ring of hard tubercles and a membrane. In the Sea-urchin, it is surrounded by a muscular membrane and minute tentacles, and is armed with five sharp teeth, set in as many jaws, resembling little conical wedges (Fig. 28).

Among the headless Mollusks, the oral apparatus is very simple, being inferior to that of some of the radiated animals. In the Oyster and Bivalves generally, the mouth is an unarmed slit-a mere inlet to the oesophagus, sitnated in a kind of hood formed by the union of the gills at their origin, and between two pairs of delicate lips. These lips make a furrow, along which pass the particles of food drawn in by the cilia.

Of the higher Mollusks, the little Clio (one of the Pteropods) has a triangular mouth, with two jaws armed with sharp horny teeth, and a tongue covered with spiny hooklets all directed backward. Some Univalves have a simple fleshy tube. Others, as the Whelk, have an extensible proboscis, which unfolds itself, like the finger of a glove, and carries within it a rasp-like tongue, which can bore

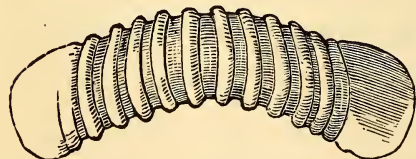

FIG. 20.-Jaw of the Common Snail (Helix albolabris). into the hardest shells. Such as feed on vegetable matter, as the Snail, have no proboscis, but on the roof of the mouth a curved horny plate fitted to cut leaves, etc., which are pressed against it by the lips, and on the floor of the mouth a small tongue covered with delicate teeth. As fast as the tongue is worn off by use, it grows out from the root. 
The mouth of the Cuttle-fish is the most elevated type below that of the Fishes. A broad circular lip nearly conceals a pair of strong horny mandibles, not unlike the beak of a parrot, but reversed, the upper mandible being the shorter of the two, and the jaws, which are cartilaginous, are imbedded in a mass of muscles, and move vertically. Between them is a fleshy tongue covered with teeth.

The parasitic Worms, living within or on the outside of other animals, generally have a sucker at one end or underneath, serving simply for attachment, and another which is perforated. The latter is a true suctorial mouth, being the sole inlet of food. It is often surrounded with hooklets or teeth, which serve both to scarify the victim and secure a firm hold. In the Leech, the mouth is a triangular opening with thick lips, the upper one prolonged, and with three jaws. In many Worms it is a fleshy tube, which can be drawn in or extended, like the eye-stalks of the Snail, and contains a dental apparatus inside (Fig. 17).

Millepedes and Centipedes have two lateral jaws and a four-lobed lip.

In Lobsters and Crabs the mouth is situated underneath the head, and consists of a soft upper lip, then a pair of upper jaws provided with a short feeler, below which is a thin bifid lower lip; then follow two pairs of membranous under jaws, which are lobed and hairy; and next, three pairs of foot-jaws (Fig. 250). The Horse-shoe Crab has no special jaws, the thighs answering the purpose. The Barnacle has a prominent mouth, with three pairs of rudimentary jaws.

With few exceptions, the mouths of Insects in the larval state are fitted only for biting, the two jaws being horny shears. But in the winged, or perfect, state, Insects may be divided into the masticating (as the Beetle) and 

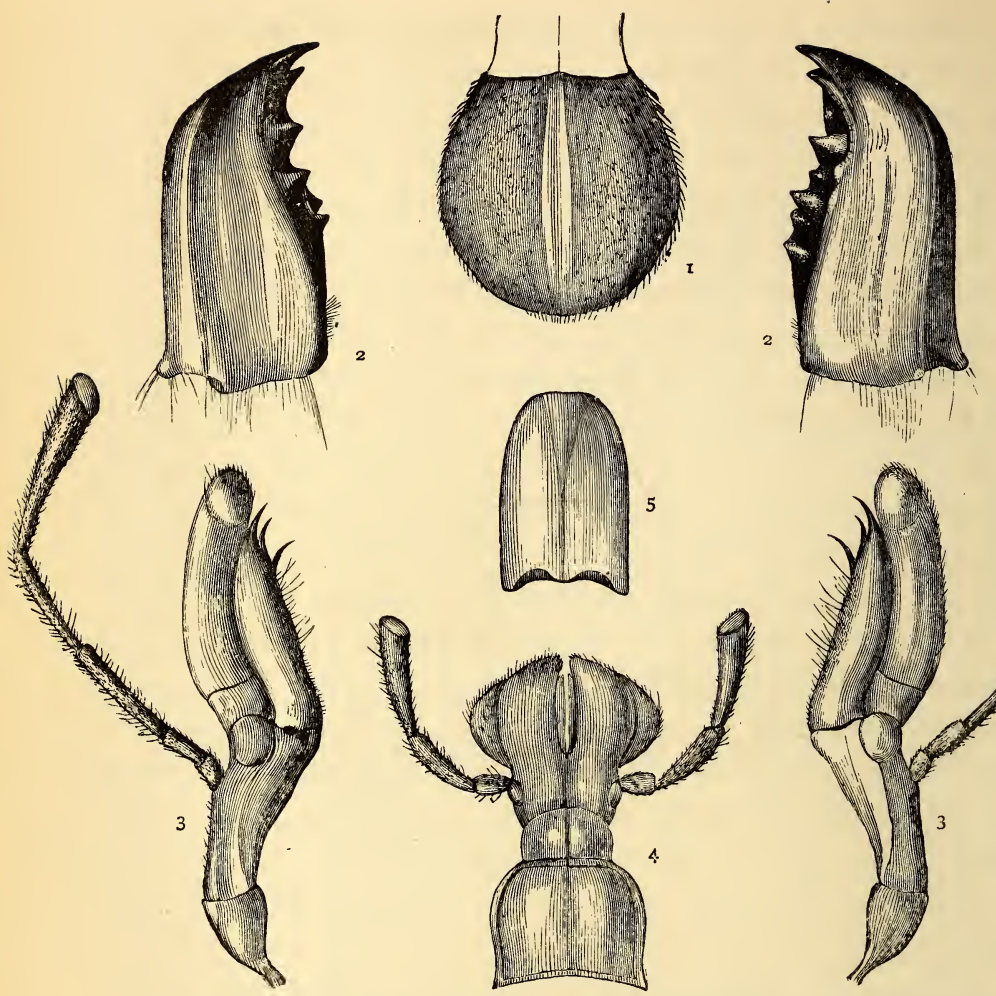

Fig. 21.-Mouth of a Locust dissected: 1, labrum, or upper lip; 2, mandibles; 3, jaws; 4, labium, or lower lip; 5, tongue. The appendages to the maxillæ and lower lip are palpi.

the suctorial (as the Butterfly). In the former group, the oral apparatus consists of two pairs of horny jaws (mandibles and maxillce), which work horizontally between an upper (labrum) and an under (labium) lip. The maxillæ and under lip carry sensitive jointed feelers (palpi). The front edge of the labium is commonly known as the tongue (ligula). ${ }^{21} \quad$ In such a mouth, the mandibles are the most important parts; but in passing to the suctorial Insects, we find that the mandibles are secondary to the maxillæ and labium, which are the only means of taking food. In 
the Bee tribe, we have a transition between the biting and the sucking Insects-the mandibles "supply the place of trowels, spades, pickaxes, saws, scissors, and knives," while the maxillæ are developed into a sheath to enclose the long, slender, hairy tongue which laps up the sweets of flowers. In the suctorial Butterfly, the lips, mandibles, and palpi are reduced to rudiments, while the maxillæ are the only useful oral organs. These are excessively lengthened into a proboscis, their edges locking by means of minute teeth, so as to form a central canal, throngh which the liquid food is pumped up into the mouth. Seen un-

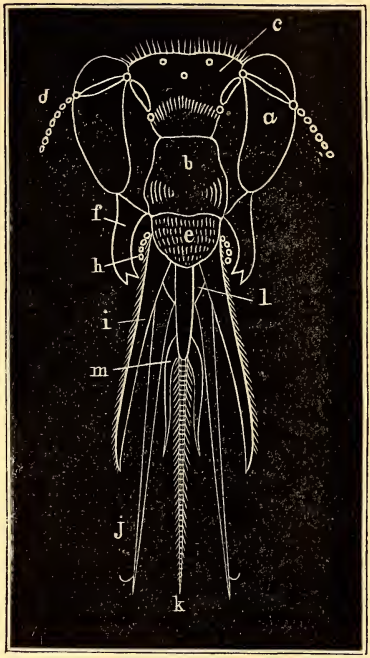

Fic. 22.-Head of a Wild Bee $(A n$ thophora retusa), front view: $a$, compound eyes; $b$, clypens; $c$, three simple eyes; $d$, antennæ; $e$, labrum : $f$, mandibles; $i$, maxillæ; $h$, maxillary palpi ; $l$, palpifer $; j$, labial palpi ; $m$, paraglossæ; $k$, ligula. der the microscope, the proboscis is made up of innumerable rings interlaced with spiral muscular fibres. The

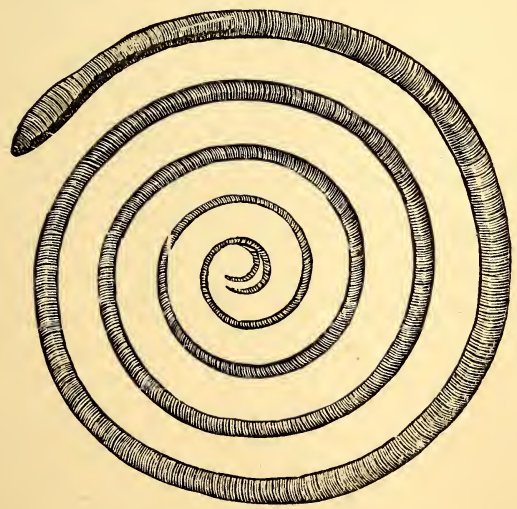

Frg. 23.-Proboscis of a Butterfly. proboscis of the Fly is a modified lower lip; that of the Bugs and Mosquitos, fitted both for piercing and suction, is formed by the union of four bristles, which are the mandibles and maxillæ strangely altered, and encased in the labinm when not in use. 


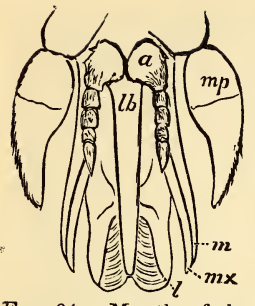

FIG. 24. -Mouth of the Horse-fly ('T'abanus lineola) : $a$, anteunæ; $m$, mandibles ; $m x$, maxillæ; $m p$, maxillary palpi ; $l b$, labrum ; $l$, labium, or tongue.

As most of the Arachnids live by suction, the jaws are seldom used for mastication. In the Scorpion, the apparent representatives of the mandibles of an Insect are transformed into a pair of small forceps, and the palpi, so small in Insects, are developed into formidable claws: both of these organs are prehensile. In Spiders, the so-called mandibles, which move more or less vertically, end in a fang; and the club-like palpi, often resembling legs, have nothing to do with ingestion or locomotion. Both Scorpions and Spiders have a soft upper lip, and a groove within the mouth, which serves as a canal while sucking their prey. The tongue is external, and situated between a pair of diminutive maxillæ.

In the Ascidians the first part of the alimentary canal is enormously enlarged and modified to serve as a gillsac. At the bottom of this sac, and far removed from its external opening, lies the entrance to the digestive tract proper. Into it the particles of food entering with the water are conveyed (Fig. 279).

The mouth of Verte-

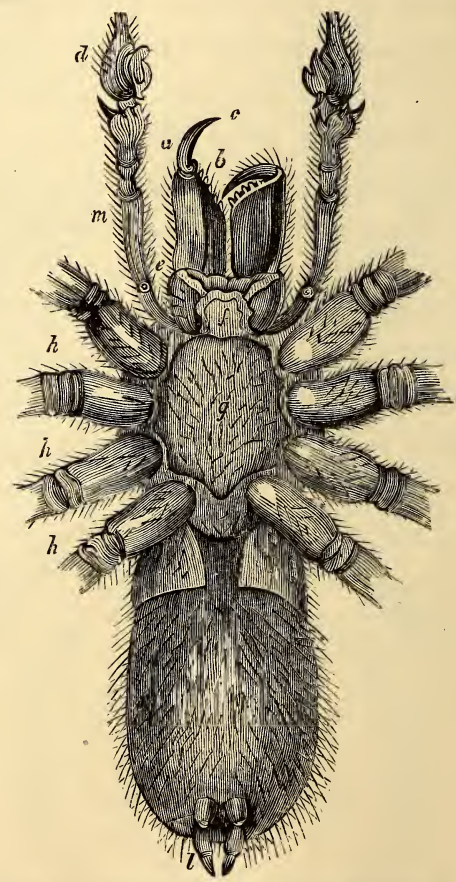

Fig. 25.-Under Surface of Male Spider: $a$, $c$, poison-fang; $b$, teeth on interior margin of mandible, $e ; f$, labium; $g$, thorax; $h$, limbs ; $i$, abdomen; $l$, spinuerets; $m$, maxillary palpus; $d$, dilated terminal joint. 
brates is a cavity with a fixed roof (the hard palate) and a movable floor (the tongue and lower jaw), having a transverse opening in front, ${ }^{22}$ and a narrow outlet behind, leading to the gullet. Save in Birds and some others, the cavity is closed in front with lips, and the margins of the jaws are set with teeth.

In Fishes the mouth is the common entry to both the digestive and respiratory organs; it is, therefore, large, and complicated by a mechanism for regulating the transit of the food to the stomach and the aërated water to the gills. The slits leading to the gills are provided with rows of processes which, like a sieve, prevent the entrance of food, and with valves to keep the water, after it has entered the gills, from returning to the mouth. So that the mouths of Fishes may be said to be armed at both ends with teeth-bearing jaws. A few Fishes, as the Sturgeon, are toothless; but, as a class, they have an extraordinary dental apparatus-not only the upper and lower jaws, but even the palate, tongue, and throat being sometimes studded with teeth. Every part of the mouth is evidently designed for prehension and mastication. Lips are usually present; but the tongue is often absent, or very small, and as often aids respiration as ingestion.

Amphibians and Reptiles have a wide mouth; even the insect-feeding Toads and the Serpents can stretch theirs enormously. True fleshy lips are wanting; hence the savage aspect of the grinning Crocodile. With some exceptions, as Toads and Turtles, the jaws are armed with teeth. Turtles are provided with horny beaks. The tongue is rarely absent, but is generally too thick and short to be of much use. In the Toad and Frog it is singularly extensile: rooted in front and free behind, it is shot from the mouth with such rapidity that the insect is seized and swallowed more quickly than the eye can follow. The Chameleon's tongue is also extensile. Snakes 


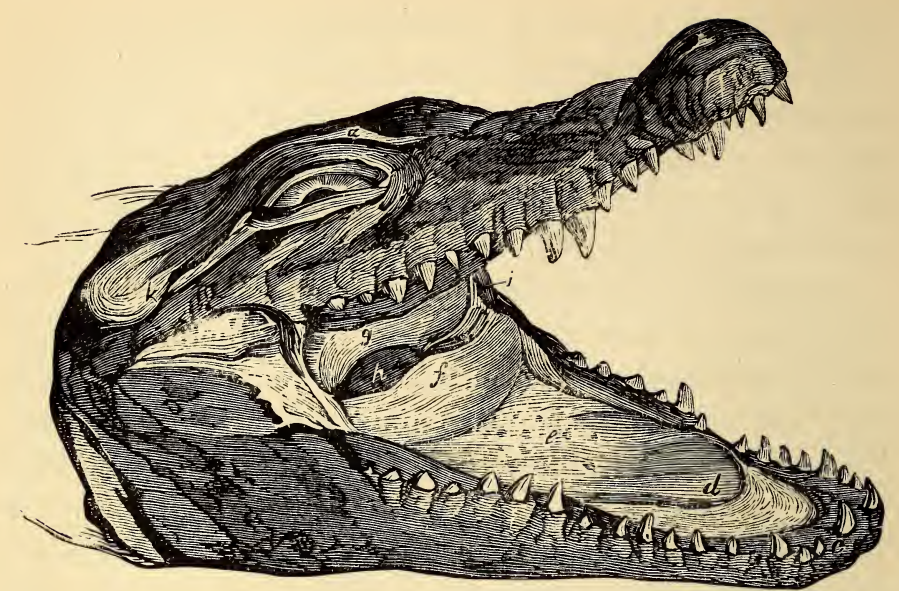

Fig. 26.--Mouth of the Crocodile: $d$, tongue; $e$, glands; $f$, inferior, and $g$, superior, valve, separating the cavity of the mouth from the throat, $h$.

have a slender forked tongue, consisting of a pair of muscular cylinders, which is solely an instrument of touch.

Birds are without lips or teeth, the jaws being covered with horn forming a beak. This varies greatly in shape, being extremely wide in the Whippoorwill, remarkably long in the Pelican, stout in the Eagle, and slender in the Hunmer. It is hardest in those that tear or bruise their food, and softest in water-birds. The tongue is also corered with a horny sheath, and generally spinous, its chief function being to secure the food when in the mouth. It is proportionally largest and most fleshy in the Parrots.

The main characteristics of the mammalian mouth are flesh lips and mobile cheeks. ${ }^{23}$ In the duck-billed Monotremes lips are wanting, and in the Porpoises they are barely represented. But in the herbivorous quadrupeds they, with the tongue, are the chief organs of prehension; in the carnivorous tribes they are thin and retractile; while in the Whale the upper lip falls down like a curtain, overlapping the lower jaw several feet. As a rule, the mouth is terminal ; but in the Elephant, Tapir, Hog, 
and Shrew, the upper lip blends with the nose to form a proboscis, or snout. The mouth is comparatively small in the Elephant and in gnawing animals like the Squirrel, wide in the Carnivores, short in the Sloth, and long in the Ant-eater. Teeth are usually present, but vary in form and number with the habits of the animal. The Ant-eater is toothless, and the Greenland Whale has a sieve made of horny plates. The tongue conforms in size and shape with the lower jaw, and is a muscular, sensitive organ, which serves many purposes, assisting in the prehension, mastication, and swallowing of food, besides being an organ of taste, touch, and speech. Its surface is covered with minute prominences, called papillce, which are arranged in lines with mathematical precision. In the Cats, these are developed into recurved spines, which the animal uses in cleaning bones and combing its fur. Similar papillæ occur on the roof and sides of the mouth of the $\mathrm{Ox}$ and other Ruminants. In some animals, as the Hamster

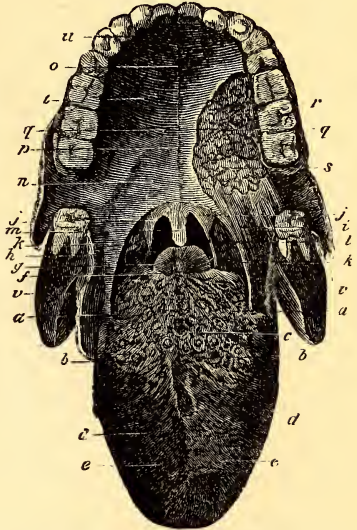

Fig. 27.-Human Tongue and adjacent parts : $a$, lingual papillæ: $b$, papillæ forming $\mathrm{V}$-shaped lines ; $d$, fungiform papillæ; $e$, filiform papillæ; $g$, epiglottis; $m$, uvula, or conical process, hanging from the soft palate, $n$; $o$, hard palate; $r$, palatine glands, the mucous membrane being removed; $v$, section of the lower jaw. and Gopher, the cheeks are developed into pouches in which the food may be carried. These may be lined with hair. The tongue is remarkably long in the Ant-eater and Giraffe, and almost immovable in the Gnawers, Elephants, and Whales.

3. The Teeth of Animals.-Nearly all animals have certain hard parts within the mouth for the prehension or trituration of solid food. If these are wanting, the legs are often armed with spines, or pincers, to serve the same 
purpose, as in the Horse-shoe Crab; or the stomach is lined with "gastric teeth," as in some marine Snails; or the deficiency is supplied by a muscular gizzard, as in Birds, Ant-eaters, and some Insects. Even the Lobster and Crab, in addition to their complicated oral organs, have the stomach furnished with a powerful set of teeth.

The Sea-urchin is the first of animals, and almost the only one below Worms and Mollusks, which exhibits

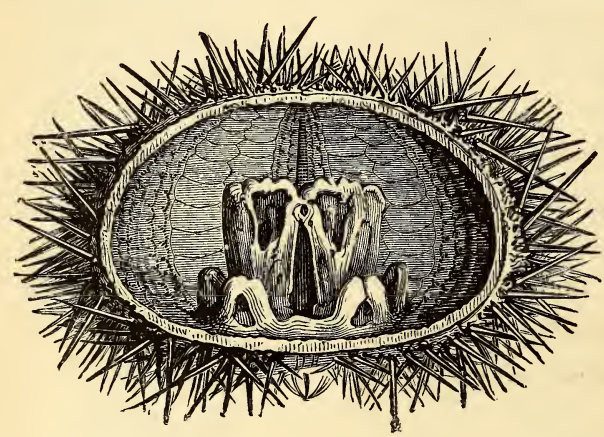

anything like a dental apparatus. Five calcareous teeth, having a wedge - shaped apex, each set in a triangular pyramid, or "jaw," are moved upon each other by a Fra.28.-Echinus bisected, showing masticating apparatns. complex arrangement of levers and muscles. Instead of moving up and down, as in Vertebrates, or from right to left, as in Arthropods, they converge towards the centre, and the food passes between ten grinding surfaces.

The Rotifers (a group of minute Worms) have a curious pair of horny jaws. That which answers to the lower jaw is fixed, and called the "anvil." The upper jaw consists of two pieces called "hammers," which are sharply notched, and beat upon the "anvil" between them (Fig. 219).

The horny-toothed mandibles of Insects, already mentioned, are prehensile, and also serve to divide the food.

The three little white ridges in the mouth of the Leech are the convex edges of horny semicircles, each bordered by a row of nearly a hundred hard, sharp teeth. When the mouth, or sucker, is applied to the skin, a sawing 
movement is given to the horny ridges, so that the "bite" of the Leech is really a saw-cut.

The dentition of the univalve Mollusks, or the Snails, is generally lingual, i. e., it consists of

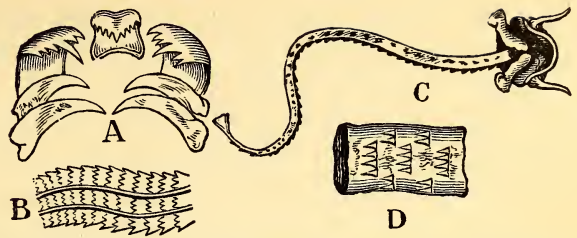

Fig. 29.-Teeth and Masticatory Apparatus of Gasteropods : A, portion of odontophore, or "tongue," of Velutina, enlarged ; B, portion of odontophore of Whelk (Buccinum undatum), magnified - the entire tongue has 100 rows of teeth ; $C$, head and odontophore of Limpet (Patella vulgata); D, portion of same, greatly magnified, to show the transverse rows of siliceous teeth.

microscopic teeth, usually siliceous and amber-colored,

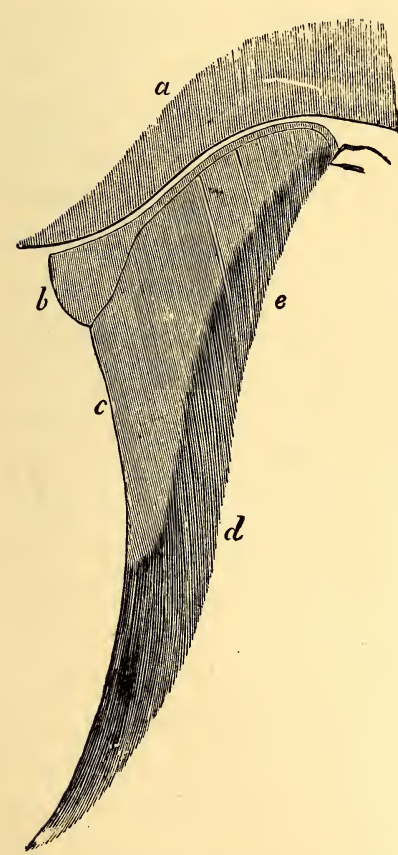
planted in rows on the tongue. The teeth are, in fact, the serrated edges of minute plates. The number of these plates varies greatly; the garden Slug has 160 rows, with 180 teeth in each row.

All living Birds, and some other Vertebrates, as Ant-eaters, ${ }^{24}$ Turtles, Tortoises, Toads, and Sturgeons, have no teeth. Their place is often supplied by a horny beak, a muscular gizzard, or both structures.

In a few Vertebrates, horny plates take the place of teeth, as the Duck Mole (Ornithorhynchus) and Whalebone Whale. In the former, the plates consist of closely set verFir. 30.-Section of one half of the Up- tical hollow tubes; in the lat-
per Jaw of a Whale (Balenoptera), showing baleen - plates: $a$, superior ter, the baleen, or whalebone,
maxillary bone; $b$, ligamentous gum maxillary bone; $b$, ligamentous gum attaching the horny body of the ba- plates, triangular in shape, and leen-plate, $c ; d$, fringe of bristles; $e$, fringed on the inner side, hang
smaller plates. 
in rows from the gums of the upper jaw. In some Whales there are about 300 plates on each side. ${ }^{25}$

True teeth, consisting mainly of a hard, calcareous substance called dentine, are found only in back-boned animals. They are distinct from the skeleton, and differ

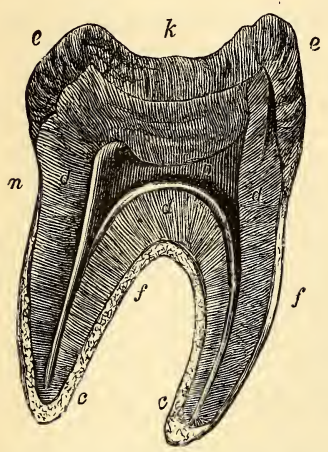

Fig. 31.-Section of Human Molar, enlarged: $k$, crown; $n$, neck; $f$, fang; $e$, enamel ; $d$, dentine; $c$, cement ; $p$, pulpcavity.

particles of blood. One modification of it is ivory, seen in the tusks of Elephants. Enamel is the hardest tissue of the body, and contains not more than two per cent. of animal matter. It consists of six-sided fibres set side by side, at right angles to the surfaces of the dentine. Cement closely resembles bone, and is present only in the teeth of the higher animals.

Teeth are usually confined to the jaws; but the number, size, form, structure, position, and mode of attachment vary with the food and habits of the animal. As a rule, animals developing large numbers of teeth in the back part of the mouth are inferior to those having fewer teeth, and those nearer the lips. The teeth of Mammals only have fangs.

The teeth of Fishes present the greatest variety. In number, they range from zero to hundreds. The Hag- 
fish (Myxine) has a single tooth on the roof of the mouth, and two serrated plates on the tongue; while the mouth of the Pike is crowded with teeth. In some we find teeth short and blunt, in the shape of cubes, or prisms, arranged like mosaic work. Such pavement-teeth (seen in some Rays) are titted for grinding sea-weed and crushing shell-fish. But the cone is the most common form: sometimes so slender and close as to resemble plush, as in the Perch; or of large size, and flattened like a spear-head with serrated edges, as in the Shark; but more often like the canines of Mammals, curved

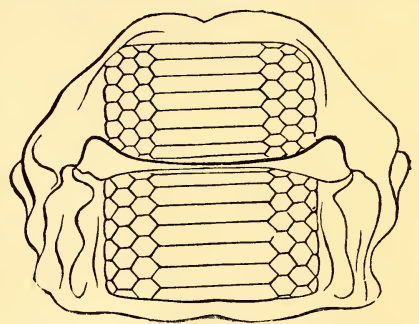

Fig. 32.-Jaws and Pavement-teeth of a Ray (Myliobates). inward to fit them for grappling. In the Shark, the teeth are confined to the fore-part of the mouth; in the Carp, they are all situated on the bones of the throat; in the Parrot-fish, they occupy both back and front; but in most Fishes the teeth are developed also on the roof, or palate, and, in fact, on nearly every bone in the mouth. They seldom appear (as in the Salmon) on the upper maxillary. As to mode of attachment, the teeth are generally anchylosed (fastened by bony matter) to the bones which support them, or simply bound by ligaments, as in the Shark. In a few Fishes, the teeth consist of flexible cartilage; but almost invariably they are composed of some kind of dentine, enamel and cement being absent.

Of Amphibians and Reptiles, Toads, Turtles, and Tortoises are toothless; Frogs have teeth in the upper jaw only; Snakes have a more complete set, but Saurians possess the most perfect dentition. The number is not fixed even in the same species: in the Alligator it varies from 72 to 88 . The teeth are limited to the jawbones in the higher forms (Saurians); but in others, as the Serpents, 
they are planted also in the roof of the mouth. With few exceptions, they are conical and curved (Fig. 33). In the Serpents they are longest and sharpest; and the venomous species have two or more fangs in the upper jaw.

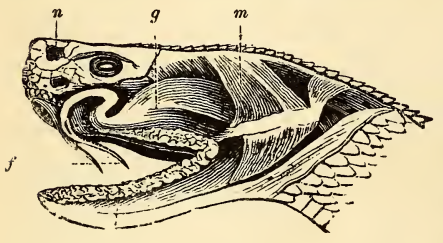

Fig. 33.-Poison Apparatus of the Rattlesnake: $g$, gland, with duct, leading to the fang, $f ; m$, elevator muscles of the jaw, which, in contracting, compress the gland; $s$, salivary glands on the edge of the jaws; $n$, nostril.

These fangs contain a canal, through which the poison is forced by muscles which compress the gland. The bones to which they are attached are movable, and the fangs ordinarily lie flat upon the gums, but are brought into a vertical position in the act of striking. As a rule, the teeth of Reptiles are simply soldered to the bone which supports them, or lodged in a groove; but those of Crocodiles are set in sockets. Reptilian teeth are made of dentine and a thin layer of cement, to which is added in most Saurians a coat of enamel on the crown.

In the majority of Mammals, the teeth are limited in number and definite in their forms. The number ranges from 1 in the Narwhal (but the longest tooth in the kingdom) to 220 in the Dolphin. The average is 32, occurring in Ruminants, Apes, and Man; but 44 (as in the Hog and Mole) is called the typical or normal number, and this number is exceeded only in the lower groups. When very numerous, the teeth are of the Reptilian type, small, pointed, and of nearly equal size, as in the Porpoise. In the higher Mammals, the teeth are comparatively few, and differ so much in size, shape, and use, that they can be classed into incisors, canines, premolars, and molars. Such a dental series exhibits a double purpose, prehension and mastication. The chisel-shaped front teeth are fitted for cutting the food, and hence called incisors. These vary in number: the Lion has six in each jaw; the Squir- 
rel has two in each jaw, but remarkably developed; the Ox has none in the upper jaw, and the Elephant none in the lower; while the Sloth has none at all. ${ }^{26}$ The canines, so called because so prominent in the Dog, are conical, and, except in Man, longer than the other teeth. They are designed for seizing and tearing; and they are the most formidable weapons of the wild carnivores. There

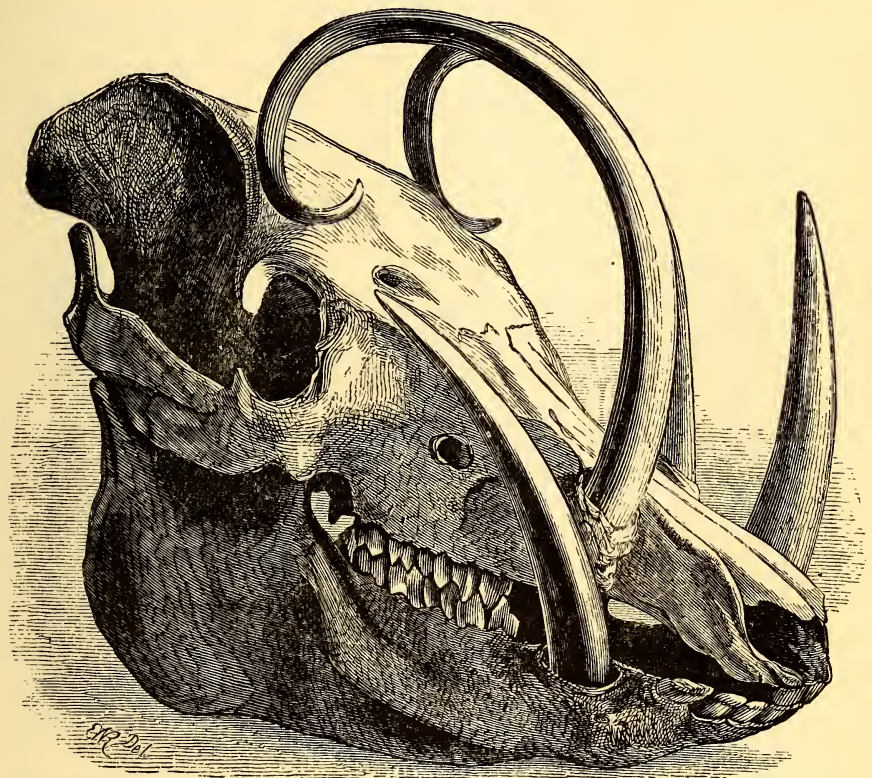

Frg. 34.-Skull of the Babirusa, or Malayan Hog, showing growth and curvature of the canines.

are never more than four. They are wanting in all Rodents, and in nearly all herbivorous quadrupeds. The molars, or grinders, vary greatly in shape, but closely correspond with the structure and habits of the animal, so that a single tooth is sufficient to indicate the mode of life and to identify the species. ${ }^{27}$. In the Ruminants, Rodents, Horses, and Elephants, the summits of the molars are flat, like mill-stones, with transverse or curving ridges 
of enamel. In the Cats and Dogs, they are narrow and sharp, passing by each other like the blades of scissors, and therefore cutting, rather than grinding, the food. The more purely carnivorous the species, and the more it feeds upon living prey, the fewer the molars. In animals living on mixed diet, as the Hog and Man, the crowns have blunt tubercles. Premolars, or bicuspids, are those which were preceded by milk-teeth; the true, or back, molars had no predecessors.

The dentition of Mammals is expressed by a formula, which is a combination of initial letters and figures in

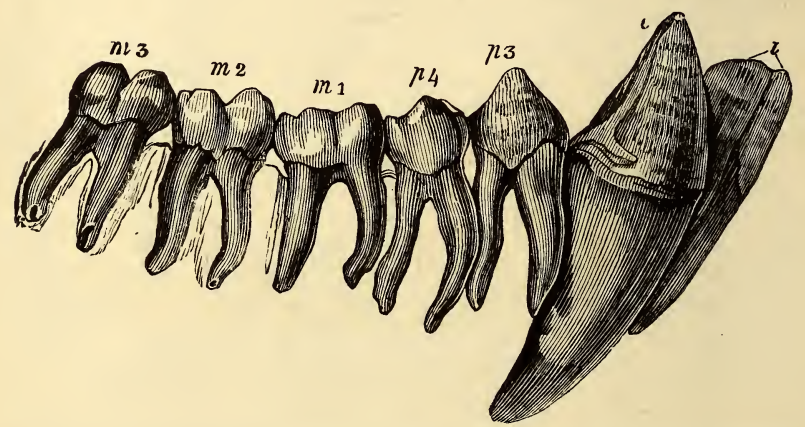

Fig. 35. -Teeth of the right lower jaw of adnlt male Chimpanzee (Troglodytes niger), natural size. The molar series does not form a curve, as in Man.

fractional form, to show the number and kind of teeth on each side of both jaws. Thus, the formula for Man is : $i, \frac{2-2}{2-2} ; c, \frac{1-1}{1-1} ; p, \frac{2-2}{2-2} ; m, \frac{3-3}{3-3}=32$.

The teeth of Mammals are always restricted to the margins of the jaws, and form a single row in each. But they rarely form an unbroken series. ${ }^{28}$ The teeth implanted in the premaxillary bone, and in the corresponding part of the lower jaw, whatever their number, are incisors. The first tooth behind the premaxillary, if sharp and projecting, is a canine.

Each tooth has its particular bony socket. ${ }^{29}$ The molars 
may be still further strengthened by having two or more diverging fangs, or roots, a feature peculiar to this class. The incisors and canines have but one fang; and those that are perpetually growing, as the incisors of Rodents and Elephants, have none at all. The teeth of flesh-eating Mammals usually consist of hard dentine, surrounded on the root with cement and capped with enamel. In the herbivorous tribes, they are very complex, the enamel and cement being inflected into the dentine, forming folds, as in the molar of the Ox, or plates, as in the compound tooth of the Elephant. This arrangement of these tissues, which differ in hardness, secures a surface with prominent

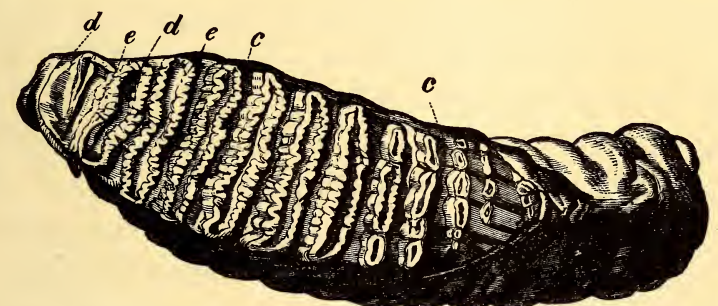

Fig. 36.-Upper Molar Tooth of Indian Elephant (Elephas Indicus), showing transverse arrangement of dentine, $d$, with festooned border of enamel plates, $e ; c$, cement; one-third natural size.

ridges, well adapted for grinding. The cutting teeth of the Rodents consist of dentine, with a plate of enamel on the anterior surface, and the unequal wear preserves a chisel-like edge. Enamel is sometimes wanting, as in the molars of the Sloth and the tusks of the Elephant.

In Fishes and Reptiles, there is an almost unlimited succession of teeth; but Mammalian teeth are cast and renewed but once in life.

Vertebrates use their teeth for the prehension of food, as weapons of offence or defence, as aids in locomotion, and as instruments for uprooting or cutting down trees. But in the higher class they are principally adapted for dividing or grinding the food..$^{30}$ While in nearly all other 
Vertebrates the food is bolted entire, Mammals masticate it before swallowing. Mastication is more essential in the digestion of vegetable than of animal food; and hence we find the dental apparatus most efficient in the herbivorous quadrupeds. The food is most perfectly reduced by the Rodents.

Teeth, as we shall see, are appendages of the skin, not of the skeleton, and, like other superficial organs, are especially liable to be modified in accordance with the habits of the creature. They are, therefore, of great zoological value; for, such is the harmony between them and their uses, the naturalist can predict the food and general structure of an animal from a sight of the teeth alone. For the same reason, they form important guides in the classification of animals; while their durability renders them available to the paleontologist in the determination of the nature and affinities of extinct species, of which they are often the sole remains. Even the structure is so peculiar that a fragment will sometimes suffice.

4. Deglutition, or How Animals Swallow.--In the lowest forms of life, the mouth is but an aperture opening immediately into the body-cavity, and the food is drawn in by ciliary currents. But in the majority of animals, a muscular tube, called the gullet, or œesophagns, intervenes between the mouth and stomach, the circular fibres of which contract, in a wave-like manner, from above downward, propelling the morsel into the stomach. ${ }^{31}$ In the higher Mollusks, Arthropods, and Vertebrates, deglutition is generally assisted by the tongue, which presses the food backward, and by a glairy juice, called saliva, which facilitates its passage through the gullet. ${ }^{32}$ Vertebrates have a cavity behind the mouth, called the throat, or pharynx, which may be considered as a funnel to the cesophagus. ${ }^{33}$ In air-breathers, it has openings leading to the windpipe, nose, and ears. In Man, as in Mammals generally, the 
process of deglutition is in this wise: the food, masticated by the teeth and lubricated by the saliva, is forced by the tongue and cheeks into the pharynx; the soft palate keeping it ont of the nasal aperture, and the valve-like epiglottis falling down to form a bridge over the opening to the windpipe. The moment the pharynx receives the food, it is firmly grasped, and, the muscular fibres contracting above it and left lax below it, it is rapidly thrust into the œsophagus. Here, a similar movement (the peristaltic) strips the food into the stomach. ${ }^{34}$ The rapidity of these contractions transmitted along the œsophagus may be observed in the neck of a Horse while drinking.

Deglutition in the Serpents is painfully slow, and somewhat peculiar. For how is an animal, withont limbs or molars, to swallow its prey, which is often much larger than its own body? The Boa-constrictor, e.g., seizes the

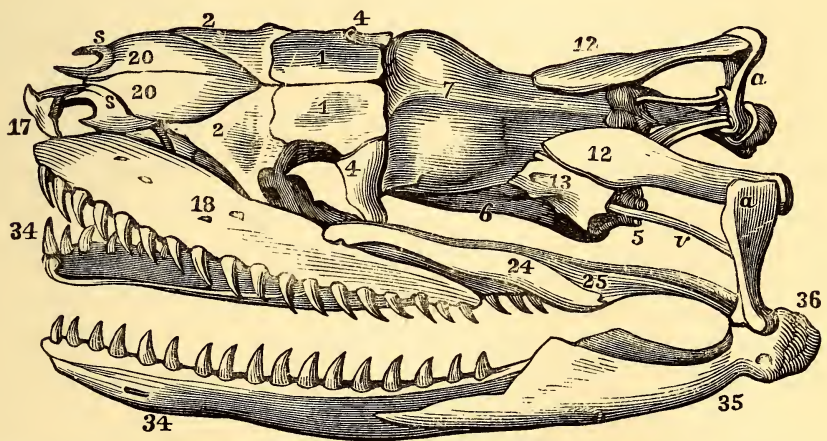

Fic. 37.-Skull of Boa-constrictor : 1, fiontal ; 2, prefrontal ; 4, postfrontal ; 5, basioccipital ; 6, sphenoid; 7 , parietal ; 12 , squamosal; 13 , proötic; 17 , premaxillary ; 18 , maxillary ; 20 , nasal ; 24 , transverse ; 25 , internal pterygoid ; 34 , dentary, lower jaw ; 35 , angular ; 36 , articular ; $a$, quadrate ; $s$, prenasal; $v$, petrosal.

head of its victim with its sharp recurving teeth, and crushes the body with its overlapping coils. Then, slowly uncoiling, and covering the carcass with a slimy mucus, it thrusts the head into its mouth by main force, the mouth stretching marvellonsly, the skull being loosely put 
together. One jaw is then unfixed, and the teeth withdrawn by being pushed forward, when they are again fastened farther back upon the animal. The other jaw is then protruded and refastened; and thus, by successive movements, the prey is slowly and spirally drawn into the wide gullet.

\section{CHAPTER IX.}

THE ALIMENTARY CANAL.

The Alimentary Canal is the great route by which nutritive matter reaches the interior of the body. It is the most universal organ in the animal kingdom, and the rest are secondary or subservient to it. In the higher animals, it consists of a mouth, pharynx, gullet, stomach, and intestine.

It is a general law, that food can be introduced into the living system only in a fluid state. While plants send forth their roots to seek nourishment from without, animals, which may be likened to plants turned ontside in, have their roots (called absorbents) directed inward along the walls of a central tube or cavity. This cavity is for the reception and preparation of the food, so that animals may be said to carry their soil about with them. The necessity for such a cavity arises not only from the fact that the food, which is usually solid, must be dissolved, so as to make its way through the delicate walls of the cavity into the system, but also from the occurrence of intervals between the periods of eating, and the consequent need of a reservoir. For animals, unlike plants, are thrown upon their own wits to procure food.

The Protozoa, as the Amœba and Infusoria, can hardly 
be said to have a digestive canal. The animal is here composed of a single cell, in which the food is digested. The jelly-like Amœba passes the food through the firmer outer layer (ectosarc) into the more fluid inner part (endosarc), where it is digested. The Infusoria, which have a cuticle, and so a more definite form, possess a mouth, or opening, into the interior of their cell-body, and at least a definite place where the excrement is passed out. But we cannot call this cell-cavity a digestive tract.

In the higher animals, the alimentary canal is a continuation of the skin, which is reflected inward, as we turn the finger of a glove..$^{35}$ We find every grade of this reflection, from the sac of the Hydra to the long intestinal tube of the Ox. So that food in the stomach is still outside of the true body.

The simplest form of such a digestive tract is seen in the Hydra (Fig. 191). Here the body is a simple bag, whose walls are composed of two layers of cells (ectoderm and endoderm). A mouth leads into the cavity, and serves as well for the outlet of matter not wanted. The endodermal cells furnish the juices by which the food is digested and absorb the nutritious portions of it. There is no radical difference, however, between the two layers of cells, for the Hydra has been turned inside out, when the former ectoderm

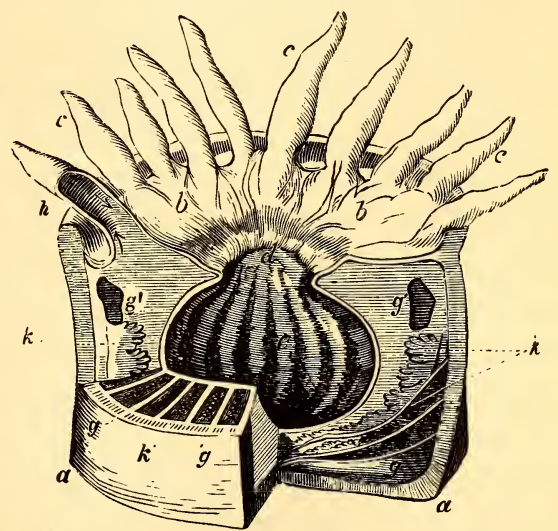

Frg. 38.-Dissected Actinia: $a$, the thick opaque skin consisting of ectoderm, lined with muscular fibres; $c$, the tubular tentacles communicating with the interspaces; $k$, between the membranous vertical folds; $g, g^{\prime}$, orifices in the walls allowing passage of respiratory water from one compartment to another; $d$, mouth leading to gastric cavity, $e$. 
has digested the food and the former endoderm has taken on the functions of the outer layer. The Polyps have also but one external opening; but from this hangs down a short tube, open at both ends, reaching about half-way to the bottom of the body-cavity. Such an arrangement would be represented by a bottle with its neck turned inward. In this suspended sac, which is somewhat constricted at the extremities, digestion takes place; but the product passes freely into all the surrounding chambers, - along with the water for respiration. The Medusæ, or Jelly-fishes, preserve the same type of a digestive apparatus; but the sac is cut off from the general cavity, and numerous canals radiate from it to a circular canal near the margin of the disk. In the Star-fishes (Fig. 126), we find a great advance. The sac-like stomach sends off two glandular branches to each arm, which doubtless furnish a fluid to aid in digestion (so-called hepatic cœca). There is also an anus present in some forms, but it hardly serves to pass off the waste matter.

Thus far we have seen but one opening to the digestive cavity, rejected portions returning by the same road by which they enter. But a true alimentary canal should have an anal aperture distinct from the oral. The simplest form of such a canal is exhibited by the Sponge, in its system of absorbent pores for the entrance of liquid, and of several main channels for its discharge. The apparatus, however, is not marked off from the general cavity of the body, and digestion is not distinct from circulation. ${ }^{36}$

The Sea-urchin presents us with an important advance -one cavity with two orifices; and the complicated apparatus of higher animals is but the development of this type. This alimentary canal begins in a mouth well provided with teeth and muscles, and extends spirally to its outlet, which generally opens on the upper, or opposite, 
surface. Moreover, while in some of the Worms the canal is a simple tube running through the axis of the cylindrical body from oral orifice to anal aperture, the canal of the Sea-urchin shows a distinction of parts, foreshadowing the pharynx, gullet, stomach, andintestines. Both mouth and vent have muscles for constriction and expansion; and, as the vent is on the summit of the shell, and the latter is covered with spines, the ejected particles are seized by delicate forks (pedicellarice), and passed on from one to the other down

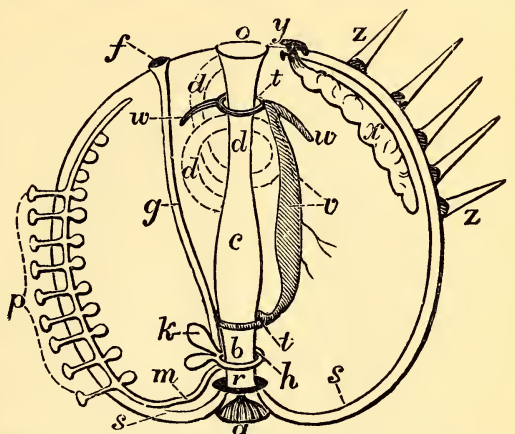

Fig. 39.-Diagrammatic Section of a Sea-urchin (Echinus): $a$, mouth ; $b$, œsophagus; $c$, stomach ; $d$, intestine: $f$, madreporiform tubercle : $g$, stone-canal ; $h$, ambulacral ring: $k$, Poliau vesicles, which are probably reservoirs of fluid; $m$, ambulacral tube; $o$, anus; $p$, ambulacra, with their contractile vesicles; $r$, nervous ring around the gullet; $s$, two nervous trunks, the right terminating, at anal pole, in a small ganglion; $t$, blood-vascular rings connected by $v$, the contractile heart; $w$, two arterial trunks radiating from the anal ring; $x$, an ovary opening at the anal pole in a genital plate, $y ; z$, spines, with their tubercles.

the side of the body, till they are dropped off into the water. ${ }^{37}$

The Worms present us with a great range of structure in the digestive tract. It is sometimes almost as simple as that of the Hydra-a mere sac. The Earth-worm has a tube running straight through the body, divided into pharynx, œsophagus, crop, gizzard, and sacculated intestine. The Leech has large sacs on each side of the intestine. The Sea-worms have the pharynx armed with teeth, and some have glandular cœea attached to the intestine. The plan is that of a straight tube extending from mouth to anus. In Myriapods and larvæ of Insects, the same general plan is continued, the canal passing in a straight line from one extremity to the other, but showing a division into gullet, stomach, and intestine. ${ }^{38}$ Crustacea, like 
the Lobster, have a short gullet leading to a large cavity, situated in the front of the animal, which is a giz-

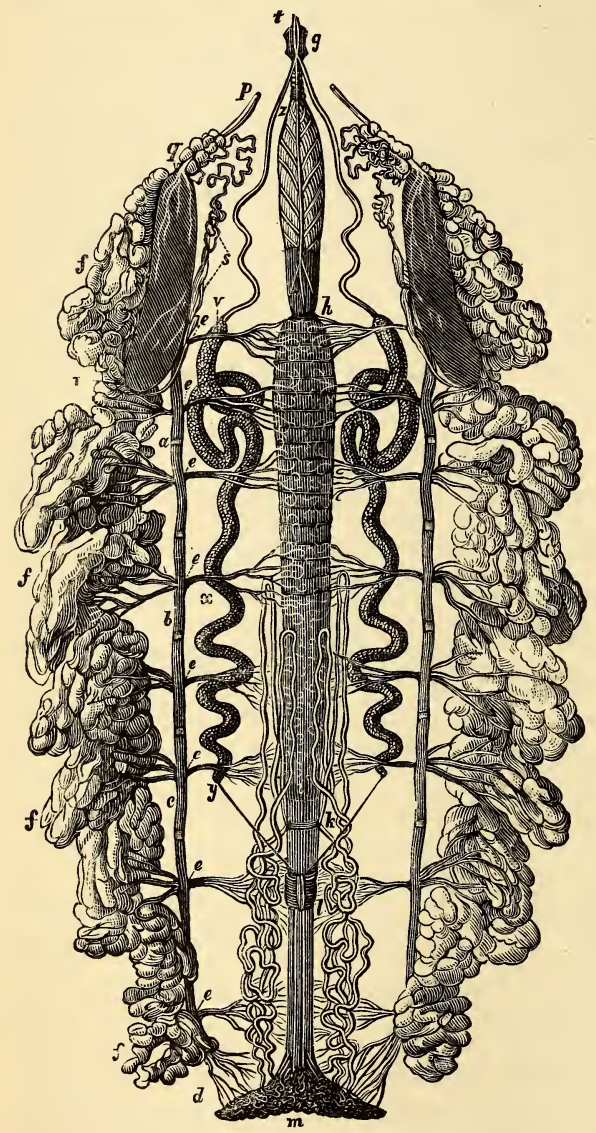

Frg. 40.-Anatomy of a Caterpillar: $g, h$, œsophagus; $h$, $i$, stomach ; $k$, hepatic vessels ; $l, m$, intestine ; $q, r$, salivary glands; $p$, salivary duct; $a, b, c$, longitudinal tracheal trunks ; $d, e$, air-tubes distributed to the viscera ; $f$, fat-mass; $v, x, y$, silk-secretors ; $z$, their excretory ducts, terminating in $t$, the spinneret, or $f u$ sulus. zard, rather than stomach, as it has thick muscular walls armed with teeth. A wellmarked constriction separates this organ from the intestine. The liver is highly developed; instead of numerons follicles, there is a large bilaterally symmetrical organ, divided into three lobes on each side, pouring its secretion into the upper part of the intestine, which is the true stomach. Among Insects, there is great variation in the form and length of the canal. The following parts can generally be distinguished: gullet, crop, gizzard, stomach, and large and small intestines, with many glandular appendages. The crop, gizzard, and large intestine are sometimes absent, especially in the carnivorous 
species. In Bees, the crop is called the "honey-bag." The gizzard is found in Insects having mandibles, and is

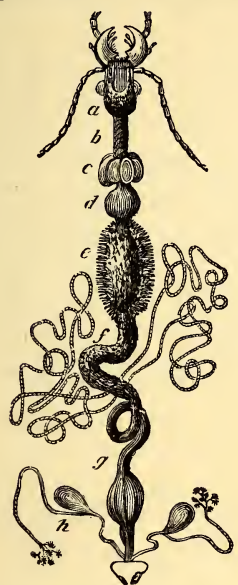

FIG. 41.-Alimentary canal of a Beetle: $a$, pharynx; $b$, gullet, leading to crop, $c$, gizzard, $d$, and stomach, $e ; f$, delicate urinary tubes; $g$, intestine; $h$, other secreting organs.

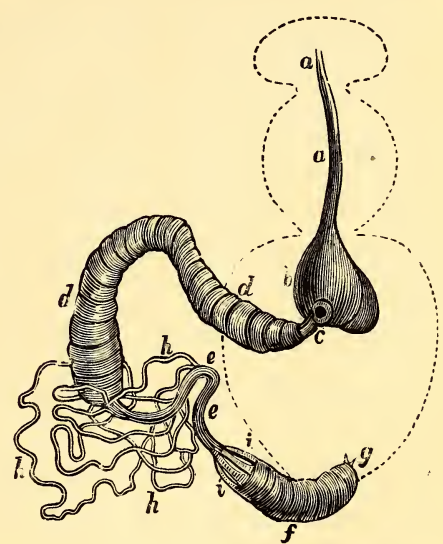

Frg. 42. - Alimentary Canal of the Bee (A pis mellifica): $a$, gullet; $b$, crop; $c, d$, stomach ; $e$, small intestine; $f$, large intestine ; $g$, anal orifice; $h$, urinary vessels ; $i$, auxiliary glands.

frequently lined with rows of horny teeth, which are specially developed in Grasshoppers, Crickets, and Locusts. The intestines are remarkable for their convolutions. Insects have no true liver; but its functions are performed by little cell-masses on the inside of the stomach. ${ }^{39}$

The alimentary canal of Spiders is short and straight, the pharynx and gullet being very minute. The stomach is characterized by sending out tubular prolongations, and

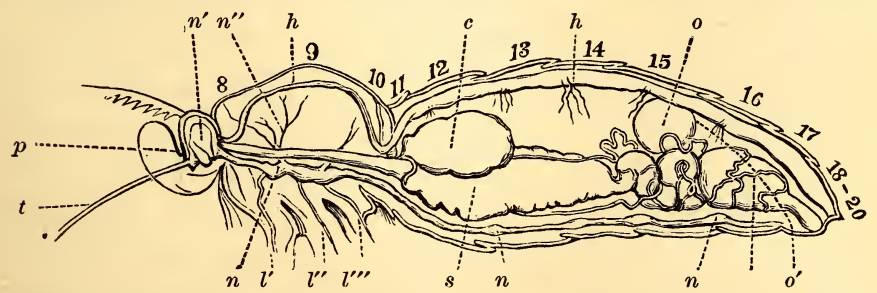

Frg. 43.-Anatomy of a Sphinx Moth: $n$, nervous cord ; $n^{\prime}$, brain sending off nerves to the legs, $l^{\prime}, l^{\prime \prime}, l^{\prime \prime \prime}$, and for the wings at $n^{\prime \prime} ; h$, dorsal vessel, or heart; $c$, crop; $s$, stomach ; $i$, intestines; $o$, reproductive organs; $o^{\prime}$, oviduct; $8-20$, segments. 
the intestines end in a large bladder-like expansion. Scorpions have no stomachal cavity - a straight intestine passes directly through the body.

In bivalve Mollusks, like the Clam, the mouth opens into a short œsophagus which leads into the stomach, which lies imbedded in a large liver, and the intestine, describing a few turns, passes directly through the heart. ${ }^{40}$ In the univalve Mollnsks, like the Snail, the gullet is long, and frequently expands into a crop; the stomach is often double, the anterior being a gizzard provided with teeth for mastication; the intestine passes through the liver, and ends in the fore-part of the body, usually on the right side.

The highest Mollusks, as the Cuttle-fish and Nantilus, exhibit a marked advance. A mouth with powerful mandibles leads to a long gullet, which ends in a strong muscular gizzard resembling that of a fowl. ${ }^{41}$ Below this is a cavity, which is either a stomach or duodenum; it receives

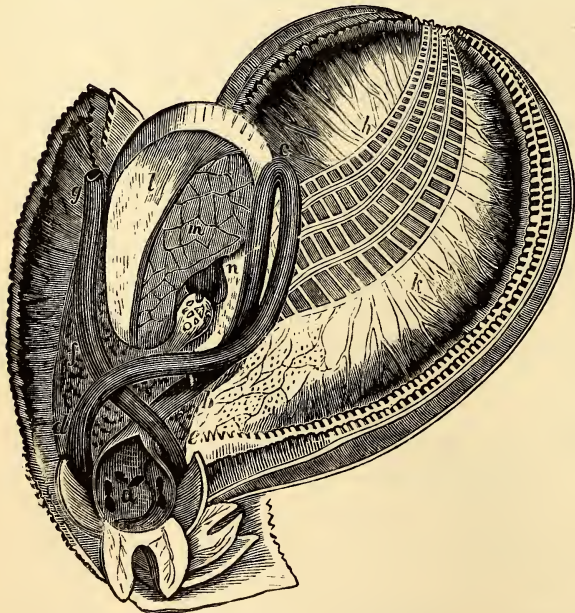

Fig. 44.-Alimentary Canal of the Oyster: $a$, stomach laid open ; $d$, liver : $b, c, d, f$, convolutions of the intestine; $g$, anal aperture; $n, o$, auricle and ventricle $l$, $m$, adductor muscle; $h, k$, lobes of mouth divided to show the venuus canals at the base of the gills. the bile from a large liver. The intestine is a tube of uniform size, which, after one or two slight curves, bends up, and opens into the "funnel" near the mouth.

Fishes have a simple, short, and wide alimentary canal. The stomach is separated from the intestine by a narrow "pyloric" orifice, or 


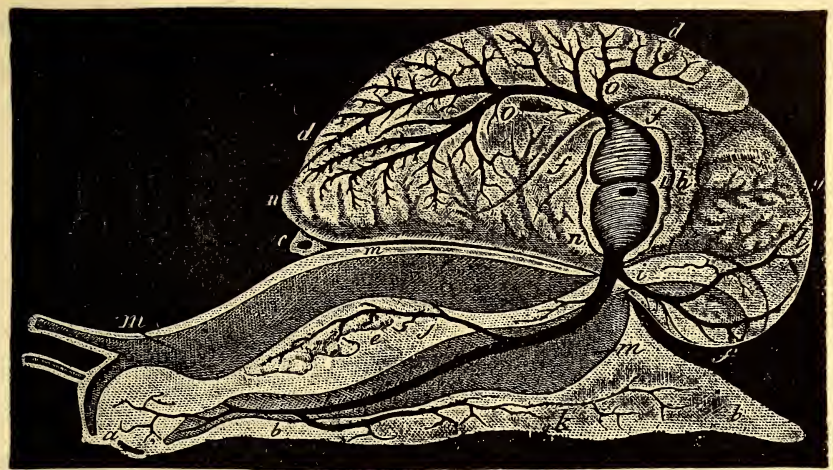

Fig. 45. - Anatomy of a Gasteropod (Snail): $a$, mouth; $b$, foot; $c$, anus; $d$, lung ; $e$, stomach, covered above by the salivary glands ; $f$, intestine ; $g$, liver; $h$, heart ; $i$, aorta $j$, gastric artery ; $l$, hepatic artery ; $k$, artery of the foot ; $m$, abdominal cavity, supplying the place of a venous sinus; $n$, irregular canal communicating with the abdominal cavity, and carrying the blood to the lung; 0 , vessel carrying blood from the lung to the heart.

valve, but is not so clearly distinguished from the gullet, so that regurgitation is easy. ${ }^{42}$ Indeed, it is common for

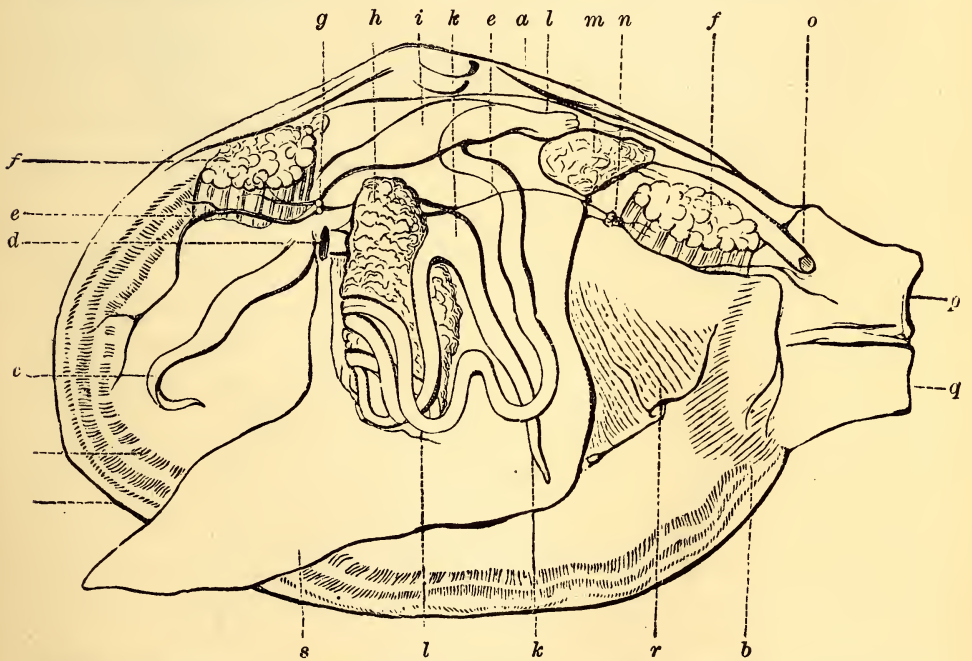

Fig. 46.-Anatomy of a Lamellibranch (Mactra) : $a$, shell; $b$, mantle ; $c$, tentacles, or lips ; $d$, mouth ; $e$, nerves ; $f$, muscles ; $g$, anterior, and $n$, posterior ganglion; $h$, liver ; $i$, heart: $k$, stomach ; $l$, intestine passing through the heart; $m$, kidney 0 , anal end of the intestine; $p$, exhalent, and $q$, inhalent respiratory tubes, or siphous ; $r$, gills; $s$, foot. 
Fishes to disgorge the indigestible parts of their food, and some, as the Carp, send the food back to the pharynx to be masticated. The stomach is usually bent, like a siphon; but the intestine is nearly straight, and withont any marked distinction into small and large. Its appendages are a large liver and a rudimentary pancreas.

In the Amphibians, as the Frogs, the digestive apparatus is very similar to that of Fishes; but the two kinds

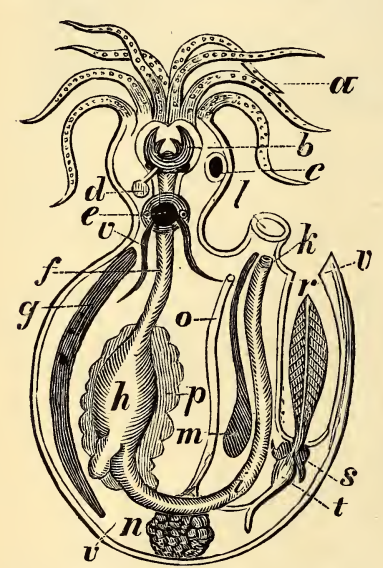
of intestines can be more readily distinguished. The Reptiles generally have a long, wide gullet, which passes insensibly into the stomach, and a short intestine (about twice the length of the body) very distinctly divided into small and large by a constriction. $^{43}$ The regetable-feeding Tortoises have a comparatively long intestinal tube; and the Serpents have a slender stomach, but little wider than the rest of Fir. 47.-Anatomy of a Cephalopod the alimentary canal.

(diagram): $a$, tentacles; $b$, masticatory apparatus ; $c$, eye; $d$, salivary gland; $e$, nervous ganglia ; $f$, csophagus; $g$, internal shell, or "cuttle-bone;" $h$, stomach ; $i$, intestine; $k$, anus; $l$, funnel; $m$, ink-bag: $n$, ovary; $o$, oviduct; $p$, that of the Cuttle-fish, but offer's liver; $r$, gill contained in the bran-
chial chamber; $s$, branchial heart; a still more striking analogy to $t$, systemic heart; $v$, mantle.

The stomach of the Crocodile is more complex than any hitherto mentioned. It resembles the gizzard of a Bird, having very thick walls, and the muscular fibres radiating precisely in the same manner, so that, in this respect, the Crocodile may be considered the connecting link between Reptiles and Birds. ${ }^{44}$ In Crocodiles also the duodenum, with which the intestine begins, is first distinctly defined. Into this part of the intestine the liver and pancreas, or sweet-bread, ponr their secretions. Furthermore, in the 
lower animals, the intestines lie more or less loose in the abdomen; but in the Crocodile, and likewise in Birds and Mammals, they are supported by a membrane called mesentery.

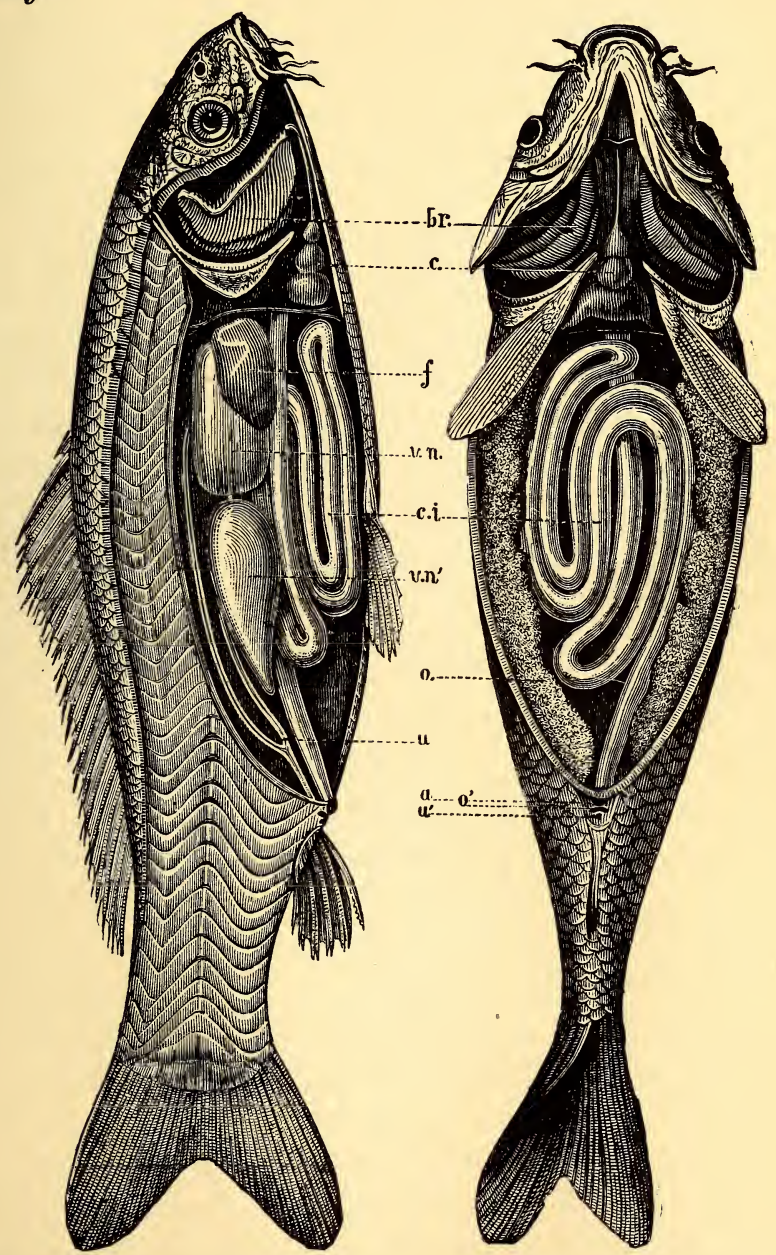

Frg. 48.-Anatomy of the Carp : $b r$, branchiæ, or gill-openings; $c$, heart; $f$, liver; $v n$, $v n^{\prime}$, swimming-bladder; $c i$, intestinal canal ; $o$, ovarium ; $u$, ureter; $a$, anus ; $o^{\prime}$, genital opening; $u^{\prime}$, opening of ureter. The side-view shows the disposition of the muscles in vertical flakes. 
In Birds, the length of the alimentary canal varies with their diet, being greatest in those living on grain and fruit. The gullet corresponds in length with the neck, which is longest in the long-legged tribes, and in width with the food. In those that swallow large fish entire, the gullet is dilatable, as in Snakes. In nearly all Birds, the food is delayed in some cavity before digestion: thus, the Pelican has a bag under the lower jaw, and the Cormorant has a

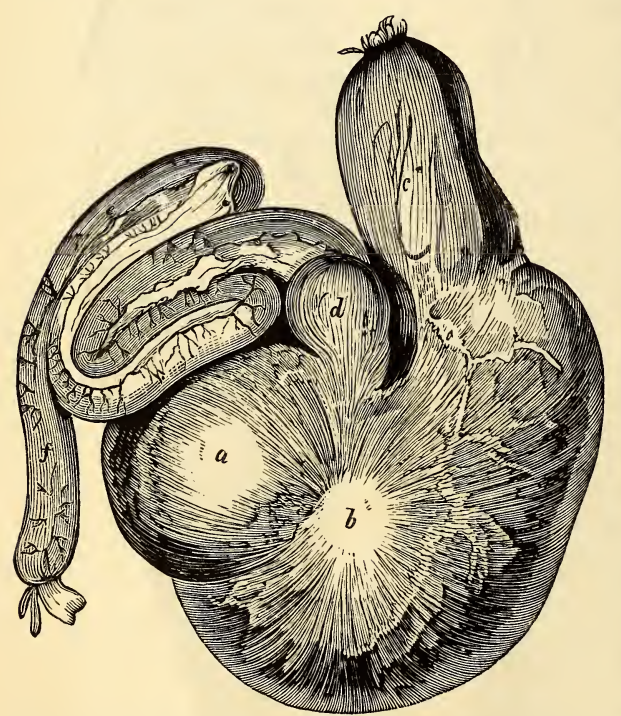

Fig. 49.-Stomach of the Crocodile: $a$, muscular fibres radiating from a central teudon, $b ; d$, commencement of duodenum; $c$, cesophagus; $f$, intestine. capacious gullet, where they store up fishes; while those that gorge themselves at intervals, as the Vulture, or feed on seeds and grains, as the Turkey, have a pouch, called the crop, developed near the lower end of the gullet. ${ }^{45}$ The Ostrich, Goose, Swan, most of the Waders, and the fruit or insect eating Birds, which find their food in tolerable abundance, and take it in small quantities, have no such reservoir. Pigeons have a double crop.

In all Birds, the food passes from the gullet into the proventriculus, or stomach proper, where it is mixed with a "gastric juice" secreted from glands on the surface. Thence it goes into the gizzard, an oval sac of highly muscular texture, and lined with a tough, horny skin. ${ }^{48}$ 
The gizzard is most highly developed, and of a deep-red color, in the Scratchers and flat-billed Swimmers (as Fowls and Swans); but comparatively thin and feeble in Birds of Prey (as the Eagle). The gizzard is followed by the intestines, which are longer than those of Reptiles: the small intestine begins with a loop (the duodenum), and is folded several times upon itself; the large intestine is short and straight, terminating in the sole outlet of the body, the cloaca. A liver and pancreas are always attached to the upper part of the small intestine.

The alimentary canal in Mammals is clearly separated into four distinct cavities: the pharynx, or throat; the œesophagus, or gullet; the stomach; and the intestines.

The pharynx is more complicated than in Birds. It is a funnelshaped bag, having seven openings leading into it: two from

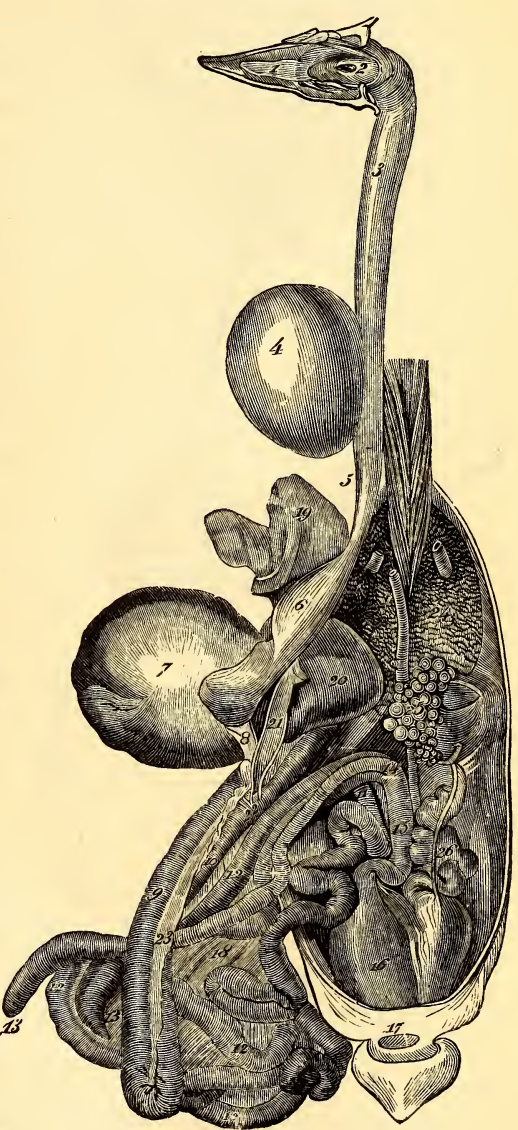

Frg. 50. -Digestive Apparatus of the Fowl: 1, tongue; 2 , pharynx; 3,5 , œsophagus ; 4 , crop: 6 , proventriculus ; 7 , gizzard ; $8,9,10$, duodenum ; 11,12 , small intestine; 13 , two cæca (analogue of the colon of mammals); 14, their insertion into the intestinal tube; 15 , rectum; 16 , cloaca; 17 , anus ; 18 , mesentery ; 19, 20 , left and right lobes of liver ; 21, gall-bladder; 22, insertion of pancreatic and biliary ducts : 23 , pancreas ; 24 , lnng; 25 , ovary ; 26 , oviduct. 


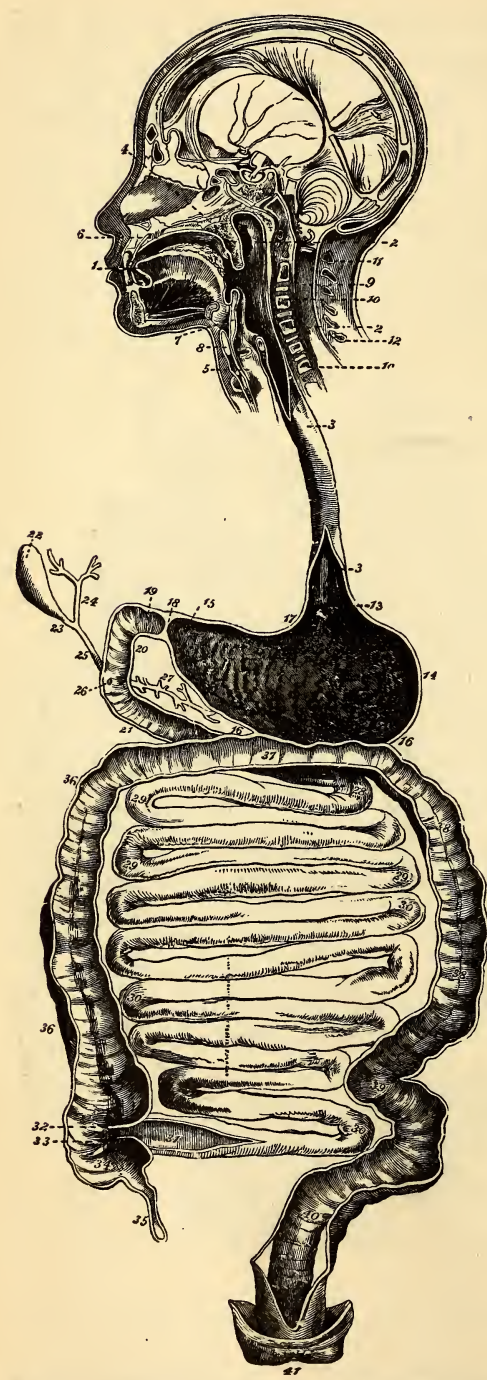

the nostrils, and two from the ears; one from the windpipe, guarded by the epiglottis; one from the mouth, with a fleshy curtain called the soft palate; and one from the œsophagus. It is the natural passage for food between the mouth and the œsophagus, and of air between the nostrils and windpipe. Like the mouth, it is lined with a soft mucous membrane.

The œsophagus is a long and narrow tube, formed of two muscular layers: in the outside one, the fibres run lengthwise; in the other, they are circular. It is lined with mucous membrane. While in all Fishes, Reptiles, and Birds the ventral chamber is one, in Mammals it is divided, by a partition called the diaphragm, into two cavities - the thorax, containing the heart, lungs,

Fia. 51.-Digestive Apparatus of Man (diagram) : 1, tongue; 2, pharynx; 3, œsophagus; 4 , soft palate; 5 , larynx; 6 , palate; 7 , epiglottis; 8 , thyroid cartilage; 9 , beginning of spinal marrow; 10, 11, 12, vertebre, with spinous processes; 13 , cardiac orifice of stomach; 14, left end of stomach ; 18, pyloric valve; 19, 20, 21, duodenum; 22, gall-bladder; 27 , duct from pancreas; 28,29 , jejunum of intestine; 30 , ileum ; 34 , cœcum; $36,3 \pi, 38$, colon, or large intestine; 40 , rectum. 
etc.; and the abdomen, containing the stomach, intestines, etc. The œsophagus passes through a slit in the

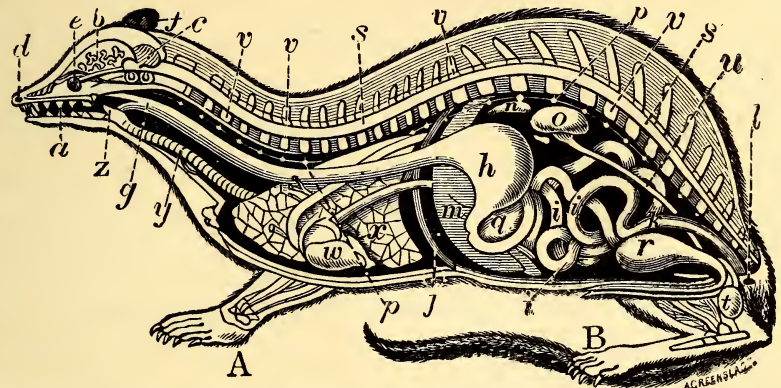

FrG. 52.-Ideal Section of a Mammalian Vertebrate: A, pectoral, or fore limb; B, pelvic, or hind limb : $a$, mouth; $b$, cerebrum; $c$, cerebellum; $d$, nose ; $e$, eye; $f$, ear ; $g$, œsophagus ; $h$, stomach ; $i$, intestine; $j$, diaphragm, or midriff ; $k$, rectum, or termination of intestine ; $l$, anns ; $m$, liver ; $x$, spleen; $\bullet$, kidney ; $p$, sympathetic system of nerves ; $q$, pancreas ; $r$, urinary bladder ; $s$, spinal cord; $u$, ureter; $v$, vertebral column; $w$, heart; $x$, lung; $y$, trachea, or windpipe; $z$, epiglottis.

diaphragm, and almost immediately expands into the stomach.

In the majority of Mammals, the stomach is a muscular bag of an irregular oval shape, lying obliquely across the abdomen. In the Flesh-eaters, whose food is easy of solution, the stomach is usually simple, and lies nearly in the course of the alimentary canal; but in proportion as the food departs more widely in its composition from the body itself, and is therefore more difficult to digest, we find the stomach increasing in size and complexity, and turned aside from the general course of the canal, so as to retain the food a longer time. The inlet, or open-

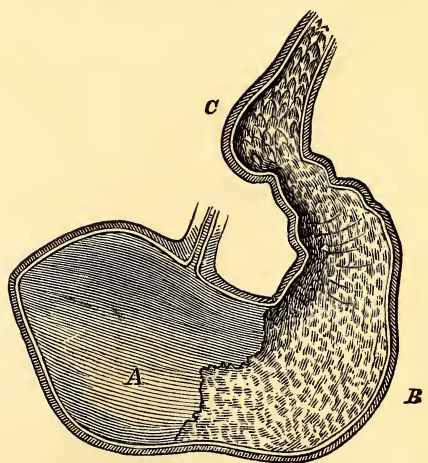

Fir. 53.-Section of Horse's Stomach : $\boldsymbol{A}$, left sac; $B$, right sac; $C$, duodenum. ing, into the osophagus is called cardiac; the outlet, or 
opening, leading into the intestines is called pyloric. In the Carnivores, Apes, and most odd-toed quadrupeds, the

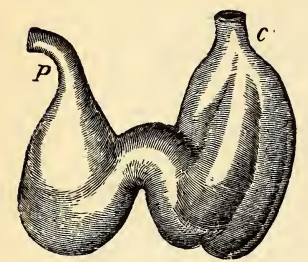

Fig. 54. - Stomach of the Porpoise: $c$, cardiac; $p$, pyloric. stomach resembles that of Man. That of the toothless Ant-eater has the lower part turned into a kind of gizzard for crushing its food. The Elephant's is subdivided by numerons folds. In the Horse, it is constricted in the middle; and in the Rodents, Porpoises, and Kangaroos, the constriction is carried so far as to make two or three sections. But animals that chew the cud (Ruminants) have the most complex stomach. It is divided into four peculiar chambers: First, the paunch (rumen), the largest of all, receives the half-masticated food when first swallowed. The inner surface is covered with papillæ, except in the Camel, which has large cells

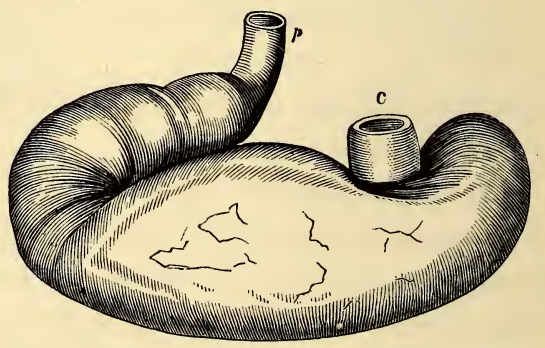
for storing up water. Frg. 55.-Stomach of the Lion: $c$, cardiac orifice, or From this, the food entrance of œsophagus; $p$, pyloric.

passes into the honey-comb stomach (reticulum), so named from its structure. Liquids swallowed usually go directly to this cavity, without passing through the paunch, and

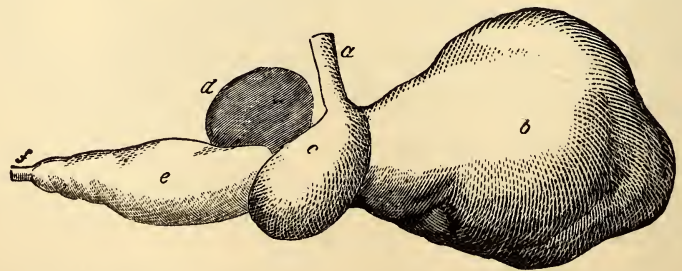

Fí. 56.-Complex Stomach of a Ruminant: $a$, gullet; $b$, rumen, or paunch ; $c$, reticuIum ; $d$, psalterium, or manyplies; $e$, abomasus ; $f$, pylorus leading to duodenum. 
hence it is sometimes called the water-bag. Here the food is made into little balls, and returned to the mouth , to undergo a thorough mastication. When finally swallowed, it is directed, by a groove from the œsophagus, to the third, and smallest, cavity, the manyplies (psalterium), named from its numerous folds, which form a strainer to keep back any undivided food; and thence it passes into the true stomach (abomasus), from which, in the calf, the rennet is procured for curdling milk in the manufacture of cheese. This fourth cavity is like the human stomach in form and function, and is the only part which secretes gastric juice. The rumen and reticulum are rather dilatations of the œsophagus than parts of the stomach itself; while the latter is divided by constriction into two chambers, the psalterium and abomasus, as in many other animals.

In structure, the stomach resembles the œsophagus. The smooth outside coat (peritoneum) is a reflection of the membrane which lines the whole abdomen. The middle, or muscular, coat consists of three layers of fibres, running length-

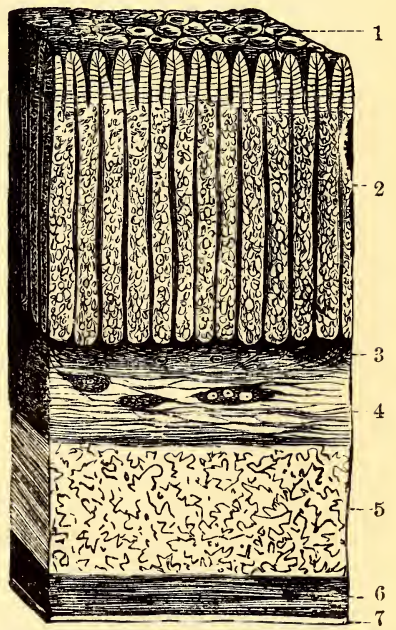

Fig. 57. - Vertical Section of the Coats of the Stomach: 1, surface of mucous membrane, and mouths of gastric follicles; 2, gastric tubuli, or follicles; 3 , dense connective tissue ; 4, submucous tissue; 5 , transverse muscular fibre; 6 , longitudinal muscular fibre; 7 , fibrous, or serous, cuat.

wise around and obliquely. The successive contraction and relaxing of these fibres produce the worm-like motion of the stomach, called peristaltic. The innermost, or mucous, membrane, is soft, velvety, of a reddish-gray color in Man, and filled with multitudes of glands, which secrete the gastric juice. The human stomach, when distended, will 
hold about five pints; that of the Kangaroo is as long as its body.

The intestinal canal in Mammals begins at the pyloric end of the stomach, where there is a kind of valve or circular muscle. Like the stomach, it varies greatly, according to the nature of the food. It is generally longest in the Vegetable-feeders, and shortest in the Flesh-feeders. The greater length in the former is due to the fact that

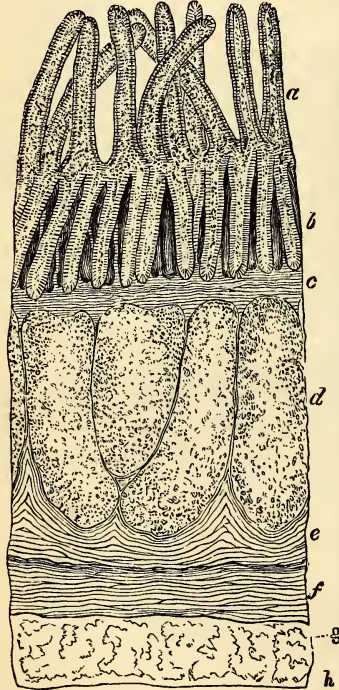

Fra. 58.-Section of the Wall of the Human Intestine (ileum), $\times 50: a$, villi; $b$ and $d$, glands; lodging-place for the useless part $c$ and $e$, mucous membrane; $f$, circular muscles; $g, h$, longitudinal muscles. time for digestion, and that a greater bulk of such food is required to obtain a given quantity of nutriment. The intestines measure 150 feet in a full-grown Ox, while they are but three times the length of the body in the Lion, and six times in Man. Save in some lower forms, as the Whales, there are two main divisions, the "small" and "large" intestines, at the junction of which is a valve. The former is the longer of the two, and in it digestion is completed, and from it absorption takes place. The large intestine is a temporary of the food, until it is expelled from the body. The beginning of vegetable food requires a longer the small intestine is called the duodenum, into which the ducts from the liver and pancreas open. The intestinal canal has the same structure as the stomach, and by a peristaltic motion its contents are propelled downward. The inside surface of the small intestine is covered with a host of thread-like processes (villi), resembling the pile of velvet. 
In taking this general survey of the succession of forms which the digestive apparatus presents among the principal groups of animals, we cannot fail to trace a gradual specialization. First, a simple sac, one orifice serving as inlet for food and outlet for indigestible matter; next, a short tube, with walls of its own suspended in the bodycavity; then a canal passing through the body, and, therefore, having both mouth and vent; next, an apparatus for mastication, and a swelling of the central part of the canal into a stomach, having the special endowment of secreting gastric juice; then a distinction between the small and large intestine, the former thickly set with villi, and receiving the secretions of large glands. We also notice that food, the means of obtaining it, the instruments for mastication, and the size and complexity of the alimentary canal, are closely related.

\section{CHAPTER $\mathrm{X}$.}

\section{HOW ANIMALS DIGEST.}

The object of the digestive process is the reduction of food into such a state that it can be absorbed into the system. For this purpose, if solid, it is dissolved; for fluidity is a primary condition, but not the only one. Many soluble substances have to undergo a chemical change before they can form parts of the living body. If albumen or sugar be injected into the veins, it will not be assimilated, but be cast out unaltered.

To produce these two essential changes, solution and transmutation, two agencies are used - one mechanical, the other chemical. The former is not always needed, for many animals find their food already dissolved, as the 
Butterfly; but solid substances, to facilitate their solution, are ground or torn into pieces by teeth, as in Man; by jaws, as in the Lobster; or by a gizzard, as in the Turkey.

The chemical preparation of food is indispensable. ${ }^{47}$ It is accomplished by one or more solvent fluids secreted in the alimentary canal. The most important, and one always present, is the gastric jnice, the secretion of which is restricted to the stomach, when that cavity exists. In the higher animals, numerous glands pour additional fluids into the digestive tube, as saliva into the upper part or mouth, and bile and pancreatic juice into the upper part of the intestine. In fact, the mucous membrane, which lines the alimentary canal throughout, abounds with secreting glands or cells.

The Digestive Process is substantially the same in all animals, but it is carried further in the more highly developed forms. In the Infusoria, the food is acted upon by some secretion from the walls of the body-cavity, the exact nature of which is unknown. In the Star-fish and Sea-urchin, we find two solvents - a gastric juice, and another resembling bile; but the two appear to mingle in the stomach. Mollusks and Arthropods show a clear distinction between the stomach and intestine, and the contents of the liver are poured into the latter. There are, therefore, two stages in the digestive act: first, the food is dissolved by the gastric juice in the stomach, forming chyme; secondly, the chyme, upon entering the intestine, is changed into chyle by the action of the bile, and is then ready to be absorbed into the system.

In Vertebrates, a third solvent is added, the pancreatic juice, which aids the bile in completing digestion. But Mainmals and Insects have a still more perfect and elaborate process; for in them the saliva of the mouth acts chemically upon the food; while the saliva in many other 
animals has no other office, so far as we know, than to moisten the food for swallowing.

Taking Man as an example, let us note the main facts in the process. During mastication, by which the relative surface is increased, the food is mixed with saliva, which moistens the food, ${ }^{48}$ and turns part of the starch into grape-sugar. Passed into the stomach, the food meets the gastric juice. This is acid, and, first, stops the action of the saliva; secondly, by means of the pepsin which it contains, and the acid, it dissolves the albumen, fibrine, and such constituents of the food. This solution of albuminoids is called a peptone, and is especially distinguished from other such solutions by its diffusibility-i.e., the ease with which it passes through a membrane. These peptones, with the sugars of the food, whether original or the product of the action of the saliva, are absorbed from the stomach. The food, while in the stomach, is kept in continual motion, and, after a time, is discharged in gushes into the intestine. The name chyme is given to the pulpy mass of food in the stomach. In the intestine the chyme meets three fluids-bile, pancreatic juice, and intestinal juice. All of these are alkaline, and at once give the acid chyme an alkaline reaction. This change permits the action of the saliva to recommence, which is aided by the pancreatic and intestinal juices. The pancreatic juice has much more important functions. It changes albuminoid food into peptones, and probably breaks up the fats into very small particles, which are suspended in the fluid chyle. This forms an

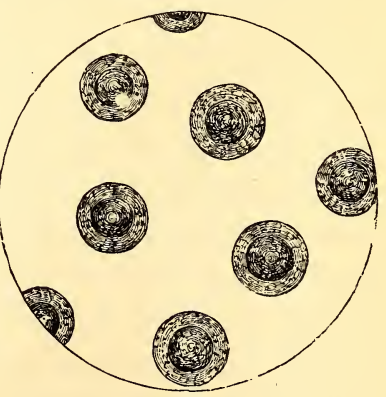

Fig. 59.-Chyle Corpuscles, $\times 500$. emulsion, like milk, and causes the chyle to appear whitish. The bile has important functions, but little under- 
stood. It saponifies part of the fats, so that they are dissolved, and prevents the food from decomposing during the process of digestion and absorption. The chyle is slowly driven through the small intestine by the creeping, peristaltic motion of its walls, ${ }^{49}$ the nutritious portion being taken up by the absorbents, as described in the next chapter, while the undigested part remaining is discharged from the large intestine..$^{50}$

\section{CHAPTER XI. \\ THE ABSORBENT SYSTEM.}

The nutritive matter (chyle), prepared by the digestive process, is still outside of the organism. How shall it enter the living tissue?

In animals, like the Infusoria and Polyps, whose digestive department is not separated from the body-cavity, the food, as soon as dissolved, mingles freely with the tissues and organs it has to nourish. In the higher Invertebrates having an alimentary canal, the chyle passes, by simple transudation, through the walls of the canal directly into the soft tissues, as in Insects, or is absorbed from the canal by veins in contact with it, as in Sea-urchins, Mollusks, Worms, and Crustaceans, and then distributed through the body.

In Vertebrates only do we find a special absorbent system. Three sets of vessels are concerned in the general process by which fresh material is taken up and added to the blood: Capillaries, Lacteals, and Lymphatics. Only the two former draw material from the alimentary canal.

It is a general law that the food is absorbed as fast as 
it is dissolved, and, therefore, there is a constant loss in the passage down the canal. In the mouth and oesophagus, the absorption is slight; but much of that which has yielded to the gastric juice, with most of the water, is greedily absorbed by the capillaries of the stomach, and made to join the current of blood which is rushing to the liver. Absorption by the capillaries also takes place from the skin and lungs. Medicinal or poisonous gases and liquids are readily introduced into the system by these channels.

We have seen that the oily part of the food passes unchanged from the stornach into the small intestine, where, acted upon by the pancreatic juice, it is cut up into extremely minute particles, and that the undigested albuminoids and starches are digested in the intestine. Two kinds of absorbents are present in the intestine, lacteals and blood-capillaries. Both the lymphatic and blood systems send vessels into the velvety villi ${ }^{51}$ with which the intestine is lined. The bloodcapillaries lie towards the outside of the villus and the lacteal in the centre. The albuminoids and sugars are

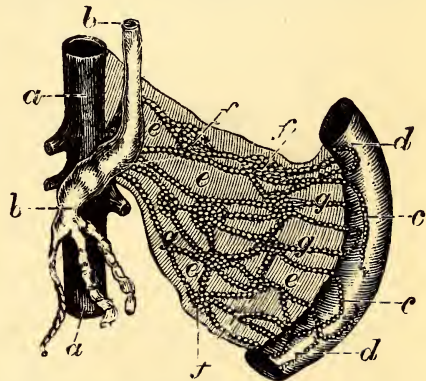

Fig. 60.-Lacteal System of Mammal : $\alpha$. descending aorta, or principal artery ; $b$, thoracic duct; $c$, origin of lacteal vessels, $g$, in the walls of the intestine, $d ; e$, mesentery, or membrane attaching the intestine to walls of the body ; $f$, lacteal, or mesenteric, glands. chiefly absorbed by the blood-vessels and go to the liver. The fats pass on into the lacteals, which receive their name from the milky appearance of the chyle. These lacteals unite into larger trunks, which lie in the mesentery (or membrane which suspends the intestine from the back wall of the abdomen), and these pour their contents into one large vessel, the thoracic duct, lying along the backbone, and joining the jugular vein in the neck. 
The lacteals are only a special part of the great lymphatic system, which absorbs and carries to the thoracic

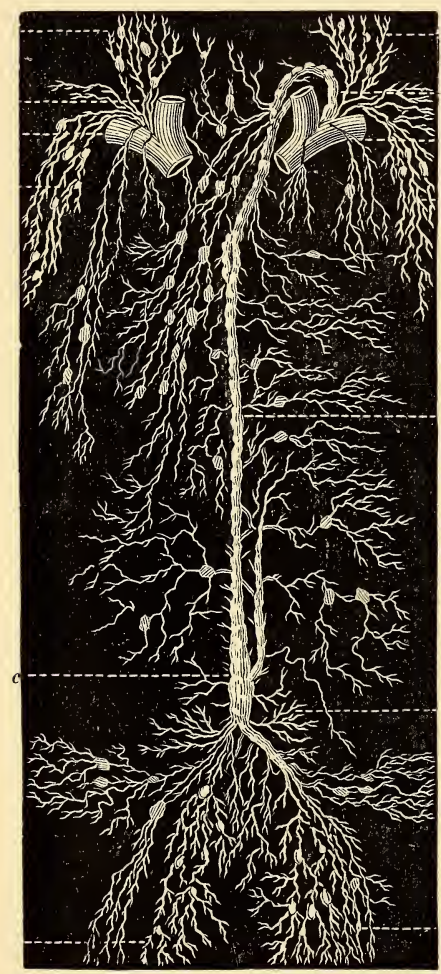

Fig. 61.-Principal Lymphatics of the $\mathrm{Hu}$ man Body : $a$, union of left jugular and subclavian veins; $b$, thoracic duct; $c$, receptaculum chyli. The oval bodies are glands. duct matter from all parts of the body. ${ }^{52}$ The lyinph is a transparent fluid having many white blood corpuscles. It is, in fact, blood, minus the red corpuscles, while chyle is the same fluid rendered milky by numerous fat-globules. During the intervals of digestion, the lacteals carry ordinary lymph. This fluid is the overflow of the blood - the plasma and white corpuscles which escape from the blood capillaries, and are not needed by the tissues in which they are. This surplus overflow is returned to the blood by the lymphatics. The current is kept up by the movements of the body, and in many Vertebrates, as Frogs and Fishes, by lymph hearts.

Like the roots of Plants, the absorbent vessels do not commence with open mouths; but the fluid which enters them must traverse the membrane which covers their minute extremities. This membrane is, however, porous, and the fluids pass through it by the forces of filtration and diffusion. How the fat gets into the lacteals is not yet well understood, but the lacteals are themselves rhythmically contractile, ${ }^{53}$ and force the absorbed chyle tow- 
ards the heart. The valves of the lymphatics prevent its return.

\section{CHAPTER XII.}

THE BLOOD OF ANIMALS.

The Blood is that fluid which carries to the living tissues the materials necessary to their growth and repair, and removes their waste and worn-out material. The great bulk of the body is occupied with apparatus for the preparation and circulation of this vital fluid.

The blood of the lower animals (Invertebrates) differs so widely from that of Man and other Vertebrates, that the former were long supposed to be without blood. In them the blood is commonly colorless; but it has a bluish cast in Crustaceans; reddish, yellowish, or greenish, in Worms; and reddish, greenish, or brownish, in Jellyfishes. The red liquid which appears when the head of a Fly is crushed is not blood, but comes from the eyes. In Vertebrates, the blood is red, excepting the whiteblooded fish, Amphioxus. ${ }^{54}$

As a rule, the more simple the fabric of the body, the more simple the nutritive fluid. In unicellular animals (as Protozoa), in those whose cells are comparatively independent (as Sponges), and in small and lowly organized animals (like Hydra), there is no special circulating fluid. Each cell feeds itself either directly from particles of food, or from the products of digestion. In Polyps and Jelly-fishes, the blood is scarcely different from the products of digestion, although a few blood-corpuscles are present. But in the more highly organized Invertebrates the blood is a distinct tissue, coagulating, and containing white corpuscles. The blood of the Vertebrates, appar- 
ently a clear, homogeneous fluid, really consists of minute grains, or globules, of organic matter floating in water.

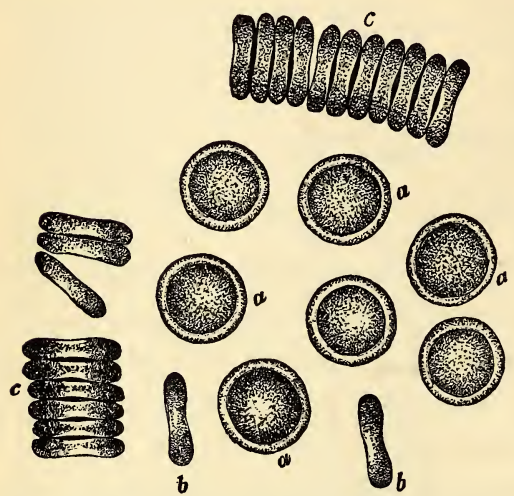

Fig. 62.-Red Blood-corpuscles of Man : $a$, shows circular contour; $b$, a biconcave section; $c$, a group in chains.
If the blood of a Frog be poured on a filter of blotting-paper, a transparent fluid (called plas$m a)$ will pass through, leaving red particles, resembling sand, on the upper surface. Under the microscope, these particles prove to be cells, or flattened disks (called corpuscles), containing a nucleus; some are colorless, and others

red. The red disks have a tendency to run together into piles; the colorless ones remain single. Meanwhile, the plasma separates into two parts by coagulating; that is, minute fibres form, consisting of fibrine, leaving a pale yellowish fluid, called serum..$^{55}$ Had the blood not been filtered, the corpuscles and fibrine would have mingled, forming a jelly-like mass, known as clot. Further, the serum will coagulate if heated, dividing into hardened albumen and a watery fluid, called serosity, which contains the soluble salts of the blood.

These several parts may be expressed thus:

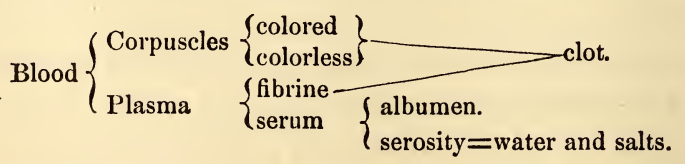

If now we examine the nutritive fluid of the simplest animals, we find only a watery fluid containing granules. In Radiates and the Worms and Mollusks, there is a similar fluid, with the addition of a few white corpuscles. But 
there is little fibrine, and, therefore, it coagulates feebly or not at all. In the Arthropods and higher Mollusks, the circulating fluid contains colorless nucleated cells, and coagulates. ${ }^{56}$ InVertebrates, there are, in addition to the plasma and white corpuscles of Invertebrates, red corpuscles, to which their blood owes its peculiar hue. In Fishes, Amphibians, Reptiles, and Birds, i.e., alloviparous Vertebrates, these red corpuscles are

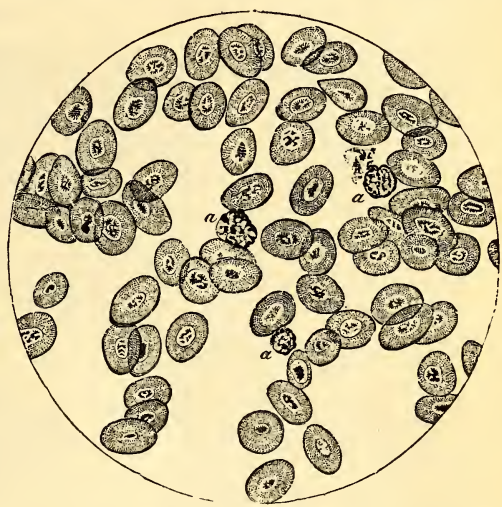

Frg. 63.-Nucleated Blood-cells of a Frog, $\times 250$. nucleated; but in those of Mammals, no nucleus has been discovered. ${ }^{67}$

All blood-corpuscles are microscopic. The white are more uniform in size than the red; and generally smaller

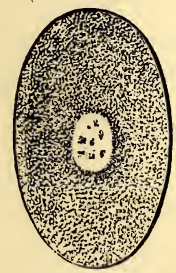

Fre 64 - Elliptical Corpus cle of the Frog, showing a white prominence at the centre. (except in Mammals), being about $\frac{1}{2500}$ of an inch in diameter. The red corpuscles are largest in Amphibians (those of Proteus being the extreme, or $\frac{1}{2} \frac{1}{5}$ of an inch), next in Fishes, then Birds and Mammals. The smallest known are those of the Muskdeer. In Mammals, the size agrees with the size of the animal only within a natural order; but in Birds the correspondence holds good throughout the class, the largest being found in the Ostrich, and the smallest in the Humming-bird. In Man, they measure $\frac{1}{3 \frac{1}{20}}$ of an inch, so that it would take 40,000 to cover the head of a pin.

As to shape, the colorless corpuscles are ordinarily glob- 
ular, or sac-like, in all animals; but they are constantly changing. The form of the red disks is more permanent, although they are soft and elastic, so that they squeeze

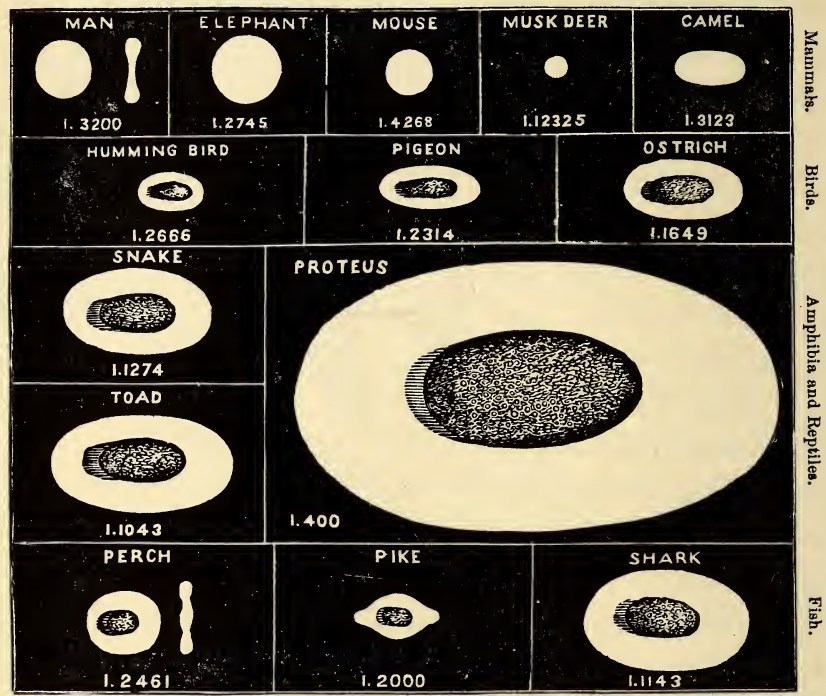

Fig. 65.-Comparative Size and Shape of the red Corpuscles of varions Animals.

through very narrow passages. They are oval, circular, or angular, in Fishes; oval in Reptiles, Birds, and the Camel tribe; and circular in the rest of Mammals. They are double-convex when nucleated, and double-concave when circular and not nucleated.

Blood is always heavier than water; but is thinner in cold-blooded than in warm-blooded animals, in herbivores than in carnivores. The blood of Birds, which is the hottest known, being $10^{\circ}$ higher than Man's, is richest in red corpuscles. In Man, they constitute about one half the mass of blood. The white globules are far less numerous than the red; they are relatively more abundant in venous than arterial blood, in the sickly and ill-fed than in the healthy and vigorous, in the lower Vertebrates than in Birds and Mammals. Their number is subject to great 
variations, increasing rapidly after a meal, and falling as rapidly.

There is less blood in cold-blooded than in warm-blooded animals; and the larger the animal, the greater is the

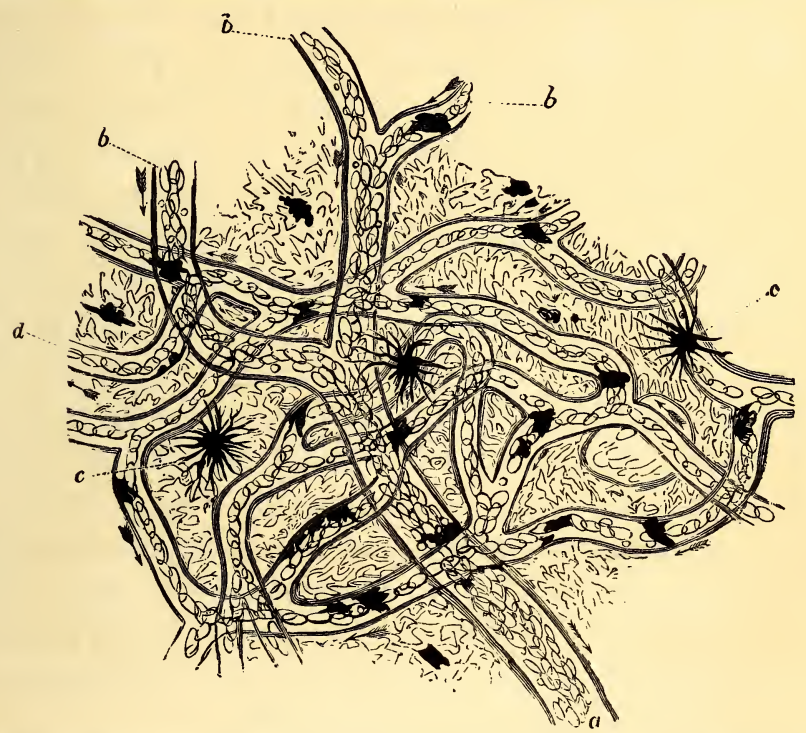

Fig. 66.-Capillary Circulation in the Web of a Frog's Foot, $\times 100: a, b$, small veins; $d$, capillaries in which the oval corpuscles are seen to follow one another in single series; $c$, pigment-cells in the skin.

proportion of blood to the body. Man has about a gallon and a half, equal to one thirteenth of his weight. The heart of the Greenland Whale is a yard in diameter.

The main Office of the Blood is to supply nourishment to, and take away waste matters from, all parts of the body. It is at once purveyor and scavenger. In its circulation, it passes, while in the arterial half of the capillaries, within an infinitesimal distance of the various tissues. The plasma, carrying the nutritive matter needed, exudes through the walls of the capillary tubes; the tissue assimilates or makes like to itself whatever is suitable for its growth and repair; and the lymphatics (the escape- 
pipes) take up any surplus, and return it to the blood. At the same time, the venous part of the capillary network absorbs the waste products of the tissues, expelling the gases by the lungs, and the solid matters by the skin and kidneys. The special function of the several constitnents of the blood is not wholly known. The colorless corpuscles in Vertebrates are supposed to be the source of the red disks. The latter are the carriers of oxygen, which is taken up by their red matter (hæmoglobin) in the lungs, and given up to the tissues. The same office is performed by the blue coloring - matter (hæmocyanin) in the blood of certain Invertebrates, as the Squid and Lobster. The carbon dioxide is taken up by the plasma.

Like the solid tissues, the blood, which is in reality a liquid tissue, is subject to waste and renewal, to growth and decay. The loss is repaired from the products of digestion, carried to the blood by the lacteals, or absorbed directly by the capillaries of the digestive tract. The white corpuscles are probably prepared in many parts of the body, especially the liver, spleen, and lymphatic glands. In the lower organisms, the nutritive food is prepared by contact with the tissues, without passing through special organs. Lymph differs from blood chiefly in containing less albumen and fibrine, and no red disks. Chyle is lymph loaded with fat globules, and is found in the lacteals and vessels connected with them during the absorption of food containing fat. 


\section{CHAPTER XIII. \\ THE CIRCULATION OF THE BLOOD.}

The Blood is kept in continual motion in order to nourish and purify the body and itself. For as life means work, and work brings waste, there is constant need of fresh material to make good the loss in every part of the system, and of the removal of matter which is no longer fit for use.

In the very lowest animals, where every part of the structure is equally capable of absorbing the digested food and is in contact with it, there is no occasion for any circulation, although in them even the blood is not allowed to stagnate. But in proportion as the power of absorption is confined to certain parts, the more is the need and the greater the complexity of an apparatus for conveying the nutritive fluid to the various tissues.

In nearly all animals, the nutritive fluid is conveyed to the various parts of the body by a system of tubes, called blood-vessels. The higher forms

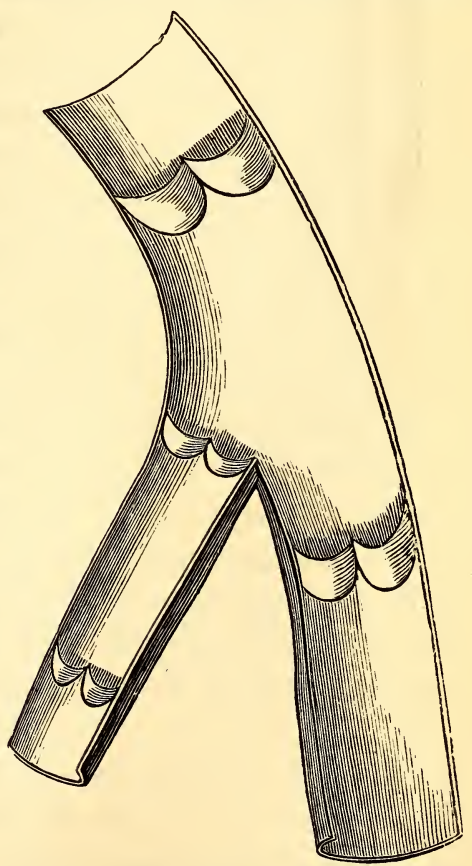

Fig. 67. -Venous Valves. They usually occur in pairs, as represented. 
have two sets-arteries and veins, in which the blood moves in opposite directions, the former carrying blood

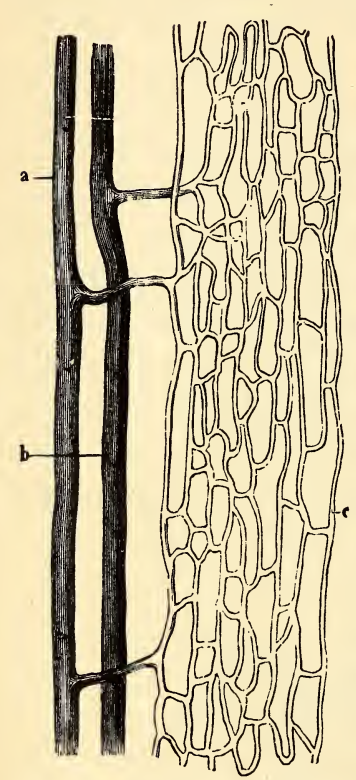
from a central reservoir or heart, the latter taking it to the heart. In the Vertebrates, the walls of these tubes are made of three coats, or layers, of tissue, the arteries being elastic, like rubber, and many of the veins being furnished with valves. ${ }^{58} \quad$ The great artery coming out of the heart is called aorta, and the grand venous trunk, entering the heart on the opposite side, is called vena cava. Both sets divide and subdivide until their branches are finer than hairs; and joining these finest arteries and finest veins are interınediate microscopic tubes, called capillaries (in Man about $\frac{1}{3000}$ of an inch Fig. 68. - Relation of artery, $a$, in diameter). ${ }^{59}$ In these only, so
vein, $b$, and capillaries, $c$, as seen in the muscles of a Dog. thin and delicate are their walls, does the blood come in contact with the tissues or the air.

In those Vertebrates which have lungs there are two sets of capillaries, since there are two circulations-the systemic, from the heart around the system to the heart again, and the pulmonary, from the heart through the respiratory organ back to the heart. This double course may be illustrated by the figure 8 . In gill-bearing animals there are capillaries in the gills, but not a double circulation.

There is no true system of blood-vessels below the Star-fish. The simplest provision for the distribution of the products of digestion is shown by the Jelly-fish, whose stomach sends off radiating tubes (Fig. 197). 
The first Approach to a Circulatory System is made by the Star-fish and the Sea-urchin. A vein runs along the whole length of the alimentary tube, to absorb the chyle, and forms a circle around each end of the tube. These circular vessels send off branches to various parts of the body; but as they are not connected by a net-work of capillaries, there can be no circuit (Fig. 39).

A higher type is exhibited by the Insects. If we examine the back of any thin-skinned Caterpillar, a long pulsating tube is seen running beneath the skin from one end of the body to the other. This dorsal vessel, or heart, as it is called, is open at both ends, and divided by valves into compartments, permitting the blood to go forward, but not backward. Each compartment communicates by a pair of slits, guarded by valves, with the body - cavity, so that fluids may enter, but cannot escape. "Circulation" is very simple. We have seen that the chyle exudes through the walls of the alimentary canal directly into the cavity of the abdomen, where it mingles with the blood already there. This mixed fluid is drawn into the dorsal tube through the valvular openings as it expands; and upon its contraction, all the side-valves are closed, and the fluid is forced towards the head. Passing out at the front opening, it is again diffused among and

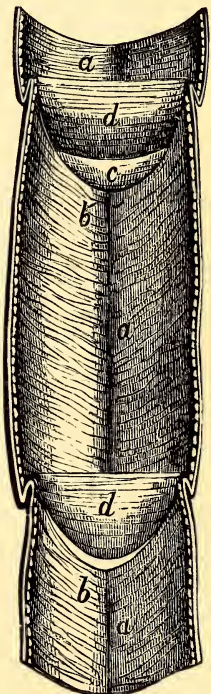

Fig. 69.-Part of the Dorsal Vessel, or Heart, of a Cockchafer bisected: $a, b$, muscular walls: $d$, valves between the compartments; $c$, valve defending one of the orifices communicating with the general cavity of the abdomen. between the tissues of the body. The blood, therefore, does not describe a circle in definite channels so as to return constantly to its point of departure.

Many worms (as the Earthworm) have a pulsating tube 
extending from tail to head above the alimentary canal, a similar tube on the ventral side through which the blood returns, and cross-tubes in every segment. In the Lobster and Crab, Spider and Scorpion, the dorsal tube sends

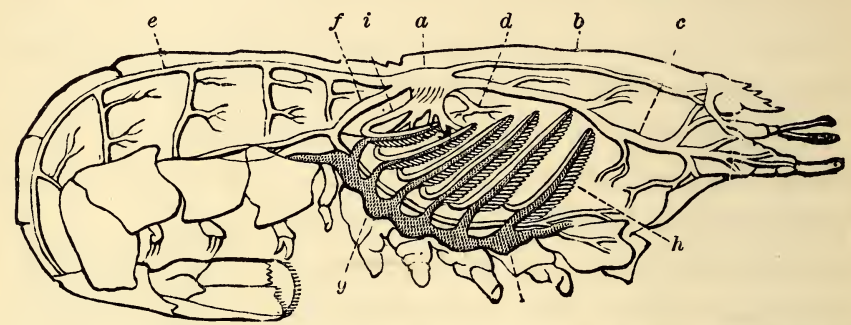

Fra. 70.-Circulation in a Lobster: $a$, heart: $b$, artery for the eyes; $c$, artery for anteunæ; $d$, hepatic artery ; e, superior abdominal artery ; $f$, sternal artery ; $g$, venous sinuses transmitting blood from the body to the branchiæ, $h$, whence it returns to the heart by the branchio-cardiac vessels, $i$.

off a system of arteries (not found in Insects); but the blood, as it leaves these tubes, escapes into the general cavity, as in other Arthropoda. The Lobster and Crab, however, show a great advance in the concentration of the propelling power into a short muscular sac.

A third development of the circulatory system is furnished by the Mollusks. Comparatively sluggish, they need a powerful force-pump in the form of a compact heart. In the Oyster and Snail (Figs. 44, 45), we find such an organ having two cavities-ain auricle and a ventricle, one for receiving, and the other for distributing, the blood. The auricle injects the blood into the ventricle, which propels it by the arteries to the various organs. Thence it passes, not immediately to the veins, as in higher animals, but into the spaces around the alimentary canal. A part of this is carried by vessels to the gills or lung, and then returned with the unpurified portion to the auricle. The whole of the blood, therefore, does not make a complete circuit. The Clam has a similar heart, but with two auricles. 
A still higher form is seen in the Cuttle-fish, the highest of the Invertebrates. This animal has a central heart, with a ventricle and two auricles, and, in addition, the veins which collect the blood from the system to send it back to the heart by the way of the gills are furnished with two branchial hearts, which accelerate the circulation through those organs. Many of the arteries and veins are joined by capillaries, but not all; so that in no invertebrate animal is the blood returned to the heart by a continuous closed system of bloodvessels.

As a rule, in all animals having any circulation at all, the current always takes one direction. This is generally necessitated by valves. But a curious exception is presented by the Ascidians, whose tubular heart is valveless, and the contractions occur alternately at one end and then the other; so that the blood oscillates to and fro, and a given vessel is at one time a vein and at another an artery. In this respect it resembles the fœtal heart of higher animals (Fig. 279).

In Vertebrates only is the circulating current strictly confined

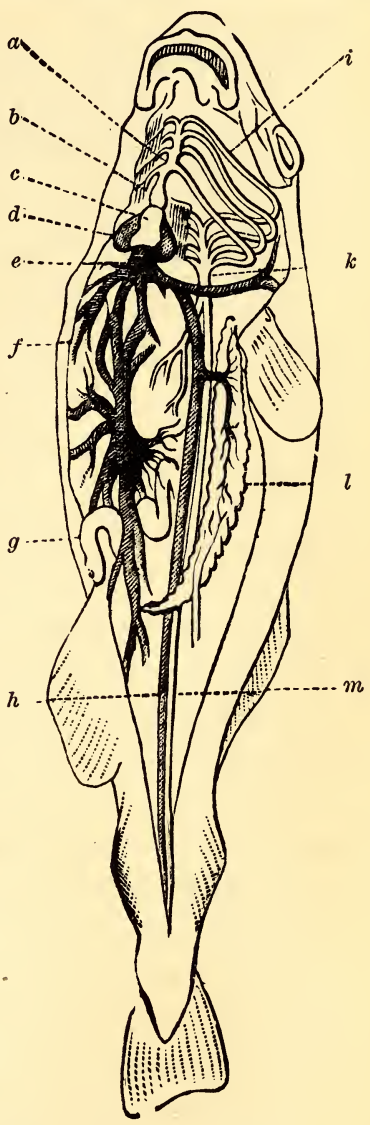

Fra. 71.-Circulating Apparatus in the Fish: $a$, branchial artery ; $b$, arterial bulb; $c$, ventricle ; $d$, auricle; $e$, venous sinus; $f$, portal vein ; $g$, intestine; $h$, vena cava ; $i$, branchial vessels ; $k$, dorsal artery, or aorta ; $l$, kidneys ; $m$, dorsal artery.

to the blood-vessels; in no case does it escape into the general cavity of the body. In other respects, there is 
no great advance in the apparatus of the lowest Vertebrates over that of the highest Mollusks. The heart of

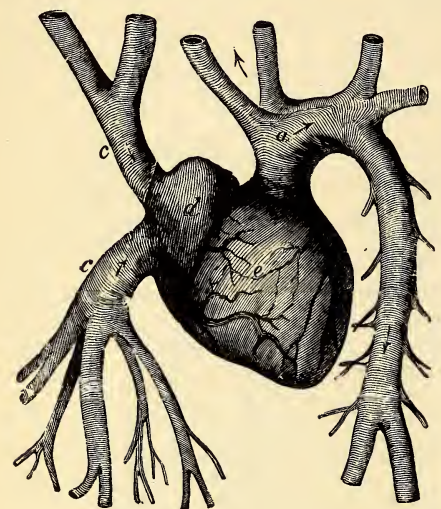

Fia. 72.-Diagram of a single Heart: $d$, auricle; $e$, ventricle; $c$, veins leading to auricle; $a$, aorta, or main artery.

Fishes, as in the Oyster, has two cavities, but its position is reversed. Instead of driving arterial blood over the body, it receives the returning, or venous, blood, and sends it to the gills. Recollected from the gills, the blood is passed into a large artery, or aorta, along the back, which distributes it by a complex system of capillaries among the tissues. These capillaries unite with the ends of the veins which pass the blood into the auricle $^{60}$ (Fig. 48).

In Amphibians and in Reptiles generally (as Frogs, Snakes, Lizards, and Turtles), the heart has three cavities - two auricles and one ventricle. The venous blood from the body is received into the right auricle, and the purified blood from the lungs into the left. Both throw their contents into the ventricle, which pumps the mixed blood in two directions-partly to the lungs, and partly around the system. Circulation is, therefore, incomplete, since the whole current does not pass through the lungs, and three kinds of blood are found in the body-arterial, venous, and mixed. In many animals, however, arrangements exist which nearly separate the venous from the arterial blood.

The ventricle of Reptiles is partially divided by a partition. In the Crocodile, the division is complete, so that there are really four cavities-two auricles, and two ventricles. But both ventricles send off aortas which cross 
one another, and at that point a small aperture brings the two into communication. The venous and arterial currents are, therefore, mixed, but not within the heart, as in the other Reptiles, nor so extensively. In the structure of the heart, as well as in that of the gizzard, Crocodiles approach the Birds.

The Highest Form of the Circulating System is possessed by the warm-blooded Vertebrates, Birds and Mam- Fir. 73.-Heart of the Dugong, a fourmals. Not a drop of blood can make the circuit of the body without passing through

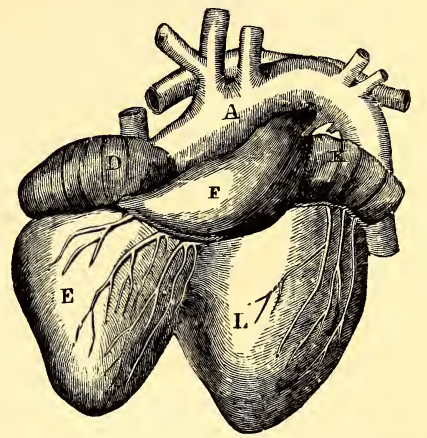
chambered heart, the parts being more separated than in higher animals: $\mathbf{E}$, right ventricle; $L$, left ventricle; $D$, right auricle; F, pulmonary artery; $\mathbf{K}$, left auricle; A, aorta. the lungs, the circulation to and from those organs being as perfect as the distribution of arterial blood. The heart

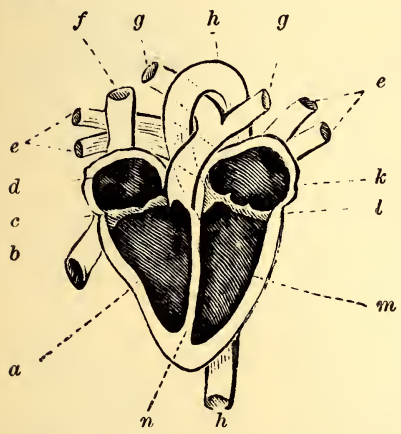

Fig. 74. - Theoretical Section of the Human Heart: $a$, right ventricle; $b$, inferior vena cava; $c$, tricuspid valve; $d$, right auricle; $e$, pulmonary veins : $f$, superior vena cava; $g$, pulmonary arteries; $h$, aorta; $k$, left auricle; $l$, mitral valve; $m$, left ventricle; $n$, septum.

consists of four cavities - a right auricle and ventricle, and a left auricle and ventricle. In other words, it is a hollow muscle divided internally by a vertical partition into two distinct chambers, each of which is again divided by a valve into an auricle and a ventricle. The work of the right auricle and ventricle is to receive the blood from the veins, and send it to the lungs; while the other two receive the blood from the lungs, and propel it over the body. The left ventricle has more to do than any other cavity. The two auricles contract at the same instant; 


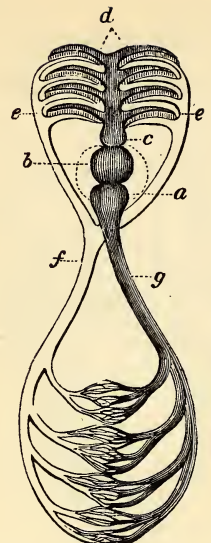

Fig. 75. -- Plan of Circulation in Fishes: $a$, auricle : $b$, ventricle ; $c$, branchial artery; $e$, branchial veins, bringing blood from the gills, $d$, and uniting in the aorta, $f ; g$, vena cava.

so also do the ventricles. The course of the current in Birds and Mammals is as follows: the venous blood brought from the system is discharged by two or three large trunks ${ }^{61}$ into the right auricle, which immediately forces it past a valve ${ }^{62}$ into the right ventricle. The ventricle then contracts, and the blood rushes through the pulmonary artery past its semilunar valves into the lungs, where it is changed from venous to arterial, returning by the pulmonary veins to the left auricle. This sends it past the mitral valves into the left ventricle, which drives it past the semilunar valves into the aorta, and thence, by its ramifying arteries and capillaries, into all parts of the body except the lungs. From the capillaries, the blood, now changed from arterial to venous, is gathered by the veins, and conveyed back to the heart.

The Rate of the Blood-current generally increases with the activity of the animal, being most rapid in Birds. $^{{ }^{* 3}}$ In Insects, however, it is comparatively slow; but this is because the air is taken to the blood-the whole
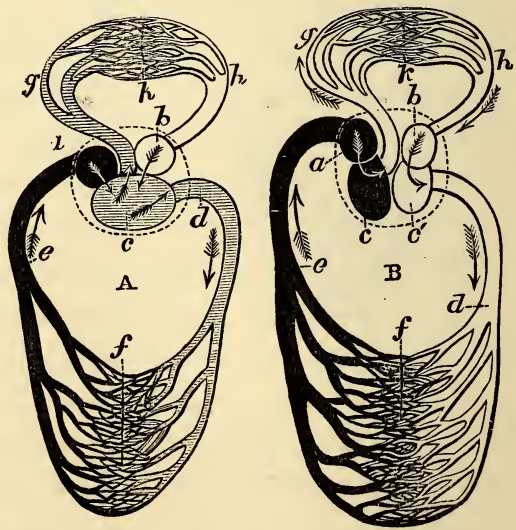

Fig. 76.-A, Plan of Circulation in Amphibia and Reptiles; B, Plan of Circulation in Birds and Mammals: $a$, right auricle receiving venous blood from the system: $b$, left auricle receiving arterial blood from the lungs; $c, c^{\prime}$, ventricles; $d, e, f$, systemic artery, vein, and capillaries; $g$, pulmonary artery; $h, k$, vein and capillaries. 
body being bathed in air, so that the blood has no need to hasten to a special organ. However, activity nearly doubles the rate of pulsation in a Bee. The motion in the arteries is several times faster than in the veins, but diminishes as the distance from the heart increases. In the carotid of the Horse, the blood moves $12 \frac{1}{2}$ inches per second; in that of Man, 16; in the capillaries of Man, 1 to 2 inches per minute; in those of a Frog, 1.

The Cause of the Blood-current may be cilia, or the contractions of the body, or pulsating tubes or hearts. In the higher animals, the impulse of the heart is not the sole means : it is aided by the contractions of the arteries themselves, the movements of the chest in respiration, and the attraction of the tissues for the arterial blood in the capillaries. In the Chick, the blood moves before the heart begins to beat; and if the heart of an animal be suddenly taken out, the motion in the capillaries will continue as before. It has been estimated that the force which the human heart expends in twenty-four hours is about equivalent to lifting 217 tons one foot.

\section{CHAPTER XIV.}

HOW ANIMALS BREATHE.

Arterial Blood, in passing through the system, both loses and gains certain substances. It loses constructive material and oxygen to the tissues. These losses are made good from the digestive tract and breathing organ. It gains also certain waste materials from the tissues, which must be got rid of. Of these waste products, one, carbon dioxide, is gaseous, and is passed off from the same organ as that where the oxygen is taken in. This exchange of 
gases between the animal and its surroundings is called Respiration.

The First Object of Respiration is to convert venous into arterial blood. It is done by bringing it to the surface, so that carbon dioxide may be exhaled and oxygen absorbed. The apparatus for this purpose is analogons to the one used for circulation. In the lowest animals, the two are combined. But in the highest, each is essentially a pump, distributing a fluid (in one case air, in the other blood) through a series of tubes to a system of cells or capillaries. They are also closely related to each other: the more perfect the circulation, the more careful the provision made for respiration.

Respiration is performed either in air or in water. So that all animals may be classed as air-breathers or water-breathers. The latter are, of course, aquatic, and seek the air which is dissolved in the water. Land-snails, Myriapods, Spiders, Insects, Reptiles, Birds, and Mammals breathe air directly; the rest, with few exceptions, receive it through the medium of water. In the former case, the organ is internal; in the latter, it is more or less on the outside. But however varied the organs - tubes, gills, or lungs-they are all constructed on the same principle - a thin membrane separating the blood from the atmosphere.

(1) Sponges, Infusoria, and Polyps have no separate respiratory apparatus, but absorb air, as well as food, from the currents of water passing through them.

In the Star-fish, Sea-urchin, and the like, we find the first distinct respiratory organs, although none are exclusively devoted to respiration. There are two sets of canals-one carrying the nutrient fluid, and the other, radiating from a ring around the mouth, distributing aerated water, used for locomotion as well as respiration. This may be called the "water-pipe system." Besides this, 
there are numerous gill-like fringes, which probably aid in respiration (Fig. 39).

Fresh-water Worms, like the Leech and Earth - worm, breathe by the skin. The body is always covered by a viscid fluid, which has the property of absorbing air. The air is, therefore, brought into immediate contact with the soft skin, underneath which lies a dense net-work of blood-vessels.

But most water-breathing animals have gills. The simplest form is seen in Marine Worms: delicate veins projecting through the skin make a series of arborescent tufts along the side of the body; as these float in the water, the blood is purified. ${ }^{64} \mathrm{Bi}$ valve Mollusks have four flat gills, consisting of delicate membranes filled with bloodvessels and covered with cilia. In the Oyster, these ribbon-like folds are exposed to

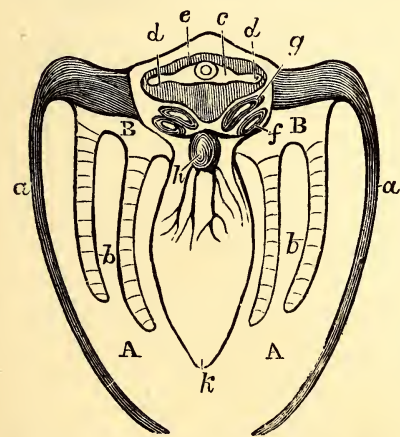

Fig. 78.-Diagrammatic Section of a

Lamellibranch (Anodon): $\boldsymbol{a}$, lobes of mantle; $b$, gills, showing transverse partitions ; $c$, ventricle of heart; $d$, auricles ; $e$, pericardium ; $f, g$, kidneys; $h$, venous sinus ; $k$, foot : $\mathbf{A}$, branchial, or pallial, chamber; $\mathrm{B}$, epibranchial chamber. the water when the shell opens; but in the Clam, the mantle en-

Fig. 77.-Lob-worm (Arenicolapiscatorum), a dorsibranchiate, showing the tufts of capillaries, or exterual gills. The large head is without eyes or jaws. closes them, forming a tube, called siphon, through which the water is driven by the cilia. The aquatic Gasteropods (Univalves) have either tufts, like the Worms, or comblike ciliated gills in a cavity behind the head, to which the water is admitted by a siphon. The Cuttle-fish has flat gills covered by the mantle; but the 
water is drawn in by muscular contractions instead of by cilia. The end of the siphon through which it is ejected is called the funnel. The gills of Lobsters and Crabs are placed in cavities covered by the sides of the shell (carapace); and the water is brought in from behind by the action of a scoop-shaped process attached to one of the jaws, which constantly bales the water out at the front.

The perfection of apparatus for aquatic respiration is seen in Fishes. The gills are comb-like fringes supported on four or five bony or cartilaginous arches, and contain myriads of microscopic capillaries, the object being to expose the venous blood in a state of minute subdivision to streams of water. The gills are always covered. In bony fishes they are attached to the hinder side of bony arches, all covered by a flap of the skin, supported by bones (the gill-cover, or operculum), and the water escapes from the opening left at its hinder edge. In Sharks, the gills are placed in pouches which open separately (Figs. 164 and 287). The act of "breathing water" resembles swallowing, only the water passes the gills instead of entering the gullet.

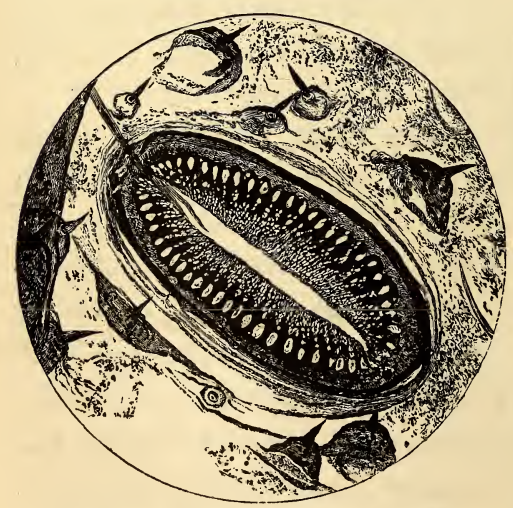

Fig. 79. -Spiracle of an Insect, $\times 75$.

(2) Air-breathers have trachece, or lungs. The former consist of two principal tubes, which pass from one end of the body to the other, opening on the surface by apertures, called,spiracles, resembling a row of button-holes along the sides of the thorax and abdomen, and ramifying through the smallest and most delicate organs, so that the air may follow 
the blood wherever it circulates. To keep the pipes ever open, and at the same time leave them flexible, they are provided with an elastic spiral thread, like the rubber tube of a drop-light. Respiration is performed by the movements of the abdomen, as may be seen in the Bee when at rest. This "air-pipe system," as it may be termed, is best developed in Insects.

The "nerves" of an Insect's wing consist of a tube within a tube: the inner one is a trachea carrying air, and the outer one, sheathing it, is a blood-vessel. So perfect

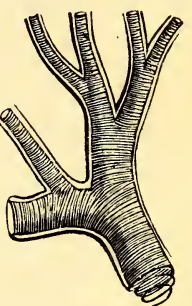

Fig. 80, - Tracheal Tube of an Insect, highly magnified, showing elastic spiral thread. is the aeration of the whole body, from brain to feet, the blood is oxygenated at the moment when, and on the spot where, it is carbonized; only one kind of fluid is,

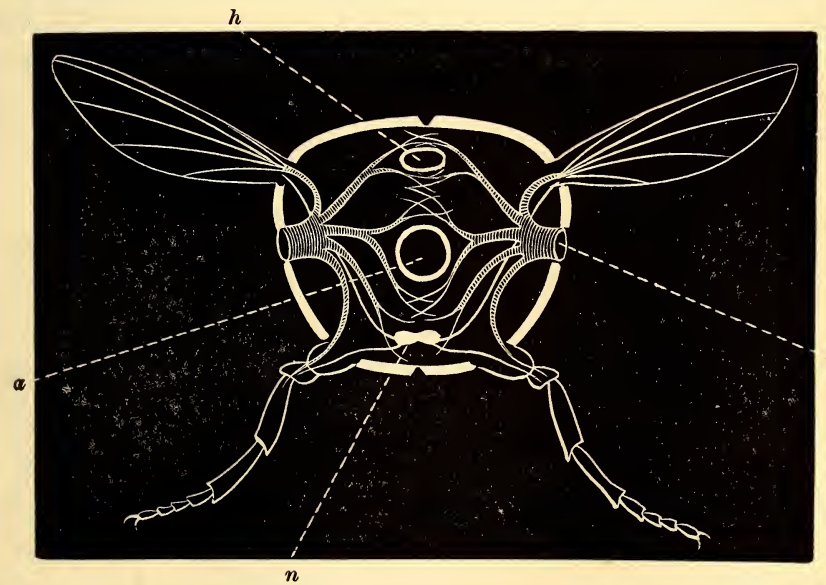

Fí. 81.-Ideal Section of a Bee: $a$, alimentary canal; $h$, dorsal vessel; $t$, trachea : $n$, nervous cord.

therefore, circulating - arterial. It is difficult to drown an Insect, as the water cannot enter the pores; but if a drop of oil be applied to the abdomen, it falls dead at once, being suffocated. The largest spiracle is usually 


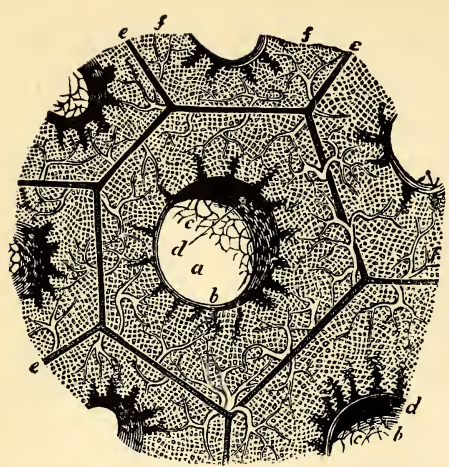

Fig. 82.-Section through a bronchial tube, Lung of a Bird, magnified : $a$, the cavity ; $b$, its lining membrane supporting bloodvessels; $c$, perforations at the orifices of the lobular passages, $d$; $e$, interlobular spaces, containing the terminal branches of the pulmonary vessels supplying the capillary plexus, $f$, to the meshes of which the air gets access by the lobular passages.

found on the thorax, as under the wing of a Moth: such may be strangled by pinching the thorax.

In Millipedes and Centipedes, the spiracles open into little sacs connected together by tubes; in Spiders and Scorpions, the spiracles, usually four in number, are the mouths of sacs without the tubes, and the interior of the sac is gathered into folds. Landsnails have one spiracle, or aperture, on the left side of the neck, leading to a large cavity, or sac, lined with fine blood-vessels. These sacs represent the primitive idea of a lung, which is but an infolding of the skin, divided up into cells, and covered with capillary veins. ${ }^{6 \hat{b}}$

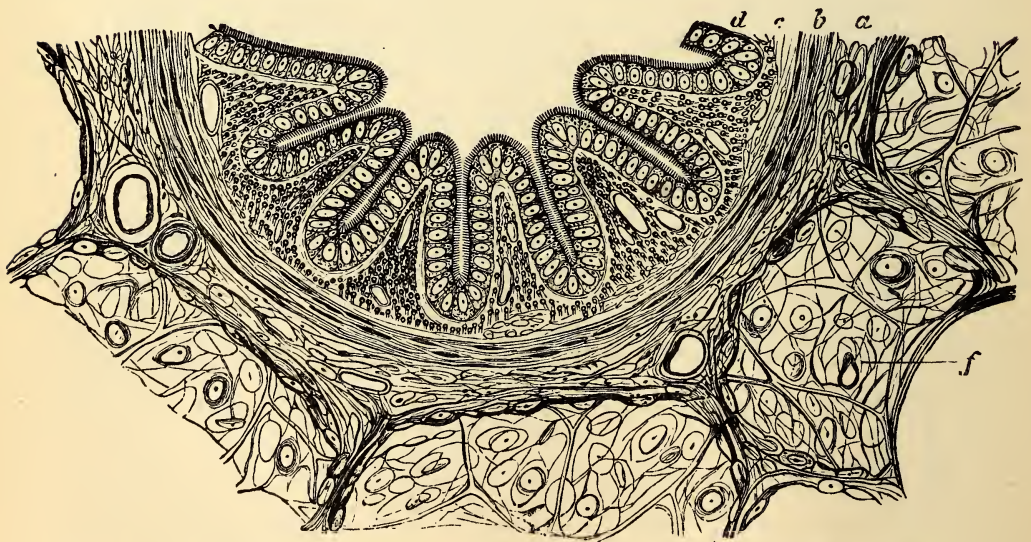

Fig. 83. - Part of a transverse section of a Pig's Brouchial Twig, $\times 240$ : $a$, outer fibrous layer; $b$, muscular layer; $c$, inner fibrous layer; $d$, epithelial layer with cilia; $f$, one of the neighboring alveoli. 
Like the alimentary canal, the lungs of an animal are really an inflected portion of the onter surface; so that breathing by the skin and breathing by lungs are one in principle. Indeed, in many animals, especially Frogs, respiration is carried on by both lungs and skin.

The lungs of Vertebrates are derived from the front part of the alimentary canal. In some Fishes, air is swallowed, which passes the whole length of the digestive tract, and is expelled from the anius. Here the whole canal serves for respiration. In Reptiles, Birds, and Mammals the hinder part of the intestine develops an outgrowth (the allantois) during embryo-life which serves as the embryo's breathing organ (Figs. 170, 171).

All Vertebrates have two kinds of respiratory organs in the course of their life. Fishes have gills; their lung (the air-bladder) rarely serves as a functional respiratory organ, and is sometimes wanting. Amphibians have gills while in the larval state. Some keep them throughout life; but all develop functional lungs, and also breathe by means of the skin.

In the remaining Vertebrates, the allantois is the breathing organ of the embryo, and the lung is the breathing organ of the adult. The skin is of small or no importance in respiration.

The lungs of Vertebrates are elastic membranous sacs, divided more or less into cells to increase the surface. Upon the walls of the cells are spread the capillary blood-vessels. The smaller the cells, the greater the extent of surface upon which the blood is

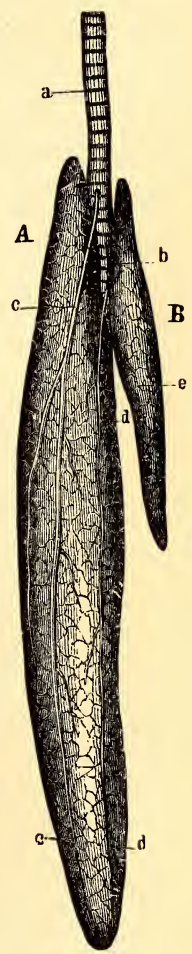

FIG. 84. - Lungs of a Snake: $a$, trachea; $b$, its bifurcation; $c$, pulmonary artery ; $d$, pulmonary vein; the lung, $B$, is rndimentary. 
exposed to the influence of the air, and, therefore, the more active the respiration and the purer the blood. The lungs are relatively largest in Reptiles, and smallest in Mammals. But in the cold-blooded Amphibians and Reptiles, the air-cells are few and large; in the warm-blooded Birds and Mammals, they are exceedingly numerous and minute. ${ }^{66}$ In Birds and Mammals, the blood in the capillaries is exposed to the air on all sides; in the Reptiles, on one only. Respiration is most perfect in Birds; they require, relatively to their weights, more air than Mammals or Reptiles, and most quickly die for lack of it. In Birds, respiration is not confined to the lungs; but, as in Insects, extends through a great part of the body. Airsacs connected with the lungs exist in the abdomen and under the skin of the neck, wings, and legs. Even the bones are hollow for this purpose; so that if the wind-

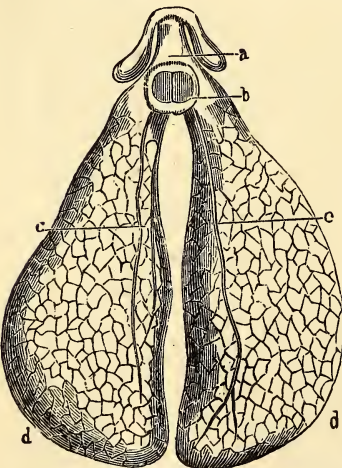

Fig. 85. - Lungs of a Frog: $a$, hyoid apparatus ; $b$, cartilaginous ring at ront of the lungs; $c$, pulmonary vessels; $d$, pulmonary sacs, having this peculiarity common to all coldblooded air-breathers, that the trachea does not divide into bronchial branches, but terminates abruptly by orifices which open at once into the general cavity. A cartilaginous net-work divides the space in to little sacs, on the walls of which the capillaries are spread.

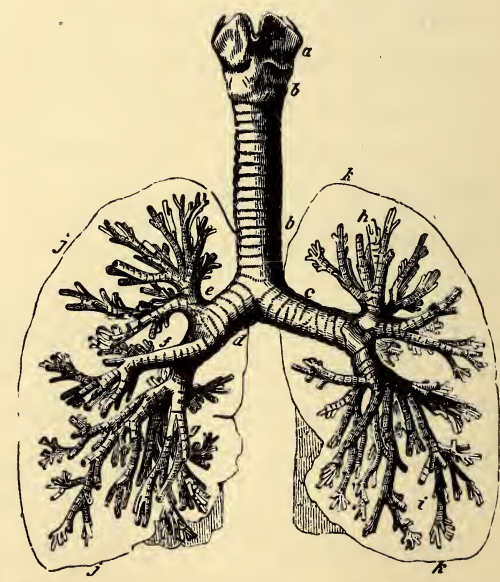

Fic. 86. - Distribution of Air-tubes in Mammalian Lungs : $a$, larynx; $b$, trachea; $c, d$, left and right bronchial tubes; $e, f, g$, the ramifications. In Man the subdivision continues until the ultimate tubes are one twenty-fifth of an inch in diameter. Each lobule represents in miniature the structure of the entire lung of a Frog. 
pipe be tied, and an opening be made in the wing-bone, the bird will continue to respire. The right lung is usnally the larger; in some Snakes, the left is wanting entirely. In most Vertebrates, lungs are freely suspended; in Birds, they are fastened to the back.

The lungs communicate with the atmosphere by means of the trachea, or windpipe, formed of a series of cartilaginous rings, which keep it constantly open. It begins in the back part of the mouth, opening into the pharynx by a slit, called the glottis, which, in Mammals, is protected by the valve-like epiglottis. The trachea passes along the neck in front of the œsophagus, and divides into two branches, or bronchi, one for each lung. In Birds and Mammals, the bronchial tubes, after entering the lungs, subdivide again into minute ramifications.

Vertebrates are the

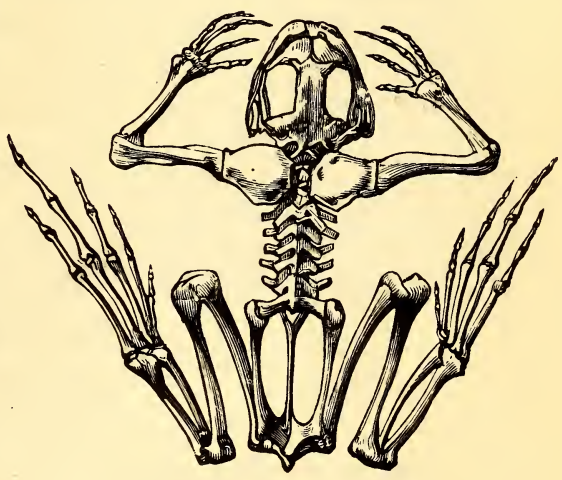

Fig. 87.-Skeletun of a Frog. only animals that breathe through the mouth or nostrils. Frogs, having no ribs, and Turtles, whose ribs are soldered together into a shield, are compelled to swallow the air. Snakes, Lizards, and Crocodiles draw it into the lungs by the play of the ribs. ${ }^{67}$ Birds, unlike other animals, do not inhale the air by an active effort; for that is done by the springing-back of the breast-bone and ribs to their natural position. To expel the air, the breast-bone is drawn down towards the back-bone by muscles, which compresses the lungs.

Mammals alone have a perfect thorax-i.e., a closed cavity for the heart and lungs, with movable walls (breast- 
bone and ribs) and a diaphragm, or muscular partition, separating it from the abdomen. ${ }^{68}$ Inspiration (or filling the lungs) and expiration (or emptying the lungs) are both accomplished by muscular exertion; the former, by raising the ribs and lowering the diaphragm, which en-

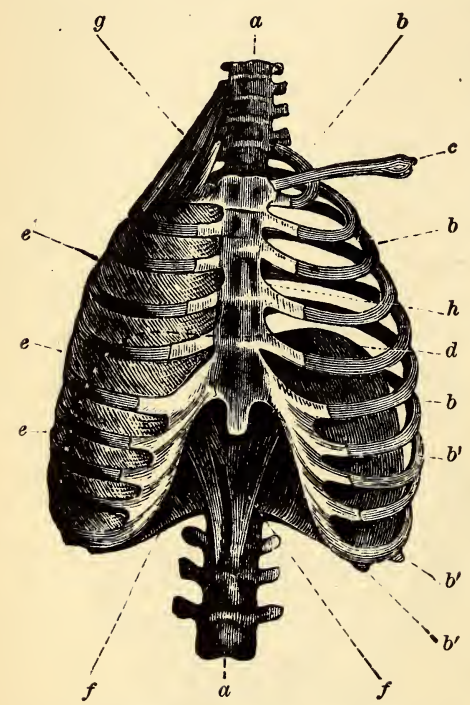

Fic. 88.-Human Thorax : $\alpha$, vertebral column; $b, b^{\prime}$, ribs, the lower ones false ; $c$, clavicle; $e$, intercostal muscles, removed on the left side to show the diaphragm, $d$; $f$, pillars of the diaphragm attached to the lumbar vertebræ; $g$, muscles for elevating the ribs; $h$, sternum.

large the capacity of the chest, and the air rushes in to prevent a vacuum; the latter, by the ascent of the diaphragm and the descent of the ribs.

As a rule, the more active and more muscular an animal, the greater the demand for oxygen. Thus, warm-blooded animals live fast, and their rapidly decaying tissues call for rapid respiration; while in the cold-blooded creatures the waste is comparatively slow. Respiration is most active in Birds, and least in water-breathing animals. The sluggish Toad respires more slowly than the busy Bee, the Mollusk more slowly than the Fish. But respirations, like beats of the heart, are fewer in large Mammals than in small ones. An average Man inhales about $300-400$ cubic feet of air per day of rest, and much more when at work.

Another result of respiration, besides the purification of the blood, is the production of heat. The chemical combination of the oxygen in the air with the carbon in the tissues is a true combustion; and, therefore, the more 
active the animal and its breathing, the higher its temperature. Birds and Mammals have a constant temperature, which is usually higher than that of the atmosphere $\left(108^{\circ}\right.$ and $100^{\circ} \mathrm{F}$. respectively). They are therefore called constant-temperatured or warm-blooded. Other animals do not vary greatly in temperature from that of their surroundings, and are called changeable-temperatured or coldblooded. Still, their temperature does not agree exactly with that of the air or water. The Bee is from $3^{\circ}$ to $10^{\circ}$, and the Earth-worm and Snail from $1 \frac{1}{2}^{\circ}$ to $2^{\circ}$, higher than the air. The mean temperature of the Carp and Toad is $51^{\circ}$; of Man, $98^{\circ}$; Dog, $99^{\circ}$; Cat, $101^{\circ}$; Squirrel, $105^{\circ}$; Swallow, $111^{\circ}$.

\section{CHAPTER XV.}

\section{SECRETION AND EXCRETION.}

Is the circulation of the blood, not only are the nutrient materials deposited within the body in the form of tissue, but certain special fluids are separated and conveyed to the external or internal surfaces of the body. These fluids are of two kinds: some, like saliva, gastric juice, bile, milk, etc., are for useful purposes; others, like sweat and urine, are expelled from the system as useless or injurious. The separation of the former is called secretion; the removal of the latter is excretion. Both processes are substantially alike.

In the lower forms, there are no special organs, but secretion and excretion take place from the general surface. The simplest form of a secreting organ closely resembles that of a respiratory organ, a thin membrane separating the blood from the cavity into which the secretion is to 
be poured. Usually, however, the cells of the membrane manufacture the secretion from materials furnished by the blood. Even in the higher animals, there are such secreting membranes. The membranes lining the nose and ali-

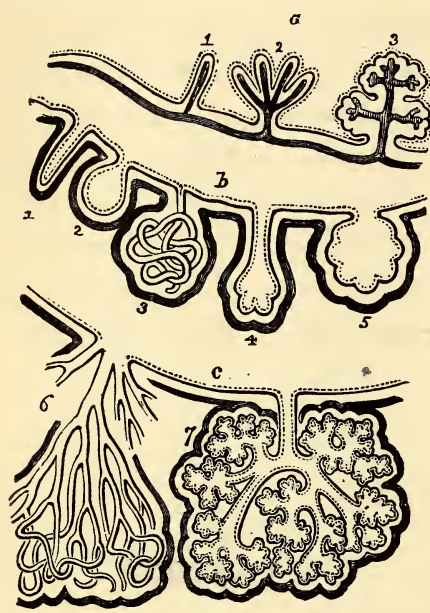

FiG. 89.-Three plans of secreting Membranes. The heavy line represents the areolar-vascular layer; the next line is the basement, or limiting membrane; and the dotted line the epithelial layer: $a$ shows increase of surface by simple plaited or fringed projections; $b$, five modes of increase by recesses, forming simple glands, or follicles; $c$, two forms of compound glands.

mentary canal and enclosing the lungs, heart, and joints, secrete lubricating fluids.

The infolding of such a membrane into little sacs or short tubes (follicles), each having its own ontlet, is the type of all secreting and excreting organs. The lower tribes have nothing higher, and the apparatus for preparing the gastric fluid attains no further development even in Man. When a cluster of these follicles, or sacs, discharge their contents by one common duct, we have a gland. But whether membrane, follicle, or gland, the organ is covered with a net-work of blood-vessels, and lined with epithelial cells, which are the real agents in the process.

The chief Secreting Organs are the salivary glands, gastric follicles, pancreas, and liver, all situated along the digestive tract.

1. The salivary glands, which open into the mouth, secrete saliva. They exist in nearly all Vertebrates, higher Mollusks, and Insects, and are most largely developed in such as live on regetable food. The saliva serves to lubricate or dissolve the food for swallowing, and, in some Mammals, aids also in digestion of starch..$^{\circ 9}$ 
2. The gastric follicles are minute tubes in the walls of the stomach secreting gastric juice. They are found in all Vertebrates, and in the higher Mollusks and Arthropods. In the lower forms, a simple membrane lined with cells serves the same purpose. Under the microscope, the soft mucous membrane of the human stomach presents a honey-comb appearance, caused by numerous depressions or cells. At the bottom of these depressions are clusters of spots, which are the orifices of the tubular follicles. The follicles are about $\frac{1}{2 \frac{1}{50}}$ of an inch in diameter, and number millions.

3. The pancreas, or "sweetbread," so important in the process of digestion, Frg. 90.-Follicles from the when present, exists only in the Vertebrates, and perhaps in the higher Mol-
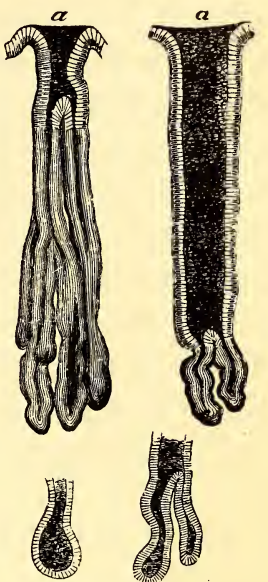
lusks. In its structure and its secretion it closely resembles the salivary glands. In the Cuttle-fish, it is repre-

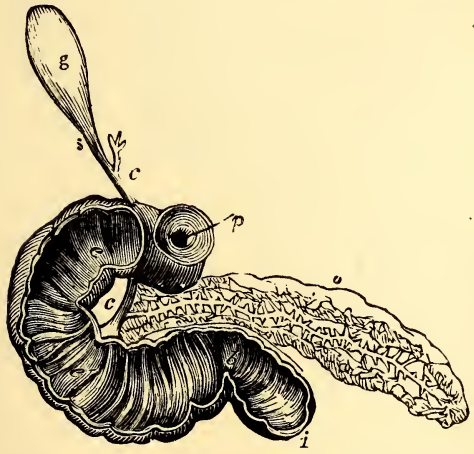

Fit. 91.-Pancreas of $M: a n, n ; g$, gall-bladder : $s$, cystic duct; $c$, duct from the liver; $p$, pyloric valve ; $e, i$, duodenum. sented by a sac; in Fishes, by a group of follicles. It is proportionally largest in Birds whose salivary glands are deficient. The pancreatic juice enters the duodenum.

4. A liver in some form is found in all animals having a distinct digestive cavity. In Mollusks and Vertebrates, it is the largest gland in the body. The higher the animal, the more compact the organ. 
Thns, in Polyps it is represented by yellowish cells lining the stomach; in Insects, by cells in the wall of the stomach ; in Mollusks, by a cluster of sacs, or follicles, forming a loose compound gland. In Vertebrates, the liver is well defined, and composed of a multitude of lobules (which give it a granular appearance) arranged on the capillary veins, like grapes on a stem, and containing nucleated secreting cells. It is of variable shape, but usually two, three, or five lobed, and is centrally situated-in Mammals, just below the diaphragm. In most Vertebrates, there is an appendage to the liver, called the gall-bladder, which is simply a reservoir for the bile when not wanted. The so-called liver of Invertebrates is probably more

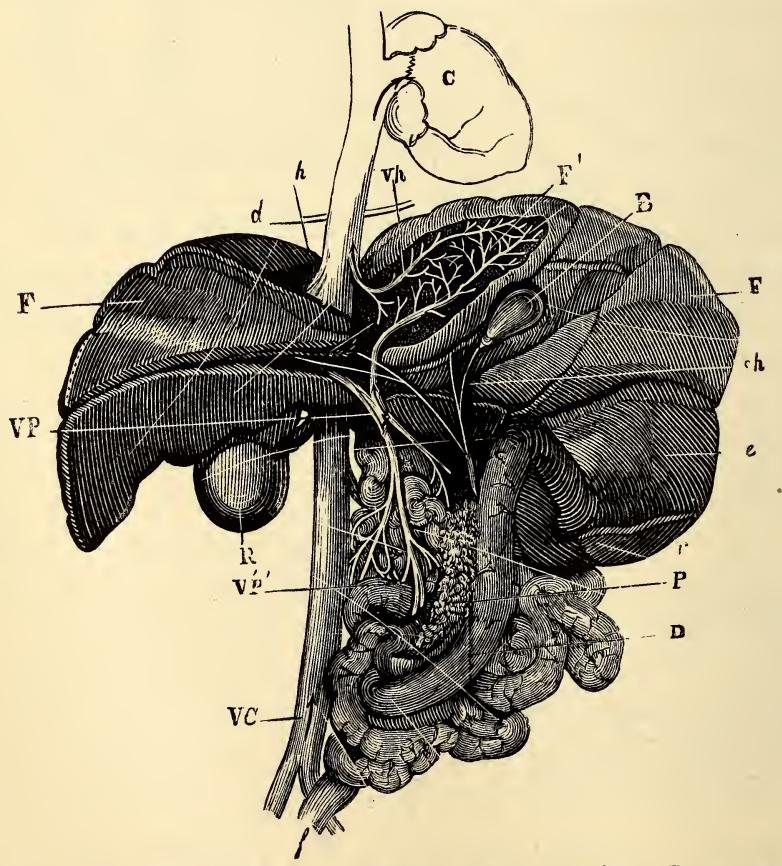

Fro. 92.-Liver of the Dog, F, F; D, duodenum and intestines: P, pancreas; $r$, spleen; $e$, stomach, $f$, rectum: $R$, right kiduey: $B$, gall-bladder; $c h$, cystic duct; $\mathbf{F}$, lobe of liver dissected to show distribution of portal vein, $\mathrm{V} P$, and hepatic vein, $v h$; $d$, diaphragm; VC, vena cava; $\mathrm{C}$, heart. 
like the pancreas of Vertebrates in function, as its secretion digests starches and albuminoids. The liver of Vertebrates is both a secretory and an excretory organ. The bile performs an important, although ill-understood, function in digestion, and also contains some waste products. The gland also serves to form sugar from part of the digested food, and may well be called a chemical workshop for the body. In animals of slow respiration, as Crustaceans, Mollusks, Fishes, and Reptiles, fat accumulates in the liver. "Cod-liver oil" is an example.

The great Excreting Organs are the lungs, the kidneys, and the skin; and the substances which they remove from the system-carbonic acid, water, and ureaare the products of decomposition, or organic matter on its way back to the mineral kingdom. ${ }^{70}$ Different as these organs appear, they are constructed upon the same principle: each consisting of a very thin sheet of tissue separating the blood to be purified from the atmosphere, and straining out, as it were, the noxious matters. All, moreover, excrete the same substances, but in very different proportions: the lungs exhale carbon dioxide and water, with a trace of urea; the kidneys expel water, urea, and a little carbon dioxide; while the skin partakes of the nature of both, for it is not only respiratory, especially among the lower animals, but it performs part of the work of the kidneys when they are diseased.

1. The lungs (and likewise gills) are mainly excretory organs. The oxygen they impart sweeps with the blood through every part of the body, and unites with the tissnes and with some elements of the blood. Thus are produced heat and work, whether muscular, nervous, secretory, etc. As a result of this oxidation, carbon dioxide, water, and urea or a similar substance, are poured into the blood. The carbon dioxide and part of the water are passed off from the respiratory organs. This process is 
more immediately necessary to life than any other: the arrest of respiration is fatal.

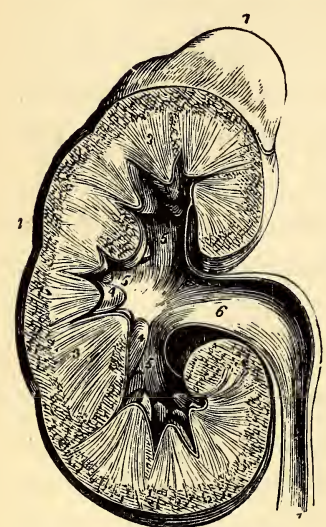

Fig. 93. - Section of Human Kidney, showing the tubular portion, 3, grouped into cones; 7 , the ureter, or outlet of the secretion.

2. While the lungs (and skin also, to a slight degree) are sources of gain as well as loss to the blood, the kidneys are purely excretory organs. Their main function is to eliminate the solid products of decay which cannot pass out by the lungs. In Mammals, they are discharged in solution; but from other animals which drink little the excretion is more or less solid. In Insects, the kidneys are groups of tubes; in the higher Mollusks, they are represented by spongy masses of follicles; in Vertebrates, they are well-developed glands, two in number, and consisting of closely packed tubes.

3. The skin of the soft-skinned animals, particularly of Amphibians and Mammals, is covered with minute pores, which are the ends of as many delicate tubes that lie coiled up into a knot within the true skin. These are the sweat-glands, which excrete water, and with it certain salts and gases.

Besides these secretions and excretions, there are others, confined to particular animals, and designed for special purposes: such are the oily matters secreted from the skin of quadrupeds for lubricating the hair and keeping the skin flexible; the tears of Reptiles, Birds, and Mammals; the milk of Mammals ; the ink of the Cuttle-fish; the poison of Jelly-fishes, Insects, and Snakes; and the silk of Spiders and Caterpillars. 


\section{CHAPTER XVI.}

THE SKIN AND SKELETON.

The Skin, or Integument, is that layer of tissue which covers the outer surface of the body. The term Skeleton is applied to the hard parts of the body, whether external or internal, which serve as a framework or protection to the softer organs, and afford points of attachment to muscles. If external, as the crust of the Lobster, it is called Exoskeleton; if internal, as the bones of Man, it is called Endoskeleton. The former is a modification of the skin; the latter, a hardening of the deeper tissues.

1. The Skin.-In the lowest forms of life, as Amœba, there is no skin. The jelly of which they are composed is firmer outside than inside, but no membrane is present. In Infusoria, there is a very thin cuticle covering the animal. They have thus a definite form, while the Amœbæ continually change. Sponges and Hydras also have no true skin. But in Polyps, the outside layer of the animal is separated into two portions--ecderon and enderon ${ }^{71}$ which may be regarded as partly equivalent to epidermis and dermis in the higher animals. These two layers are, then, generally present. The outer is cellular, the latter fibrous, and may contain muscular fibres, blood-vessels, nerves, touch-organs, and glands. It thus becomes very complicated in some animals.

In Worms and Arthropods, the cellular layer, here called hypodermis, excretes a structureless cuticle, which may become very thick, as in the tail of the Horseshoe Crab, or may be hardened by deposition of lime-salts, as in many Crustacea. The loose skin, called the mantle, 
which envelopes the body of the Mollusk corresponds to the true skin of higher animals. The border of the mantle is surrounded with a delicate fringe, and, moreover, contains minute glands, which secrete the shell and the coloring matter by which it is adorned. The Tunicates have a leathery epidermis, remarkable for containing, instead of lime, a substance resembling vegetable cellulose.

In Mammals, whose skin is most fully developed, the dermis is a sheet of tough elastic tissue, consisting of interlacing fibres, and containing blood-vessels, lymphatics, sweat-glands, and nerves. It is the part converted into leather when hides are tanned, and attains the extreme thickness of three inches in the Rhinoceros. The upper surface in parts of the body is covered with a vast number of minute projections, called papilloe, each containing the termination of a nerve; these are the essential agents in the sense of touch. ${ }^{72}$ They are best seen on the tongue of an $\mathrm{Ox}$ or Cat, and on the human fingers, where they are arranged in rows.

Covering this sensitive layer, and accurately moulded to all its furrows and ridges, lies the bloodless and nerveless epidernis. It is that part of the skin which is raised in a blister. It is thickest where there is most pressure or hard usage: on the back of the Camel it attains unusual thickness. The lower portion of the epidermis (called rete mucosum) is comparatively soft, and consists of nucleated cells containing pigment-granules, on which the color of the animal depends. Towards the surface the cells become flattened, and finally, on the outside, are changed to horny scales (Fig. 2,c).

These scales, in the higher animals, are constantly wearing off in the form of scurf, and as constantly being renewed from below. In Lizards and Serpents, the old epidermis is cast entire, being stripped off from the liead to the tail; in the Toad, it comes off in two pieces; in the 


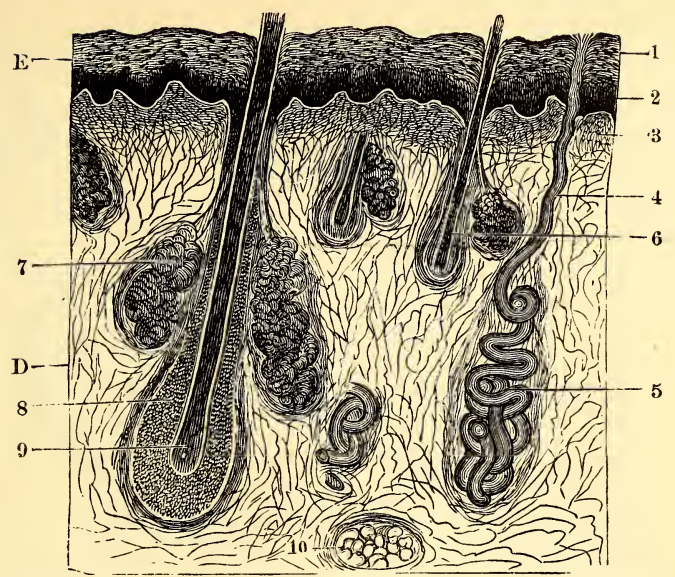

Fig. 94.-Section of Skin from Horse's Nostril : E, epidermis ; D, deımis; 1, horny layer of epidermis; 2 , rete mucosum; 3 , papillary layer of dermis ; 4, excretory duct of a sudoriparous, or sweat, gland; 5 , glomerule, or convoluted tube of the same; 6 , hair follicle; 7 , sebaceons gland; 8 , internal sheath of the hair follicle; 9 , bulb of the hair; 10 , mass of adipose tissue.

Frog, in shreds; in Fishes and some Mollusks, in the form of slime. However modified the epidermis, or whatever its appendages, the like process of removal goes on. Mammals shed their hair; Birds, their feathers; and Crabs, their shells. When the loss is periodical, it is termed moulting.

2. The Skeletons. - (1) The Exoskeleton is developed by the hardening of the skin, and, with very few exceptions, is the only kind of skeleton possessed by invertebrate animals. The usual forms are coral, shells, crusts, scales, plates, hairs, and feathers. It is horny or calcareous; while the endoskeleton is generally a deposit of earthy material within the body, and is nearly confined to the Vertebrates. The exoskeleton may be of two kinds - dermal and epidermal.

The microscopic particles of living jelly, called Polycistina and Foraminifera, possess siliceous and calcareous shells of the most beautiful patterns. The Sponge has a 
skeleton of horny fibres, which is the sponge of commerce. Coral is the solid framework of certain Polyps. There are two kinds: one represented by the common white coral, which is a calcareous secretion within the body of
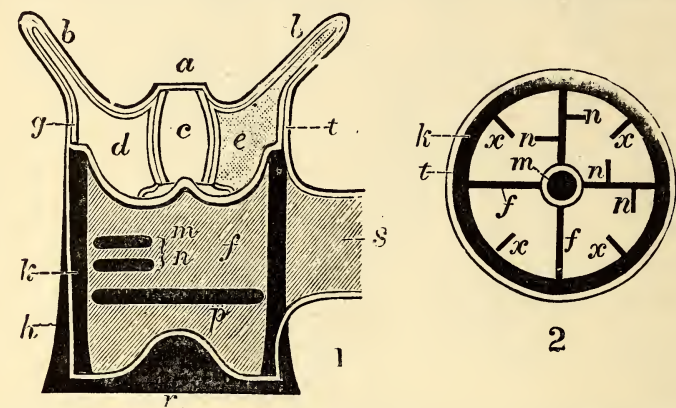

Fis. 95.-1, Vertical Section, and, 2, Transverse Section, of a sclerodermic Corallite : $a$, mouth; $b$, tentacles; $c$, stomach; $d$, intermesenteric chamber; $e$, mesentery ; $f$, septum : $g$, endoderm; $h$, epitheca ; $k$, theca, or outer wall; $m$, columella ; $n$, short partitions; $p$, tabula, or transverse partition; $r$, sclerobase; $s$, cœnenchyma, or common substance connecting neighboring corallites; $t$, ectuderm; $x$, pali, or imperfect partitions.

the Polyp, in the form of a cylinder, with partitions radiating towards a centre (scleroderm); the other, represented by the solid red coral of jewelry, is a central axis deposited by a group of Polyps on the outside (sclero-

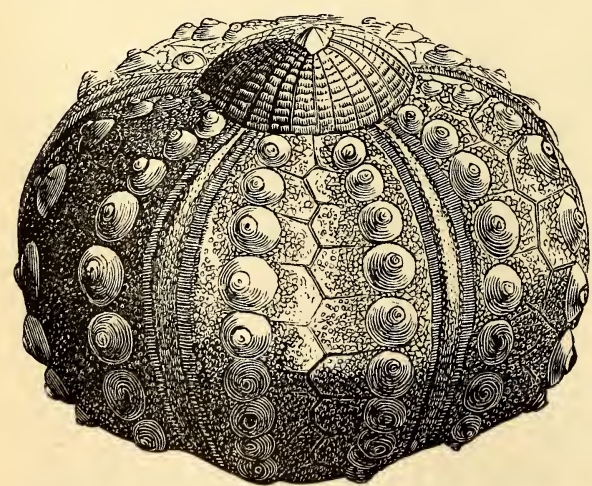

Fig. 96.-Bhell of Sea-urchin (Cidaris) without its spines.

base). The first sort is a dermal, the latter an epidermal, exoskeleton.

The skeleton of the Star-fish is a leathery skin studded with calcareous particles and plates. The Seaurchin is covered with an inflexible shell of elaborate and beautiful construction. The shell is really a calcified 
skin, being a net-work of fibrous tissue and earthy matter. It varies in shape from a sphere to a disk, and consists of hundreds of angular pieces accurately fitted together, like mosaic-work. These form ten zones, like the ribs of a melon, five broad ones alternating with five narrower

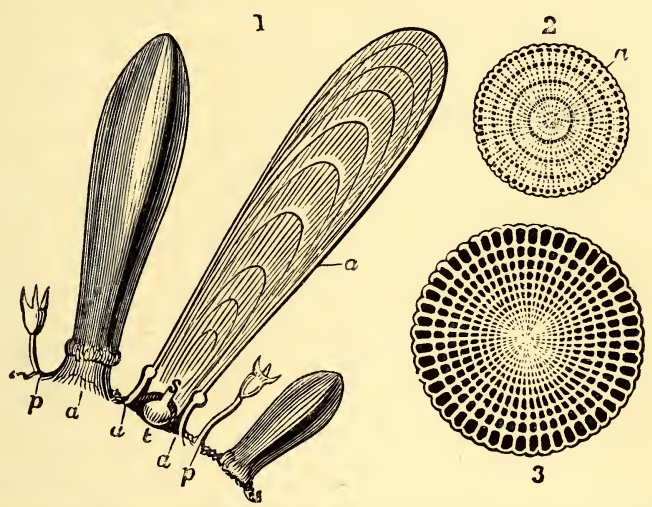

Fı. 97.-Structure of Sea-urchins' Spines: 1, $a$, spine of Cidaris cut longitudinally: $t, s$, ball-and-socket joint ; $p$, pedicellariæ; 2,3 , transverse sections of spines of Cidaris and Echinus.

ones. The former (called interambulacra) are covered with tubercles bearing movable spines. The narrow zones (called ambulacra, as they are likened to walks through a forest) are pierced with small holes, through which the animal sends out fleshy sucker-feet.

The skin of the Crab and Lobster is hardened by calcareous deposit into a "crust," or shell $;^{73}$ but, instead of forming one piece, it is divided into a series of segments, which move on each other. The number of these segments, or rings, is usually twenty-one-to the head, thorax, and abdomen, seven each. In the adult, however, the rings of the head and thorax are often soldered together into one shield, called cephalo-thorax; and in the Horseshoe Crab the abdominal rings are also united. The shell of Crustaceans is periodically cast off, for the animals continue to grow even after they have reached their 
mature form. This moulting is a very remarkable operation. How the Lobster can draw its legs from their cases

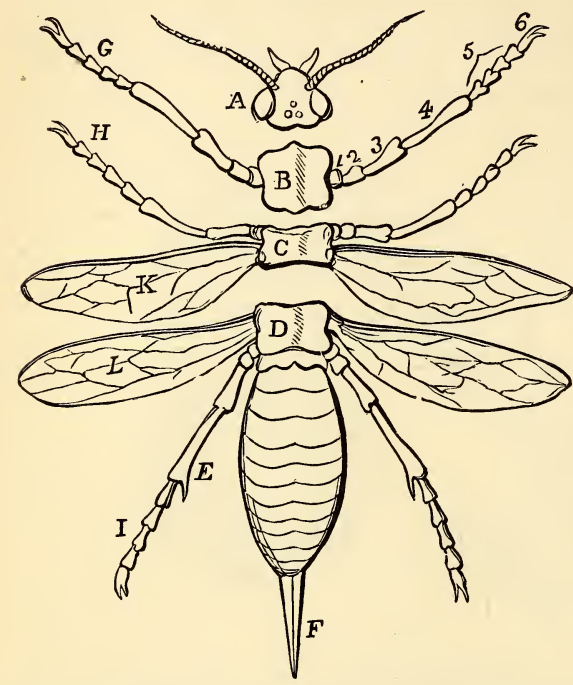

Fig. 98.-Diagram of an Insect: A, head bearing the eyes and antennæ: B, prothorax, carrying the first pair of legs; C, mesothorax, carrying the second pair of legs and first pair of wings; D, carrying the third pair of legs and second pair of wings; $\mathrm{E}$, abdomen, with ovipositor, F; 1 , coxa, or hip; 2 , trochanter ; 3 , femur, or thigh ; 4 , tibia, or shank; 5 , tarsus, or foot; 6 , claw. without unjointing or splitting them was long a puzzle. The flesh becomes soft, and is drawn through the joints, the wounds thus caused quickly healing. The castoff skeleton is a perfect copy of the animal, retaining in their places the delicate coverings of the eyes and antennæ, and even the lining membrane of the stomach with its teeth.

The horny crust of Insects differs

from that of Crustaceans in consisting mainly of a horny substance called chitine and in containing no lime. The head, thorax, and abdomen are distinct, and usually consist of fourteen visible segments-one for the head, three for the thorax (called prothorax, mesothorax, and metathorax), and ten for the abdomen. The antennæ, or feelers, legs, and wings, as well as hairs, spines, and scales, are appendages of the skeleton. As Insects grow only during the larval, or caterpillar, state, moulting is confined to that period. These skeletons are epidermal, deposited in successive layers, from the inside, and are, therefore, capable of but slight enlargement when once formed. 
The shells of Mollusks are well-known examples of exoskeletons. The mantle, or loose skin, of these animals secretes calcareous earth in successive layers, converting the epidermis into a "shell." " So various and characteristic is the microscopic character of shells, that a fragment is sometimes sufficient to determine the group to which it belongs. Many shells resemble that of the Fresh-water Mussel (Unio), which is composed of three parts: the external brown epidermis, of horny texture; then the prismatic portion, consisting of minute columns set perpendicularly to the surface; and the internal nacreous layer, or " mother-of-pearl," made up of exceedingly thin plates. The pearly lustre of the last is due to light falling upon the outcropping edges of wavy laminæ. ${ }^{75}$ In many cases, the prismatic and nacreous layers are traversed by minute tubes. Another typical shell-structure is seen in the common Cone, a section of which shows three layers, besides the epidermis, consisting of minute plates set at different angles. The Nautilus is composed of two distinct layers: the outer one having the fracture of broken china; the inner one, nacreous.

Most living shells are made of one piece, as the Snail; these are called " univalves." Others, as the Clam, consist of two parts, and are called " bivalves." In either case, a valve may be regarded as a hollow cone, growing in a spiral form. The ribs, ridges, or spines on the ontside of a shell mark the successive periods of growth, and, therefore, correspond to the age of the animal. The figures on the following page show the principal parts of the ordinary bivalves and univalves. The valves of a bivalve are generally equal, and the umbones, or beaks, a little in front of the centre. The valves are bound together by a ligature near the umbones, and often, also, by means of a "hinge" formed by the "teeth" of one valve interlocking into cavities in the other. The aperture of 
a univalve is frequently closed by a horny or calcareous plate, called "operculum," which the animal carries on its back, and which is a part of the exoskeleton. The shells of Mollusks are epidermal, and are, therefore, dead and incapable of true repair. When broken, they can be mended

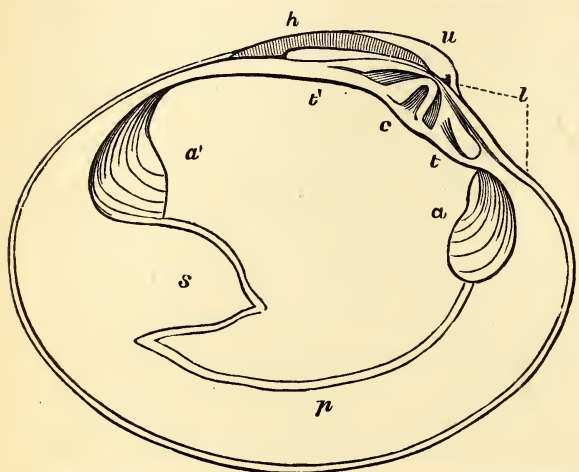

Fig. 99.-Left Valve of a Bivalve Mollusk (Cytherea chione): $h$, hinge ligament; $u$, umbo; $l$, lunule ; $c$, cardinal, and $t, t^{\prime}$, lateral teeth ; $a, a^{\prime}$, impressions of the anterior and posterior adductor muscles; $p$, pallial impression ; $s$, sinus, occupied by the retractor of the siphous.

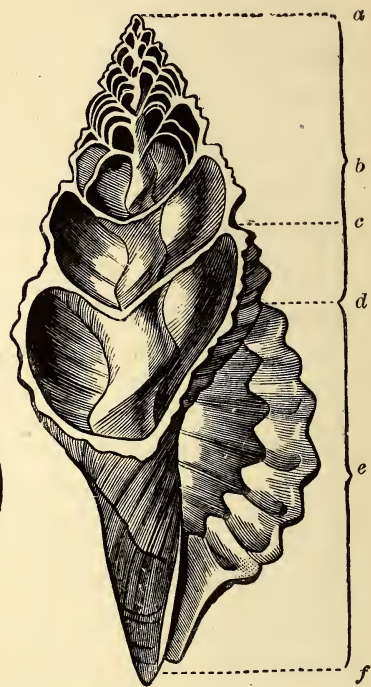

FIG. 100. - Section of a Spiral Univalve (Triton corrugatus): $a$, apex ; $b$, spire; $c$, suture : $d$, posterior canal; $e$, outer lip of the aperture; $f$, anterior canal.

only by the animal pouring out lime to cement the parts together. They cannot grow together, like a broken bone.

Imbedded in the back of the Cuttle-fish is a very light spongy "bone," which, as already observed, is a secretion from the skin, and therefore belongs to the exoskeleton. It has no resemblance to true bone, but is formed, like shells, of a number of calcareous plates. Nevertheless, the Cuttle-fish does exhibit traces of an endoskeleton: these are plates of cartilage, one of which surrounds the brain, and hence may be called a skull. To this cartilage, not to the "cuttle-bone," the muscles are attached.

In Vertebrates, the exoskeleton is subordinate to the endoskeleton, and is feebly developed in comparison. It 
is represented by a great variety of appendages to the skin, which are mainly organs for protection, not for support. Some are horny developments of the epidermis, such as hairs, feathers, nails, claws, hoofs, horns, and the scales of Reptiles; others arise from the hardening of the dermis by calcareous matter, as the scales of Fishes, the bony plates of Crocodiles and

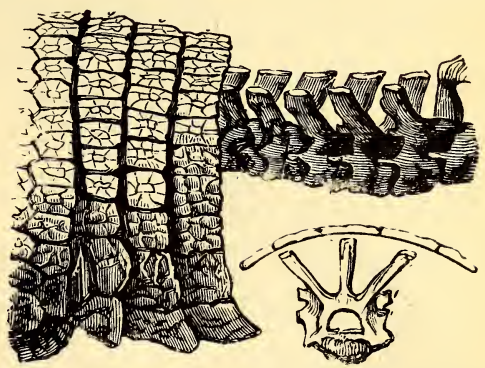

Fia. 101.-Skeletal Architecture in the Armadillo, showing the relation of the carapax to the Turtles, and the shield of the Armadillo.

The scales of Fishes (and likewise the spines of their vertical fins) lie imbedded in the overlapping folds of the skin, and are covered with a thin, slimy epidermis. The scales of the bony Fishes (Perch, Salmon, etc.) consist of

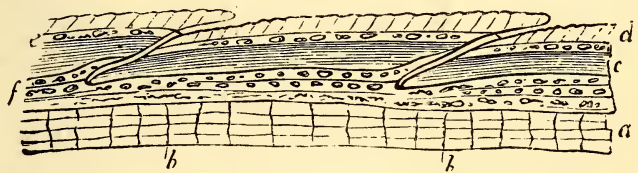

Fit. 102.-Diagrammatic Section of the Skin of a Fish (Carp) : a, derm, showing laminated structure with vertical fibles, $b: c$, gristly layer; $e$, laminated layer, with calcareous granules; $d$, superficial portion developing into scales; $f$, scale-pit.

two layers, slightly calcareous, and marked by concentric and radiating lines. Those of the Shark have the structure of teeth, while the scutes, or plates, of the Crocodiles, Turtles, and Armadillos are of true bone.

The scales of Snakes and Lizards are horny epidermal plates covering the overlapping folds of the true skin. In some Turtles these plates are of great size, and are called "tortoise-shell;" they cover the scutes. The scales on the legs of Birds, and on the tail of the Beaver and Rat, have the same structure. Nails are flattened horny plates developed from the upper surface of the fingers 


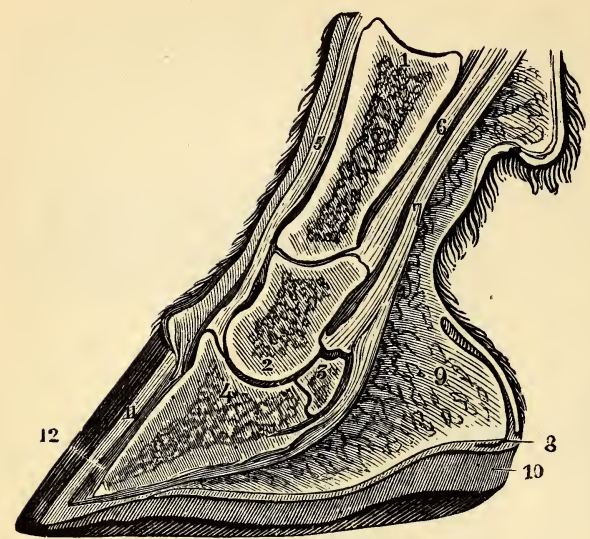

Frg. 103.-Vertical Section of the Forefoot of the Horse (middle digit): 1, 2, 4, proximal, middle, and distal, or ungual, phalanges; 3 , sesamoid, or nut-bone; 5 , 6,7 , tendons; 9 , elastic tissue; 8,10 , internal and external floor of the hoof; 11, 12, internal and external walls.

rattles of the Rattlesnake, and the beaks of Turtles and Birds, are likewise epidermal.

Hairs, the characteristic clothing of Mammals, are elongated horny cones, composed of "pith" and "crust." The latter is an outer layer of minute overlapping scales, which are directed towards the point, so that rubbing a human hair or fibre of wool between the thumb and finger pushes the rootend away. The root is bulbous, and is contained in a minute depression, or sac, formed by an infolding of the skin. Hairs are usually set obliquely into the skin. Porcupine's quills and Hedgehog's spines make an easy transition to and toes. Claws are sharp conical nails, being developed from the sides as well as upper surface; and hoofs are blunt cylindrical claws. Hollow horns, as of the Ox, may be likened to claws sheathing a bony core. The horn of the Rhinoceros is a solid mass of epidermal fibres. "Whalebone," the

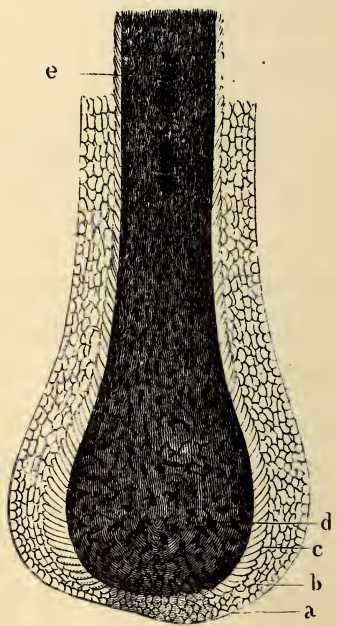

Frg.104. - Section of the Root and part of the Shaft of a Human Hair; it is covered with epidermic scales, the inner layer, $c$, forming the outer covering of the shaft, being imbricated : the root consists of angular cells loaded with pigment. 
feathers, which differ from hairs only in splitting up into numerous laminæ. They are the most complicated of all the modifications of the epidermis. They consist of a "quill" (answering to the bulb of a hair), and a "shaft," supporting the "vane," which is made up of "barbs," "barbules," and interlocking "processes." The quill alone is hollow, and has an orifice at each end. Thus feather is moulded on a papilla, the shaft lying in a groove on one side of it, and the vane wrapped around it. When the feather emerges from the skin, it unfolds itself. Thus shaft and vanes together resemble the quill split down one side and spread out.

The teeth of Mollusks, Worms, and Arthropods are also epidermal structures. Those of Vertebrates are mixed in their origin, the dentine being derived from the dermis and the enamel from the epidermis. In all cases teeth belong to the exoskeleton.

(2) The Endoskeleton, as we have seen, is represented in the Cuttlefish. With this and some other exceptions, it is peculiar to Verte-

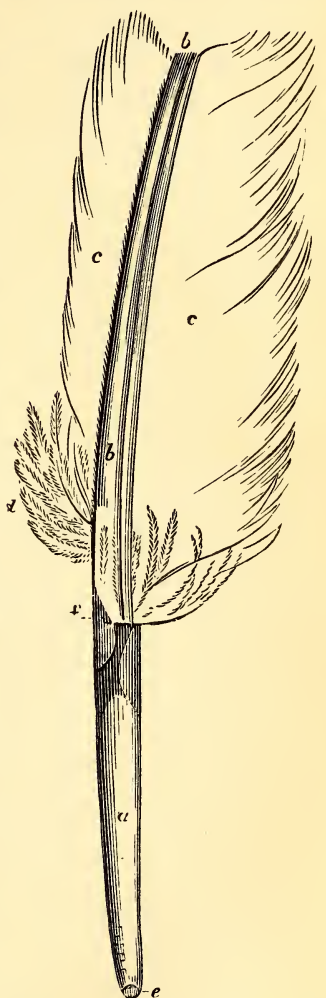

Fig. 105.-Parts of a Feather: $a$, quill, or barrel; $b$, shaft; $c$, vane, or beard; $d$, accessory plume, or down : $e, f$, lower and upper umbilicus, or orifice, leading to the interior of the quill. brates. In the Cuttle-fish, and some Fishes, as the Sturgeon and Shark, it consists of cartilage; but in all others (when adult) it is bone or osseous tissue. Yet there is a diversity in the composition of bony skeletons; that of fresh-water Fishes contains the least earthy matter, and that of Birds the most. Hence the density and ivory- 
whiteness of the bones of the latter. Unlike the shells of Mollusks and the crust of the Lobster, which grow by the addition of layers to their borders, bones are inoist, living parts, penetrated by blood-vessels and nerves, and covered with a tough membrane, called periosteum, for the attachinent of muscles.

The surface of bones is compact; but the interior may be solid or spongy (as the bones of Fishes, Turtles, Sloths, and Whales), or hollow (as the long bones of Birds and the active quadrupeds). There are also cavities (called "sinuses") between the inner and outer walls of the skull, as is remarkably shown by the Elephant. The cavities in the long bones of quadrupeds are filled with marrow; those in the long bones of Birds and in skulls contain air.

The number of bones not only differs in different animals, but varies with the age of an individual. In very early life there are no bones at all; and ossification, or the conversion of cartilage into bone, is not completed until maturity. This process begins at a multitude of points, and theoretically there are as many bones in a skeleton as centres of ossification. But the actual number is usually much less-a result of the tendency of these centres to coalesce. Thus, the thigh-bone in youth is composed of five distinct portions, which gradually unite. So in the lower Vertebrates many parts remain distinct which in the higher are joined into one. The occiput or back-bone of Man's skull is the union of four bones, which are seen separate in the skull of the Fish, or of a baby.

A complete skeleton, inade up of all the pieces which might enter into its composition, does not exist. Every Vertebrate has some deficiency. All, except Amphioxus, have a skull and back-bone; but in the developinent of the various parts, and especially of the appendages, there is endless variety. Fishes possess a great number of skullbones, but have no finger's and toes. The Snake has plenty 
of ribs and tail, but no breast-bone; the Frog has a breastbone, but neither tail nor ribs. As the skeleton of a Fish is too complicated for the primary student, we will select for illustration the skeleton of a Lion-the type of quad-

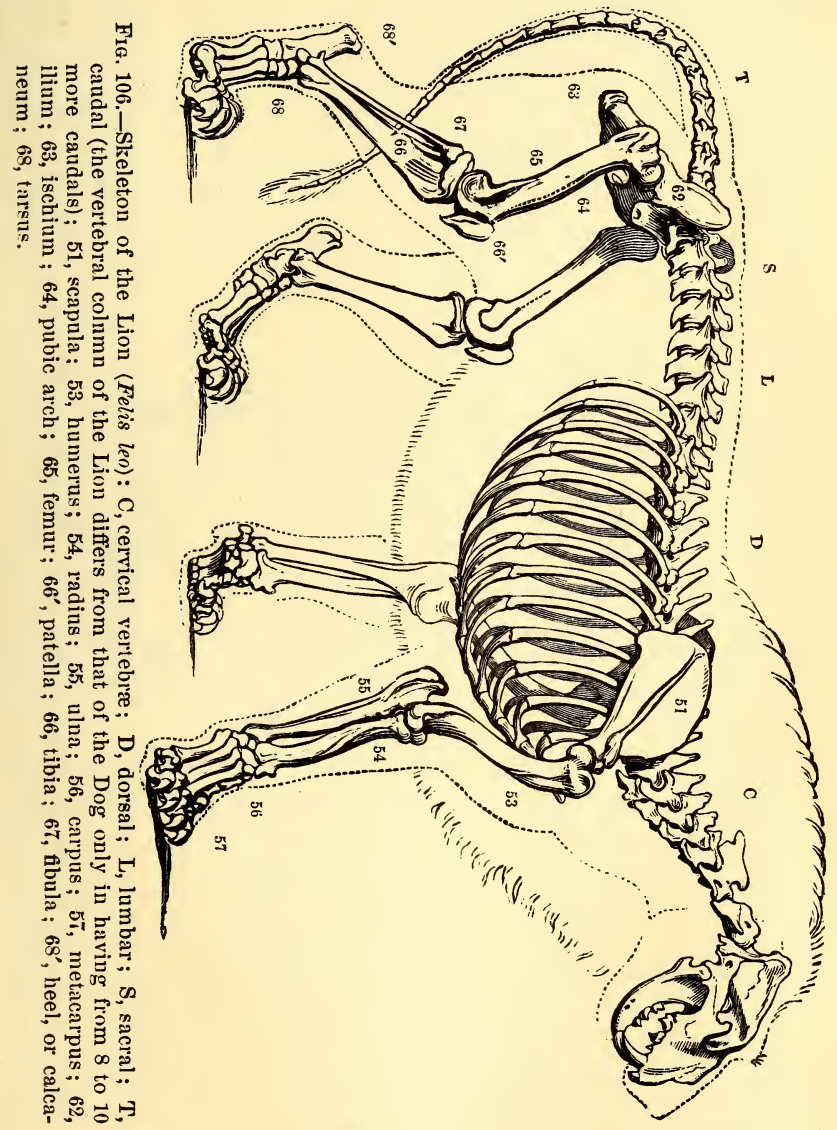

rupeds. It should be remembered, however, that all Vertebrates are formed on one plan.

In the lowest Vertebrate, Amphioxus, the only skeleton is a cartilaginous rod running from head to tail. There is no skull, nor ribs, nor limbs. In the cartilaginous Fishes, 
the backbone is only partially ossified. But usually it consists of a number of separate bones, called vertebroe, arranged along the axis of the body. They range in number from 10 in the Frog to 305 in the Boa-constrictor. The skull, with its appendages, and the vertebræ, with the ribs and sternum, make up the axial skeleton. The shoulder and pelvic girdles and the skeleton of the limbs constitute the appendicular skeleton.

A typical vertebra consists of a number of bony pieces so arranged as to form two arches, or hoops, connected by

B.
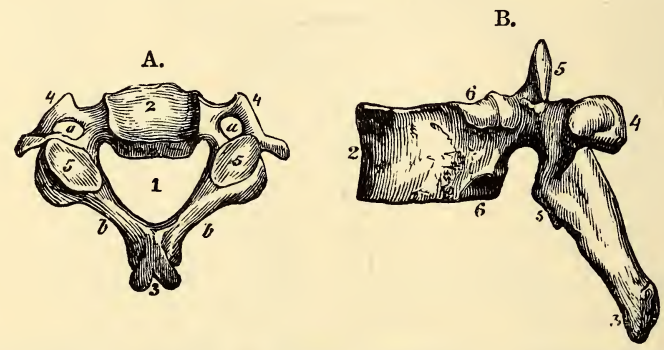

Frg. 107.-Vertebræ-A, cervical; B, dorsal ; 2, centrum ; 4, transverse process, containing foramen, $a$, for artery ; 5 , articular process; 3 , spinous process, or neural spine; 1 , neural canal; 6 , facets for head of rib, the tubercle of the rib fitting in a facet on the process, $4 ; b$, laminæ, or neurapophyses.

a central bone, or centrum. ${ }^{76}$ The upper hoop is called the neural arch, because it encircles the spinal marrow; the lower hoop is called the homal arch, because it encloses the heart and the great central blood-vessels. An actual vertebra, however, is subject to so many modifications, that it deviates more or less from this ideal type. Selecting one from the middle of the back for an example, we see that the centrum sends off from its dorsal side two branches, or processes, called neurapophyses. These meet to form the neural arch, under which is the neural canal, and above which is a process called the neural spine. On the anterior and posterior edges of the arch are smooth surfaces, or zygapophyses, which in the natural state are covered with cartilage, and come in contact with 
the corresponding surfaces of the preceding and succeeding vertebræ. The bases of the arch are notched in front and behind, so that when two vertebræ are put together a round opening (intervertebral foramen) appears between the pair, giving passage to the nerves issuing from the spinal cord. From the sides of the arch, blunt transverse processes project outward and backward, called diapophyses. Such are the main elements in a representative vertebra. The hæmal arch is not formed by any part of the vertebra, but by the ribs and breast-bone. Theoretically, however, the ribs are considered as elongated processes from the centrum (pleurapophyses), and in a few cases a hoemal spine is developed corresponding to the neural spine.

The vertebræ are united together by ligaments, but chiefly by a very tough, dense, and elastic substance between the centra. The neural arches form a continuous canal which contains and protects the spinal cord; hence the vertebral column is called the neuroskeleton. The column is always more or less curved; but the beautiful sigmoid curvature is peculiar to Man. The vertebræ gradually increase in size from the head towards the end of the trunk, and then diminish to the end of the tail. The neural arch and centrum are seldom wanting; the first vertebra in the neck has no centrum. and the last in the tail is all centrum. The vertebræ of the extremities (head and tail) depart most widely from the typical form.

The vertebral column in Fishes and Snakes is divisible into three regions - head, trunk, and tail. But in the higher animals there are six kinds of vertebræ: cranial, cervical, dorsal, lumbar, sacral, and caudal.

The cranial vertebrce form the skull. ${ }^{77}$ They are greatly modified, as the neural arches are expanded to enclose the brain. The number of distinct bones composing the skull is greatest in Fishes, and least in Birds: this arises partly 


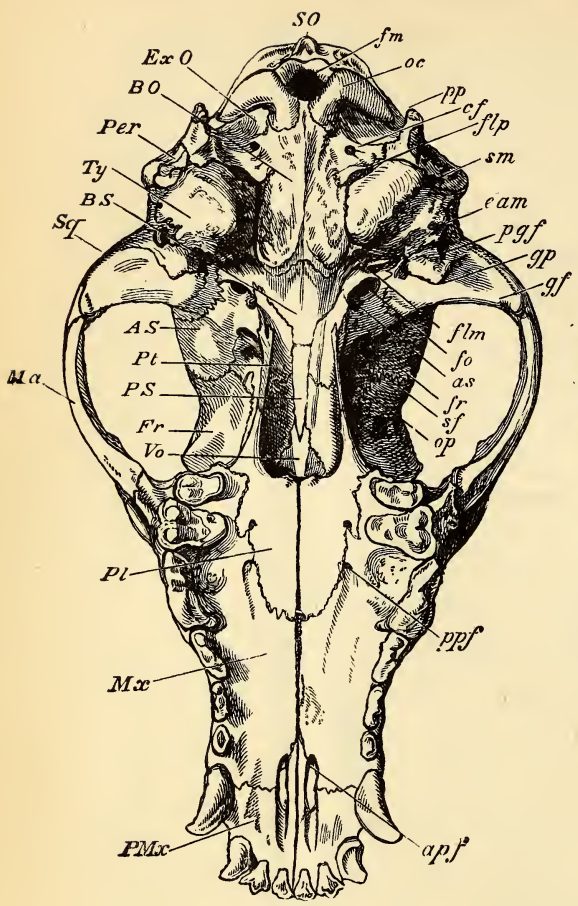

Fig. 108.

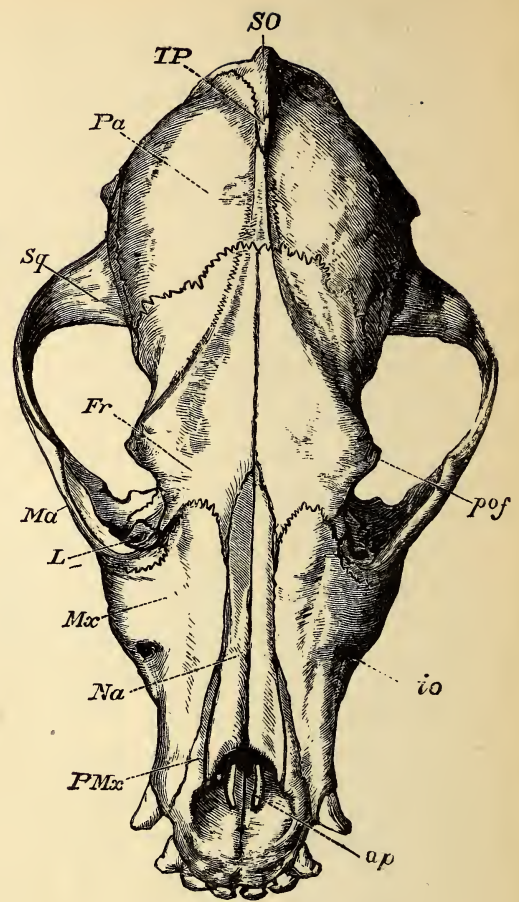

FIG. 109 .

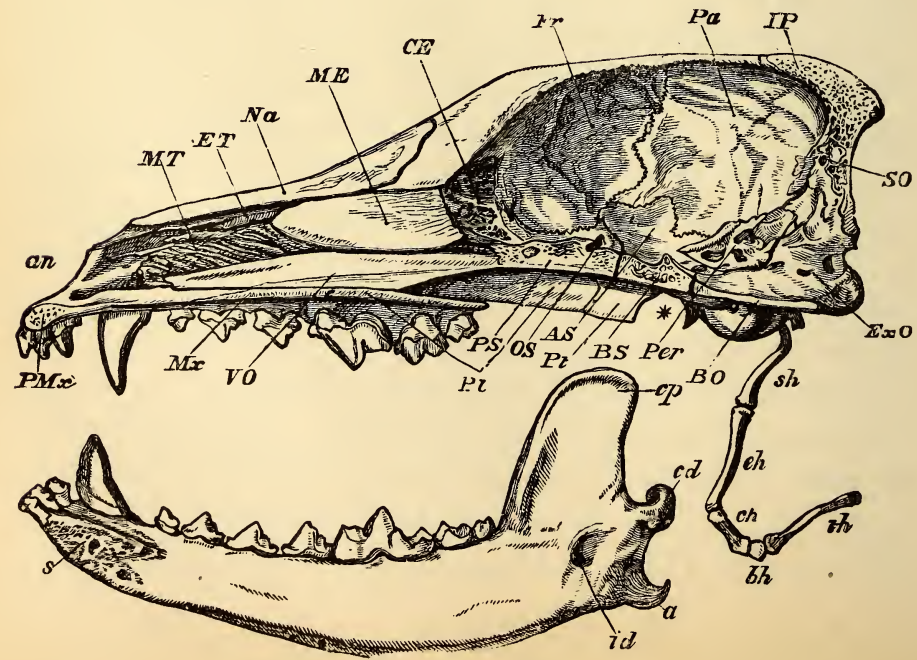

FIG. 110. 


\section{BONES OF THE MAMMALIAN SKULL**}

\section{BRAIN-CASE.}

\begin{tabular}{l|lccc|}
\cline { 2 - 4 } NASAL. & FRONTAL. & PARIETAL. & SUPRAOCCIPITAL. \\
NOSE. & HRYMAL. & SQUAMOSAL. & \\
ORBITOSPHENOID. EYE. ALISPHENOID. & PERI- EAR. OTIC. & EXOCCIPITAL. \\
MALAR. & TYMPANIC. & \\
ETHMOID. & BASISPHENOID. & BASIOCCIPITAL. \\
\hline
\end{tabular}

VOMER.

PREMaXilla. MAXilla. PALATINe. PTERYgoid,

HYOID ARCH.

LOWER JAW, OR MANDIBLE.

\section{THE SKULL OF THE DOG.}

F1G. 108.-Under surface. FIG. 109.-Upper surface. FiG. 110.-Longitudinal vertical section; one-half natural size: $S O$, supraoccipital : $E x O$, exoccipital ; $B O$, basioccipital ; $I P$, interparietal ; $P a$, parietal ; $F r$, frontal ; $S q$, squamosal ; $M a$, malar; $L$, lachrymal ; $M x$, maxilla ; $P M x$, premaxilla ; $N a$, nasal ; $M T$, maxilloturbinal: $E T$, ethmoturbinal ; $M E$, ossitied portion of the mesethmoid ; $C E$, cribriform, or sieve-like, plate of the ethmoturbinal ; VO, vomer ; $P S$, presphenoid : $O S$, orbitosphenoid ; $A S$, alisphenoid ; $B S$, basisphenoid; $P l$, palatine ; $P t$, pterygoid ; Per, periotic ; $T y$, tympanic bulla ; $a n$, anterior narial aperture ; $\alpha p$, or $a p f$, anterior palatine foramen ; $p p f$, posterior palatine foramen ; io, infraorbital foramen; $p o f$, postorbital process of frontal bone ; op, optic foramen ; $s f$, sphenoidal fissure; $f r$, foramen rotundum, and anterior opening of alisphenoid canal ; $a s$, posterior opening of alisphenoid caual ; fo, foramen ovale ; $\mathrm{fm}$, foramen lacerum medium ; $g f$, glenoid fossa ; $g p$, postglenoid process ; $p g f$, postglenoid foramen ; eam, external auditory meatus ; $\mathrm{sm}$, stylomastoid foramen ; $f l p$, foramen lacerum posterius ; $c f$, condylar foramen ; $p p$, paroccipital process ; $o c$, occipital condyle ; $f m$, foramen magnum ; $a$, angular process ; $s$, symphysis of the mandible where it unites with the left ramus; $i d$, inferior dental canal; $c d$, condyle; $c p$, coronoid process; the ${ }^{*}$ indicates the part of the cranium to which the condyle is articulated when the mandible is in place; the upper border in which the teeth are implanted is called alveolar; $s h, e h, c h, b h, t h$, hyoidean apparatus, or os linguce, supporting the tongue. In the skulls of old animals, there are three ridges: occipital, behind; sagittal, median, on the upper surface; and superorbital, across the frontal, in the region of the eyebrows. The last is highly developed in the Gorilla and other Apes.

- In this diagram, modified from Huxley's, the italicized bones are single: the rest are double. Those in the line of the Ethmoid form the Cranio-facial Axis: these, with the other sphenoids and occipitals, are developed in cartilage; the rest are membrane bones. In the Human skull, the four occipitals coalesce into one. 
from the fact that the bones remain separate in the former case, while those of the chick become united together (anchylosed) in the full-grown Bird; but many bones are present in the Fish which have no representatives in the Bird. The skull consists of the brain-case and the face. The principal parts of the skull, as shown in the Dog's, are: 1. The occipital bones behind, enclosing a large hole, or foramen magnum, on each side of which are rounded prominences, called condyles, by which the skull articulates with the first cervical vertebra. 2. The parietal. 3. The frontal. These three form the main walls of the brain. 4. The sphenoid, on the floor of the skull in front of the occipital, and consisting of six pieces. 5. The temporal, in which is situated the ear. In Man this is one bone; but in most animals there are three or more-the periotic, tympanic, and squamosal. 6. The malar, or "cheek-bone," which sends back a process to meet one from the squamosal, forming the zygomatic arch. 7. The nasal, or roof of

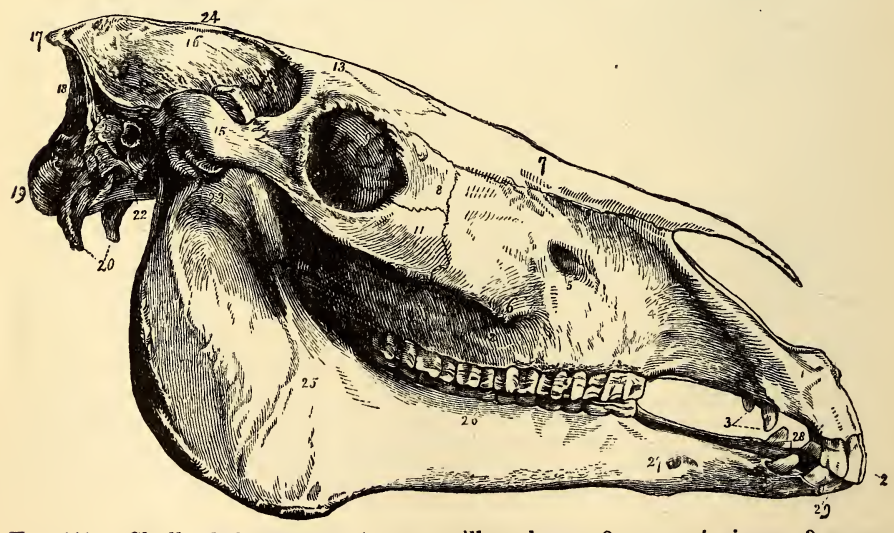

Fig. 111. - Skull of the Horse: 1, premaxillary bone; 2, upper incisors; 3, upper canines; 4 , superior maxillary; 5 , infraorbital foramen; 6 , superior maxillary spine; 7 , nasal bones; 8 , lachrymal; 9 , orbital cavity; 10 , lachrymal fossa; 11 , malar; 12, upper molars; 13, frontal; 15, zygomatic arch ; 16, parietal ; 17, occipital protuberance; 18 , occipital crest ; 19 , occipital condyles ; 20 , styloid processes: 21, petrous bone; 22 , basilar process; 23 , condyle of inferior maxillary : 24 , parietal crest ; 25 , inferior maxillary ; 26 , lower molars ; 27 , anterior maxillary foramen; 28 , lower canines; 29 , lower incisors. 
the nose. 8. The maxilla; that part of the upper jaw in which the canines, premolars, and molars are lodged. 9 . The premaxilla, in which the upper incisors are situated. 10. The palatine, which, with the maxillary bones, forms the roof of the mouth. There are two appendages to the skull: the mandible, or lower jaw, whose condyles, or rounded extremities, fit into a cavity (the glenoid) in the temporal bone; and the hyoid, situated at the root of the tongue.

The simplest form of the skull is a cartilaginous box, as in Sharks, enclosing the brain and supporting the cartilaginous jaws and gill arches. In higher Fishes this box is overlaid with bony plates and partly ossified. In Frogs the skull is mainly bony, although a good deal of the cartilage remains inside the bones. In higher Vertebrates the cartilage never makes an entire box, and early disappears.

The cervical vertebrce, or bones of the neck, are peculiar in having an orifice on each side of the centrum for the passage of an artery. The first, called atlas, because it supports the head, has no centrum, and turns on the second, called axis, around a blunt process, called the odontoid. The centra are usually wider than deep, and the neural spines very short, except in the last one. The number of cervical vertebræ ranges from 1 in the Frog to 25 in the Swan.

The dorsal vertebrce are such as bear ribs, which, uniting with the breast-bone, or sternum, form a bony arch over the heart and lungs, called the thorax. The sternum may be wanting, as in Fishes and Snakes, or greatly developed, as in Birds. When present, the first vertebra whose ribs are connected with it is the first dorsal. The neural spines of the dorsal series are generally long, pointing backward.

The lumbar vertebroe are the massive vertebræ lying in the loins between the dorsals and the hip-bones.

The sacral vertebra lie between the hip-bones, and are 
generally consolidated into one complex bone, called $s a$ crum.

The caudal vertebrice are placed behind the sacrum, and form the tail. They diminish in size, losing processes and neural arch, till finally nothing is left but the centrum. They number from 3 or 4 in Man to 270 in the Shark.

Besides the lower jaw, hyoid, and ribs, Vertebrates have other appendages to the spinal column-two pairs of limbs. ${ }^{78}$ The fore limb is divided into the pectoral arch (or shoulder girdle), the arm, and the hand. The arch is fastened to the ribs and vertebræ by powerful muscles, and consists of three bones, the scapula, or shoulder-blade, the coracoid, and the clavicle, or collar-bone. The scapula and coracoid are generally united in Mammals, the latter forming a process of the former; and the clavicles are frequently wanting, as in the hoofed animals. The humerus, radius, and ulna are the bones of the arm, the first articulating by ball-and-socket joint with the scapula, and by a hinge-joint with the radius and ulna. The humerus and radius are always present, but the ulna may be absent. The bones of the hand are divided into those of the carpus, or wrist; the metacarpus, or palm; and the phalanges, or fingers. The fingers, or "digits," range in number from 1 to 5 .

The hind limb is composed of the pelvic arch (or hipbones), the leg, and the foot. These parts correspond closely with the skeleton of the fore limb. Like the shoulder, the pelvic arch, or os innominatum, consists of three bones-ilium, ischium, and pubis. The three are distinct in Amphibians, Reptiles, and in the young of higher animals; but in adult Birds and Mammals they become united together, and are also (except in Whales) solidly attached to the sacrum. The two pelvic arches and the sacrum thus soldered into one make the pelvis. The leg-bones consist of the femur, or thigh; the tibia, or 
shin-bone; and the fibula, or splint-bone. The rounded head of the femur fits into a cavity (acetabulum) in the pelvic arch, while the lower end articulates with the tibia, and sometimes (as in Birds) with the fibula also. An extra bone, the patella, or knee-pan, is hung in a tendon in front of the joint between the femur and tibia of the higher animals. The foot is made up of the tarsus, or ankle; the metatarsus, or lower instep; and the phalanges, or toes. The toes number from 1 in the Horse to 5 in Man.

Certain parts of the skeleton, as of the skull, are firmly joined together by zigzag edges or by overlapping; in either case the joint is called a suture. But the great majority of the bones are intended to move one upon another. The vertebræ are locked together by their processes, and also by a tough fibrous substance between the centra, so that a slight motion only is allowed. The limbs furnish the best examples of movable articulations, as the ball-and-socket joint at the shoulder, and the hinge-joint at the elbow. The bones are held together by ligaments, and, to prevent friction, the extremities are covered with cartilage, which is constantly lubricated with an unctuous fluid called synovia.

\section{CHEMICAL COMPOSITION OF BONES.}

\begin{tabular}{|c|c|c|c|c|}
\hline \multirow[b]{2}{*}{$\begin{array}{l}\text { Phosphate of Lime, with trace of } \\
\text { Fluate of Lime................................. }\end{array}$} & Cod. & TORTOIsE. & HAWK. & Man. \\
\hline & 57.29 & 52.66 & 64.39 & 59.63 \\
\hline Carbonate of Lime & 4.90 & 12.53 & 7.03 & 7.33 \\
\hline Phosphate of Magnesia.............. & 2.40 & 0.82 & 0.94 & 1.32 \\
\hline 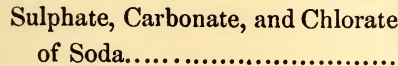 & 1.10 & 0.9 & 0.92 & 0.69 \\
\hline Glutine and Chondrine.............. & 32.31 & 31.75 & 25.73 & 29.70 \\
\hline 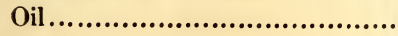 & 2.00 & 1.34 & 0.99 & 1.33 \\
\hline & 100.00 & 100.00 & 100.00 & 100.00 \\
\hline
\end{tabular}




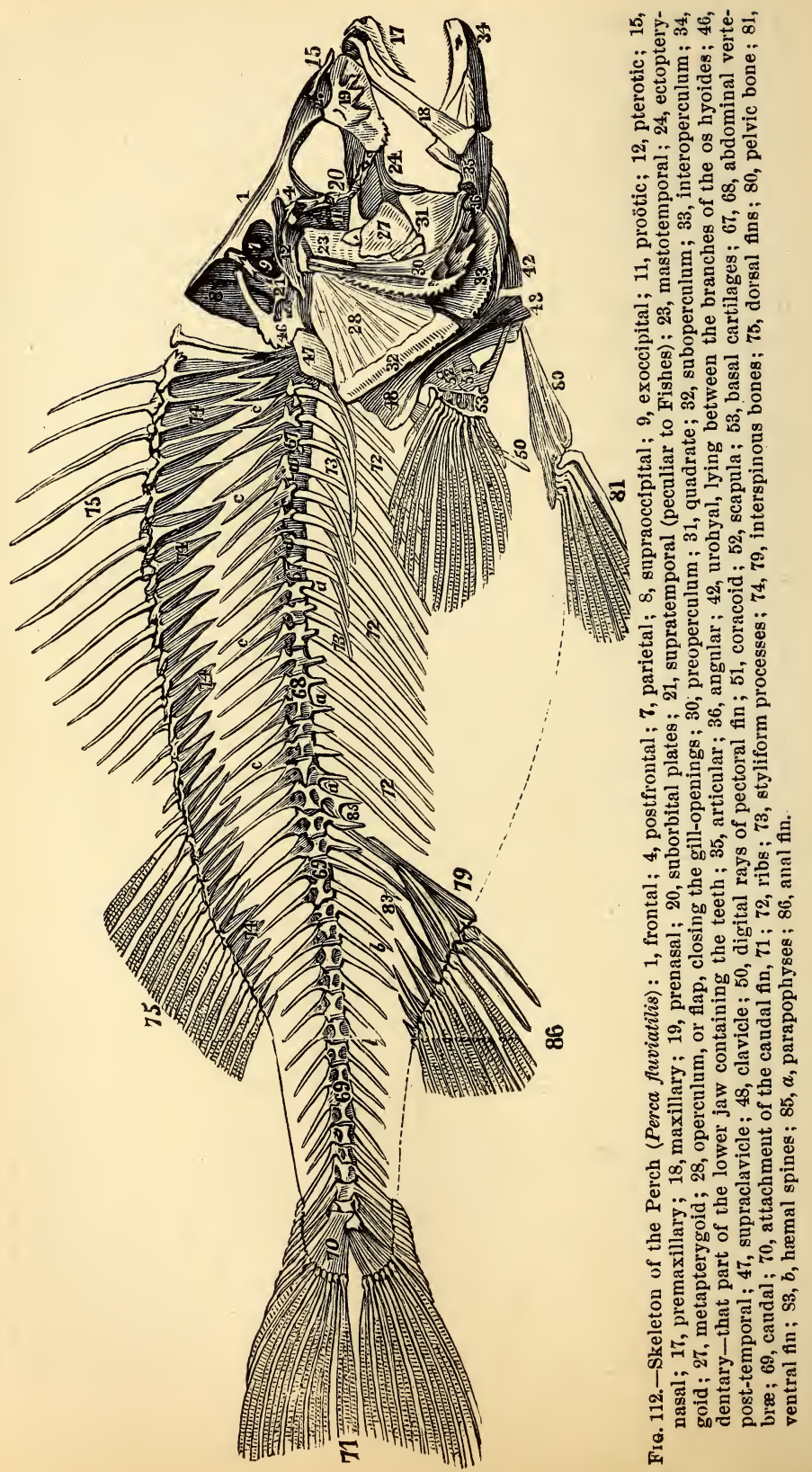


THE SKIN AND SKELETON.
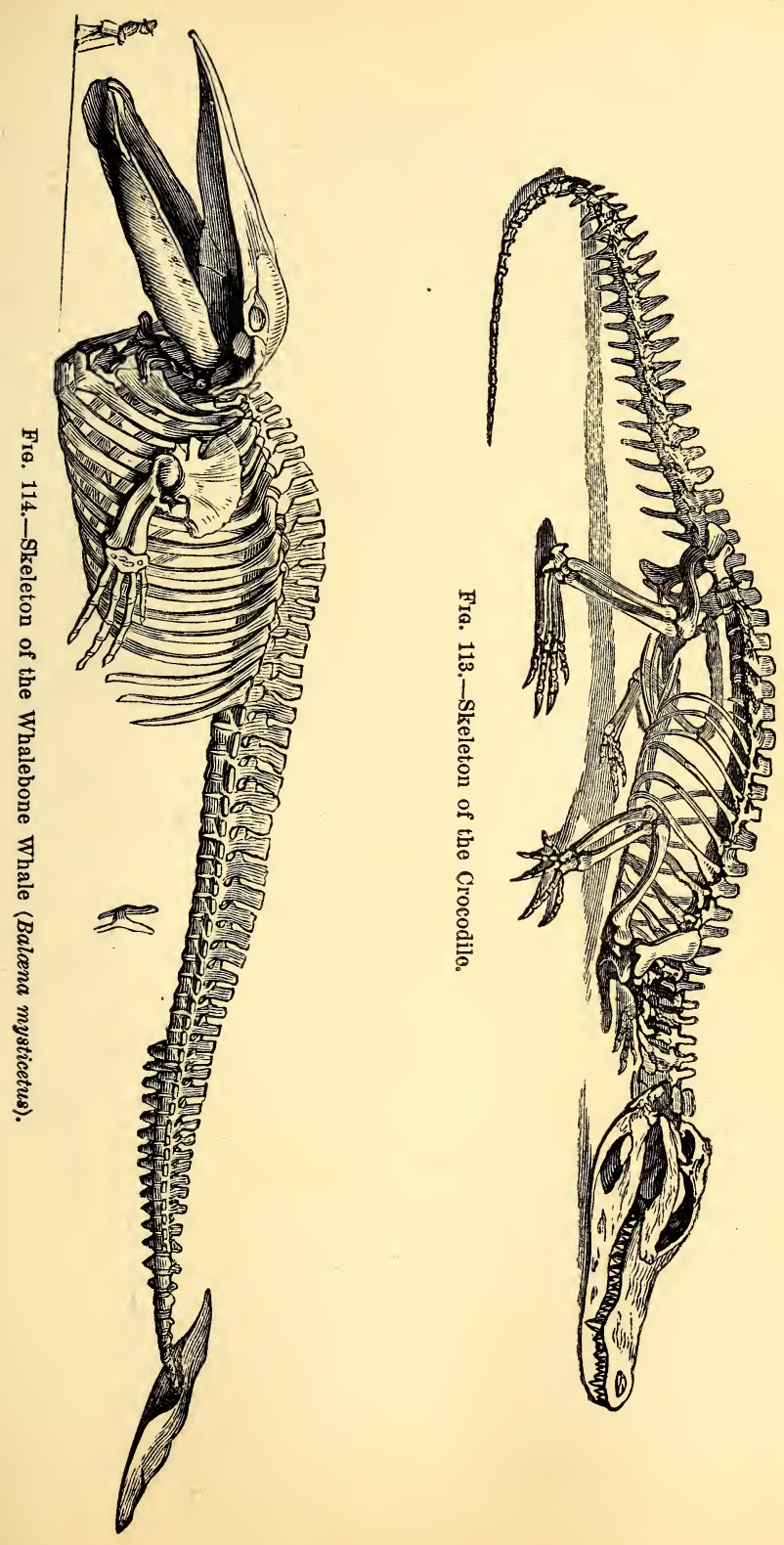


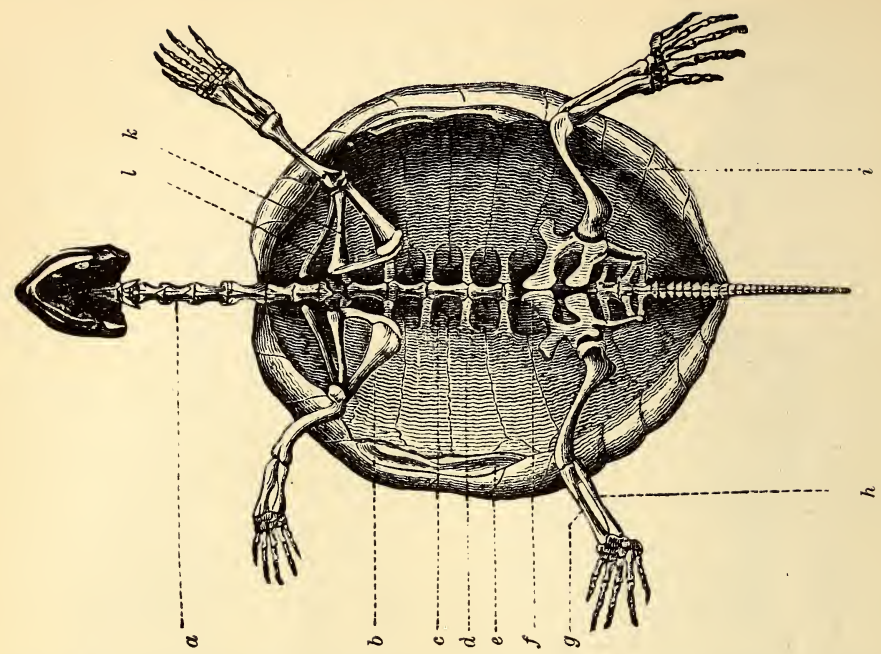

F16. 115.-Skeleton of the Tortoise (plastron removed): $a$, cervical vertebræ; $c$, dorsal vertebræ; $d$, ribs; $e$, marginal bones of the carapace; $l$, scapula; $k$, precoracoid ; $b$, coracoid ; $f$, pelvis ; $i$, femur ; $g$, tibia ; $h$, fibula.

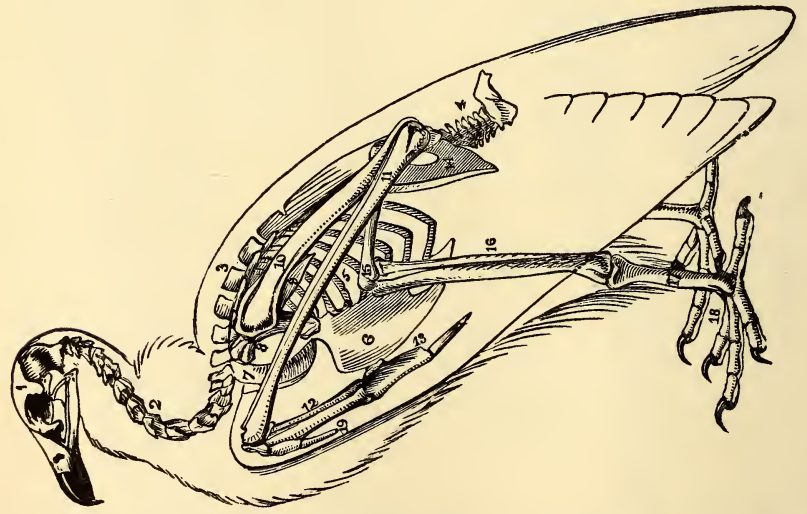

Fre. 116.-Skeleton of a Vulture : 1, cranium-the parts of which are separable only in the chick; 2, cervical vertebræ; 3 , dorsal ; 4, coccygeal, or caudal; the lumbar and sacral are consolidated; 5 , ribs; 6 , sternum, or breast-bone, extraordinarily developed ; 7, furculum, clavicle, or "wish-bone;" 8 , coracoid; 9, scapula; 10 , humerus: 11 , ulna, with rudimentary radius; 12 , metacarpals; 13 , phalanges of the great digit of the wing: 19 , thumb ; 14 , pelvis ; 15 , femur : 16 , tibia-tarsus and fibula, or crus; 17 , tarso-metatarsus ; 18 , internal digit, or toe, formed of three phalanges; the middle toe has four phalanges; the outer, five; and the back toe, or thumb, two. 


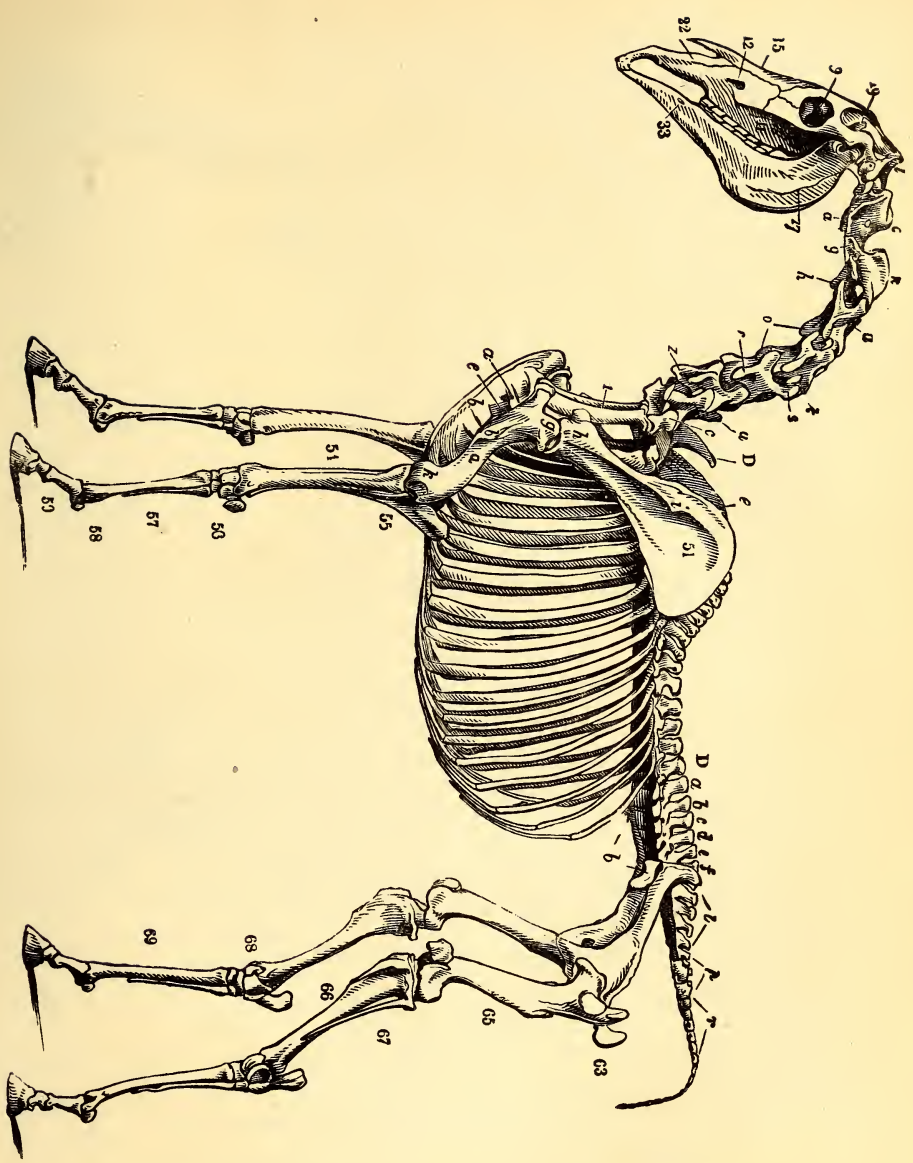

Fig. 117.-Skeleton of the Horse (Equus caballus): 22, premaxillary: 12, foramen in the maxillary ; 15 , nasal ; 9 , orbit ; 19 , coronoid process of lower jaw ; 17 , surface of implantation for the masseter muscle; there are seven cervical vertebræ, nineteen dorsal, D-D; five lumbar, $a-e$; five sacral, $f-l$; and seventeen caudal, $p-r$; 51 , scapula, or shoulder-blade; $i$, spine, or crest ; $h$, coracoid process (acromion wanting); 1, first pair of ribs (clavicle wanting, as in all Ungulates) ; $e$, sternum : $a$, shaft of humerus; $b$, deltoid ridge; $g$, head fitting in the glenoid cavity of the scapula-near it is a great tuberosity for the attachment of a powerful muscle; $k$, condyles ; 54, radius, to which is firmly anchylosed a rudimentary ulna, 55 , the olecranon; 56, the seven bones of the carpus, or wrist ; 57 , large metacarpal, or "cannon-bone," with two "splint-bones ;" 58, fetlock-joint; 59, phalanges of the developed digit, corresponding to the third finger in Man; 62, pelvis ; 63, the great trochanter, or prominence on the femur, $65 ; 66$, tibia; 67 , rudimentary fibula ; 68 , hock, or heel, falsely called knee; 69 , metatarsals. 


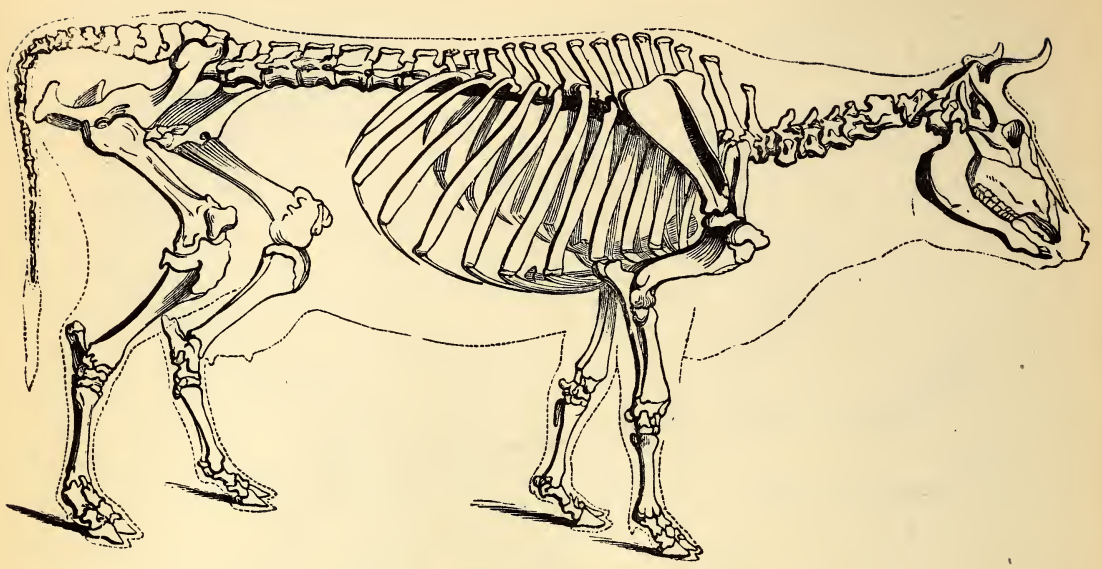

FiG. 118.-Skeleton of the Cow (Bos taurus).

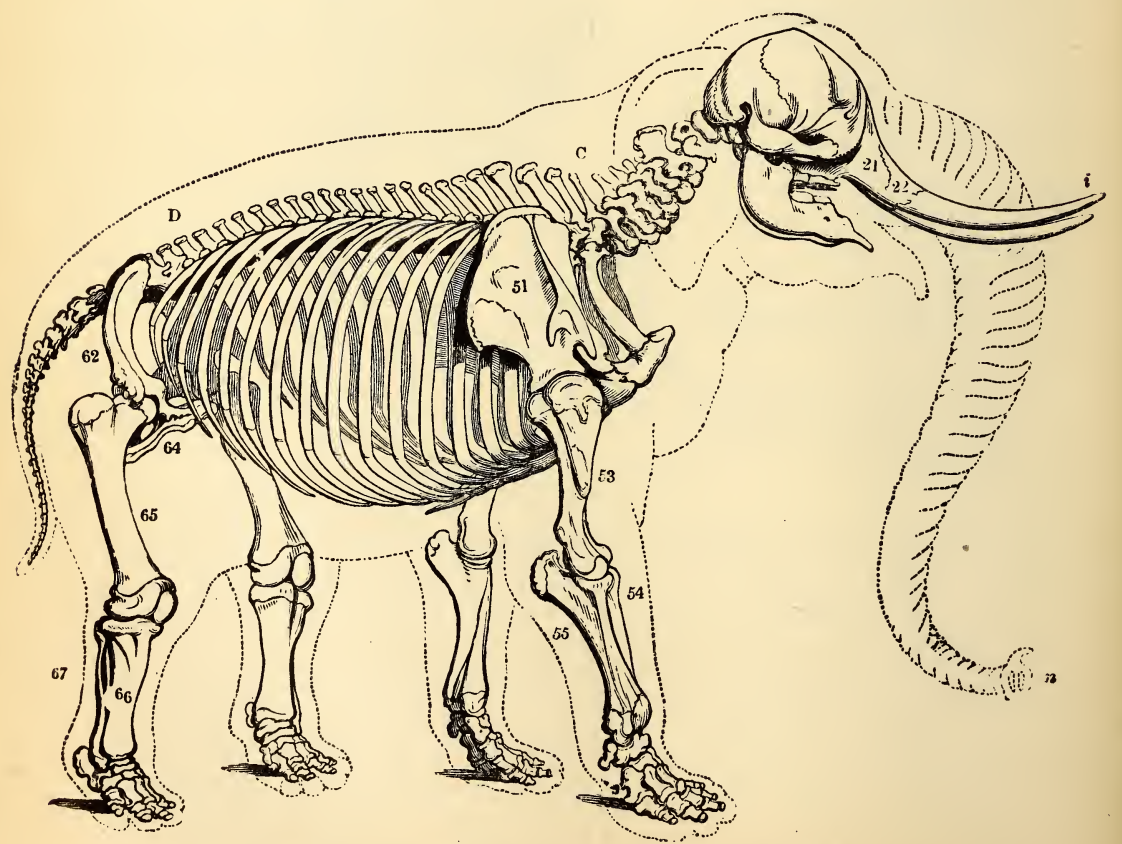

Fig. 119.-Skeleton of an Elephant (Elephas Indicus). 


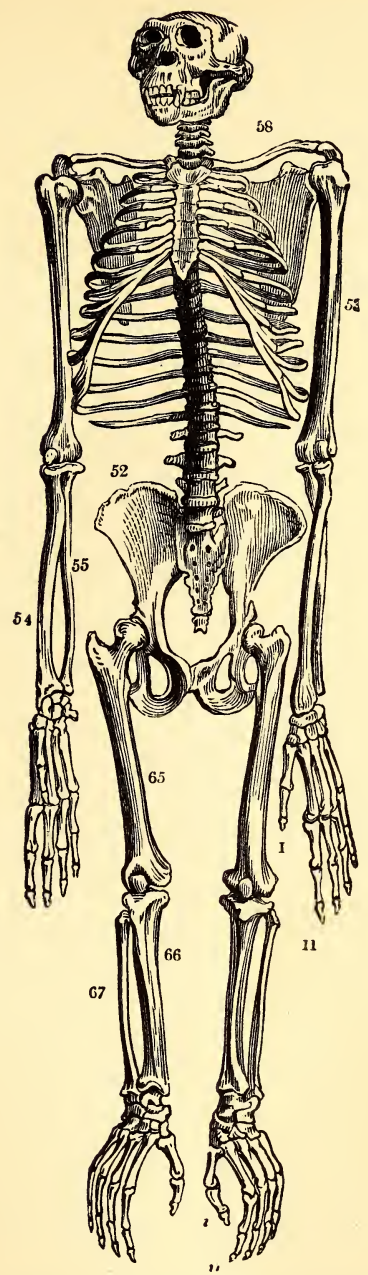

Fio. 120.-Skeleton of the Chimpanzee (Troglodytes Niger). 


\section{CHAPTER XVII.}

HOW ANIMALS MOVE.

1. The power of animal motion is vested in protoplasm, cilia, and muscles. The power of contractility is one of the ultimate physiological properties of protoplasm, like sensibility and the power of assimilation. Protoplasmaanimals, like the Amœba and Rhizopoda, move by the contractility of their protoplasm, as also may the germs of higher animals upon the yolk of the egg. The protoplasm may be extended into projections called pseudopodia, by whose contraction the animal may move (Fig. 186).

Infusoria, and nearly all higher animals, possess cilia (Fig. 188). These are microscopic hairs (Fig. 2,b) which have the power of bending into a sickle-shape and straightening out. As they bend much faster than they straighten, and as they all work together, they can cause motion of the animal, or may serve to produce currents in the water, the animal remaining at rest. They are seen on the outside of Infusoria, and of very many embryos of higher animals, serving as paddles for locomotion; they fringe the gills of the Oyster, creating currents for respiration; and they line the passage to our lungs to expel the mucus. Flagella (Fig. 189) are a sort of long cilia, which are thrown into several curves when active, resembling a whip-lash, whence their name. Both cilia and flagella seem to be wanting in Arthropods.

The cause of ciliary motion is unknown. Their onesided contraction is their property, as the straight contraction of the muscle-fibre belongs to it. No structure can, however, be seen in them with the microscope. No 
nerves go to them, yet they work in concert, waves of motion passing over a surface covered with cilia, as over a field of grain moved by the wind.

But muscular tissue is the great motor agent, and exists in all animals from the Coral to Man. ${ }^{79}$ The power of contractility, which in the Amœba is diffused throughout the body, is here confined to bundles of highly elastic fibres, called muscles. When a muscle contracts, it tends

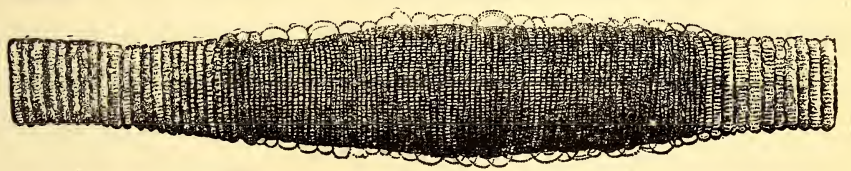

Fı. 121.-A Contractiug Muscle.

to bring its two ends together, thus shortening itself, at the same time increasing in thickness. This shrinking property is excited by external stimulants, such as electricity, acids, alkalies, sudden heat or cold, and even a sharp blow; but the ordinary cause of contraction is an influence from the brain conveyed by a nerve. The property, however, is independent of the nervous system, for the muscle may be directly stimulated. The amount of force with which a muscle contracts depends on the number of its fibres; and the amount of shortening, on their length.

As a rule, muscles are white in cold-blooded animals, and red in the warm-blooded. They are white in all the Invertebrates, Fishes, Batrachians, and Reptiles, except Salmon, Sturgeon, and Shark; and red in Birds and Mammals, except in the breast of the common fowl, and the like. ${ }^{\text {so }}$

It is also a rule, with some exceptions, that

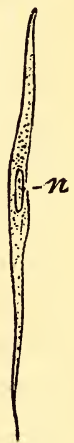

Fig. 122. - Unstriped Muscular Fibre, much enlarged; $n$, nucleus. the voluntary muscles of Vertebrates, and all the muscles 
of the Lobster, Spider, and Insect tribes, are striated; while the involuntary muscles of Vertebrates, and all the muscles of Radiates, Worms, and Mollusks, are smooth. All muscles attached to internal bones, or to a jointed external skeleton, are striated. The voluntary muscles of Vertebrates are generally solid, and the involuntary hollow. ${ }^{81}$

This leads to another classification of muscles: into those which are attached to solid parts within the body; those which are attached to the skin or its modifications; and those having no attachments, being complete in themselves. The last are hollow or circular muscles, enclosing a cavity or space, which they reduce by contraction. Examples of such are seen in the heart, blood-vessels, stomach, iris of the eye, and around the mouth. In the lower Invertebrates, the muscular system is a net-work of longitudinal, transverse, and oblique fibres intimately blended with the skin, and not divisible into separate muscles. As in the walls of the human stomach, the fibres are usually in three distinct layers. This arrangement is exhibited by soft-bodied animals, like the Sea-anemone, the Snail, and the Earth-worm. Four thousand muscles have been counted in a Caterpillar. There are also "skin-muscles" in the higher animals, as those by which the Horse produces a twitching of the skin to shake off insects, and those by which the hairs of the head and the feathers of Birds are made to stand on end. Invertebrates whose skin is hardened into a shell or crust have muscles attached to the inside of such a skeleton. Thus, the Oyster has a mass of parallel fibres connecting its two valves; while in the Lobster and Bee fibres go from ring to ring, both longitudinally and spirally. The muscles of all Invertebrates are straight parallel fibres, not in bundles, but distinct, and usually flat, thin, and soft.

The great majority of the muscles of Vertebrates are attached to the bones, and such are voluntary. The fibres, 
which are coarsest in Fishes (most of all in the Rays), and finest in Birds, are bound into bundles by connective tissue; and the muscles thus made up are arranged in layers around the skeleton. Sometimes their extremities are attached to the bones (or rather to the periosteum) directly; but generally by means of white inelastic cords, called tendons. In Fishes, the chief masses of muscle are disposed along the sides of the body, apparently in longitudinal bands, reaching from head to tail, but really in a series of vertical flakes, one for each vertebra. In proportion as limbs are developed, we find the muscles concentrated about the shoulders and hips, as in quadrupeds. The bones of the limbs are used as levers in locomotion, the fulcrum being the end of a bone with which the moving one is articulated. Thus, in raising the arm, the humerus is a lever working upon the scapula as a fulcrum. The most important muscles are called extensors and flexors. The latter are such as bring a bone into an angle with its fulcrum-as in bending the arm-while the former straighten the limb. Abductors draw a limb away from the middle line of the body, or a finger or toe away from the axis of the limb, while adductors bring them back.

2. Locomotion.-All animals have the power of voluntary motion, and all, at one time or another, have the means of moving themselves from place to place. Some are free in the embryo-life, and fixed when adult, as the Sponge, Coral, Crinoid, and Oyster. There may be no regular well-defined means of progression, as in the Amœba, which extemporizes arms to creep over the surface; or movement may be accomplished by the contraction of the whole body, as in the Jelly-fish, which, pulsating about fifteen times in a minute, propels itself through the water. So the Worms and Snakes swim by the undulations of the body.

But, as a rule, animals are provided with special organs 
for locomotion. These become reduced in number, and progressively perfected, as we advance in the scale of rank. Thus, the Infusorian is covered with thousands of hair-like cilia ; the Star-fish has hundreds of soft, unjointed, tubular suckers; the Centipede has from 30 to 40 jointed hollow legs; the Lobster, 10 ; the Spider, 8 ; and the Insect, 6 ; the Quadruped has 4 solid limbs for locomotion; and Man, only 2.

(1) Locomotion in Water.-As only the lower forms of life are aquatic, and as the weight of the body is partly sustained by the element, we must expect to find the organs of progression simple and feeble. The Infusoria swim with great rapidity by the incessant vibrations of the delicate filaments, or cilia, on their bodies. The common Squid on our coast admits water into the interior of the body, and then suddenly forces it out through a funnel, and thus moves backward, or forward, or around, according as the funnel is turned-towards the head, or tail, or to one side. The Lobster has a fin at the end of its tail, and propels itself backward by a quick down-stroke of the abdomen.

But Fishes, whose bodies offer the least resistance to progression through water, are the most perfect swimmers. Thus, the Salmon can go twenty miles an hour, and even

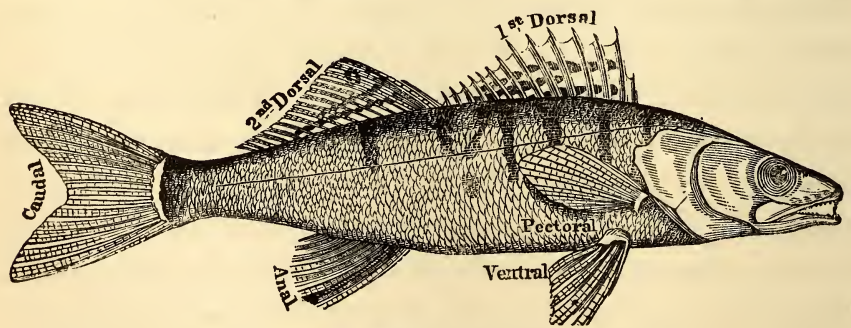

Fic. 123. -The Fins of a Fish (Pike-perch).

ascend cataracts. They have fins of two kinds: those set obliquely to the body, and in pairs; and those which are 
vertical, and single. The former, called pectoral and ventral fins, represent the fore and hind limbs of Quadrupeds. The vertical fins, which are only expansions of the skin, vary in number; but in most Fishes there are at least three: the caudal, or tail-fin; the dorsal, or back-fin; and the anal, situated on the abdomen, near the tail. The chief locomotive agent is the tail, which sculls like a stern-oar; the other fins are mainly used to balance and raise the body. When the two lobes of the tail are equal, and the vertebral column stops near its base, as in the Trout, it is said to be homocercal. If the vertebræ extend into the upper lobe, making it longer than the lower one, as in the Shark, the tail is called heterocercal. The latter is the more effective for varying the course; the Shark, e. g., will accompany and gambol around a ship in full sail

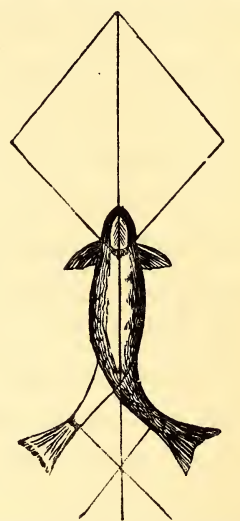

Fig. 124.-Diagram illustrating the locomotion of a Fish. The tail describes the arc of an ellipse; the resultant of the two impulses is the straight line in front.

across the Atlantic. The Whale swims by striking the water up and down, instead of laterally, with a fin-like horizontal tail. Many air-breathing animals swim with facility on the surface, as the Water-birds, having webbed toes, and most of the Reptiles and Quadrupeds.

(2) Locomotion in Air.-The power of flight requires a special modification of structure and an extraordinary muscular effort, for air is 800 times lighter than water. Nevertheless, the velocity attainable by certain Birds is greater than that of any Fish or Quadruped; the Hawk being able to go at the rate of 150 miles an hour. The bodies of Insects and Birds are made as light as possible by the distribution of air-sacs or air-cavities. ${ }^{82}$

The wings of Insects are generally four in number; 
sometimes only two, as in the Fly. They are moved by muscles lying inside the thorax. They are simple expansions of the skin, or crust, being composed of two delicate films of the epidermis stretched upon a net-work of tubes. There are three main varieties: thin and transparent, as in the Dragon-fly ; opaque, and covered with minute colored scales, which are in reality flattened hairs, as in the Butterfly; and hard and opaque, as the first pair (called elytra) of the Beetle.

The wings of Birds, on the other hand, are modified fore-limbs, consisting of three sets of feathers (called primary, secondary, and tertiary), inserted on the hand, forearm, and arm. The muscles which give the downward stroke of the wing are fastened to the breast-bone; and their power, in proportion to the weight of the Bird, is very great. Yet the Insect is even superior in vigor and velocity of flight. ${ }^{83}$ In ascending, the Bird slightly rotates the wing, striking downward and a little backward; while the tail acts as a rudder. A short, rounded, concave wing, as in the common Fowl, is not so well fitted for high and prolonged flight as the long, broad, pointed, and flat wing

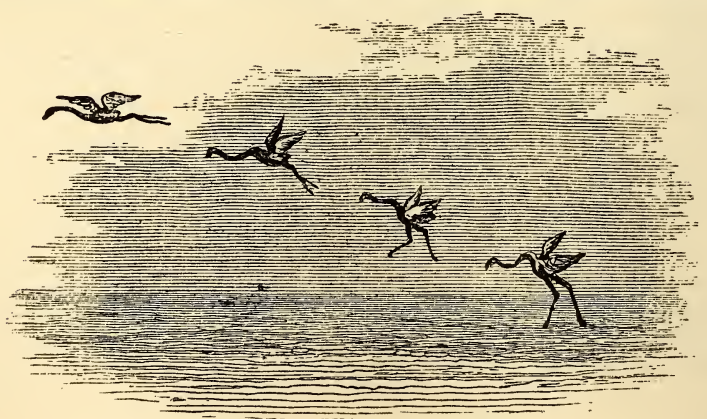

Fra. 125.-Flamingoes taking Wing.

of the Eagle. The wing is folded by means of an elastic skin and muscle connecting the shoulder and wrist. Besides Insects and Birds, a few other animals have the power 
of flight, as Bats, by means of long-webbed fingers ; Flying Fishes, by large pectoral fins. Flying Reptiles, Flying Squirrels, and the like, have a membrane stretched on the long ribs, or connecting the fore and hind limbs, which they use as a parachute, enabling them to take very long leaps.

(3) Locomotion on Solids. - This requires less muscular effort than swimming or flying. The more unyielding the basis of support, the greater the amount of force left to move the animal along. The simplest method is the suctorial, the animal attaching itself to some fixed object, and then, by contraction, dragging the body onward. But the higher and more common method is by the use of bones, or other hard parts, as levers.

The Star-fish creeps by the working of hundreds of tubular suckers, which are extended by being filled with

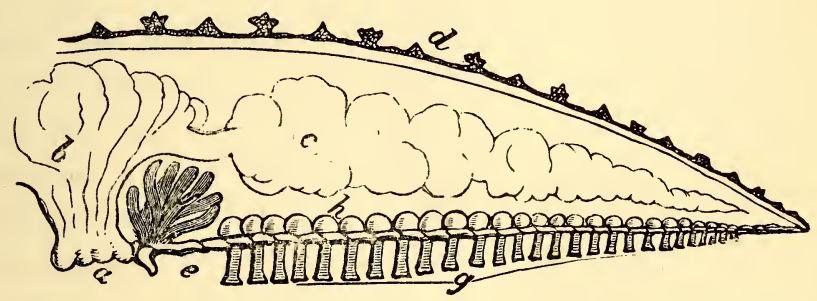

Fre. 126. -Diagrammatic section of Star-fish : $a$, mouth ; $b$, stomach ; $c$, hepatic cæcum; $d$, dorsal or aboral surface ; $e$, ambulacral plates; $f$, ovary ; $g$, tubular feet : $h$, internal sacs for extending the feet.

fluid forced into them by little sacs. The Clam moves by fixing and contracting a muscular appendage, called a "foot." The Snail has innumerable short muscles on the under side of its body, which, by successive contractions, resembling minute undulations, enable the animal to glide forward apparently withont effort. The Leech has a sucker at each end: fixing itself by the one on its tail, and then stretching the body, by contracting the muscular fibres which run around it, the creature fastens its mouth by suction, and draws forward the hinder parts by 
the contraction of longitudinal muscles. The Earth-worm lengthens and shortens itself in the same way as the Leech, but instead of suckers for holding its position, it has numerous minute spines pointing backward; while the Caterpillar has short legs for the same purpose. The legless Serpent moves by means of the scutes, or large scales, on the under side of the body, acted upon by the ribs. In a straight line, locomotion is slow; but by curving the body, laterally or vertically, it can glide or leap with great rapidity.

Most animals have movable jointed limbs, acted upon as levers by numerous muscles. The Centipede has forty-

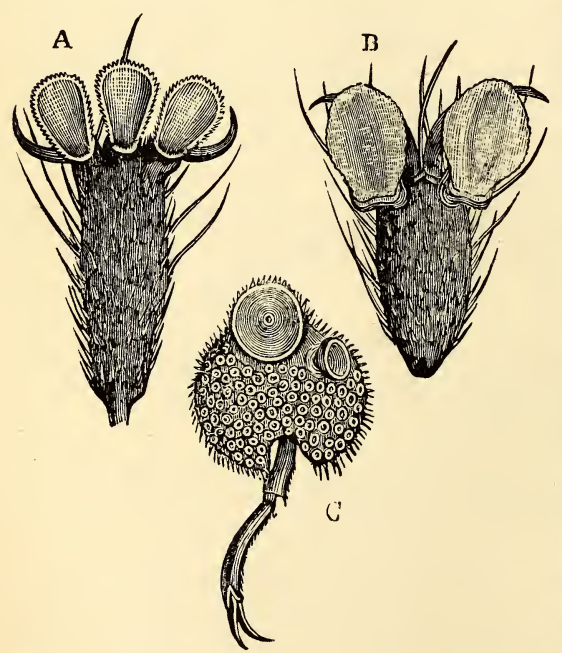
two legs, each with five joints and a claw. The Crab has five pairs of six - jointed legs; but the front pair is modified into pincers for prehension. With the rest, which end in a sharp claw, the Crab moves backward, forward, or sideways. The Spider has eight legs, usually seven - jointed, and terminating

Fra. 127. - Feet of Insects: A, Bibio febrilis; B, in two claws toothed House-fly (Musca domestica); C, Water-beetle (Dytiscus).

like a comb, and a third which acts like a thumb. In running, it moves the first right leg, then the fourth left; next, the first left, and then the fourth right; then the third right and second left together; and lastly, the third left and second right together. The front and hind pairs are, therefore, moved like those of a quadruped. The Insect has six 
legs, each of five parts: the coxa; trochanter; femur; tibia, or shank; and tarsus. The last is subdivided usually into five joints and a pair of claws. Such as can walk upside down, as the Fly, have, in addition, two or three pads between the claws. ${ }^{84}$ These pads bear hairs which secrete a sticky fluid, by means of which the Fly adheres to the surface. While the leg-bones of Vertebrates are covered by the muscles which move them, the limbs of Insects are hollow, and the muscles inside. The fore legs are directed forward, and the two hinder pairs backward. In motion, the fore and hind feet on one side, and the middle one on the other, are moved simultaneously, and then the remaining three.

The four-legged animals have essentially the same apparatus and method of motion. The Crocodile has an awkward gait, owing to the fact that the limbs are short, and placed far apart, so that the muscles act at a mechanical disadvantage. The Tortoise is proverbially slow, for a similar reason. Both swim better than they walk. Lizards are light and agile, but progression is aided by a wriggling of the body.

The locomotive organs of the mammalian quadrupeds are much more highly organized. The bones are more compact; the vertebral column is arched, and yet elastic, between the shoulder and hip, and the limbs are placed vertically underneath the body. The bones of the fore limb are nearly in a line; but those of the hind limb, which is mainly used to project the body forward, are more or less inclined to one another, the angle being most marked in animals of great speed, as the Horse. Some walk on hoofs, as the Ox (Ungulate); some on the toes, as the Cat (Digitigrade); others on the sole, touching the ground with the heel, as the Bear (Plantigrade). In the Pinnigrade Seal, half of the fore limb is buried under the skin, and the hind limbs are turned backward to form a fin with the tail. The normal number of toes is five; but 

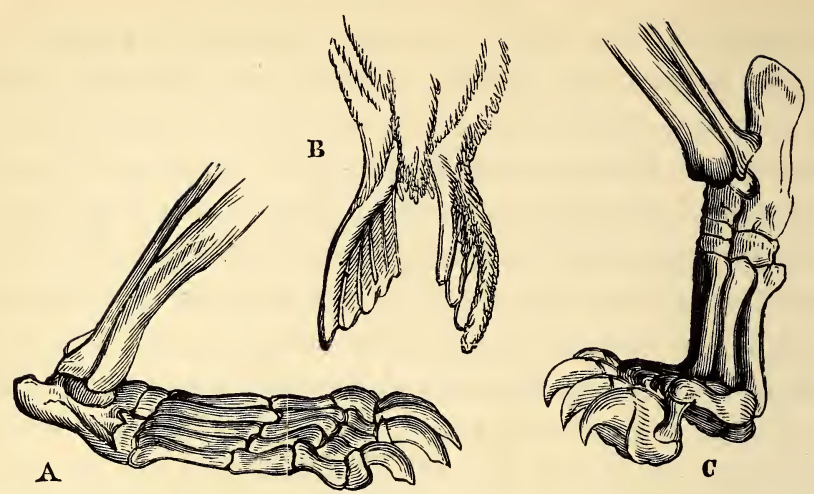

Fic. 128. - Feet of Carnivores : A, Plantigrade (Bear); B, Pinnigrade (Seal): C, Digitigrade (Lion).

some may be wanting, so that we have one-toed animals (as Horse), two-toed (as $\mathrm{Ox}$ ), three-toed (as Rhinoceros), four-toed (as Hippopotamus), and five-toed (as the Elephant). The Horse steps on what corresponds to the nail of the middle finger; and its swiftness is conditioned on the solidity of the extremities of the limbs. Horses of the greatest speed have the shoulder-joints directed at a considerable angle with the arm.
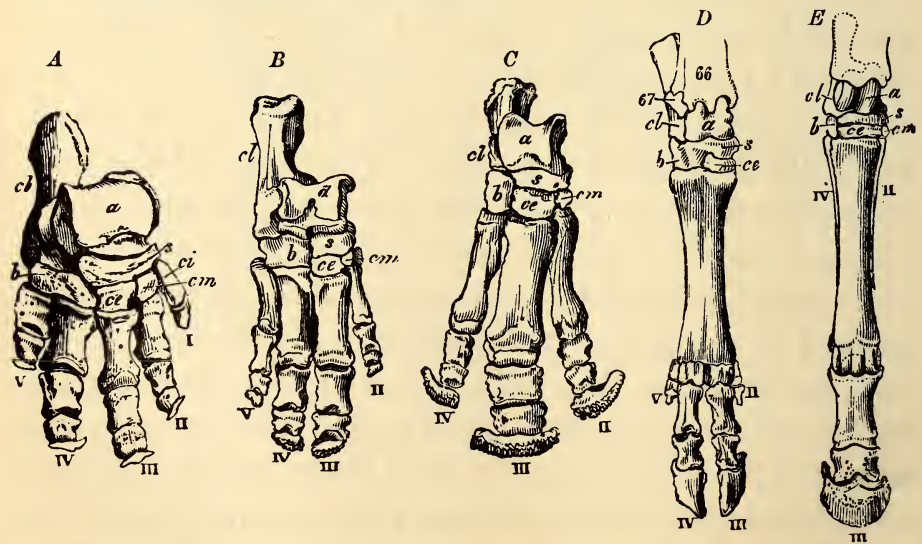

Fic. 129. - Feet of Hoofed Mammals: $A$, Elephant; $B$, Hippopotamus; $C$, Rhinoceros; $D, O \mathrm{x} ; E$, Horse. $a$, astragalus ; $c l$, calcaneum, or heel; $s$, naviculare ; $b$, cuboides; $c e, c i, c m$, cuneiform bones; the numbers indicate the digits in use. 
The order in which the legs of Quadrupeds succeed each other determines the various modes of progression, called the walk, trot, gallop, and leap. Many, as the Horse, have all these movements; while some only leap, as the Frog and Kangaroo. In leaping animals, the hind limbs are extraordinarily developed. In many Mammals, like the Squirrel, Cat, and Dog, the fore legs are used for prehension as well as locomotion. Monkeys use all four,

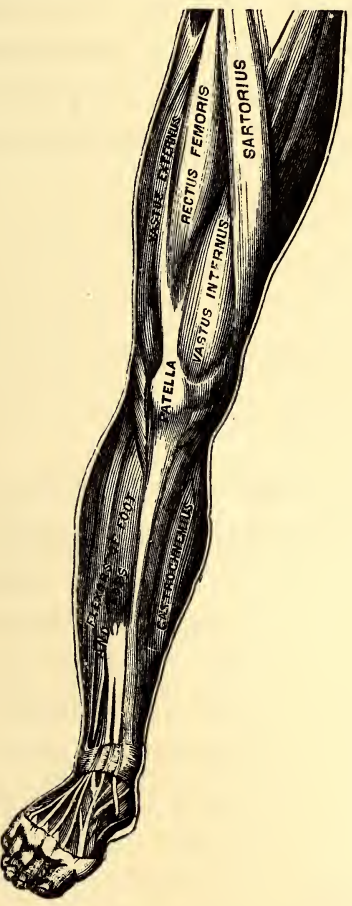

F1木. 130.-Muscles of the Human Leg: sartorius, or "tailor's muscle," the longest muscle in the body, flexes the leg upon the thigh; rectus feamoris and vastus externus and internus extend the leg, maintaining an erect posture; gastrocnemius, or "calf," used chiefly in walking, for raising the heel. Another layer underlies these superficial muscles.

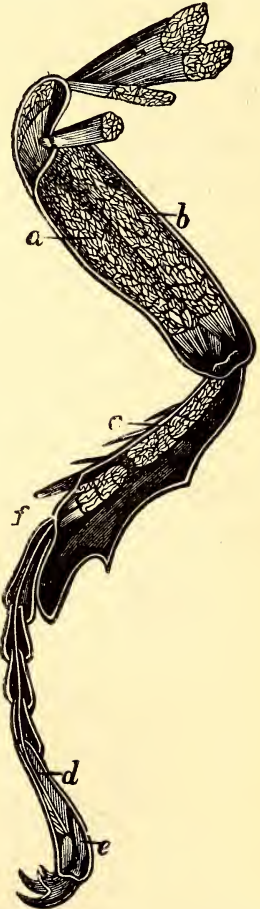

Fig. 131. - Muscles of an Insect's Leg (Melolontha vulgaris): $\boldsymbol{a}$, flexor, and $b$, extensor, of tibia; $c$, flexor of foot ; $d$, accessory muscle; $e$, extensor of claw ; $f$, extensor of tarsus. The joints are restricted to movements in one plane; and therefore the muscles are simply flexors and extensors. All the muscles are within the skeleton. 
and also the tail, for locomotion and prehension, keeping a horizontal attitude; while the Apes, half erect, as if they were half-quadruped, half-biped, go shambling along, touching the ground with the knuckles of one hand and then of the other. In descending the scale, from the most anthropoid Ape to the true Quadruped, we find the centre of gravity placed increasingly higher up-that is, farther forward. Birds and Men are the only true bipeds; the former standing on their toes, the latter on the soles of the feet. Terrestrial Birds walk and run; while Birds of flight usually hop. The Ostrich can for a time outrun the Arabian Horse; and the speed of the Cassowary exceeds that of the swiftest Greyhound.

\section{CHAPTER XVIII.}

THE NERVOUS SYSTEM.

Nervous Matter exists in the form of cells, fibres, or tubes. In the cellular state it is grayish, and accumulated

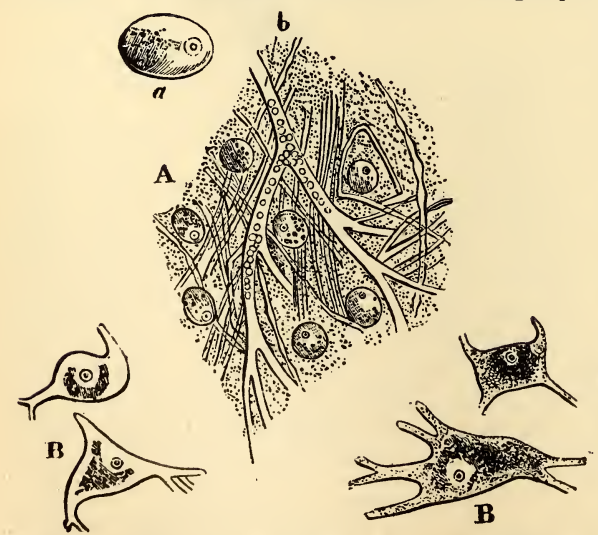
in masses, called ganglia, or centres, which alone originate nervous force; the fibrous and tubularkinds are generally white, and arranged in bundles, called nerves, which serve only as conductors. Most nerves contain two Fra. 132. - Nerve-cells from Human Brain: A, associ- kinds of fibres, like ated with nerve-tubes and blood-vessels; B, multipolar nucleated cells.

in structure, but 
each having its distinct office: one carries impressions received from the external world to the gray centres, and hence is called an afferent, or sensory, nerve; the other conducts an influence generated in the centre to the muscles, in obedience to which they contract, and hence it is called an efferent, or motor, nerve. Thus, when the finger is pricked with a pin, afferent nerve-fibres convey the Fra.133.-Nervous System of Starimpression to the centre - the spinal cord, which immediately

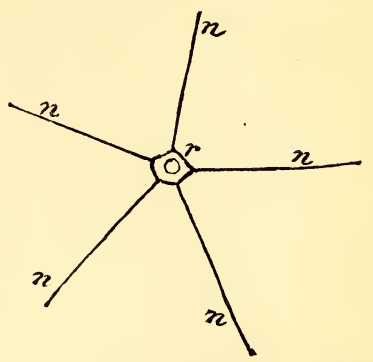
fish: Diagram $-r$, nervous ring around mouth ; $n$, radial nerves to each arm, ending in the eye.

transmits an order by efferent fibres to the muscles of the hand to contract. If the former are cut, sensation is lost, but voluntary motion remains; if the latter are cut, the animal loses all control over the muscles, although sensibility is perfect; if both are cut, the animal is said to be

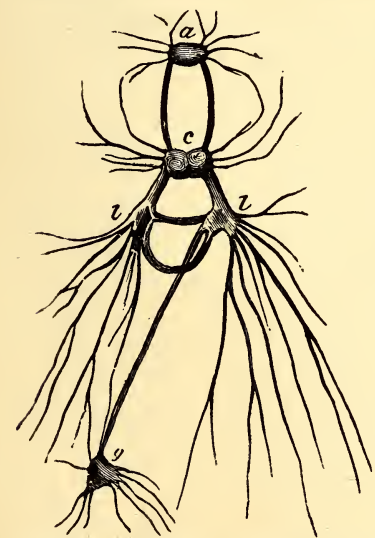

Fig. 134. - Nervons System of a Mollusk (the Gasteropod Aplys$i a)$ : $a$, anterior ganglion; $c$, cephalic; $l$, lateral; $g$, abdominal. paralyzed. The nerve-fibres are connected with nerve-cells in the central organs, and at the outer ends are connected with the muscular fibres, or with various sensory end-organs in the skin or other parts of the body. The nature of nerve-force is not known. As to the velocity of a nervous impulse, we know it is far less than that of electricity or light, and that it is more rapid in warm-blooded than in cold-blooded animals, being faster in Man than in the Frog. In the latter it averages about 85 feet per second, in the former over 100 feet. 
The very lowest animals, like the Amœba and Infusoria, have no nerves, although their protoplasm has a gen-

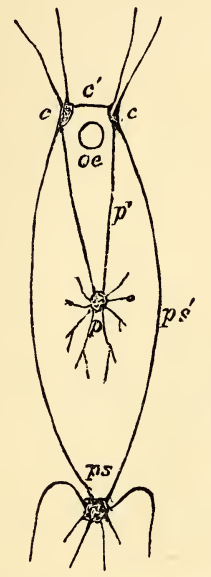

FIG. 135.-Nervous System of Clam: $c$, cerebral ganglion ; $p$, pedal ganglia; $p s$, parietosplauchnic ganglia; $c^{\prime}$, cerebral commissure ; $p^{\prime}$, commissure from cerebral to pedal ganglia ; $p s^{\prime}$, commissure from cerebral to parietosplanchnic ganglia; oe, œsophagus.

eral sensibility. The Hydra has certain cells which are, perhaps, partly nervous and partly muscular in function. The Jelly-fish has a nervous system, consisting of a net-work of threads and ganglia scattered all over its disk. We should look for a definite system of ganglia and nerves only in those animals which possess a definite muscular structure, and show definitely co-ordinated muscular movements. In the Star-fish we detect the first clear specimen of such a system. It consists of a ring around the mouth, made of five ganglia of equal size, with radiating nerves. The Mollusks are distinguished by an irregularly scattered nervous system. The Clam has three main pairs of connected ganglia - one near the mouth, one in the foot, and the third in the posterior region, near the siphons. In the Snail, these are united into a ring around the gullet, and there are other ganglia scattered through the body. The same is true of the Cuttle- Fra. 136. - Nervous fish, where the brain is partly enclosed in a cartilaginous box (Fig. 151).

In the simpler worms there is but a sin-

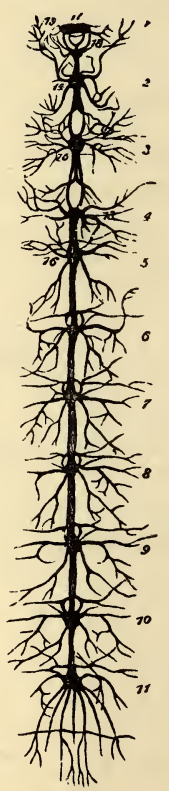
System of a Caterpillar (Sphinx 7 gustri): the first is the cephalic, or head, ganglion. gle ganglion or a single pair. The Earth-worm has a pair of brain-ganglia lying above the gullet, and connected by 
two cords with a ventral chain of ganglia-one pair, apparently a single one, for each segment. In the lower Arthropods, such as Crustacea, Centipedes, and Larval Insects, the arrangement is substantially the same. In higher Insects and Crustacea, many of the ganglia are fused together in the head and thorax, indicating a concentration of organs for sensation and locomotion.

In Vertebrates, the nervous system is more highly developed, more complex, and more concentrated than in the lower forms. In fact, there are some parts, as the brain, to which we find nothing homologous in the Invertebrates; and while the actions of the latter are mainly, if not wholly, automatic, those of backboned animals are voluntary. Its position, moreover, is peculiar, the great mass of the nervous matter being accumulated on the dorsal side, and enclosed by the neural arches of the skeleton.

The brain and spinal cord lie in the cavity of the skull and spinal column, wrapped in three membranes. Both consist of gray and white nervous matter; but in the brain the gray is on the outside, and the white within; while

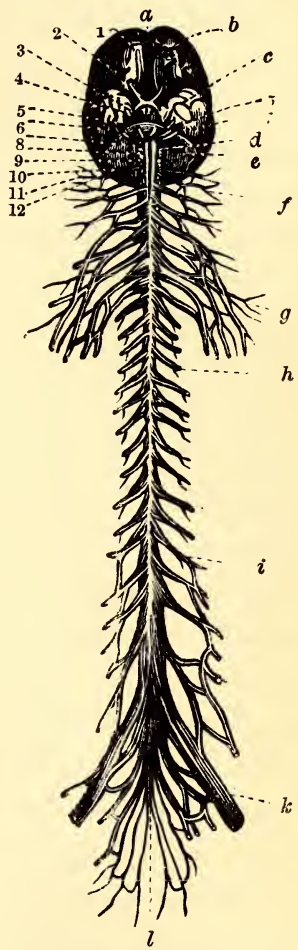

Frg. 137._Human Brain and Spina! Cord, one fifth natural size: $a$, great longitudinal fissure; $b$, anterior lobe; $c$, middle lobe; $d$, medulla oblongata; $e$, cerebellum; $f$, first spinal nerve; $g$, brachial plexus of nerves supplying the arms; $h$, dorsal nerves ; $i$, lumbar nerves; $k$, sacral plexus of nerves for the limbs; $l$, cauda equina: the figures indicate the twelve pairs of cranial nerres, of which 1 is olfactory, 2 optic, and 8 auditory. the white of the spinal cord is external, and the gray internal. Both are double, a deep fissure running from the 
forehead backward, dividing the brain into two hemispheres, and the spinal cord resembling two columns welded together; even the nerves come forth in pairs to the right and left. The brain is the organ of sensation and voluntary motion; the spinal cord is the organ of involuntary life and motion. The brain, above the medulla oblongata, may be removed, and yet the animal, though it cannot feel, will live for a time, showing that it is not absolutely essential to life; in fact, the brain does nothing in apoplexy and deep sleep. All of the cord, except that part containing the centres for respiration and circulation, may also be destroyed, without causing immediate death.

The Brain is that part of the nervous system contained in the skull. ${ }^{85}$ It increases in size and complexity as we pass from the Fishes, by the Amphibians, Reptiles, and Birds, to Mammals. Thus, the body of the Cod is 5000 times heavier than its brain-in fact, the brain weighs less than the spinal cord; while in Man, the brain, compared with the body, is as 1 to 36 , and is 40 times heavier than the spinal cord. The brains of the Cat weigh only $1 \mathrm{oz}$; of the Dog, 6 oz. $5 \frac{1}{2} \mathrm{dr}$.; and of the Horse, $22 \mathrm{oz} .15 \mathrm{dr}$. The only animals whose brains outweigh Man's are the Elephant and Whale-the maximum weight of the Elephant's being $10 \mathrm{lbs}$., and of the Whale's $5 \mathrm{lbs}$; while the human does not exceed $4 \mathrm{lbs}$. Yet the human brain is heavier in proportion to the body. But quality must be considered as well as quantity, else the Donkey will outrank the Horse, and the Canary-bird, Man; for their brains are relatively heavier.

The main parts of the brain are the cerebrum, cerebellum, and medulla oblongata.

The cerebrum is a mass of white fibrous matter covered by a layer of gray cellular matter. In the lower Vertebrates, the exterior is smooth; but in most of the Mammals it is convoluted, or folded, to increase the amount of, 
the gray surface. The convolutions multiply and deepen as we ascend the scale of size and intelligence, being very complex in the Elephant and Whale, Monkey and Man. As a rule, they are proportioned to the intelligence of the animal; yet the brains of the Dog and Horse are smoother than those of the Sheep and Donkey. Evidently the quality of the gray matter must be taken into account. Save in the bony Fishes, the cerebrum is the largest portion of the brain; in Man it is over eight times heavier than the cerebellum.

The cerebellum, or "little brain," lies behind the cerebrum, and, like it, presents an external gray layer, with a white interior. In Mammals, it is likewise finely convoluted, consisting of gray and white laminæ, and is divided into two lobes,

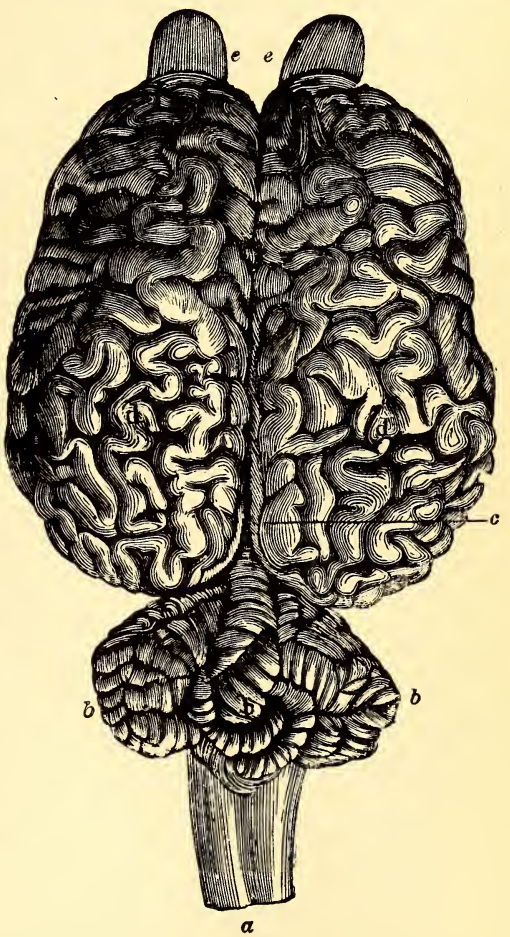

Frg. 138. - Brain of the Horse-npper view, one half natural size: $a$, medulla oblongata; $b$, lateral and middle lobes of cerebellum; $c$, interlobular fissure; $d$, cerebral hemispheres; $e$, olfactory lobes.

or hemispheres. In the rest of the Vertebrates, the cerebellum is nearly or quite smooth; and in the lowest Fishes it is merely a thin plate of nervous matter. In many Vertebrates, however, it is larger, compared with the cerebrum, than in Man, since in Man the cerebrum is extraordinarily developed. 
The mednlla oblongata is the connecting link between the cerebrum and cerebellum and the spinal cord. In structure, it resembles the spinal cord-the white matter being external and the gray internal. The former lies beneath or behind the brain, passing through the foramen magnum of the skull, and merging imperceptibly into the cord. The latter is a continuous tract of gray matter enclosed within strands of white fibres. It usually ends in the lumbar region of the vertebral column, but in Fishes it reaches to the end of the tail. In Fishes, Amphibians, and Reptiles, the cord outweighs the brain: in Birds and Mammals, the brain is heavier than the cord. In Man, it weighs about an ounce and a half.

Besides these parts, there are also the olfactory and the optic lobes, which give rise respectively to the nerves of smell and sight.

The parts of the brain are always in pairs; but in rela-

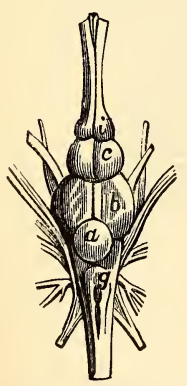

Fig. 139.-Brain of the Perch, upper view : $a$, cerebellum; $b$, optic lobes; $c$, cerebrum ; $i$, olfactory lobes; $g$, medulla oblongata. tive development and position they differ widely in the several classes of Vertebrates. In Fishes and Reptiles, they are arranged in a horizontal line; in Birds and Mammals, the axis of the spinal cord bends to nearly a right angle in passing through the brain, so that the lobes no longer lie in a straight line. In Man, the fore-brain is so developed that it covers all the other lobes. In looking down upon the brain of a Perch, we see in front a pair of olfactory lobes (which send forth the nerves of smell), behind

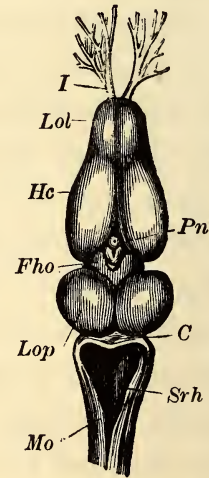

Fig. 140. - Brain of the Frog, upper view, $\times 4$ : $I$, olfactory nerves; $\mathrm{Lol}$, olfactory lobes; $\boldsymbol{H c}$, cerebral hemispheres; $P$, pineal gland; Fho and Srh, third and fourth ventricles; $L o p$, optic lobes; $C$, cerebellum; $M o$, medulla oblongata. 
them the small cerebral hemispheres, then the large optic lobes (in which originate the nerves of sight), and, last of all, the cerebellum. Not till we reach Man and the Apes do we find the cerebrum so highly developed as to overlap both the olfactory lobes in front and the cerebellum behind.

Functions of the Brain.-The cerebrum is the seat of intelligence and will. It has no direct communication with the outside world, receiving its consciousness of external objects and events through the spinal cord and the nerves of special sense. ${ }^{86}$

The cerebellum seems to preside over the co-ordination of the muscular movements. When removed, the animal

A.

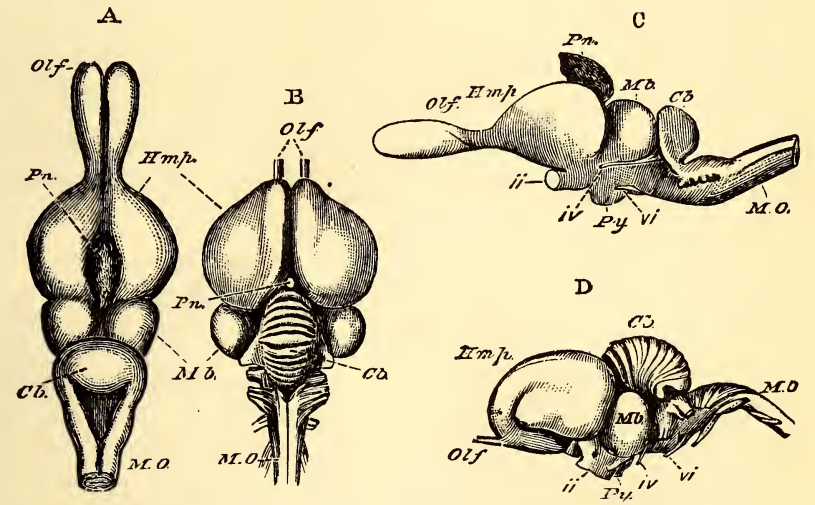

Frf. 141.-A, C, upper and side views of the Brain of a Lizard; B, D, upper and side views of the Brain of a Turkey : Olf, olfactory lobes; Hmp, cerebral hemispheres; $P n$, pineal gland; $M b$, optic lobes of the middle brain; $C b$, cerebellum ; $M O$, medulla oblongata; $i i$, optic nerves; $i v$ and $v i$, nerves for the muscles of the eye; $P y$, pituitary body.

desires to execute the mandates of the will, but cannot; its motions are irregular, and it acts as if intoxicated. It is usually largest in animals capable of the most complicated movements; being larger in the Ape than in the Lion, in the Lion than in the Ox, in Birds than in Reptiles. The cerebellum of the Frog is, however, smaller than that of Fishes (Figs. 139,140). The olfactory and op. tic lobes receive the messages from their respective nerves. 
The medulla oblongata is not only the medium of communication between the brain and the spinal cord, but it

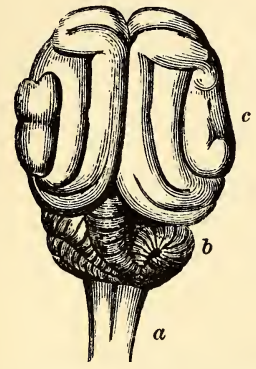

Fra. 142.-Brain of the Cat (Felis domestica) : $a$, medulla oblongata; $b$, cerebellum; $c$, cerebrum.

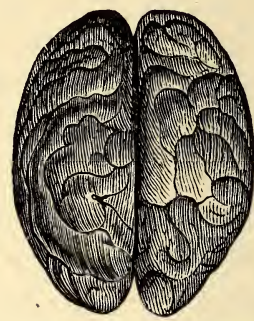

Fig. 143. - Brain of the Orang - utan, upper surface; one third natural size.

is itself a nervous centre: the brain above and the cord below may be removed without death to the animal, but the destruction of the medulla is fatal. Of the twelve pairs of nerves issuing from the contents of the skull (encephalon), ten come from the medulla oblongata. Among these are the nerves of hearing

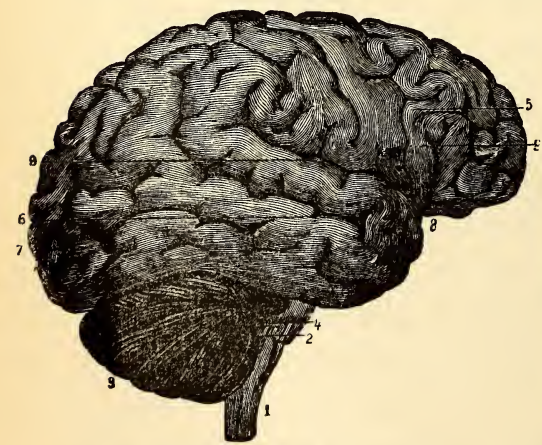

Fig. 144.-Human Brain, side view: 1, medulla oblongata ; 3 , cerebellum ; 5 , frontal convolutious of cerebrum.

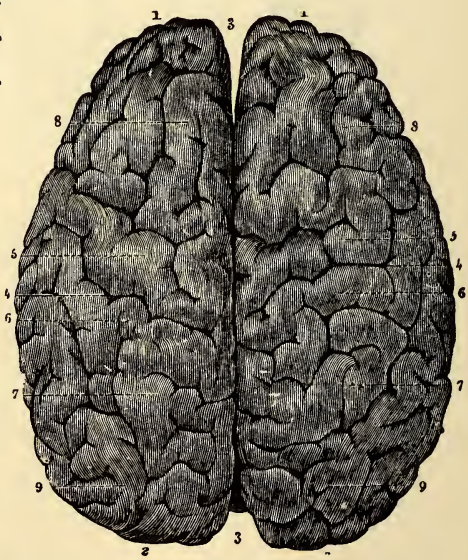

Frg. 145. - Human Brain, upper view, one third natural size: 1 , anterior lobes ; 2 , posterior; 3 , great median fissure.

and taste, and those that control the lungs and heart. Respiration ceases immediately when the medulla is injured. 
The spinal cord is a centre for originating involuntary actions, and is also a conductor-propagating through its central gray matter the impressions received by the nerves to the brain, and taking back through its fibrous part the impulses of the brain. In Man, thirty-one pairs of nerves arise from the cord to supply the whole body, except the head. Each nerve has an anterior and a posterior root. The fibres of the former go to the muscles, and hence carry the impulses which cause muscular contraction (hence called motor fibres); those of the posterior root convey sensations from the exterior to the central organs (sensory). The fibres leading from the brain to the cord cross one another in the medulla oblongata, so that if the right cerebral hemisphere be diseased,

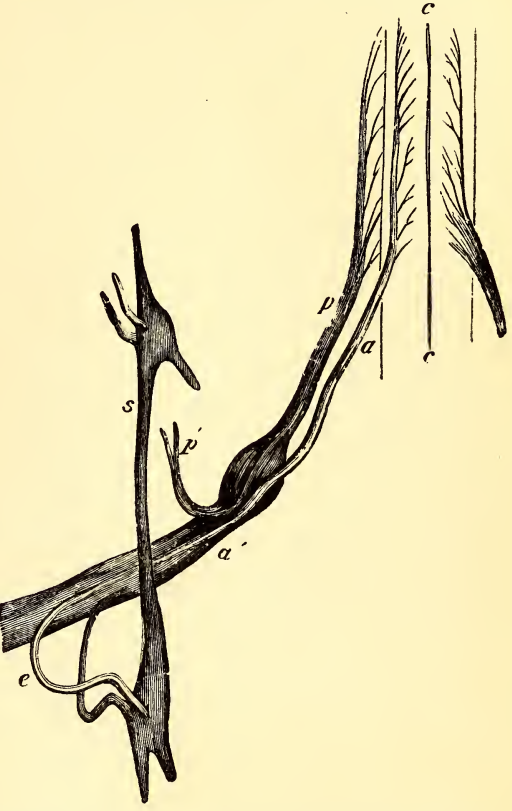

Fig. 146.-Relation of the Sympathetic and Spinal Nerves : $c$, fissure of spinal cord; $a$, anterior of a dorsal spinal nerve; $p$, posterior root, with its ganglion; $\alpha^{\prime}$, anterior branch; $\boldsymbol{p}^{\prime}$, posterior branch; $s$, sympathetic; $e$, its double junction by white and gray filaments. the left side of the body loses the power of voluntary motion.

The sympathetic nervous system is a double chain of ganglia, lying along the sides of the vertebral column in the ventral cavity. From these ganglia nerves are given off, which, instead of going to the skin and muscles, like the spinal nerves, form net-works about those internal organs over which the will has no control, as the heart, stomach, 
and intestines. Their apparent office is to stimulate these organs to constant activity, but is little understood.

\section{The Senses.}

Sensation is the consciousness of impressions on the sensory nerves. These impressions produce some change in the brain; but what that change is, is a darkness on which no hypothesis throws light. Obviously, we feel only the condition of our nervous system, not the objects which excite that condition. ${ }^{87}$

All animals possess a general sensibility diffused over the greater part of the body. ${ }^{88}$ This sensibility, like assimilation and contractility, is one of the primary physiological properties of protoplasm. But, besides this (save in the very lowest forms), they are endowed with special nerves for receiving the impressions of light, sound, etc. These nerves of sense, as they are called, although structurally alike, transmit different sensations: thus, the Ear cannot recognize light, and the Eye cannot distinguish sounds. In the Vertebrates, the organs of sight, hearing, and smell are situated in pairs on each side of the head; that of taste, in the mucous membrane covering the tongue; while the sense of touch is diffused over the skin. Sight and hearing are stimulated, each by one agent only; while touch, taste, and smell may be excited by various substances. The agents awakening sight, hearing, and touch are physical; those causing taste and smell are chemical. Animals differ widely in the numbers and keenness of their senses. But there is no sense in any one which does not exist in some other.

Touch is the simplest and the most general sense; no aninal is without it, at least in the form of general sensibility. It is likewise the most positive and certain of the senses. In the Sea-anemone, Snail, and Insect, it is most acute in the "feelers" (tentacles, horns, and antennæ), ${ }^{s 9}$ in the Oys- 
ter, the edge of the mantle is most sensitive; in Fishes, the lips; in Snakes, the tongue; in Birds, the beak and under side of the toes; in Quadrupeds, the lips and tongue; and in Monkeys and Man, the lips and the tips of the tongue and fingers. In the most sensitive parts of Birds and Mammals, the true skin is raised up into multitudes of minute elevations, called $p a$ pilloe, containing loops of

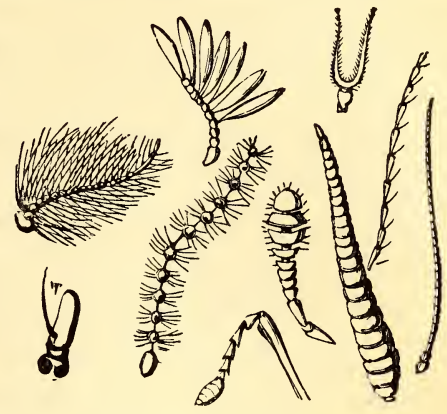

Fia. 147.-Antennæ of Various Insects. capillaries and nerve-filaments. There is a correspondence between the delicacy of touch and the development of intelligence. The Cat and Dog are more sagacious than hoofed animals. The Elephant and Parrot are remarkably intelligent, and are as celebrated for their tactual power.

Taste is more refined than touch, since it gives a knowledge of properties which cannot be felt. It is always placed at the entrance to the digestive canal, as its chief purpose is to guide animals in their choice of food.

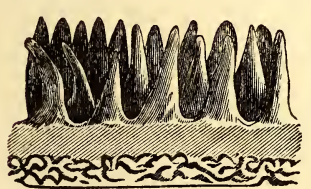

Frg. 148.-Papillæ of Human Palm, $\times 35$, the cuticle being removed. No special organ of taste can be detected in the Invertebrates, although all seem to exercise a faculty in selecting their food. Even in Fishes, Amphibians, Reptiles, and Birds this sense is very obtuse, for they bolt their food. But the higher Vertebrates have it well developed. It is confined to the tongue, and is most delicate at the root. ${ }^{90} \mathrm{~A}$ state of solution and an actual contact of the fluid are necessary conditions.

Smell is the perception of odors, $i$.e., certain substances 
in the gaseous state. Many Invertebrates have this sense: Snails, e.g., seem to be guided to their food by its scent, and Flies soon find a piece of meat. In the latter the organ is probably located on the antennæ. In Verte-

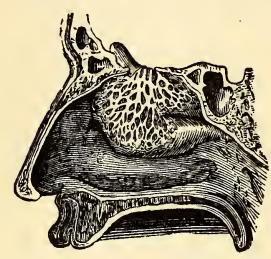

Fig. 149._Olfactory Nerves on the wall of the nasal cavity.

brates, it is placed at the entrance to the respiratory tube, in the upper region of the nose. There the olfactory nerves, which issue from the olfactory lobe of the brain, and pass through the ethmoid bone, or roof of the nasal cavity, are distributed over a moist mucous membrane. The odorous substance, in a gaseous or finely divided state, is dissolved in the mucus covering this membrane. In Fishes and Reptiles generally, this organ is feebly developed; Sharks, however, gather from a great distance around a carcass. In the Porpoises and Whales it is nearly or entirely wanting. Among Birds, Waders have the largest olfactory nerves. It is most acute in the carnivorous Quadrupeds, and in some wild herbivores, as the Deer. In Man it is less delicate, but has a wider range than in any brute.

Hearing is the perception of sound. The simplest form of the organ is a sac filled with fluid, in which float the soft and delicate ends of the auditory nerve. The vibrations of the fluid are usually strengthened by the presence of minute hard granules, called otoliths. Most Invertebrates have no higher apparatus than this; and it is probable that they can distinguish one noise from another, but neither pitch nor intensity. The organ is generally double, but not always located

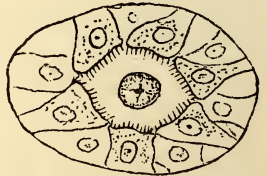

Fig. 150. - Ear of a Mol. lusk (Cyclas), greatly enlarged. in the head. In the Clam, it is found at the base of the foot; some Grasshoppers have it in the fore-legs; and in 
many Insects it is on the wing. Lobsters and Crabs have the auditory sacs at the base of the antennæ. ${ }^{91}$

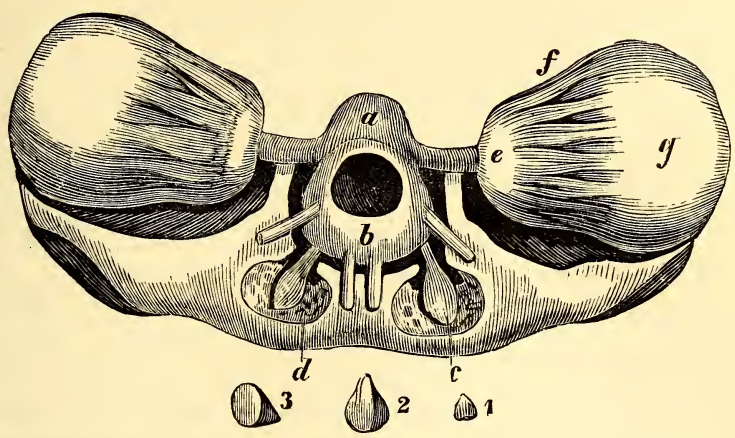

Frg. 151.-Brain and Auditory Apparatus of the Cuttle-fish : $a, b$, brain ; $c$, auditory apparatus; $d$, the cavity in which it is lodged; $e, f, g$, eyes; $1,2,3$, otoliths.

A complex organ of hearing, located in the head, exists in all Vertebrates, save the very lowest Fishes. As complete in Man, it consists of the following parts: 1st. The external ear (which is peculiar to Mammals) ; the auditory canal, about an inch long, lined with hairs and a waxy secretion, and closed at the bottom by a membrane, called tympanum, or "drum of the ear." $2 \mathrm{~d}$. The middle ear, containing three little bones (the smallest in the body), malleus, incus, and stapes, articulated together. The

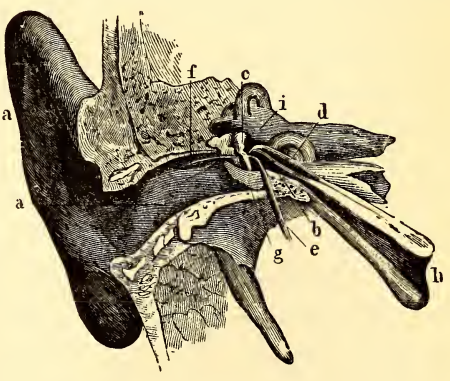
cavity communicates with the external air by means of the Eustachian tube, which opens at the back part of the mouth. 3d.

Fig. 152.-Section of Human Ear : $a$, external ear, with anditory canal; $b$, tympanic cavity containing the three bones; $c$, hammer, and its three muscles, $d, e, f ; g$, tympanic membrane, or head of the drum; $h$, Eustachian tube leading to the pharynx; $i$, labyrinth, with semicircular canals and cochlea visible.

The internal ear, or labyrinth, an irregular cavity in the solid part of the temporal bone, and separated from the 
middle ear by a bony partition, which is perforated by two small holes. The labyrinth consists of the vestibule, or entrance; the semicircular canals, or tubes; and the cochlea, or spiral canal. While the other parts are full of air, the labyrinth is filled with a liquid, and in this are the ends of the auditory nerve. The vibrations of the air, collected by the external ear, are concentrated upon the tympanum, and thence transmitted through the chain of little bones to the fluid in the labyrinth.

Now, the essential organ of hearing is the labyrinth, which is, substantially, a bag filled with fluid and nervefilaments. Fishes generally have but little more. In Amphibians and Reptiles there are added a tympanum, a single bone, connecting this with the internal ear, the cochlea, and the Eustachian tube; the tympanum being external. Birds have, besides, an auditory passage, opening on a level with the surface of the head, and surrounded by a circle of feathers. Mammals only have an external ear. ${ }^{92}$

Sight is the perception of light..$^{93}$ In all animals it depends upon the peculiar sensitiveness of the optic organ to the luminous vibrations. In Vertebrates the optic nerve comes from the middle mass of the brain, in Invertebrates it is derived from a ganglion. Many animals are utterly destitute of visual organs, as the Protozoa, and the lower Radiates and Mollusks, besides intestinal Worms and the blind Fishes and other cave-animals. Around the margin of the Jelly-fish are colored spots, supposed to be rudimentary eyes; but, as a lens is wanting, there is no image; so that the creature can merely distinguish light from darkness and color without form. Such an eye is nothing but a collection of pigment granules on the expansion of a nervous thread, and the perception of light is the sensation of warmth, the pigment absorbing the rays and converting them into heat. 
Going higher, we find a lens introduced forming a distinct image. The Snail, for example, has two simple eyes, called ocelli, mounted on the tip of its long tentacles, consisting of a globular lens, ${ }^{94}$ with a transparent skin (cornea) in front, and a

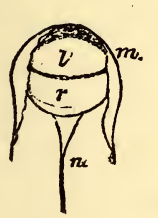

c o l o r e d membrane (choroid) and a nervous net-

Fig. 153. - Eye of work (retiPecten, much enlarged: $m$, mouth; $l$, lens ; $r$, retina and choroid; $n$, nerve.

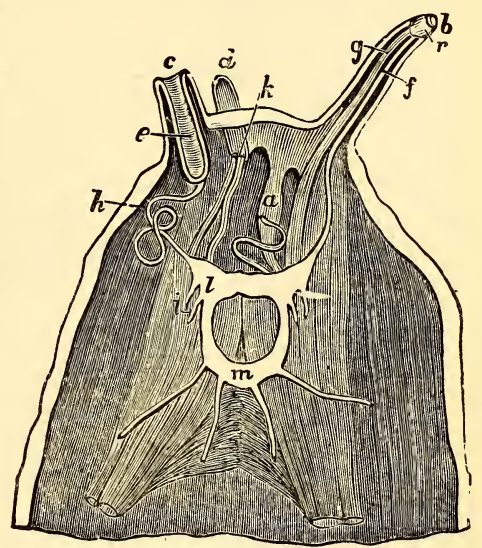

such eyes in the edge of its mantle (Fig. 153). Such organs are the only eyes possessed by Myriapods, Spiders, Scorpions, and Caterpillars. Adult In-

Frg. 154. - Head of a Snail bisected, showing structure of tentacles: $a$, right inferior tentacle retracted within the body; $b$, right superior tentacle fully protruded; $c$, left superior tentacle partially inverted ; $d$, left inferior tentacle; $f$, optic nerve ; $g$, retractor muscle; $h$, optic nerve in loose folds; $i$, retractor muscle of head; $k$, nerve and muscle of left inferior tentacle; $l, m$, nervous collar. sects usually have three ocelli on the top of the head. But the proper visual organs of Lobsters, Crabs, and Insects are two compound eyes, perched on pedestals, or fixed on the sides of the head. They consist of an immense number of ocelli pressed together so that they take an angular form-foursided in Crustacea, six-sided in Insects. They form two rounded protuberances variously colored - white, yellow, red, green, purple, brown, or black. Under the microscope, the surface is seen to

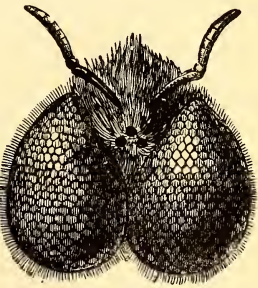

Fig. 155.-Head of the Bee, showing compoundeyes, the three ocelli; or stemmata, and the antennæ. be divided into a host of facets, ${ }^{95}$ each being an ocellus complete in itself. Each cornea is convex on one side, 
and either convex or flat on the other, so that it produces

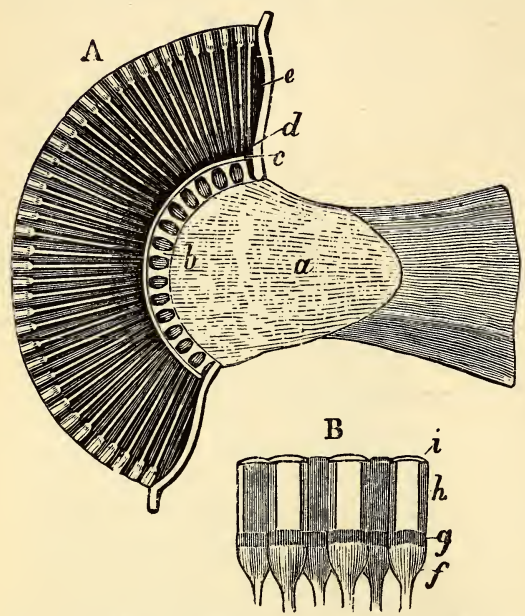
a focus like a lens. Behind the cornea, or lens, is the pigment, having a minute aperture or "pupil." Next is a conical tube-one for each facet - with sides and bottom lined with pigment. These tubes converge to the optic ganglion, the fibres of which pass through the tubes to the cornea. ${ }^{96}$ Vision

Fig. 156.-Eye of a Beetle (Melolontha): A, section; by such a compound
$a$, optic ganglion; $b$, secondary nerves; $c$, retina; $d$, pigment layer; $e$, proper optic nerves; $B$, group eye is not a mosaic; of ocelli; $f$, bulb of optic nerve ; $g$, layer of pigment; $h$, vitreous humor ; $i$, cornea.

but each ocellus gives a complete image, although a different perspective from its neighbor. The multiplied images are reduced to one mental stereoscopic pictnre, on the principle of single vision in ourselves.

The eyes of the Cuttle-fish are the largest and the most perfect among Invertebrates. They resemble the eyes of higher animals in having a crystalline lens

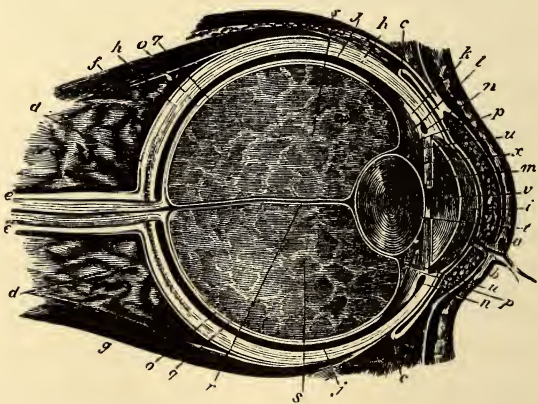

Fig. 157.-Section of Human Eye : $a$ and $b$, upper and lower lid; $c$, conjunctiva, or mucous membrane, lining the inner surface; $d$, external membrane; $e$, sheath of optic nerve: $f, g$, muscles for rolling the eye up or down; $h$, sclerotic; $i$, transparent cornea; $j$, choroid; $k, l$, ciliary muscle for adjnsting the eye for distance; $m$, iris and pupil $; n$, canal; $o$, retina; $s$, vitreous humor; $t$, crystalline; $v$, anterior chamber; $x$, posterior chamber.

with a chamber in front (open, however, to the sea- 
water), and a chamber behind it filled with "vitreous humor."

The eye of Vertebrates is formed by the infolding of the skin to create a lens, and an outgrowth of the brain to make a sensitive layer; both enclosed in a white spherical case (sclerotic) made of tough tissue, with a transparent front, called the cornea. This case is kept in shape by two fluids - the thin aqueous humor filling the cavity just behind the cornea, and the ielly-like vitreous humor occupying the larger posterior chamber. Between the two humors lies the doubleconvex crystalline lens. On the front face of the lens is a contractile circular curtain (iris), with a hole in the centre (pupil); and lining the sclerotic coat is the choroid membrane, covered with dark pigment. The optic nerve, entering at the back of the eye

\author{
9
}

8 7

6

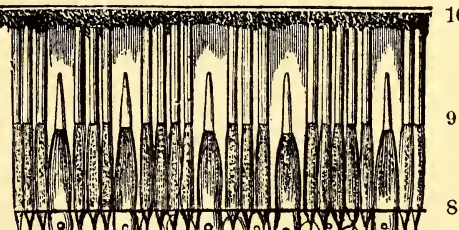

\section{0} - (5) $(1)-100$ (-) (0) 0.0 .10 .0

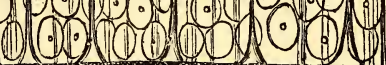

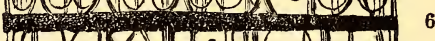

4 18000
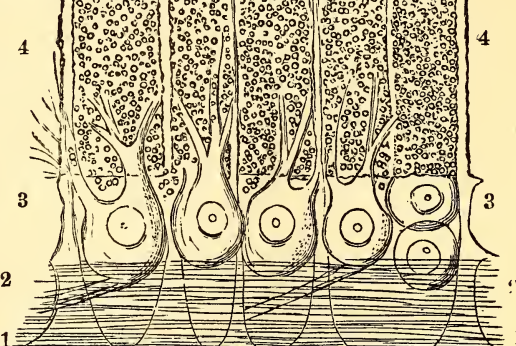

Frg. 158.-Section of the Human Retina, $\times 400: 1$, internal limiting membrane; 2 , optic-nervefibres; 3 , ganglion cells ; 4 , internal molecular layer; 5 , internal granules ; 6 , external molecular layer ; 7 , externalgranules; 8 , externallimiting membrane; 9 , layer of rods and cones; 10 , pigment layer. through the sclerotic and choroid coats, expands into the transparent retina, which consists of several layers - 
fibrous, cellular, and granular. The most sensitive part is the surface lying next to the black pigment. And here is a peculiarity of the vertebrate eye: the nerve-fibres, entering from behind, turn back and look towards the bottom of the eye, so that vision is directed backward; while invertebrate vision is directly forward. In Vertebrates only, the optic nerves cross each other (decussate) in passing from the brain to the eyes; so that the right side of the brain, e.g., receives the impressions of objects on the left side of the body. ${ }^{97}$

Generally, the eyes of Vertebrates are on opposite sides of the head; but in the Flat-fishes both are on the same side. Usually, both eyes see the same object at once; but in most Fishes the eyes are set so far back, the fields of vision are distinct. The cornea may be flat, and the lens globular, as in Fishes; or the cornea very convex, and the lens flattened, as in Owls. Purely aquatic animals have neither eyelids nor tears, but nearly all others (especially Birds) have three lids. ${ }^{98}$ The pupil is usually round; but it may be rhomb-shaped, as in Frogs; vertically oval, as in Crocodiles and Cats: or transversely oval, as in Geese, Doves, Horses, and Ruminants. Many Quadrupeds, as the Cat, have a membrane (tapetum) lining the bottom of the eyeball, with a brilliant metallic lustre, usually green or pearly: it is this which makes the eyes of such animals luminous in the dark.

\section{Instinct and Intelligence.}

The simplest form of nervous excitement is mere sensation. Above this we have sensation awakening consciousness, out of which come those voluntary activities grouped together under the name of Instinct; and, finally, Intelligence.

The lowest forms of life are completely under law, for their movements seem to be due solely to their organiza- 
tion. They are automatons, or creatures of necessity. Such, also, are some actions in the higher animals, as breathing, the beating of the heart, the contractions of the iris, and all the first movements of an infant." But, generally, the actions of animals are not the result of mere bodily organization.

The inferior orders are under the control of Instinct, i. e., an apparently untaught ability to perform actions which are useful to the animal. ${ }^{100}$ They seem to be born with a measure of knowledge and skill (as Man is said to have innate ideas), acquired neither by reason nor experiment. For what could have led Bees to imagine that by feeding a worker-larva with royal jelly, instead of beebread, it would turn out a queen, instead of a neuter? In this case, neither the habit nor the experience could be inherited, for the worker-bees are sterile. We can only guess that the discovery has been communicated by the survivors of an older swarm. Uniformity is another characteristic feature of instinct. Different individuals of the same species execute precisely the same movements under like circumstances. The career of one Bee is the career of any other. We do not find one clever and another stupid. Honey-combs are built now as they were before the Christian era. The creatures of pure instinct appear to be tied down, by the constitution of their nervous system, to one line of action, from which they cannot spontaneously depart. The actions vary only as the structure changes. ${ }^{101}$ There is a wonderful fitness in what they do, but there is no intentional adaptation of means to ends.

All animals, from the Star-fish to Man, are guided more or less by instinct; but the best examples are furnished by the insect-world, especially by the social Hymenopters (Ants, Bees, and Wasps). The Butterfly carefully provides for its young, which it is destined never to see; many Insects feed on particular species of plants, which 
they select with wonderful sagacity; and Monkeys avoid poisonous berries; Bees and Squirrels store up food for the future; Bees, Wasps, and Spiders construct with marvellous precision; and the subterranean chambers of Ants and the dikes of the Beaver show engineering skill; while Salmon go from the ocean up the rivers to spawn; and Birds of the temperate zones migrate with great regularity.

But in the midst of this automatism there are the glimmerings of intelligence and free-will. We see some evidence of choice and of designed adaptation. Pure instinct should be infallible. Yet we notice mistakes that remind us of mental aberrations. Bees are not so economical as has been generally supposed. A mathematician can make five cells with less wax than the Bee uses for four; while the Humble-bee uses three times as much material as the Hive bee. An exact hexagonal cell does not exist in nature. Flies lay egge on the carrion-plant because it happens to have the odor of putrid meat. The domesticated Beaver will build a dam across its apartment. Birds frequently make mistakes in the construction and location of their nests. In fact, the process of cheating animals relies on the imperfection of instinct. Nor are the actions of the brute creation always perfectly uniform; and, so far as animals conform to circumstances, they act from intelligence, not instinct. There is proof that some animals profit by experience. Birds do learn to make their nests; and the older ones build the best. Trappers know well that young animals are more easily caught than old ones. Birds brought up from the egg, in cages, do not make the characteristic nests of their species; nor do they have the same song peculiar to their species, if they have not heard it. Chimney-swallows certainly built their nests differently in America three hundred years ago. A Bee can make cells of another shape, 
for it sometimes does; its actions, therefore, being elective and conditional, are in a measure the result of calculation.

The mistakes and variations of instinct are indications that animals have something more - a limited range of that principle of Intelligence so luminous in Man. No precise line can be drawn between instinctive and intelligent acts; all we can say is, there is more freedom of choice in the latter than the former; and that some animals are most instinctive, others most intelligent. Thus, we speak of the instinct of the Ant, Bee, and Beaver, and the intelligence of the Elephant, Dog, and Monkey. Instinct loses its peculiar character as intelligence becomes developed. Ascending from the Worm and Oyster to the Bee, we see the movements become more complex in character and more special in their objects; but instinct is supreme. Still ascending, we observe a gradual fadingaway of the instincts, till they become subordinate to higher faculties-will and reason. We can predict with considerable certainty the actions of animals guided by pure instinct; but in proportion as they possess the power of adapting means to ends, the more variable their actions. Thus, the architecture of Birds is not so uniform as that of Insects. ${ }^{.02}$

We must credit brutes with a certain amount of observation and imitation, curiosity and cunning, memory and reason. Animals have been seen to pause, deliberate, or experiment, and resolve. The Elephant and Horse, Dog and Monkey, particularly, participate in the rational nature of Man, up to a certain point. Thinking begins wherever there is an intentional adaptation of means to ends; for that involves the comparison and combination of ideas. Animals interchange ideas: the whine of a Dog at the door on a cold night certainly implies that he wants to be let in. Bees and Ants, it is well known, confer by 
passing their antennæ. All the higher animals, too, have similar emotions-as joy, fear, love, and anger.

While instinct culminates in Insects, the highest development of intelligence is presented in Man. ${ }^{103}$ In Man only does instinct cease to be the controlling power. He stands alone in having the whole of his organization conformed to the demands of his brain; and his intelligent acts are characterized by the capacity for unlimited progress. The brutes can be improved by domestication; but, left to themselves, they soon relapse into their original wildness. Civilized Man also goes back to savagery; yet Man (though not all Men) has the ambition to exalt his mental and moral nature. He has a soul, or conscious relation to the Infinite, which leads him to aspire after a lofty ideal. Only he can form abstract ideas. And, finally, he is a completely self-determining agent, with a prominent will and conscience-the highest attribute of the animal creation. In all this, Man differs profoundly from the lower forms of life.

\section{The Voices of Animals.}

Most aquatic animals are mute. Some Crabs make noises by rubbing their fore-legs against their carapace; and many Fishes produce noises in various ways, mostly by means of the swim-bladder. Insects are the Invertebrates which make the most noise. Their organs are usually external, while those of Vertebrates are internal. Insects of rapid flight generally make the most noise. In some the noise is produced by friction (stridulation); in others, by the passage of air through the spiracles (humming). The shrill notes of Crickets and Grasshoppers are produced by rubbing the wings against each other, or against the thighs; but the Cicada, or Harvest-fly, has a special apparatus-a tense membrane on the abdomen, acted upon by muscles. The buzzing of Flies and humming of Bees 
are caused, in part, by the vibrations of the wings; but the true voice of these Insects comes from the spiracles of the thorax.

Snakes and Lizards have no vocal cords, and can only hiss. Frogs croak ${ }^{104}$ and Crocodiles roar, and the huge Tortoise of the Galapagos Islands utters a hoarse, bellowing noise.

The vocal apparatus in Birds is situated at the lower end of the trachea, where it divides into the two bronchi. $^{105}$ It consists mainly of a bony drum, with a crossbone, having a vertical membrane attached to its upper edge. The membrane is put in motion by currents of air passing on either side of it. Five pairs of muscles (in the Songsters) adjust the length of the windpipe to the pitch of the glottis. The various notes are produced by differences in the blast of air, as well as by changes in the tension of the membrane. The range of notes is commonly within an octave. Birds of the same family have a similar voice. All the Parrots have a harsh utterance; Geese and Ducks quack; Crows, Magpies, and Jays caw; while the Warblers differ in the quality, rather than the kind, of note. ${ }^{106}$ The Parrot and Mocking-bird use the tongue in imitating human sounds. Some species possess great compass of voice. The Bell-bird can be heard nearly three miles; and Livingstone said he could distinguish the voices of the Ostrich and the Lion only by knowing that the former roars by day, and the latter by night.

The vocal organ of Mammals, unlike that of Birds, is in the upper part of the larynx. It consists of four cartilages, of which the largest (the thyroid) produces the prominence in the human throat known as "Adam's apple," and two elastic bands, called "vocal cords," just below the glottis, or upper opening of the windpipe. The various tones are determined by the tension of these cords, which is effected by the raising or lowering of the thyroid 
cartilage, to which one end of the cords is attached. The will cannot influence the contraction of the vocalizing muscles, except in the very act of vocalization. The vo-

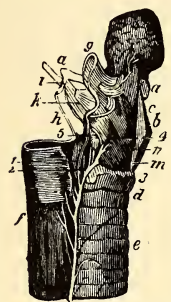

Fıg. 159.-Human Larynx, seen in profile; $a$, half of the hyoid bone ; $e$, trachea: $f$, œsophagns ; $g$, epiglottis.

cal sounds produced by Mammals may be distinguished into the ordinary voice, the cry, and the song. The second is the sound made by brutes. The Whale, Porpoise, Armadillo, Ant-eater, Porcupine, and Giraffe are generally silent. The Bat's voice is probably the shrillest sound audible to human ears. There is little modulation in brute utterance. The Opossum purrs, the Sloth and Kangaroo moan, the Hog grunts or squeals, the Tapir whistles, the Stag bellows, and the Elephant gives a hoarse trumpet sound from its trunk and a deep groan from its throat. All Sheep have a guttural voice; all the Cows low, from the Bison to the Musk-ox; all the Horses and Donkeys neigh; all the Cats miau, from the domestic animal to the Lion; all the Bears growl; and all the Canine familyFox, Wolf, and Dog-bark and howl. The Howlingmonkeys and Gorillas have a large cavity, or sac, in the throat for resonance, enabling them to utter a powerful voice; and one of the Gibbon-apes has the remarkable power of emitting a complete octave of musical notes. The human voice, taking the male and female together, has a range of nearly four octaves. Man's power of speech, or the utterance of articulate sounds, is due to his intellectual development rather than to any structural difference between him and the Apes. Song is produced by the vocal cords, speech by the mouth. 


\section{CHAPTER XIX.}

\section{REPRODUCTION.}

IT is a fundamental truth that every living organism has had its origin in some pre-existing organism. The doctrine of "spontaneous generation," or the supposed origination of organized structures out of inorganic particles, or out of dead organic matter, has not yet been sustained by facts.

Reproduction is of two kinds-sexual and asexual. All animals, probably, have the first method, while a very great number of the lower forms of life have the latter also.

Of asexual reproduction there are two kinds - Self-division and Budding.

Self-division, the simplest mode possible, is a natural breaking-up of the body into distinct surviving parts. This process is sometimes extraordinarily rapid, the increase of one animalcule (Paramœcium) be-

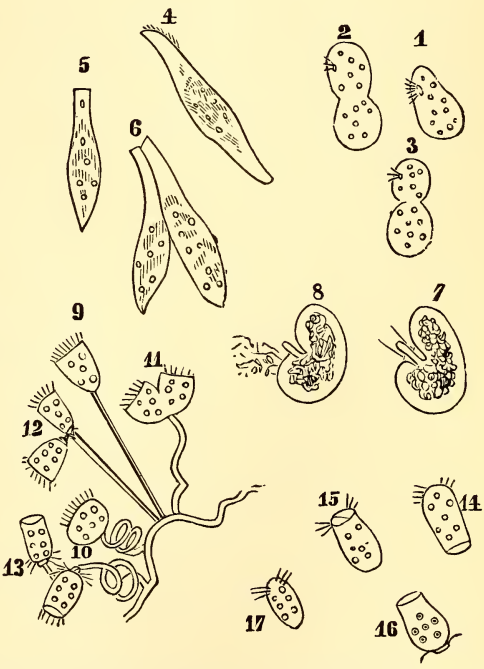
ing computed at 268 Fia. 160.-Reproduction of Infusoria (Vorticelmillions in a month. It loe and others) by fission or self-division. may be either transverse or longitudinal. Of the first sort, Figs.1,2, and 3 (Fig. 160) are exainples; of the latter, 
Figs. 4, 6, 9-13. This form of reproduction is, naturally, confined to animals whose tissues and organs are simple, and so can easily bear division, or whose parts are so arranged as to be easily separable without serious injury. The process is most common in Protozoa, Worms, and Polyps.

Budding is separated by no sharp line from Self-division. While in the latter a part of the organs of the parent go to the offspring, in the former one or more cells of the original animal begin to develop and multiply so as to grow into a new animal like the parent. The process in animals is quite akin to the same operation in plants. The buds may remain permanently attached to the parent-stock, thus making a colony, as in Corals and Bryozoa (continuous budding), or they may be detached at some stage of growth (discontinuous budding). This separation may occur when the bud is grown up, as in Hydra (Fig. 191), or as in Plant-lice, Daphnias (Fig. 255), and among other animals the buds may be internal, and detached when entirely undeveloped and externally resembling an egg. They differ, however, entirely from a true egg in developing directly, without fertilization.

Sexual Reproduction requires cells of two kinds, usually from different animals. These are the germ-cell or egg, and the sperm-cell. The embryo is developed from the union of the two cells. ${ }^{107}$

The egg consists essentially of three parts, the germinal 'vesicle, the yolk, and the vitelline membrane, which surrounds both the first. It is ordinarily globular in shape. Of the three parts, the primary one is the germinal vesicle-a particle of protoplasm. The yolk serves as food for this, and the membrane protects both. When a great mass of yolk is present, it is divisible into two parts-formative and food yolk. The latter is of a more oily nature than the former, and is usually not segmented with the 
egg. 'The structure of the hen's egg is more complicated. The outside shell consists of earthy matter (lime) deposited in a net-work of animal matter. It is minutely porous, to allow the passage of vapor and air to and fro. Lining the shell is a double membrane (membrana putaminis) resembling delicate tissue-paper. At the larger end, it separates to enclose a bubble of air for the use of the chick. Next comes the albumen, or "white," in spirally arranged layers, within which floats the yolk. The yolk is

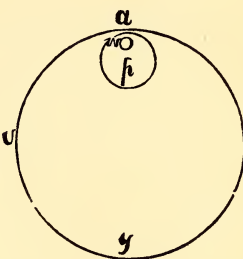

FIG. 161. - Theoretical Egg, or Cell : $v$, vitelline membrane; $y$, oleaginous pole ; $a$, albuminous pole; $p$, Purkinjean, or germiual, vesicle; $w$, Wagnerian, or germinal, dot. prevented from moving towards either end of the egg by two twisted cords of albumen, called chalazoe; yet is allowed to rise towards one side, the yolk being lighter than the albumen. The yolk is composed of oily granules (about $\frac{1}{250}$ of an inch in diameter), enclosed in a sac, called the vitelline membrane, and disposed in concentric layers, like a set of vases placed one within the other. That part of the yolk which extends from the centre to a white

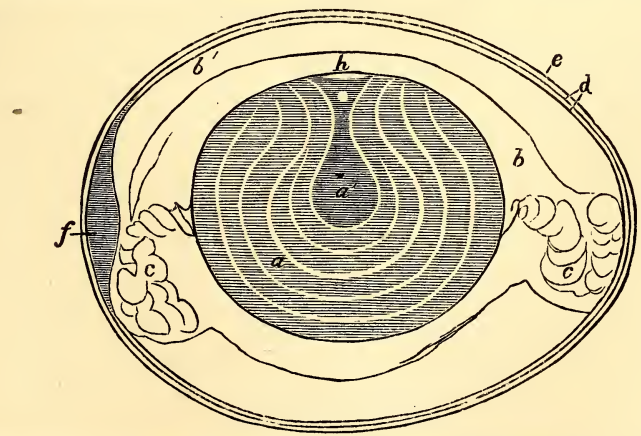

Frg. 162. - Longitudinal Section of Hen's Egg before incubation : a, yolk, showing concentric layers; $a^{\prime}$, its semi-fluid centre, consisting of a white granular substance - the whole yolk is enclosed in the vitelline membrane; $b$, inner dense part of the albumen ; $b^{\prime}$, outer, thinner part; $c$, the chalazæ, or albumen, twisted by the revolutions of the yolk; $d$, double shell-membrane, split at the large end to form the chamber, $f$; $e$, the shell; $h$, the white spot, or cicatricula. 
spot (cicatricula) on the outside cannot be hardened, even with the most prolonged boiling. The cicatricula, or embryo-spot-the part for which all the rest was made-is a thin disk of cellular structure, in which the new life first appears. This was originally a simple cell, but development has gone some way before the egg is laid. It is always on that side which naturally turns uppermost, for the yolk can turn upon its axis; it is, therefore, always nearest to the external air and to the Hen's bodytwo conditions necessary for its development. There is another reason for this polarity of the egg: the lighter and most delicate part of the yolk is collected in its upper part, while the heary, oily portion remains beneath.

In most eggs the shell and albumen are wanting. When the albumen is present, it is commonly covered by a membrane only. In Sharks, the envelope is horny; and in Crocodiles it is calcareous, as in Birds.

The egg of the Sponge has no true vitelline membrane, and is not unlike an ordinary amœboid cell. An egg is,

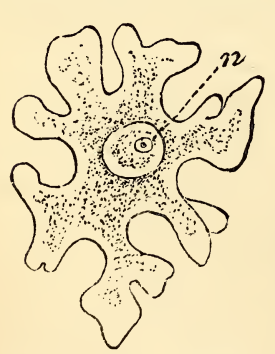

Fra. 163.-Egg of Sponge : in fact, little more than a very large cell, of which the germinal vesicle is the nucleus.

The size of an egg depends mainly upon the quantity of yolk it contains; and to this is proportioned the grade of development which the embryo attains when it leaves the egg. ${ }^{108}$ In the eggs $n$, nucleus. of the Star-fishes, Worms, Insects, Mollusks (except the Cuttle-fishes), many Amphibians, and Mammals, the yolk is very minute and formative, i.e., it is converted into the parts of the future embryo. In the eggs of Lobsters, Crabs, Spiders, Cephalopods, Fishes, Reptiles, and Birds, the yolk is large and colored, and consists of two parts - the formative, or 
germ-yolk, immediately surrounding the germinal vesicle; and the nutritive, or food-yolk, constituting the greater part of the mass, by which the young animal in the egglife is nourished. In the latter case, the young come forth more mature than where the food-yolk is wanting.

As to form, eggs are oval or elliptical, as in Birds and Crocodiles; spherical, as in Turtles and Wasps; cylindrical, as in Bees and Flies; or shaped like a hand-barrow, with tendrils on the corners, as in the Shark. The eggs

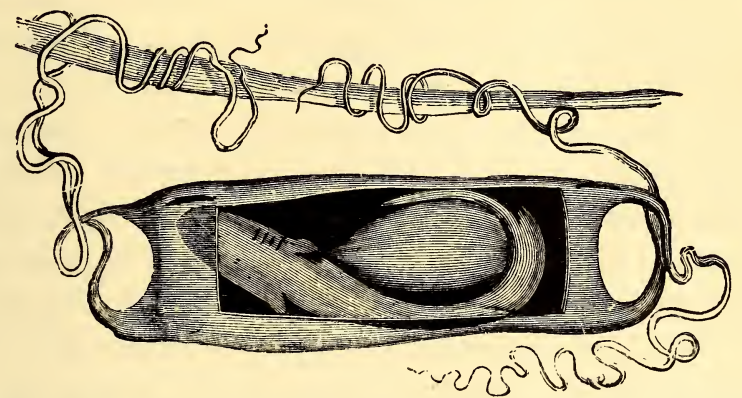

Fig. 164.-Egg of a Shark (the external gills of the embryo are not represented).

of some very low forms are sculptured or covered with hairs or prickles.

The number of eggs varies greatly in different animals, as it is in proportion to the risks during development. Thus, the eggs of aquatic tribes, being unprotected by the parent, and being largely consumed by many animals, are multiplied to prevent extinction. The spawn of a single Cod contains millions of eggs ; that of the Oyster, 6,000,000. A Queen-bee, during the five years of her existence, lays about a million eggs.

Eggs are laid one by one, as by Birds ; or in clusters, as by Frogs, Fishes, and most Invertebrates. The spawn of the Sea-snails consists of vast numbers of eggs adhering together in masses, or in sacs, forming long strings.

As a rule, the higher the rank, the more care animals 
take of their eggs and their young, and the higher the temperature needed for egg-development. In the majority of cases, eggs are left to themselves. The fresh-water Mussel (Unio) carries them within its gills, and the Lobster under its tail. The eggs of many Spiders are enveloped in a silken cocoon, which the mother guards with jealous care. Insects, as Flies and Moths, deposit their eggs where the larva, as soon as born, can procure its own food. Most Fishes allow their spawn, or roe, to float in the water; but a few build a kind of flat nest in the sand or mud, hovering over the eggs until they are hatched; while the Acará of the Amazons carries them in its mouth. The Amphibians, generally, envelop their eggs in a gelatinous mass, which they leave to the elements; but the female of the Surinain Toad carries hers on her back, where they are placed by the male. The great Amazon Turtles lay their eggs in holes two feet deep, in the sand; while the Alligators simply cover theirs with a few leaves and sticks. Nearly all Birds build nests, those of the Perchers being most elaborate, as their chicks are dependent for a time on the parent. ${ }^{109}$ The young of Marsupials, as the Kangaroo, which are born in an extremely immature state, are nourished in a pouch outside of the body. But the embryo of all other Mammals is developed within the parent to a more perfect condition, by means of a special organ, the placenta. It is a general law, that animals receiving in the embryo state the longest and most constant parental care ultimately attain the highest grade of development.

The Protozoa, which have no true eggs, have a sort of reproduction called conjugation. In this process two Amœbæ unite into one mass, surround themselves with a case, in which they divide into several parts, each portion becoming a new Amœba.

The sperm-cells differ from the egg in being very small, 
usually motile, and in that a large number are usually produced from a single cell of the animal, while the egg represents an entire cell. The union of the sperm-cell with the germinal vesicle (fertilization) is the first step in development, and without it the egg will not develop. But the nature of the process is unknown.

\section{CHAPTER XX.}

\section{DEVELOPMENT.}

Development is the evolution of a germ into a complete organism. The study of the changes within the egg constitutes the science of Embryology; the transformations after the egg-life are called metamorphoses, and include growth and repair.

The process of development is a passage from the general to the special, from the simple to the complex, from the homogeneous to the heterogeneous, by a series of differentiations. It brings out first the profounder distinctions, and afterwards those more external. That is, the most essential parts appear first. And not only does development tend to make the several organs of an individual more distinct from one another, but also the individual itself more distinguished from other individuals and from the medium in which it lives. With advancing development, the animal, as a rule, acquires a more specific, definite form, and increases in weight and locomotive power. Life is a tendency to individuality.

The first step in development, after fertilization, is the segmentation of the egg, by a process of self-division. In the simplest form, the whole yolk divides into two parts; these again divide, making four, eight, sixteen, etc., parts, 
until the whole yolk is subdivided into very small portions (cells) surrounding a central cavity. This stage is known as the "mulberry-mass," or blastula (Fig. 165, c).

A

$B$

$C$

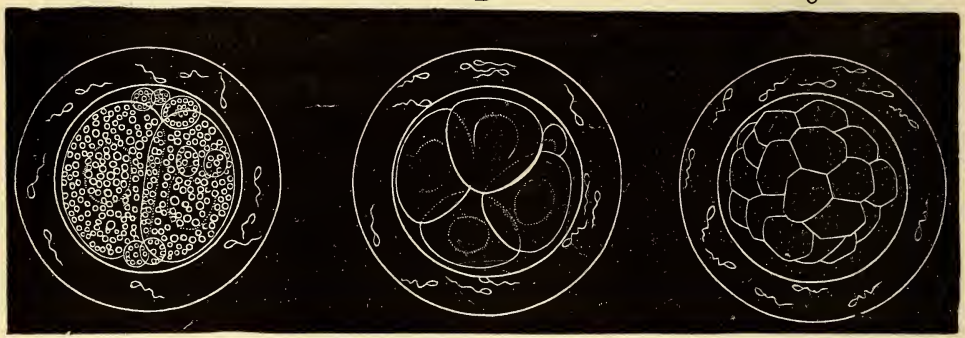

Fig. 165. - First Stages in Segmentation of a Mammalian Egg: $A$, first division into halves, with spermatozoa around it; $B$ and $C$, progressive subdivision, ultimatcly transforming the vitellus, or yolk, into a "mulberry mass" of glubules, or embryo-cells.

If the yolk is larger, relatively to the germinal vesicle, the process of division may go on more slowly in one of the two parts of the egg, first formed; or in very large eggs, like those of Birds and Cuttle-fishes, only a small part of the yolk subdivides.

In some form, the process of segmentation is found in the eggs of all animals, as is also the following stage.

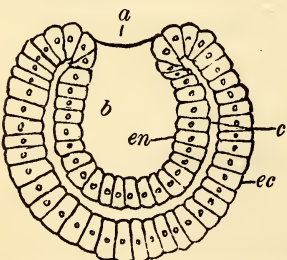

This step is the differentiation of the single layer of cells into two parts, one for the body-wall, the other for the wall of the digestive tract. In the typical examples, this is accomplished by one part of the wall of Fra. 166.-Diagram of Gastru- the blastula turning in, so far as to la of a Worm (Sagitta): $a$,
primitive mouth; $b$, primi- convert the blastula into a sort of tive digestive cavity; $c$, double-walled cup, the gastrula (Fig.
primitive body-cavity; en, endoderm: ec, ectoderm. 166). One half of the wall of the blastula is now the outer wall of the germ, the other half that of the digestive cavity; the original blastula-cavity is now the body-cavity, and the new cavity formed by the infolding is the stomach, and its opening is both mouth 
and vent (Figs. 165, 166). Some adult animals are little more than such a sac. Hydra (Fig. 191), for instance, is little different from a gastrula with tentacles, and one of its relatives wants even these additions.

Ordinarily, however, development goes much further. From the two original layers arises, in various ways, a third between them, making the three primitive germ-layersepiblast, mesoblast, and hypoblast. This new layer is necessarily in the primitive body-cavity, which it may fill up; or usually a new body-cavity is formed, in different ways in different groups. In by far the great majority of animals the digestive tract gets a new opening, which usually becomes the mouth; and the old mouth may close, or serve only the functions of the vent. From this point the development of each group must be traced in detail.

Development of a Hen's Egg. - After the segmentation the germinal disk divides into two layers, between which a third is soon formed. The upper layer (epiblast) gives
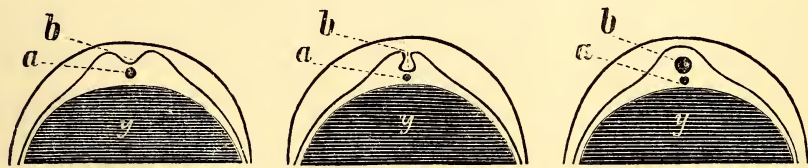

F1G. 167.-Vertical Sections of an Egg, showing progressive stages of development: $a$, notochord; $b$, medullary furrow, becoming a closed canal in the last.

rise to the cuticle, brain, spinal cord, retina, crystalline lens, and internal ear. From the lower layer (hypoblast) is formed the epithelium of the digestive canal. From the middle layer (mesoblast) come all the other organsmuscles, nerves, bones, etc. The mesoblast thickens so as to form two parallel ridges running lengthwise of the germ, and leaving a groove between them (medullary furrow and ridges). ${ }^{110}$ The ridges gradually rise, carrying with them the epiblast, incline towards each other, and at last unite along the back. So that we have a 
tube of epiblast surrounded by mesoblast, which is itself covered by epiblast. This tube becomes the brain and spinal cord, whose central canal, enlarging into the ventricles of the brain, tells the story of its original formation. Beneath the furrow, a delicate cartilaginous thread appears (called notochord)-- the predecessor of the backbone. Meanwhile the mesoblast has divided into two layers, except in the middle of the animal, beneath the spinal cord, and in the head. One of these layers remains attached to the epiblast, and with it forms the body-wall; the other bends rapidly downward, carrying the hypoblast with it, and forms the wall of the intestine. The space thus left between the layers of the mesoblast is the bodycavity. At the same time, the margin of the germ extends farther and farther over the yolk, till it completely encloses it. So that now we see two cavities - a small one, containing the nervous system; and a larger one below, for the digestive organs. Presently, numerous rows
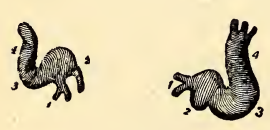
of corpuscles are seen on the middle layer, which are subsequently enclosed, forming a net-work of capillaries,

Fig. 168.-Rudimentary Hearts, human : 1 , venous trunks; 2 , auricle; 3 , ventricle ; 4 , bulbus arteriosus.

called the vascular area. A dark spot indicates the situation of the heart, which is the first distinctly bounded cavity of the circulatory system. It is a short tube lying lengthwise just behind the head, with a feeble pulsation, causing the blood to flow backward and forward. The tube is gradually bent together, until it forms a double cavity, resembling the heart of a Fish. On the fourth day of incubation, partitions begin to grow, dividing the cavities into the right and left auricles and ventricles. The septum between the auricles is the last to be finished, being closed the moment respiration begins. 
The blood-vessels ramify in all directions through the yolk, making it a spongy mass, and all perform the same office; it is not till the fourth or fifth day that arteries can be distinguished from veins, by being thicker, and by carrying blood only from the heart. ${ }^{111}$
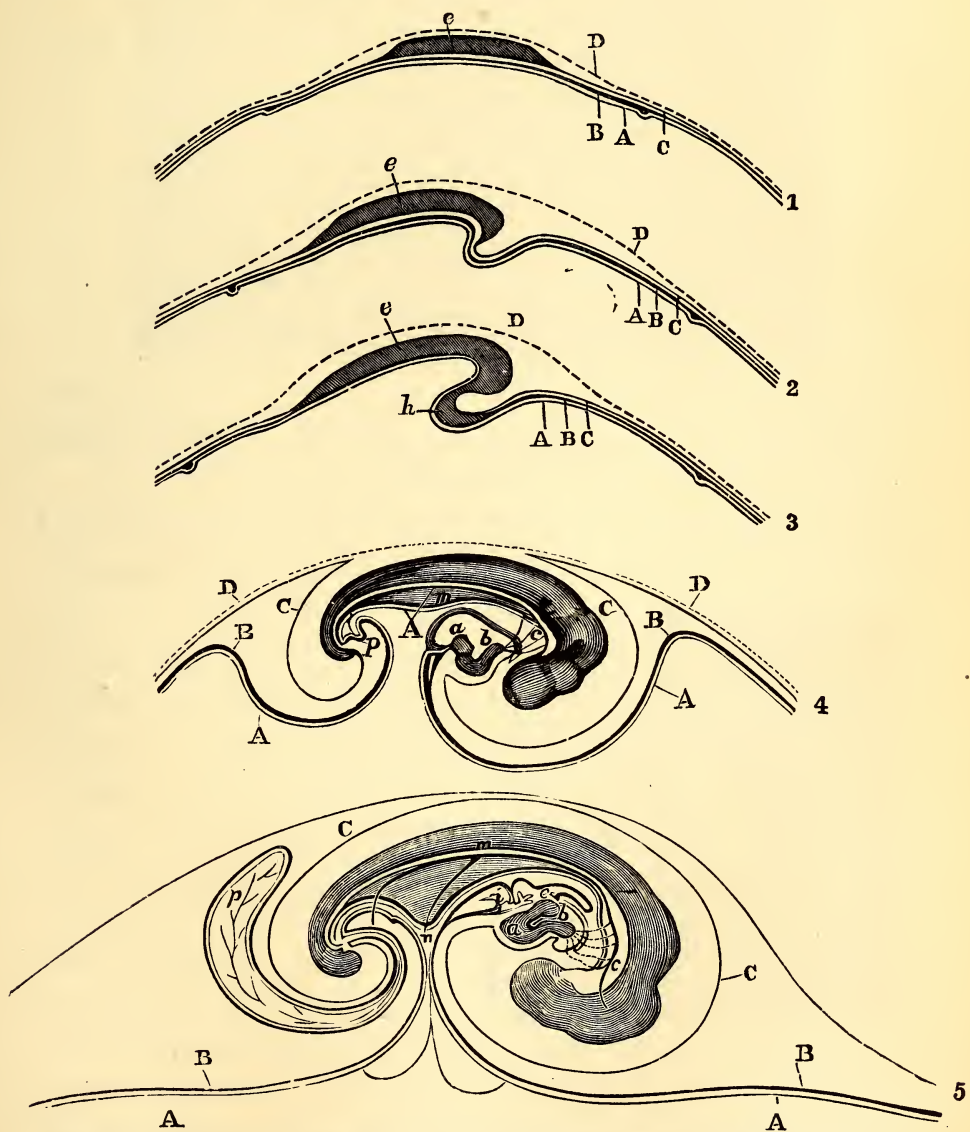

Fig. 169.-Embryo in a Hen's Egg during the first five days: A, hypoblast; B, lower layer of mesoblast; $C$, npper layer of mesoblast and epiblast united, in the last figures forming the amniotic sac; $\mathrm{D}$, vitelline membrane; $e$, thickened blastoderm, the first rudiment of the dorsal part (in the last fignre it marks the place of the lungs); $h$, heart ; $a, b$, its two chambers; $c$, aortic arches; $m$, aorta; $i$, liver; $p$, allantois. 
The embryo lies with its face, or ventral surface, towards the yolk, the head and tail curving towards each

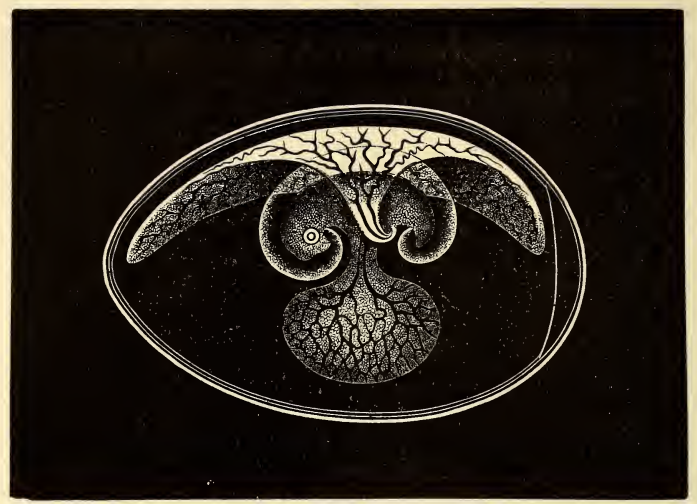

Fra. 170.-Hen's Eurg, more highly developed. The embryo is enveloped by the amnion, and has the umbilical vessel, or remnant of the yolk, hanging from its under surface; while the allantois turns upward, and spreads out over the internal surface of the shell-membrane. (From Dalton's "Physiology.")

other. Around the embryo on all sides the epiblast and upper layer of the mesoblast rise like a hood over the

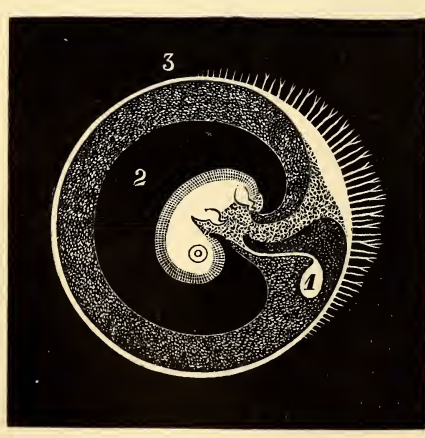

Fıg. 171. - Manmalian Embryo, with allantois fully formed: 1 , umbilical vesicle, containing the last of the yolk; 2 , amnion; 3 , allantois, on which the fringes of the placenta are developing. (From Dalton's "Physiology.") back of the embryo till they form a closed sac, called the amnion. It is filled with a thin liquid, which serves to protect the embryo. Meanwhile, another important organ is forming on the other side. From the hinder portion of the alimentary canal an outgrowth is formed which extends beyond the wall of the embryo proper into the cavity of the amnion and spreads out over the whole inner surface of the shell, so that it partly surrounds both embryo and inner layer of the amnion (amnion prop- 
er). This is the allantois. It is full of blood-vessels, and it serves as the respiratory organ until the chick picks the shell and breathes by its lungs. ${ }^{112}$ The chorion is the outermost part of the allantois, and the placenta of Mammals is the shaggy, vascular edge of the chorion.

The alimentary canal is at first a straight tube closed at both ends, the middle being connected with the yolk-bag. As it grows faster than the body, it is thrown into a spiral coil; and at several points it dilates, to form the crop, stomach, gizzard, etc. The mouth is developed from an infolding of the skin. The liver is an outgrowth from the digestive tube, at first a cluster of cells, then of follicles, and finally a true gland. The lungs are developed on the third day as a minute bud from the upper part of the alimentary canal, or pharynx. As they grow in size, they pass from a smooth to a cellular condition.

The skeleton at the beginning consists, like the notochord, of a cellular material, which gradually turns to cartilage. Then minute canals containing blood-vessels arise, and earthy matter (chiefly phosphate of lime) is deposited between the cells. The primary bone thus formed is compact: true osseous tissue, with canaliculi, laminæ, and Haversian canals, is the result of subsequent absorption. ${ }^{113}$ Certain bones, as those of the face and cranium, are not preceded by cartilage, but by connective tissue: these are called membrane bones. Ossification, or bone-making, begins at numerous distinct points, called centres; and, theoretically, every centre stands for a bone, so that there are as many bones in a skeleton as centres of ossification. But the actual number in the adult animal is much smaller, as many of the centres coalesce. ${ }^{114}$ The development of the backbone is not from the head or from the tail, but from a central point midway between: there the first vertebræ appear, and from thence they multiply forward and backward. 
The limbs appear as buds on the sides of the body; these lengthen and expand so as to resemble paddlesthe wings and legs looking precisely alike; and, finally, they are divided each into three segments, the last one subdividing into digits. The feathers are developed from the outside cells of the epidermis : first, a horny cone is formed, which elongates and spreads out into a vane, and this splits up into barbs and barbules.

The muscle-fibres are formed either by the growth in length of a single cell, or by the coalescence of a row of cells: the cell-wall thus produces a long tube-the sarcolemma of a fibre-and the granular contents arrange themselves into linear series, to make fibrillæ.

Nervous tissue is derived from the multiplication and union of embryo-cells. The white fibres at first resemble the gray. The brain and spinal marrow are developed from the epiblastic lining of the medullary furrow. Soon the brain, by two constrictions, divides into fore-brain, mid-brain, and hind-brain. The fore-brain throws out two lateral hemispheres (cerebrum), and from these protrude forward the two olfactory lobes. From the middle-brain grow the optic lobes; and the hind-brain is separated into cerebellum and medulla oblongata. The essential parts of the eye, retina and crystalline lens, are developed, the former as a cup-like outgrowth from the fore-brain, the latter as an ingrowth of the epidermis. An infolding of the epidermis gives rise to the essential parts of the inner ear, and from the same layer come the olfactory rods of the nose and the taste-buds of the tongue. So that the central nervous system and the essential parts of most of the sense-organs have a common origin.

Modes of Development.-The structure and embryology of a Hen's egg exhibit many facts which are common to all animals. But every grand division of the Animal Kingdom has its characteristic method of developing. 
Protozoans differ from all higher forms in having no true eggs.

The egg of the Hydroid, after segmentation, becomes a hollow, pear-shaped body, covered with cilia. Soon one end is indented; then the indentation deepens until it reaches the interior and forms the mouth. The animal fastens itself by the other end, and the tentacles appear as buds. In the Sea-anemone, the stomach is turned in, and the partitions appear in pairs.

In the Oyster, the egg segments into two unequal parts, one of which gives rise to the digestive tract and its derivatives, while from the smaller part originate the skin, gills, and shell. It is soon covered with cilia, by whose help it swims about.

The embryo of an Insect shows from the first a right and left side; but the first indication that it is an Articulate is the development of a series of indentations dividing the body into successive rings, or joints. Next, we observe that the back lies near the centre of the egg, the ventral side looking outward; i.e., the embryo is doubled upon itself backward. And, finally, the appearance of three pairs of legs proves that it will be an Insect, rather than a Worm, Crustacean, or Spider.

The Vertebrate embryo lies with its stomach towards the yolk, reversing the position of the Articulate; but the grand characteristic is the medullary groove, which does not exist in the egg of any Invertebrate. This feature is connected with another, the setting apart of two distinct regions - the nervous and nutritive. There are three modifications of Vertebrate development: that of Fishes and Amphibians, that of True Reptiles and Birds, and that of Mammals. The amnion and allantois are wanting in the first group ; while the placenta (which is the allantois vitally connected with the parent) is peculiar to Mammals. In Mammals, the whole yolk is segmented; in 
Birds, segmentation is confined to the small white speck seen in opening the shell.

At the outset, all animals, from the Sponge to Man, appear essentially alike. All, moreover, undergo segmentation, and most have one form or other of the gastrula stage. But while Vertebrates and Invertebrates can travel together on the same road up to this point, here they diverge-never to meet again. For every grand group early shows that it has a peculiar type of construction. Every egg is from the first impressed with the power of developing in one direction only, and never does it lose its fundamental characters. The germ of the Bee is divided into segments, showing that it belongs to the Articulates; the germ of the Lion has the medullary stripe-the mark of the coming Vertebrate. The blastodermic layer of the Vertebrate egg rolls up into two tubes -one to hold the viscera, the other to contain the nervous cord; while that of the Invertebrate egg forms only one such tubular division. The features which determine the subkingdom to which an animal belongs are first developed, then the characters revealing its class.

There are differences also in grade of development as well as type. For a time there is no essential difference between a Fish and a Mammal: they have the same nervous, circulatory, and digestive systems. There are many such cases, in which the embryo of an animal represents the permanent adult condition of some lower form. In other words, the higher species, in the course of their development, offer likenesses, or analogies, to finished lower species. The human germ, at first, cannot be distinguished from that of any other animal: for aught we can see, it may turn out a Frog or a Philosopher. The appearance of a medullary stripe excludes it at once from all Invertebrates. It afterwards has, for a time, structures found in the lower classes and orders of Vertebrates as permanent 
organs. For a time, indeed, the human embryo so closely resembles that of the lower forms as to be indistinguishable from them; but certain structures belonging to those forms are kept long after the embryo is clearly human. ${ }^{115}$ All the members of a group do not reach the same degree of perfection, some remaining in what corresponds to the immature stages of the higher animals. Such may be called permanently embryonic forms.

Sometimes an einbryo develops an organ in a rudimentary condition, which is lost or useless in the adult. Thus, the Greenland Whale, when grown up, has not a tooth in its head, while in the embryo life it has teeth in both jaws; unborn Calves have canines and upper incisors; and the female Dugong has tusks which never cut the gum. The "splint-bones" in the Horse's foot are unfinished metatarsals.

Animals differ widely in the degree of development reached at ovulation and at birth. The eggs of Frogs are laid when they can hardly be said to have become fully formed as eggs. The eggs of Birds are laid when segmentation is complete, while the eggs of Mammals are retained by the parent till after the egg-stage is passed.116 Ruminants and terrestrial Birds are born with the power of sight and locomotion. Most Carnivores, Rodents, and perching Birds come into the world blind and helpless; while the human infant is dependent for a much longer time.

\section{Metamorphosis.}

Few animals come forth from the egg in perfect condition. The vast majority pass through a great variety of forms before reaching maturity. These metamorphoses (which are merely periods of growth) are not peculiar to Insects, though more apparent in them. Man himself is developed on the same general principles as the Butterfly, but the transformations are concealed from view. The 
Coral, when hatched, has six pairs of partitions; afterwards, the spaces are divided by six more pairs; then twelve intermediate pairs are introduced; next, twentyfour, and so on. The embryonic Star - tish has a long body, with six arms on a side, in one end of which the young Star-fish is developed. Soon the twelve-armed body is absorbed, and the young animal is of age. Worms are continually growing by the addition of new segments. Nearly all Insects undergo complete metamorphosis, i. e., exhibit four distinct stages of existence-egg, larva, pupa, and imago. The worm-like larva ${ }^{117}$ may be called a locomotive-egg. It has little resemblance to the parent in structure or habits, eating and growing rapidly. Then it enters the pupa state, wrapping itself in a cocoon, or case, and remaining apparently dead till new organs are developed; when it escapes a perfect winged Insect,

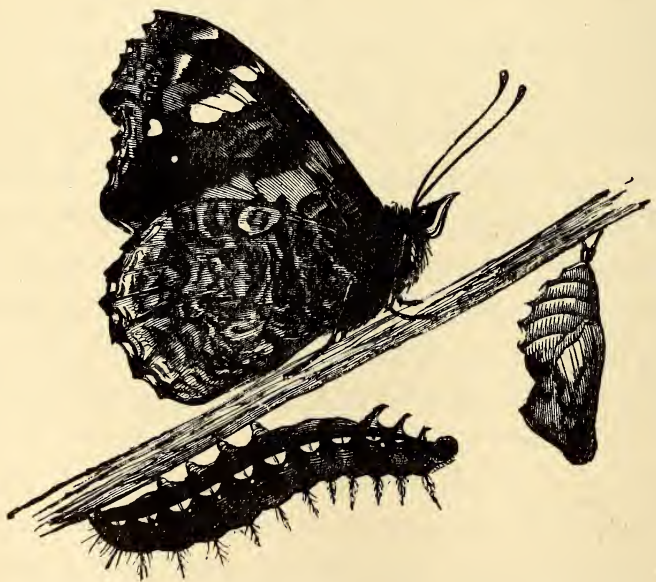

Fis. 172.-Butterfly in the Imago, Pupa, and Larva States.

or imago. ${ }^{118}$ Wings never exist externally in the larva; and some Insects which undergo no apparent metamorphosis, as Lice, are wingless. The Grasshopper develops from the young larva to the winged adult without chang- 
ing its mode of life. In the development of the common Crab, so different is the ontward form of the newly
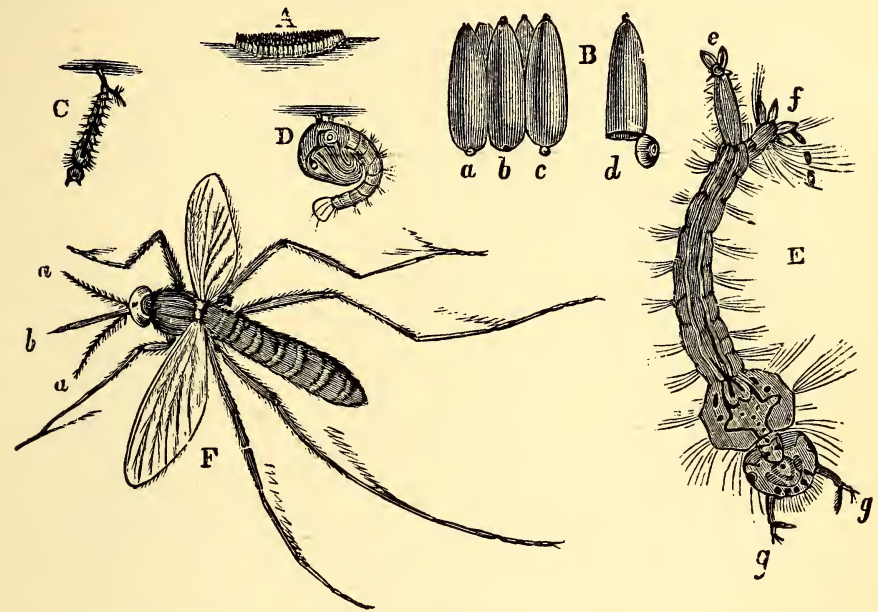

Fig. 173.-Metamorphosis of the Mosquito (Culex pipiens): A, boat of eggs ; B, some of the eggs highly magnified; $d$, with lid open for the escape of the larva, $\mathbf{C} ; \mathbf{D}$, pupa; E, larva magnified, showing respiratory tube, $e$, anal fins, $f$, antennæ, $g$; $\mathrm{F}$, imago; $a$, antennæ; $b$, beak.

hatched embryo from that of the adult, that the former has been described as a distinct species.

The most remarkable example of metamorphosis among Vertebrates is furnished by the Amphibians. A Tadpole -the larva of the Frog-has a tail, but no legs; gills, instead of lungs; a heart precisely like that of the Fish; a horny beak for eating vegetable food, and a spiral intestine to digest it. As it matures, the hinder legs show themselves, then the front pair; the beak falls off; the tail and gills waste away; lungs are created; the digestive apparatus is changed to suit an animal diet; the heart is altered to the Reptilian type by the addition of another auricle; in fact, skin, muscles, nerves, bones, and bloodvessels vanish, being absorbed atom by atom, and a new set is substituted. Moulting, or the periodical renewal of epidermal parts, as the shell of the Lobster, the skin of 
the Toad, the scales of Snakes, the feathers of Birds, and the hair of Mammals, may be termed a metamórphosis.

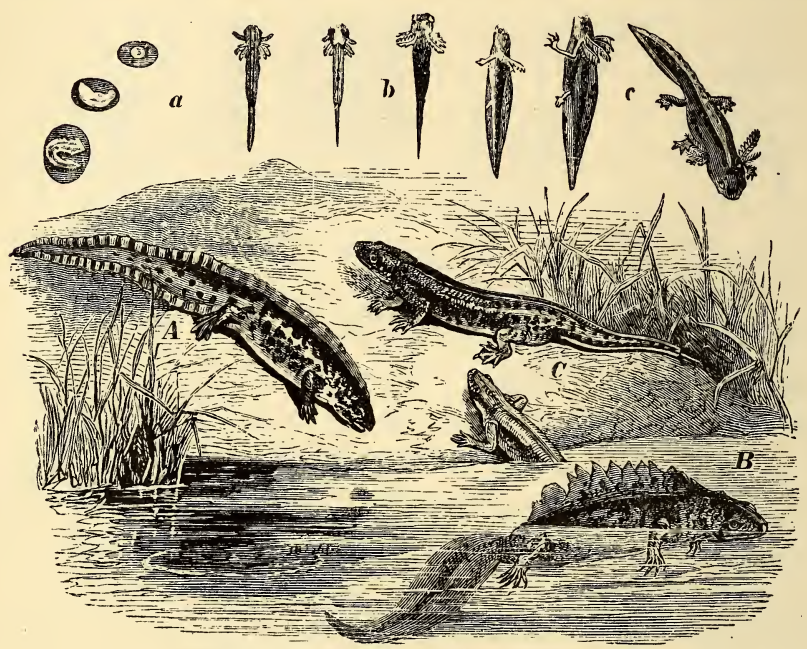

Frg. 174.-Metamorphosis of the Newt.

The change from milk-teeth to a permanent set is another example.

An animal rises in organization as development advances. Thus, a Caterpillar's life has nothing nobler about it than the ability to eat, while the Butterfly expends the power garnered up by the larva in a gay and busy life. But there are seeming reversals of this law. Some mature animals appear lower in the scale than their young. The larval Cirripede has a pair of magnificent compound eyes and complex antennæ; when. adult, the antennæ are gone, and the eyes are reduced to a single, simple, minute eye-spot. So the germs of the sedentary Sponge and Oyster are free and active. The adult animal, however, is always superior in alone possessing the power of reproduction. Such a process is known as retrograde metamorphosis.

There are certain larval forms so characteristic of the 
great groups of the animal kingdom as to demand notice. Most Worms leave the egg as a larva, called the trochosphere (Fig. 175), an oval larva, having mouth and anus, and a circle of cilia anterior to the mouth. This larval stage is common to Worms with the most diverse adult forms and habits. It is also found in all the great groups of Mollusks. Clams, Snails, and Cuttle-fish all have the stage represented in their history. The Mol-

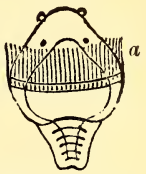

Fig. 1io.-Trochosphere of Worm (Phyllodoce ): $a$, circle of cilia. lusks usually pass through a later stage called the veliger
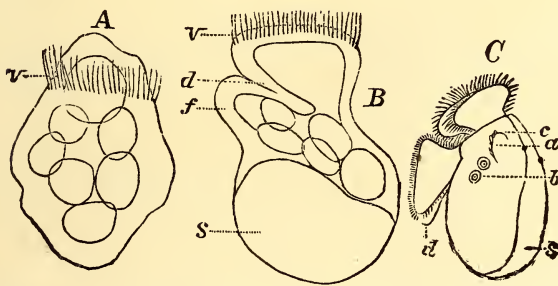

Fig. 176.--Larval Gasteropoda: $A, B$, Trochus; $C$, Tergipes ; $a$, trochosphere : $v$, velum; $\mathrm{B}$, veliger ; $d$, mouth ; $f$, foot ; $s$, shell; $\mathrm{C}$, veliger; $d$, foot ; $c$, tentacle ; $b$, ear.

(Fig. 176), in which a circle of cilia homologous to that of the trochosphere is borne by a lobed expansion on the head, called the velum, or sail. The Crustacea, which exhibit so great a range of form in the adult state, all pass through a stage in which they are substantially alike. Forms as different in appearance as Barnacles, Entomostracans, and Prawns hatch out as $N$ auplii, little oval animals, with a straight intestine, three pairs of legs, and a simple eye (Fig. 177). See Figs. 253, 254, 255, 256. Fig. 256 represents the Lobster, which does not hatch as a Nauplius, but is not very unlike the Prawn. These larval forms are of great interest, because they disclose the relationships of the adult forms, as the gastrula stage hints at the common relationships of all animals above Protozoa.

\section{Alternate Generation.}

Sometimes a metamorphosis extending over several generations is required to evolve the perfect animal; "in 


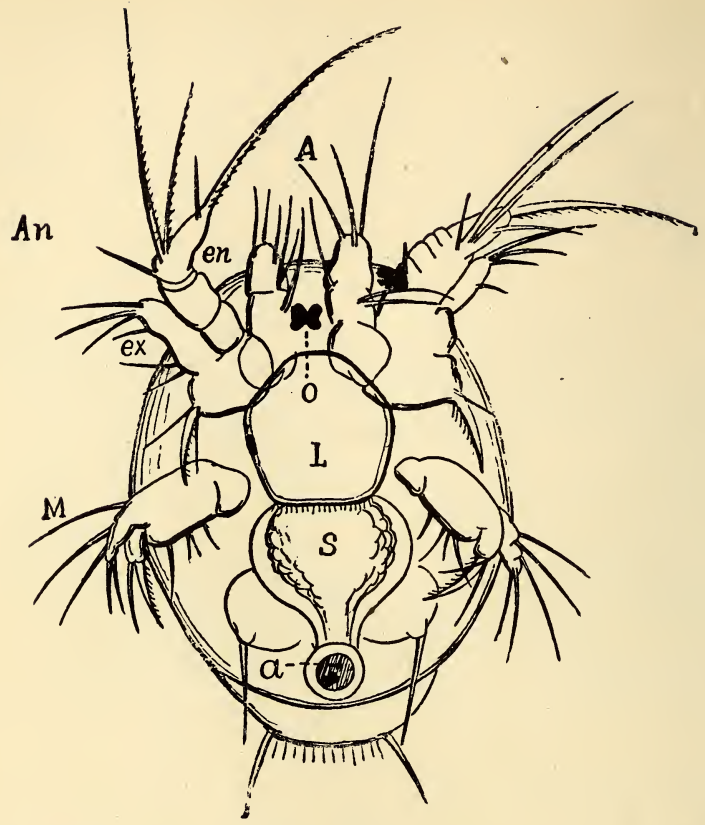

Fig. 177.-Nanplius of Entomostracan (Canthocamptus). See Fig. 255. A, first antenna; $A n$, second antenna; $a$, anus ; $L$, labrum; $O$, ocellus; $S$, stomach. (From Brooks, after Hoek.)

other words, the parent may find no resemblance to himself in any of his progeny, until he comes down to the great-grandson." Thus, the Jelly-fish, or Medusa, lays eggs which are hatched into larvæ resembling Infusorialittle transparent oval bodies covered with cilia, by which they swim about for a time till they find a resting-place. One of them, for example, becoming fixed, develops rapidly; it elongates and spreads at the upper end; a mouth is formed, opening into a digestive cavity; and tentacles multiply till the mouth is surrounded by them. At this stage it resembles a Hydra. Then slight wrinkles appear along the body, which grow deeper and deeper, till the animal looks like "a pine-cone surmounted by a tuft of tentacles ;" and then like a pile of saucers (about a dozen 
in number) with scalloped edges. Next, the pile breaks up into separate segments, which are, in fact, so many distinct animals; and each turning over as it is set free, so as to bring the mouth below, develops into an adult $\mathrm{Me}$ dusa, becoming more and more convex, and furnished with tentacles, circular canals, and other organs exactly like those of the progenitor that laid the original egg.

Here we see a Medusa producing eggs which develop into stationary forms resembling Hydras. The Hydras

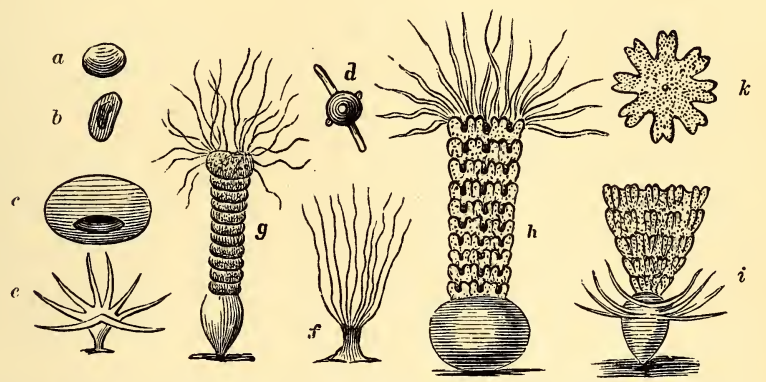

Fig. 178. -Alternate Generation : $a, b, c$, ova of an Acaleph (Chrysaora); $d, e, f$, Hydras; $g, h$, Hydras with constrictions; $i$, Hydra undergoing fission; $k$, one of the separated segments, a free Medusa.

then produce not only Medusæ by budding in the manner described, but also other Hydras like themselves by budding. All these intermediate forms are transient states of the Jelly-fish, but the metamorphoses cannot be said to occur in the same individual. While a Caterpillar becomes a Butterfly, this Hydra-like individual produces a number of Medusæ. Alternate generation is, then, an alternation of asexnal and sexual methods of reproduction, one or more generations produced from buds being followed by a single generation produced from eggs. Often, as in the fresh-water Hydra, the two kinds of generations are alike in appearance. The process is as wide-spread as asexual reproduction, being found mostly in Sponges, Cœlenterates, and Worms. It is also found in certain 
Crustacea and Insects. The name is sometimes limited to cases where the two kinds of generations differ in form.

\section{Growth and Repair.}

Growth is increase of bulk, as Development is increase of structure. It occurs whenever the process of repair exceeds that of waste, or when new material is added faster than the tissues are destroyed. There is a specific limit of growth for all animals, although many of the low cold-blooded forms, as the Trout and Anaconda, seem to grow as long as they live. After the body has attained its maturity, $i . e$, has fully developed, the tissues cease to grow; and nutrition is concerned solely in supplying the constant waste, in order to preserve the size and shape of the organs. A child eats to grow and repair; the adult eats only to repair. ${ }^{119}$ Birds develop rapidly, and so spend most of their life full-fledged; while Insects generally, Fishes, Amphibians, Reptiles, and Mammals mature at a comparatively greater age. The perfect Insect rarely changes its size, and takes but little food; eating and growing are almost confined to larval life. The crust of the Sea-urchin, which is never shed, grows by the addition of matter to the margins of the plates. The shell of the Oyster is enlarged by the deposition of new laminæ, each extending beyond the other. At every enlargement, the interior is lined with a new nacreous layer; so that the number of such layers in the oldest part of the shell indicates the number of enlargements. When the shell has reached its full size, new layers are added to the inner surface only, which increases the thickness. It is the margin of the mantle which provides for the increase in length and breadth, while the thickness is derived from the whole surface. The edges of the concentric laminæ are the "lines of growth." The Oyster is full-grown in about five years. The bones of Fishes and Reptiles are 
continually growing; the long bones of higher animals increase in length so long as the ends (epiphyses) are separate from the shaft. The limbs of Man, after birth, grow more rapidly than the trunk.

The power of regenerating lost parts is greatest where the organization is lowest, and while the animal is in the young or larval state. It is really a process of budding. The upper part of the Hydra, if separated, will reproduce the rest of the body; if the lower part is cut off, it will add the rest. Certain Worms may be cut into several pieces, and each part will regain what is needed to complete the mangled organism. The Star-fish can reproduce its arms; the Holothurian, its stomach; the Snail, its tentacles; the Lobster, its claws; the Spider, its legs; the Fish, its fins; and the Lizard, its tail. Nature makes no mistake by putting on a leg where a tail belongs, or joining an immature limb to an adult aniinal. ${ }^{120}$ In Birds and Mammals, the power is limited to the reproduction of certain tissues, as shown in the healing of wounds. Very rarely an entire human bone, removed by disease or surgery, has been restored. The nails and hair continue to grow in extreme old age.

\section{Likeness and Variation.}

It is a great law of reproduction that all animals tend to resemble their parents. A member of one class never produces a member of another class. The likeness is very accurate as to general structure and form. But it does not descend to every individual feature and trait. In other words, the tendency to repetition is qualified by a tendency to variation. Like produces like, but not exactly. The similarity never amounts to identity. So that we have two opposing tendencies - the hereditary tendency to copy the original stock, and a distinct tendency to deviate from it. 
This is one of the most universal facts in nature. Every development ends in diversity. All know that no two individuals of a family, human or brute, are absolutely alike. There are always individual differences by which they can be distinguished. Evidently a parent does not project precisely the same line of influences upon each of its offspring.

This variability makes possible an indefinite modification of the forms of life. For the variation extends to the whole being, even to every organ and mental characteristic as well as to form and color. It is very slight from generation to generation; but it can be accumulated by choosing from a large number of individuals those which possess any given varration in a marked degree, and breeding from these. Nature does this by the very gradual process of " natural selection ;" Man hastens it, so to speak, by selecting extreme varieties. Hence we have in our day remarkable specimens of Poultry, Cattle, and Dogs, differing widely from the wild races.

Sometimes we notice that children resemble, not their parents, but their grandparents or remoter ancestors. This tendency to revert to an ancestral type is called atavism. Occasionally, stripes appear on the legs and shoulders of the Horse, in imitation of the aboriginal Horse, which was striped like the Zebra. Sheep have a tendency to revert to dark colors:

The laws governing inheritance are unknown. No one can say why one peculiarity is transmitted from father to son, and not another; or why it appears in one member of the family, and not in all. Among the many causes which tend to modify animals after birth are the quality and quantity of food, amount of temperature and light, pressure of the atmosphere, nature of the soil or water, habits of fellow-animals, etc.

Occasionally animals occur, widely different in struct- 
ure, having a very close external resemblance. Barnacles were long mistaken for Mollusks, Polyzoans for Polyps, and Lamprey-eels for Worms. Such forms are termed homomorphic.

Members of one group often put on the outward appearance of allied species in the same locality: this is called mimicry. " "They appear like actors or masqueraders dressed up and painted for amusement, or like swindlers endeavoring to pass themselves off for well-known and respectable members of society." Thus, certain Butterflies on the Amazons have such a strong odor that the Birds let them alone; and Butterflies of another family in the same region have assumed for protection the same form and color of wing. So we have bee-like Moths, beetle-like Crickets, wasp-like Flies, and ant-like Spiders; harmless and venomous Snakes copying each other, and Orioles departing from their usual gay coloring to imitate the plumage, flight, and voice of quite another style of Birds. The species which are imitated are much more abundant than those which mimic them. There is also a general harmony between the colors of an animal and those of its habitation. We have the white Polar Bear, the sand-colored Camel, and the dusky Twilight-moths. There are Birds and Reptiles so tinted and mottled as exactly to match the rock, or ground, or bark of a tree they frequent; and there are Insects rightly named "Walkingsticks" and "Walking-leaves." These coincidences are not always accidental, but often intentional on the part of nature, for the benefit of the imitating species. Generally, they wear the livery of those they live on, or ape the forms more favored than themselves.

\section{Homology, Analogy, and Correlation.}

The tendency to repetition in the development of animals leads to some remarkable affinities. Parts or organs, 
having a like origin and development, and therefore the same essential structure, whatever their form or function, are said to be homologous; while parts or organs corresponding in use are called analogous. By serial homology is meant the homology existing between successive parts of one animal.

The following are examples of homology: the arms of Man, the fore-legs of a Horse, the paddles of a Whale, the wings of a Bird, the front flippers of a Turtle, and the pectoral fins of a Fish; the proboscis of a Moth, and the jaws of a Beetle; the shell of a Snail, and both valves of a Clam. The wings of the Bird, Flying Squirrel, and Bat are hardly homologous, since the wing of the first is developed from the fore-limb only; that of the Squirrel is an extension of the skin between the fore and hind limbs; while in the Bat the skin stretches between the fingers, and then down the side to the tail. Examples of serial homology: the arms and legs of Man; the upper and lower set of teeth; the parts of the vertebral column, however modified; the scapular and pelvic arches; the humerus and femur; carpus and tarsus; the right and left sides of most Animals; the dorsal and anal fins of Fishes. The legs of a Lobster and Lizard, the wings of a Butterfly and Bird, the gills of a Fish, and the lungs of other Vertebrates, are analogous. The air-bladder of a Fish is homologous with a lung, and analogous to the air-chambers of the Nautilus.

In the midst of the great variety of form and structure in the animal world, a certain harmony reigns. Not only are different species so related as to suggest a descent from the same ancestor, but the parts of any one organism are so closely connected and mutually dependent that the character of one must receive its stamp from the character of all the rest. Thus, from a single tooth it may be inferred that the animal had a skeleton and spinal cord, 
and that it was a carnivorous, hot-blooded Mammal. Certain structures always co-exist. Animals with two occipital condyles, and non - nucleated blood - corpuscles, suckle
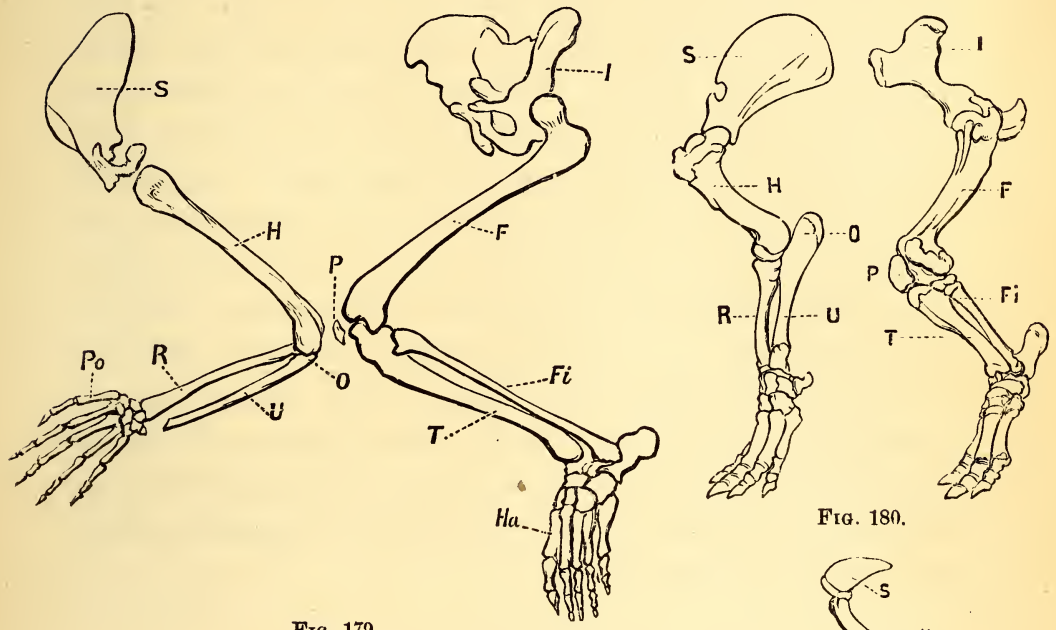

Frg. 180.

FIG. 179.

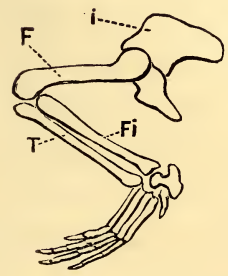

Fr6. 181.

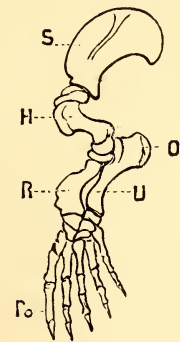

HOMOLOGIES OF LIMBS.

Fig. 179.-Arm and Leg of Man, as they are when he gets down on all-fours. FiG. 1S0.-Fore and Hind Legs of Tapir. Fra. 181.-Fore Leg of Seal and Hind Leg of Alligator. Fre. 182.-Wing of the Bat. S, scapula; I, ilium, or shin-bone of pelvis; H, humerus ; $\mathrm{F}$, femur ; O, olecranon, or tip of the elbow; $\mathrm{P}$, patella ; U, ulna ; T, tibia ; R, radius ; Fi, Fibula ; Po, pollex, or thumb ; Ha, hallex, or great toe. Compare the fore and hind limbs of the same animal, and the fore or hind limbs of different animals. Note the directions of the homologous segments. 
their young, $i$. e., they are Mammals. All Ruminant hoofed beasts have horns and cloven-feet. If the hoofs are even, the horns are even, as in the $\mathrm{Ox}$; if odd, as in the Rhinoceros, the horns are odd, $i$. e., single, or two placed one behind the other. Recent creatures with feathers always have beaks. Pigeons with short beaks have small feet; and those with long beaks, large feet. The long limbs of the Hound are associated with a long head. A white spot in the forehead of a Horse generally goes with white feet. Hairless Dogs are deficient in teeth. Long wings usually accompany long tail-feathers. White Cats with blue eyes are usually deaf. A Sheep with numerous horns is likely to have long, coarse wool. Homologous parts tend to vary in the same manner; if one is diseased, another is more likely to sympathize with it than one not homologous. This association of parts is called correlation of growth.

\section{Individuality.}

It seems at first sight very easy to define an individual animal. A single Fish, or Cow, or Snail, or Lobster is plainly an individual; and the half of one such animal is plainly not one. But when we consider animals in colonies, like Corals, it is not so easy to say whether the individual is the colony or the single Polyp. Is the tree the individual, or the bid? If we say the former-the colony - what shall we say to the free buds of a Hydroid colony, living independent lives, and scattered over square miles of ocean? Are they parts of one individual? If we choose the latter as our standard, we are in equal difficulty; for we must then call an individual the bud of the Portuguese Man - of - war, reduced to a mere bladder or feeler, and incapable of leading an independent life. We thus find it necessary to distinguish at least two kinds of individuals - physiological individuals, applying that 
name to any animal form capable of leading an independent life; and morphological individuals, one of which is the total product of an egg. Such an individual may be a single physiological individual, as the Fish; or many united, as the Coral stock; or many separate physiological individuals, as in the Hydroids or Plant-lice. The single members of such a compound morphological individual are called zooids, or personce, and are found wherever asexual reproduction takes place.

\section{Relations of Number, Size, Form, and Rank.}

The Animal Kingdom has been likened to a pyramid, the species diminishing in number as they ascend in the scale of complexity. This is not strictly true. The number of living species known is at least 300,000, of which more than nine tenths are Invertebrates. A late enumeration gives the following figures for the number of described species:

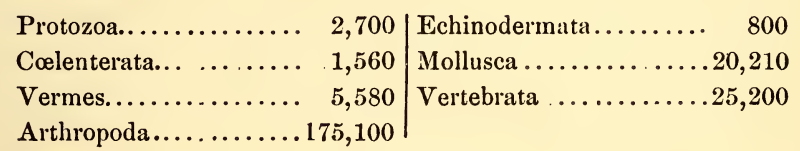

These figures are lower than those usually given. Of Vertebrates, Fishes are most abundant; then follow Birds, Marnmals, Reptiles, and Amphibians. There are usually said to be about 200,000 species of Insects.

The largest species usually belong to the higher classes. The aquatic members of a group are generally larger than the terrestrial, the marine than the fresh-water, and the land than the aerial. The extremes of size are an Infusorium, $\frac{1}{16000}$ of an inch in diameter, the smallest animal ever measured, and the Whale, one hundred feet long, the largest animal ever created. The female is sometimes larger than the male, as of the Nautilus, Spider, and Eagle. The higher the class, the more uniform the size. Of all 
groups of animals, Insects and Birds are the most constant in their dimensions.

Every organism has its own special law of growth: a Fish and an Oyster, though born in the same locality, develop into very different forms. Yet a symmetry of plan underlies the structure of all animals. In the embryo, this symmetry of the two ends, as well as the two sides, is nearly perfect; but it is subsequently interfered with to adapt the animal to its special conditions of life. It is a law that an animal grows equally in those directions in which the incident forces are equal. The Polyp, rooted to the rocks, is subjected to like conditions on all sides, and, therefore, it has no right and left, or fore and hind parts. The lower forms, generally, are more or less geometrical figures: spheroidal, as the Sea-urchin; radiate, as the Star-fish; and spiral, as many Foraminifers. The higher animals are subjected to a greater variety of conditions. Thus, a Fish, always going through the water head foremost, must show considerable difference between the head and the hinder end; or a Turtle, moving over the ground with the same surface always down, must have distinct dorsal and ventral sides.

Nevertheless, there is a striking likeness between the two halves or any two organs situated on opposite sides of an axis. And, first, a bilateral symmetry is most common. It is best exhibited by the Articulates and Vertebrates, but nearly all animals can be clearly divided into right and left sides - in other words, they appear to be donble. A vertical plane would divide into two equal parts our brain, spinal cord, vertebral column, organs of sight, hearing, and smell; our teeth, jaws, limbs, lungs, etc. In fact, the two halves of every egg are identical. There are many exceptions: the heart and liver of the higher Vertebrates are eccentric; the nervous system of Mollusks is scattered; the hemispheres of the human 
brain are sometimes unequal; the corresponding bones in the right and left arms are not precisely the same length and weight; the Narwhal has an immense tusk on the left side, with none to speak of on the other; Rabbits have been born with one ear, and Stags with one horn; the Rattlesnake has but one lung; both eyes of the Flounder and Halibut are on the same side; the claws of the Lobster differ; and the valves of the Oyster are unequal. But all these animals and their organs are perfectly symmetrical in the embryo state.

Again, animals exhibit a certain correspondence between the fore and hind parts. ${ }^{121}$ Thus, the two ends of the Centipede repeat each other. Indeed, in some Worms, the eyes are developed in the last segment as well as the first. So a Vertebrate may be considered not only as two individuals placed side by side, but also as two individuals put end to end-the head and arms representing one, and the legs the other. In the embryo of Quadrupeds, the four limbs are closely alike. But in the adult, the fore and hind limbs differ more than the right and left limbs, because the functions are more dissimilar. An extreme want of symmetry is seen in Birds which combine aerial and land locomotion.

There is also a tendency to a vertical symmetry, or up-and-down arrangement - the part above a horizontal plane being a reversed copy of the part below. A good example is the posterior half of a Cod, while the tail of a Shark shows the want of it. This symmetry decreases as we ascend the scale. In most animals there is considerable difference between the dorsal and ventral surfaces; and in all the nervous system is more symmetrically disposed than the digestive.

Every animal is perfect in its kind and in its place. Yet we recognize a gradation of life. Some animals are manifestly superior to some others. But it is not so easy 
to say precisely what shall guide us in assorting living forms into high and low. Shall we make structure the criterion of rank? Plainly the simple Jelly-fish is beneath complicated Man. An ounce of muscle is worth a pound of protoplasm, and a grain of nervous matter is of more account than a ton of flesh. The intricate and finished build of the Horse elevates him immeasurably above the stupid Snail. The repetition of similar parts, as in the Worm, is a sign of low life. So also a prolonged posterior is a mark of inferiority, as the Lobsters are lower than the Crabs, Snakes than Lizards, Monkeys than Apes. The possession of a head distinct from the region behind it is a sign of power. And in proportion as the forelimbs are used for head purposes, the animal ascends the scale: compare the Whale, Horse, Cat, Monkey, and Man.

But shall the Fish, never rising above the "monotony of its daily swim," be allowed to outrank the skilful Bee? Shall the brainless, sightless, almost heartless Amphioxus, a Vertebrate, be allowed to stand nearer to Man than the Ant? What is the possession of a backbone to intelligence? No good reason can be given why we might not be just as intelligent beings if we carried, like the Insect, our hearts in our backs and our spinal cords in our breasts. So far as its activity is concerned, the brain may be as effective if spread out like a map as packed into its present shape. Even animals of the same type, as Vertebrates, cannot be ranked according to complexity. For while Mammals, on the whole, are superior to Birds, Birds to Reptiles, and Reptiles to Fishes, they are not so in every respect. Man himself is not altogether at the head of creation. We carry about in our bodies embryonic structures. That structural affinity and vital dignity are not always parallel may be seen by comparing an Australian and an Englishman. ${ }^{122}$ 
Function is the test of worth. Not mere work, however; for we must consider its quality and scope. An animal may be said to be more perfect in proportion as its relations to the external world are more varied, precise, and fitting. Complexity of organization, variety, and amount of power are secondary to the degree in which the whole organism is adapted to the circumstances which surround it, and to the work which it has to do. Ascent in the animal scale is not a passage from animals with simple organs to animals with complex organs, but from simple individuals with organs of complex function to complex individuals with organs of simple function: the addition as we ascend being not function, but of parts to discharge those functions; and the advantage gained, not another thing done, but the same thing done better. Advance in rank is exhibited, not by the possession of more life (for some animalcules are ten times more lively than the busiest Man), but by the setting apart of more organs for special purposes. The higher the animal, the greater the number of parts combining to perform each function. The power is increased by this division of labor. The most important feature in this specialization is the tendency to concentrate the nervous energy towards the head (cephalization). It increases as we pass from lower to higher animals.

As a rule, fixed species are inferior to the free, water species to land species, fresh-water animals to marine, arctic forms to tropical, and the herbivorous to the carnivorous. Precocity is a sign of inferiority: compare the chicks of the Hen and the Robin, a Colt with a Kitten, the comparatively well-developed Caterpillar with the footless grub of the Bee. Among Invertebrates, the male is frequently inferior, not only in size, but also in grade of organization. Animals having a wide range as to cli- 
mate, altitude, or depth are commonly inferior to those more restricted: Man is a notable exception.

There is some relation between the duration of life and the size, structure, and rank of animals. Vertebrates not only grow to a greater size, but also live longer than Invertebrates. Whales and Elephants are the longest-lived; and Falcons, Ravens, Parrots and Geese, Alligators and Turtles, and Sharks and Pikes, are said to live a century. The life of Quadrupeds generally reaches its limit when the molar teeth are worn down: those of the Sheep last about 15 years; of the Ox, 20; of the Horse, 40 ; of the Elephant, 100. Many inferior species die as soon as they have laid their eggs, just as herbs perish as soon as they have flowered.

\section{The Struggle for Life.}

Every species of animal is striving to increase in a geometrical ratio. But each lives, if at all, by a struggle at some period of its life. The meekest creatures must fight, or die.

"There is no exception to the rule that every organic being naturally increases at so high a rate that, if not destroyed, the earth would soon be covered by the progeny of a single pair." If the increase of the human race were not checked, there would not be standing-room for the descendants of Adam and Eve. A pair of Elephants, the slowest breeder of all known animals, would become the progenitors, in seven and one half centuries, of $19,000,000$ of Elephants, if death did not interfere. Evidently a vast number of young animals must perish while immature, and a far greater host of eggs fail to mature. A single Cod, laying millions of eggs, if allowed to have its own way, would soon pack the ocean.

Yet, so nicely balanced are the forces of nature, the average number of each kind remains about the same. 
The total extinction of any one species is exceedingly rare. The number of any given species is not determined by the number of eggs produced, but by its conditions. ${ }^{123}$ Aquatic birds outnumber the land birds, because their food never fails, not because they are more prolific. The Fulmar-petrel lays but one egg, yet it is believed to be the most numerous bird in the world.

The main checks to the high rate of increase are: climate (temperature and moisture), acting directly or indirectly by reducing food; and other animals, either rivals requiring the same food and locality, or enemies, for the vast majority of animals are carnivorous. Offspring are continually varying from their parents, for better or worse. If feebly adapted to the conditions of existence, they will finally go to the wall. But those forms having the slightest advantage over others inhabiting the same region, being hardier or stronger, more agile or sagacious, will survive. Should this advantageous variation become hereditary and intensified, the new variety will gradually extirpate or replace other kinds. This is what Mr. Darwin means by Natural Selection, and Herbert Spencer by the Survival of the Fittest. 



\section{PART II.}

\section{SYSTEMATIC ZOOLOGY.}


Facts are stupid things until brought into connection with some general law.-Agassiz.

No man becomes a proficient in any science who does not transcend system, and gather up new truth for himself in the boundless field of research. -Dr. A. P. Peabody.

Never ask a question if you can help it; and never let a thing go unknown for the lack of asking a question if you can't help it.-BEECHER.

$\mathrm{He}$ is a thoroughly good naturalist who knows his own parish thoroughly. - Charles Kingsley. 


\section{CHAPTER XXI.}

THE CLASSIFICATION OF ANIMALS.

The Kingdom of Nature is a literal Kingdom. Order and beauty, law and dependence, are seen everywhere. Amidst the great diversity of the forms of life, there is unity; and this suggests that there is one general plan, but carried out in a variety of ways.

Naturalists have ceased to believe that each animal or group is a distinct, circumscribed idea. "Every animal has a something in common with all its fellows: much with many of them; more with a few; and, usually, so much with several, that it differs but little from them." The object of classification is to bring together the like, and to separate the unlike. But how shall this be done? To arrange a library in alphabetical order, or according to size, binding, date, or language, would be unsatisfactory. We must be guided by some internal character. We must decide whether a book is poetry or prose; if poetry, whether dramatic, epic, lyric, or satiric; if prose, whether history, philosophy, theology, philology, science, fiction, or essay. The more we subdivide these groups, the more difficult the analysis.

A classification of animals, founded on external resemblances - as size, color, or adaptation to similar habits of life-would be worthless. It would bring together Fishes and Whales, Birds and Bats, Worms and Eels. Nor should it be based on any one character, as the quality of the blood, structure of the heart, development of the brain, embryo-life, etc.; for no character is of equal value in every tribe. A natural classification must rest on those 
prevailing characters which are the most constant. ${ }^{124}$ And such a classification cannot be linear. It is impossible to arrange all animal forms from the Sponge to Man in a single line, like the steps of a ladder, according to rank. Nature passes in so many ways from one type to another, and so multiplied are the relations between animals, that one series is out of the question. There is a number of series, and series within series, sometimes proceeding in parallel lines, but more often divergent. The animals arrange themselves in radiating groups, each group being connected, not with two groups merely, one above and the other below, but with several. Life has been likened to a great tree with countless branches spreading widely from a common trunk, and deriving their origin from a common root; branches bearing all manner of flowers, every fashion of leaves, and all kinds of fruit, and these for every use.

The groups into which we are able to cast the various forms of animal development are very unequal and dissimilar. We must remember that a genus, order, or class is not of equal value throughout the kingdom. Moreover, each division is allied to others in different degrees-the distance between any two being the measure of that affinity. The lines between some are sharp and clear, between others indefinite. Like the islands of an archipelago, some groups merge into one another through connecting reefs, others are sharply separated by unfathomable seas, yet all have one common basis. Links have been found revealing a relationship, near or distant, even between animals whose forms are very unlike. There are Fishes (Dipnoi) with some Amphibian characters, and fish-like Amphibians $(A x o l o t l)$. The Ichthyosaurus is a Lizard with fishcharacteristics. Birds seem isolated, but they are closely connected with Reptiles by fossil forms. Even the great gap in the Animal Kingdom-that separating Vertebrates 
and Invertebrates - is partially bridged on the one side by Amphioxus, and on the other by the Tunicates.

We have, then, groups subordinate to groups, and interlocking, but not representing so many successive degrees of organization. For, as already intimated, complication of structure does not rise in continuous gradation from one group to another. Every type starts at a lower point than that at which the preceding class closes; so that the lines overlap. While one class, as a whole, is higher than another, some members of the higher class may be inferior to some members of the lower one. Thus, certain Star-fishes are nobler than certain Mollusks; the Nautilus is above the Worm, and the Bee is more worthy than the lowest Fish. The groups coalesce by their inferior or less specialized members; e.g., the Fishes do not graduate into Amphibians through their highest forms, but the two come closest together low down in the scale. Man appears to be the goal of creation; but even within the Vertebrate series, every step of development, say of the Fish, is away from the goal. The highest Fish is the one farthest from Man.

A number of animals may, therefore, have the same grade of development, but conform to entirely different types. While a fundamental unity underlies the whole Animal Kingdom, suggesting a common starting-point, we recognize several distinct plans of structure. ${ }^{125}$ Animals like the Amœba, with no cellular tissues nor true eggs, form the subkingdom Protozoa. Animals like the Sponge, with independent cells, one excurrent and many incurrent openings, form the subkingdom Spongida. Animals like the Coral, unlike all others, have an alimentary canal but no body-cavity, have no separate nervous and vascular regions, and the parts of the body radiate from a centre. Such form a subkingdom called Coelenterata. Animals like the Star-fish, having also a radiating body, but a closed 
alimentary canal, and a distinct symmetrical nervous system, constitute the subkingdom Echinodermata. ${ }^{126}$ Animals like the Angle-worm, bilaterally symmetrical, onejointed, or composed of joints following each other from front to rear, with no jointed limbs, constitute the subkingdom Vermes. Animals like the Snail, with a soft, unjointed body, a mantle, a foot, a two or three chambered heart, and a nervous system in the form of a ring around the gullet, constitute the subkingdom Mollusca. Animals like the Bee, with a jointed body and jointed limbs, form the subkingdom Arthropoda. Animals like the Sea-squirts, sack or barrel shaped, with a mantle cavity penetrated by an excurrent and an incurrent opening, with heart and gills, form the subkingdom Tunicata. Animals like the Ox, having a double nervous system, one (the sympathetic) lying on the upper side of the alimentary canal, the other and main part (spinal) lying along the back, and completely shut off from the other organs by a partition of bone or gristle, known as the "vertebral column," and having limbs, never more than four, always on the side opposite the great nervous cord, constitute the subkingdom Vertebrata.

Comparing these great divisions, we see that the Vertebrates differ from all the others chiefly in having a donble body-cavity and a double nervous system, the latter lying above the alimentary canal; while Invertebrates have one cavity and one nervous system, the latter being placed either below or around the alimentary canal. The Vermes are closely related to all the following subkingdoms of Invertebrates, most nearly to Mollusks and Tunicates, while the latter have affinities with the Vertebrates. The Echinoderms and Cœlenterates are built on the common type of a star; but they differ from each other in the presence or absence of distinct alimentary, circulatory, and nervous systems. 
But there are types within types. Thus, there are five modifications of the Vertebrate type-Fish, Amphibian, Reptile, Bird, and Mammal; and these are again divided and subdivided, for Mammals, e. g., differ among themselves. So that in the end we have a constellation of groups within groups, founded on peculiar characters of less and less importance, as we descend from the general to the special.

Individuals are the units of the Animal Creation. An animal existence, complete in all its parts, is an individual, whether separate, as Man, or living in a community, as the Coral. ${ }^{127}$

Species is the smallest group of individuals which can be defined by distinct characteristics, and which is separated by a gap from all other like groups. A well-marked subdivision of a species is called a variety. Crosses between species are called hybrids, as the Mule.

Genus is a group of species having the same essential structure. Thus, the closely allied species Cat, Tiger, and Lion belong to one genus.

Family, or Tribe, is a group of genera having a similar form. Thus, the Dogs and Foxes belong to different genera, but betray a family likeness.

Order is a group of families, or genera, related to one another by a common structure. Cats, Dogs, Hyenas, and Bears are linked together by important anatomical features; their teeth, stomachs, and claws show carnivorous habits.

Class is a still larger group, comprising all animals which agree simply in a special modification of the type to which they belong. Thus, Fishes, Amphibians, Reptiles, Birds, and Mammals are so many aspects of the Vertebrate type.

Subkingdom is a primary division of the Animal Kingdom, which includes all animals formed upon one of the various types of structure; as Vertebrate. 
The subkingdoms are grouped into two great Series, according to their histological structure and mode of development. ${ }^{128}$

These terms were invented by Linnæus, except Family, Subkingdom, and Series. To Linnæus we are also indebted for a scientific method of naming animals. Thus, a Dog, in Zoology, is called Canis familiaris, which is the union of a generic and a specific name, corresponding to the surname and the Christian name in George Washington, only the specific name comes last. It will be understood that these are abstract terms, expressing simply the relations of resemblance: there is no such thing as genus or species.

Classification is a process of comparison. $\mathrm{He}$ is the best naturalist who most readily and correctly recognizes likeness founded on structural characters. As it is easier to detect differences than resemblances, it is much easier to distinguish the class to which an animal belongs than the genus, and the genus than the species. In passing from species to classes, the characters of agreement become fewer and fewer, while the distinctions are more and more manifest; so that animals of the same class are more like than unlike, while members of distinct classes are more unlike than like.

To illustrate the method of zoological analysis by searching for affinities and differences, we will take an example suggested by Professor Agassiz. Suppose we see together a Dog, a Cat, a Bear, a Horse, a Cow, and a Deer. The first feature which strikes us as common to any two of them is the horn in the Cow and the Deer. But how shall we associate either of the others with these? We examine the teeth, and find those of the Dog, the Cat, and the Bear sharp and cutting; while those of the Cow, the Deer, and the Horse have flat surfaces, adapted to grinding and chewing, rather than to cutting and tearing. We 
compare these features of their structure with the habits of these animals, and find that the first are carnivorousthat they seize and tear their prey; while the others are herbivorous, or grazing, animals, living only on vegetable substances, which they chew and grind. We compare, further, the Horse and Cow, and find that the Horse has front teeth both in the upper and the lower jaw, while the Cow has them only in the lower; and going still further, and comparing the internal with the external features, we find this arrangement of the teeth in direct relation to the different structure of the stomach in the two animals-the Cow having a stomach with four pouches, while the Horse has a simple stomach. Comparing the Cow and Deer, we find the digestive apparatus the same in both; but though both have horns, those of the Cow are hollow, and last through life; while those of the Deer are solid, and are shed every year. Looking at the feet, we see that the herbivorons animals are hoofed; the carnivorous, clawed. The Cow and Deer have cloven feet, and are ruminants; the Horse has a single hoof, and does not chew the cud. The Dog and Cat walk on the tips of their fingers and toes (digitigrade); the Bear treads on the palıns and soles (plantigrade). The claws of the Cat are retractile; those of the Dog and Bear are fixed.

In this way we determine the exact place of each animal. The Dog belongs to the kingdom Animalia, subkingdom Vertebrata, class Mammalia, order Carnivora, family Canidoe, genus Canis, species Familiaris, variety Hound (it may be), and its individual name, perhaps, is "Rover." The Cat differs in belonging to the family Felidae, genus Felis, species Catus. The Bear belongs to the family Ursidce, genus Ursus, and species Ferox, if the Grizzly is meant. The Horse, Cow, and Deer belong to the order Ungulata; but the Horse is of the family Equidce, genus Equus, species Caballus; the Cow is of 
the family Bovidoe, genus Bos, species Taurus; the Deer is of the family Cervidoe, genus Cervus, species Virginianus, if the common Deer is meant.

The diagram on the opposite page roughly represents (for the relations of animals cannot be expressed on a plane surface) the relative positions of the subkingdoms and classes according to affinity and rank.*

\section{SERIES I.-PROTOZOA.}

Animals without cellular tissues, and with no true eggs. The body which corresponds to the egg does not develop a blastoderm.

\section{Subkingdom.-PвотоzоA.}

This division was proposed by Von Siebold in 1845 , to contain that vast cloud of microscopic beings on the verge of the Animal Kingdom which could not be received into the other subkingdoms. It is artificial and provisional. The classes composing it are not founded on a common type, but are distinguished by the absence rather than the presence of positive characters. Many stand parallel to the Protophyta of the Vegetable World, and no definite line can be drawn between them.

Protozoans agree in being minute, aquatic, and exceedingly simple in structure, their bodies consisting mainly or wholly of the contractile, gelatinous matter called protoplasm, or sarcode - the first homogeneous substance which has the power of controlling chemical and physical forces. They have no cellular organs or tissues, yet they take and assimilate food, grow, and multiply, which are

* The student should master the distinctions between the great groups, or classes, before proceeding to a minuter classification. "The essential matter, in the first place," says Huxley, "is to be quite clear about the different classes, and to have a distinct knowledge of all the sharply definable modifications of animal structure which are discernible in the Animal Kingdom." 
THE CLASSIFICATION OF ANIMALS.

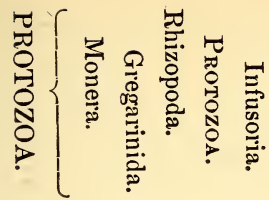

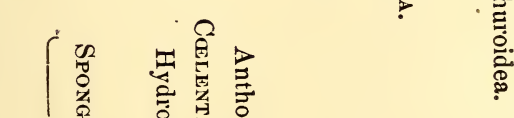

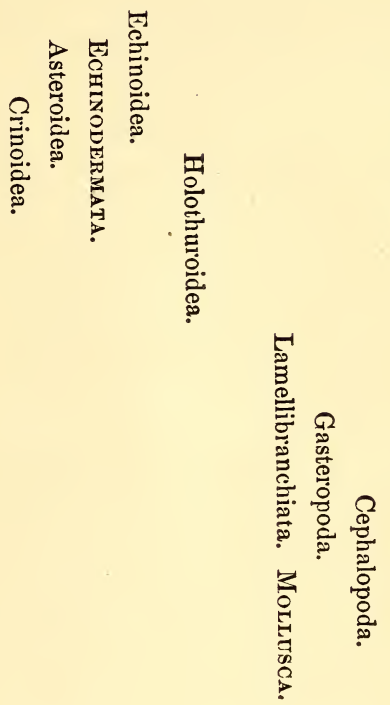

崖

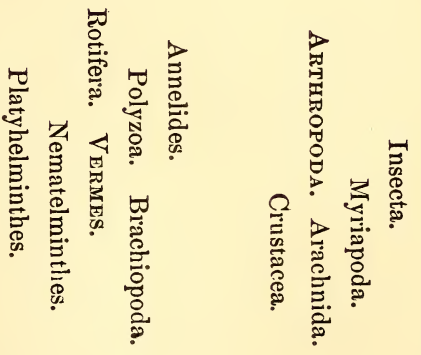

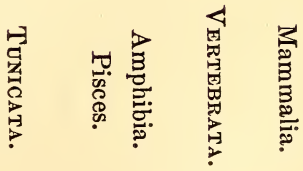
宽 
the essential signs of life. The usual methods of reproduction are self-division and budding.

The subkingdom may be divided into four classes: $M o$ nera, Gregarinida, Rhizopoda, and Infusoria.

\section{Class I.-Monera.}

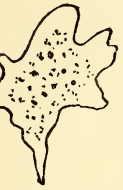

Fig. 183.-Protamoba primitiva.

These simplest living beings are organless bits of protoplasma, with no distinction of layers, round when at rest, and with pseudopodia when active. They are all aquatic, and some are parasitic. Such is Protamœba, Fig. 183.

Class II.-Gregarinida.

The Gregarinæ, discovered by Dufour in 1828, are among the simplest animal forms of which we have any knowledge. They closely resemble a cell, or microscopic egg; the only organ is a nucleus, suspended in extremely mobile granular matter; and the most conspicuous signs

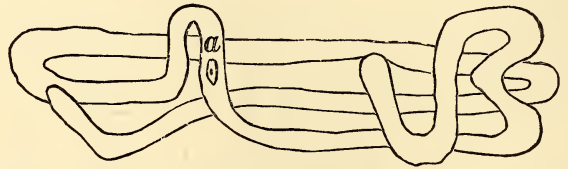

FIG. 184.-Gregarina gigantea, highly magnified: $\alpha$, nucleus.

of life are the contraction and lengthening of the wormlike body. They feed by absorption, and are all parasites, living in the alimentary canal of higher animals; as in the Cockroach, Earth-worm, and Lobster. The name is derived from the fact that they occur in large numbers crowded together.

\section{Class III.-Rhizopoda.}

The Rhizopods are characterized by the power of throwing out at will delicate processes of their bodies, called pseudopodia, or false feet, for prehension or locomotion. 
They possess no cilia. The representative forms are $A m \infty$ boe, Foraminifera, and Polycystina.

An Amœba is a naked fresh-water Rhizopod; an indefinite bit of protoplasm, as structureless as a speck of jelly, save that it is made of two distinct layers, and has a nucleus and a contractile cavity inside. It thus differs from the Monera. It has no particular form, as it changes continually. It moves by putting forth short, blunt processes, and eats by wrapping

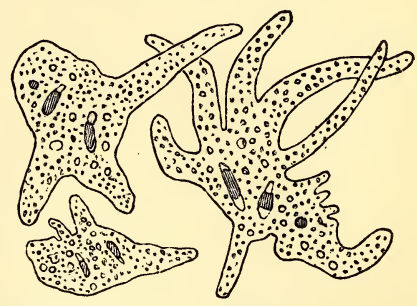

FIg. 185. - A moeba princeps, $\times 150$; the same animal in various shapes. its body around the particle of food. The size ranges from $\frac{1}{70}$ to $\frac{1}{2800}$ of an inch in diameter. Specimens can be obtained by scraping the mucous matter from the stems and leaves in stagnant ponds.

A Foraminifer differs from an Amœba in having an apparently simpler body, the protoplasm being without layers or cavity ; its pseudopodia are long and thread-like, and may unite where they touch each other. It has the property of secreting an envelope, usually of carbonate of
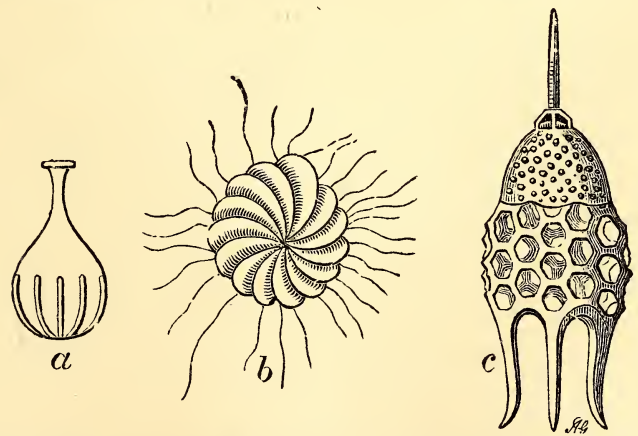

Fig. 186.-Rhizopods: $a$, a monothalamons, or single-chambered, Foraminifer ( $L a-$ gena striata); $b$, a polythalamous, or many-chambered, Foraminifer (Polystomella crispa), with pseudopodia extended; $c$, a Radiolarian, one of the Polycystines (Podocyrtis Schomburgkii). 
lime. The shell thus formed is sometimes of extraordinary complexity and singular beanty. It is generally perforated by innumerable minute orifices (foramina) through which the animal protrudes its myriad of glairy, threadlike arms. The majority are compound, resembling chambered shells, formed by a process of budding, the new cells being added so as to make a straight series, a spiral, or a flat coil. As a rule, the many-chambered species have calcareous, perforated shells; and the one-chambered have an imperforated membranous, porcelaneous, or arenaceous envelope. The former are marine. There are few parts of the ocean where these microscopic shells do not occur, and in astounding numbers. A single ounce of sand from the Antilles was calculated to contain over three millions. The bottom of the ocean, up to about $50^{\circ}$ on each side of the Equator, and at depths not greater than 2400 fathoms, is covered with the skeletons of these animals, which are constantly falling upon it (globigerinaooze). Their remains constitute a great proportion of the so-called sand-banks which block up many harbors. Yet they are the descendants of an ancestry still more prolific; for the Foraminifera are among the most important rockbuilding animals. The chalk-cliffs of England, the building-stone of Paris, and the blocks in the Pyramids of Egypt are largely composed of extinct Foraminifers. Foraminifera are both marine and fresh-water, chiefly marine.

A Polycystine differs from a Foraminifer in secreting a siliceous, instead of a calcareous, shell, studded with spines; and the central part of the body is made up of many cells, and surrounded by a strong membrane. They are also more minute, but as widely diffused. They enter largely into the formation of some strata of the earth's crust, and abound especially in the rocks of Barbadoes and at Richmond, Va. The living forms are mostly marine, but some are fresh-water. 


\section{Class IV.-Infusoria.}

This unassorted group of living particles derived its name from the fact that they were first discovered in vegetable infusions. Every drop of a stagnant pool is crowded with them. They are all single and microscopic, yet of various sizes, the difference between the smallest and largest being greater than the difference between a Mouse and an Elephant. Some are fixed

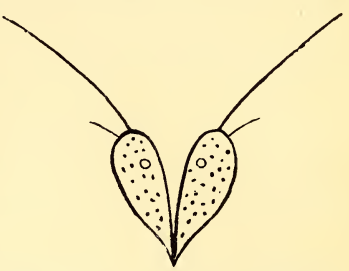

Fig. 157.-A Componnd Monad (Uvella), $\times 1000$. (as Vorticella), but the majority are free, and constantly in motion, propelled by countless cilia, as a galley by its oars. The delicate body consists of two layers of sarcode (there are no cellular tissues, but the whole body represents a single cell), covered by a membrane, or skin, having one or two contractile cavities, and a nucleus. Food-granules can often be seen. On one side is a slight depression, or "mouth," leading to a short, funnel-shaped throat. A mouth and a rudimentary digestive cavity are among the distinctive features of these

FiG. 188. - Infusorium (Paramecium aurelia), $\times 300: m$, mouth; $v$, contractile vesicles; $n$, nucleus.
Protozoans. Some have a pigment-speck - the simplest sense organ-and in the stem of Vorticella the first rudiments of muscle may be found. They multiply so rapidly (chiefly by self-division), that a Paramecium, the most coinmon form, may become the parent of 1,364,000 in forty-two days.

There are two main groups: Flagellata, or Monads, provided with one or two flagella, or long, bristle-like cilia; and Ciliata, which are furnished with numerous vibratile cilia. 


\section{SERIES II.-METAZOA.}

The Metazoa include all those animals which reproduce by true eggs and spermatozoa, whose germ develops a blastoderm, and which have cellular tissues. There are seven subkingdoms.

\section{Subkingdom I.-SPONGIDA.}

The position of the Sponges has been much disputed. At first they were thought to be on the border-line between animals and plants, and were assigned by some to the animals and by others to the vegetables. Later, and up to very recent years, they were assigned to the Protozoa. The discovery of their mode of reproduction and development has determined that they belong to the Metazoa.

The Sponges are formed of an aggregate of membraneless amœboid or ciliated cells. They usually have a skeleton, which may be calcareous, horny, or siliceous. They have a central cavity, with numerous incurrent orifices and one excurrent opening. They reproduce by true eggs, as well as by budding and fission.

The cells of the Sponge are relatively independent, whence they have been regarded as colonies of amœboid animals, and by some naturalists are still so considered.

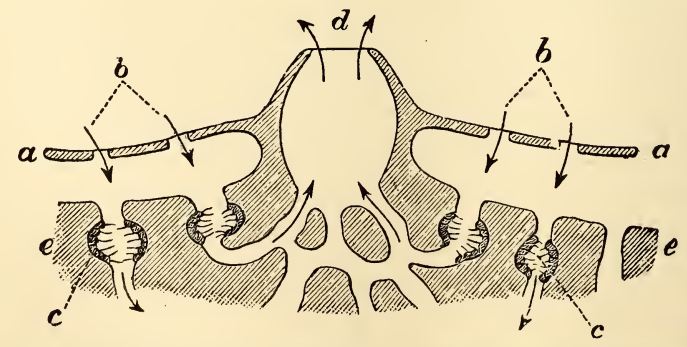

Fı. 189.-Hypothetical Section of a Sponge: $a$, superficial layer; $b$, inhalant pores: $c$, ciliated chambers; $d$, exhalant aperture, or osculum; $e$, deeper substance of the Sponge. 
They develop, however, regularly from the egg, and the cells acquire their independence only at a late date in development. Some of the cells gain cilia, or flagella, and drive the water through numerous channels into the central cavity, whence it is discharged by one opening. Each cell of the Sponge feeds itself from the particles contained in the water.

The Sponge-individual consists of one exhalant orifice, with the channels leading into it. An ordinary bathing-

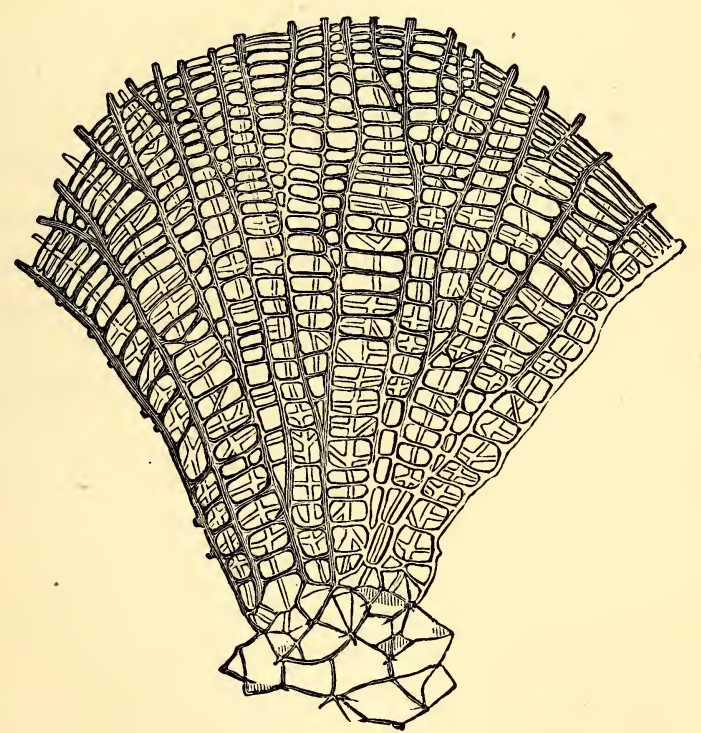

Fia. 190.-Horny Skeleton of a Sponge.

sponge constitutes a colony of such individuals, which are not definitely marked off from each other. Other Sponges have only one osculum, and such are a single individual.

Some few Sponges have no skeleton. Most have one of horny fibres, strengthened with siliceous spicules. These last are absent in the commercial Sponges, and in them the horny fibres are much tougher than in most Sponges. 
A few Sponges, as the Venus's Flower-basket (Euplectella), have siliceous and others have calcareons skeletons.

Excepting a few small fresh-water species (as Spongilla), Sponges are marine. In the former, the cellular part is greenish, containing chlorophyll; in the latter, it is brown, red, or purple. In preparing the Sponge of commerce, this is rotted by exposure, and washed out. The best fishing-grounds are the eastern end of the Mediterranean and around the Bahama Islands.

\section{Subkingdom II.--Ceelenterata.}

These radiate animals are distinguished by having a distinct cavity, whose walls have, at least, two layers of cellular tissue, an outer (ectoderm) and inner (endoderm), and usually a middle layer (mesoderm). They have thread cells, minute sacs containing a fluid, and connected with barbed filaments capable of being thrown ont for stinging purposes. Most are provided with hollow tentacles around the mouth. All are aquatic, and nearly all are marine. There are two classes, represented by the Hydra and Seaanemone. Both reproduce by budding and by eggs.

\section{Class I.-Hydrozoa.}

These Cœlenterates have no separate digestive sac, so that the body is a simple tube, or cavity, into which the month opens. The nervous system is slightly developed. Such are the fresh-water Hydra and the oceanic Jelly-fish (Acaleph or Medusa).

The body of the Hydra is tubular, soft, and sensitive, of a greenish or reddish color, and seldom over half an inch long. It is found spontaneously attached by one end to submerged plants, while the free end contains the orifice, or month, crowned with tentacles, by which the creature feeds and creeps. The body-wall consists of two cellular layers-ectoderm and endoderm. These surround 
a central cavity with one opening. The animal may be compared to a bag with a two-layered wall, and tentacles around the opening. It buds, and also reproduces by eggs. The buds, when adult, become detached from the parent.

In most of the other Hydroids the colony is permanent, and supported by a horny skeleton. There are two kinds of Polyps in each colony, one for feeding and the other for reproduction.
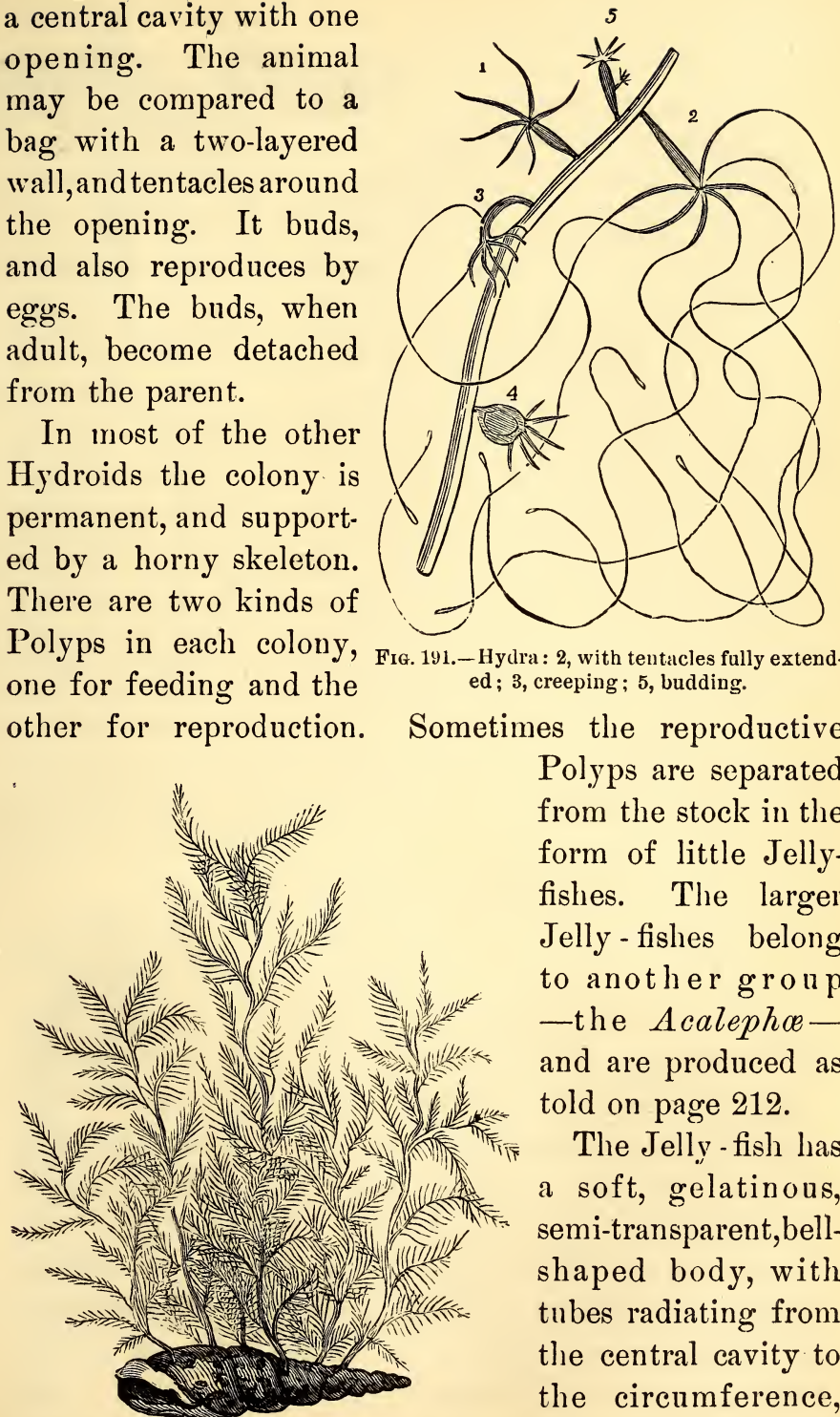

Fig. 191.-Hydra: 2, with tentacles fully extended; 3 , creeping; 5 , budding.

Sometimes the reproductive Polyps are separated from the stock in the form of little Jellyfishes. The larger Jelly - fishes belong to another group -the Acalephoand are produced as told on page 212.

The Jelly - fish has a soft, gelatinous, semi-transparent, bellshaped body, with tubes radiating from the central cavity to the circumference,

Fig. 192.-Hydroid (Sertularia) growing on a Shell. and with the margin 


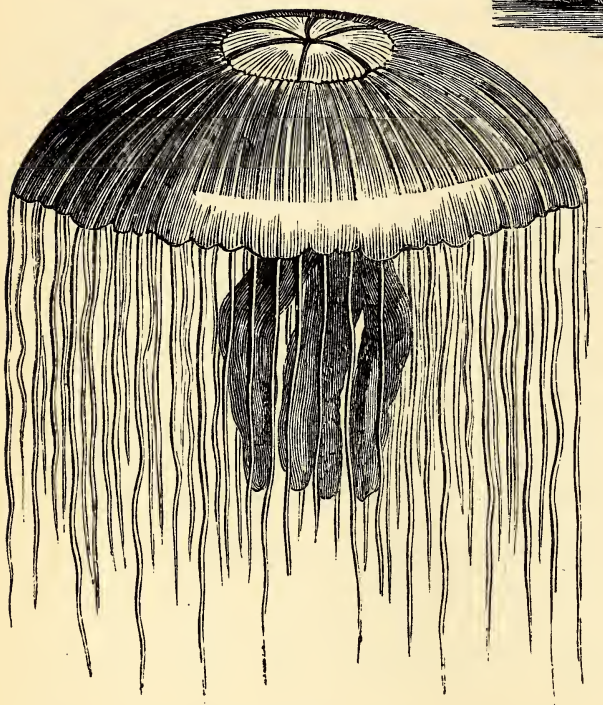

Fig. 193.-Jelly-fish (Pelagia noctiluca). Mediterranean.

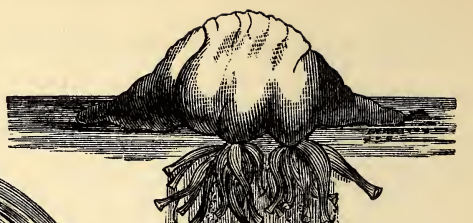

$$
\text { 1. }
$$

(w)

\%

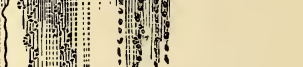

约跑 ! ! !

1 影

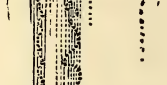

留

翼

楼

翠

i:

"

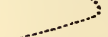

Fra. 194.-Portuguese Manof-war (Physalia), $\frac{1}{3}$ naturalsize. Tropical Atlantic.

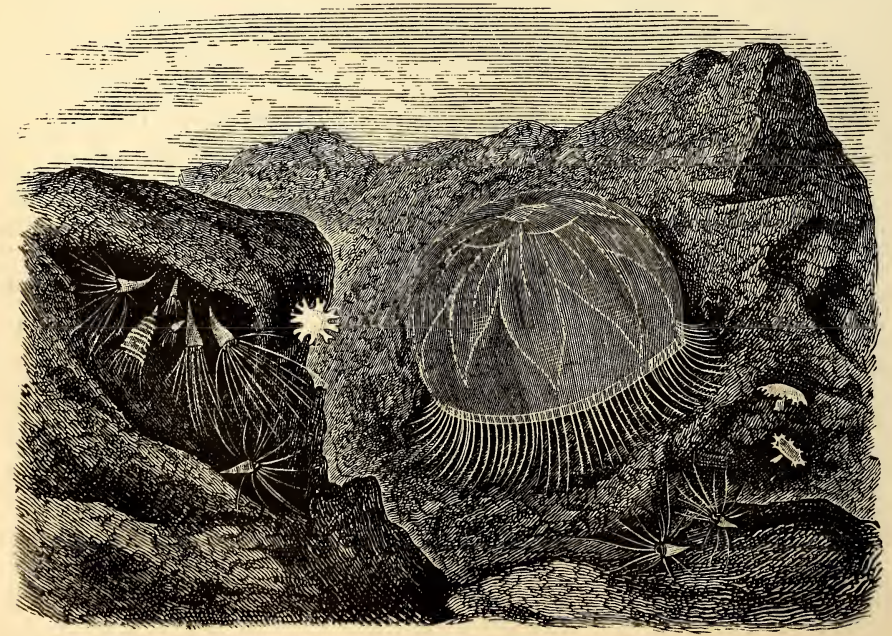

Fig. 195.-Jelly-fish (A urelia aurita), with young in various stages.. 
fringed with tentacles, furnished with stinging threadcells. The radiating parts are in multiples of four. Around the rim are minute colored spots, the "eye-specks." In fine weather, these "sea-blubbers" are seen floating on the sea, mouth downward, moving about by flapping their sides, like the opening and shutting of an umbrella, with great regularity. They are frequently phosphorescent when disturbed. Some are quite small, resembling little glass bells; the common Aurelia is over a foot in diameter when full-grown; while the Cyanea, the giant among Jelly-fishes, sometimes measures eight feet in diameter, with tentacles one

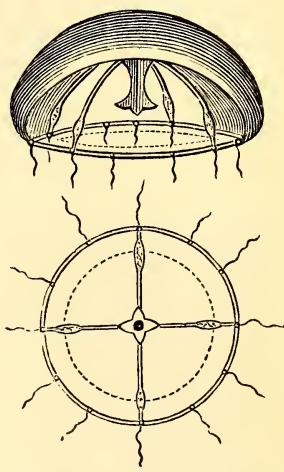

Frg. 196.-A Medusa, seen in profile and from below, showing central polypite, radiating and marginal canals. hundred feet long. When dried, nothing is left but a film of membrane weighing only a few grains.

There are two representative types: the Lucernaria, the Umbrella-acaleph, having a short pedicel on the back

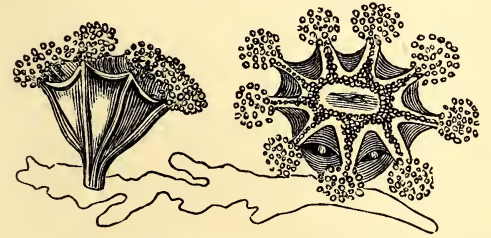

Fis. 197.-Lucernaria auricula attached to a piece of sea-weed; natural size. The one on the right is abnormal, having a ninth tuft of tentacles. for attachment; tentacles disposed in eight groups around the margin, the eight points alternating with the four partitions of the body-cavity and the four corners of the mouth; not less than eight radiating canals, and no membranons veil. The common species on the Atlantic shore, generally found attached to eel-grass, is an inch in diameter, of a green color. Discophora, the ordinary Jelly - fish, is free and oceanic. It differs from the Lucernaria in its usually larger size and solid disk, four 
radiating canals, which ramify and open into a circular vessel, and a "veil," or shelf, always running around the mouth of the disk. ${ }^{129}$

\section{Class II.-Anthozoa.}

These marine animals, which by their gay tentacles convert the bed of the ocean into a flower-garden, or by their

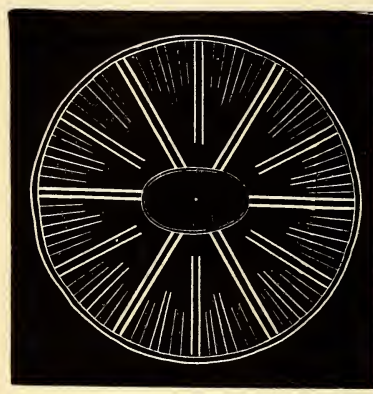

Fig. 198.-Horizontal Section of Actinia through the stomach, showing septa aud compartments. secretions build up coral-islands, have a body like a cylindrical gelatinous bag. One end, the base, is usually attached; the other has the mouth in the centre, surrounded by numerons hollow tentacles, which are covered with nettling lasso-cells. This upper edge is turned in so as to form a sac within a sac, like the neck of a bottle turned outside in. The inner sac, which is the digestive cavity, does not reach the bottom, but opens into the general body-cavity. ${ }^{130}$ The space between these two concentric tubes is divided by a series of vertical partitions, some of which extend from the bodywall to the digestive sac, but others fall short of it. Instead, therefore, of the radiating tubes of the Acaleph, there are radiating spaces. No members of this class are microscopic. All are

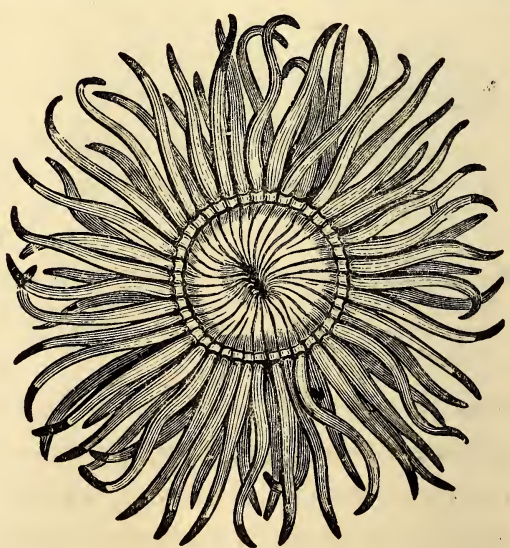

F1a. 199.-Actinia expanded, seen frum above, showing mouth. 
long-lived compared with the Hydrozoa, living for several years. One kept in aquaria in England is now more than sixty years old.

1. Soft-bodied Polyps.-The best-known representative of this group is the Actinia, or Sea-anemone. It leads a single life, and is capable of a slow locomotion. Muscular fibres run around the body, and others cross these at right angles. The tentacles, which often number over two hundred, and the partitions, which are in reality double, are in multiples of six. At night, or when alarmed, the tentacles are drawn in, and the aperture firmly closed, so that the animal looks like a rounded lump of fleshy substance plastered on the rock. It feeds on Crabs and Mollusks. It abounds on every shore, especially of tropical seas. The size varies from one eighth of an inch to a foot in diameter.

2. Coral Polyps. - The majority of Anthozoa secrete a calcareous or horny framework called "coral." With few exceptions, they are fixed and composite, living in colonies formed by a continuous process of budding. Their structures take a variety of shapes: often domelike, but often imitating shrubbery and clusters of leaves. The members of a coral community are organically connected; each feeds himself, yet is not independent of the rest. We can speak of the individual Corals, $a, b, c$, but we must write them down $a b c$. The compound mass is "like a living sheet of animal matter,

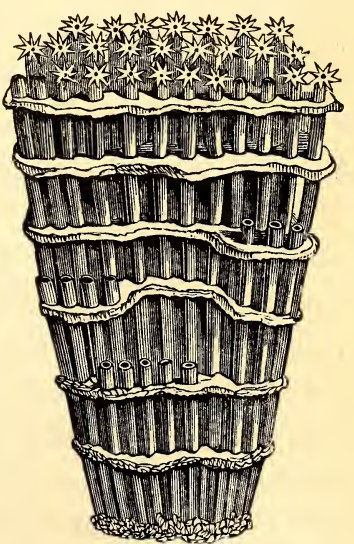

Fig. 200.-Organ-pipe Coral (Tubipora musica). Indian Ocean. fed and nourished by numerous mouths and as many stomachs." Life and death go on together, the old 
Polyps dying below as new ones are developed above. The living part of an Astroea is only half an inch thick. The growth of the branching Madrepore is about three inches a year. The prevailing color of the Coral Polyps is green; and the usual size varies from that of a pin's head to half an inch, but the Mushroom-coral (which is a single individual) may be a foot in diameter.

Corals are of two kinds: those deposited within the tissues of the animal (sclerodermic), and those secreted by the onter surface at the foot of the Polyp (sclerobasic). The Polyps producing the former are Actinoid, resembling the Actinia in structure. ${ }^{131}$ The skeleton of a single Polyp (called corallite, Fig. 95) is a copy of the animal, except the stomach and tentacles, the earthy matter being secreted within the outer wall and between each pair of partitions. So that a corallite is a short tube with vertical septa radiating towards the centre. ${ }^{132}$ A sclerobasic Coral is a true exoskeleton, and is distinguished by being smooth and solid. The Polyps, having eight fringed tentacles; are situated on the outside of this as a common axis, and are connected together by the fleshy conosarc covering the Coral.

(1) Sclerodermic Corals.-Astrcea is a hemispherical mass covered with large cells. Meandrina, or "Brain-coral," is also globular; but the mouths of the Polyps open into each other, forming furrows. Fungia, or "Mushroomcoral," is disk-shaped, and differs from other kinds in being the secretion of a single gigantic Polyp, and in not being fixed. Madrepora is neatly branched, with pointed extremities, each ending in a small cell about a line in diameter. Porites, or "Sponge-coral," is also branching, but the ends are blunt, and the surface comparatively smooth. Tubipora, or "Organ-pipe coral," consists of smooth red tubes connected at intervals by cross-plates. The Astrcea, Meandrina, Madrepora, and Porites are the chief reef-forming Corals. They will not live in waters 


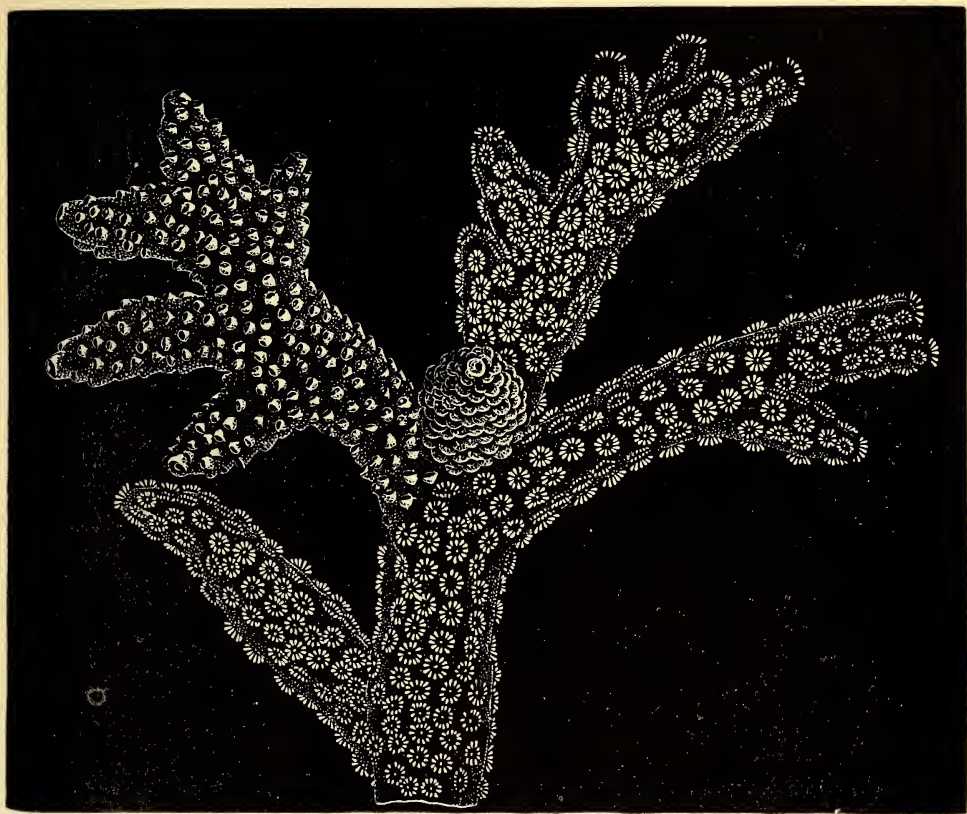

Fir. 201.-Madrepora aspera, living and expanded; natural size. Pacific.

whose mean temperature in the coldest month is below $68^{\circ}$ Fahr., nor at greater depth than twenty fathoms. The most luxuriant reefs are in the Central and Western $\mathrm{Pa}$ cific and around the West Indies.

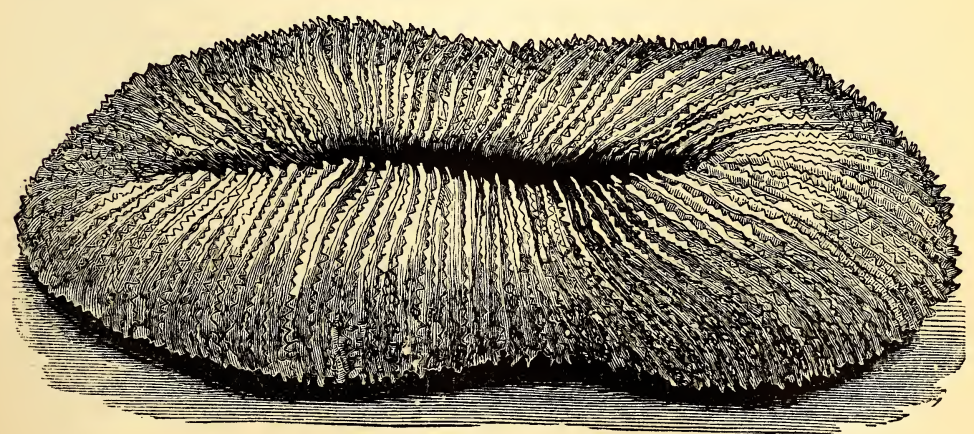

FIG: 202.-Ctenactis echinata, or "Mushroom-coral ;" one fourth natural size. Pacific. 


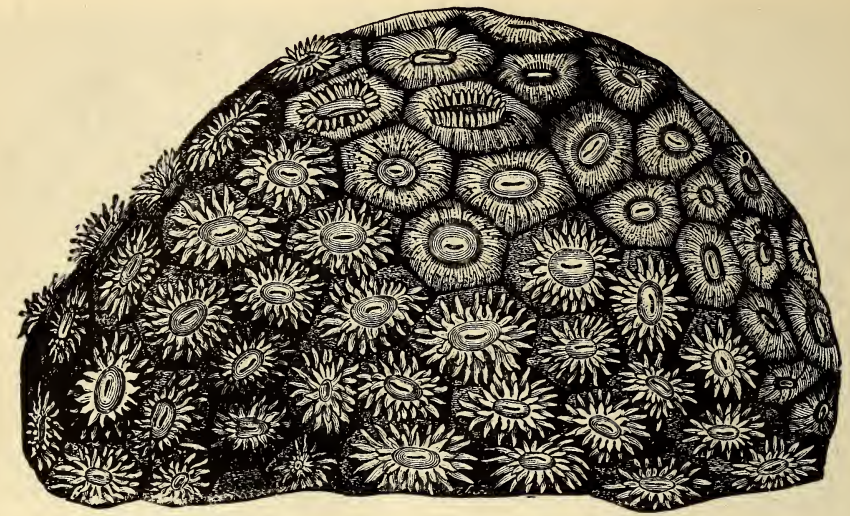

Fig. 203.-Astraea pallida; natural size. Fejee Islands.

A coral-reef is formed by many Corals growing together. It is to the single Coral-stock as a forest is to a tree.

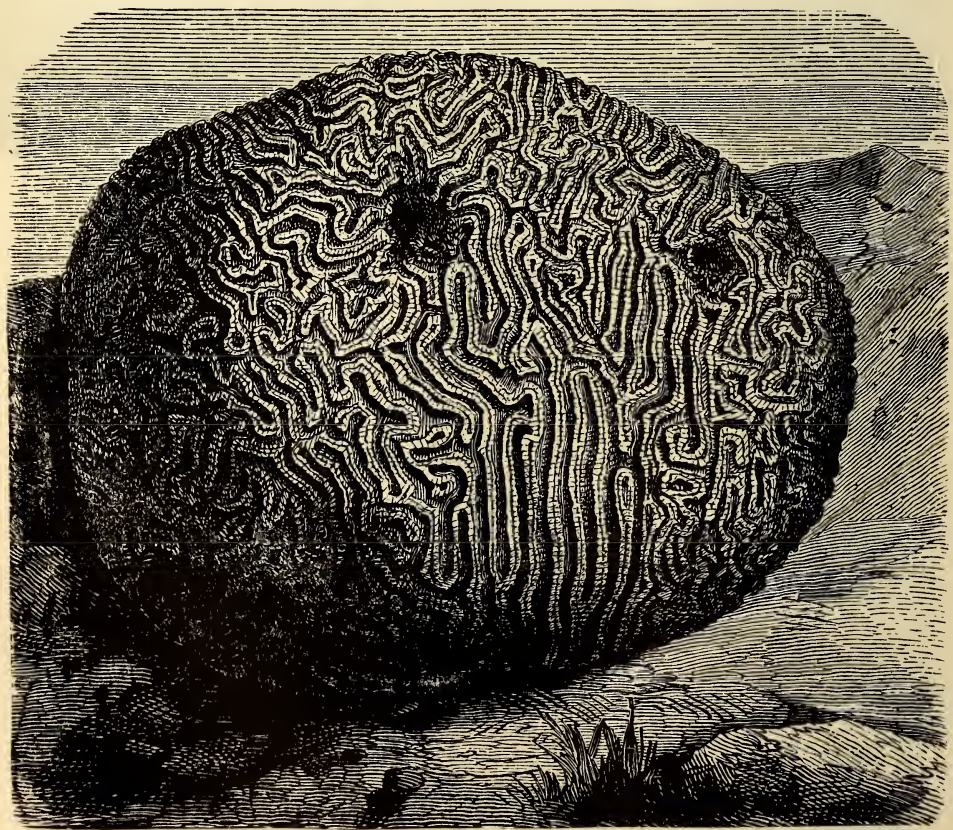

Fig. 204.-Diploria cerebriformis, or "Brain-coral;" one half natural size. Bermudas. 


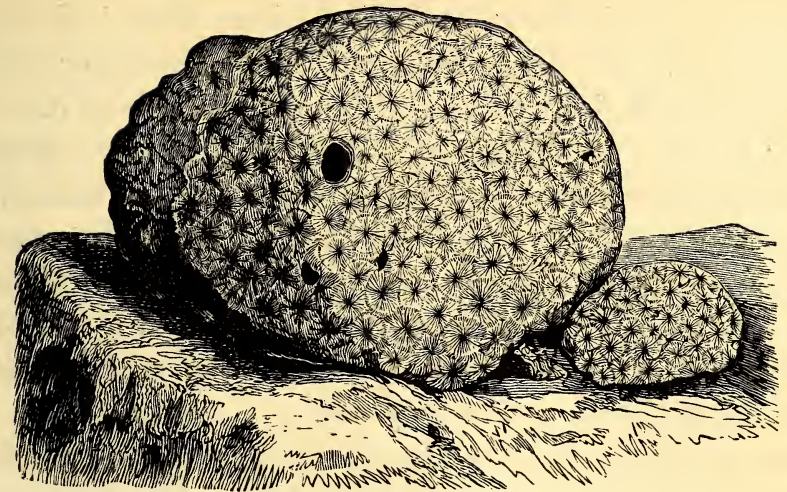

Fig. 205. - A stroea rotulosa. West Indies.

The main kinds of reefs are fringing, where the reef is close to the shore; barier, where there is a channel be-

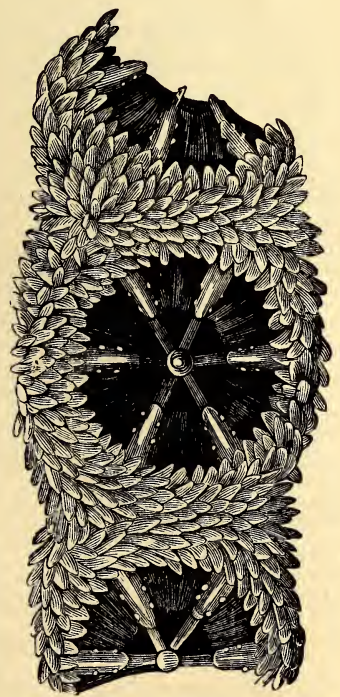

Fia. 206.-Cell of Madrepore Coral, magnified. The cup-like depression at the top of a coral skeleton is called calicle.

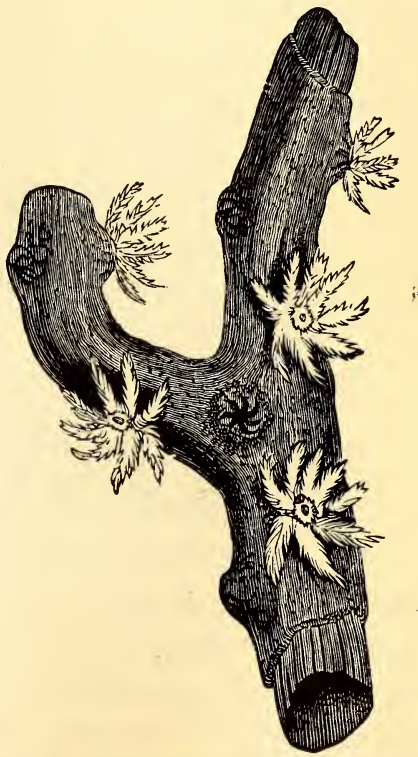

Fig. 207.-Fragment of Red Coral (Corallium rubrum), showing living cortex and expanded Polyps. Mediterrauean. 
tween reef and shore; encircling, where there is a small island inside of a large reef; and coral islands, or atolls, where there is simply a reef with no land inside of it. All reefs begin as fringing-reefs, and are gradually changed into the other forms by the slow sinking of the bottom of the ocean. This sinking must be slower than the upward growth of the reef, else it will be drowned out. Probably the reef does not grow more than five feet in a thousand years; and, as reefs are often more than two thousand feet thick, they must be very old.

(2) Sclerobasic Corals.-Corallium rubrum, the precious coral of commerce, is shrub-like, about a foot high, solid throughout, taking a high polish, finely grooved on the surface, and of a crimson or rose-red color. In the living

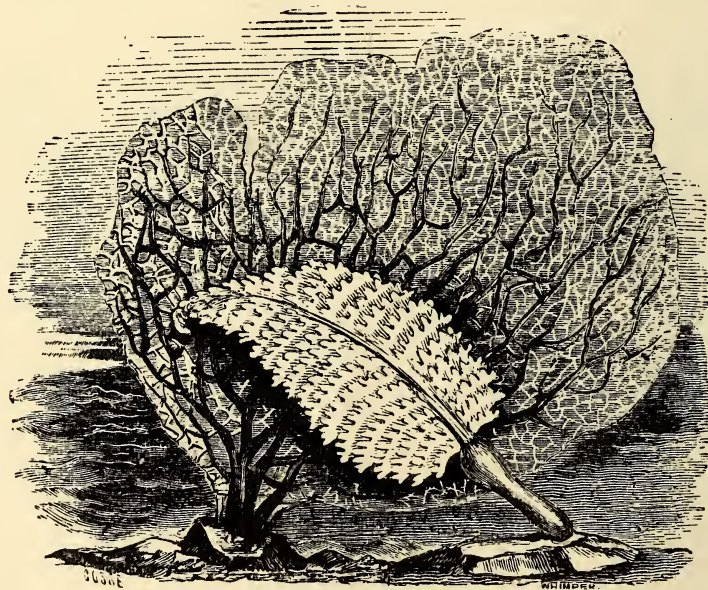

FIG. 208.-Sea-fan (Gorgonia) and Sea-pen (Yennutula).

state the branches are covered with a red cœnosarc studded with Polyps. Gorgonia, or "Sea-fan," differs from all the other representative forms in having a horny axis covered with calcareous spicules. The branches arise in the same vertical plane, and unite into a beautiful network. 


\section{Class III.-Ctenophora.}

The Ctenophora (as the Pleurobrachia, Cestum, and Beroë) secrete no hard deposit. They are transparent and gelatinous, swimming on the ocean by means of eight comblike, ciliated bands, which work like paddles. The body is not contractile, as in the Jelly-fishes. They are considered the highest of Cœlenterates, having a complex nutritive ap- Fra. 209.-A Ctenophore (Plenparatus and a definite nervous robrachia pileus); natural paratus and a definite nervous sys- size.

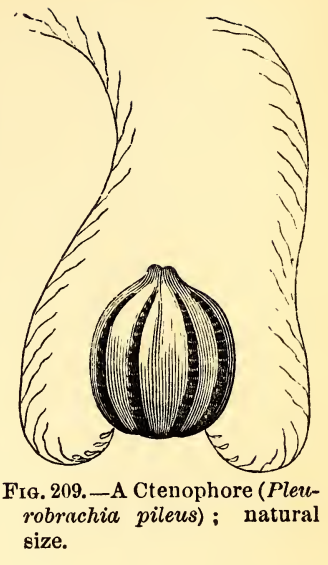
tem.

\section{Subkingdom III.-Echinodermata.}

The Echinoderms, as Star-fishes and Sea-urchins, are distinguished by the possession of a distinct nervous system (a ring around the mouth); an alimentary canal, com-

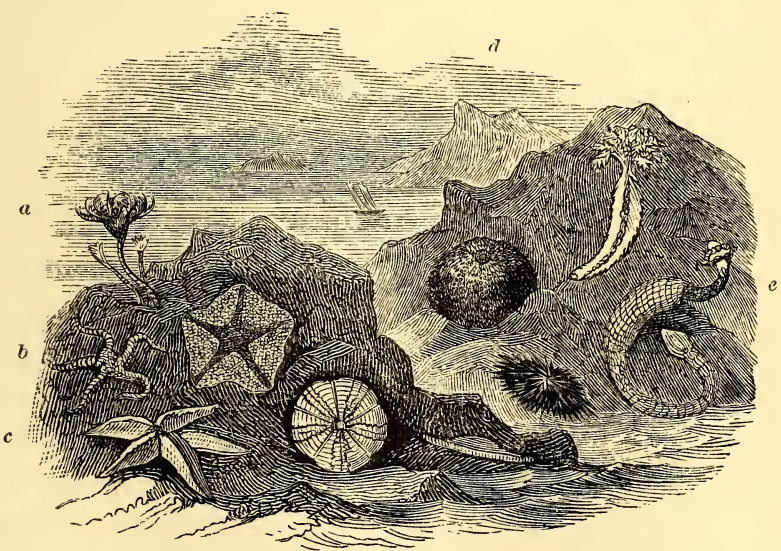

Frg. 210.-Forms of Echinoderms, from radiate to annulose type: $a$, Crinoids; $b$, Ophiurans ; $c$, Star-fish ; $d$, Echini; $e$, Holothurians.

pletely shut off from the body-cavity, and having both oral and anal apertures; a water-vascular systern of circu- 
lar and radiating canals, connected with the outside water by means of the madreporic tubercle, and a symmetrical arrangement of all the parts of the body around a central axis in multiples of five. ${ }^{133}$ There are four principal classes, all exclusively marine and solitary, and all having the power of secreting more or less calcareous matter.

\section{Class I.-Crinoidea.}

The Crinoids, or "Sea-lilies," are fixed to the sea-bottom by means of a hollow, jointed, flexible stem. On the top of the stem is the body proper, resembling a bud or expanded flower, containing the digestive apparatus, with the surrounding arms, or tentacles. The mouth looks upward. There is a complete skeleton for strength and support, the entire animal-body, arms, and stem-consisting of thousands of stellate pieces connected together by living matter. Crinoids were very abundant in the old geoologic seas, and many limestone strata were formed out of their remains. They are now nearly extinct: dredging in the deep parts of the oceans has brought to light a few living representatives.

\section{Class II.-Asteroidea.}

Ordinary Star-fishes consist of a flat central disk, with five or more arms, or lobes, radiating from it, and containing branches of the viscera. The skeleton is leathery, hardened by small calcareous plates (twelve thousand by calculation), but somewhat flexible. The mouth is below; and the rays are furrowed underneath, and pierced with numerous holes, through which pass the sucker-like tentacles-the organs of locomotion and prehension. The red spots at the ends of the rays are eyes. The usual color of Star-fishes is yellow, orange, or red. They abound on every shore, and are often seen at low tide half buried in the sand, or slowly gliding over the rocks. Cold fresh 


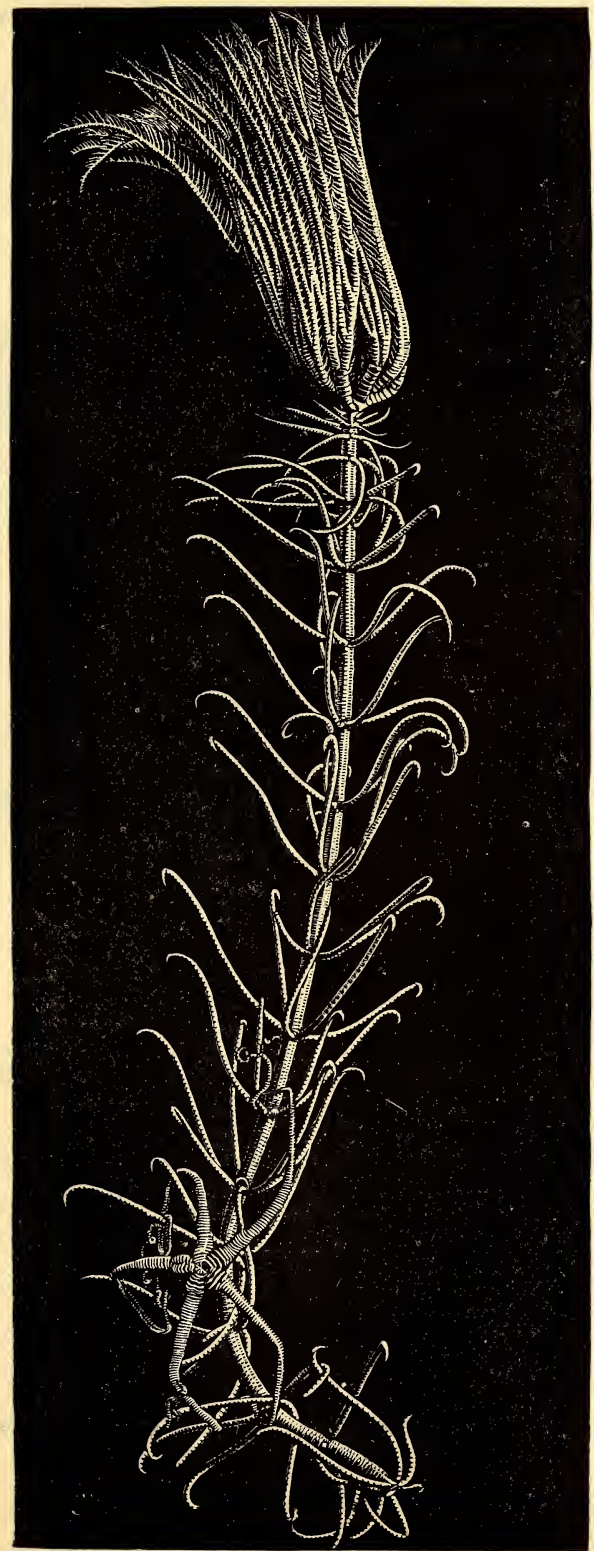

Fic. 211.-A living Crinoid (Pentacrinus asteria); one fourth natural size. West Indian Seas. 
water is instant death to them. They have the power of reproducing lost parts to a high degree. They are very voracious, and are the worst enemies of the Oyster.

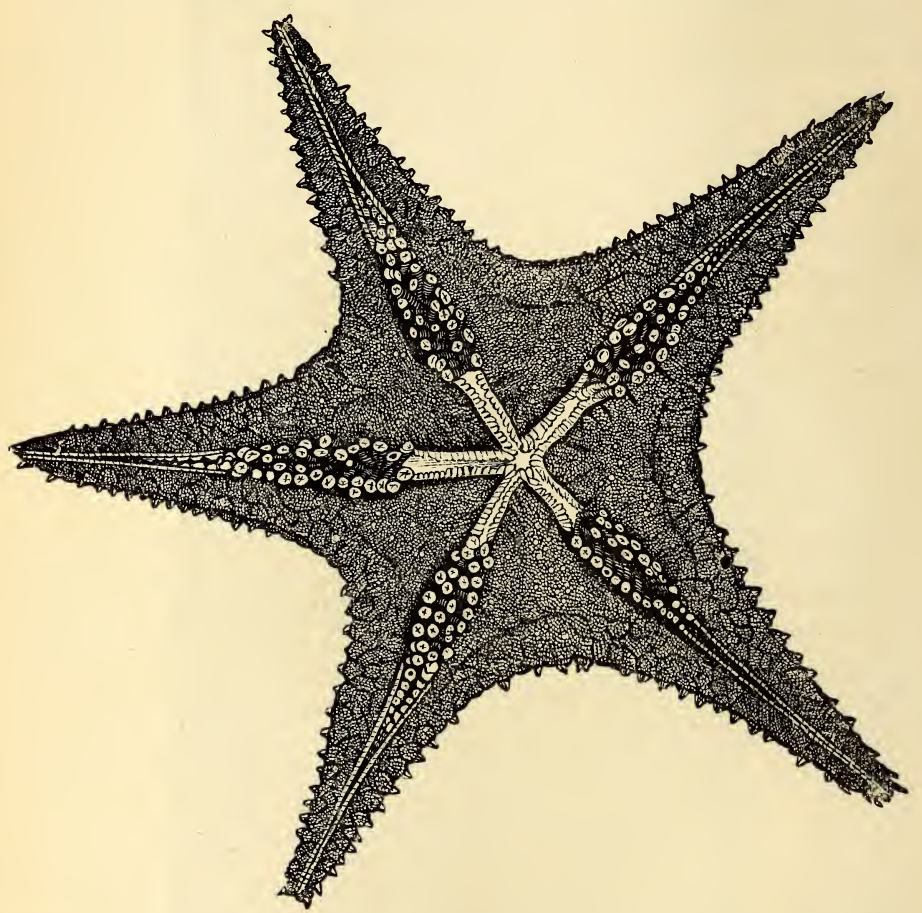

Fig. 212. - Under-surface of Star-fish (Goniaster reticulatus), showing ambulacral grooves and protruded suckers.

About one hundred and fifty species are known. These may be divided into three groups: (1) species having four rows of feet, represented by the common five-fingered Asterias ; (2) species having two rows of feet, as the manyrayed Solaster, or "Sun-star," and the pentagonal Goniaster; (3) species having long, slender arms, which are not prolongations of the body, and are not provided with suckers, as the Ophiura, or "Brittle-star," and Astrophyton, or "Basket-fish." The last are of inferior rank, and resemble 
inverted, stemless Crinoids. The digestive sac is confined to the disk, and the madreporic tubercle is concealed.

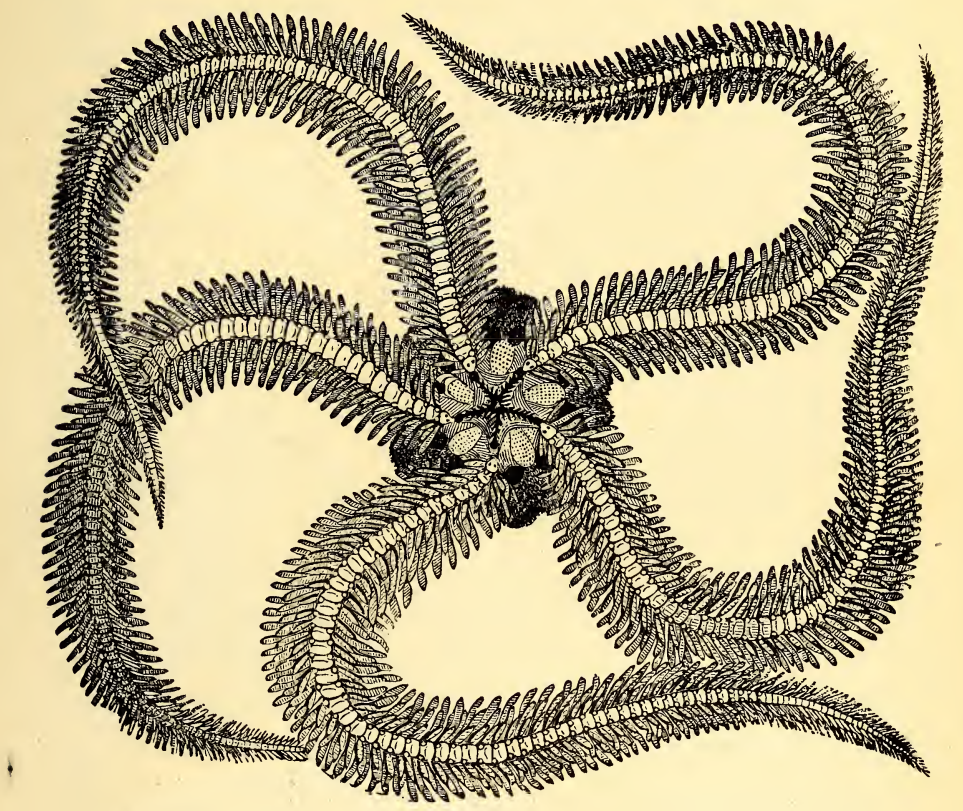

Fig. 213. - Ophiocoma Russei, an Ophiuran; natural size. West Indies.

\section{Class III.-Echinoidea.}

The Sea-urchin is encased in a thin, hollow shell covered with spines, and varying in shape from a sphere to a disk. ${ }^{134}$ The mouth is underneath, and contains a dental apparatus more complicated than that of any other creature. It leads to a digestive tube, which extends spirally to the summit of the body. The spines are for burrowing and locomotion, and are moved by small muscles, each being articulated by ball-and-socket joint to a distinct tubercle. When stripped of its spines, the shell (or "test") is seen to be formed of a multitude of pentagonal plates, fitted together like a mosaic. ${ }^{135}$ Five double rows of plates, 
passing from pole to pole, like the ribs of a melon, alternate with five other double rows. In one set, called the

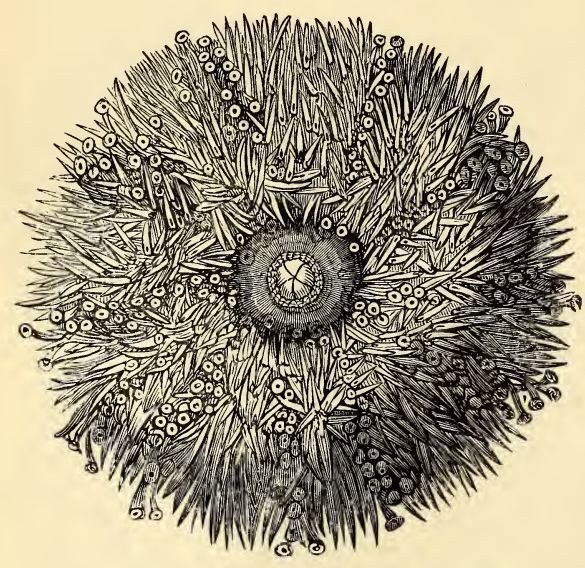

Fra. 214. -Under-surface of a Sea-urchin (Echinus escu. lentus), showing rows of suckers among the spines. British seas. ambulacra, the plates are perforated for the protrusion of tubular feet, or suckers, as in the Star-fish. So that altogether there are twenty series of platesten ambulacral, and ten interambulacral. The shell is not cast, but grows by the enlargement of each individual plate, and the addition of new ones around the month and the opposite pole. Every part of an Echinus, even sections of the spines, show the principle of radiation. If the upper surface of a Star-fish should shrink so as to bring the points of the arms to meet above the mouth, we should have a close imitation of a Sea-urchin. Echini live near the shore, in rocky holes or under sea-weed. They are less active than Star-fishes; but, like them, feed on Mollusks and Crabs. They reproduce by minute red eggs. Regular Echini, as the common Cidaris, are nearly globular, and the oral and anal openings are opposite. Irregular Echini, as the Clypeaster, are flat, and the anal orifice is near the margin.

\section{Class IV.-Holothuroidea.}

These worm-like "Sea-slugs," as they are called, have a soft, elongated body, with a tough, contractile skin contain- 
ing calcareous granules. One end, the head, is abruptly terminated, and has a simple aperture for a mouth, encircled with feathery tentacles. There are usually five longitudinal rows of ambulacral suckers, but only three are used for locomotion, of which one is more developed than the rest. The mouth opens into a pharynx leading to a long intestinal canal. Holothurians have the singular power of ejecting most of their internal organs, surviving

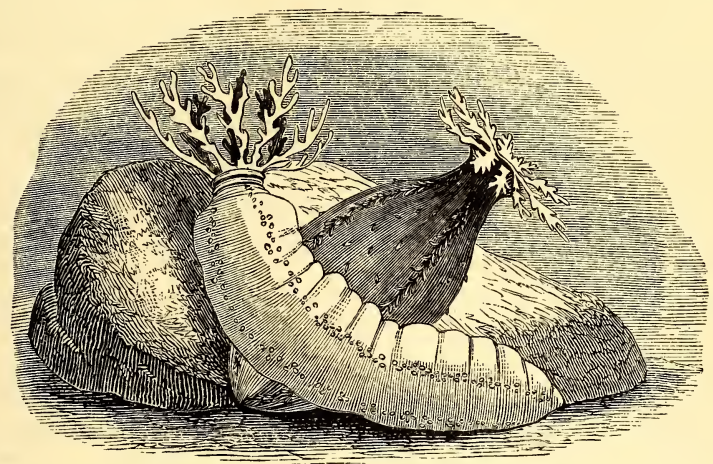

FIG. 215.-Sea-slugs (Holothuria).

for some time the loss of these essential parts, and afterwards reproducing them. They occur on nearly every coast, especially in tropical waters, where they sometimes attain the length of three or four feet. As found on the beach after a storm, or when the tide is out, they are leathery lumps, of a reddish, brownish, or yellowish color. They may be likened to a Sea-urchin devoid of a shell, and long drawn out, with the axis horizontal, instead of vertical.

\section{Subkingdom IV.-VERMES.}

The Vermes, ${ }^{136}$ or Worms, form the lowest subkingdom of the bilaterally symmetrical animals. The group includes animals very different in form and rank, and the different classes are widely separated from each other. 
It has also close relations with the other subkingdoms of the bilaterally symmetrical animals. Through the Polyzoa and Brachiopoda, it approaches the Mollusca; through the Annelides, the Arthropoda; and through other forms, the Tunicata, and so the Vertebrata. The subkingdom thus stands in the centre of several subkingdoms, with affinities towards all. Nor are indications of connection with Cœlenterata and Echinodermata wanting.

The Vermes are bilaterally symmetrical animals, with one or many segments, no jointed legs. They usually have a soft skin, and peculiar excretory organs-the segmental organs.

Many of the Worms are parasitic, and most of the Endoparasites belong to this group.

There are numerous classes, of which only the most important are mentioned.

Class I.-Platyhelminthes.

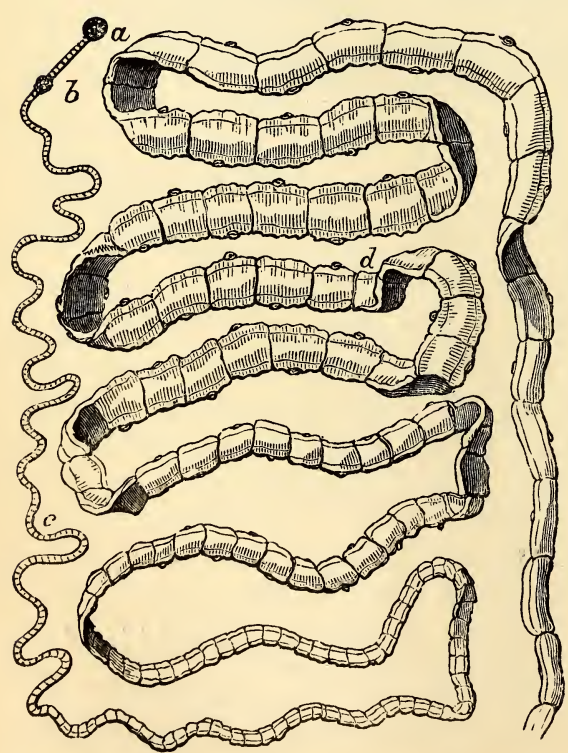

Fic. 216.-Tape-worm (Tonia solium) : $a$, head; $b, c$, $d$, segments of the body.

The Flat-worms include some free forms, as the Planaria, common in fresh water, and the Tapeworms and Flukes among the parasites.

The Tape-worm consists of the socalled head-the proper worm - and the body segments,

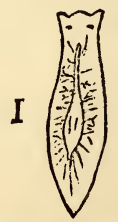

Fra. 217.-Planarian worm. 
which are really reproductive joints. It develops from the egg in the digestive canal of the Pig, burrows into the cellular tissue of the animal, and there becomes encased. It thus causes the disease "measles." If the pork be eaten by man, in an uncooked condition, this case is dissolved by the gastric juice, and the embryo develops into the Tape-worm, attaching itself to the intestine by its "head," and budding off the reproductive segments. As these become ripe and filled with fertilized eggs, they are detached, and pass off with the excrement.

The disease called "rot," in Sheep, is produced by the Fluke (Distoma), a member of this class.

\section{CLASS II.-Nematelminthes.}

The Round, or Thread, Worms include free forms, as the Vinegar-eel; parasitic forms, as the Pin-worm and Trichina; and forms free when adult, and parasitic when young, as the Hair-worm (Gordius).

The Trichina is usually derived by Man from the flesh of the Pig. It exists in the muscles, enclosed in microscopic cases. If the meat be eaten uncooked or partially cooked, the cases are dissolved, and the Trichinæ become sexually mature in the intestines. The young are produced and bur-Fra. 218.-Trichina spiralis: I, male; $a$, mouth; row their way into the $c$, intestine; II, caps

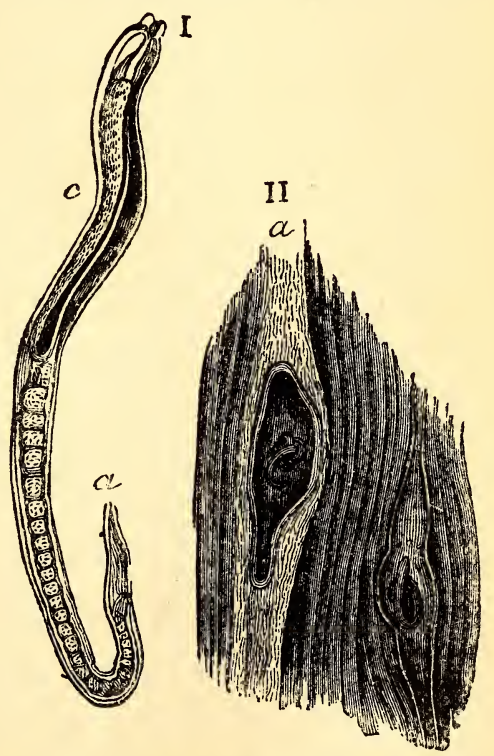
$c$, intestine; II, capsules, with Trichinæ in mus- 
muscles, where they become encysted. In burrowing, they cause great pain and fever, and sometimes death. The adult Worm is about $\frac{1}{12}$ inch long.

\section{Class III.-Rotifera.}

The Wheel-animalcules, mostly found in fresh water, are minute Worms of few segments, having on the ante-

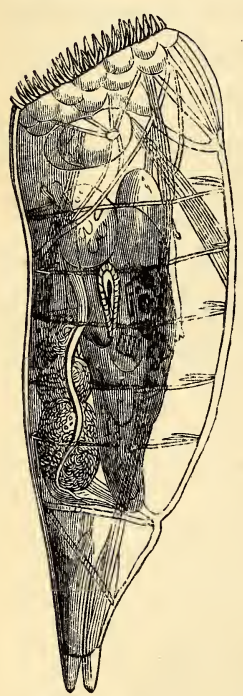
rior end a disk ciliated on the edge, whence their name. They are from $\frac{1}{200}$ to $\frac{1}{36}$ of an inch long. They can bear drying and revivifying, like seeds.

Class IV.-Polyzoa.

These minute Worms resemble the Polyps in appearance, living in clusters, each individual inhabiting a delicate cell, or tube, and having a simple mouth surrounded with ciliated tentacles. The colony often takes a plant-like form; sometimes spreads, like fairy - chains or lace-work, over other bodies; or covers rocks and sea-weeds in patches with a delicate film. The majority secrete carFra. 219. - Rotifer, or bonate of lime. A Polyzoan shows its su"Wheel-animalcule" (Hydatina), highly periority to the Coral, which it imitates, magnified.

in possessing a distinct alimentary canal and a well-defined nervous system. The cells of a group never have connection with a common tube, as in Cœlenterates. There are both marine and fresh-water species.

This group and the next following are related to the Mollusca.

\section{Class V.-Brachiopoda.}

These Worms have a bivalve shell, the valves being applied to the dorsal and ventral sides of the body. The valves are unequal, the ventral being usually larger, and 


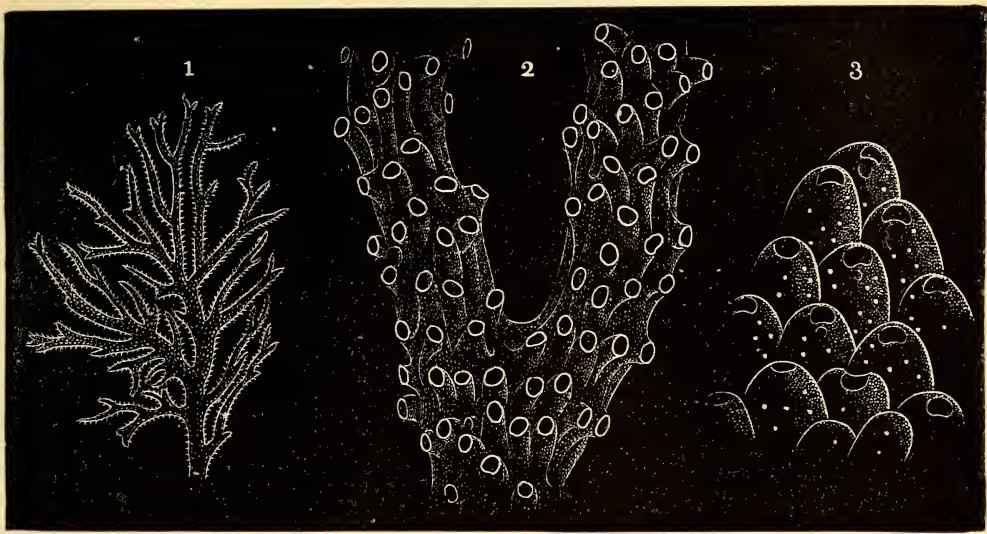

Fig. 220.-Polyzoans: 1. Hornera lichenoides, natural size. 2. Branch of the same, magnified. 3. Discopora Skenei, greatly enlarged.

more convex; but they are symmetrical, $i$. e., a vertical line let fall from the hinge divides the shell into two equal parts. The ventral valve has, in the great majority, a prominent beak, perforated by a foramen, or hole, through which a fleshy foot protrudes to attach the animal to submarine rocks. The valves are opened and shut by means of muscles, and in most cases they are hinged, having teeth and sockets

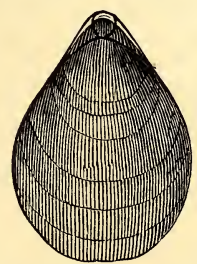

Fra. 221. - A Brachiopod (Terebratulina septentrionalis). Atlantic coast.

near the beak. The mouth faces the middle of the margin opposite the beak; and on either side of it is a long,

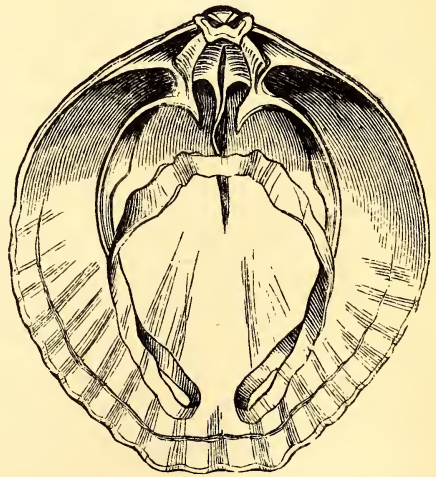

Fic. 222.-Dorsal Valve of a Brachiopod (Terebratula), showing, in descending order, cardinal process, dental sockets, hinge-plate, septum, and loop supporting the ciliated arms. 
fringed "arm," generally coiled up, and supported by a calcareous framework. The animal, having no gills, respires by the arms and the mantle. Brachiopods were once very abundant, over two thousand extinct species having been described; but less than a hundred species are now living. ${ }^{137}$ They are all marine, and fixed; but of all Worms, they enjoy the greatest range of climate and depth.

\section{Class VI.-Annelides.}

The Annelides include the highest and most specialized Worms. They have many segments, spines or suckers for locomotion, a superœsophageal brain, a ventral chain

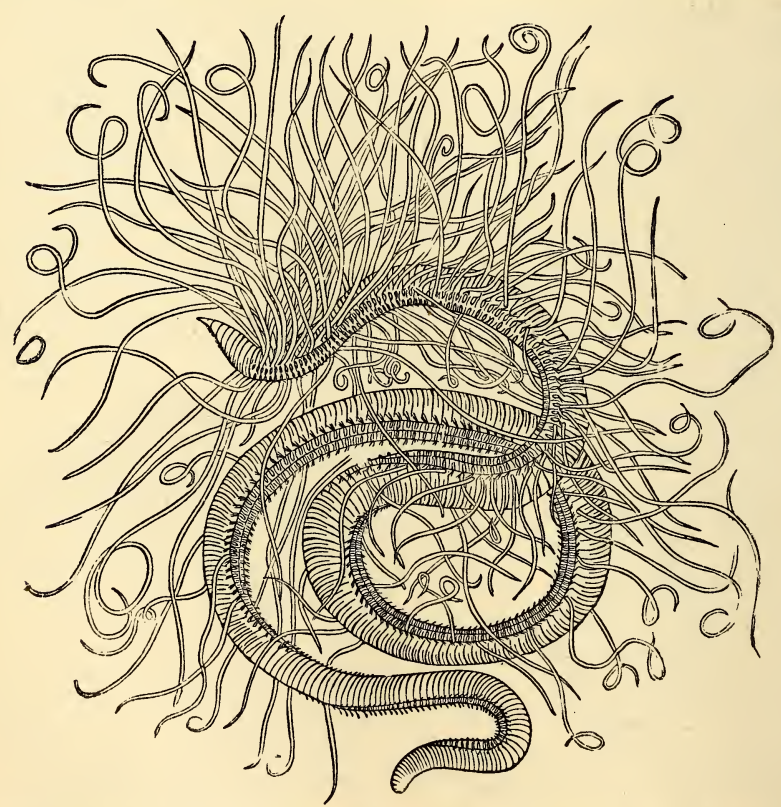

Frg. 223.-Marine Worm (Cirratulus grandis), with extended cirri. Atlantic.

of ganglia, and a closed blood-system. There are three main divisions: the flattened Leeches, without definite segments or bristles, and with suckers for locomotion; the 
Earth-worms and their allies, which have few bristles on each segment (Oligochoetce); and the Sea-worms, with numerous bristles, arranged in two clusters on each side of each segment (Polychoetoe).

These last are the largest of the Worms, and may have a distinct head, bearing tentacles and eyes. The cesophagus is often turned in, so as to form a proboscis, which bears horny jaws, and can be protruded at the will of the animal (Fig. 17).

\section{Subkingdom V.-Mollusca.}

A Mollusk is a soft-bodied animal, without internal skeleton, and without joints, covered with a moist, sensitive, contractile skin, which, like a mantle, loosely envelops the creature. In some cases the skin is naked, but generally it is protected by a calcareous covering (shell). The length of the body is less in proportion to its bulk than in other animals. The lower class has no distinct head. The nervous system consists of three well-developed pairs of ganglia, which are principally concentrated around the entrance to the alimentary canal, forming a ring around the throat. The other ganglia are, in most cases, scattered irregularly through the body, and in such the body is unsymmetrical. The digestive system is greatly developed, especially the liver, as in most aquatic animals. Except in the Cephalopods, the muscles are attached to the skin, or shell. There is a heart of two chambers (auricle and ventricle) or three (two auricles and ventricle). As in all Invertebrates, the heart is arterial. In Mollusks, with rare exceptions, we find no repetition of parts along the antero-posterior axis. They are best regarded as Worms of few segments, which are fused together and much developed. The total number of living species probably exceeds twenty thousand. The great majority are water-breathers, and marine; some are 
fluviatile or lacustrine, and a few are terrestrial air-breathers. All bivalves, and nearly all univalves, are aquatic. Each zone of depth in the sea has its particular species.

\section{Class I.-Lamellibranchiata.}

Lamellibranchs are all ordinary bivalves, as the Oyster and Clam. The shells differ from those of Brachiopods

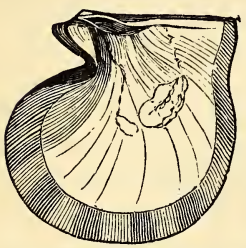

Fig. 224.-Pearl Oyster (Meleagrina margariti: fera) ; one fourth natural size. Ceylon. in being placed on the right and left sides of the body, so that the hinge is on the back of the animal, and in being unequilateral and equivalved. ${ }^{138}$ The umbo, or beak, is the point from which the growth of the valve commences. Both Brachiopods and Lamellibranchs are headless; but in the latter the mouth points the same way as the umbo, i. e., towards the anterior part. The length of the shell is measured from its anterior to its posterior margin, and its breadth from the dorsal side, where the hinge is, to the opposite, or ventral, edge. The valves are united to the animal by one muscle (as in the Oyster), or two (as in the Clam), and to each other by a hinge. In some species, as some freshwater Mussels, the hinge is simply an elastic ligament, passing on the outside from one valve to the other just behind the beak, so that it is on the stretch when the valves are closed, and another placed between the edges of the valves, so that it is squeezed as they shut, like the spring

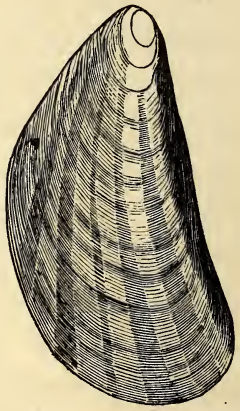

Fig. 225. - Salt - water Mussel (Mytilus pellucidus). Atlantic coasts.

in a watch-case. Such bivalves are said to be edentulous. But in the majority, as the Clam, the valves also articulate by interlocking parts called teeth. The valves are, therefore, opened by the ligaments, and closed by the muscles. 
The margin of the shell on which the ligament and teeth are situated is termed the hinge-line.

Lamellibranchs breathe by four plate-like gills (whence the name), two on each side underneath the mantle (Fig. 78). In the higher forms, the mantle is rolled up into two tubes, or siphons, for the inhalation and exhalation of water. They feed on infusorial particles filtered from the water. A few are fixed; the Oyster, e.g., habitually lying

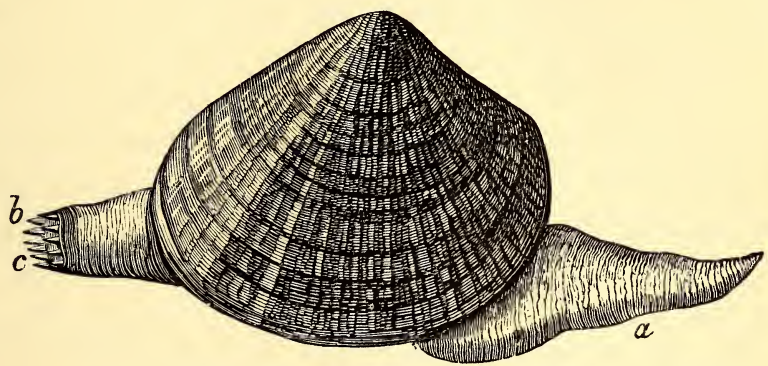

Fia. 226. -Lamellibranch (Mactra) : $a$, foot; $b, c$, siphons.

on its left valve, and the Salt-water Mussel hanging to the rocks by a cord of threads called "byssus ;" but most have a "foot," by which they creep about. Unlike the Oyster, also, the majority live in an erect position, resting on the edges of their shells. Over four thousand living species are known. These are fresh-water and marine, and range from the shore to a depth of a thousand feet. .

The chief characters for distinguishing Lamellibranchs are the muscular impressions, ${ }^{139}$ whether one or two; the presence of a pallial sinus, which indicates the possession of siphons; the structure of the hinge, and the symmetry of the valves.

The following are the leading types of structure, as shown by the shells:

1. Monomya: with one adductor muscle; no siphons; foot wanting, or very small; shell unequivalve and eden- 
tulous-as the Oyster (Ostrea), Scallop (Pecten), and Pearl Oyster (Avicula).

2. Heteromya: with two unequal adductor muscles and

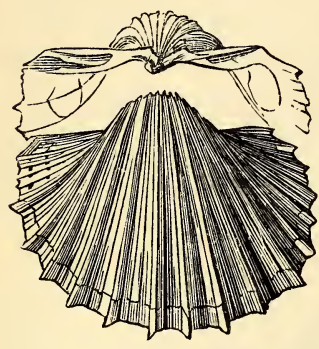

Fıg. 227.-Cockle (Cardium costutum); one third natural size. China seas. no siphons-as the Sea-mussel ( $M y$ tilus).

3. Isomya: with two equal adductor muscles. There are two sections of this order: $a$. Those with no siphons, and hence no pallial sinus - as the Fresh - water Mussel (Unio), Cockle (Cardium), and "the giant of the bivalve race" (Tridac$n e)$. b. Those with siphons and pallial sinus-as the common Clam (Mya), Quohog (Venus), and Razor-shell (Solen). ${ }^{140}$

\section{Class II.-Gasteropoda.}

The Snails are, with rare exceptions, all univalves. ${ }^{141}$ The body is coiled up in a conical shell, which is usually

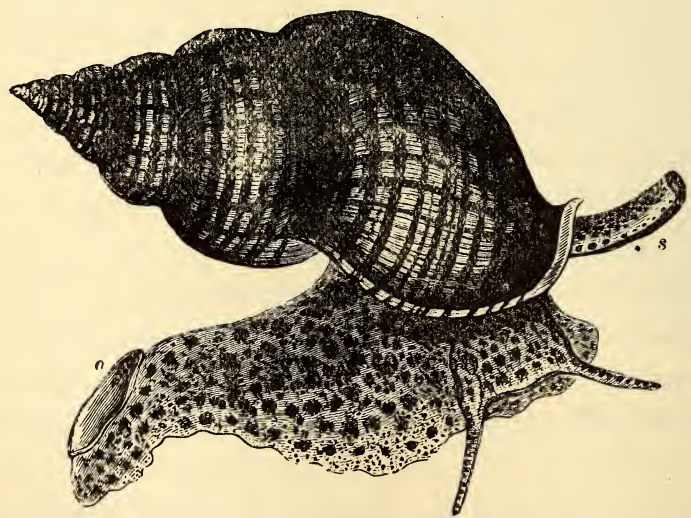

Fig. 228.-Whelk (Buccinum), showing operculum, 0 , and siphon, 8 .

spiral, the whorls passing obliquely (and generally from right to left), ${ }^{142}$ around a central axis, or "columella." 
When the columella is hollow (perforated), the end is called the "umbilicus." When the whorls are coiled around the axis in the same plane, we have a discoidal shell, as the Planorbis. The mouth, or "aperture," of the shell is "entire" in most vegetable-feeding Snails, and notched or produced into a canal for the siphons in the carnivorous species. The former are generally land and fresh-water forms, and the latter all marine. In some Gasteropods, as the River-snails and most Sea-snails, a horny or calcareous plate (operculum) is secreted on the foot, which closes the aperture when the animal withdraws into its shell. In locomotion, the shell is carried with the apex directed backward.

The body of most Gasteropods is unsymmetrical, the organs not being in pairs, but single, and on one side, instead of central. The mantle is continuous around the body, not bilobed, as in Lamellibranchs. A few, as the common Garden-snail, have a lung; but the vast majority breathe by gills. The head is more or less distinct, and provided with two tentacles, with auditory sacs at their bases; two eyes, which are often on stalks; and a straplike tongue covered with minute teeth. The heart is situated, in the majority, on the right side of the back, and has two cavities. The nervous ganglia are united into an œsophageal ring or collar. All, except the Pteropods, move by means of a ventral disk or foot.

Gasteropods are now the reigning Mollusks, comprising three fourths of all the living species, and are the types of the subkingdom. They have an extraordinary range in latitude, altitude, and depth.

Omitting a few rare and aberrant forms, we may separate the class into the following orders:

1. Pteropods.-These are small, marine, floating Mollusks, whose main organs of motion resemble a pair of wings or fins coming out of the neck, whence the com- 
Inon name, "Sea-butterflies." Many have a delicate, transparent shell. The head has six appendages, armed

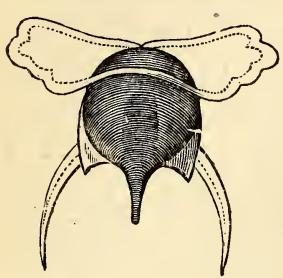

Fig. 229. - A Pteropod ( $H y$ alea tridentata). Atlantic. with several hundred thousand microscopic suckers - a prehensile apparatus unequalled in complication. Pteropods occur in every latitude, but generally in mid-ocean, and in the arctic regions are the food of Whales and Sea-birds.

2. Opisthobranchs.-These low GasSea-slugs, a few only having a small shell. The feathery gills are behind the heart (whence the naine). They are found in all seas, from the arctic to the torrid, generally on rocky coasts. When disturbed, most of them draw themselves up into a lump of jelly or tough skin.

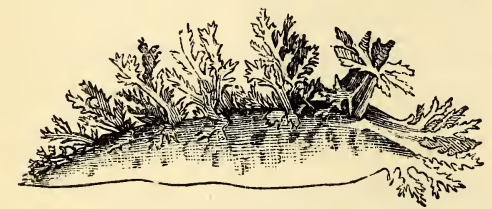

Fig. 230.-A Tritonian (Dendronotus arborescens). British seas.

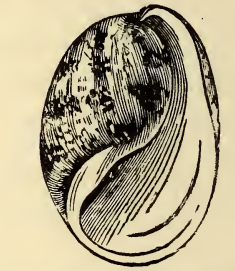

Frg. 231.-Bulla ampul$l a$, or "Bubble-shell ;" three fourths natural size. Indian Ocean

Examples: Sea-lemon (Doris), the beautiful Tritonia, the painted Aolis, the Sea-hare (Aplysia), which discharges a purple fluid, and the Bubble-shell (Bulla).

3. Pulmonates.-These air-breathing Gasteropods, represented by the familiar Snail, have the simplest form of lung-a cavity lined with a delicate net-work of bloodvessels, which opens externally on the right side of the neck. This is the mantle-cavity. The entrance is closed by a valve, to shut out the water in the aquatic tribes, and the hot, dry air of summer days in the land species. They are all fond of moisture, and are more or less slimy. Their shells are lighter (being thinner, and containing less 
earthy matter) than those of marine Mollusks, having to be carried on the back without the support of the water.

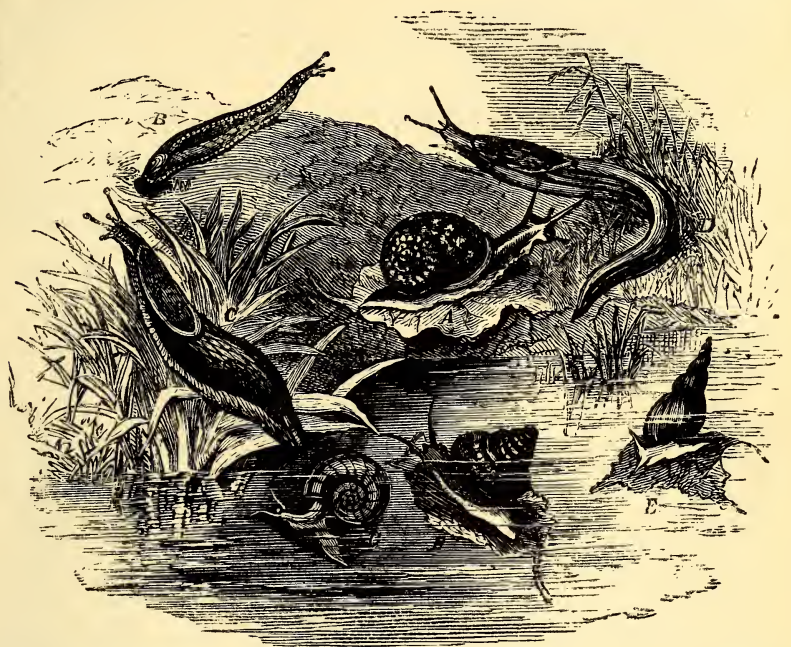

Fig. 232- $A$, Land-snail (Helix); $B, C, D$, Slugs (Limax); $E, F, G$, Pond-snails (Limnoea, Paludina, and Planorbis).

Their eggs are laid singly, while the eggs of other orders are laid in chains.

They are found in all zones, but are most numerous where lime and moisture abound. All feed on vegetable matter. A few are naked, as the Slug; some are terrestrial; others live in fresh water. The Land - snails, represented by the common Helix, the gigantic Bulimus, and the Slug (Limax), are distinguished by their four "horns," the short front pair being the true tentacles, and the long hinder pair being the eye-stumps. They have a saw-like upper jaw for

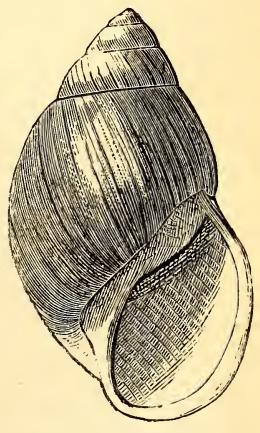

Frg. 233.-Bulimus oblongus; one half natural size. Guiana. biting leaves, and a short tongue covered with minute teeth. The Pond-snails, as Limnoea and Planorbis, differ 


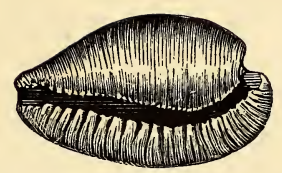

Fig. 234.-Cowry (Cyproea capensis); two thirds natural size. South Africa.

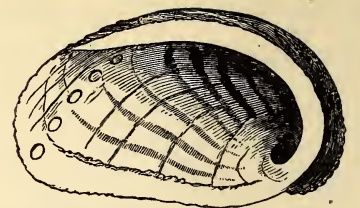

Frg. 235.-Haliotis, or " Pearly Earshell." Pacific coasts.

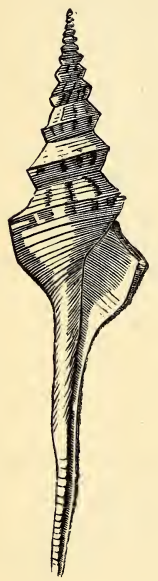

Fig. 236. - Spindleshell (Fusus colus): one half natural size. Ceylon.

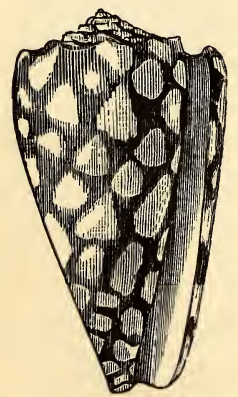

Fig. 239.-Cone-shell (Conus marmoreus); two thirds natural size. China seas.

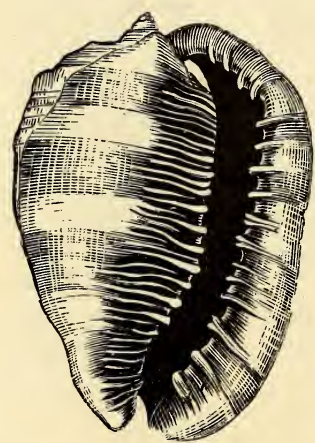

Fig. 237. - Cassis rufa, or "Helmet-shell;" one fourth natural size. Indian Ocean.

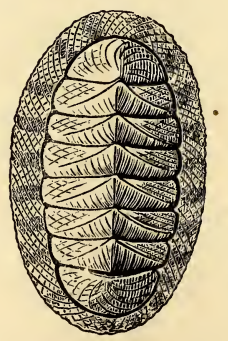

Frg. 240.-Chiton squamosus; one half natural size. West Indies.

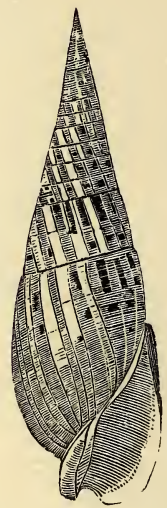

Fig. 233.-Auger-shell (Terebra maculata): one half natural size. China seas.

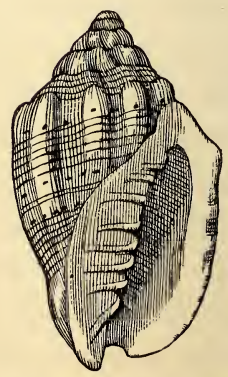

Fig. 241.-Volute (Voluta musica); one half natural size. West Indies. 


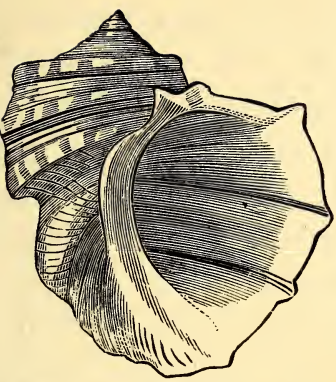

Fig. 242. - Top-shell (Turbo marmoratus); one fourth natural size. China seas.

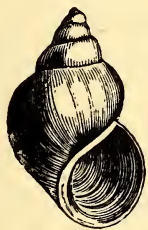

Fra. 244. - Paludina, a Fresh-water Snail.

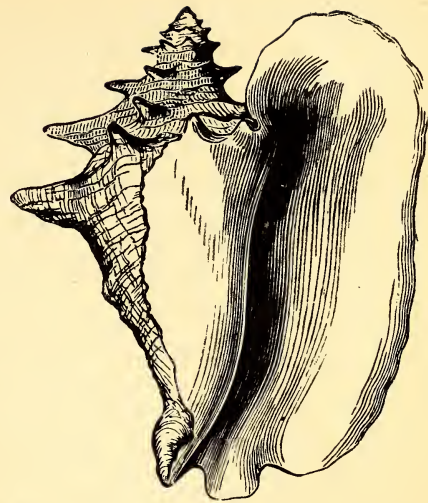

Fra. 243.-Strombus gigas, or "Wingedshell;" one fifth natural size. West Indies.

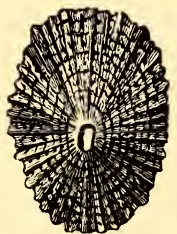

Frg. 245. - Key-hole Limpet (Fissurella listeri). West Indies.

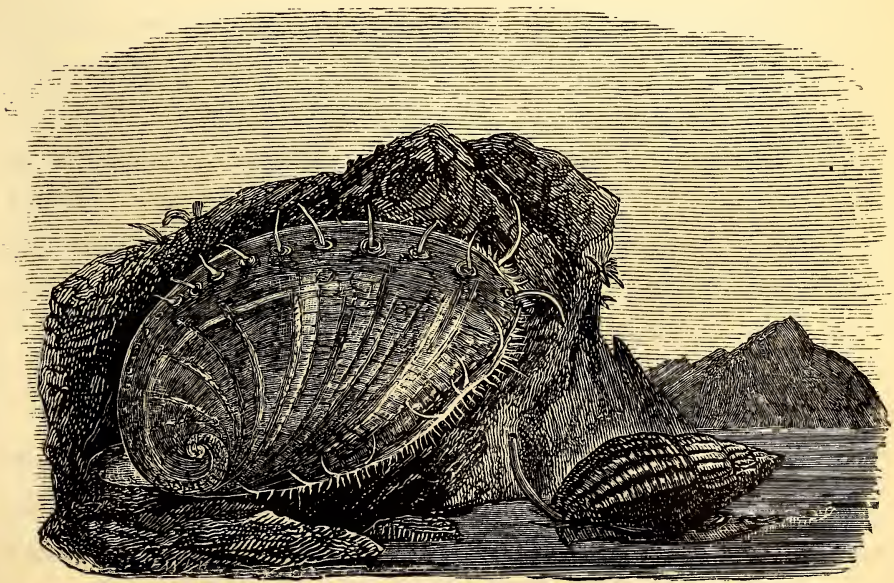

Fig. 246. - Ear-shell (H. tuberculata), and Dog-whelk (Nassa reticulata). England. 
in having no eye-stalks, the eyes being at the base of the tentacles. They are obliged to come frequently to the surface of the water to breathe.

4. Prosobranchs. - These are aquatic Gasteropods, breathing by gills situated in front of the heart. They are the most highly organized and the most abundant of the crawling Mollusks. Nearly all are marine, and all have a shell.

Among the lower forms are the singular Chiton, covered with eight shelly plates; Limpet (Patella), well known to every sea-side visitor; and the beantiful Earshell (Haliotis), frequently used for ornaments and inlaidwork.

In the higher Prosobranchs, the gills are comb-shaped and the sexes are distinct. The group includes all the spiral nnivalve sea-shells, and a few fresh-water shells. Many have the aperture entire, which is closed with an operculum: as the dull-colored Paludina and Melania from fresh water, and the pyramidal Trochus, pearly Turbo, screw-like Turritella, common Periwinkle (Littorina), and globular Natica from the sea. Others, the highest of the race, have the margin of the aperture notched or produced into a canal, and are carnivorous and marine: such are nearly all the sea-shells remarkable for their beautiful forms, enamelled surfaces, and brilliant tints, as the Cowry (Cyprcea), Volute, Olive, Cone, Harp, Whelk (Buccinum), Cameo-shell (Cassis), Rock - shell (Murex), Truinpet-shell (Triton), Spindle-shell (Fusus), and Wingshell (Strombus).

\section{Class III.-Cephalopoda.}

The Cephalopods stand at the head of the subkingdom. The head is set off from the body by a slight constriction, and furnished with a pair of large, staring eyes, a mouth armed with a rasping tongue and a parrot-like beak, and 
eight or more tentacles or arms. The body is symmetrical, and wrapped in a muscular mantle.

The nervous system is more concentrated than in other Invertebrates; the cerebral ganglia are partly enclosed in a cartilaginous cranium. All the five senses are present. The class is entirely marine (breathing by plume-like gills on the sides of the body), and carnivorous. The naked species are found in every sea. Those with chambered shells (as Nautilus, Ammonites, and Orthoceras) were once. very abundant: more than two thousand fossil species are known, but only one living representative - the Pearly Nautilus.

1. Tetrabranchs. - This order is characterized by the possession of four gills, forty or more short tentacles, and an external, chambered shell. The partitions, or septa, of the shell are united by a tube called "siphuncle," and the

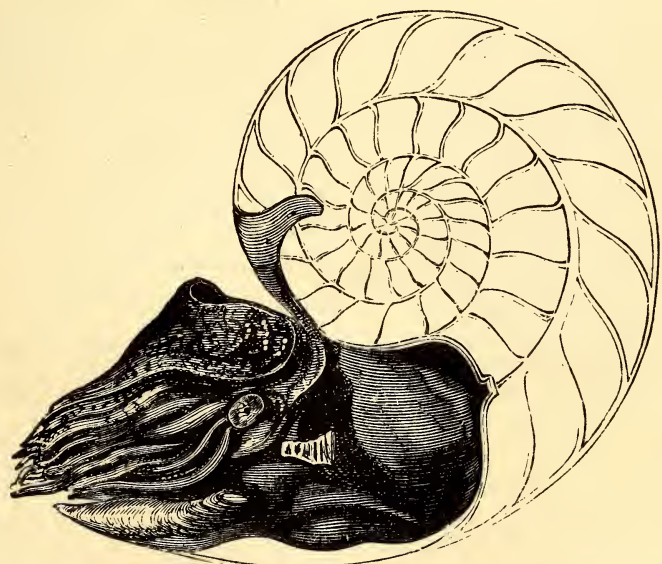

Fig. 247.-Pearly Nautilus, witn shell bisected; one half natural size. Indian Ocean.

animal lives in the last and largest chamber. ${ }^{143}$ The living Nautilus has a smooth, pearly shell, a head retractile within the mantle or "hood," and calcareous mandibles, well fitted for masticating Crabs, on which it feeds. This 
straggler of a mighty race dwells in the deep parts of the Indian Ocean, crawling on the bottom; and, while the shell is well known, only a few specimens of the animal have ever been obtained.

2. Dibranchs.-These are the most active of Mollusks, and the tyrants of the lower tribes. Among them are the largest of invertebrate animals. They are naked, having no external shell covering the body, but usually a horny or calcareous part within. They have a distinct

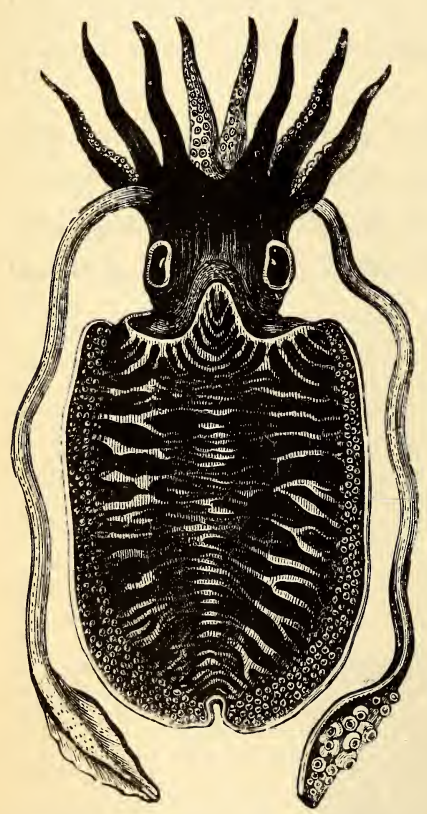

Fra. 248. -Cuttle-fish (Sepia officinalis); one fifth natural size. Atlantic coasts. head, prominent eyes, horny mandibles, eight or ten arms furnished with suckers, two gills, a complete tubular funnel, and an ink-bag containing a peculiar fluid (sepia), of intense blackness, with which. the water is darkened to facilitate escape. They have the power of changing color, like the Chameleon. They crawl with their arms on the bottom of the sea, head downward, and also swim backward or forward, usually with the back downward, by means of fins, or squirt themselves backward by forcing water forward through their breathing funnels.

The Paper Nautilus ( $A r$ gonauta) and the Poulpe (Octopus) have eight arms. The female Argonaut secretes a thin, unchambered shell for carrying its eggs. The Squid (Loligo) and Cuttle-fish (Sepia) have ten arms, the additional pair being much longer than the others. Their eyes are movable, while 
those of the Argonaut and Poulpe are fixed. The Squid, so much used for bait by cod-fishermen, has an internal horny "pen," and the Cuttle has a spongy, calcareous "bone." The extinct Belemnite had a similar structure.

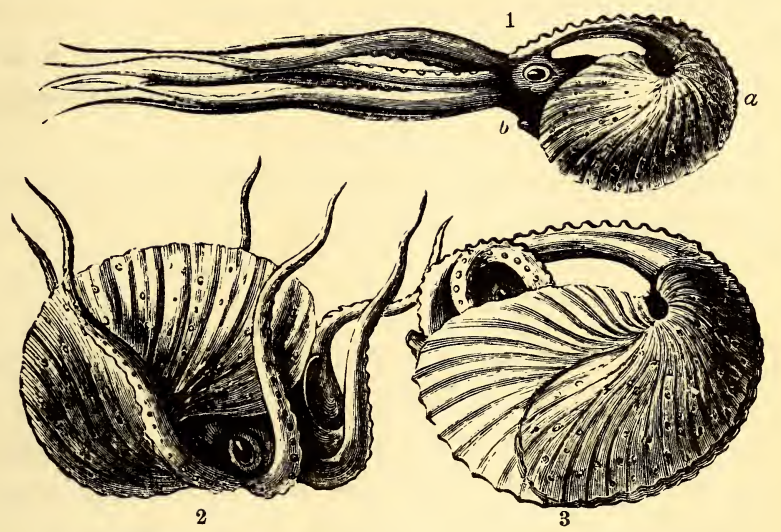

Fia. 249.-Paper Nautilus (Argonauta argo): 1, swimming towards $a$ by ejecting water from funnel, $b ; 2$, crawling on the bottom; 3 , coiled within its shell, which is one fourth natural size. Mediterranean.

Squid have been found with a body seven feet and arms twenty-four feet long, and parts of others still larger-as much as fifty feet in total length.

\section{Subkingdom VI.-ARTHROPODA.}

This is larger than all the other subkingdoms put together, as it includes the animals with jointed legs, such as Crabs and Insects. These differ widely from the Molluscan type in having numerous segments, and in showing a repetition of similar parts; and from the Worms in having a definite number of segments and jointed legs.

The skeleton is outside, and consists of articulated segments or rings. The limbs, when present, are likewise jointed and hollow. The jaws move from side to side. The nervous system consists mainly of a double chain of 
ganglia running along the ventral surface of the body under the alimentary canal. The brain is in the form of a ring encircling the gullet. The alimentary canal and the circulatory apparatus are nearly straight tubes lying lengthwise - the one through the centre, and the other along the back. The skeleton is composed of a horny substance (chitine), or of this substance with carbonate of lime. All the muscles are striated.

There are four classes, of which the first is water-breathing, and the others air-breathing.

\section{Class I.-Crustacea.}

The Crustacea ${ }^{144}$ are water-breathing Arthropoda, usually with two pairs of antennæ. ${ }^{145}$ Among them are the largest, strongest, and most voracions of the subkingdom, armed with powerful claws and a hard cuirass bristling with spines. Although constructed on a common type, Crustaceans exhibit a wonderful diversity of external form: contrast, for example, a Barnacle and a Crab. We will select the Lobster as illustrative of the entire group.

A typical Crustacean consists of twenty-one segments, of which seven belong to the head, seven to the thorax, and seven to the abdomen. ${ }^{146}$ In the Lobster, however, as in all the higher forms, the joints of the head and thorax are welded together into a single crust, called the cephalo-thorax. On the front of this shield is a pointed process, or rostrum; and attached to the last joint of the abdomen (the so-called "tail") is the sole representative of a tail-the telson. This skeleton is a mixture of chitine and calcareous matter. ${ }^{147}$

On the under-side of the body we find numerous appendages, feelers, jaws, claws, and legs beneath the cephalo-thorax, and flat swimmerets under the abdomen. In fact, as a rule, every segment carries a pair of movable appendages. The seven segments of the head are com- 
pressed into a very small space, yet have the following members: the eye-stalks; the short and the long antennæ; the mandibles, or jaws, between which the mouth opens; the two pairs of maxillæ; and a pair of modified limbs, called "foot-jaws." The thorax carries two more pairs of foot-jaws and five pairs of legs. The foremost legs, "the great claws," are extraordinarily developed, and terminated by strong pincers (chelce). Of the four slender pairs succeeding, two are furnished with claws, and two are pointed. The last pair of swimmerets, together with the telson, form the caudal finthe main instrument of locomotion; the others (called "false feet") are used by the female for carrying her eggs. The eyes are raised on stalks so as to be movable (since the head is fixed to the thorax), and are compound, made up of about two

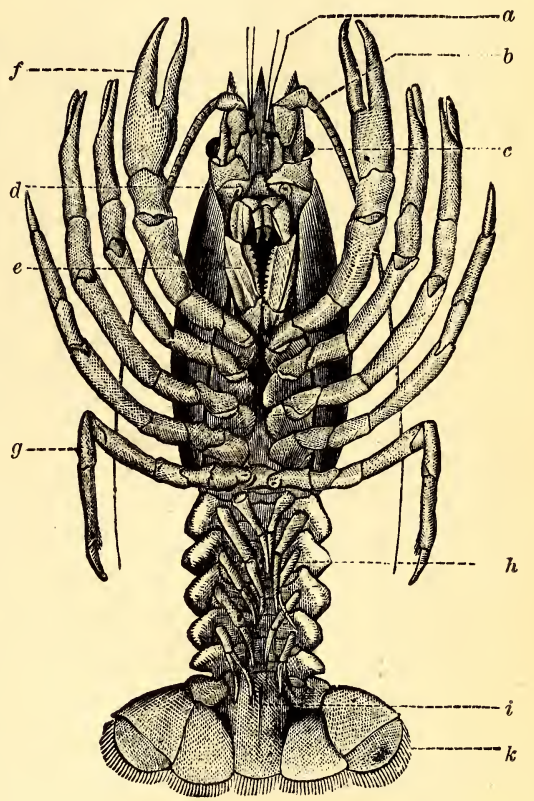

Fig. 250. -Under-side of the Cray-fish, or Freshwater Lobster (A stacus fluviatilis) : $a$, first pair of antennæ; $b$, second pair, $c$, eyes; $d$, opening of kidney; $e$, foot-jaws; $f, g$, first and fifth pair of thoracic legs; $h$, abdominal feet; $i$, anus; $k$, caudal fin.

thousand five hundred square facets. At the base of each small antenna is a minute sac, whose month is guarded by hairs: this is the organ of hearing. The gills, twenty on a side, are situated at the bases of the legs and enclosed in two chambers, into which water is freely admitted, in fact, drawn, by means of a curious attachment to one of the 
maxillæ, which works like the "screw" of a propeller. The heart is a single oval cavity, and drives arterial blood -a dusky fluid full of corpuscles. The alimentary canal consists of a short gullet, a gizzard-like stomach, and a straight intestine.

Crustaceans pass through a series of strange metamorphoses before reaching their adult form. They also periodically cast the shell, or moult, every part of the integument being renewed; and another remarkable endowment is the spontaneous rejection of limbs and their complete

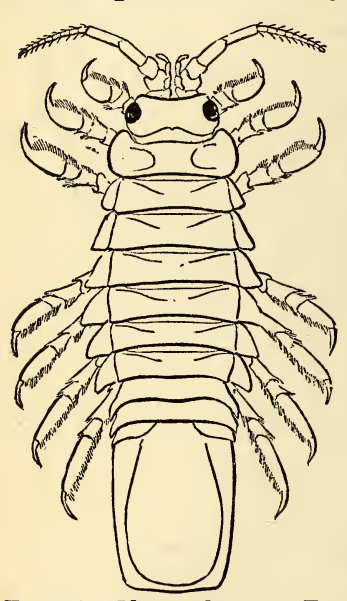

Fig. 251.-1dotea robusta: a Tetradecapod. U.S. coast. restoration. Many species are found in fresh water, but the class is essentially marine and carnivorous.

Of the numerous orders of this great class we will mention only four :

1. Cirripeds, distinguished by being fixed, by having a shelly covering, and by their feathery arms (cirri). Such are Barnacles (Lepas) and Acorn-shells(Balanus), so cornmon on rocks and timbers by the sea-shore.

2. Entomostracans, which agree in having a horny shell and no abdominal limbs; represented by the little Water-fleas (Cyclops) of our ponds, and

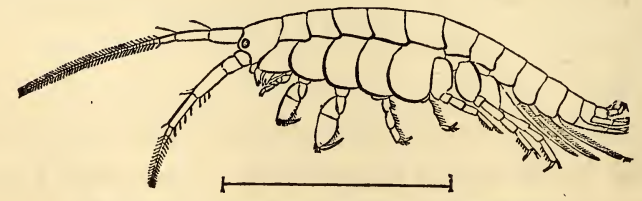

Fic. 252.-Amphithoë maculata: a Sand-flea.

the Brine-shrimps (Artemia), and many others. The Kingcrabs (Limulus) and the extinct Trilobites were formerly 


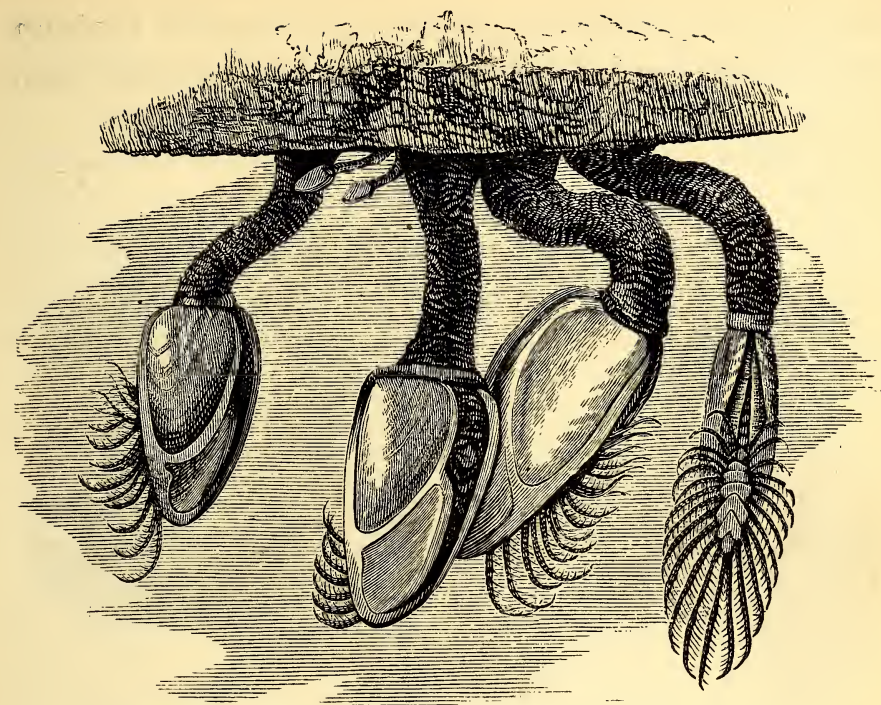

Fig. 253.-Barnacles, or Pedunculate Cirripedes (Lepas anatifera).

united to this class, but now are known to be widely removed from it. The former is by some authors removed from the Crustacea.

3. Tetradecapods, small, fourteen-footed species; as the

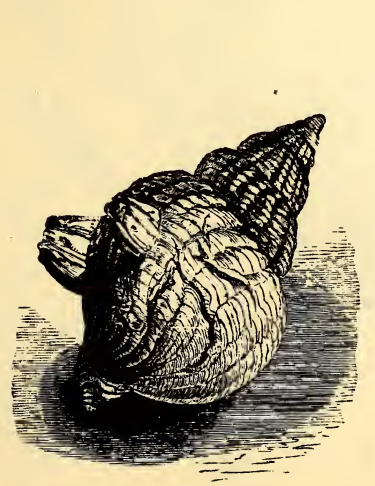

Fig. 254.-Acorn-shells (Balanus) on the Shell of a Whelk (Buccinum).

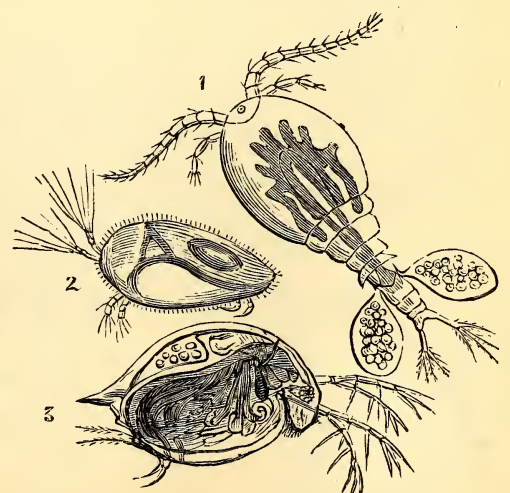

Fıg. 255.-Water-fleas: 1, Cyclops communis; 2, Cypris unifasciata; 3, Daphnia pulex. 
Wood-louse, or Sow-bug (Oniscus), so common in damp places, the Slaters (Idotea), and the Sand-fleas (Gammarus), seen by the sea-side.

4. Decapods, having ten legs, as the Shrimp (Crangon),
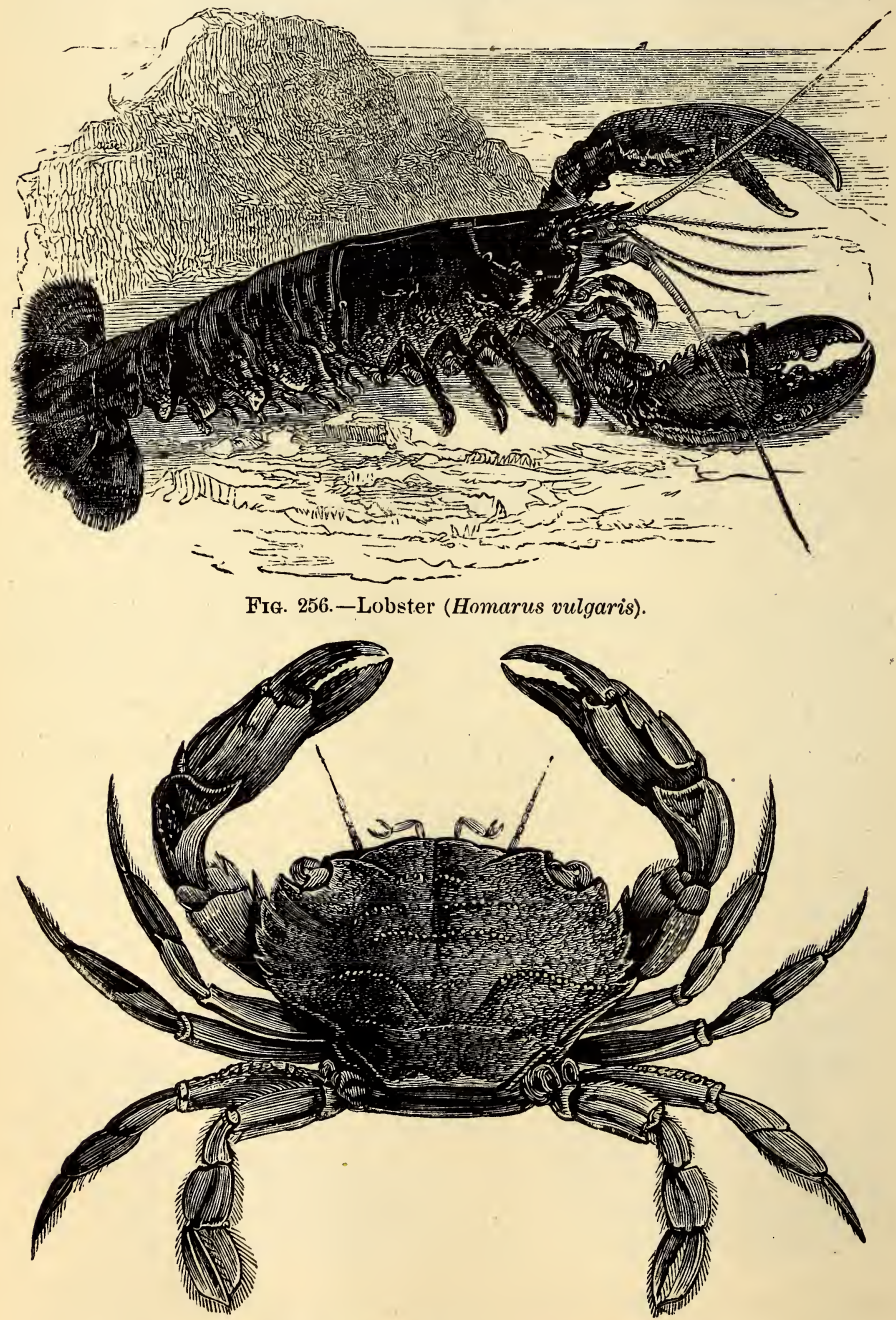

Fra. 257.-Swimming Crab (Platyonychrı). 
Cray-fish (Astacus), Lobster (Homarus), and Crab (Cancer). Crabs differ from Lobsters chiefly in being formed for creeping at the bottom of the sea instead of swimming, and in the reduction of the abdomen or "tail" to a rudiment, which folds into a groove under the enormous thorax. They are the highest and largest of living Crustacea: they have been found at Japan measuring fifteen feet between the tips of the claws.

\section{Class II.-Arachnida.}

The Arachnids are closely related to the Crustaceans, having the body divided into a cephalo-thorax and abdomen. ${ }^{148}$ To the former are attached eight legs of seven joints each; the latter has no locomotive appendages. The head carries two, six, or eight eyes, smooth and sessile (i.e., not faceted and stalked, as in the Lobster), and approaching the eye of the Vertebrates in the completeness and perfection of their apparatus. The antennæ, if present, are only two, and these are not "feelers," but inodified to serve for the prehension of food. ${ }^{149}$ They are all air-breathers, having spiracles which open either into air-sacs or tracheæ. The young of the higher forms undergo no metamorphosis after leaving the egg.

Arachnids number nearly five thousand species. The typical forms are divided into three groups:

1. Acarina, represented by the Mites and Ticks. They have an oval or rounded body, without any marked articulations, the head, thorax, and abdomen being apparently merged into one. They have

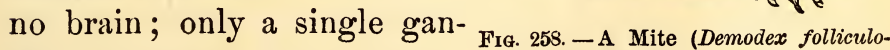
glion lodged in the abdomen. rum), one of the lowest Arachnids; They breathe by tracheæ. The

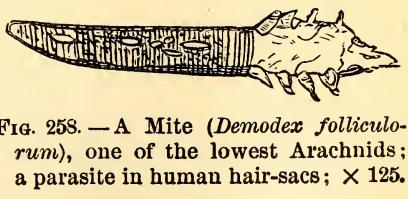
mouth is formed for suction, and they are generally parasitic. The Mites (Acarus) are among the lowest of Ar- 
ticulates. The body is soft and minute. The Ticks (Ixodes) have a leathery skin, and are sometimes half an inch long. The mouth is furnished with a beak for piercing the animal it infests.

2. Pedipalpi, or Scorpions, characterized by very large maxillary palpi ending in forceps, and a prolonged, jointed abdomen. The nervous and circulatory systems are more highly organized than those of Spiders; but the long, tail-like abdomen and the abnormal jaws place them

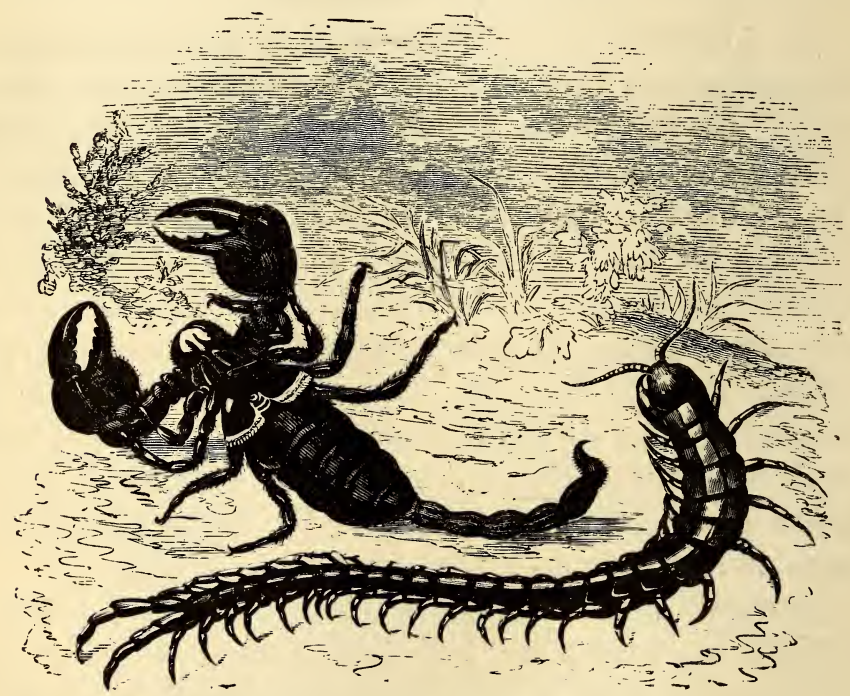

F19. 259.-Scorpion (under surface) and Centipede.

in a lower rank. The abdomen consists of twelve segments: the anterior half is as large as the thorax, with no well-marked division between; the other part is comparatively slender, and ends in a hooked sting, which is perforated by a tube leading to a poison-sac. The mandibles are transformed into small, nipping claws, and the eyes generally number six. Respiration is carried on by four pairs of pulmonary sacs which open on the under surface 
of the abdomen. The heart is a strong artery, extending along the middle of the back, and divided into eight separate chambers. Scorpions are confined to the warm-temperate and tropical regions, usually lurking in dark, damp places.

The Harvest-men (Phalangium), frequently seen about our houses, belong to this order. They have a short, thick body and extremely long legs, and breathe by tracheæ.

3. Araneina, or Spiders. They are distinguished by their soft, unjointed abdomen, separated from the thorax by a narrow constriction, and provided at the posterior end with two or three pairs of appendages, called "spin-

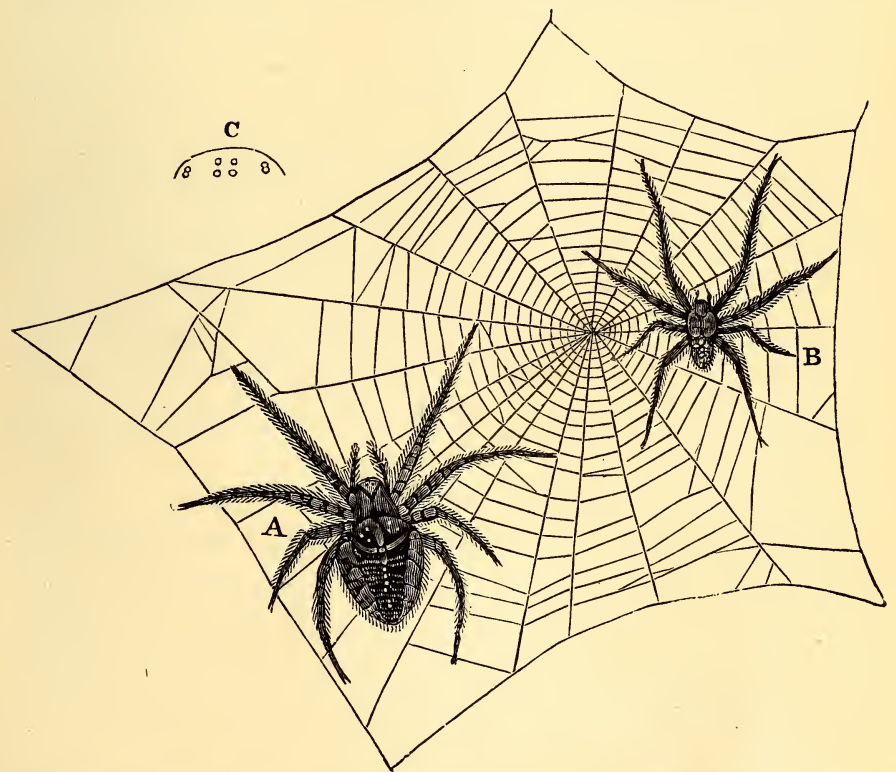

Fra. 260.-A, female Spider; B, male of same species; C, arrangement of the eyes. nerets," which are homologons with legs. The office of the spinnerets is to reel out the silk from the silk-glands, the tip being perforated by a myriad of little tubes, through which the silk escapes in excessively fine threads. An ordinary thread, just visible to the naked eye, is the 
union of a thousand or more of these delicate streams of silk. ${ }^{150}$ These primary threads are drawn out and united by the hind legs.

The mandibles are vertical, and end in a powerful hook, in the end of which opens a duct from a poison-gland in

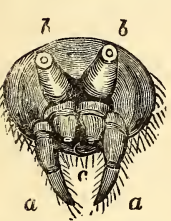

Fig. 261. - SpinneretsoftheSpider, $b, c ; a$, palpiform organs. the head. The maxillæ, or "palpi," which in Scorpions are changed to formidable claws, in Spiders resemble the thoracic feet, and are often mistaken for a fifth pair. The brain is of larger size, and the whole nervous system more concentrated than in the preceding order. There are generally eight simple eyes, rarely six. They breathe both by tracheæ and lung-like sacs, from two to four in number, situated under the abdomen. All the species are carnivorous.

The instincts of Spiders are of a high order. They are, perhaps, the most wily of Articulates. They display remarkable skill and industry in the construction of their webs; and sonie species (called "Mason Spiders") even excavate a subterranean pit, line it with their silken tapestry, and close the entrance with a lid which moves upon a hinge. ${ }^{151}$

\section{Class III.-Myriapoda.}

Myriapods differ from Crustaceans and Spiders in having the thorax merged in the abdomen, while the head is free. In other words, the body is divided into similar segments, so that thorax and abdomen are scarcely distinguishable. They resemble Worms in form and in the simplicity of their nervous and circulatory systems; but the skin is stiffened with chitine, and the legs (indefinite in number) are articulated. The legs resemble those of Insects, and the head appendages follow each other in the same order as in Insects-eyes, antennæ, mandibles, maxillæ, and labium. They breathe by tracheæ, and have two antennæ and a variable number of eyes. 
There are two orders:

1. Chilognatha, having a cylindrical body, each segment furnished with two pairs of legs. They are of slow locomotion, harmless, and vegetarian. The Thousand-legged Worm (Julus) is a common representative.

2. Chilopoda, characterized by having a flattened body composed of about twenty segments, each carrying one pair of legs, of which the hindermost is converted into spines. They have longer antennæ than the preceding, and the mouth is armed with two formidable fangs connected with poisonous glands. They are carnivorous and active. Such is the Centipede (Scolopendra, Fig. 259).

\section{Class IV.-Insecta.}

Insects are distinguished by having head, thorax, and abdornen distinct, three pairs of jointed legs, one pair of antennæ, and generally two pairs of wings. The number of segments in the body never exceeds twenty. The head, apparently one, is formed by the union of four segments. The thorax consists of three - the prothorax, mesothorax, and metathorax-each bearing a pair of legs; the wings, if present, are carried by the last two segments. The abdomen is normally composed of ten segments, more or less movable upon one another. The skin is hardened with chitine, and to it, as in all Arthropods, the muscles are attached. The organs of sense are confined to the cephalic division of the body, the motor organs to the thoracic, and the vegetative to the abdominal. All the appendages are hollow.

The antennæ are inserted between or in front of the eyes. There is a great variety of forms, but all are tubular and jointed. They are supposed to be organs of touch, and also seem to be sensitive to sound. The eyes are usually compound, composed of a large number of hexagonal corneæ, or facets (from fifty in the Ant to many thou- 
sands in the winged Insects). They are never placed on

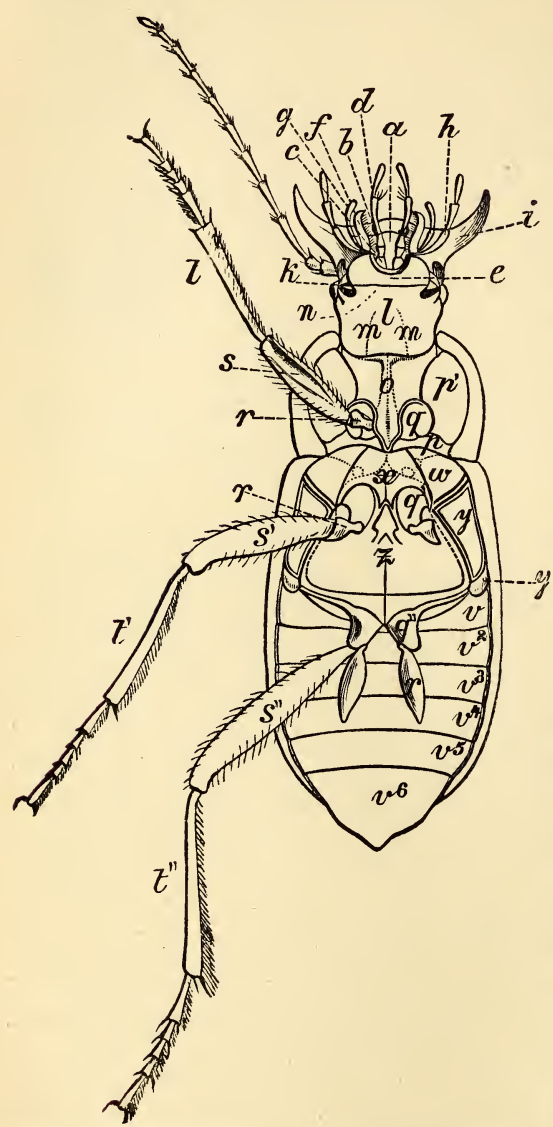

Fia. 262.-Under surface of a Beetle (Harpalus caliginosus): $a$, ligula; $b$, paraglossæ; $c$, supports of labial palpi ; $d$, labial palpus; $e$, mentum ; $f$, inner lobe of maxilla; $g$, outer lobe; $h$, maxillary palpus ; $i$, mandible; $k$, buccal opening ; $l$, gula, or throat: $m$, buccal sutures; $n$, gular suture; $o$, prosternum ; $p$, episternum of prothorax ; $p^{\prime}$, epimeron; $q, q^{\prime}, q^{\prime \prime}$, coxæ: $r, r, r$, trochanters: $s$, $s^{\prime}, s^{\prime \prime}$, femora, or thighs; $t, t^{\prime}, t^{\prime \prime}$, tibæ; $v$, ventral abdominal segments ; $w$, episterna of mesothorax ; $x$, mesosternum ; $y$, episterna of metathorax ; $y^{\prime}$, epimeron; $z$, metasternum.

and foot. ${ }^{152}$ Some larvæ have also movable stalks, as the Lobster's. Besides these, there are three simple eyes, called ocelli. The mouth may be fitted for biting (masticatory), as in Beetles, or for sucking (suctorial), as in Butterflies. The masticatory type, which is the more complete, and of which the other is but a modification, consists of four horny jaws (mandibles and maxilloe) and an upper and an under lip (labrum and labium). Sensitive palpi (maxillary and labial) are developed from the lower jaw and lower lip. The labium is also prolonged into a ligula, or tongue.

The legs are invariably six in the adult, the fore-legs directed forward and the hinder pairs backward. Each consists of a hip, thigh, shank, "false legs," without 
joints, on the abdomen, upon which they chiefly rely in locomotion. The wings are expansions of the crust, stretched over a net-work of horny tubes. The venation, or arrangement of these tubes (called veins and veinlets), particularly in the fore-wings, is peculiar in each genus. In many Insects, the abdomen of the female ends in a tube which is the sheath of a sting, as in the Bee, or of an ovipositor, or "borer," as in the Ichneumon, by means of which the eggs are deposited in suitable places.

Cephalization is carried to its maximum in this class, and we have animals of the highest instincts under the articulate type. The "brain" is formed of several ganglia massed together, and lies across the upper side of the throat, just behind the mouth. The main cord lies along the ventral side of the body, with a swelling for each segment; besides this, there is a visceral nerve representing, in function, the sympathetic system of Vertebrates. The digestive apparatus consists of a pharynx, gullet (to which a crop is added in the Fly, Butterfly, and Bee tribes), gizzard, stomach, and intestine. There are no absorbent vessels, the chyme simply transuding through the walls of the canal. The blood, usually a colorless liquid, is driven by a chain of hearts along the back, $i$. e., by a pulsating tube divided into valvular sacs, ordinarily eight, which allow the current to flow only towards the head. As it leaves this main pipe, it escapes into the cavities of the body, and thus bathes all the organs. Although the blood does not circulate in a closed system of blood-vessels, as in Vertebrates, yet it always takes one set of channels in going from the heart, and another in returning. Respiration is carried on by tracheæ, a system of tubes opening at the surface by a row of apertures (spiracles), generally nine on each side of the body.

The sexes are distinct, and the larvæ are hatched from eggs. As a rule, an Insect, after reaching the adult, or 
imago, state, lives from a few hours to several years, and dies after the process of reproduction. Growth takes place only during larval life, and all metamorphoses occur then. Among the social tribes, as Bees and Ants, the majority (called "workers") do not develop either sex.

Insects (the six-footed Arthropods) comprise nearly one half of the whole Animal Kingdom, or from one hundred and seventy thousand to two hundred thousand species. They are grouped into seven orders:

Lower series: body usually flattened; prothorax large and Neuroptera, squarish ; mouth-parts usually adapted for biting; met- Orthoptera, amorphosis often incomplete; pupa often active; larva flattened, often resembling the adult.

Hemiptera, Coleoptera.

Higher series: body usually cylindrical; prothorax small; mouth-parts more generally formed for sucking; metamorphosis complete ; pupa inactive ; larva usually cylindrical, very unlike the adult.

Diptera, Lepidoptera, Hymenoptera.

1. Neuroptera have a comparatively long, slender body,

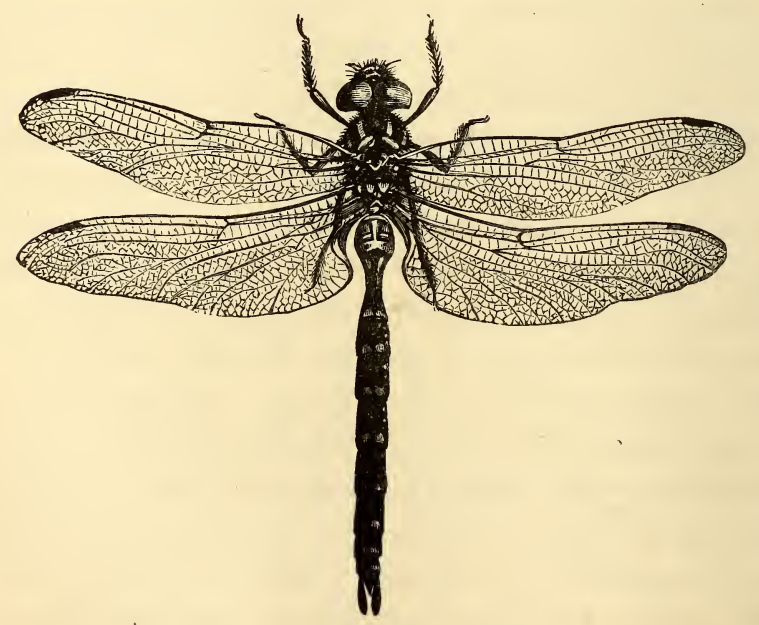

FIG. 263.-Dragon-fly (Libellula).

and four large, transparent wings, nearly equal in size, membranous and lace-like. Such are the brilliant Dragon- 
flies, or Devil's Darning-needles (Libellula), well known by the enormous head and thorax, large, prominent eyes (each furnished with twenty-eight thousand polished lenses), and Scorpion-like abdomen; the delicate and short-lived May-flies (Ephemera); Caddis-flies (Phryganea), whose larvæ live in a tubular case made of minute stones, shells, or bits of wood; the Horned Corydalis (Corydalus), of which the male has formidable mandibles twice as long as the head; and the White Ants (Termes) of the tropics.

2. Orthoptera have four wings: the front pair somewhat thickened, narrow, and overlapping along the back; the hind pair broad, net-veined, and folding up like a fan

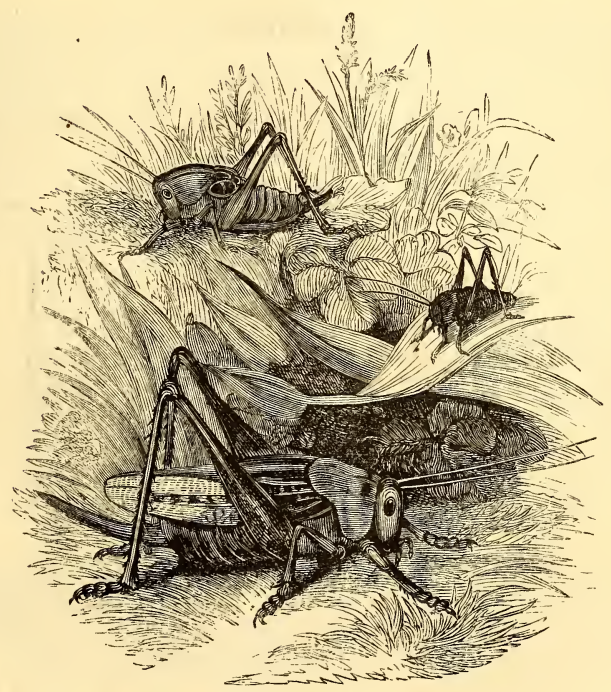

Fig. 264.-Metamorphosis of a Cricket (Gryllus).

upon the abdomen. The hind legs are usually large, and fitted for leaping, all the species being terrestrial, although some fly as well as leap. The eyes are small, the mouth remarkably developed for cutting and grinding. The lar- 


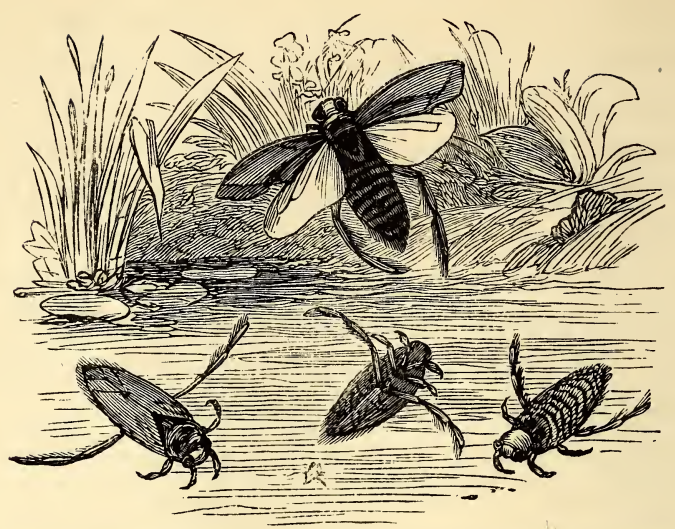

FiG. 265.-Metamorphosis of an Hemipter, Water-boatman (Notonecta).

væ and pupæ are active, and resemble the imago. They are nearly all vegetarian. Each family produces characteristic sounds (stridulation). The representative forms

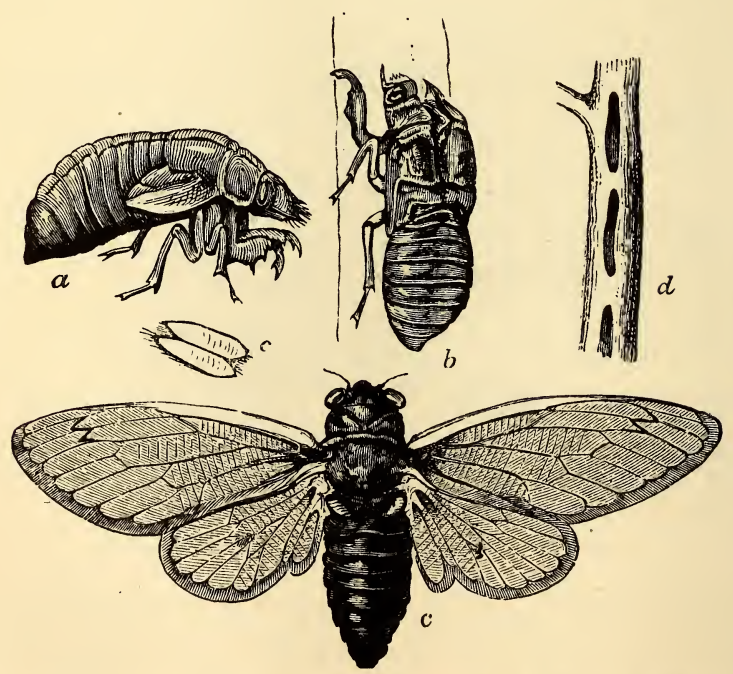

Fia. 266. -Seventeen-year Cicada (Cicada septendecim): $a$, pupa; $b$, the same, after the imago, $c$, has escaped through a rent in the back; $d$, holes in a twig, where the eggs, $e$, are inserted. 
are Crickets (Gryllus), Locusts (Locusta), Grasshoppers (Acrydium), Walking-sticks (Phasma), and Cockroaches (Blatta).

3. Hemiptera, or "Bugs," are chiefly characterized by a suctorial mouth, which is produced into a long, hard, beak, in which mandibles and maxillæ are modified into bristles and enclosed by the labium. The four wings are irregularly and sparsely veined, sometimes wanting. The body is flat above, and the legs slender. The larva differs from the imago in wanting wings. In some species the fore-wings are opaque at the base and transparent at the apex, whence the name of the order. Some feed on the juices of animals, others on plants. Here belong the wingless Bed-bug (Cimex) and Louse (Pediculus), the Squash-bug (Coreus), Water-boatman (Notonecta), Seventeen-year Locust (Cicada), Cochineal (Coccus), and Plantlouse (Aphis).

4. Coleoptera, or "Beetles." This is the largest of the orders, the species numbering about ninety thousand. They are easily recognized by the elytra, or thickened,
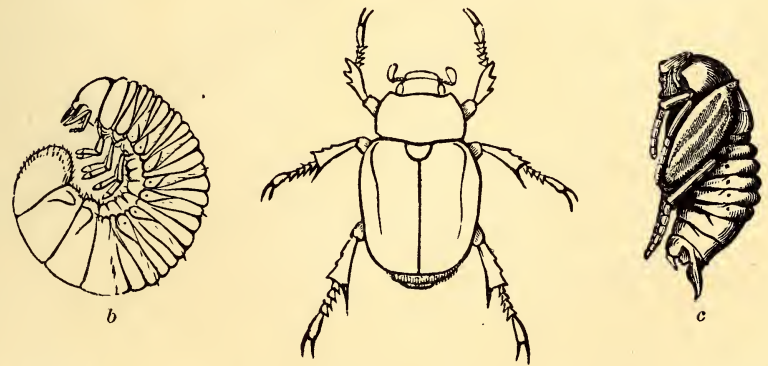

Fia. 267. $-a$, imago, and $b$, larva, of the Goldsmith Beetle (Cotalpa lanigera); $c$, pupa of June-bug (Lachnosterna fusca).

horny fore-wings, which are not used for flight, but serve to cover the hind pair. When in repose, these elytra are always united by a straight edge along the whole length. The hind wings, when not in use, are folded transversely. 
The mandibles are well developed, and the integument generally is hard. The legs are strong, for the Beetles are among the most powerful running Insects. The larvæ are worm-like, and the pupa is motionless. The highest tribes are carnivorous. The most prominent forms

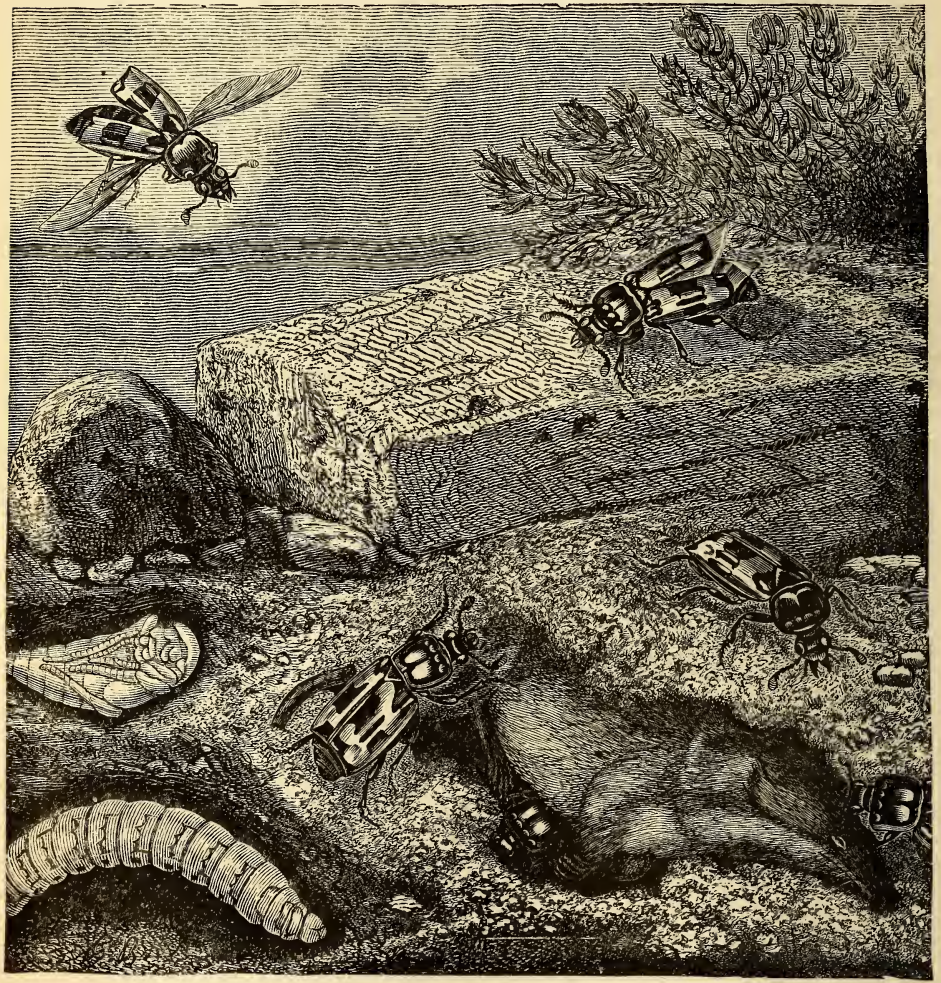

FIg. 268.-Sexton Beetles (Necrophorus vespillo), with larva and uymph. They are burying a mouse, preparatory to laying their eggs in it. ,

are the savage but beautiful Tiger Beetles (Cicindela); the common Ground Beetles (Carabus), whose hind wings are often absent; the Diving Beetles (Dytiscus), with boat-shaped body, and hind legs changed into oars; the Carrion Beetles (Silpha), distinguished by their black, flat 
bodies and club-shaped antennæ; the Goliath Beetles (Scaraboeus), the giants of the order; the Snapping-bugs (Elater); the Lightning-bugs (Pyrophorus); the spotted Lady-birds (Coccinella); the showy, Long-horned Beetles

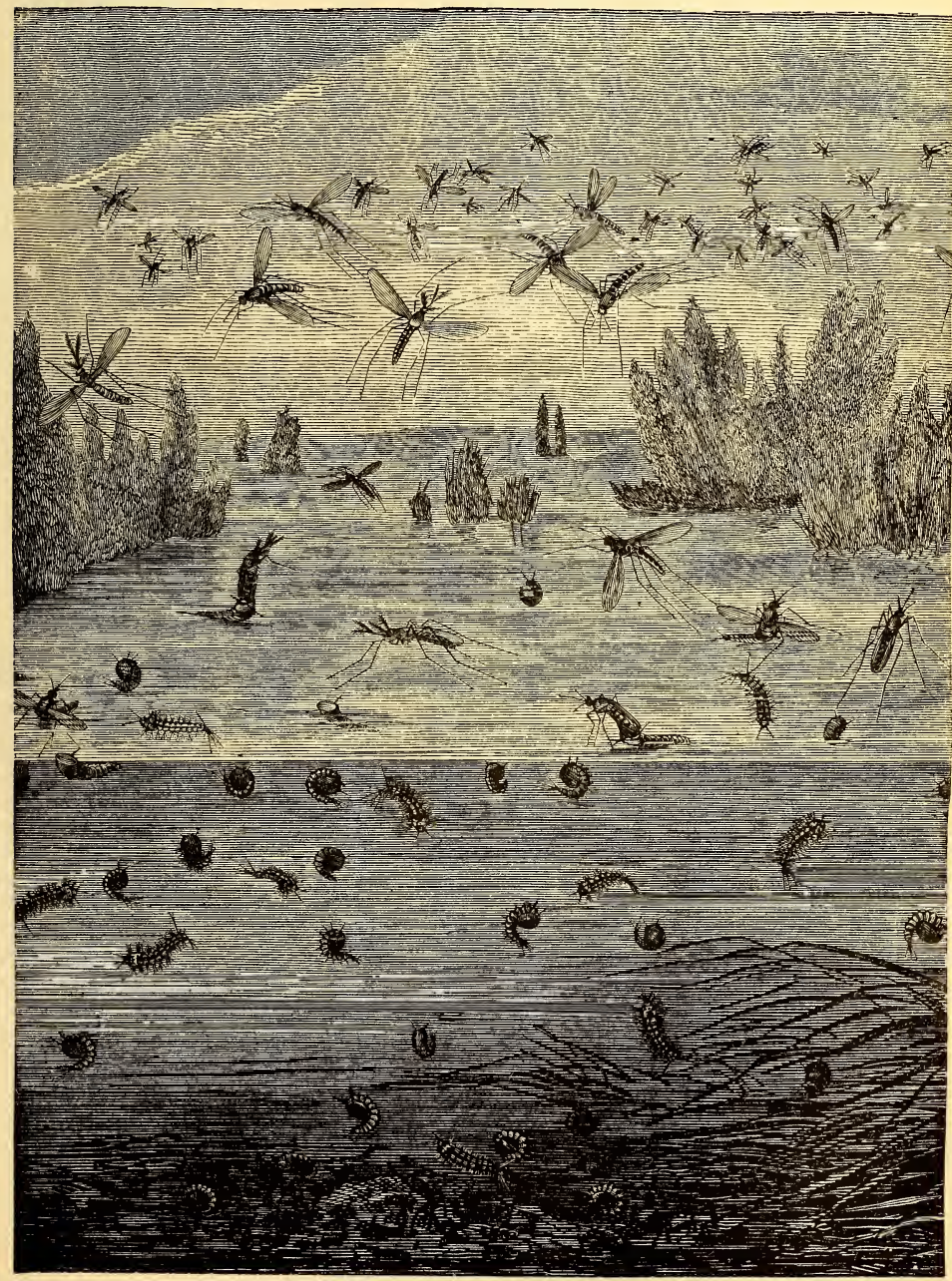

Fra. 269.-Metamorphosis of the Mosquito (Culex pipiens). 
(Cerambycidce); and the destructive Weevils (Curculionidoe), with pointed snouts.

5. Diptera, or "Flies," are characterized by the rudimentary state of the hinder pair of wings. Althoughhaving, therefore, but one available pair, they are gifted with the power of very rapid flight. While a Bee moves its wings one hundred and ninety times a second, and a Butterfly nine times, the House-fly makes three hundred and thirty strokes. A few species are wingless. The eyes are large, with numerous facets. In some forms, as the Housefly, all the mouth-parts, except the labium, are rudimentary; and the labium has an expanded tip, by means of

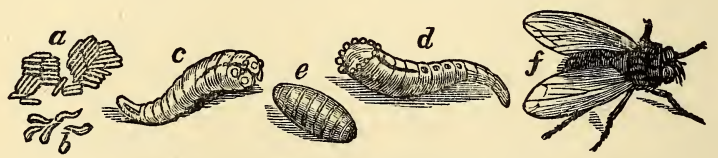

FIG. 270.-Metamorphosis of the Flesh-fly (Sarcophaga carnaria): $a$, eggs; $b$, young maggots just hatched; $c, d$, full-grown maggots ; $e$, pupa ; $f$, imago.

which the fly licks up its food. In other forms, as the Mosquito, the other mouth-parts are present as bristles or lancets, fitted for piercing; the thorax is globular, and the legs slender. The larvæ are footless grubs. The Diptera number about twenty-four thousand. Ainong them are the Mosquitoes (Culex); Hessian-fly (Cecidomyia), so destructive to wheat; Daddy-long-legs (Tipula), resembling a gigantic Mosquito; the wingless Flea (Pulex); besides the immense families represented by the House-fly (Mus-

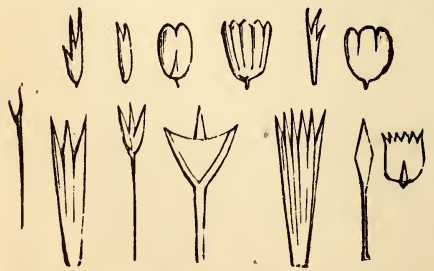

Fig. 271.-Scales from the Wings of various Lepidoptera. $c a)$ and Bot-fly (CEstrus).

6. Lepidoptera, or "Butterflies" and "Moths," are known chiefly by their four large wings, which are thickly covered on both sides by minute, overlapping scales. The scales are of different 
colors, and are often arranged in patterns of exquisite beauty. They are in reality modified hairs, and every family has its particular form of scale. The head is small, and the body cylindrical. The legs are not used for locomotion. All the mouth parts are nearly obsolete except the maxillæ, which are fashioned into a "proboscis" for pumping up the nectar of flowers.

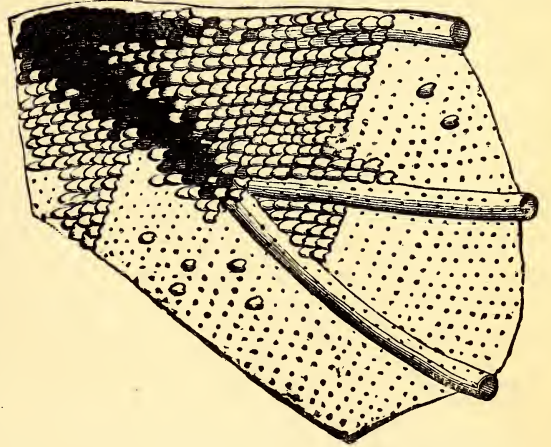

Fia. 272.-Part of the Wing of a Moth (Saturnia), magnified to show the arrangement of scales. The larvæ, called "caterpillars," have a worm-like form, and from one to five pairs of abdominal legs, in addition to the three on the thorax. The month is formed for mas-

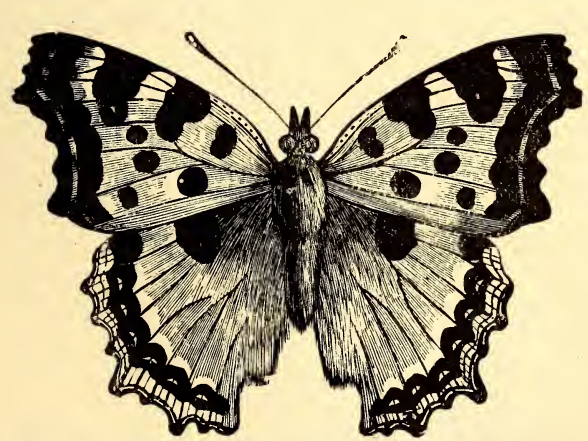

Frg. 273.-Vanessa polychloros, or "Tortoise-shell Butterfly." tication, and (except in the larvæ of Butterflies) the lip has a spinneret connected with silkglands.

There are three groups : the gay Butterflies, having knobbed or hooked antennæ, and flying in the day only; the dull-colored Sphinges, with antennæ thickened in the middle, and flying at twilight; and the nocturnal Moths, which generally prefer the night, and whose antennæ are thread-like and often feathery. Generally, when at rest, the Butterflies keep their wings raised vertically, while 


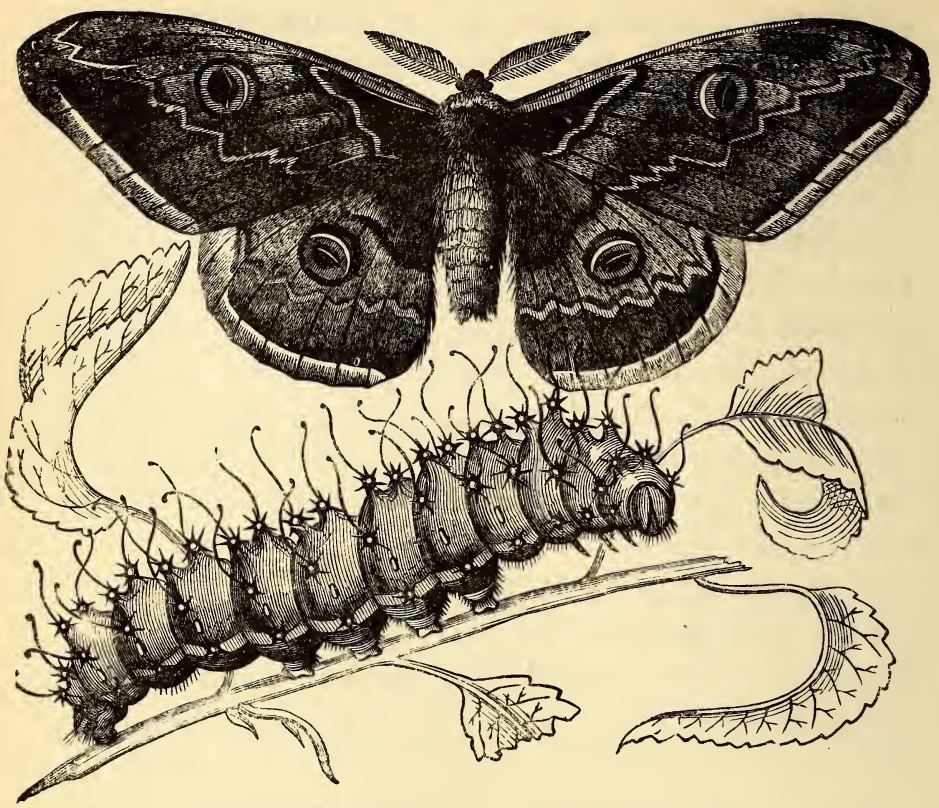

Fig. 274.-Moth and Larva of Attacus pavonia-major.

the others hold theirs horizontally. The pupa of the former is unprotected, and is usually suspended by a bit of silk $:^{153}$ the pupa of the Moths is enclosed in a cocoon.

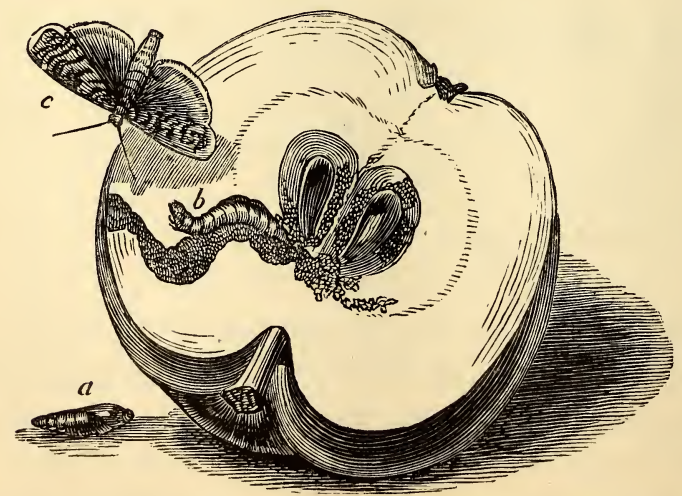

Fic. 275.-Fruit-moth (Carpocapsa pomonella): $b$, larva ; $a$, chrysalis ; $c$, imago. 
From twenty-two thousand to twenty-four thousand Lepidopterous species have been identified. Some of the most common Butterflies are the swallow-tail Papilio, the white Pieris, the sulphuryellow Colias; the Argynnis, with silver spots on the under side of the hind wings; the Vanessa, with notched wings. The Sphinges exhibit little variety. They have narrow, powerful wings, and are sometimes mistaken for Hummingbirds. The "potato-worm" is the caterpillar of a Sphinx. The most conspicuous Moths are the large and beautiful Attacus, distinguished by a triangular, transparent spot in the centre of the wing; the white Bombyx, or "silk-

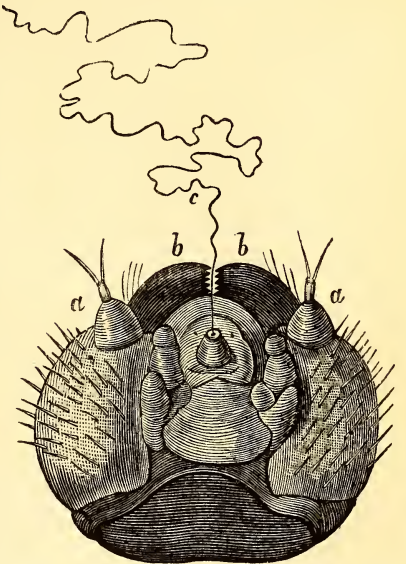

Frg. 276. - Head of a Caterpillar, from beneath: $a$, antennæ; $b$, horny jaws; $c$, thread of silk from the conical fusulus, on either side of which are rudimentary palpi.

worm ;" the reddish-brown Clisiocampa, whose larva, "the American Tent-caterpillar," spreads its web in many an apple and cherry tree; the pale, delicate Geometrids; and the small but destructive Tineids, represented by the Clothes-moth.

7. Hymenoptera, comprising at least twenty-five thousand species, include the highest, most social, and, we may add (if we except the Silk-worm), the most useful, of Insects. They have a large head, with compound eyes and three ocelli, mouth fitted both for biting and lapping, legs formed for locomotion as well as support, and four wings equally transparent, and interlocking by small hooks during flight. The females are usually provided with a sting, or borer. The larvæ are footless, helpless grubs, and generally nurtured in cells, or nests. Such are 
the Honey-bees (Apis), Humble-bees (Bombus), Wasps (Vespa), Ants (Formica), Ichneumon-flies, and Gall-flies. Those living in societies exhibit three castes: females, or "queens ;" males, or "drones ;" and neuters, or sexless "workers." There is but one queen in a hive, and she is treated with the greatest distinction, even when dead. She dwells in a large, pear-shaped cell, opening downward. She lays three kinds of eggs: from the first come forth workers, the second produces males, and the last females. The drones, of which there are about eight hundred in an ordinary hive, are marked by their great size, their large eyes meeting on the top of the head, and
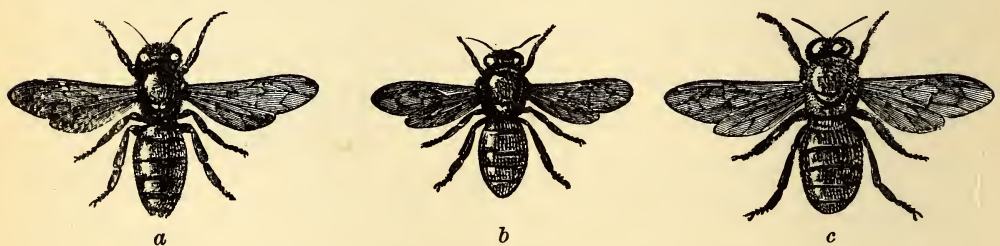

FIg. 277.-Honey-bee (Apis mellifica) : $a$, female ; $b$, worker ; $c$, male.

by being stingless. The workers, which number twenty to one drone, are small and active, and provided with stings, and hollow pits in the thighs, called "baskets," in which they carry pollen. Their honey is nectar elaborated in the crop by an unknown process; while the wax is secreted from the sides of the abdomen and mixed with saliva. There is a subdivision of extra labor: thus there are wax-workers, masons, and nurses. Ants (except the Saüba) have but two classes of workers. While Ants live in hollow trees or subterranean chambers (called formicarium), Honey-bees and Wasps construct hexagonal cells. The comb of the Bee is hung vertically, that of the Wasp is horizontal. 


\section{Subkingdom VII.-Tunicata.}

This small and singular group of animals has relations with the worms on the one hand and with the Vertebrates on the other. The most common forms (the solitary $A s$ cidians) are enclosed in a leathery, elastic bag, one end of which is fastened to the rocks, while the other has two orifices, for the inlet and exit of a current of water for nutrition and respiration. They are without head, feet, ar'ms, or shell. Indeed, few animals seem more

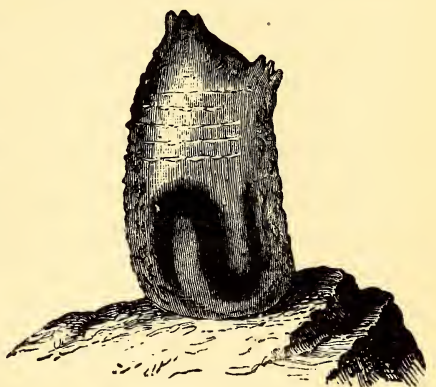

Frg. 278.-Au Ascidian. helpless and apathetic than these apparently shapeless beings. The tubular heart exhibits the curious phenomenon of reversing its action at brief intervals, so that the blood

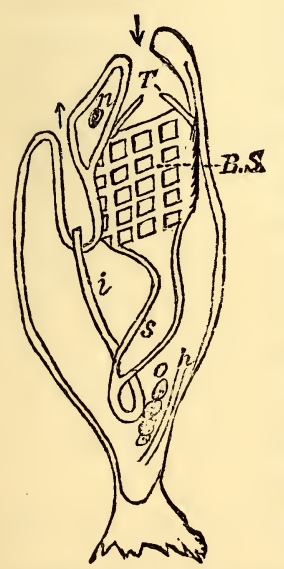

Fra.279.-Diagran of Simple Ascidian : $B, S$, branchial sac; $n$, nervons ganglion; $s$, stomach; $i$ intestine; $o$, reproductive organ; $h$, heart. oscillates backward and forward in the same vessels. Another peculiarity is the presence of cellulose in the skin. The water is drawn by cilia into a branchial sac, an enlargement of the first part of the intestine, whence it escapes through openings in the sides, to the excurrent orifice, while the particles of food drawn in with the water are retained and passed into the intestine. The larva is active, swimming by means of a long tail. It looks like a tadpole, and has a notochord and a nervous system closely resembling those of a Vertebrate. Afterwards it attaches itself by the head, the tail is absorbed, and the nervous system is reduced to a single small ganglion. 


\section{Subkingdom VIII.-VERTEBRATA.}

This grand division includes the most perfect animals, or such as have the most varied functions and the most numerous and complex organs. Besides the unnumbered host of extinct forms, there are about twenty-five thousand living species, widely differing among themselves in shape and habits, yet closely allied in the grand features of their organization, the general type being endlessly modified.

The fundamental distinctive character of Vertebrates is the separation of the main mass of the nervous system

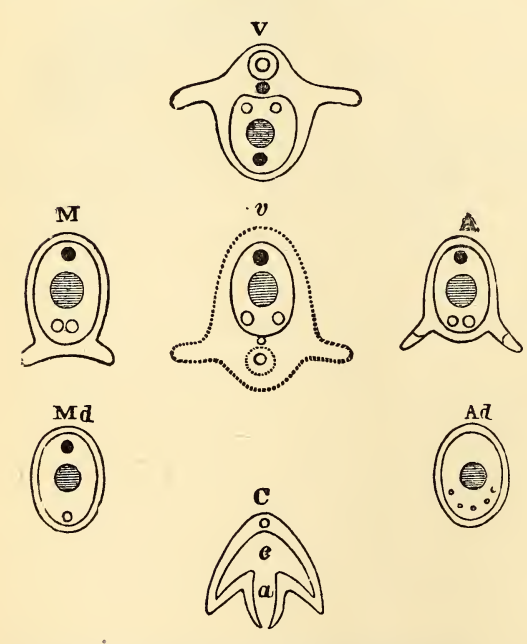

Fic. 280.-Ideal Plans of the Subkingdoms. $\boldsymbol{V}$, transverse section of vertebrate type; $v$, the same, inverted. $M$, transverse section of molluscons type; and $M d$, of molluscoid. $A$ and $A d$, transverse sections of articulate type, high and low. $C$, longitudinal section of cœlenterate type; $a$, alimentary canal; $c$, body-cavity. In the other figures, the alimentary canal is shaded, the heart is black, and the nervous cords are open rings.

from the general cavity of the body. A transverse section of the body exhibits two cavities, or tubes - the dorsal, containing the cerebro-spinal nervous system; the ventral, inclosing the alimentary canal, heart, lungs, and a double chain of ganglia, or sympathetic system. This ventral, or hæmal, cavity corresponds to the whole body of an Invertebrate; while the dorsal, or neural, is added.

Vertebrates are also distinguished by an internal, jointed skeleton, endowed with vitality, and capable of growth and repair. During embryo-life it is represented by the notochord; but this is afterwards replaced 
by a more highly developed vertebral column of cartilage or bone. The column and cranium are never absent in the craniota ; other parts may be wanting, as the ribs in Frogs, limbs in Snakes, etc. ${ }^{154}$ The limbs are never more than four, and are always articulated to the hæmal side of the body, while the legs of Invertebrates are developed from the neural side. The muscles moving the limbs are attached to the endoskeleton.

The circulation of the blood is complete, the arteries being joined to the veins by capillaries, so that the blood never escapes into the visceral cavity as in the Invertebrates. All have a portal vein, carrying blood through the liver; all have lacteals and lymphatics. The blood is red, and contains both kinds of corpuscles. ${ }^{165}$ The teeth are developed from the dermis, never from the cuticle, as in Mollusks and Articulates; the jaws move vertically, and are never modified limbs. The liver and kidneys are always present. The respiratory organs are either gills or lungs,

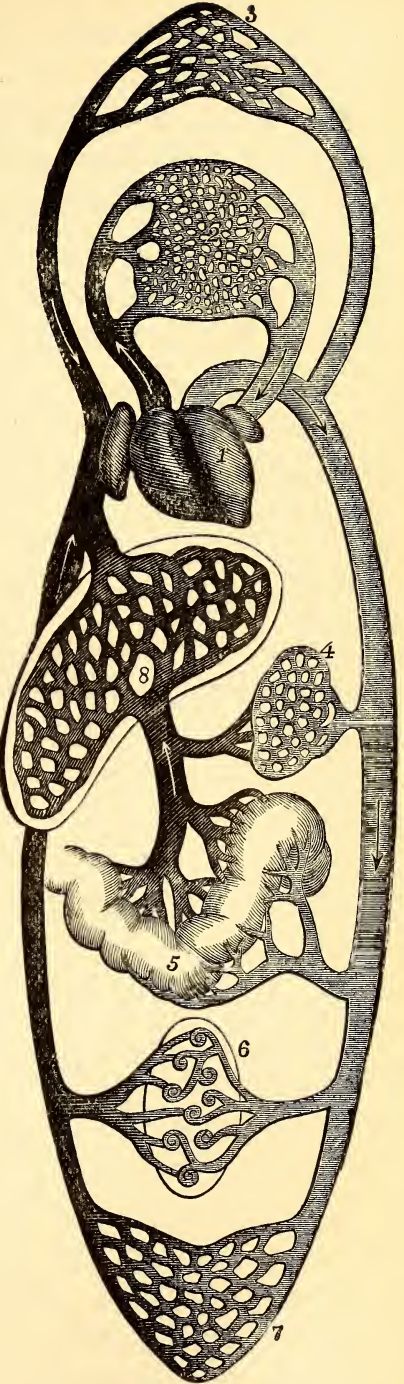

Frg. 251. - Diagram of Circulation in the higher Vertebrates: 1, heart; 2, lungs; 3, head and upper extremities; 4 , spleen; 5 , intestine ; 6 , kidney ; 7 , lower extremities; 8, liver. (From Dalton's " Physiology.") 
or both. Vertebrates are the only animals which breathe through the mouth.

The nervous system has two marked divisions: the cerebro-spinal, presiding over the functions of animal life (sensation and locomotion); and the sympathetic, which partially controls the organic functions (digestion, respiration, and circulation). In no case does the gullet pass through the nervous system, as in Invertebrates, and the mouth opens on the side opposite to the brain. Probably none of the five senses are ever altogether absent. The form of the brain is modified by the relative development of the various lobes. In the lower Vertebrates, the cerebral hemispheres are small - in certain Fishes they are actually smaller than the optic lobes-in the higher, they nearly or quite overlap both olfactories and cerebellum. The brain may be smooth, as in most of the cold-blooded animals, or richly convoluted, as in Man.

There is no skull in Amphioxus. In the Marsipobranchii and Elasmobranchii it is cartilaginous. In other fishes it is cartilage overlaid with bone. In Amphibians and Reptiles, it is mingled bone and cartilage. In Birds and Mammals, mainly or wholly bony. The human skull contains fewer bones than the skull of most animals, excepting Birds. The skull of all Vertebrates is divisible into two regions: the cranium, or brain-case, and the face. The size of the cranial capacity, compared with the area of the face, is generally the ratio of intelligence. In the lower orders, the facial part is enormously predominant, the eye-orbits are directed outward, and the occipital condyles are nearly on a line with the axis of the body. In the higher orders, the face becomes subordinate to the cranium, the sensual to the mental, the eyes look forward, and the condyles approach the base of the cranium. Compare the "snouty" skull of the Crocodile and the almost vertical profile of civilized Man. A straight line drawn 
from the middle of the ear to the base of the nose, and another from the forehead to the most prominent part of the upper jaw, will include what is called the facial angle, which roughly gives the relation between the two regions, and therefore the rank of the animal. ${ }^{156}$ In the cold-blooded Vertebrates the brains do not fill the craninın; while in Birds and Mammals a cast of the cranial cavity well exhibits the general features of the cerebral surface. ${ }^{157}$

All Vertebrates are single and free. Mammals bring forth their young alive, having directly nourished them from the mother before birth (viviparous). In almost all the others the nourishment is laid up in the egg, which is laid before hatching (oviparous), or is retained in the mother until hatched (ovoviviparous), as in some Reptiles and Fishes.

There are two great divisions of the subkingdom, Acrania and Craniota, or Vertebrates withont skulls and those with skulls.

The Craniota are divided into five great classes: Fishes, Amphibians, Reptiles, Birds, and Mammals. The first three are "cold-blooded," the other two are "warmblooded." Fishes and Amphibians have gills during the whole or a part of their lives, while the rest never have gills. Fishes and Amphibians in embryo have neither amnion nor allantois, while the other three are provided with both.

There are three provinces of skull-bearing Vertebrates.

Fishes and Amphibians agree in having gills, in wanting amnion and allantois, and in possessing nucleated red blood-corpuscles (Ichthyopsida).

Birds and Reptiles agree in having no gills, but both amnion and allantois, in the articulation of the skull with the spine by a single condyle, in the development of the skin into feathers or scales, and in circulating oval, nucleated, red corpuscles (Sauropsida).

Manmals differ from Birds and Reptiles in having two 
occipital condyles, and their blood-corpuscles are not nucleated ${ }^{168}$ (Mammalia).

\section{Division I.-Acrania.}

Vertebrates without a skull.

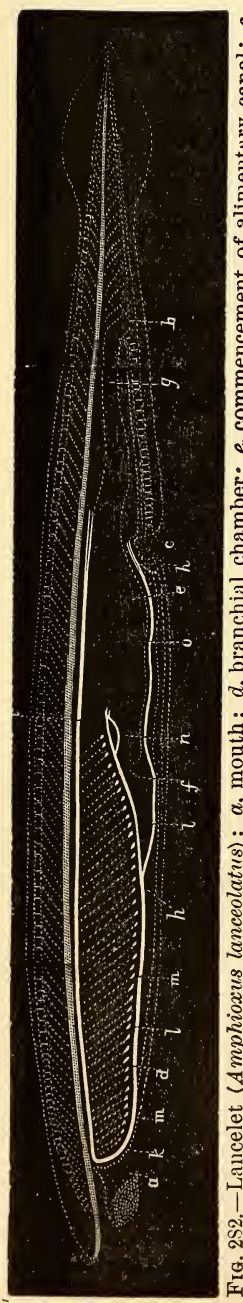

Class.-Pharyngobranchii.

The Acrania are represented by the singular animal Amphioxus or Lancelet. It is about two inches long, semi-transparent, without skull, limbs, brain, heart, or red blood-corpuscles. It has for a skeleton a notochord only. It breathes by very numerous gill arches, without fringes, and the water is drawn in by cilia, which line the gill slits. The embryo develups into a gastrula closely resembling that of the Invertebrates. The animal lives in the sandy bottom of shallow parts of the ocean, and has been found in the Mediterranean Sea, in the Indian Ocean, and on the east coast of North and Sonth America.

\section{Division II.-Craniota.}

Vertebrates with a distinct skull.

\section{Class I.-Pisces.}

Fishes are the lowest of Vertebrates. They fall far behind the rest in strength, intelligence, and sensibility. The eyes, though large, are almost immovable, bathed by no tears, and protected by no lids. Dwelling in the realm of silence, ears are little 
needed, and such as they have are without external parts, the sound being obliged to pass through the cranium. Taste and smell are blunted, and touch is nearly confined to the lips.

The class yields to no other in the number and variety of its forms. It includes nearly one half of all the vertebrated species. So great is the range of variation, it is difficult to frame a definition which will characterize all the finny tribes. It may be said, however, that Fishes are the only backboned animals having median fins (as dorsal and anal) supported by fin-rays, and whose limbs (pectoral and ventral fins) do not exhibit that threefold division (as thigh, leg, and foot) found in all other Vertebrates. ${ }^{159}$

The form of Fishes is admirably adapted to the element in which they live and move. Indeed, Nature nowhere presents in one class such elegance of proportions with such variety of form and beanty of color. The head is

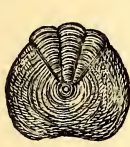

$A$

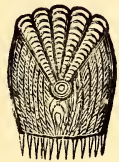

$B$

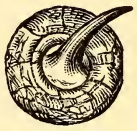

C

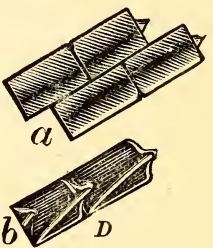

Fia. 283.-Scales of Fishes: $A$, cycloid scale (Salmon); $B$, ctenoid scale $($ Perch) $; C$, placoid scale $(R a y) ; D$, ganoid scales (Amblypterus) $-a$, upper surface ; $b$, under surface, showing articulating processes.

disproportionately large, but pointed to meet the resistance of the water. The neck is wanting, the head being a prolongation of the trunk. The viscera are closely packed near the head, and the long, tapering trunk is left free for the development of muscles which are to move the tail-the instrument of locomotion. The biconcave vertebræ, with intervening cavities filled with elastic gelatine, are designed for rapid and versatile movements. The body is either naked, as in the Lamprey, or covered with 
polished, overlapping scales, as in the Perch. . Rarely, as in the Sturgeon, it is defended by bony plates, or by minute, hard spines, as in the Shark. Scales with smooth, circular outline are called cycloid; those with notched or spiny margins are ctenoid. Enameled scales are ganoid, and those with a sharp spine, like those of the Shark, are placoid.

The vertical fins (dorsal, anal, and caudal) are peculiar to Fishes. The dorsal vary in number, from one, as in the Herring, to three, as in the Cod; and the first dorsal may be soft, as in the Trout, or spiny, as in the Perch.

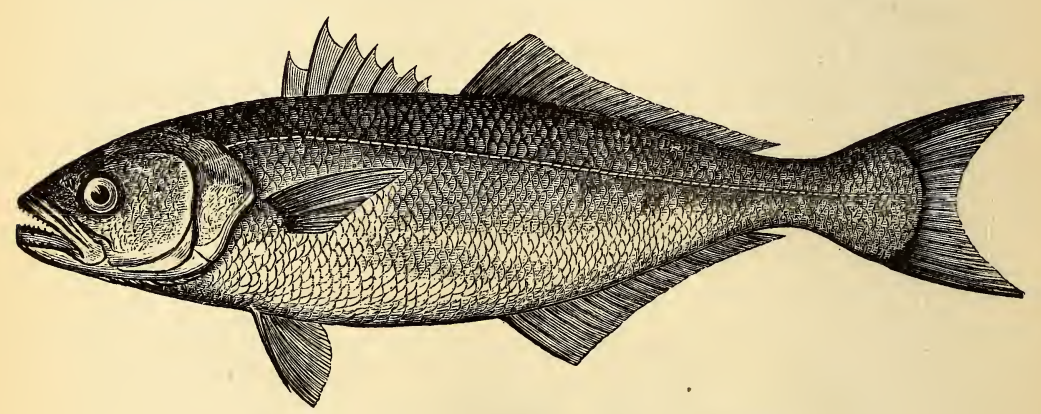

Fig. 284.-Blue-fish (T'emnodon saltator). All seas.

If the dorsals are cut off, the Fish reels to and fro. The candal may be homocercal, as in ordinary species; or heterocercal, as in Sharks. In ancient heterocercal Fishes, the tail was frequently vertebrated. The pectoral and ventral fins stand for the fore and hind limbs of other Vertebrates. As the specific gravity of the body is greater than that of the water, most Fishes are provided with an air-bladder, which is an outgrowth from the œsophagus. This is absent in such as grovel at the bottom, as the Rays, and in those, like the Sharks, endowed with compensating muscular power.

Fishes have no prehensile organ besides the mouth. Both jaws are movable. The teeth are numerous, and 
may be recurved spines, as in the Pike; flat and triangular, with serrated edges, in the Shark; or flat and tessellated in the Ray. They feed principally on animal matter. The digestive tract is relatively shorter than in other Vertebrates. ${ }^{160}$ The blood is red, and the heart has rarely more than two cavities, an auricle and a ventricle, both on the venous side. Ordinary Fishes have four gills, which are covered by the operculum, and the water escapes from an opening behind this. In Sharks there is no operculum,

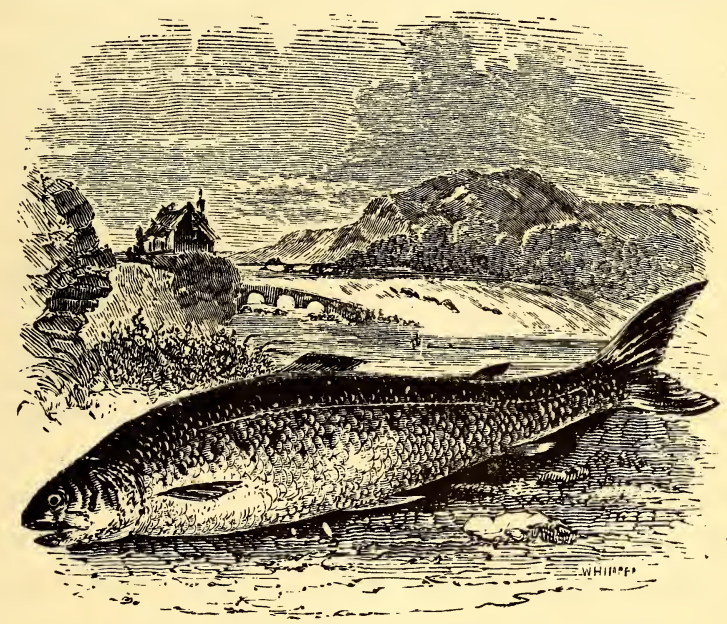

Fig. 285.-Salmon (Salmo salar). Both hemispheres.

and each gill opens separately. The brain consists of several ganglia placed one behind the other, and occupies but a small part of the cranial cavity. Its average weight to the rest of the body may be as low as 1 to 3000 . The eggs of bony Fishes are naked and multitudinous, sometimes numbering millions in a single spawn; those of the Sharks are few, and protected by a horny shell.

There are about thirteen thousand species of Fishes, of which over two thirds are Teleostei. There are two subclasses of Pisces. 
SubClass I.-Marsipobranchii.

The Lampreys and Hag-fish have a persistent noto-

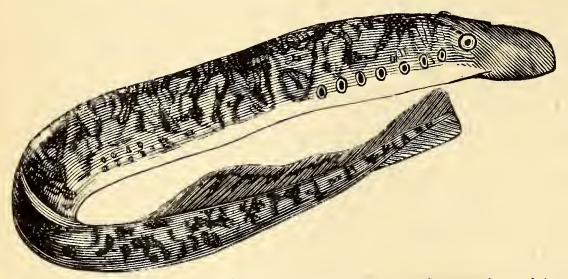

Fia. 286.-Lamprey (Petromyzon Americanus). Atlantic. chord, a cartilaginous skull, no lower jaw, a round, suctorial mouth, horny teeth, one nasal-organ, no scales, limbs, or gillarches. The gills are ponch-like (whence the name of the class), and open separately. They are found both in salt and fresh water.

\section{Subclass II.-Pisces Proper.}

The true Fishes have two nasal organs, and well-developed jaws and gill-arches. There are four orders:

1. Elasmobranchï, having a cartilaginous skeleton, and a skin naked or with placoid scales. The gill-openings are uncovered; and the mouth is generally under the head. The ventral tins are placed far back; the pectorals are large, in the Rays enormously developed; and the tail is heterocercal. Such are the Sharks, Rays, and Chimæra.

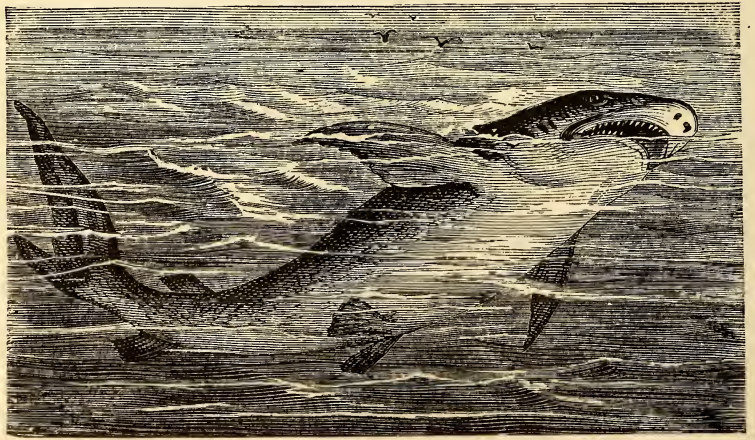

Fig. 287.-Shark (Carcharias vulgaris). Atlantic. 
They are all marine. The largest Shark found, and therefore the largest Fish, measured forty feet in length.

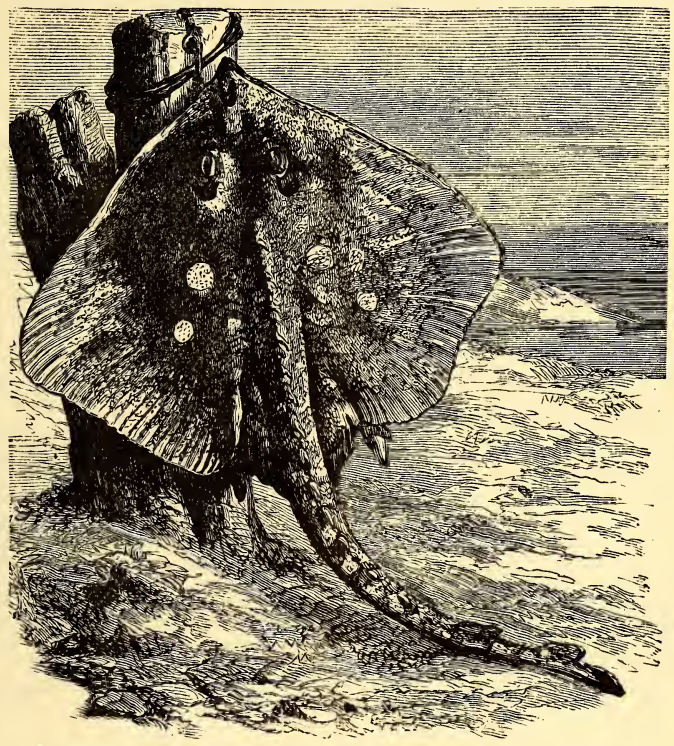

FIG. 288.-Thornback (Raia clavata). Enropean seas.

2. Ganoidei, distinguished by their enameled scales or bony plates. The endoskeleton is usually not completely ossified; the ventral fins are placed far back; and the tail is generally heterocercal. The gills are like those of the bony Fishes, and the air-bladder has a duct, and may aid in respiration. This was one of the largest orders in old geological history. The few modern representatives, as the Sturgeon, Gar-pike, Mud (or Dog) Fish, and Polypterus, are essentially fresh-water.

3. Teleostei, including all the common Fishes having a bony endoskeleton

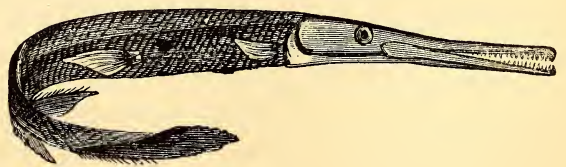

Frg. 289.-Gar-pike (Lepidos'eus osseus). Lake Ontario. 


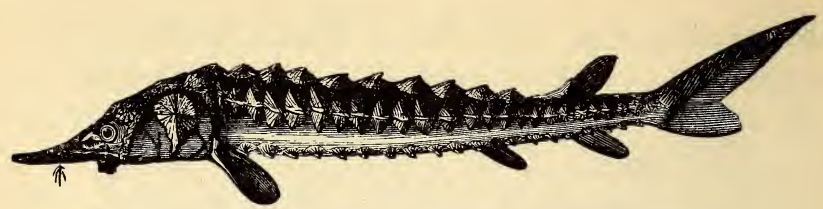

FIg. 290.-Sturgeun (Acipenser sturio). Atlantic coast.

and a scaly exoskeleton. The skull is extremely complicated; the upper and lower jaws are complete, and the

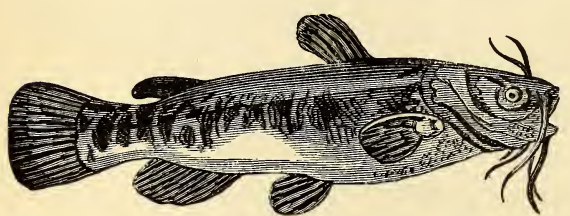

Fig. 291.-Cat-tiol, ur horued Pout (Pimelodus catus). American rivers.

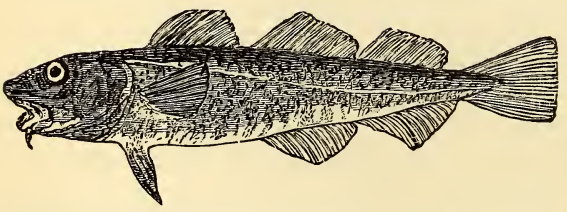

Frg. 292.-Cod (Morrhua Americana). Atlautic coast. placed under the throat, as in the Cod, Haddock, and Flounder. In the spiny-finned Fishes, the ventrals are generally under or in front of the pectorals, and the scales ctenoid, as in the Perches, Mullets, and Mackerels.

4. Dipnoi. These Fishes connect the class with the Amphibia. They have an eel-like body, covered with cycloid scales; an embryonic notochord for a back-bone;

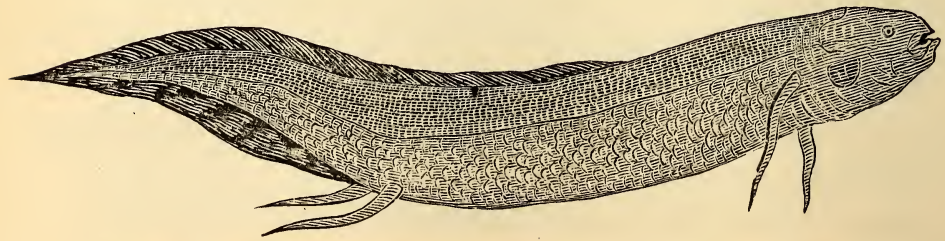

Fig. 293.-Protopterus annectens; one fourth natural size. African rivers. 
long, ribbon-like pectoral and ventral fins, set far apart; two auricles, and one ventricle; and, besides gills, a cellular air-bladder, which is used as a lung.

The representatives are Ceratodus from Australia, Protopierus from Africa, and Lepidosiren from Brazil.

\section{Class II.-Amphibia.}

These cold-blooded Vertebrates are distinguished by having gills when young, and true lungs when adult. They have no fin-rays, and the limbs, when present, have the same divisions as those of higher animals. The skin is soft, and generally naked, and the skeleton is ossified. The skull is flat, and articulates with the spinal column by two condyles. There is no distinct neck; and the ribs are usually small or wanting. The heart consists of two auricles and one ventricle. All undergo metamorphosis upon leaving the egg, passing through the "tadpole" state. They cornmence as water-breathing larvæ, when they resemble Fishes in their respiration, circulation, and locomotion. In the lowest forms, the gills are retained through life; but all other's have, when mature, lungs only, the gills disappearing. The cuticle is frequently shed, the mode varying with the habits of the species. ${ }^{161}$ The common Frog, the type of this class, stands intermediate between the two extremes of the vertebrate series; no fundamental part is excessively developed.

There are about four hundred and fifty living species, grouped in four orders:

1. Urodela have a naked skin, a tail, and two or four limbs. Some retain their gills through life, as the Fra. 294.-Head and Gills of Menobranchus. Cayuga

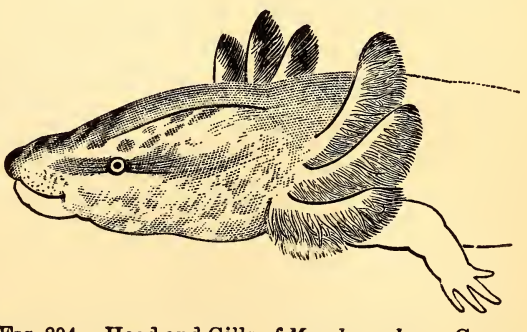
Lake. 
Proteus of Austria, Menobranchus of the eastern United States, and the two-legged Mud-eel (Siren) of South Carolina. Others drop their gills, and always have four limbs, as the aquatic Newts and land Salamanders. ${ }^{162}$ The fore limbs first make their appearance in the tadpole.

2. Labyrinthodontia, now extinct, resembled gigantic Salamanders, except in their complex teeth and exoskeleton of bony plates.

3. Cocilia have neither tail nor limbs, a snake-like form,

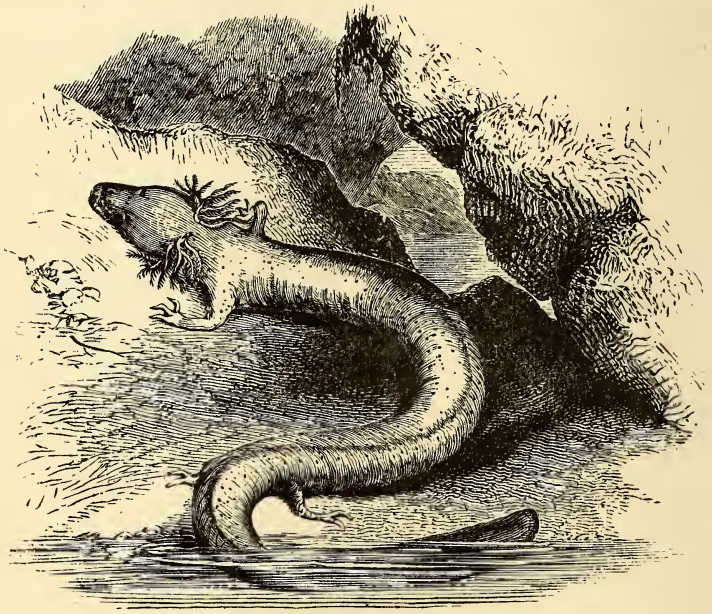

FrG. 295.-Proteus anguinus. Europe.

minute scales in the skin, and well-developed ribs. They are confined to the tropics.

4. Batrachia include all the well-known tailless Am-

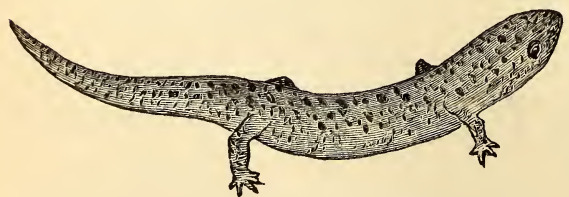

Fis. 296.-Red Salamander (Pseudotriton ruber). United States. phibians, as Frogs and Toads. They have a moist, naked skin, ten vertebræ, and no ribs. As they breathe by swallowing the air, they can be suffocated by holding the mouth open. They have 
four limbs-the hinder the longer, and the first developed. They have four fingers and five toes. The tongue is long, and, fixed by its anterior end, it can be rapidly thrown out as an organ of prehension. ${ }^{163}$ The eggs are laid in the water enveloped in a glairy mass; and the tadpoles

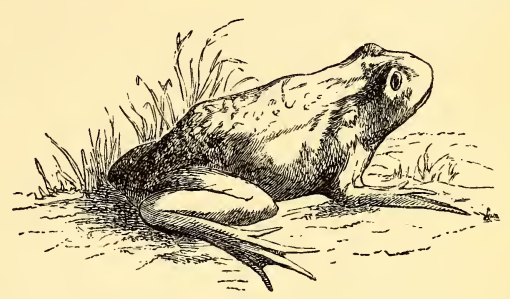

FLG. 297.-Frog (Rana). resemble the Urodelans, till both gills and tail are absorbed. Frogs (Rana) have teeth in the upper jaw, and webbed feet; Toads (Bufo) are higher in rank, and have neither teeth nor fully webbed feet. The former have been known to live sixteen years, and the latter thirty-six.

\section{Class III.-Reptilia.}

These air-breathing, cold-blooded Vertebrates are distinguished from all Fishes and Amphibians by never having gills, and from Birds by being covered with horny scales or bony plates. The skeleton is never cartilaginous; and the skull has one occipital condyle. The vertebræ are ordinarily concave in front; and the ribs are well developed. With few exceptions, all are carnivorous; and teeth are always present, except in the Turtles, where a horny sheath covers the jaws. The teeth are never fastened in sockets, except in Crocodiles. The jaws are usually very wide. The heart has three chamber's, save in Crocodiles, where the ventricle is partitioned. But in all cases a mixture of arterial and venous blood is circulated. The lungs are large, and coarsely cellular. The limbs, when present, are provided with three or more fingers as well as toes.

There are about fifteen hundred species and four orders of living Reptiles : the first two have horny 
scales, the others have bony plates combined with scales.

1. Ophidia, or Snakes, are characterized by the absence of visible limbs $;^{164}$ by the great number of vertebræ, amounting to over four hundred in the great Serpents; by a corresponding number of ribs, but no sternum; and no true eyelids, the eyes being covered with a transparent

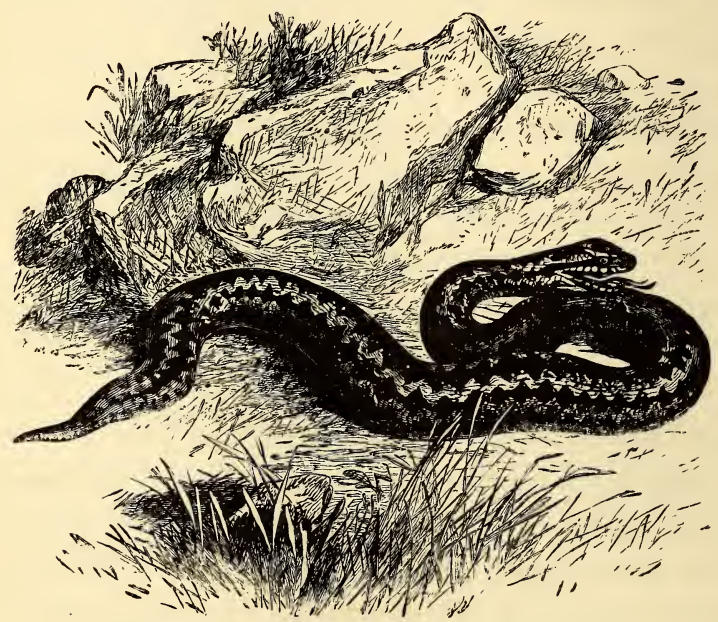

Frg. 298.-Adder, or Viper (Pelias berus). England.

skin. The tongue differs from that of nearly all other Reptiles in being bifid and extensile. The mouth is very dilatable. The skin is frequently shed, and always by reversing it. Snakes make their way on land or in water with equal facility.

As a rule, the venomous Snakes, as Vipers and Rattlesnakes, are distinguished by a triangular head covered with small scales; a constriction behind the head; two or more fangs, and few teeth; small eyes, with vertical pupil; and short, thick tail. In the harmless Snakes, the head gradually blends with the neck, and is covered with plates; the teeth are comparatively numerous in both jaws; the pu- 


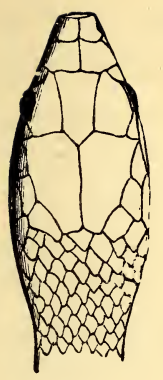

$a$
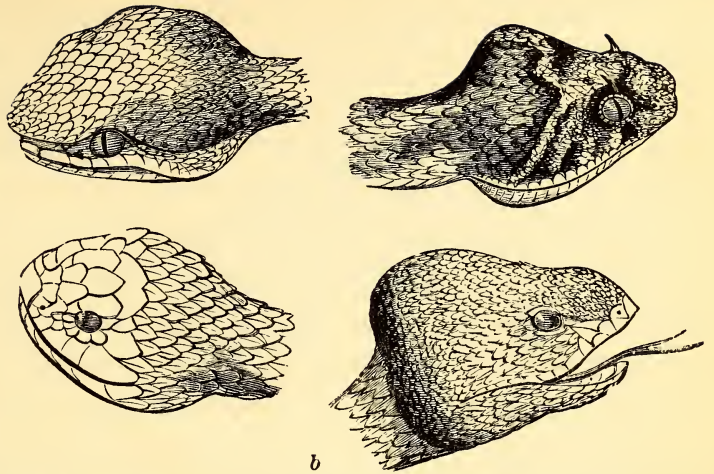

Fig. 299. - $a$, Head of a Harmless Snake (upper view); $b$, heads of various Venomous Snakes.

pil is round, and the tail tapering. This rule, however, has many exceptions.

2. Lacertilia, or Lizards, may be likened to Snakes provided with four limbs, each having five digits. ${ }^{165}$ The body is covered with horny scales. All have teeth, which are simple in structure; and the halves of the lower jaw are firmly united in front, while those of Snakes are

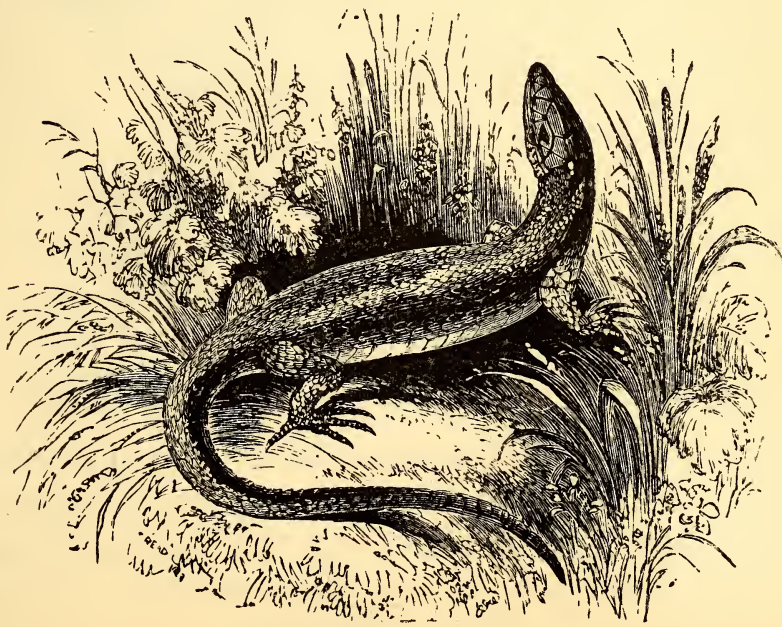

Fig. 300.-Lizard (Lacerta). 
loosely tied together by ligaments. Nearly all have a breast-bone, and the eyes (save in the Gecko) are furnished with movable lids. In the common Lizards and Chameleon, the tongue is extensile. The tail is usually long, and in some cases each caudal vertebra has a division in the middle, so that the tail, when grasped, breaks off at one of these divisions. The Chameleon has a prehensile tail. The Iguana is distinguished by a dewlap on the throat and a crest on the back. Except some of the Monitors of the Old World, all the Lizards are terrestrial.

3. Chelonia, or Tortoises and Turtles, are of anomalous structure. The skeleton is external, so as to include not only all the viscera, but also the whole muscular system, which is attached internally; and even the limbs are

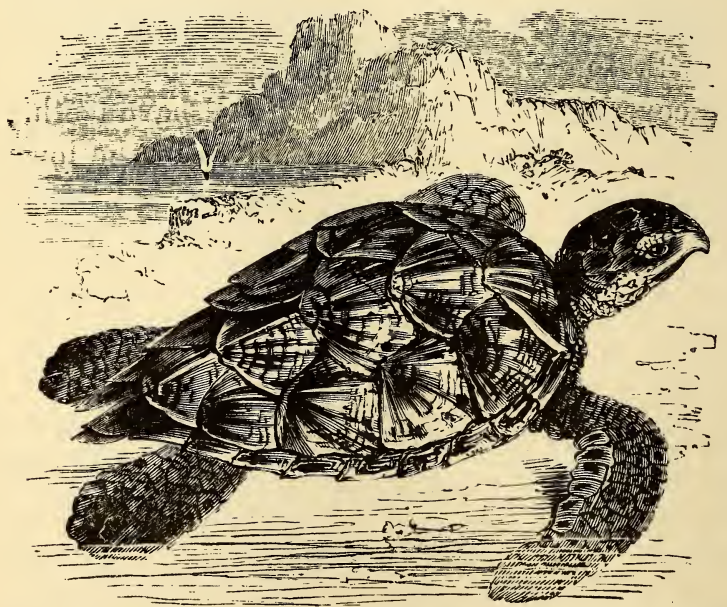

Fig. 301.-Hawk's-bill Turtle (Eretmochelys imbricata). Tropical Atlantic.

inside, instead of outside, the thorax. The exoskeleton unites with the endoskeleton, forming the carapace, or case, in which the body is enclosed. The exoskeleton consists of horny plates, known as "tortoise-shell" (in the soft Tortoises, Trionyx, this is wanting), and of dermal 
bones, united to the expanded spines of the vertebræ and to the ribs, making the walls of the carapace. The ventral pieces form the plastron, or sternum. ${ }^{166}$ All are toothless. There are always four stout legs; and the order furnishes the only examples of Vertebrates lower than

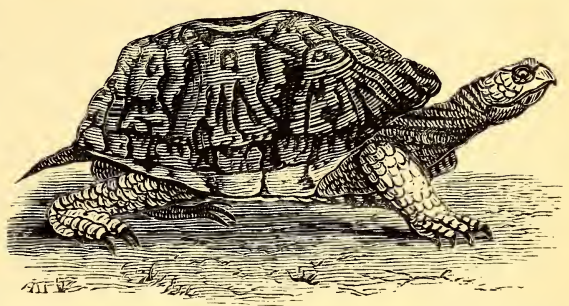
Birds that really walk, for Lizards and Crocodiles wriggle, and drag the body along. There are no teeth, but a horny beak. The eggs are covered with a calcareous shell.

The Sea-turtles, as the edible Green Turtle and the Hawk's-bill Turtle, which furnish the "tortoise-shell" of commerce, have the limbs converted into paddles. The fresh-water forms, represented by the Snapping Turtle (Chelydra), are amphibious, and have palmated feet. Land Tortoises (Testudo) have short, clumsy limbs, fitted for slow motion on the land; the plastron is very broad, and the carapace is arched (while it is flattened in the aquatic species), and head, legs, and tail can be drawn within it. The land and marine species are vegetable-feeders; the others, carnivorous.

4. Crocodilia, the highest and largest of Reptiles, have also two exoskeletons-one of horny scales (epidermal), and another of bony plates (dermal). The bones of the skull are firmly united, and furnished with numerous teeth, implanted in distinct sockets. The lower jaw extends back of the cranium. The heart has four cavities, but the pulmonary artery and aorta communicate with each other, so that there is a mixture of venous and arterial blood. They have external ear-openings, closed by a flap of the 
skin, and eyes with movable lids; a muscular gizzard; a long, compressed tail; and four legs, with feet more or less webbed, and having five toes in front and four behind. The existing species are confined to tropical rivers, and are carnivorous. The eggs are covered with a hard shell.

There are three representative forms : the Gavial of the Ganges, remarkable for its long snout and uniform teeth; the Crocodiles, mainly of the Old World, whose teeth are unequal, and the lower canines fit into a notch in the edge of the upper jaw, so that it is visible when the mouth is

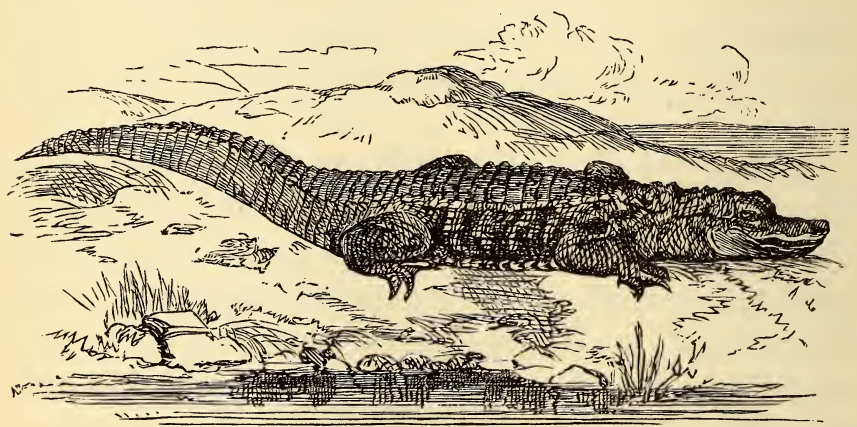

Frg. 303.-Alligator (A. Mississippiensis). Southern States.

closed; and the Alligators of the New World, whose canines, in shutting the mouth, are concealed in a pit in the upper jaw. The toes of the Gavials and Crocodiles are webbed to the tip; those of the Alligators are not more than half-webbed.

In the mediæval ages of geological history, the class of Reptiles was far more abundantly represented than now. Among the many forms which geologists have unearthed are numerous gigantic Saurians, which cannot be classified with any of the four living orders. Such are the Ichthyosaurus, Plesiosaurus, Pterodactyle, Megalosaurus, and Iguanodon. 


\section{Class IV.-Aves.}

Birds form the most clearly defined class in the whole Animal Kingdom. The Eagle and Hummer, the Ostrich and Duck, widely as they seem to be separated by size, form, and habits, still exhibit one common type of structure. On the whole, Birds are more closely allied to Reptiles than to Mammals. In number, they approach the Fishes, ornithologists having determined eight thousand species, or more.

A Bird is an air-breathing, egg-laying, warm-blooded, feathered Vertebrate, with two limbs (legs) for perching, walking, or swimming, and two limbs (wings) for flying or swimming. Organized for flight, it is gifted with a light skeleton, very contractile muscular fibre, and a respiratory function of the highest development.

The skeleton is more compact than those of Reptiles and Mammals, at the same time that it is lighter, and the bones are harder and whiter. It contains fewer bones than usual, many parts being anchylosed together, as the skull-bones, the dorsal vertebræ, and bones of the tarsus and metatarsus. The lumbar vertebræ are united to the ilia. The neck is remarkably long (containing from nine to twenty-four vertebræ) and flexible, enabling the head to be a most perfect prehensile organ. The ribs are generally jointed in the middle, as well as with the backbone and sternum. The last, where the muscles of flight originate, is highly developed. The skull articulates with the spinal column by a single condyle, and with the lower jaw, not directly, as in Mammals, but through the intervention of a separate bone, as in Reptiles.

All Birds always have four limbs, while every other vertebrate class shows exceptions. The fore-limbs are fitted for flight. They ordinarily consist of nine separate bones, and from the hand, fore-arm, and humerus are de- 
veloped the primary, secondary, and tertiary feathers of the wing. The hind-limbs are formed for progressionwalking, hopping, running, paddling, and also for perching and grasping. The modifications are more numerous and important than those of the bill, wing, or tail. There are twenty bones ordinarily, of which the tibia is the principal; but the most characteristic is the tarso-metatarsus,

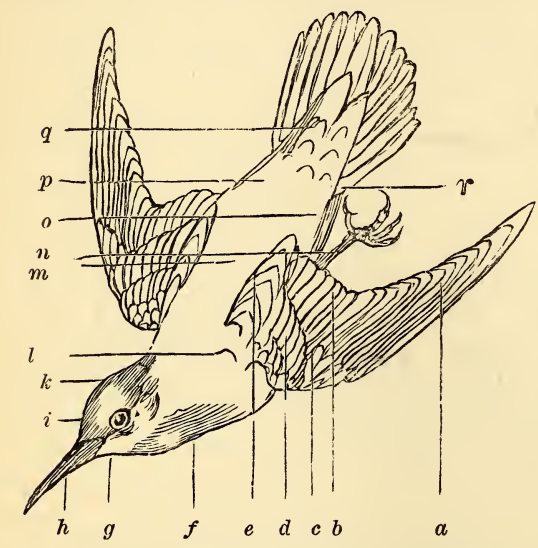

Frg. 304.-Principal Parts of a Bird: $\alpha$, primaries ; $b$, secondaries ; $c$, spurious wing ; $d$, wing-coverts; $e$, tertiaries ; $f$, throat, or jugulum ; $g$, chin; $h$, bill; the meeting-line between the two mandibles is the commissure; the ridge on the upper mandible is called culmen; that of the lower, gonys; the space between the base of the upper mandible and the eye is the lore; $i$, forehead; $k$, crown; $l$, scapular feathers; $m$, back ; $n$, metatarsus, often called tarsus or tarso-metatarsus; $o$, abdomen ; $p$, rump ; $q$, upper tail-coverts ; $r$, lower tail-coverts.

which is a fusion of the lower part of the tarsus with the metatarsus. The rest of the tarsus is fused with the tibia. The thigh is so short that the knee is never seen outside of the plumage; the first joint visible is the heel. ${ }^{167}$. Most Birds have four toes (the external or "little" toe is always wanting); many have three, the hallux, or "big" toe, being absent; while the Ostrich has but two, answering to the third and fourth. The normal number of phalanges, reckoning from the hallux, is $2,3,4,5$. The toes always end in claws.

Birds have neither lips nor teeth, epiglottis nor diaphragm. The teeth are wanting, because a heavy masticating apparatus in the head would be unsuitable for flight. The beak, crop, and gizzard vary with the food. It is a peculiarity of all Birds, though not confined to 
them, that the generative products and the refuse of digestion are all discharged through one common outlet.

The sole organs of prehension are the beak and feet. The circulation is double, as in Mammals, starting from a four-chambered leart. Respiration is more complete than in other Vertebrates. The lungs are fixed, and communicate with air-sacs in various parts of the body, as along the vertebral column, and also with the interior of many bones, as the humerus and femur, which are usually hollow and marrowless. ${ }^{188}$ Both brain and cord are much larger relatively than in Reptiles; the cranium is larger in proportion to the face; and the parts of the brain are not situated in one plane, one behind the other. The cerebrum is round and smooth, and the cerebellum singlelobed. The ears resemble those of Crocodiles; but the eyes are well developed, and protected by three lids. They are placed on the sides of the head, and the pupil is always round. The sexes generally differ greatly in plumage, in some cases more widely than two distinct species, but the coloration of either sex of any one species is very constant.

There are two subclasses. ${ }^{169}$

\section{Subchass I.--Ratitæ (Cursores).}

This small and singular group is characterized by having no keel on the breastbone, rudimentary wings, feathers with disconnected barbs, and stout legs. The African Ostrich has two toes, the Cassowary three, and the Apteryx four.

Its representatives are the Ostrich (Struthio) of Africa and Arabia, South American Ostrich (Rhea), Cassowary (Casuarius) of the East Indian Archipelago and Australia, Emu (Dromceus) of Australia, and Apteryx, or Kiwikiwi, of New Zealand. Besides these, there are extinct gigantic forms from Madagascar (Apyornis) and from 


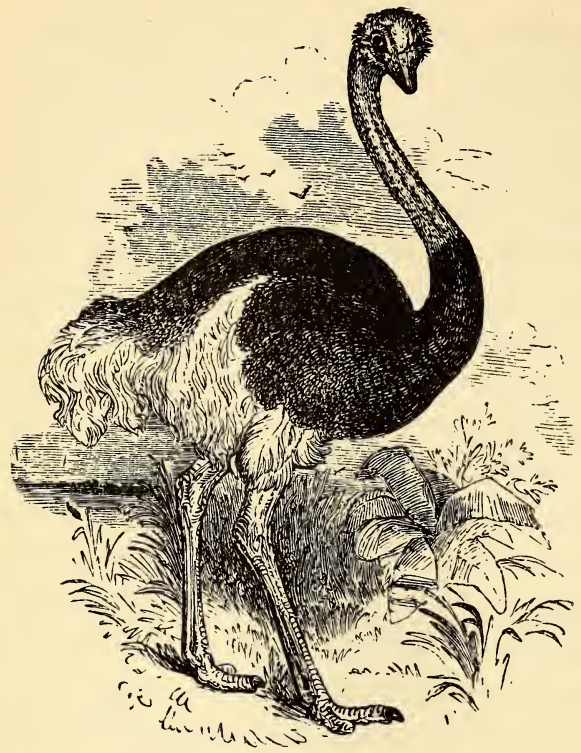

Frg. 305.-African Ostrich (Struthio camelus).

New Zealand ( $D$ inornis, or Moa). This singular geographical distribution, like that of the Dipnoi and Marsupials, shows that the group was once widely spread over the earth, but is now greatly restricted in area.

Subclass II. Carinatæ.

Birds with a keeled sternum, and with developed functional wings.

A. Aquatic Birds.-Specially organized for swimming; the body flattened, and covered with water-proof clothing-feathers and down; the legs short (the knees being wholly withdrawn within the skin of the body), and set far apart and far back; the feet webbed, and hind-toe elevated or absent. The legs are always feathered to the heel at least. They are the only Birds whose neck is sometimes longer than the legs.

1. Pygopodes, or Divers.These lowest of the feathered

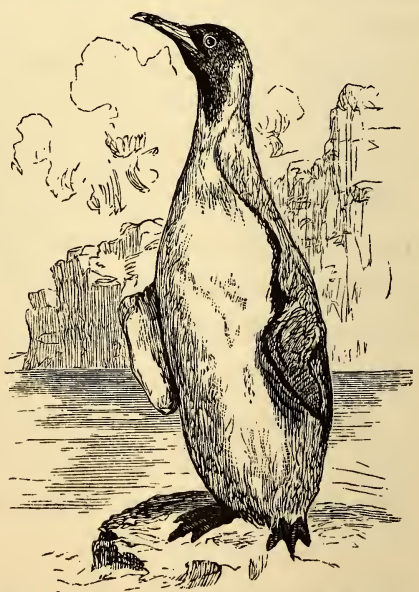

Fra. 306.-Penguin (Aptenodytes Pennantii). Falkland Islands. 


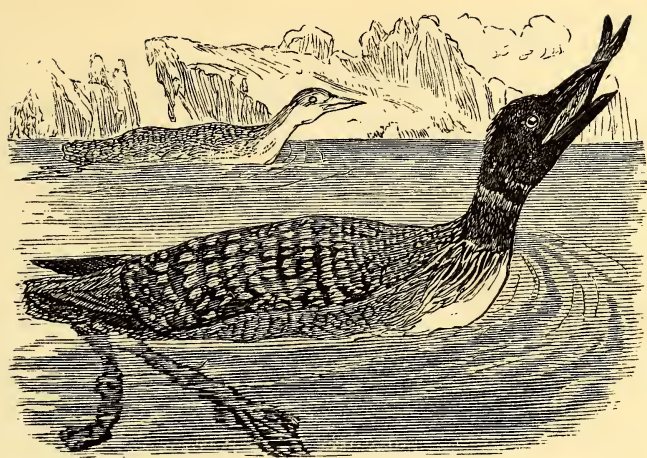

Fig. 307.-Loon (Colymbus torquatus). North America.

tribe have very short wings and tail, and the legs are placed so far back that they are obliged, when on land, to stand nearly bolt upright. They are better fitted for diving than for flight, or even swimming. They belong to the high latitudes, living on Fishes mainly, and are represented by the Penguins, Auks, Loons, and Grebes.

2. Longipennes, or Gulls.-Distinguished by their long,

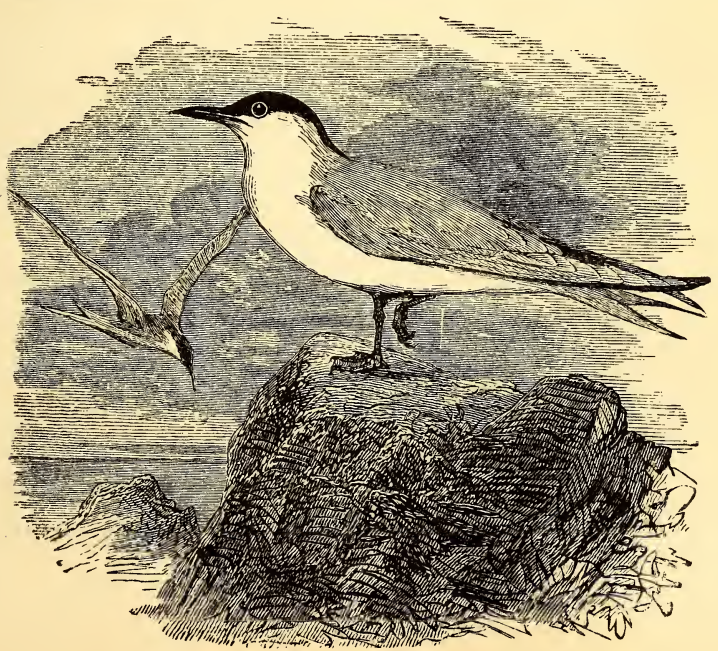

Fig. 308.-Tern (Sterna). 


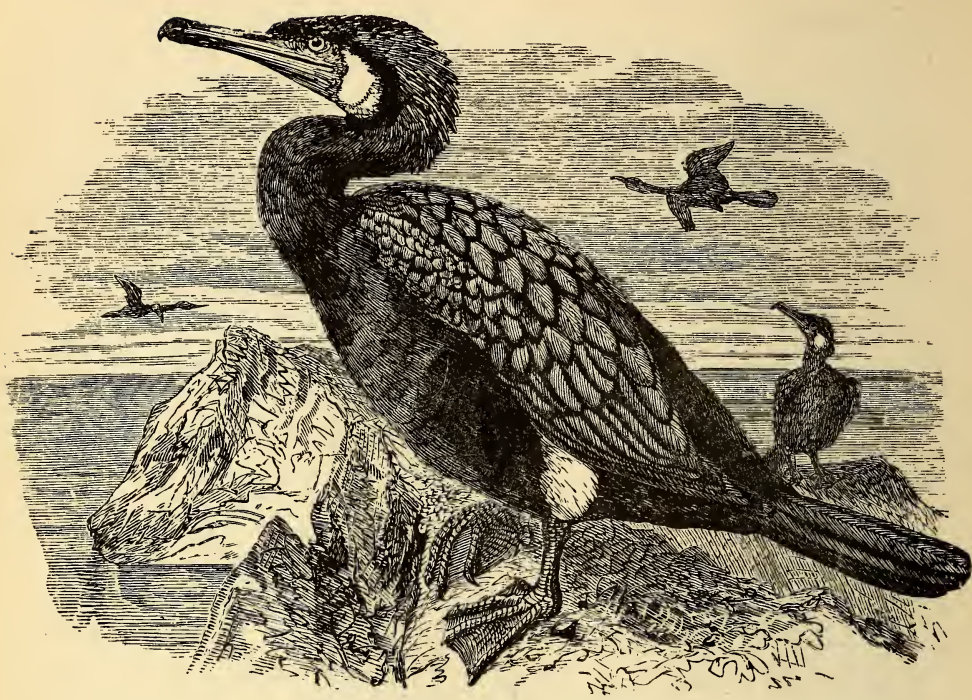

Fig. 309. -Cormorant (Graculus).

pointed wings, usually long tail, and by great powers of flight. They are all carnivorous. Such are the Gulls and Terns, which frequent the sea-coast, lakes, and rivers ; and

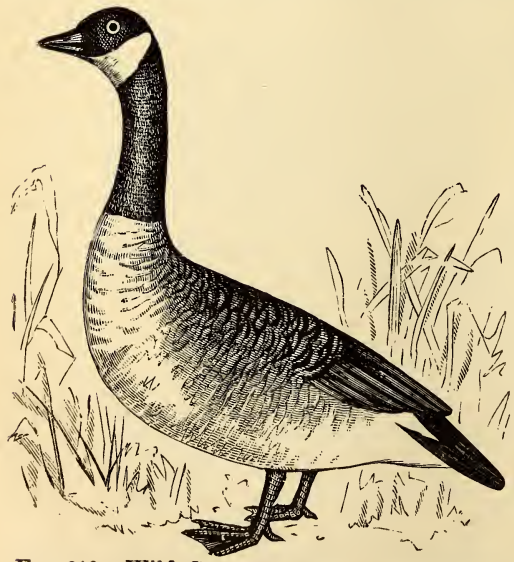

FIG. 310.-Wild Goose (Bernicla Canadiensis). United States. the Albatrosses and $\mathrm{Pe}$ trels (the largest and smallest of web-footed Birds), which are oceanic.

3. Totipalmates, or Cormorants. - Characterized by a long bill, generally hooked; wings rather long; and toes long, and all four joined together by broad webs. Throat generally naked, and furnished with a sac. The majority are large sea-birds, 
and feed on Fishes, Mollusks, and Insects. Examples are the Cormorants, Pelicans, and Gannets.

4. Lamellirostres, or Ducks, have a heavy body, moderate wings, short tail, flattened bill, covered by a soft skin,

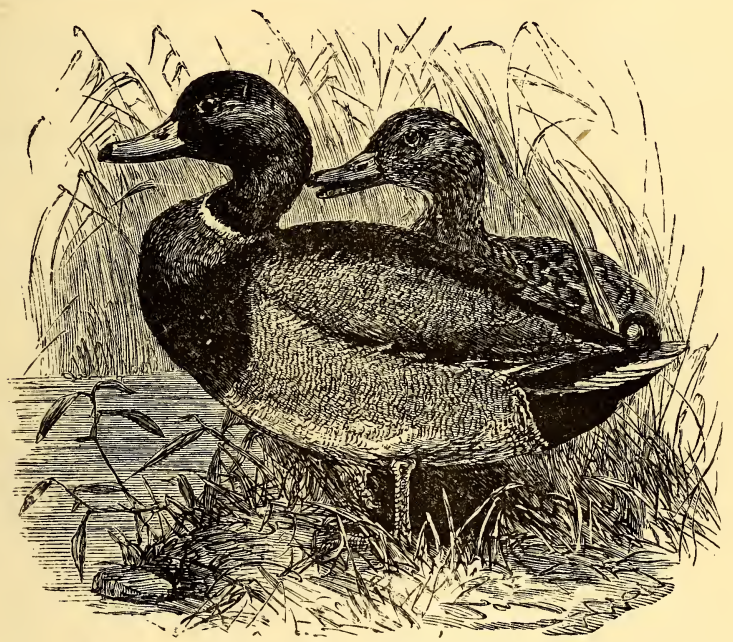

Fig. 311. -Wild Duck (Anas boschas). North America.

with ridges along the edges. Diet more commonly vegetarian than animal. The majority inhabit fresh wateras the Ducks, Geese, Swans, and Flamingoes.

B. Terrestrial Birds. - This group exhibits great diversity of structure; but all agree in being especially terrestrial in habit, spending most of the time on the ground, not on trees or the water, although many of them fly and swim well.

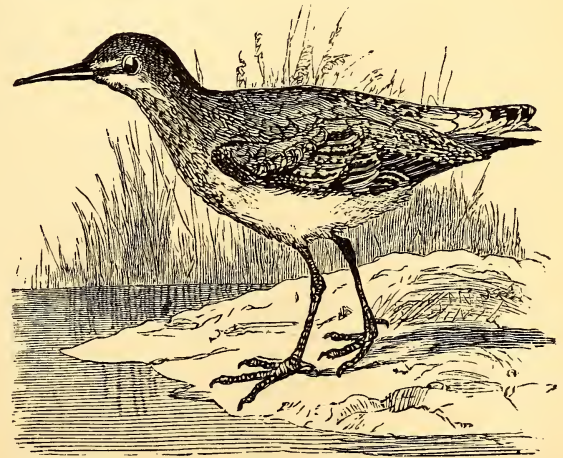

Fig. 312.-Sandpiper (Tringa hypoleuca). England. 
The legs are long or strong, and the knee is free from the

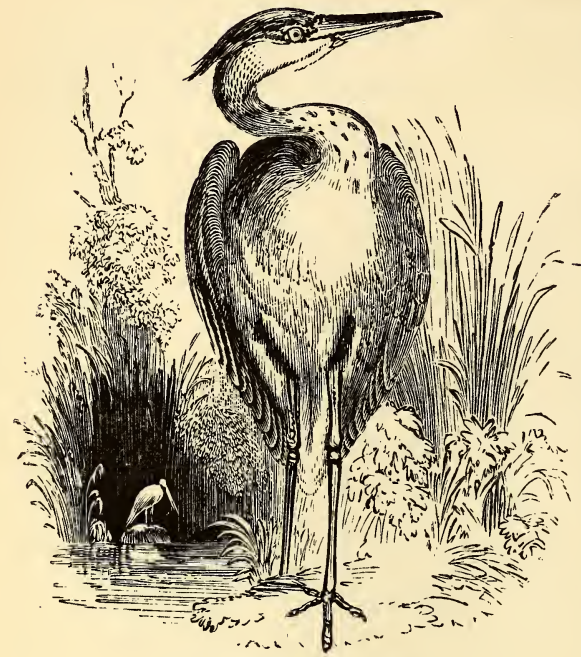

Fig. 313.-Heron (Ardea). body. The hind toe, when present, is small and elevated.

5. Grallatores, or $\mathrm{W}$ a ders.-These are readily distinguished by their long and bare legs. Generally, also, the toes, neck, and bill are of proportionate length, and the tail short. They feed on small animals, and, with a few exceptions, frequent the banks of rivers. In flying, their legs are stretched out behind, while in most other Birds they are folded under the body. Such are the Rails, Cranes, Herons, Storks, Ibises, Stilts, Snipes, Sandpipers, and Plovers.

6. Rasores, or Scratchers. - As a rule, this order, so valuable to Man, is characterized by a short, arched bill; short and concave wings, unfitted for pro- Fig. 314.-Rail, or Marsh Hen (Rallus elegans). tracted flight; stout

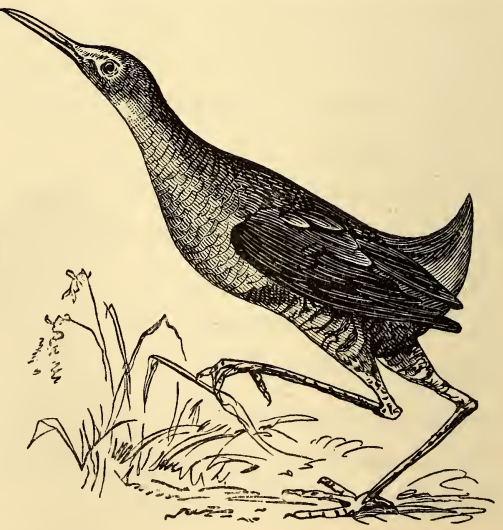
United States. legs, of medium length; and four toes, the three in front 
being united by a short web, and terminating in blunt claws. The legs are usually feathered to the heel, sometimes (as in Grouse) to the toes. The feathers of the body are large and coarse. The males generally have gay plumage, and some appendage to the head. The nostrils are covered by a scale or valve. Their main food is grain. Such are the

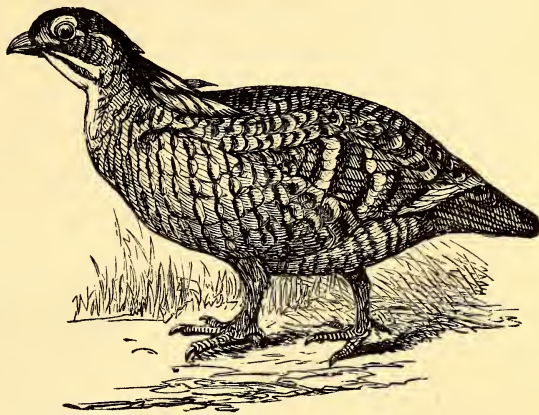

Fı. 315.-Prairie-chicken (Cupidonia cupido). Western prairies. Grouse, Partridges, Turkeys, Pheasants, Poultry, and $\mathrm{Cu}-$ rassows. To these may be added,

7. Columbor, or Pigeons and Doves, although they stand

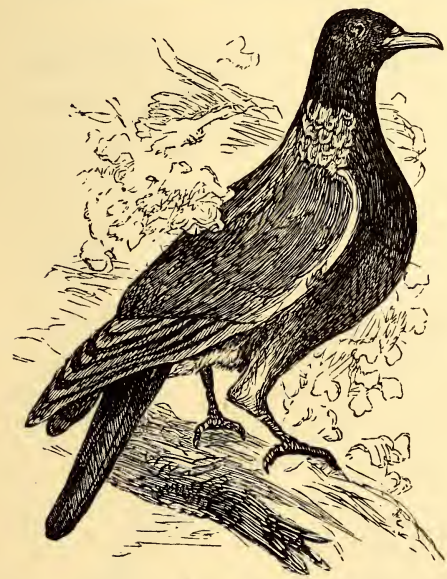

FIG. 316.-Ring-dove (Columba palumbus). England. intermediate between the terrestrial and perching Birds, as the Flamingoes link the aquatic and terrestrial. They differ from the typical Rasores in having wings for prolonged flight, and slender legs, fitted rather for an arboreal life, with toes not united, and the hind toe on a level with the rest.

C. Az̈rial Birds.-This highest and largest group includes all those Birds whose toes are fitted for grasping or perching, the hind toe being on a level with the rest. The knee is free from the body, and the leg is generally feathered to the heel. 
The wings are adapted for rapid or long flight; and they hop, rather than walk, on the ground. ${ }^{170}$ They always live in pairs; and the young are hatched helpless.

8. Raptores, or Birds of Prey, differ from all other

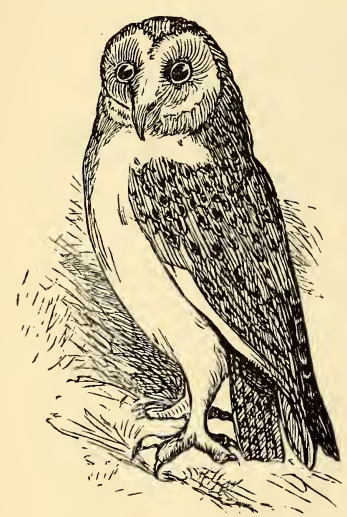

Fig. 317.-Barn-owl (Strix flammea). Both hemispheres. Birds, except Parrots, in having a strongly hooked bill and a waxy membrane (cere) at the base of the upper mandible; and from Parrots,

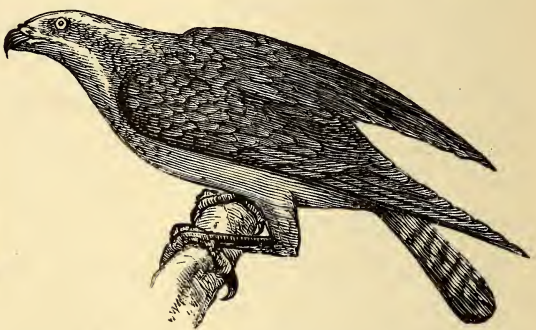

Fig. 318. - Fish - hawk (Pandion Carolinensis). United States.

in having three toes in front and one behind. The toes are armed with long, strong, crooked talons; the legs are robust; and the wings are of considerable size, adapted

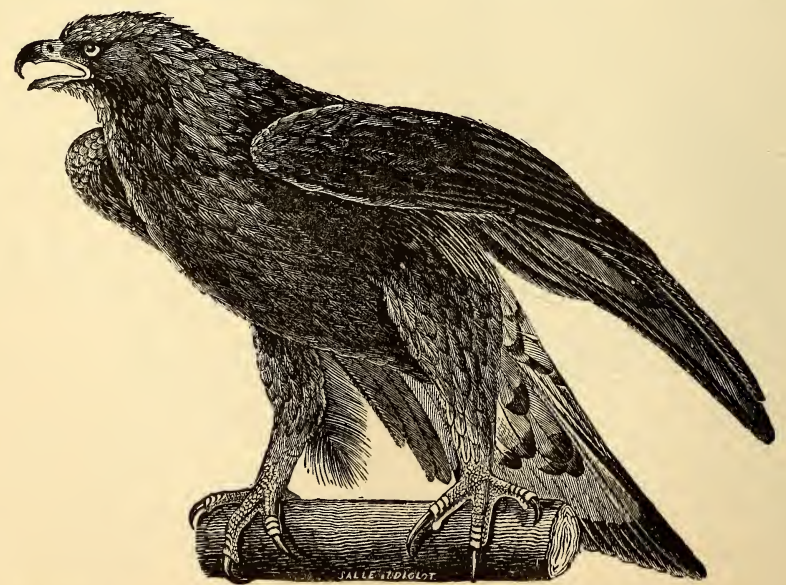

Fig. 319.-Golden Eagle (Aquila chrysaetos). North America and Europe. 
for rapid and powerful flight. The bill is stout and sharp, and usually toothed. All are carnivorous. The female is larger than the male, except the Condor. There are two
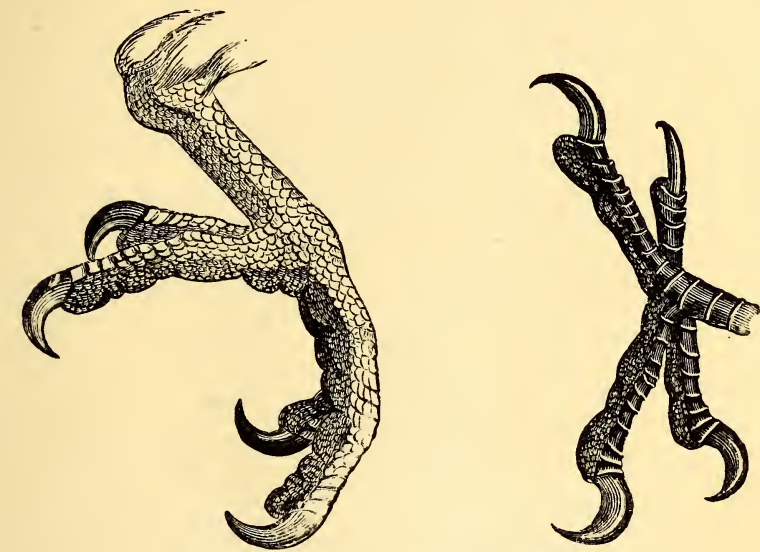

Fia. 320.-Foot of Parrot and Woodpecker.

sections: the Diurnal, whose eyes are on the sides of the head, wings pointed, and metatarsus and toes covered over with scales, as the Vultures, Kites, Hawks, Falcons, and Eagles; the Nocturnal, whose large eyes are directed forward, and surrounded by radiating feathers, metatarsus feathered, and plumage soft, as the Owls.

9. Picarice.-This polymorphic group has hardly any peculiarities in common. ${ }^{171}$ The toes are usually paired, two in front and two behind.

There are three divisions of the order: Cypseli, or Swifts, Goat-suckers, and Humming-birds ; Cuculi, or Cuckoos, Kingfishers, Trogons, Toucans, Hornbills, and Hoopoes ; and Pici, or Woodpeckers. These Birds are not musical, and only ordinary fliers. They feed on Insects or fruit. The majority make nests in the hollows of old trees; but the Cuckoos lay in the nests of other Birds. In climbing, the Woodpeckers are assisted by their stiff tail. 


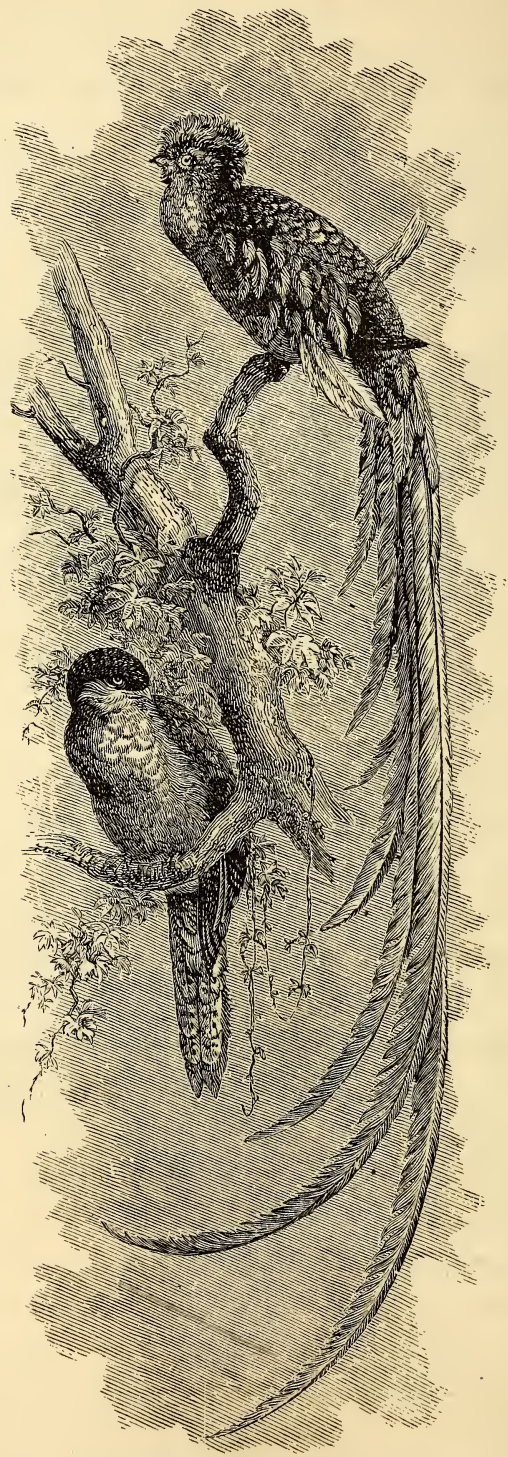

Frg. 321.-Trogon elegans. Central America. 
10. Psittaci, or Parrots.-These birds have a strong, arched upper bill, with a cere at the base, a fleshy, thick,

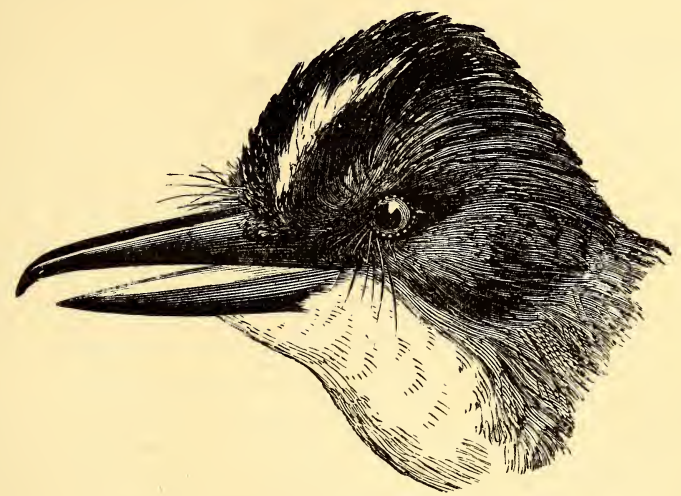

FIG. 322.-Head of a Fly-catcher (Tyrannus).

and movable tongue, and paired toes. They have, usually, brilliant plumage. They live in trees and feed on fruits. Such are the Parrots, Paroquets, and Cockatoos.

11. Insessores, or Perchers.-This order is the most nu-

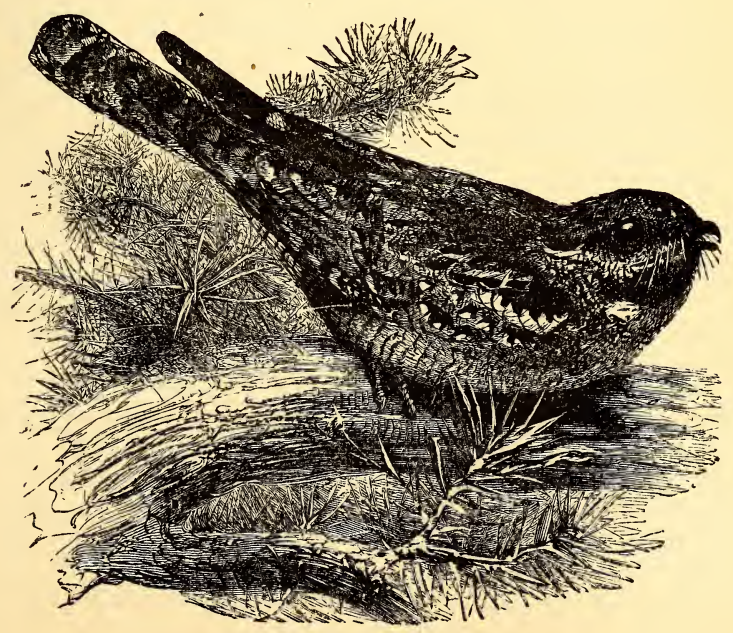

Fig. 323.-Goat-sucker (Caprimulgus). 
merous and varied in the whole class. It comprehends all those tribes which live habitually among trees, excepting

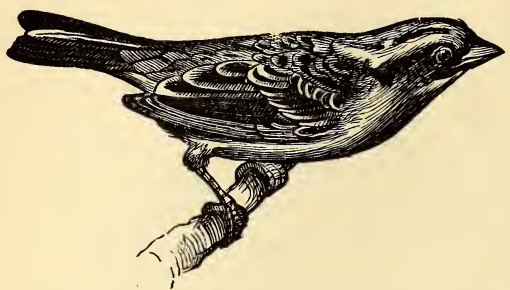

Fre. 324. - White-throated Sparrow (Zonotrichia albicollis). United States.

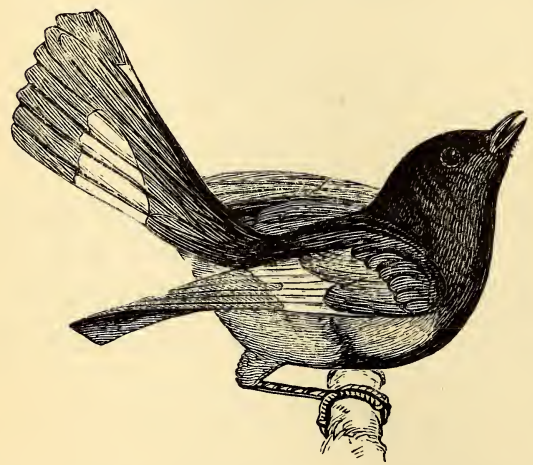

Fig. 325.-Redstart (Setophaga ruticilla). United States.

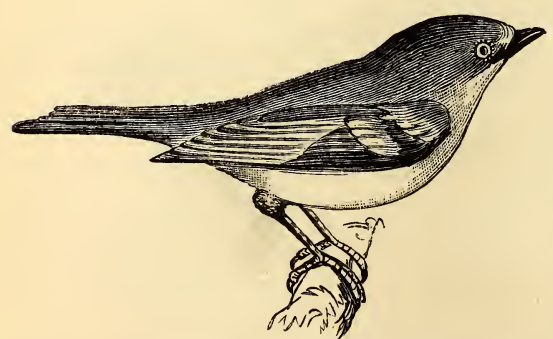

Fig. 326._White-eyed Vireo (Vireo Noveboracensis). United States. tarsus is one continuous plate, or divided transversely into large scales; and the plates on the sides meet beClimbing Birds, and whose toes - three in front, and one behind-are eminently fitted for perching only. The legs are slender, and seldom used for locomotion.

They are divisible into two sections: a. Clamatores, with nothing in common but a harsh voice. In most, the tarsus is enveloped in a row of plates, which meet behind in a groove, and the bill broad, and bent down abruptly at the tip. The typical representatives are the Tyrant Fly-catchers. b. Oscines, or Songsters, all of whom have a vocal apparatus, thongh all do not sing. The anterior face of the

the Rapacious and 
hind in a ridge. The toes, always three in front and one behind, are on the same level. The eggs are usu-

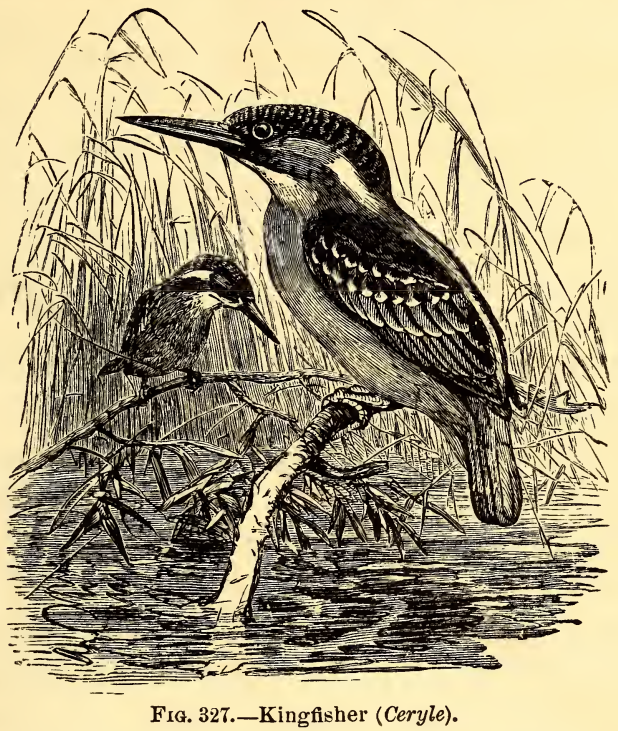

ally colored. Here belong the Ravens, Crows, Jays, Birdsof - Paradise, Blackbirds, Orioles, Larks, Sparrows, Tan-

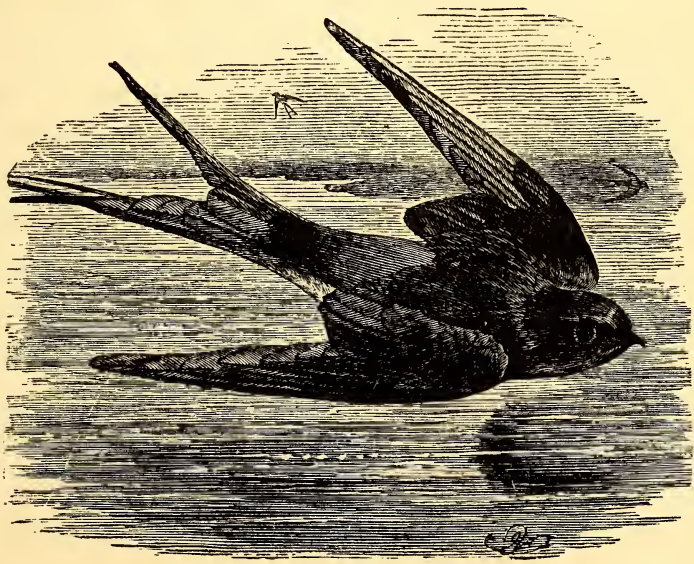

Fı. 328.-Swallow (Hirundo). 
agers, Wax-wings, Swallows, Wrens, Warblers, Thrushes, etc.

\section{Class V.-Mammalia.}

Mammals are distinguished from all other Vertebrates by any one of the following characters: they suckle their young; the thorax and abdomen are separated by a perfect diaphragm; the red corpuscles of the blood have no nucleus, and are therefore double-concave; and either a part or the whole of the body is hairy at some time in the life of the animal. ${ }^{172}$

They are all warm-blooded Vertebrates, breathing only by lungs, which are suspended freely in the thoracic cavity; the heart is four-chambered, and the circulation is double, as in Birds; the aorta is single, and bends over the left bronchial tube; the large veins are furnished with valves; the red corpuscles differ from those of all other Vertebrates in having no nucleus and in being circular (except in the Camel); the entrance to the windpipe is always guarded by an epiglottis; the cerebrum is more highly developed than in any other class, containing a greater amount of gray matter and (in the higher orders) more convolutions; the cerebellum has lateral lobes, a mammalian peculiarity, and there is a corpus callosum and a pons varolii; the cranial bones are united by sutures, and they are fewer than in cold-blooded Vertebrates; the skull has two occipital condyles, a feature shared by the Amphibians; the lower jaw consists of two pieces only (often united), and articulates directly with the cranium; with four exceptions there are always seven cervical vertebræ $;^{173}$ the dorsal vertebræ, and therefore the ribs, vary from ten to twenty-four; the lumbar vertebræ number from two to nine; the sacral from three to nine, and the caudal from two to forty-six ; the articulating surfaces of the vertebræ are generally flat; the fore-limbs are never wanting, and the hind-limbs only in 
a few aquatic forms ; excepting the Whales, each digit carries a nail, claw, or hoof; the teeth (always present, save

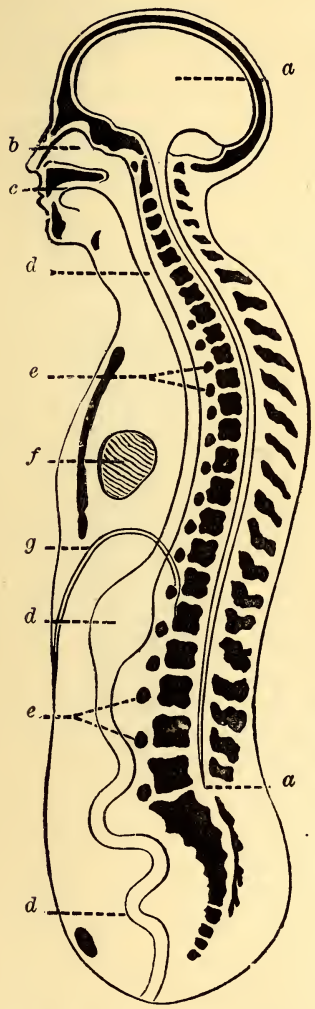

Fıt. 329.-Longitudinal Section of Human Body (theoretical) : $a$, cerebro-spinal nervous system ; $b$, cavity of nose ; $c$, cavity of month ; $d$, alimentary canal; $e$, chain of sympathetic ganglia ; $f$, heart; $g$, diaphragm. in certain low tribes) are planted in sockets; the mouth is closed by flexible lips; an external ear is rarely absent $;^{174}$ the eyes are always present, though rudimentary in some burrowing animals; they are viviparous; and, finally, and perhaps above all, while in all other animals the embryo is developed from the nourishment laid up in the egg itself, in Mammals it draws its support, almost from the beginning, directly from the parent, and, after birth, it is sustained for a time by the milk secreted by the mammary glands. From the first, therefore, till it can care for itself, the young Mammal is in vital connection with the parent.

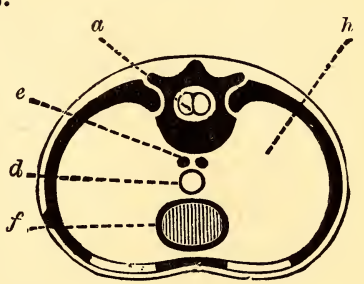

Fig. 330. - Transverse Section of Human Body (theoretical): $a$, cerebro-spinal nervous axis contained in neural tube; $e$, chain of sympathetic ganglia; $d$, alimentary canal; $f$, heart; $h$, hæmal tube.

\section{Subclass I.-Ornithodelphia.}

These Mammals have but one outlet for the intestine, urinary and reproductive organs, as in Birds. They are implacental. There is but one order. 
1. Monotremata. - This order includes two singular forms, the Duck-mole (Ornithorhynchus) and Spiny Anteater (Echidna), both confined to the Australian continent and New Guinea. The former has a covering of fur, a bill like that of a Duck, and webbed feet. The latter is covered with spines, has a long, toothless snout, like the Ant-eater's, and the feet are not webbed. Both bur-

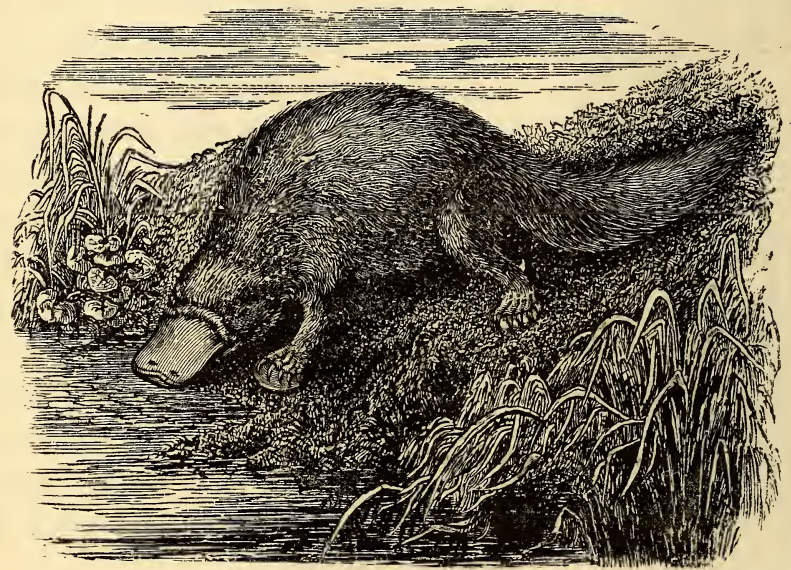

FıG. 331.-Ornithorhynchus.

row, and feed upon Insects. The brain is smooth in the Ornithorhynchus, and folded in the Echidna. In both, the cerebral hemispheres are loosely united by transverse fibres, and do not cover the cerebellum and olfactory lobes. ${ }^{175}$

\section{Subclass II.-Didelphia.}

In these implacental Mammals the uterus is divided into two parts.

2. Marsupialia are distinguished by the fact that the young, always born premature, are transferred by the mother to a pouch on the abdomen, where they are attached to the nipples, and the milk is forced into their mouths by special muscles. ${ }^{176}$ They have "marsupial 
bones" projecting from the pelvis, which may serve to support the pouch; but as the Monotremes have the same bones, but no pouch, they doubtless have some other function. These bones are peculiar to animals having no placenta, namely, to Monotremes and Marsupials. The brains of Marsupials resemble those of the Monotremes, except that the cerebrum of the Kangaroo covers the olfactory lobes. All have the four kinds of teeth, and all are covered with fur, never with spines or scales. Except the Opossums of America, all are restricted to Australia and

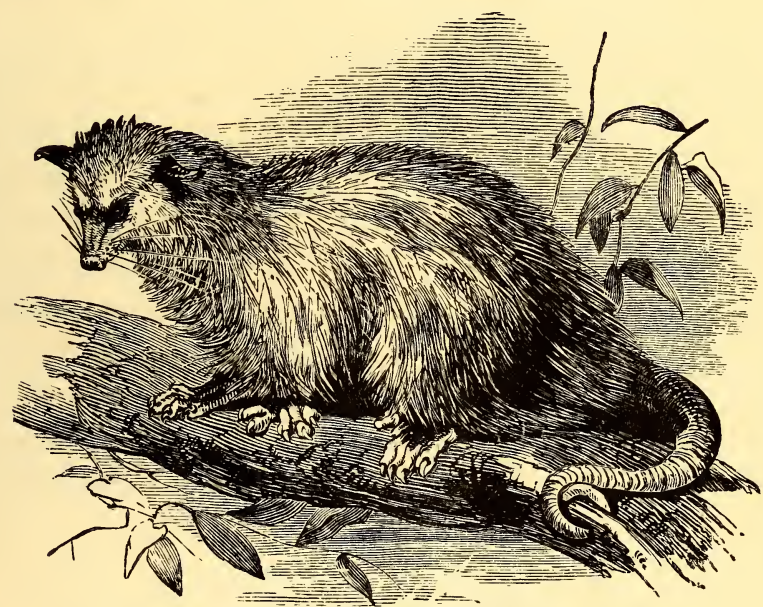

Fig. 332.-Virginian Opossum (Didelphys Virginiana).

adjacent islands. The Marsupials are almost the only Mammals of Australia, a few species of Rodents and Bats being the only placental Mammals. The Marsupials have here developed into forms corresponding in their habits to the orders of placental Mammals in the rest of the world. The Kangaroos take the place of the large herbivores - the Ungulates. The Thylacinus and Dasyurus are the marsupial carnivora. Other forms are squirrellike in shape and habits, and still others are insectivorous. 
SubClass III.-Monodelphia or Placental Mammals.

In these Mammals the young are connected with the mother by means of a vascular structure, the placenta, by which they are nourished. They are born in a relatively perfect condition.

3. Edentata.-This strange order contains very diverse forms, as the leaf-eating Sloths and the insectivorous Anteaters and Armadillos of South America, and the Pangolin and Orycteropus of the Old World. The gigantic fos-

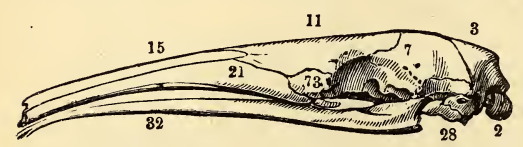

Fig. 333.-Skull of the Great Ant-eater (Myrmecophaga jubata) : 15 , nasal ; 11 , frontal ; 7 , parietal ; 3, superoccipital ; 2, occipital condyles ; 28, tympanic; 73 , lachrymal; 32, lower mandible. Teeth wanting.

sils, Megatherium and Glyptodon, belong to this group. The Sloths and Ant-eaters are covered with coarse hair; the Armadillos and Pangolins, with an armor of plates or scales. The Ant-eaters and Pangolins are strictly edentate, or toothless; the rest have molars, wanting, however, enamel and roots. In general, it may be said that the order. includes all quadrupeds having separate, clawed toes and no incisors. The Sloths are arboreal; the

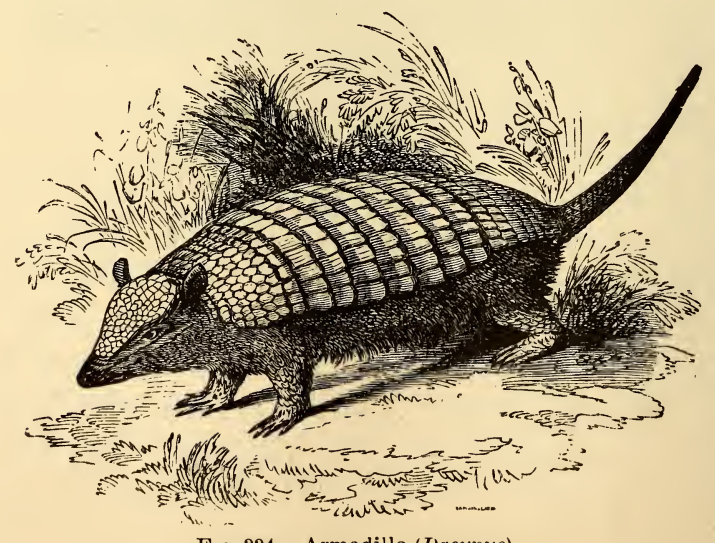

Fig. 334.-Armadillo (Dasypus). 
others burrow. The brain is generally smooth; but that of the Ant-eater is convoluted, and has a large corpus callosum; but in all the cerebellum and part of the olfactory lobes are exposed.

4. Rodentia, or Gnawers, are characterized by two long, curved incisors in each jaw, enameled in front, and perpetually growing; they are specially formed for nibbling.

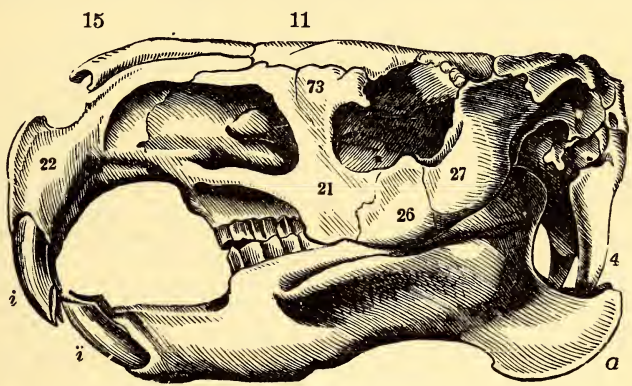

Fig. 335.-Skull of a Rodent (Capybara) : 22, premaxillary ; 21, maxillary ; 26, molar ; 27 , squamosal; 73 , lachrymal ; 15 , nasal; 11, frontal ; 4, occipital processes, unusually developed; $i$, incisors; $a$, angle of lower jaw.

Separated from them by a wide space (for canines are wanting), are the flat molars, admirably fitted for grinding. The lower jaw has longitudinal condyles, which work freely backward and forward in longitudinal furrows. Nearly all have clavicles; and the toes'are clawed. The cerebrum is nearly or quite smooth, and covers but a small part of the cerebellum. All are vegetarian.

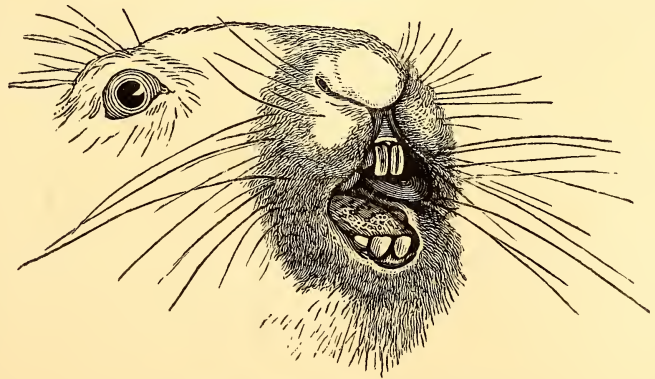

Fig. 336.-Incisor 'I'eeth of the Hare. 
More than one half of all known Mammals are Rodents. They range from the equator to the poles, over every continent, over mountains and plains, deserts and woods. The

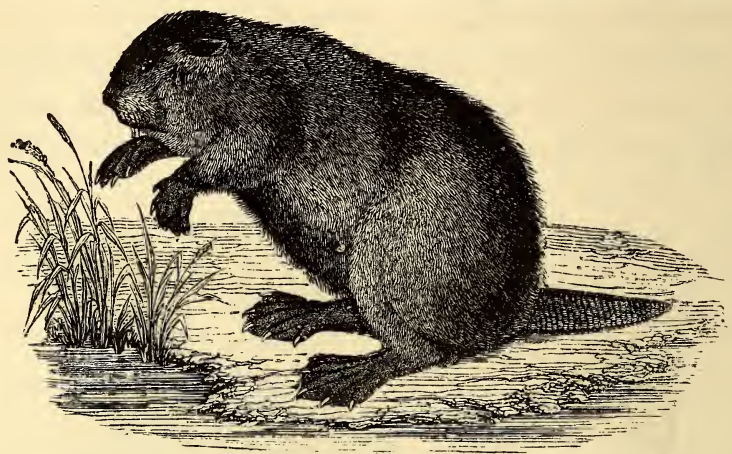

Fra. 337.-Beaver (Castor Canadensis). North America.

more important representatives are the Porcupines, Capybaras, Guinea-pigs, Hares, Mice, Rats, Squirrels, and Beavers. The Capybara and Beaver are the giants of the race.

5. Insectivora are diminutive, insect-eating animals, some, as the Shrew, being the smallest of Mammals.

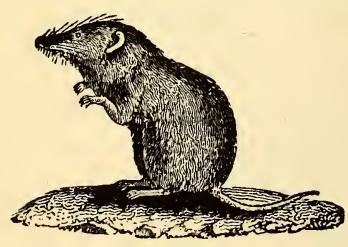

Fig. 338.--Shrew Mouse (Sorex). They have small, smooth brains, which, as in the preceding orders, leave uncovered the cerebellum and olfactory lobes. The molar teeth bristle with sharp, pointed cusps, and are associated with canines and incisors. They have a long muzzle, short legs, and clavicles. The feet are formed for walking or grasping, and are plantigrade, five-toed, and clawed. The Shrew, Hedgehog, and Mole are examples.

6. Cheiroptera, or Bats, repeat the chief characters of the Insectivores; but some (as the Flying-fox) are fruiteaters, and have corresponding modifications of the teeth. They are distinguished by their very long fore-limbs, 
which are adapted for flight, the fingers being immensely lengthened, and united by a membranous web. The toes, and one or two of the fingers, are armed with hooked

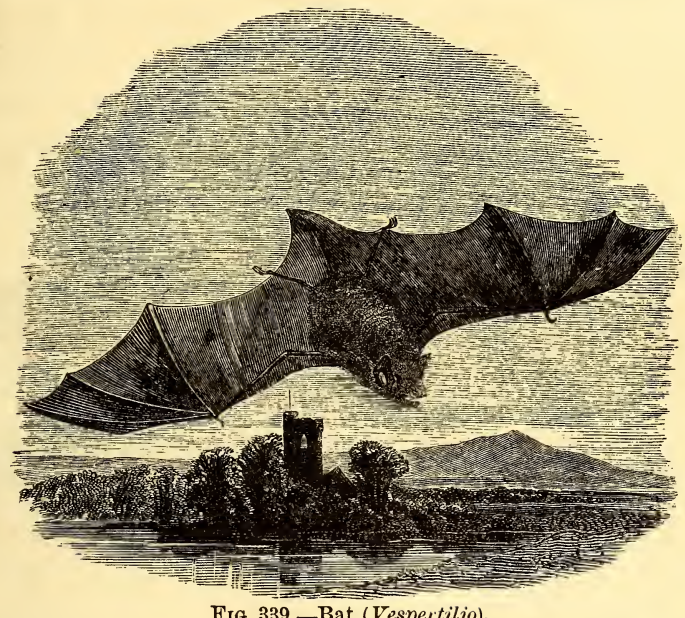

Frg. 339.-Bat (Vespertilio).

nails. The clavicles are remarkably long, and the sternum is of great strength; but the whole skeleton is extremely light, though not filled with air, as in Birds. The eyes are small, the ears large, and the sense of touch is very acute. The favorite attitude of a Bat when at rest is that of suspension by the claws, with head downward. They are all nocturnal.

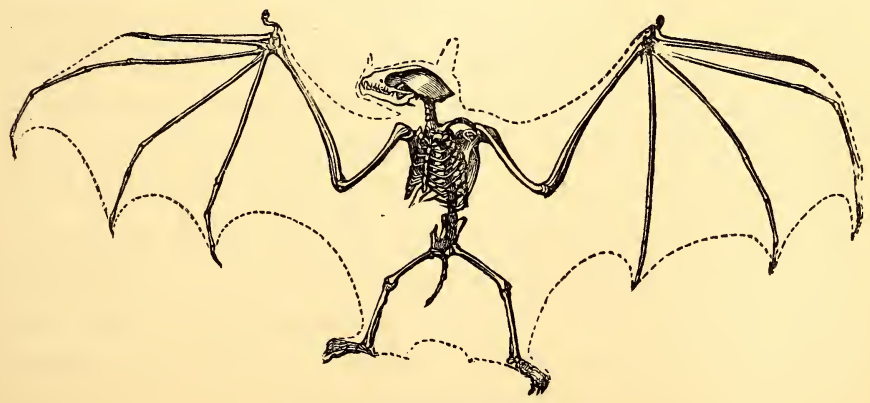

Fig. 340.-Skeleton of a Bat. 
7. Cetacea, or Whales, have the form and life of Fishes, yet they possess a higher organization than the preceding orders. They have a broad brain, with many and deep foldings; the foramen magnum of the skull is entirely posterior; the whole head is disproportionately large, and the jaws greatly prolonged. The body is covered with a thick, smooth skin, with a layer of fat ("blubber") under-

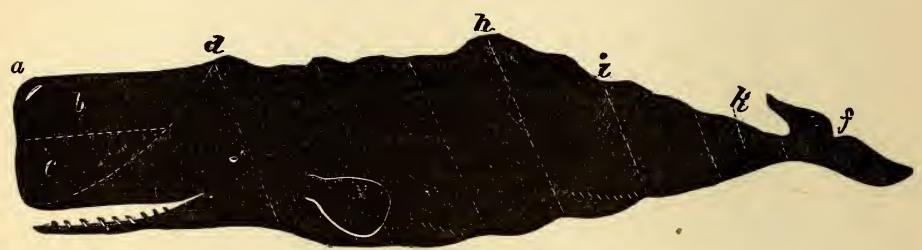

Fig. 341.-Ontline of the Sperm-whale (Physeter) : $a$, blow-hole; $b$, the case containing spermaceti ; $c$, junk; $d$, bunch of the neck-between it and the corner of the mouth is the eye; $h$, hump; $i$, ridge $k$, the small; $f$, tail, or flukes. Between the dotted lines are the spiral strips of blubber. Maximum length, sixty feet. South Atlantic.

neath; there are no clavicles; the hind-limbs are wanting, and the front pair changed to paddles; the tail expands into a powerful, horizontal fin; neck and external ears are wanting; the eyes small, with only two lids; the nostrils ("blow-holes")-double in the Whale, single in the Porpoise-are on the top of the head. All are carnivorous, and essentially marine, a few Dolphins only being found in the great rivers. In the Whalebone Whales, the teeth are absorbed, and disappear before birth, and their place is supplied by horny "baleen" plates. "The Whale feeds by putting this gigantic strainer into operation, as it swims through the shoals of minute Mollusks, Crustaceans, and Fishes, which are constantly found at the surface of the sea. Opening its capacious mouth, and allowing the sea-water, with its multitudinous tenants, to fill the oral cavity, the Whale shuts the lower jaw upon the baleen plates, and, straining out the water through them, swallows the prey stranded upon its vast tongue." In the 


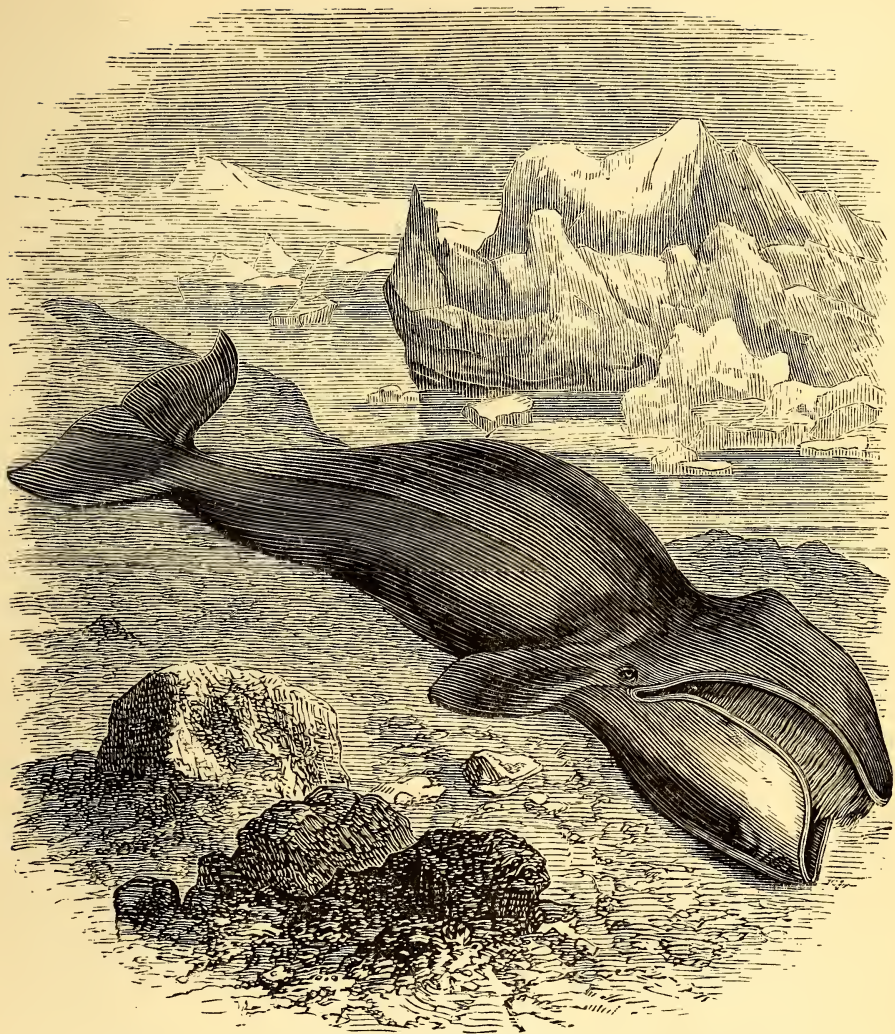

Fig. 342.-Greenland Whale (Balcena mysticetus). North Atlantic.

other Cetaceans teeth are developed, especially in Dolphins and Porpoises ; but the Sperm Whale has them only in the lower jaw, and the Narwhal can show but a single tusk. The Dolphins are the only Mammals having no organ of smell.

8. Sirenia resemble the Cetaceans in shape, but are closely allied to the hoofed animals in organization. They have the limbs of the Whales, and are aquatic; but they are herbivorous, and frequent great rivers and estuaries. They have two sets of teeth, the Cetaceans having but 


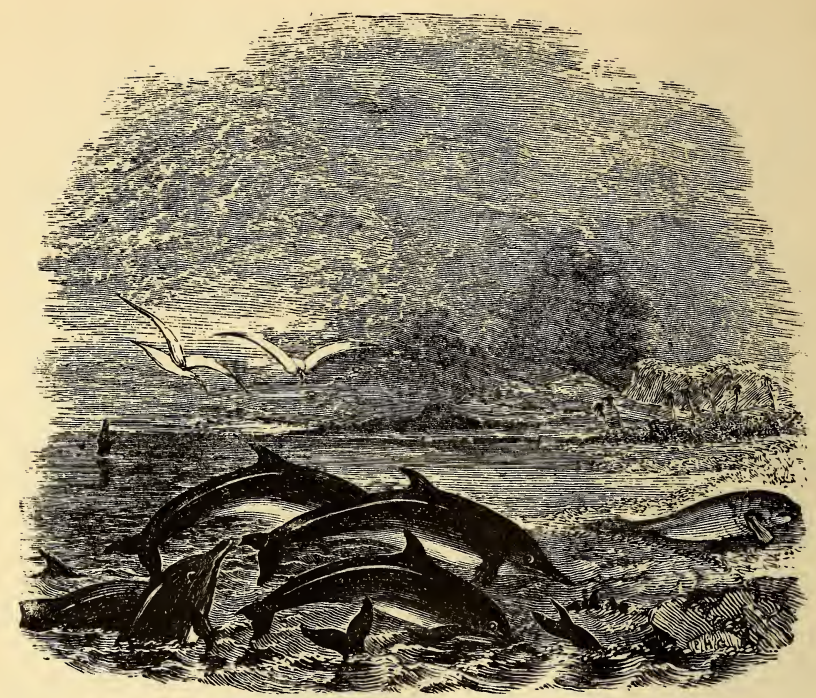

Fic. 343. -Troop of Dolphins, with Mayatee in the distance.

one. They have a narrow brain; bristles scantily covering the body; and nostrils placed on the snout, which is large and fleshy. The living representatives are the Manatee, of both sides of the tropical Atlantic Ocean, and the - Dugong, of the East Indies.

9. Proboscidia. - This race of giants, now nearly extinct, is characterized by two upper incisors in the form of tusks, mainly composed of dentine (ivory). In the extinct Dinotherium the tusks projected from the lower jaw ; and in the Mastodon, from both jaws. Canines are wanting. The molars are few and large, with transverse ridges (Elephant) or tubercles (Mastodon). The cerebrum is large and convoluted, but does not cover the cerebellum. The skull is enormous, the size arising in great measure from the development of air-cavities between the inner and outer plates. The nose is prolonged into a flexible trunk, which is a strong and delicate organ of prehension. There are four massive limbs, each with five toes incased in 
broad, shallow hoofs, and also with a thick, tegumentary pad. The knee is below and free from the body, as in Monkeys and Men. Clavicles are wanting. The body of the Elephant is nearly naked; but the Mammoth, an extinct species, had a covering of long woolly hair. Elephants live in large herds, and subsist on foliage and grass. There are but two living species: the Asiatic, with long head, concave forehead, small ears, and short tusks; and the African, with round head, convex forehead, large ears, and long tusks. ${ }^{177}$

10. Ungulata, or Hoofed Quadrupeds.-This large order, comprehending many animals most useful to Man, is distinguished by four well-developed limbs, each furnished with not more than four complete toes, and each toe incased in a hoof. The leg, therefore, has no prehensile power; it is only for support and locomotion. Clavicles are wanting; and the radius and ulna are so united as to prevent rotation. There are always two sets of teeth, i.e., milk-teeth are succeeded by a permanent set. The grinders have broad crowns. As a rule, all are herbivorous. The brain is always convoluted, but the cerebellum is largely uncovered.

Ungulates are divided into the odd and even toed. $a$. The Odd-toed, as the three-toed Rhinoceros and Tapir, ${ }^{178}$ and the one-toed Horse. ${ }^{179}$ The first is distinguished by its very thick skin, the absence of canines, and one or two horns on the nose. The Tapir has the four kinds of teeth, and a short proboscis. The dental formula of the Horse is-

$$
i \frac{3-3}{3-3}, c \frac{1-1}{1-1}, p m \frac{3-3}{3-3}, m \frac{3-3}{3-3}=40 \text {. }
$$

The canines are often wanting in the mare. The Horse walks on the third finger and toe. The metacarpals and metatarsals are greatly elongated, so that the wrist and heel are raised to the middle of the leg. $\quad b$. The Even-toed 
Ungulates - Hog, Hippopotamus, and Ruminants - have two or four toes. The Hog and Hippopotamus have the

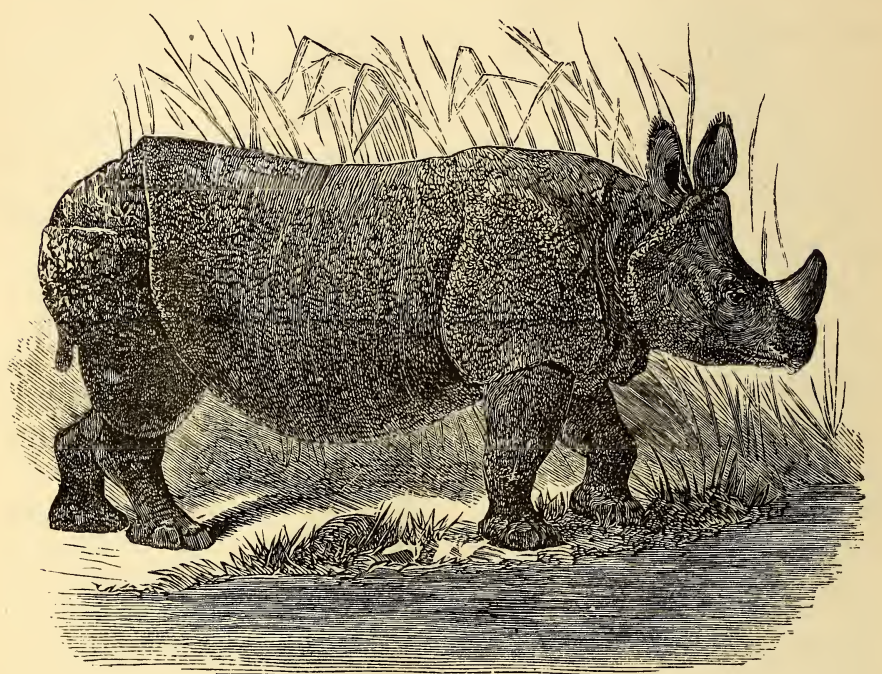

Fig. 344.-Indian Rhinoceros (R. unicornis).

four kinds of teeth, and, in the wild state, are vegetarian. The Ruminants have two toes on each foot, enveloped in hoofs which face each other by a flat side, so that they appear to be a single hoof split or "cloven." Usually there are also two supplementary hoofs behind, but they do not ordinarily touch the ground. All chew the cud, and have a complicated stomach. They have incisors in the lower jaw only, and these are apparently eight; but the two outer ones are canines. ${ }^{180}$ The molars are flat, typical grinders. The dental formula of the $\mathrm{Ox}$ is-

$$
i \frac{0-0}{3-3}, c \frac{0-0}{1-1}, p m \frac{3-3}{3-3}, m \frac{3-3}{3-3}=32 .
$$

With few exceptions, as the Camel, all Ruminants have horns, which are always in pairs. Those of the Deer are solid, bony, and deciduous; those of the Giraffe and An- 


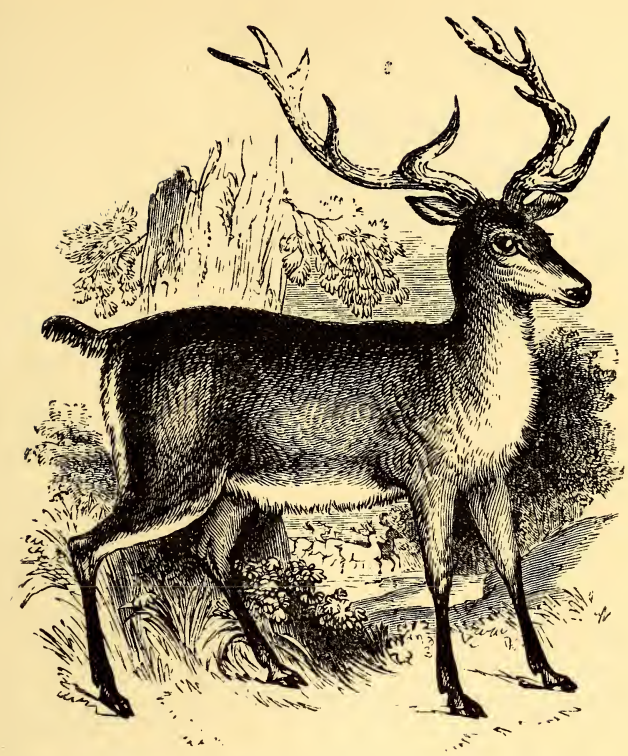

Frg. 345. -Stag, or Red Deer (Cervus elaphus). Europe.

telope are solid, horny, and permanent; in the Goat, Sheep, and Ox they are hollow, horny, and permanent.

11. Carnivora, or Beasts of Prey, may be recognized by their four long, curved, acute, canine teeth, the gap between the incisors and canines in the upper jaw for the reception of the lower canine, and molars graduating from a tuberculate to a trenchant form, in proportion as the diet deviates from a miscellaneous kind to one strictly of flesh. The incisors, except in the Pinnigrades, number Fra. 346.-Raccoon (Procyon lotor). United States.

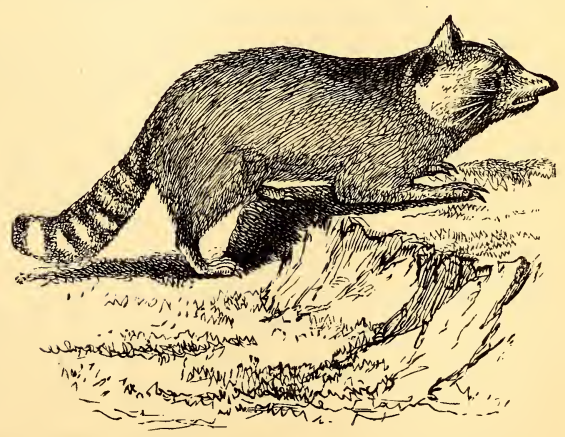


six in each jaw. There are always two sets. The skull is comparatively small, the jaws are shorter and

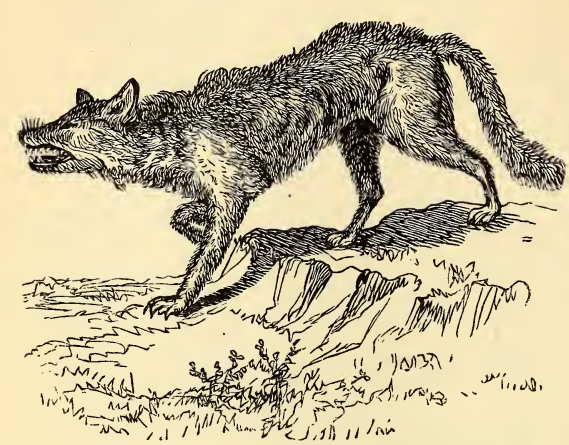

FIG. 347.-Wolf (Lupus occidentalis). United States.

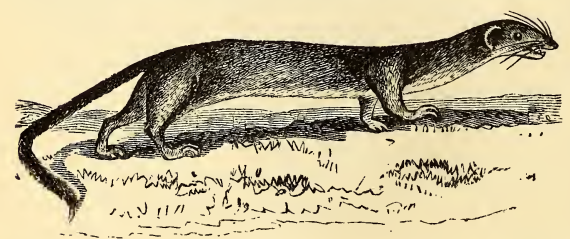

FIG. 348.-Ermine-weasel (Putorius Noveboracensis). United States.

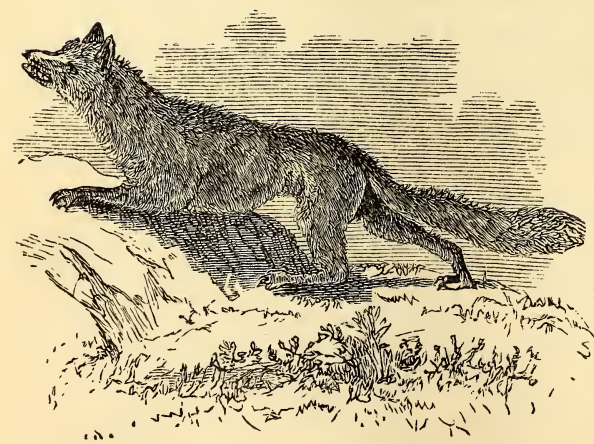

Fig. 349.-Red Fox (Vulpes fulvus). United States. deeper than in Ungulates, and there are numerousbony ridges on the inside and outside of the craniumthe high occipital crest being specially characteristic. The cerebral hemispheres are joined by a large corpus callosum, but the cerebellum is never completely covered. Both pairs of limbs are well developed, the front being prehensile; but the clavicles are rudimentary. The humerus and femur are mainly enclosed in the body. The digits, never less than four, always have sharp and pointed claws. ${ }^{181}$ The body is covered with abundant hair.

Carnivores are divided according to the modifications of the limbs: a. Pinnigrades, having short feet expanded 
into webbed paddles for swimming, the hinder ones being bound in with the skin of the tail. Such are the Seals, Walrus, and Eared Seals, or Sea-lions. b. Plantigrades, in which the whole, or nearly the whole, of the hind-foot forms a sole, and rests on the ground. The claws are not retractile; the ears are small, and tail short. Bears, Badgers, and Raccoons are well-known examples. c. Digitigrades keep the heel raised above the ground, walking on the toes. The majority have long tails. Such are the Weasels, Otters, Civets, Hyenas, Foxes, Jackals, Wolves, Dogs, Cats, Panthers, Leopards, Tigers, and Lions. The

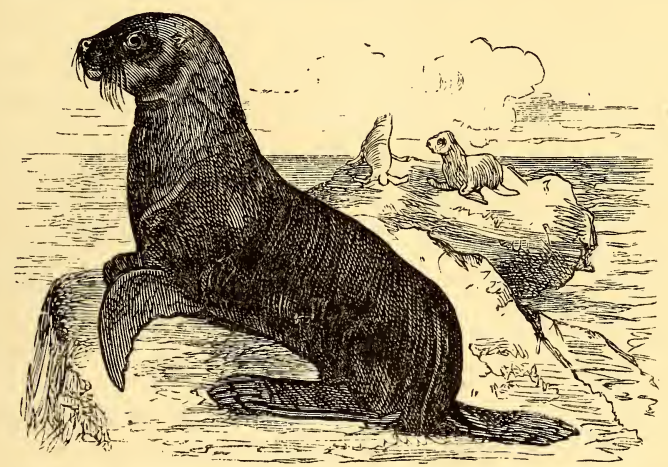

Fig. 350.-Southern Sea-lion (Otaria jubata). Antarctic Ocean.

last five differ from all others in having retractile claws, and the radius rotating freely on the ulna. The Cats have thirty teeth; the Dogs, forty-two, or twelve more molars. In the former, the tongue is prickly; in the latter, smooth.

12. Prosimii or Lemurs. These singular mammals, sometimes included in the next order, have affinities with Rodents, Insectivora, and Primates. They are covered with soft fur, have usually a long tail, pointed ears, foxlike muzzle, and curved nostrils. They walk on all fours, and the thumb and great toe are generally opposable to the digits. The second toe has a long, pointed claw in- 
stead of a nail. The cerebrum is relatively small, and flattened, and does not cover the cerebellum and olfactory

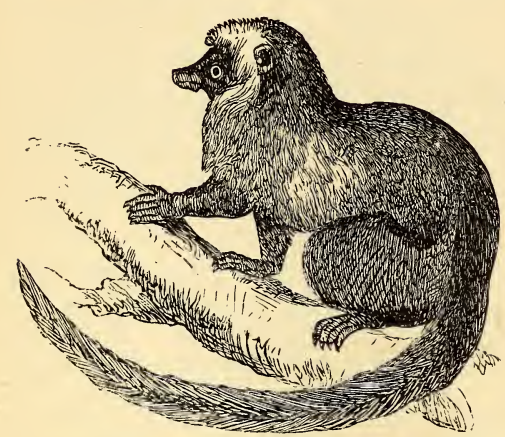

Fia. 351.-Lemur (L. ruber). Madagascar. lobes. ${ }^{182}$ They are found mainly in Madagascar.

13. Primates, the head of the kingdom, are characterized by the possession of two hands and two feet. The thigh is free from the body, and all the digits are furnished with nails, the first on the foot enlarged to a "great toe." Throughout the order, the hand is eminently or wholly prehensile, and the foot, however prehensile it may be, is always locomotive. ${ }^{18 s}$ The clavicles are perfect. The eyes are situated in a complete bony cavity, and look forward. There are two sets of teeth, all enamelled; and the incisors number four in each jaw. They are divided into Monkeys and Apes, and Man.

The Monkeys of tropical America have, generally, a long, prehensile tail; the nostrils are placed far apart, so that the nose is wide and flat; the thumbs and great toes are fitted for grasping, but are not opposable to the other digits; and they have four molars more than the Apes or Man - that is, thirty-six teeth in all. In the Apes of the Old World the tail is never prehensile, and is sometimes wanting; the nostrils are close together; both thumbs and great toes are opposable; and the teeth, though numbering the same as Man's, are uneven (the incisors being prominent, and the canines large), and the series is interrupted by a gap on one side or other of the canines. Their average size is much greater than that of the Monkeys, and they are not so strictly arboreal. In both Monkeys and Apes, the cerebrum covers the cere- 
VER'TEBRATA.

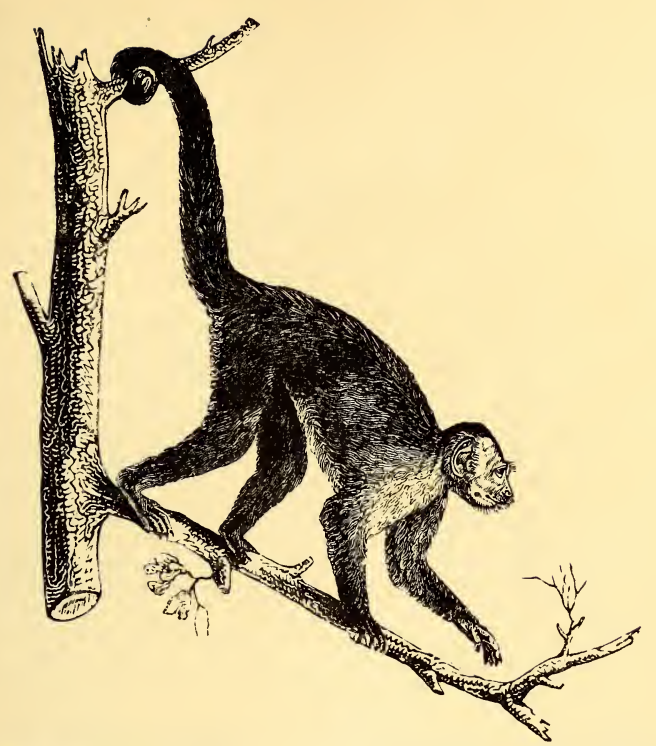

Fig. 352.-White-throated Sapajou (Cebus hypolencus). Central America.

bellum. ${ }^{184}$ While in the Monkeys the skull is rounded and smooth, that of the Apes, especially those coming nearest to Man-the anthropoid, or long-armed, Apes, as Gorilla, Chimpanzee, Orang, and Gibbon-is characterized by strong crests. Monkeys take a horizontal position;

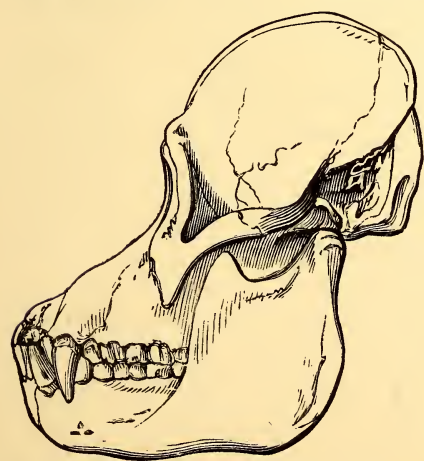

Fr'. 353.-Skull of Orang-utan (Simia satyrus). but the Apes assume a semierect attitude, the legs being shorter than the arms. In

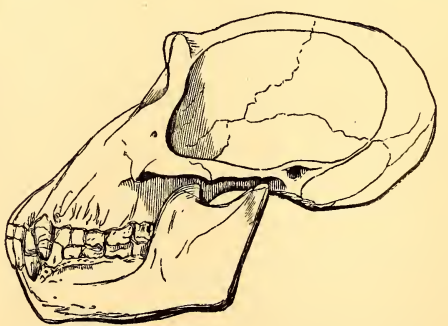

F1G. 354.-Skull of Chimpanzee (Troglodytes Niger). 
all the Primates but Man, the body is clothed with hair, which is generally longest on the back. Several Monkeys and Apes have a beard, as the Howler and Orang.

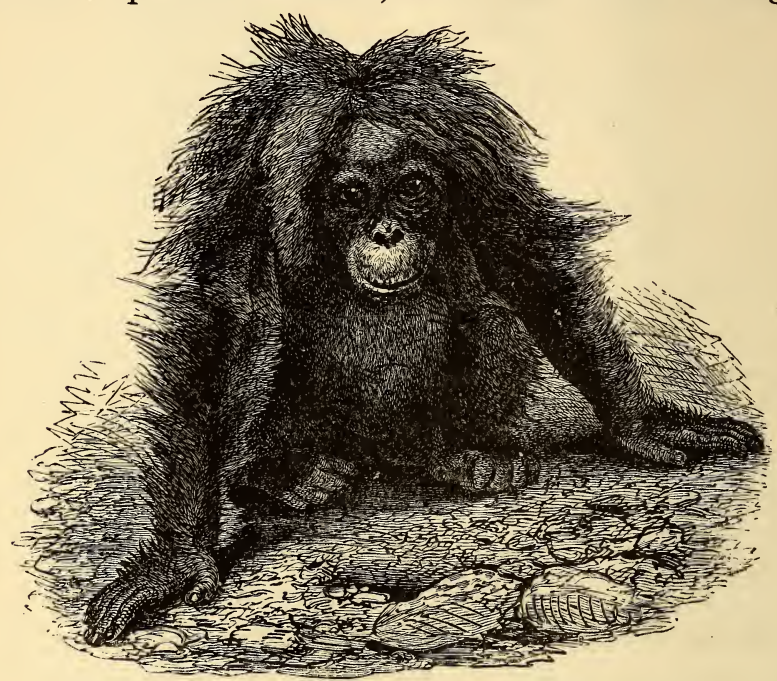

Fig. 355.-Female Orang-utan (from photograph). Borneo.

The Orang is the least human of all the anthropoid

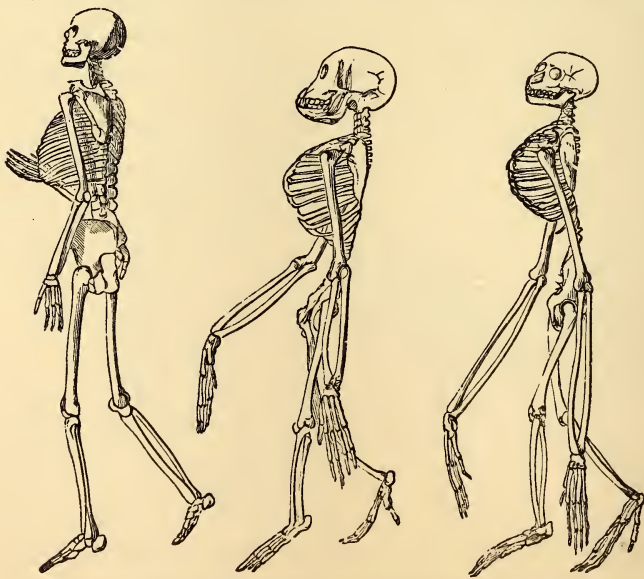

Fig. 356.-Skeletons of Man, Chimpanzee, and Orang. 
Apes as regards the skeleton, but comes nearest to Man in the form of the brain. The Chimpanzee approaches Man more closely in the character of its cranium and teeth, and the proportional size of the arms. The Gorilla is most Man-like in bulk (sometimes reaching the height of five feet six inches), in the proportions of the leg to the body and of the foot to the hand, in the size of the heel, the form of the pelvis and shoulder-blade, and volume of brain. ${ }^{185}$

Man differs from the Apes in being an erect biped. In him, the vertebrate type, which began in the horizontal Fish, finally became vertical. No other animal habitually stands erect; in no other are the fore-limbs used exclusively for head-purposes, and the hind pair solely for locomotion.

His limbs are naturally parallel to the axis of his body, not perpendicular. They have a near equality of length, but the arms are always somewhat shorter than the legs. In all the great Apes the arms reach below the knee, and the legs of the Chimpanzee and Gorilla are relatively shorter than Man's.

Man only has a finished hand, most perfect as an organ of touch, and most versatile. Both hand and foot are relatively shorter than in the Apes. The foot is planti-
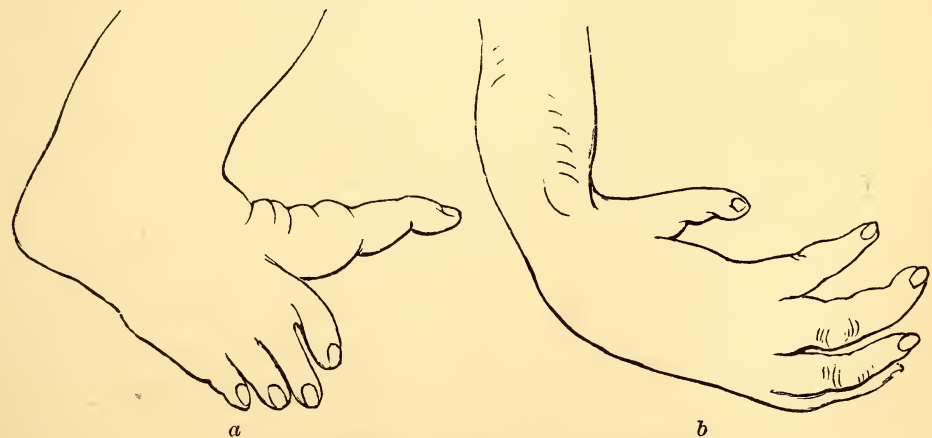

Fig. 357.-Foot $(a)$ and Hand $(b)$ of the Gorilla. 
grade; the leg bears vertically upon it; the heel and great toe are longer than in other Primates; and the great toe is not opposable, but is used only as a fulcrum in locomotion. The Gorilla has both an inferior hand and inferior foot. The hand is clumsier, and with a shorter thumb than Man's; and the foot is prehensile, and is not applied flat to the ground. ${ }^{186}$

The scapular and pelvic bones are extremely broad, and the neck of the femur remarkably long. Man is also singular in the double curve of the spine: the $\mathrm{Ba}$ boon comes nearest to Man in this respect.

The human skull has a smooth, rounded outline, elevated in front, and devoid of crests. The cranium greatly predominates over the face, being four to one $;^{187}$ and no other animal (except the Siamang Gibbon) has a chin.

Man stands alone in the peculiarity of his dentition: his teeth are vertical, of nearly uniform height, and close together. In every other animal the incisor's and canines are more or less inclined, the canines project, and there are vacant spaces. ${ }^{188}$

Man has a longer lobule to his ear than any Ape, and no muzzle. The bridge of his nose is decidedly convex; in the Apes generally it is flat.

Man has been called the only naked terrestrial Mammal. His hair is most abundant on the scalp; never on the back, as in the Apes.

Man has a more pliable constitution than the Apes, as shown by his world-wide distribution. The animals nearest him soon perish when removed from their native places.

Though Man is excelled by some animals in the acuteness of some senses, there is no other animal in which all the senses are capable of equal development. He only has the power of expressing his thoughts by articulate speech, and the power of forming abstract ideas.

Man differs from the Apes in the absolute size of 


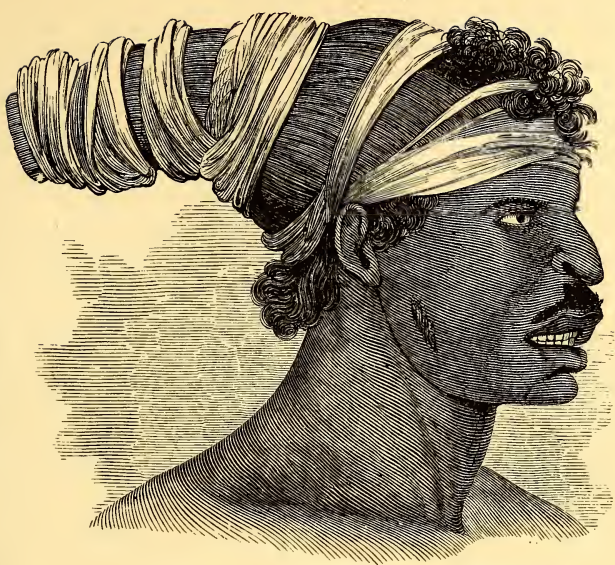

Frg. 358.-Australian Savage.

brain, and in the greater complexity and less symmetrical disposition of its convolutions. The cerebrum is larger in proportion to the cerebellum (being as $8 \frac{1}{2}$ to 1 ), and the former not only covers the latter, but projects beyond it. The brain of the Gorilla scarcely amounts to one third in volume or one half in weight of that of Man.

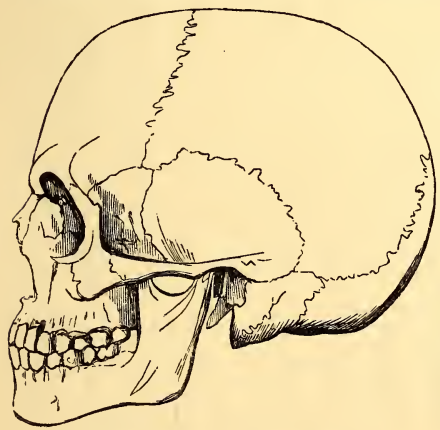

Fia. 359.-Skull of European.

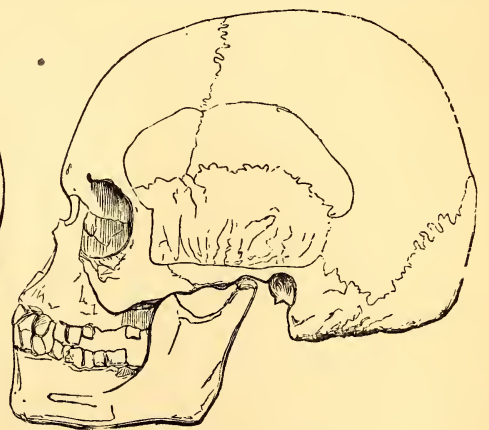

Fig. 360.-Skull of Negro.

Yet, so far as cerebral structure goes, Man differs less from the Apes than they do from the Monkeys and Lemurs. The great gulf between Man and the brute is not physical, but psychical. ${ }^{189}$ 
ARRANGEMENT OF REPRESENTATIVE FORMS. 363

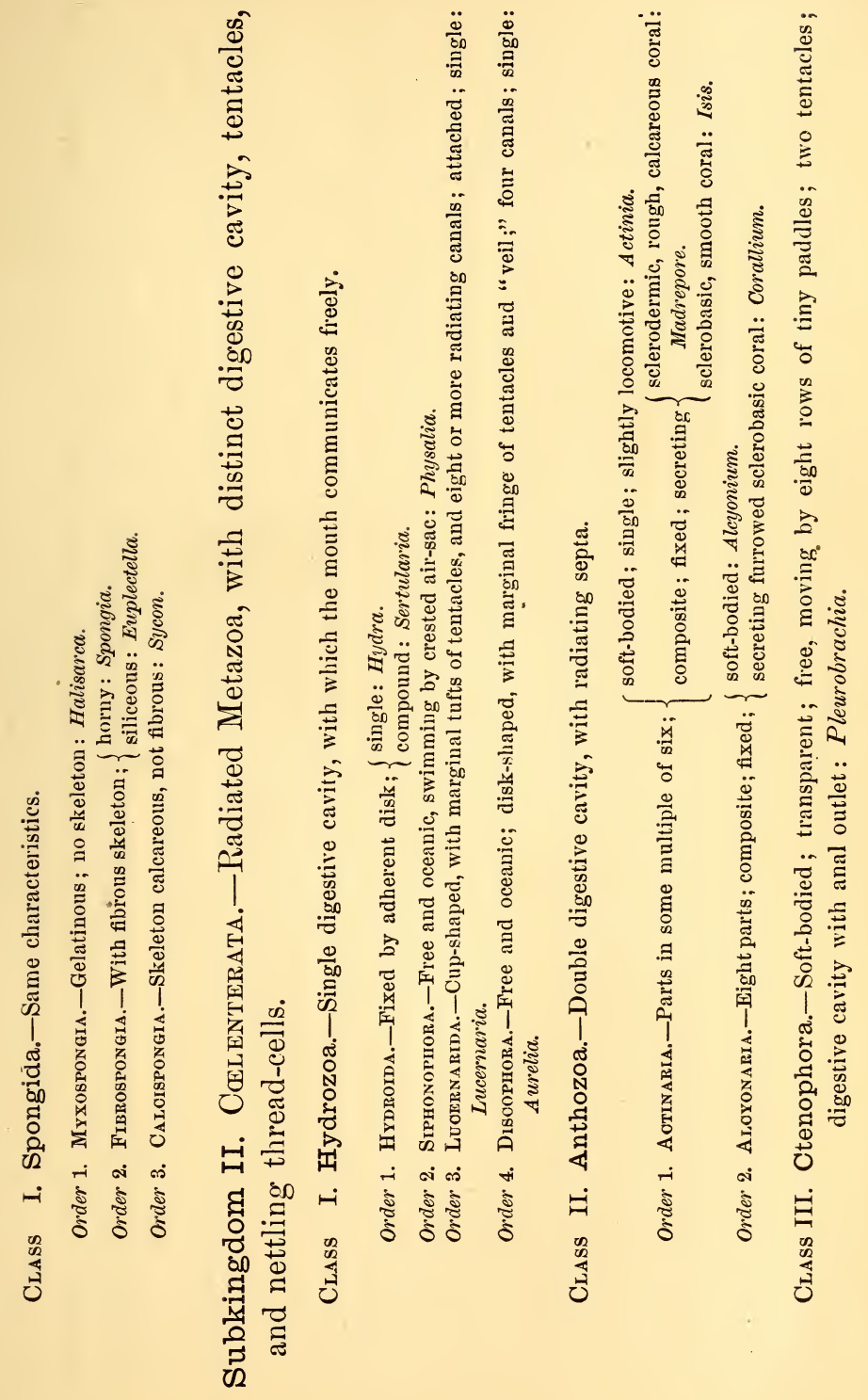


$\frac{1}{\overline{0}}$

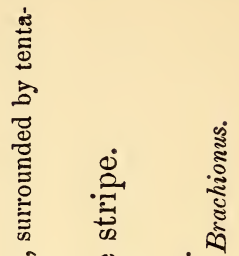

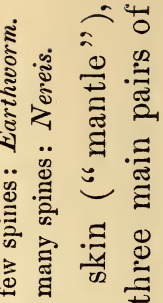

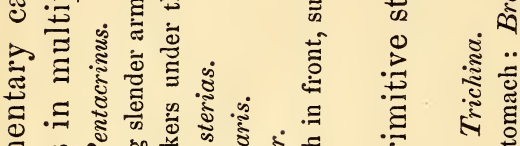

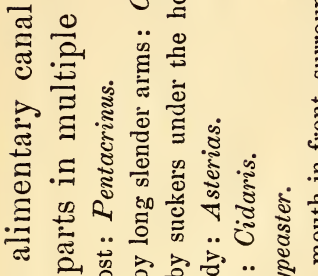
ฮ艹

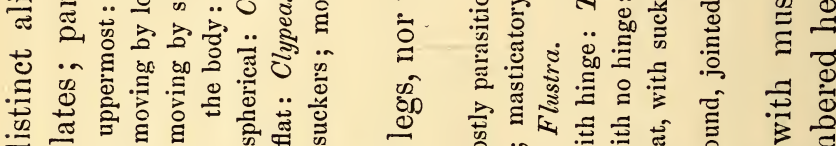

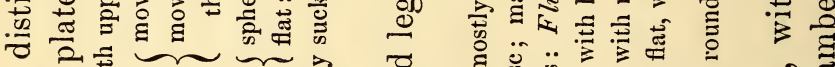

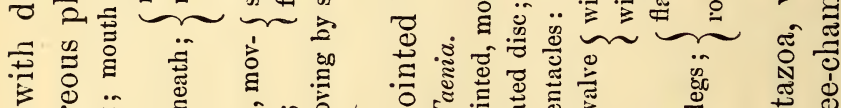

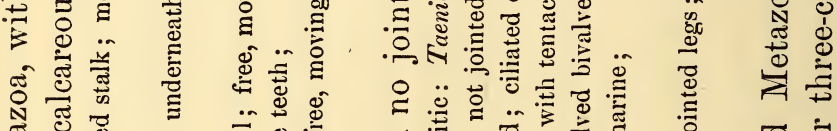

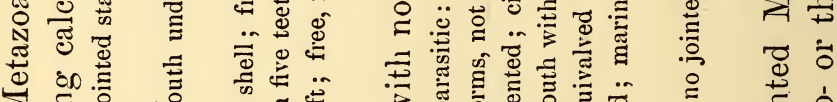

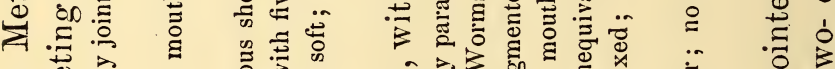

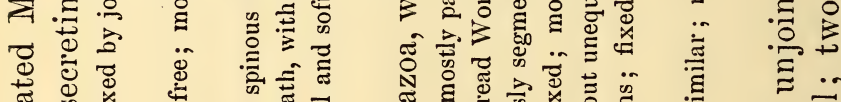

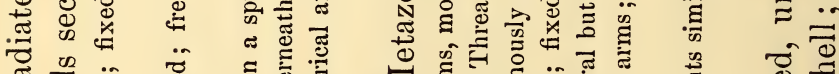

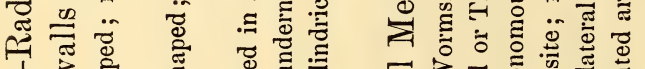

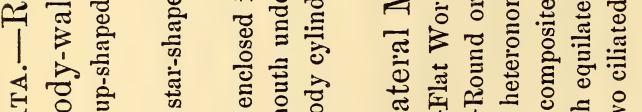
녕

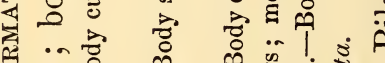

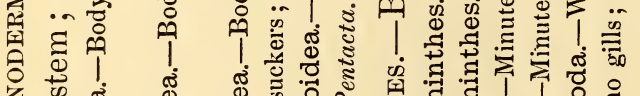

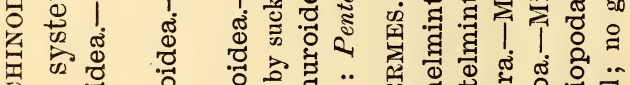

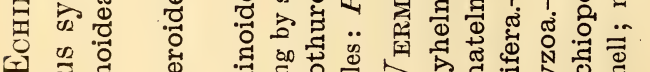

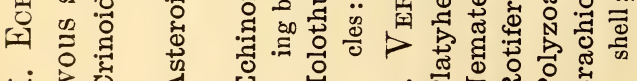

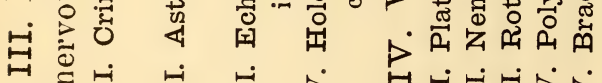
व्वे

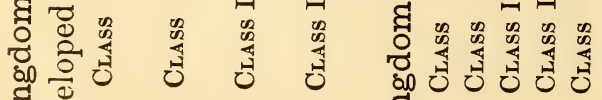
牙芒 黄

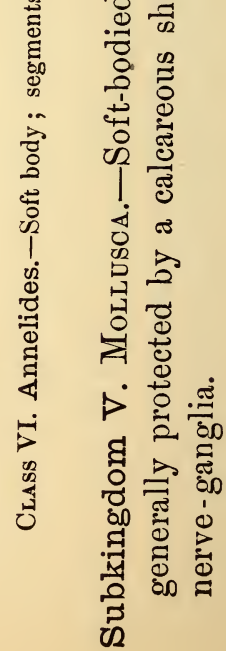


ARRANGEMENT OF REPRESENTATIVE FORMS. 365

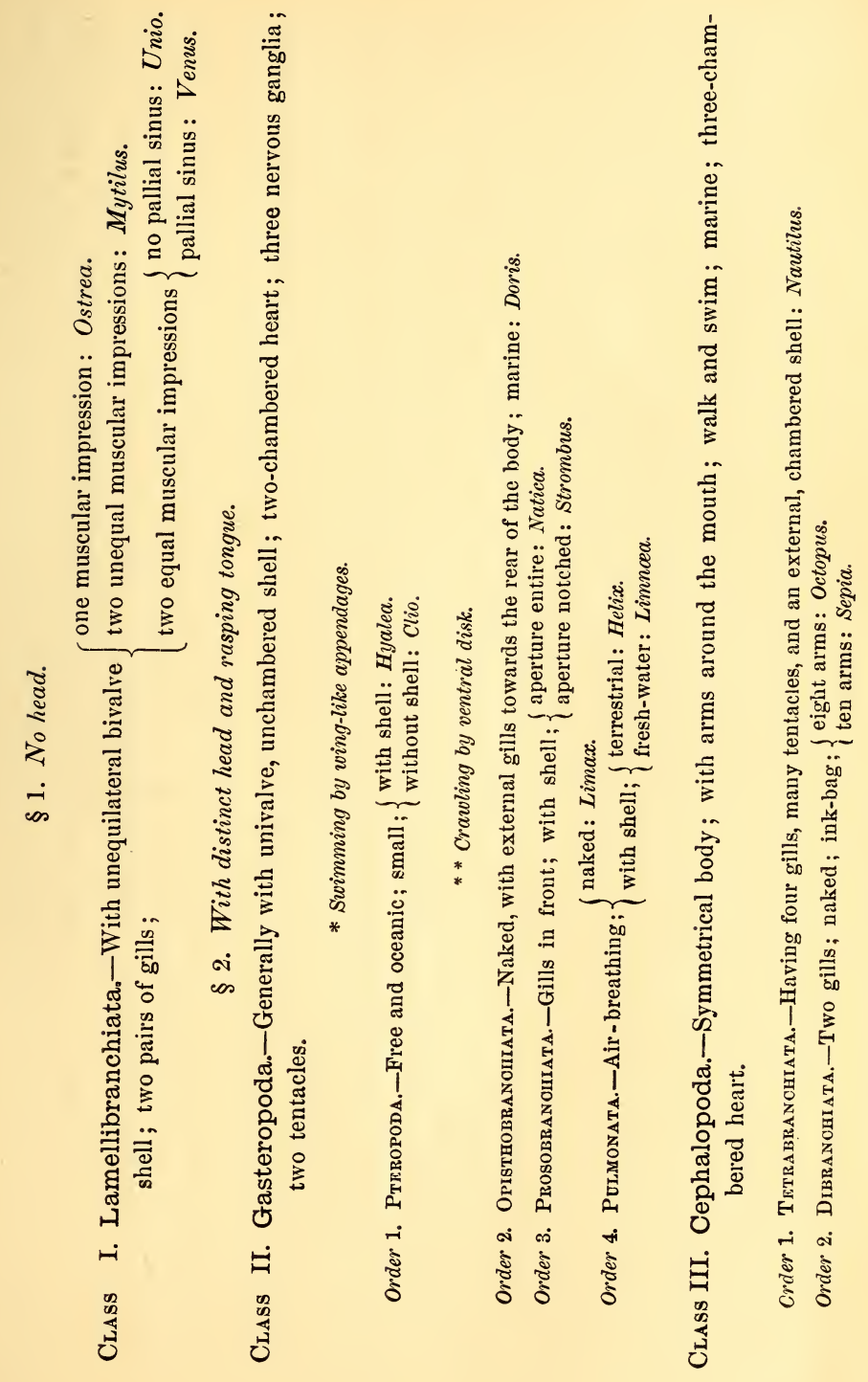




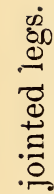

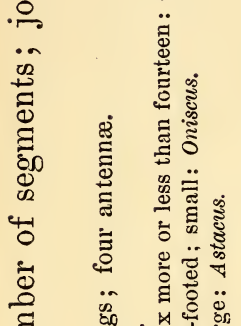

है

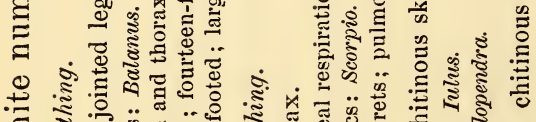

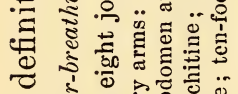

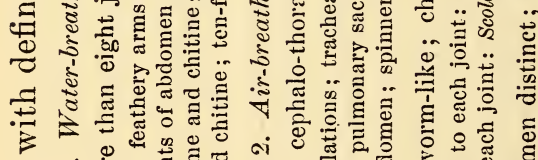

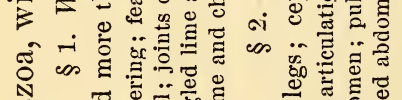

胥

年

T.

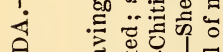

总能

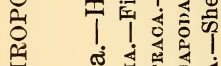

Е

焉

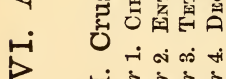

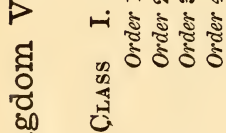

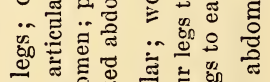

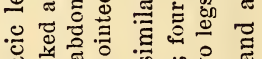

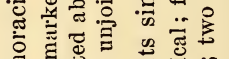

을

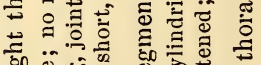

कo

1.

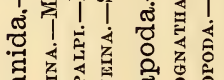

表弯

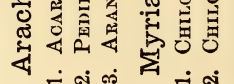

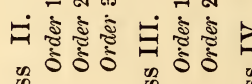

:ี

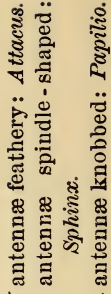

嵒

范

ฐ 60

ง.

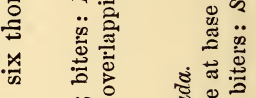

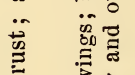

छํ.

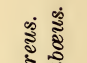

$\ddot{z}$

E

产亳

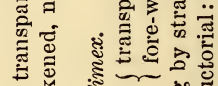

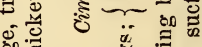

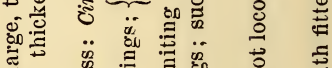

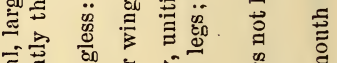

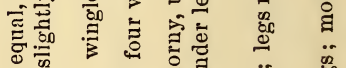

के $\underbrace{2}_{0}$

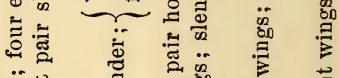

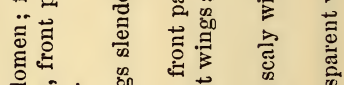

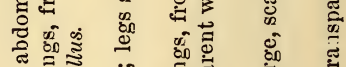

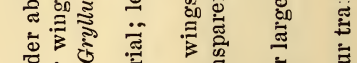
范 这䓂 $11:$ \& 旸

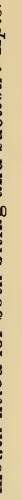




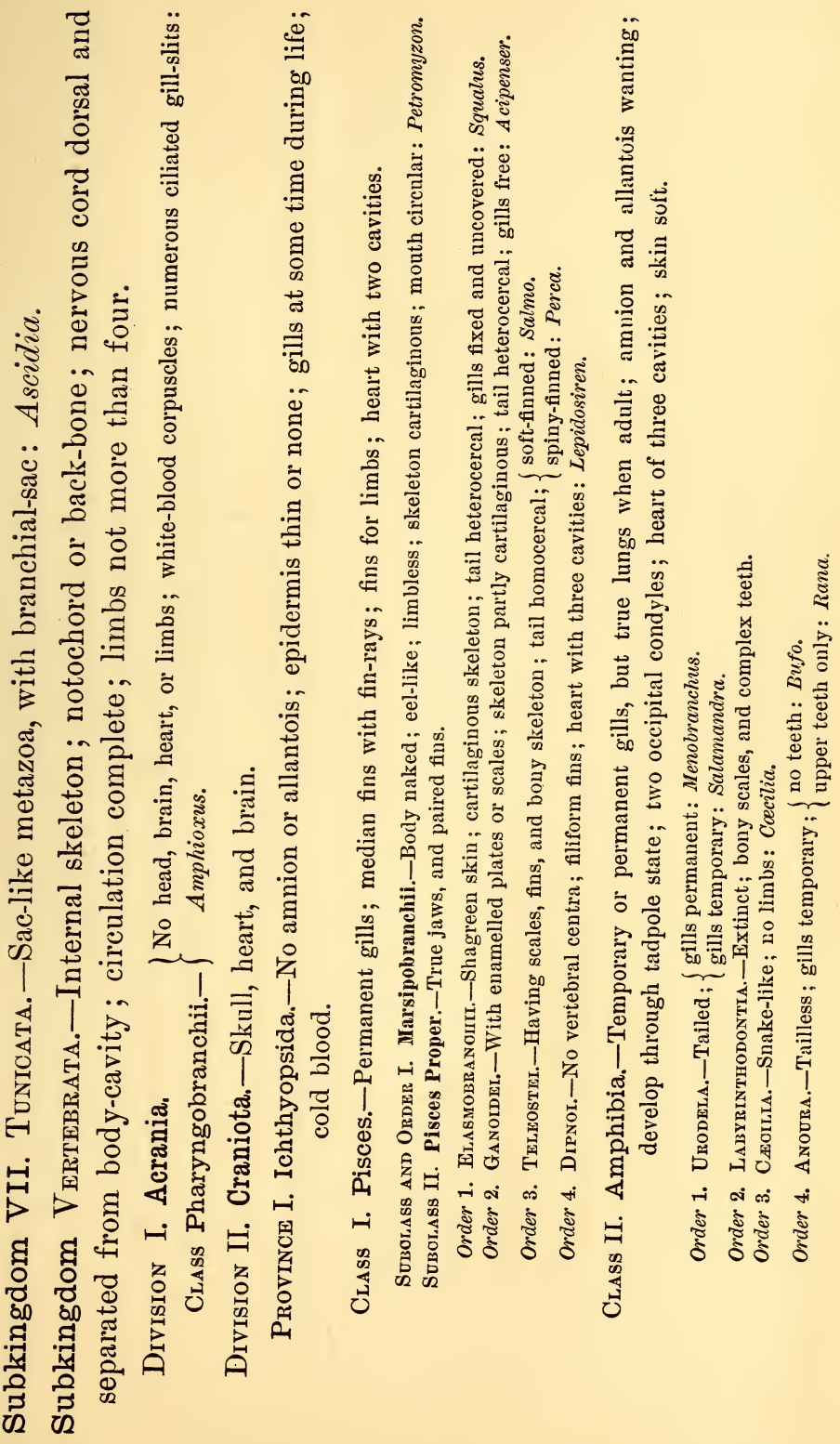




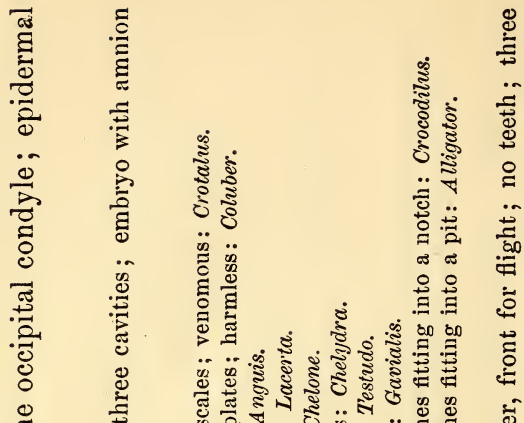

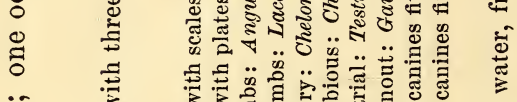

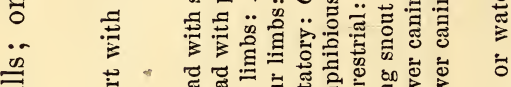

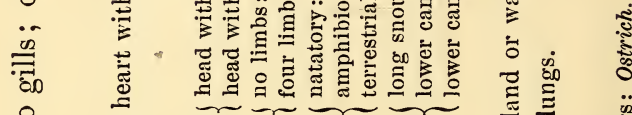

\& $\ldots$ \&

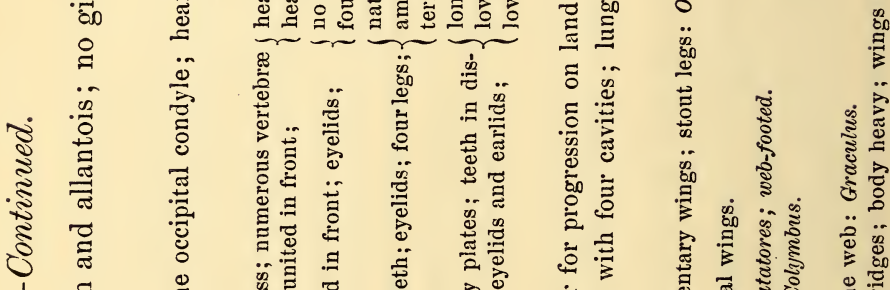

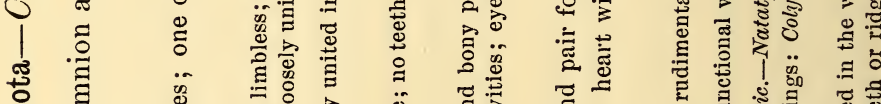

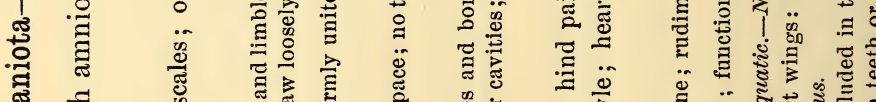

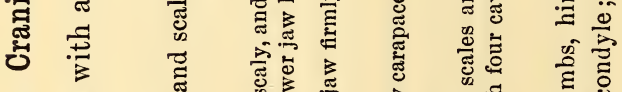

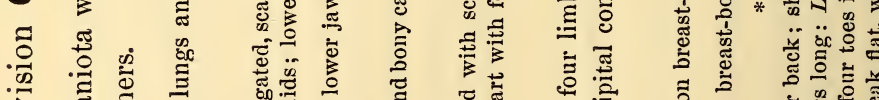

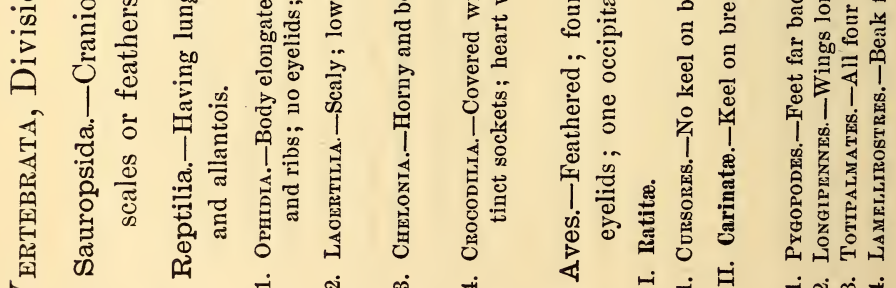

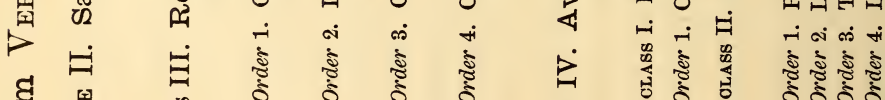

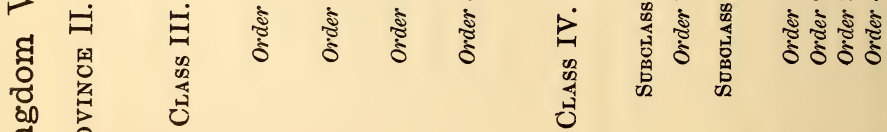




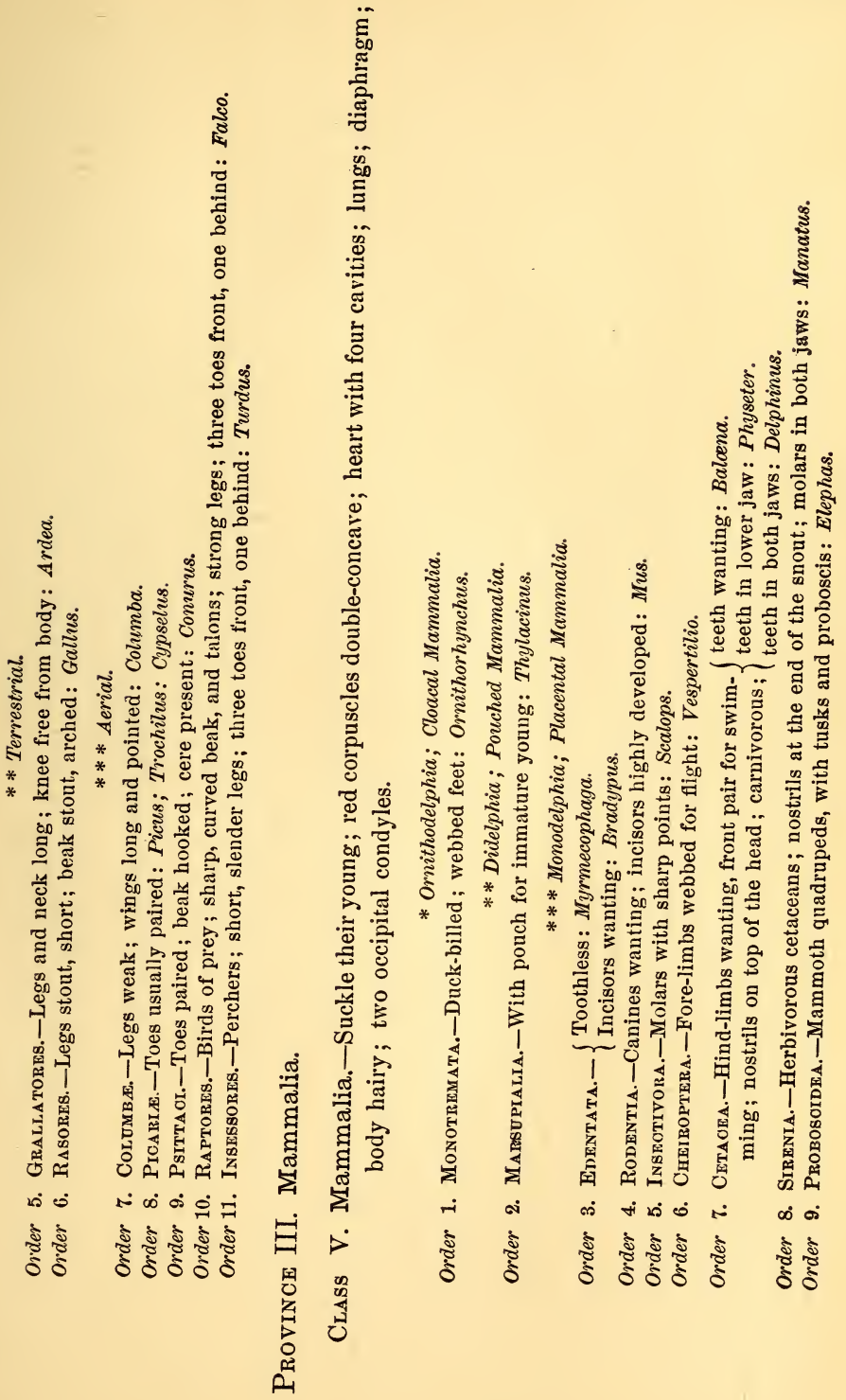




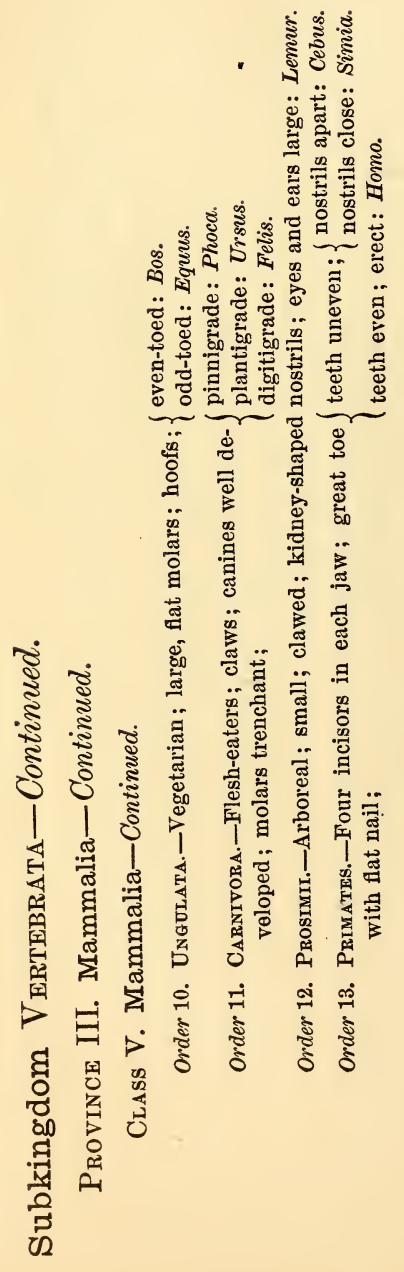




\section{CHAPTER XXIII.}

\section{THE DISTRIBUTION OF ANIMALS.}

LiFe is everywhere. In the air above, the earth beneath, and the waters under the earth, we are surrounded with life. Nature lives: every pore is bursting with life; every death is only a new birth, every grave a cradle. The air swarms with Birds, Insects, and invisible animalcules. The waters are peopled with innumerable forms, from the Protozoan, millions of which would not weigh a grain, to the Whale, so large that it seems an island as it sleeps upon the waves. The bed of the sea is alive with Crabs, Shells, Polyps, Star-fishes, and Foraminifera. Life everywhere-on the earth, in the earth, crawling, creeping, burrowing, boring, leaping, running.

Nor does the vast procession end here. The earth we tread is largely formed of the débris of life. The quarry of limestone, the flints which struck the fire of the old Revolutionary muskets, are the remains of countless skeletons. The major part of the Alps, the Rocky Mountains, and the chalk cliffs of England are the monumental relics of by-gone generations. From the ruins of this living architecture we build our Parthenons and Pyramids, our St. Peters and Louvres. So generation follows generation. But we have not yet exhansted the survey. Life cradles within life. The bodies of animals are little worlds having their own fauna and flora. In the fluids and tissues, in the eye, liver, stomach, brain, and muscles, parasites are found; and these parasites often have their parasites living on them. 
"Great fleas have little fleas and smaller fleas to bite 'em; And these again have other fleas, and so ad infinitum."

Thus the ocean of life is inexhaustible. It spreads in every direction, into time past and present, flowing everywhere, eagerly surging into every nook and corner of creation. On the mountain-top, in the abysses of the Atlantic, in the deepest crevice of the earth's crust, we find traces of animal life. Nature is prodigal of space, but economical in filling it. ${ }^{190}$

Animals are distributed over the globe according to definite laws, and with remarkable regularity.

Each of the three great provinces, Earth, Air, and Water, as also every continent, contains representatives of all the classes; but the various classes are unequally represented. Every great climatal region contains some species not found elsewhere, to the exclusion of some other forms. Every grand division of the globe, whether of land or sea, each zone of climate and altitude, has its own fauna. And, in spite of the many causes tending to disperse animals beyond their natural limits, each country preserves its peculiar zoological physiognomy.

The space occupied by the different groups of animals is often inversely as the size of the individuals. Compare the Coral and Elephant.

The fauna now occupying a separate area is closely allied to the fauna which existed in former geologic times. Thus, Australia has always been the home of Marsupials, and South America of Edentates.

It is a general rule that groups of distinct species are circumscribed within definite, and often narrow, limits. Man is the only cosmopolitan; yet even he comprises sev. eral marked races, whose distribution corresponds with the great zoological regions. The natives of Australia are as grotesque as the animals. Certain brutes likewise have a great range: thus, the Puma ranges from Canada to Pata- 
gonia; the Musk - rat, from the Arctic Ocean to Florida; the Ermine, from Behring's Straits to the Himalayas; and the Hippopotamus, from the Nile and Niger to the Orange River. ${ }^{191}$

Frequently, species of the same genus, living side by side, are widely different, while there is a close resemblance between forms which are antipodes. The Mud-eel of South Carolina and Menobranchus of the Northern States have their relatives in Japan and Austria. The American Tapir has its mate in Sumatra; the Llama is related to the Camel, and the Opossum to the Kangaroo.

The chief causes modifying distribution are temperature, topography, ocean and wind currents, humidity and light. To these may be added the fact that animals are ever intruding on each other's spheres of existence. High mountain-ranges, wide deserts, and cold currents in the ocean are impassable barriers to the migration of most species. Thus, river-fish on opposite sides of the Andes differ widely, and the cold Peruvian current prevents the growth of coral at the Galapagos Islands. So a broad river, like the Amazons, or a deep, narrow channel in the sea, is an effectual barrier to some tribes. Thus, Borneo belongs to the Indian region, while Celebes, though but a few miles distant, is Australian in its life. The faunæ of North America, on the east coast, west coast, and the open plains between, are very different.

Animals dwelling at high elevations resemble those of colder latitudes. The same species of Insects are found on Mount Washington, and in Labrador and Greenland.

The range does not depend upon the powers of locomotion. The Oyster extends from Halifax to Charleston, and the Snapping - turtle from Canada to the equator; while many Quadrupeds and Birds have narrow habitats.

The distribution of any group is qualified by the nature 
of the food. Carnivores have a wider range than herbivores.

Life diminishes as we depart from the equator north or south, and likewise as we descend or ascend from the level of the sea.

The zones of geography have been divided by zoologists into narrower provinces. Five vertical regions in the sea have been recognized: the Littoral, extending between tide-marks; the Laminarian, from low water to fifteen fathoms; the Coralline, from fifteen to twenty fathoms; the deep-sea Coral, from fifty to one hundred fathoms; and the Bathybian, from one hundred fathoms down; but since life has been found to extend to great depths in the ocean-as great as three thousand fathoms -these divisions are of little importance. Every marine species has its own limits of depth. It would be quite as difficult, said Agassiz, for a Fish or a Mollusk to cross from the coast of Europe to the coast of America as for a Reindeer to pass from the arctic to the antarctic regions across the torrid zone. Marine animals congregate mainly along the coasts of continents and on soundings. The meeting - place of two maritime currents of different temperatures, as on the Banks of Newfoundland, favors the development of a great diversity of Fishes.

Every great province of the ocean contains some representatives of all the subkingdoms. Deep-sea life is diversified, though comparatively sparse. Examples of all the five invertebrate divisions were found in the Bay of Biscay, at the depth of two thousand four hundred and thirty-five fathoms. ${ }^{192}$

Distribution in the sea is influenced by the temperature and composition of the water and the character of the bottom. The depth acts indirectly by modifying the temperature. Northern animals approach nearer to the equator in the sea than on the land, on account of cold 
currents. The heavy aquatic Mammals, as Whales, Walruses, Seals, and Porpoises, are mainly polar.

The land consists of the following somewhat distinct areas : the Neotropic, comprising South America, the West Indies, and most of Mexico; the Nearctic, including the rest of America; the Palæarctic, composed of the eastern continent north of the Tropic of Cancer, and the Himalayas; the Ethiopian, or Africa south of the Tropic of Cancer; the Oriental, or India, the southern part of China, the Malay Peninsula, and the islands as far east as Java, Borneo, and the Philippine Islands; and the Australian, or the eastern half of the Malay Islands and Australia. These are Mr. Wallace's regions. Other writers unite the rorthern parts of both hemispheres into one region, and the Oriental with the Ethiopian regions.

Life in the polar regions is characterized by great uniformity, the species being few in number, though the number of individuals is immense. The same animals inhabit the arctic portions of the three continents; while the antarctic ends of the continents, Australia, Cape of Good Hope, and Cape Horn, exhibit strong contrasts. Those three continental peninsulas are, zoologically, separate worlds. In fact, the whole southern hemisphere is peculiar. Its fauna is antique. Australia possesses a strange mixture of the old and new. South America, with newer Mammals, has older Reptiles; while Africa has a rich vertebrate life, with a striking uniformity in its distribution. Groups, old geologically and now nearly extinct, are apt to have a peculiar distribution; as the Edentata in South America, Africa, and India ; the Marsupials in Australia and America; the Ratitæ in South America, Africa, Australia, and New Zealand.

In the tropics, diversity is the law. Life is more varied and crowded than elsewhere, and attains its highest development. 
The New-world fauna is old-fashioned, and inferior in rank and size, compared with that of the eastern continents.

As a rule, the more isolated a region the greater the variety. Oceanic islands have comparatively few species, but a large proportion of endemic or peculiar forms. Batrachians are absent, and there are no indigenous terrestrial Mammals. The productions are related to those of the nearest continent. When an island, as Britain, is separated from the mainland by a shallow channel, the mammalian life is the same on both sides.

Protozoans, Cœlenterates, and Echinoderms are limited to the waters, and nearly all are marine. Sponges are mostly obtained from the Grecian Archipelago and Bahamas, but species not commercially valuable abound in all seas. Coral-reefs abound throughout the Indian Ocean and Polynesia, east coast of Africa, Red Sea, and Persian Gulf, West Indies, and around Florida ; and Corals which do not form reefs are much more widely distributed, being found as far north as Long Island Sound and England. Crinoids have been found, usually in deep sea, in very widely separated parts of the world-off the coast of Norway, Scotland, and Portugal, and near the East and West Indies. The other Echinoderms abound in almost every sea: the Star-fishes chiefly along the shore, the Seaurchins in the Laminarian zone, and the Sea-slugs around coral-reefs. Worms are found in all parts of the world, in sea, fresh water, and earth. They are most plentiful in the muddy or sandy bottoms of shallow seas. Living Brachiopods, though few in number, occur in tropical, temperate, and arctic seas, and from the shore to great depths. Polyzoa have both salt and fresh water forms, and Annelids include land forms, as the Earth-worm and some Leeches.

Mollusks have a world -wide distribution over land and 
sea. The land forms are restricted by climate and food, the marine by shallows or depths, by cold currents, by a sandy, gravelly, or mud bottom. The Bivalves are also found on every coast and in every climate, as well as in rivers and lakes, but do not flourish at the depth of much more than two hundred fathoms. The fresh-water Mussels are more numerous in the United States than in Europe, and west of the Alleghanies than east. The seashells along the Pacific coast of America are unlike those of the Atlantic, and are arranged in five distinct groups: Alentian, Californian, Panamic, Peruvian, and Magellanic. On the Atlantic coast, Cape Cod and Cape Hatteras separate distinct provinces. Of land Snails, Helix has an almost universal range, but is characteristic of North America, as Bulimus is of South America, and Achatina of Africa. The Old World and America have no species in common, except a few in the extreme north.

The limits of Insects are determined by temperature and vegetation, by oceans and mountains. There is an insect-fauna for each continent, and zone, and altitude. The Insects near the snow-line on the sides of mountains in the temperate region are similar to those in polar lands. The Insects on our Pacific slope resemble those of Europe, while those near the Atlantic coast are more like those of Asia. Not half a dozen Insects live in the sea.

The distribution of Fishes is bounded by narrower limits than that of other animals. A few tribes may be called cosmopolitan, as the Sharks and Herrings; but the species are local. Size does not appear to bear any relation to latitude. The marine forms are three times as numerous as the fresh-water. The migratory Fishes of the northern hemisphere pass to a more southern region in the spring, while Birds migrate in the autumn.

Living Reptiles form but a fragment of the immense number which prevailed in the Middle Ages of Geology. 
Being less under the influence of Man, they have not been forced from their original habitats. None are arctic. America is the most favored spot for Frogs and Salamanders, and India for Snakes. Australia has no Batrachians, and two thirds of its Snakes are venomous. In the United

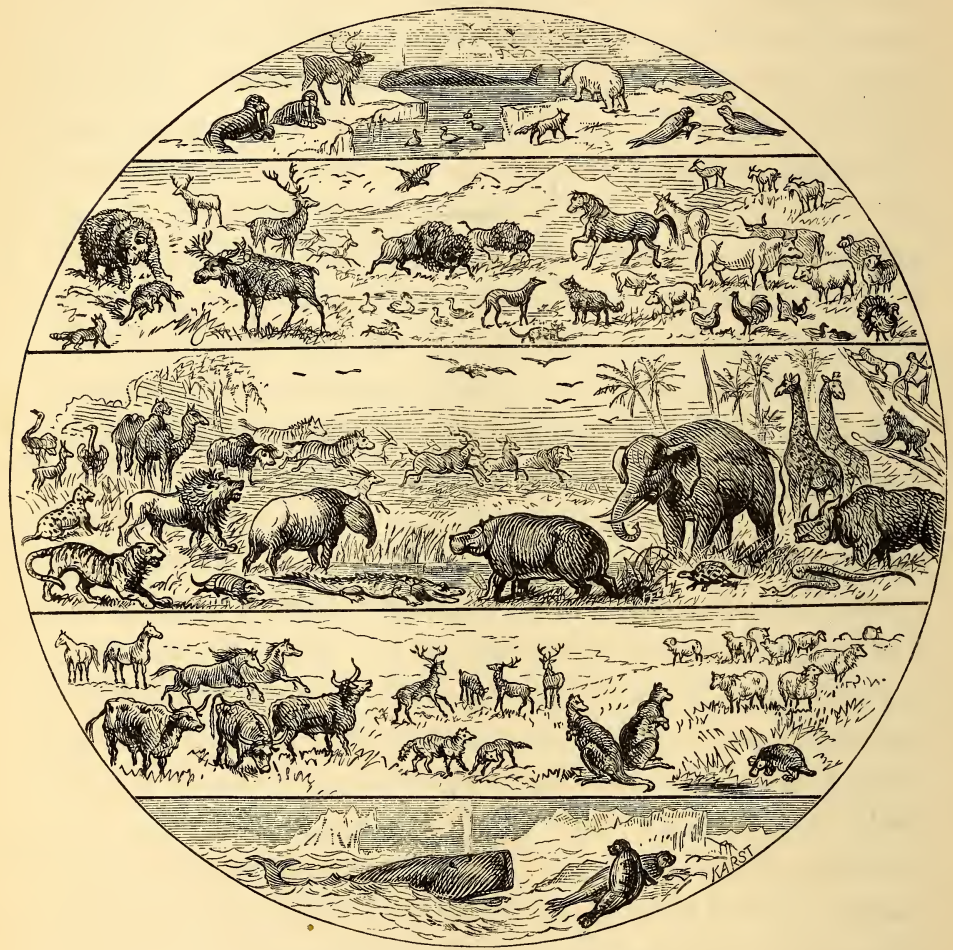

Fig. 361.-Zones of Animal Life.

States, only twenty-two out of one hundred and seventysix are venomons. Frogs, Snakes, and Lizards occur at elevations of over fifteen thousand feet. Crocodiles, and most Lizards and Turtles, are tropical.

Swimming Birds, which constitute about one fourteenth of the entire class, form one half of the whole number in 
Greenland. As we approach the tropics, the variety and number of land Birds increase. Those of the torrid zone are noted for their brilliant plumage, and the temperate forms for their more sober hues, but.sweeter voices. India and South America are the richest regions. Hummers, Tanagers, Orioles, and Toucans are restricted to the New World. Parrots are found in every continent except Europe ; and Woodpeckers occur everywhere, save in Australia.

The vast majority of Mammals are terrestrial; but Cetaceans and Seals belong to the sea, Otters and Beavers delight in lakes and rivers, and Moles are subterranean. As of Birds, the aquatic species abound in the polar regions. Marsupials inhabit two widely separated areas - America and Australia. In the latter continent they constitute two thirds of the fauna, while all placental Mammals, except Bats and a few Rats and Squirrels, are wanting. Excepting a few species in South Africa and South Asia, Edentates are confined to tropical Sonth America. The equine family is indigenous to South and East Africa and Southern Asia. In North America, Rodents form about one half the number of Mammals; there are but three species in Madagascar. Ruminants are sparingly represented in America. Carnivores flourish in every zone and continent. The prehensile-tailed Monkeys are strictly South American; while the anthropoid Apes belong to the west coast of Africa, and to Borneo and Sumatra. Both Monkeys and Apes are most abundant near the equator; in fact, their range is limited by the distribution of palms. 



\section{N OTES.}

1 The complete and elaborate natural history of a single species or limited group is called a Monograph, as Darwin's "Monograph of the Cirripedia." A Memoir is not so formal or exhaustive, giving mainly original investigations of a special subject, as Owen's "Memoir on the Gorilla."

${ }^{2}$ Before the time of Linnæus, the Lady-bug, e. g., was called "the Coccinella with red coleopters having seven black spots." He called it Coccinella septem-punctata.

${ }^{3}$ Mandino (1315) and Berenger (1518), of Bologna, and Vesalius, of Brussels (1550), were the first anatomists. Circulation of the blood discovered by Harvey, 1616. The lacteals discovered by Asellius, 1622, and the lymphatics by Rudbek, 1650. Willis made the first minute anatomy of the brain and nerves, 1664. The red blood-corpuscles were discovered by Leeuwenhoek and Malpighi, 1675. Infusoria first observed by Leeuwenhoek, 1675 ; the name given by Müller, 1786. Swammerdam was the founder of Entomology, 1675. Comparative anatomy was first cultivated by Perrault, Pecquet, Duverney, and Méry, of the Academy of Paris, the latter part of the seventeenth century. Malpighi, the founder of structural anatomy, was the first to demonstrate the structure of the lungs and skin, 1690. About the same time, Ray and Willoughby first classified Fishes on structural grounds. Foraminifers were seen by Beccarius one hundred and fifty years ago; but their true structure was not demonstrated till 1835, by Dujardin. Peyssonel published the first elaborate treatise on Corals, 1727. Haller was the first to distinguish between contractility and sensibility, 1757. White blood-corpuscles discovered by Hewson in 1775. Spallanzani was the first to demonstrate the true nature of the digestive process, 1780. Cuvier and Geoffroy, in 1797, proposed the first natural classification of animals. Before that, all Invertebrates were divided into Insects and Worms. Lamarck was the first to study Mollusks, 1800; before him, attention was confined to the shell. He separated Spiders from Insects in 1812. The law of correlation enunciated by Cuvier, 1826. Von Baer was the founder of Embryology, establishing the doctrine omnia ex ovo, 1827 ; but the first researches in Reproduction were made by Fabricius about 1600, and by Harvey in 1651. Wolff, in the last century, was the pioneer in observing the phenomena of Development. Sars first observed alternate generation, 1833. Duméril is considered the father of Herpetology, and Owen of Odontology. Schleiden and Schwann published their celebrated researches in cell-structure, 1841; but Bichat, who died 1802, was the founder of Histology. Protoplasm was discovered by Dujardin in 1835 , and called Sarcode. 
4 This twofold division is arbitrary. No essential distinction, founded on the nature of the elements concerned, or the laws of their combination, can be made; and so many so-called organic substances, as urea, ammonia, alcohol, tartaric and oxalic acids, alizarine, and glucose, have been prepared by inorganic methods, that the boundary-line is daily becoming fainter, and may in time vanish altogether. We would here utter our protest against the introduction of any more terms like inorganic, invertebrate, acephalous, etc., which express no qualities.

${ }^{5}$ Even the works of nearly all animals proceed in curves.

${ }^{6}$ London Quarterly Review, January, 1869, p. 142. It is true of any great primary group of animals, as of a tree, that it is much more easy to define the summit than the base.

7 De Bary on "Myxomycetæ ;" Darwin on "Carnivorous Plants."

8 "There are certain phenomena, even among the higher plants, connected with the habits of climbing plants and with the functions of fertilization, which it is very difficult to explain without admitting some low form of a general harmonizing and regulating function, comparable to such an obscure manifestation of reflex nervous action as we have in Sponges and in other animals in which a distinct nervous system is absent."-Prof. Wrville THOMson's Introductory Lecture at Edinburgh.

9 "If nature had endowed us with microscopic powers of vision, and the integuments of plants had been rendered perfectly transparent to our eyes, the vegetable world would present a very different aspect from the apparent immobility and repose in which it is now manifested to our senses."-HuMBoldT's Cosmos, i., 341.

${ }^{10}$ See Gray's "Structural Botany," p. 350 ; Rolleston's "Forms of Animal Life," p. 143.

11 "Life has been called the vital force, and it has been suggested that it may be found to belong to the same category as the convertible forces, heat and light. Life seems, however, to be more a property of matter in a certain state of combination than a force. It does no work, in the ordinary sense." -Prof. Wrville Thomson.

12 There was a time in our history when a single membrane discharged all the functions of life - digesting, respiring, secreting. The separation of a heart, lung, stomach, liver, etc., for special duty was an after-consideration.

13 The vegetable cell has usually two concentric coverings: cell-wall and primordial utricle. In animal cells the former is wanting, the membrane representing the utricle. As a general fact, animal cells are smaller than vegetable cells.

${ }^{14}$ Cells are not the sources of life, as once thought, but are the products of protoplasm. "They are no more the producers of vital phenomena than the shells scattered in orderly lines along the sea-beach are the instruments by which the gravitation - force of the moon acts upon the ocean. Like these, the cells mark only where the vital tides have been and how they have acted."-Prof. HuxLex.

${ }^{15}$ Many of the bones of the skull are preceded by membrane-hence called membrane-bones. 
${ }_{16}$ In the heart, the muscular fibres are striated, yet involuntary; but the sarcolemma is wanting.

${ }^{17}$ Other names are medullary sheath and white substance of Schwann.

${ }_{18} \mathrm{We}$ may, however, infer that the animal functions are not absolutely essential to the vegetative, from the facts that plants digest without muscles or nerves, and that nutrition takes place in the embryo long before the nerves have been developed.

19 This is not strictly true, for the Elm and Oak, the Trout and Alligator, do reach a maximum size.

${ }^{20}$ Scorpions and Spiders properly feed upon the juices of their victims after lacerating them with their jaws, but fragments of Insects have been found in their stomachs.

${ }^{21}$ The real tongue forms the floor of the mouth, and is found as a distinct part in a few Insects, as the Crickets.

${ }^{22}$ In the Marsipobranchii, it is circular or oval.

${ }^{23}$ The mouth of the Whale is exceptional, the walls not being dilatable. The act of sucking is characteristic of all young Mammals, hence the need of lips.

${ }^{24}$ 'The Ant-eater has two callous ridges in the mouth, against which the insects are crushed by the action of the tongue.

25 The baleen plates do not represent teeth; for in the embryo of the Whale we find minute calcareous teeth in both jaws, which never cut the gum. The whalebone is a peculiar development of hair in the palate, and under the microscope it is seen to be made up of fibres which are hollow tubes.

${ }^{26}$ 'The "tusks" of the Elephant are prolonged incisors; those of the Walrus, Wild Boar, and Narwhal are canines.

27 "I was one day talking with Prof. Owen in the Hunterian Museum; when a gentleman approached, with a request to be informed respecting the nature of a curious fossil which had been dug up by one of his workmen. As he drew the fossil from a small bag, and was about to hand it for examination, Owen quietly remarked, "That is the third molar of the underjaw of an extinct species of rhinoceros." -Lewes's Studies in Animal Life.

${ }^{28}$. This gap or interspace, so characteristic of the inferior Mammals, is called diastema. It is wanting in the extinct Anoplotherium, is hardly perceptible in one of the Lemurs, and is not found in Man.

${ }^{29}$ In the Spermaceti-whale, the teeth are fixed to the gum.

:o The Iguana among Reptiles, and Fishes with pavement-teeth, approach the Mammals in this respect.

${ }^{31}$ This movement is called peristaltic or vermicular, and characterizes all the successive movements of the alimentary canal.

${ }^{32}$ Fishes and Amphibians have no saliva, but a short gullet. Birds are aided by a sudden upward jerk of the head.

${ }^{33}$ Fishes and Reptiles have no pharynx proper, the nostrils and glottis opening in to the mouth.

34 This movement of the pharynx and œsophagus is wholly involuntary. Liquids are swallowed in exactly the same way as solids. 
${ }^{35}$ The few animals in which the digestive cavity is wanting are called agastric, and agree in having a very simple structure. Such are some Entozoa (as Tape-worm) and unicellular Protozoa (as Gregarina). They absorb the juices, already prepared, by the physical process of endosmose. There are other minute organisms which seem to be able to extract the necessary elements, $\mathrm{CHON}$, from the medium in which they live.

${ }^{36}$ The cavity of a Sponge is perhaps homologous with the digestive cavity, but is not functionally such. Each cell lining it does its own digestion, taking the food from the water circulating in the cavity.

${ }^{37}$ " Nothing is more curious and entertaining than to watch the neatness and accuracy with which this process is performed. One may see the rejected bits of food passing rapidly along the lines upon which these pedicellariæ occur in greatest number, as if they were so many little roads for the conveying away of the refuse matters; nor do the forks cease from their labor till the surface of the animal is completely clean and free from any foreign substance."-AGassiz's Sea-side Studies.

${ }^{38}$ In the larva of the Bee, the anal orifice is wanting.

${ }^{39}$ The length of the canal in Insects is not so indicative of the habits as in Mammals. Thus, it is nearly as long and more complicated in the carnivorous Beetles than in the honey-sipping Butterflies.

${ }^{40}$ The object of this is unknown. It does not occur in the Oyster.

${ }^{41}$ In the Nautilus, this is preceded by a capacious crop.

${ }^{42}$ In the Shark, this is impossible, owing to a great number of fringes in the gullet hanging down towards the stomach.

${ }^{43}$ At the beginning of the large intestine in the Lizards (and in many Vertebrates above them, especially the vegetarian orders), there is a blind sac, called cacum.

- ${ }^{44}$ The Crocodile is said to swallow stones sometimes, like Birds, to aid the gastric mill.

${ }^{45}$ In the crop of the common Fowl, vegetable food is detained sixteen hours, or twice as long as animal food. The Dormouse, among Mammals, has an approach to a crop.

${ }^{46}$ In Invertebrates, the gizzard, when present, is situated between the crop and the true stomach; in Birds, it comes after the stomach.

${ }^{47}$ The Tape-worm has no digestive apparatus, but absorbs the already digested food of its host. This is no exception to the rule. The chemical preparation of the food has preceded its absorption.

${ }^{48}$ We find the most abundant saliva in those Mammals that feed on herbs and grain, but its action on starch is extremely feeble.

${ }^{49} \mathrm{It}$ is probable that the digestive part of the alimentary canal in all animals manifests a similar mechanical movement. It is most remarkable in the gizzard of a fowl, which corresponds to the pyloric end of the human stomach. This muscular organ, supplying the want of a masticatory apparatus in the head, is powerful enough to pulverize not only grain, but even pieces of glass and metal. This is done by two hard muscles moving obliquely upon each other, aided by gravel purposely swallowed by the bird. The grinding may be heard by means of the stethoscope. 
${ }^{50}$ Chyle is opaque in carnivores ; more or less transparent in all other Vertebrates, as in Birds, since the food does not contain fatty matter.

${ }^{51}$ In Fishes, the villi are few or wanting. In Man, they number about 10,000 to the square inch.

${ }^{52}$ Except, perhaps, the tendons, ligaments, epidermis, etc.

${ }^{53}$ The phenomenon produced by these properties conjointly, capillary attraction and diffusion, is called endosmosis.

54 The blood is colorless also in the muscular part of Fishes. That of Birds is of the deepest red. The coloring matter of the red blood in worms is not in the corpuscles, but in the plasma.

${ }^{55}$ Coagulation may be artificially arrested by common salt. Arterial blood coagulates more rapidly than venous. The disposition of the red corpuscles in chains, or rouleaux, does not occur within the blood-vessels. The cause has not been discovered.

${ }^{56}$ The corpuscles of Invertebrates are usually colorless, even when the blood is tinged.

${ }^{57}$ Except during the fotal life. The corpuscles of the Camel are nonnucleated, as in other Mammals. If the transparent fluid from a boil be examined with a microscope, it will be seen to be almost composed of colorless corpuscles, showing their use in repairing injuries.

58 There are no valves in the veins of Fishes, Reptiles, and Whales, and few in Birds.

${ }^{59}$ Capillaries are wanting in the epidermis, nails, hair, teeth, and cartilages. Hence, the epidermis, for example, when worn out by use, is not removed by the blood, like other tissues, but is shed.

${ }^{60}$ A part of the blood, however, in going from the capillaries to the heart, is turned aside and made to pass through the liver and kidneys for purification. This is called the portal circulation, and exists in all Vertebrates, except that in Birds and Mammals it is confined to the liver.

${ }^{61}$ Two in the higher Mammals, three in the lower Mammals, Birds, and Reptiles. They are called vence cavo.

62 Tricuspid in Mammals, triangular in Birds.

${ }^{63}$ The pulse of a Hen is 140 ; of a Cat, 110 to 120 ; of a Dog, 90 to 100; and of an $\mathrm{Ox}, 25$ to 42 .

${ }^{64}$ The bivalve Brachiopods breathe by delicate arms about the mouth, and by the "mantle."

65 The air-bladder, found in most Fishes, is another rudiment of a lung, although it is used, not for respiration, but for altering the specific gravity of the Fish. In the Gar-pike of our Northern lakes, it very closely resembles a lung, having a cellular structure, a tracheal tube, and a glottis. It is here functional. The gills represent lungs only in function; they are totally distinct parts of the organism.

${ }^{66}$ In the human lungs they number $600,000,000$, each about $\frac{1}{10} \overline{0}$ of an inch in diameter, with an aggregate area of 132 square feet. The thickness of the membrane between the blood and the air is $\frac{1}{2400}$ of an inch. The lungs of Carnivores are more highly developed than those of Herbivores. In the Manatee, they are not confined to the thorax, but extend down nearly to the tail. 
${ }^{67}$ Crocodiles are the only Reptiles whose nostrils open in the throat behind the palate, instead of directly into the mouth-cavity. This enables the Crocodile to drown its victim without drowning itself; for, by keeping its snout above water, it can breathe while its mouth is wide open.

${ }^{68}$ A rudimentary diaphragm is seen in the Crocodile and Ostrich.

${ }^{69}$ The poison-glands of venomous Serpents and the silk-vessels of Caterpillars are considered to be modified salivary glands. Birds, Snakes, and Cartilaginous Fishes have no urinary bladder.

${ }^{70}$ Since the weight of a full-grown animal remains nearly uniform, it must lose as much as it receives; that is, the excretions, iucluding the solid residuum ejected from the intestinal canal, equal the food and drink.

${ }^{71}$ Other names for derm are, cutis, corium, enderon, and true skin; and for epidermis, cuticle, ecderon, and scarf-skin. The derm is often so intimately blended with the muscles that its existence as a distinct layer is not easily made out. Even in Infusoria, we find the tunic double, an outside cuticula lined by a soft cortical layer; and in Jelly-fishes, naturalists distinguish an ectoderm, endoderm, and mesoderm.

${ }^{72}$ See Fig. 148. Papillæ are scarcely visible in the skin of Reptiles and Birds.

${ }^{73}$ The animal basis of this structure is chitine, a peculiar horn-like substance found in the hard parts of all the articulated animals.

74 The shell is always an epidermal structure, even when apparently internal. The horny "pen" of the squid, the "bone" of the Cuttle-fish, and the calcareous spot on the back of the Slug are only concealed under a fold of the mantle. So the shell of the common Unio, or fresh-water clam, is covered with a brownish or greenish membrane, which is the outer layer of the epidermis. Where the mantle covers the lips of a shell, as in most of the large seasnails, or where its folds cover the whole exterior, as in the polished Cowry, the epidermis is wanting, or covered up by an additional layer.

75 The pearls of commerce, found in the mantle of some Mollusks, are similar in structure to the shell; but what is the innermost layer in the shell is placed on the outside in the pearl, and is much finer and more compact. The pearl is formed around some nucleus, as an organic particle, or grain of sand.

${ }^{76}$ When the centrum is concave on both sides, as in Fishes, it is said to be amphicclous; when concave in front and convex behind, as in Crocodiles, it is called procolous; when concave behind and convex in front, as in the neck-vertebræ of the $\mathrm{Ox}$, it is opisthocolous. In the last two cases, the vertebræ unite by ball-and-socket joints.

${ }^{77}$ Whether the skull represents any definite number of vertebræ is still under discussion. We cannot speak of "cranial vertebræ" in the same sense as "cervical vertebræ." The most that can be said is that in a general way the skull is homologous to part of the vertebral column (B).

${ }^{78}$ A few have but one pair, the Whale and Siren wanting the hind pair; while some have none at all, as the Snakes and lowest Fishes. In land animals, the posterior limbs are generally most developed : in aquatic animals, the anterior. Dr. Wyman contends that the limbs are tegumentary organs, and attached to the vertebral column in the same sense that the teeth are attached to the jaws. Other theories are that they originate from gill-arches (Gegenbaur) or that they are remains of a once continuous lateral fin (Thacher). 
79 The first trace of muscular tissue is found in the stem of Vorticella-an Infusorian. In Hydra we find neuro-muscular cells, and the Jelly - fishes have muscular tissue.

so The muscles of some Invertebrates, as Spiders, are yellow.

81 The muscles of the heart and gullet are striped. In the lower animals these distinctions of voluntary and involuntary, striated and smooth, solid and hollow, muscles can seldom be made.

82 The skeleton of the Carrion-crow, for example, weighs, when dry, only twenty-three grains.

83 The Dragon-fly can outstrip the Swallow; nay, it can do in the air more than any bird-it can fly backward and sidelong, to right or left, as well as forward, and alter its course on the instant without turning. It makes twenty-eight beats per second with its wings; while the Bee makes one hundred and ninety, and the House-fly three hundred and thirty. The swiftest Racehorse can double the rate of the Salmon. So that Insect, Bird, Quadruped, and Fish would be the order according to velocity of movement.

${ }^{84}$ The theory that Flies adhere by atmospheric pressure is now abandoned.

${ }^{85}$ More precisely, the term brain, or brains, applies only to the cerebrum, while the total contents of the cranium are called encephalon.

${ }^{86}$ The exact functions of the cerebrum are not yet clearly understood. If we remove it from Fishes, or even Birds, their voluntary movements are little affected; while the Amphioxus, the lowest of Fishes, has no brain at all, but its life is regulated by the spinal cord. Such mutilated animals, however, make no intelligent efforts. The substance of the cerebrum, as also the cerebellum, is insensible, and may be cut away without pain to the animal; and when both are thus removed, the animal still retains sensation, but not consciousness.

${ }^{87}$ It is very difficult to define sensation, or sensibility. The power is possessed by animals which have neither nervous system nor consciousness. These low manifestations of sensibility are called irritability-the power by which an animal is capable of definitely responding to a stimulus from without. The response is not called out by the direct action of the stimulus, but is determined mainly by the internal structure and condition of the animal.

${ }^{88}$ Parts destitute of blood-vessels, as hair, teeth, nails, cartilage, etc., are not sensitive. The impressibility of the nerves is proportioned to the activity of circulation. According to the recent investigations of Dr. Bowditch, the channels of motor and sensitive impressions lie in the lateral, and not in the anterior and posterior, columns of the spinal cord.

89 "Tentacles" and "horns" are more or less retractile, while antennæ are not, but all are hollow. Antennæ alone are jointed.

${ }_{90}$ In Man, the soft palate and tonsils also have the power of tasting.

${ }^{91}$ No organ of hearing has been discovered with certainty in the Radiates and Spiders. The "ear" of many lower animals is probably an organ for perceiving the animal's position rather than sound-an "equilibrium organ."

${ }^{92} \mathrm{It}$ is wanting in the aquatic Mammals. Crocodiles have the first representative of an outside ear in the form of two folds of skin.

${ }^{93}$ This, like the definition of smell and hearing, is loose language. There is no such thing as sound till the vibrations strike the tympanum, nor even 
then, for it is the work of the brain, not of the auditory nerve. Sound is the sensation produced by the wave-movement of the air. If thus defined in terms of sensation, light is nothing; without eyes the world would be wrapped in darkness. Some Protozoa have a pigment spot as an eye.

${ }_{94}$ In Invertebrates and aquatic Vertebrates, the crystalline lens is globular; or, in other words, it is round in short-sighted animals, and flattish in the long-sighted. The lens of the Invertebrate is not exactly the same as the lens of the Vertebrate eye, though it performs the same function; it is really a part of the cornea.

95 The Ant has fifty in each eye, the House-fly four thousand, the Dragonfly twenty-eight thousand.

96 The pigment, therefore, while apparently in front of the retina, is really behind it, as in Vertebrates. The layer beneath the cornea, serving as an " iris," is wanting in nocturnal Insects, since they need every ray of light. The optic nerve alone is insensible to the strongest light.

${ }^{97}$ It should be noticed that this corresponds with another peculiar fact already mentioned, that either hemisphere of the brain controls the muscles on the opposite side of the body. In Invertebrates, the motor apparatus is governed on its own side.

${ }^{98}$ Sharks have eyelids, while Snakes have none. The third eyelid (called nictitating membrane) is rudimentary in many Mammals.

${ }_{99}$ An infant would doubtless learn to walk if brought up by a wild beast, since it was made to walk. Just as an Infusorium moves its cilia, not because it has any object, but because it can move them. New-born puppies, deprived of brains, have suckled; and decapitated Centipedes run rapidly. Such physical instincts exist without mind, and may be termed "blind impulses."

100 We say "apparently," because it may be a fixed habit, first learned by experience, transmitted from generation to generation. A duckling may go to the water, and a hound may follow game in some sense, as Sir John Herschel takes to astronomy, inheriting a taste from his father. Breeders take advantage of this power of inheritance.

101 We may divide the apparently voluntary actions of animals into three classes. First, organic, in which consciousness plays no part, and which are due wholly to the animal machine. Second, instinctive, in which consciousness may be present, but which are not controlled by intelligence. Third, associative, in which the animals act under conscious combination of distinct, single ideas, or past impressions. To these we may add rational acts, in which the mental process takes place under the laws of thought.

102 "Thus, while the human organism may be likened to a keyed instrument, from which any music it is capable of producing can be called forth at the will of the performer, we may compare a Bee, or any other Insect, to a barrel-organ, which plays with the greatest exactness a certain number of tunes that are set upon it, but can do nothing else."-Carpenter's Mental Physiology, p. 61. This constancy may be largely due to the uniformity of conditions under which Insects live.

${ }^{103}$ We may say, as a rule, that the proportion of instinct and intelligence in an animal corresponds to the relative development of the spinal cord and 
cerebrum. As a rule, also, the addition of the power to reason comes in with the addition of a cerebrum, and is proportioned to its development. Between the lowest Vertebrate and Man, therefore, we observe successive types of intelligence. Intelligence, however, is not according to the size of the brain (else Whales and Elephants would be wisest), but rather to the amount of gray matter in it. A honey-comb and an Oriole's nest are constructed with more care and art than the hut of the savage. It is true, this is no test of the capability of the animal in any other direction; but when they are fashioned to suit circumstances, there is proof of intelligence in one direction.

${ }^{104}$ An exception to the general rule that the smaller animals have more acute voices.

${ }^{105}$ It is wanting in a few, as the Storks.

106 'The Nightingale and Crow have vocal organs similarly constructed, yet one sings and the other croaks.

${ }_{107}$ These cells are detached portions of the parental organisms. Generally, these two kinds of cells are produced by separate sexes; but in some cases, as the Snail, they originate in the same individual. Such an animal, in which the two sexes are combined, is called an hermaphrodite.

108 The eggs of Mammals are of nearly uniform size; those of Birds, Insects, and most other animals are proportioned to the size and habits of the adult. Thus, the egg of the Epyornis, the great extinct bird of Madagascar, has the capacity of fifty thousand Humming-birds' eggs.

${ }^{109}$ As a general rule, when both sexes are of gay and conspicuous colors, the nest is such as to conceal the sitting Bird; while, whenever there is a striking contrast of colors, the male being gay and the female dull, the nest is open. Such as form no nest are many of the Waders, Swimmers, Scratchers, and Goatsuckers.

110 This lies at first transversely to the long axis of the egg. As the chick develops, it turns upon its side.

111 The blood appears before the true blood-vessels, in intercellular spaces. It is at first colorless, or yellowish.

${ }^{112}$ Exactly as the blood in the capillaries of the lungs is aerrated by the external air.

${ }^{113}$ Thus, the hollow wing-bone was at first solid, then a marrow-bone, and finally a thin-walled pneumatic bone. The solid bones of Penguins are examples of arrested development.

114 The thigh-bone ossifies from five centres. The bone eventually unites to one piece.

115 Muscle is mainly fibrine and myosin, while nerve is neurin.

116 For this reason, Mammals are called viviparous ; but, strictly speaking, they are as oviparous as Birds. The process of reproduction is the same, whether the egg is hatched within the parent or without. The eggs of Birds contain whatever is wanted for the development of the embryo, except heat, which must come from without. Mammals, having no food-yolk, obtain their nutrition from the blood of the parent, and after birth from milk.

117 The larvæ of Butterflies and Moths are called caterpillars; those of Beetles, grubs; those of Flies, maggots; those of Mosquitoes, wigglers. The 
terms larva, pupa, and imago are relative only; for, while the grub and caterpillar are quite different from the pupa, the bee-state is reached by a very gradual change of form, so that it is difficult to say where the pupa ends and the imago begins. In fact, a large number of Insects reach maturity through an indefinite number of slight changes. The Humble-bee moults at least ten times before arriving at the winged state.

118 Every tissue of the larva disappears before the development of the new tissues of the imago is commenced. The organs do not change from one into the other, but the new set is developed out of formless matter. The pupa of the Moth is protected by a silken cocoon, the spinning of which was the last act of the larva; that of the Butterfly is simply enclosed in the dried skin of the larva, which is called chrysalis because of its golden spots. The pupa of the Honey-bee is called nymph; it is kept in a wax-cell lined with silk, spun by the nursing-bee, not by the larva. The time required to pass from the egg to the imago varies greatly : the Bee consumes less than twenty days, while the Cicada requires seventeen years.

119 Compare the amount of food required in proportion to the bulk of the body, and also with the amount of work done, in youth, manhood, and old age. 120 Excepting, perhaps, that the new tail of a Lizard is cartilaginous.

121 The patella, or knee-pan, has no representative in the fore-limb, and, strictly, it belongs to the muscular system, rather than to the skeleton. Some anatomists contend that the great toe is homologous with the little finger, instead of the thumb.

${ }^{122}$ "'The structure of the highest plants is more complex than is that of the lowest animals; but, for all that, powers are possessed by Jelly-fishes of which oaks and cedars are devoid."-Mivart.

${ }^{123}$ It is, however, true that the number of eggs laid is proportioned to the risk in development.

${ }^{124}$ According to Mr. Darwin, the characters which naturalists consider as showing true affinity between two or more species are those which have been inherited from a common parent; and, in so far, all true classification is genealogical; i. e., it is not a mere grouping of like with like, but it includes like descent, the cause of similarity. In the existing state of science, a perfect classification is impossible, for it involves a perfect knowledge of all animal structure and life's history. As it is, it is only a provisional attempt to express the real order of nature, and it comes as near to it as our laws do in explaining phenomena. It simply states what we now know about comparative anatomy and physiology. As science grows, its language will become more precise and its classification more natural.

125 The term type is also used to signify that form which presents all the characters of the group most completely. Each genus has its typical species, each order its typical genus, etc. The word is also applied to the specimen on which a new species is founded. A persistent type is one which has continued with very little change through a great range of time. The family of Oysters has existed through many geological ages.

${ }_{126}$ The Colenterata and Echinodermata together make up the Radiata, the old subkingdom of Cuvier. Echinoderma is probably more correct than Echinodermata, but we retain the old orthography. 
${ }^{127}$ Strictly speaking, no individual is independent. Such is the division of labor in a hive, that a single Bee, removed from the community, will soon die, for its life is bound up with the whole. An individual repeats the type of its kingdom, subkingdom, class, order, family, genus, and species, through its whole line of descent.

128 These definitions of the various groups are mainly taken from Agassiz. They are not practically very useful, as they are not used by working naturalists. The kind and degree of difference entitling a group to a particular rank varies greatly with the naturalist, and the part of the Animal Kingdom where the group is found. Some families of Insects are separated by gaps less than those which divide genera of Mammals.

129 The Millepore coral, so abundant in the West Indian Sea, is the work of Hydroids. The surface is nearly smooth, with minute punctures. Gegenbauer, Haeckel, and others hold that the Acalephs have no body-cavity at all, the internal system of canals being homologous with the intestinal cavity of other animals.

130 This digestive cavity is really homologous to the proboscis of the Jellyfish, turned in. It is lined with ectoderm. The "body-cavity" is not really such, but homologous to the digestive sac of the Hydra.

${ }^{131}$ Among the exceptions are Tubipora, which have eight tentacles and no septa, and the extinct Cyathophylla, whose septa are eight or more.

${ }^{132}$ The longer septa (called primary) are the older; the shorter, secondary ones, are developed afterwards. As a rule, sclerodermic corals are calcareous, and a section is star-like; the sclerobasic are horny and solid. The latter are higher in rank.

${ }^{133}$ Some Star-fishes (Solaster) have twelve rays. In all Echinoderms, probably, sea-water is freely admitted into the body-cavity around the viscera.

134 The shell is not strictly external, like the crust of a Lobster, but is coated with the soft substance of the animal.

${ }^{135}$ Six hundred pieces have been counted in the shell alone, and twelve hundred spines. The feet number about eighteen hundred. They can be protruded beyond the longest spines.

136 The classification of this edition may be compared with that of the former by the following table, in which the order of the groups is altered to show the relation more easily.

Former Edition.

Subkingdom.

Class.

Present Edition.

III. $\quad\left\{\begin{array}{l}\text { 4. Lamellibranchiata. } \\ \text { 5. Gasteropoda. } \\ \text { 6. Cephalopoda. } \\ \text { 3. Tunicata. } \\ \text { 2. Brachiopoda. } \\ \text { 1. Polyzoa. }\end{array}\right.$

IV. $\left\{\begin{array}{l}\text { 1. Annelida }= \\ \\ \text { 2. Crustacea. } \\ \text { 3. Arachnida. } \\ \text { 4. Myriapoda. } \\ \text { 5. Insecta. }\end{array}\right.$

1. Platyhelminthes.

2. Nematelminthes.

3. Rotifera.

6. Annelides.

Do.

Do.

Do.

Do.

Class.

Subkingdom.

1. V.

Do. 2. Mollusca.

Do. 3. J VII.

Tunicata.
IV.
Vermes.
4.
5.

VI.

4. Myriapoda.
5. Insecta.

4.

Arthropoda. 
The two subkingdoms of the earlier edition are thus divided into four. The Classes remain the same, except the Annelida.

${ }^{137}$ The most important genera are Terebratula, Rhynchonella, Discina, Lingula, Orthis, Spirifer, and Productus. The first four have representatives in existing seas. Most naturalists now admit their affinity to the worms, although some still keep them in the subkingdom Mollusca.

138 There are some exceptions : the Oyster is unequivalved, and the Pecten equilateral.

139 The chief impressions left on the shell are those made by the musclesthe dark spots called "eyes" by oyster-men; the pallial line made by the margin of the mantle; and the bend in the pallial line, called pallial sinus, which exists in those shells having retractile siphons, as the Clam.

140 The Clam is the highest of Lamellibranchs, and the Oyster one of the lowest. The Mya arenaria, or "Soft Clam," has its shell always open a little; while Venus mercenaria, or "Hard Clam," keeps its shell closed.

141 The Slug has no shell to speak of, and the Chiton is covered with eight pieces. It may be remembered, as a rule, that all univalve shells in and around the United States are Gasteropods, and that all bivalves in our rivers and lakes, and along our sea-coasts (save a few Brachiopods), are Lamellibranchs.

${ }^{142}$ Hold the shell with the apex up and the mouth towards the observer. If the mouth is on his right, the shell is right-handed or dextral, if on his left, sinistral. In other words, a right-handed shell is like a right-handed screw.

${ }^{143}$ Instead of a strong breathing-tube with a valve, answering for a forcepump and propeller, as in the Cuttle-fish, it has only an open gutter made by a fold in the mantle, like the siphons of the Gasteropods. The back chambers are filled with nitrogen gas.

The common Poulpe has two thousand suckers, each a wonderful little airpump, under the control of the animal's will.

144 The order of the classes is one of relation rather than of rank. They cannot be arranged serially. The Myriapods have a worm-like multiplication of parts, degrading them, and their nervous system is simpler than that of Caterpillars; yet their heads show a close relationship to Insects. The Arachnids include some lower forms than Myriapods; on the other hand, for their wonderful instincts, Owen places them above the Insects. They are closely allied to Crustaceans, and stand more nearly between Crustaceans and Insects than between Myriapods and Insects.

${ }^{145}$ Certain Crabs live on dry land, but they manage to keep their gills wet.

${ }^{146}$ The student should remember that this threefold division is not equivalent to the like division of a vertebrate body.

${ }^{147}$ Each ring (called somite) is divisible in two arcs, a dorsal and ventral, and each arc consists of four pieces.

148 The four pairs of legs in Arachnids answer to the third pair of maxillæ and the three pairs of maxillipedes in the Lobster. The great claws of Scorpions are the first maxillæ of the Lobster, as are the pedipalpi of Spiders. 
${ }^{149}$ The antennæ are more probably altogether undeveloped, and the jaws of the Spider correspond to the mandibles of the Lobster.

${ }^{150}$ Compare the single thread of the Silk-worm and other caterpillars.

${ }^{151}$ The common Spider, Epeira, which constructs with almost geometrical precision its net of spirals and radiating threads, will finish one in forty minutes, and just as regularly if confined in a perfectly dark place.

152 These parts do not correspond to the parts so named in human anatomy. See also p. 162.

${ }^{153}$ The pupa-case is often ornamented with golden spots in Butterflies; hence the common name chrysalis.

${ }^{154}$ In aquatic animals the posterior limbs are the ones aborted or reduced, if any; in land animals the fore-limbs are usually sacrificed.

${ }^{155}$ The smallest corpuscles are found in Ruminants; the largest in Amphibians with permanent gills. The average size in Birds is double that in Man, and about equal to that in the Elephant. Those of Monkeys are a trifle smaller than the human. In the embryo they are larger than in the adult. Camels only among Mammals have oval disks.

${ }^{156}$ The facial angle becomes of less and less importance as we go away from man, and for two reasons. Where the brains do not fill the brain-case the angle is obviously of little value, and if the jaws are largely dereloped the angle is reduced, although intelligence may not be altered.

${ }^{157}$ Oblong human skulls, whose diameter from the frontal to the occipital greatly exceeds the transverse diameter, are called dolichocephalic; and such are usually prognathous, $i . e$, have projecting jaws, as the negro's. Round skulls, whose extreme length does not exceed the extreme breadth by a greater proportion than 100 to 80 , are brachycephalic; and such are generally orthognathous, or straight-jawed.

${ }_{158}$ The classes are variously grouped into the Hormatocrya, or Coldblooded, and the Hcematotherma, or Warm-blooded; into the Branchiata and Abranchiata; into the Allantoidea and Anallantoidea.

${ }^{159}$ It would be safe to say that any living Vertebrate with side fins supported by fin-rays is a Fish; but the extinct Reptile Ichthyosaurus also had them.

160 " The capacity for growing as long as life lasts, which some Fishes are said to possess, may be explained by the facts that their bodies are, firstly, of very nearly the same specific gravity as the water in which they live, and, secondly, of a temperature which is but a very little higher than that which they are there exposed to. Thus the force which in other animals is expended in the way of opposition to that of gravity and in the way of producing heat is available for sustaining continuous growth."-RoLLESTON.

${ }^{161}$ Amphibians with a moist skin are also remarkable for their cutaneous respiration. They will live many days after the lungs are removed. Their vertebræ vary in form: in the lowest they are biconcave, like those of Fishes; in Salamanders they are opisthocœlous: in the Frogs and Toads they are usually procœlous.

${ }^{162}$ Salamanders are often taken for Lizards, but differ in having gills in early life and a naked skin. The Proteus and Siren resemble a tadpole arrested in its development. 
${ }^{163}$ The Surinam Toad has no tongue.

164 The posterior pair of limbs is sometimes represented by a pair of small bones; and the Boas and Pythons show traces of external hind-limbs.

165 There are some notable exceptions. The Slow-worm is legless, and the Chameleon has a soft skin, with minute scales.

${ }^{166}$ According to Owen; but Huxley insists that the plastron belongs to the exoskeleton.

${ }^{167}$ Knees always bend forward, and heels always bend backward.

${ }^{168}$ We cannot claim that this airy skeleton is necessary for flight. The bones of the Bat are free from air, yet it is able to keep longer on the wing than the Sparrow. The common Fowl has a hollow humerus; while some Birds of long flight, as the Snipe and Curlew, have airless bones.

${ }^{169}$ The fossil Archceopteryx, a lizard-like Bird, is placed in a separate division, Saururce. Birds have also been divided according to their degree of development at birth into (1) Hesthogenous, as Fowls, Ostriches, Plovers, Snipes, Rails, Divers, and Ducks, whose chick is hatched completely clothed, has perfect senses, runs about, and feeds itself. When full grown, it uses its feet rather than wings, flying with a rapid, labored stroke, and taking the first opportunity to settle on land or water, not on trees; the male is polygamous and pugnacious; the female makes little or no nest; and neither sex sings. This group is of the best use to man, and approaches more nearly to Mammals, the habitual use of the legs and preference for land or water degrading it as a Bird and raising it in the list of animals; (2) Gymnogenous, as Gulls, Pelicans, Birds of Prey, Herons, Sparrows, Woodpeckers, and Pigeons, whose chick comes helpless, blind, and naked; it can neither walk nor feed itself, but gapes for food; the adult is monogamous, and builds elaborate nests in trees and perches; many sing; all are habitual fliers. These are birds par excellence, gifted with higher intelligence than the others, and are never domesticated for food.

${ }^{170}$ Hopping is characteristic of and confined to the Perchers; but many of them, as the Meadow-lark, Blackbird, and Crow, walk.

171 This order is artificial. But it is better to retain it until ornithologists agree upon some natural arrangement. The classification of birds is taken from Coues's "Key to North American Birds," as being the work on ornithology in most general use.

${ }^{172}$ The Whales are hairy during fotal life only.

${ }^{173}$ The Manati has 6 ; Hoffmann's Sloth 6 ; and two species of three-toed Sloth have respectively 8 and 9 .

${ }^{174}$ As in the Whale, Porpoise, Seal, and Mole. Teeth are wanting in the Whalebone Whales, Ant-eaters, Manis, and Echidna.

${ }^{175}$ The Monotremes resemble Marsupials in having marsupial bones, but have no pouch. They differ from all other Mammals in having no distinct nipples.

176 The pouch is wanting in some Opossums and the Dasyurus.

177 For the best account of the Elephant, see Tennant's "Ceylon" or Brehm's "Thierleben."

${ }^{178}$ The fore-feet of the Tapir have four toes, but one does not touch the ground. 
179 The extinct Horse (Hipparion) had three toes, two small hoofs dangling behind. The foot of the Horse is of wonderful structure. The bones are constructed and placed with a view to speed, lightness, and strength, and bound together by ligaments of marvellous tenacity. There are elastic pads and cartilages to prevent jarring; and all the parts are covered by a living membrane which is exquisitely sensitive, and endows the foot with the sense of touch, without which the animal could not be sure-footed. The hoof itself is a world of wonders, being made of parallel fibres, each a tube composed of thousands of minute cells, the tubular form giving strength. There are three parts, "wall," "sole," and "frog "-the triangular, elastic piece in the middle, which acts as a cushion to prevent concussion and also slipping.

180 The Camel and Llama are exceptional, having two upper incisors and canines, are not strictly cloven-footed, having pads rather than hoofs, and are hornless.

181 The Hyena alone of the 'Carnivores has only four toes on all the limbs, and the Dog has four hind-toes. The Lion is the king of beasts in majesty, but not in strength. Five men can easily hold down a Lion, while it requires nine to control a Tiger.

182 The eye-orbits of the Lemurs are open behind. The Flying Lemur (Galeopithecus) is considered an Insectivore.

${ }_{183}$ The old term Quadrumana is rejected because it misleads, for Apes, as well as Men, have two feet and two hands. There is as much anatomical difference between the feet and hands of an Ape as between the feet and hands of Man. Owen, however, with Cuvier, considers the Apes truly "fourhanded."

${ }^{184}$ It fails to cover in the Howling Monkey and Siamang Gibbon; but in the Squirrel Monkey it more than covers, overlapping more than in Man. As to the convolutions, there is every grade, from the almost smooth. brain of the Marmoset to that of the Chimpanzee or Orang, which falls but little below Man's.

${ }^{185}$ The tailed Apes of the Old World have longer legs than arms, and generally have "cheek-pouches," which serve as pockets for the temporary stowage of food.

${ }^{186}$ In the human infant, the sole naturally turns inward; and the arms of the embryo are longer than the legs.

${ }^{187}$ The Aye-aye, the lowest of the Lemurs, is remarkable for the large proportion of the cranium to the face.

${ }_{188}$ This feature was shared by the extinct Anoplotherium, and now to some extent by one of the Lemurs (Tarsius).

${ }^{189}$ We have treated Man zoologically only. His place in Nature is a wider question than his position in Zoology; but it involves metaphysical and psychological considerations which do not belong here.

${ }^{190}$ See Lewes's charming "Studies in Animal Life." Doubtless an examination of all the strata of the earth's crust would disclose forms immensely outnumbering all those at present known. And even had we every fossil, we would have but a fraction of the whole, for many deposits have been so altered by heat that all traces have been wiped out. Animal life is 
much more diversified now than it was in the old geologic ages; for several new types have come into existence, and few have dropped out.

${ }^{191}$ Among the types characteristic of America are the Gar-pike, Snappingturtle, Hummers, Sloths, and Musk-rat. Many of our most common animals are importations from the Old World, and therefore are not reckoned with the American fauna; such as the Horse, Ox, Dog and Sheep, Rats and Mice, Honey-bee, House-fly, Weevil, Currant-worm, Meal-worm, Cheesemaggot, Cockroach, Croton-bug, Carpet-moth and Fur-moth. Distribution is complicated by the voluntary migration of some animals, as well as by Man's intervention. Besides Birds, the Bison and Seals, some Rats, certain Fishes, as Salmon and Herring, and Locusts and Dragon-flies among Insects, are migratory.

${ }^{192}$ When the cable between France and Algiers was taken up from a depth of eighteen hundred fathoms, there came with it an Oyster, Cockle-shells, Annelid tubes, Polyzoa, and Sea-fans. Ooze brought up from the Atlantic plateau (two thousand fathoms) consisted of ninety-seven per cent. of Foraminifers. 


\section{THE NATURALIST'S LIBRARY.}

THE following works of reference, accessible to the American student, are recommended :

General Works and Text-books. Agassiz, Methods of Study in Natural History.

Agassiz and Gould, Principles of Zoot ogy.

Rolleston, Forms of Animal Life.

Lew rs, Studies of Animal Life.

Jonks, General Outline of the Organization of the Animal Kingdom.

HuXiey and Martin, Elementary Biology.

OwEN, Comparative Anatomy of Invertebrates and Vertebrates.

VAN DER HOEVEN, Handbook of Zoology.

Wood, Illustrated Natural History.

Nichouson, Manual of Zoology.

Tennex, Elements of Zoology.

Morse, First Book of Zoology.

Jones, Animal Creation.

PAOKARD, Zoology.

Gegenbaur, Comparative Anatomy.

\section{Invertebrates.}

Hoxlex, Anatomy of Invertebrated Animals.

Macallister, Introduction to Animal Morphology.

Brooks, Handbook of Invertebrate Zoology.

SiEBoLd, Anatomy of Invertebrates.

Vertebrates.

Huxuer, Anatomy of Vertebrated Animals.

Madallister, Morphology of Vertebrates.

Huxley and Hawkins, Atlas of Comparative Osteology.

FLower, Osteology of Mammalia.

Chadveat, Comparative Anatomy of Domesticated Animals.

Mrvart, Lessons in Elementary Anatomy.
Mrvart, The Cat.

GRAY, Anatomy, Descriptive and Surgical. Strioker, Handbook of Human and Comparative Histology.

Embryology.

BALFour, Comparative Embryology.

Foster and Balfour, Elements of Embryology.

Packard, Life Histories of Animals.

\section{Physiology.}

Carpenter, Comparative Physiology.

Hoxuery, Lessons in Elementary Physiology.

Foster, Text-book of Physiology.

Martin, The Human Body.

Fuint, Physiology.

\section{Geographical Distribution.}

WALLAOE, Geographical Distribution of Animals.

Murray, Geographical Distribution of Mammals.

\section{Microscopy.}

Carpenter, The Microscope and its Revelations.

Griffiths and Henfrey, The Micrographic Dictionary.

Darwinism.

Schmidt, Descent and Darwinism.

HAEOKEL, History of Creation.

DarwIN, Origin of Species.

HuxLey, Lay Sermons, etc.

Mrvart, Lessons from Nature.

Special Works.

Crask, Mind in Nature.

Agassiz, Sea-side Studies in Natural History. 
TAYLOR, Half-hours at the Sea-side.

Greene, Manuals of Sponges and Cœlenterata.

DANA, Corals and Coral Islands.

VerRILL, and SмITH, Invertebrates of Vineyard Sound:

Gout.D and BInNey, Invertebrata of Massachusetts.

Woodward, Manual of Mollusca.

Packard, Guide to the Study of Insects. DUnOan, Transformations of Insects.

Storkr, Fishes and Reptiles of Massachusetts.

Cours, Key to North American Birds.

Jordan, Popular Key to the Birds, etc., of Northern United States.

Baird, Brewer, and Ridgway, Birds of North America.

BaIRD, Mammals of North America.

Arten, Mammalia of Massachusetts.

Soammon, Marine Mammals of North Pacific.

Pesohel, The Races of Man.

Marsh, Man and Nature.

Tyıor, Primitive Culture.

Nionolson, Palæontology.

Of serial publications, the student should have access to the American Naturalist, American Journal of Science, Popular Science Monthly, Smithsonian Contributions and Miscellaneous Collections, Bulletins and Proceedings of the various societies, Annals and Magazine of Natural History, and Nature.

The following German works are recommended as having no English equivalents :

Cr.Aus, Grundzüge der Zoologie.

Payensteoher, Allgemeine Zoologie.

Brons, Classen und Ordnungen des Thier-

Also the periodicals-

Zoologischer Anzeiger. reichs (unfinished and expensive, but indispensable to the working zoologist).

Biologisches Centralblatt. 


\section{N D E X.}

In the Index the numbers in Roman type (21) refer to pages; those in bold-faced type (40) refer to cuts. No attempt is made to analyze the statements made for each group in Part II. Reference is made for each class or prominent order to those cuts in Part I. which illustrate the group.

Absorption, Invertebrates, 94 .

Acalephæ, 247.

$$
\text { Vertebrates, 94, 60, } 61 .
$$

$$
\text { " see Jelly-fish. }
$$

Acarina, 287, 258.

Acarus, 287.

Acetabulum, 147.

Acipenser, 315, 290.

Acorn-shell, 284, 254.

$$
\text { " see Barnacle. }
$$

Acrania, 309, 310, 282.

Actinaria, 251, 199, 201-206.

Actinoid Polyp, 251, 199.

“ anatomy of, $38,95,198$.

“ blood of, 97.

“ development of, 205, 208.

" liver-cells of, 124 .

“ mouth of, $55,199$.

" nettle-cells of, 51 .

" prehension of, 51 .

“ reproduction of, 192

" respiration of, 112.

“ skeleton of, 130, 95.

" skin of, 127.

Adder, 320, 298.

Adipose Tissue, 35, 10.

ÆÆolis, 274.

Air-bladder, 117.

Albatross, 330.

Albumen, 19.

Alcyonaria, 256, 200, 207, 208.

Alcyonium, 256, 208.

Alimentary Canal, 74.

$\begin{array}{lll}\text { “ } & \text { " } & \text { Cœlenterata, 75. } \\ \text { " } & \text { " } & \text { development of, } 203 . \\ \text { “ } & \text { " } & \text { duodenum, 90. } \\ \text { " } & \text { " } & \text { Echinoderms, 76. } \\ \text { " } & \text { " } & \text { Fishes, 80. } \\ & & \text { Insects, 78. }\end{array}$

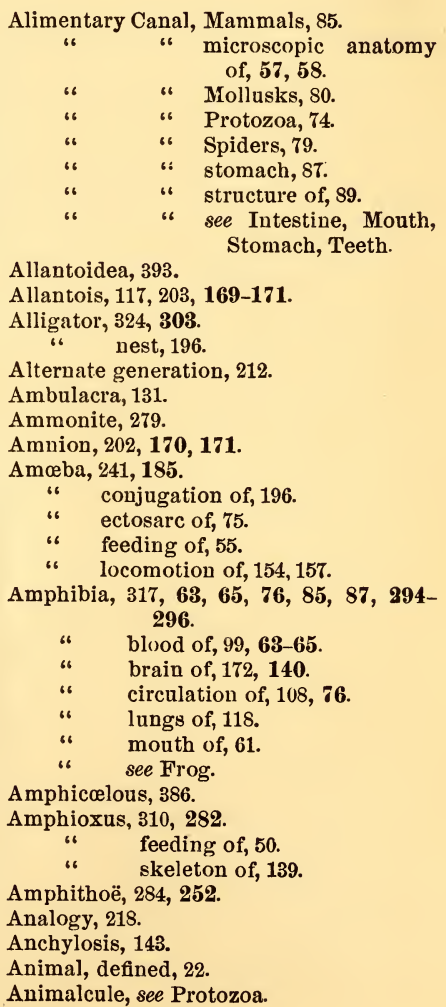


Annelides, 268, 17, 223.

Anodon, 78 ; see Clam.

Anoura, 318.

Ant, 304 .

Ant-eater, 344, 333.

Antennæ, 177, 147.

Anthozoa, 250, 38, 95, 198, 208.

Ape, 357, 120, 35̃3-357.

Apis, 304, 277.

Aplysia, 274.

Apteryx, 327.

Arachnida, 287.

"6 see Centipede, Scorpion, Spider.

Araneina, 289, 18, 25, 260, 261.

$$
\text { " sce Spider. }
$$

Ardea, 332, 313

Arenicola, 113, 77.

Areolar Tissue, 35, 3.

Argonauta, 280, 249.

Armadillo, 135, 344, 101, 334.

Artery, 104.

Arthropoda, 281.

$\begin{array}{ll}\text { "6 } & \text { blood of, } 99 . \\ \text { "6 } & \text { number of, } 221 . \\ \text { " } & \text { skin of, 127. } \\ \text { "6 } & \text { see Crab, Insect, Lobster, My- } \\ & \text { riapoda, Spider. }\end{array}$

Ascidian, 305, 278, 279.

$$
\text { riapoda, Spider. }
$$

$$
\text { “6 circulation of, } 107 .
$$

Astacus, 283, 250.

Asterias, 260.

$$
\text { " see Starfish. }
$$

Asteroidea, 258, 126, 133, 212, 213.

Astræa, 252, 203.

Astrophyton, 260.

Atavism, 216.

Attacus, 302, 274.

Auger-shell, 276, 238.

Auk, 329.

Aurelia, 248, 195.

$$
\text { " see Jelly-fish. }
$$

Aves, $325,50,65,76,105,116,125,162$, 170.

Babirusa, 69, 34.

Baboon, 359.

Balæna, see Whale.

Balanus, 284, 254.

Barnacle, 284, 253, 254.

$$
\text { " } \text { " metamorphosis of, } 210 .
$$

Basket-fish, 260.

Batrachia, 318, 63, 65, 76, 85, 87, 296, 297.

$$
\text { "s see Frog. }
$$

Bats, 346, 339, 340.

Beaver, 346, 337.
Bed-bug, 297.

Bee, 303, 277.

" alimentary canal of, 42

" eggs of, 195.

" eye of, 155.

" instincts of, 185 .

" mode of feeding of, 50 .

" mouth of, $59,22$.

" section of, $\mathbf{8 1}$.

" temperature of, 121

" see Hymenoptera, Insecta.

Beetle, 297, 267, 268.

" alimentary canal of, $\mathbf{4 1}$.

“ development of, $297, \mathbf{2 6 7}$.

"6 eye of, $182,156$.

" mouth of, 57.

" skeleton of, 292, 262.

" see Coleoptera, Insecta.

Belemnite, 281.

Bernicla, 310.

Beroë, 257.

Bile, 93.

Bird-of-Paradise, 339.

Birds, 325, 304-328.

" alimentary canal of, 84, 50.

" anatomy of, 50, 304.

" beak of, 54 .

“ blood corpuscles of, 99, 65 .

" brain of, 141.

" breathing of, 119.

" circulation of, $107,76$.

" distribution of, 378 .

" drinking of, 50 .

" egg of, 193, 162

" embryo of, 170.

"، eye of, 184.

" feather of, 137, 204, 105.

"6 flight of, 160, 125.

" gizzard of, 84, 384, 50.

" heart of, 109.

" locomotion of, 166.

"6 luugs of, 118, 50 .

"6 mouth of, 62 .

" skeleton of, 143, 116.

(6 smell of, 118 .

"6 temperature of, 121.

" voice of, 189

"6 wings of, 160, 304 .

Bivalve, see Clam, Lamellibranchiata, Oyster.

Blackbird, 339.

Blastema, 33.

Blastula, 198, 165.

Blood, 97.

" circulation of, 103.

" corpuscles, 98, 99, 62-65.

" development of, 200.

" functions of, 97

" of Invertebrates, 97.

“ rate of motion of, 111.

" temperature of, 100. 
Blood of Vertebrates, 98.

" vessels, 104.

Blubber, 34S.

Bluefish, 312, 284.

Boa, skull of, 72,37 .

Bone, composition of, 147.

" development of, 203.

“ structure of, $36,7,8$.

Bos, see Ox.

Brachiopoda, 266, 221, 222.

Brachycephalic, 393.

Bradypus, 344 .

Brail, 170.

" case of, see Skull.

"6 development of, 204.

" functious of, 173.

" parts of, 170 .

"weight of, 170 .

Braili-coral, 232, 204.

Bronchus, 119, 86.

Bryozoa, see Polyzoa.

Bubble-shell, 274, 231.

Buccinum, 272, 228.

Bndding, 192.

Bufo, 318.

"6 see Toad.

Bugs, mouth of, 59 .

“ see Hemiptera.

Bulimus, 275, 233.

Bulla, 272, 281.

Butterfly, 273.

$\begin{array}{ll}\text { " } & \text { anatomy of, } \mathbf{4 3 .} \\ \text { " } & \text { metamorphosis of, 20S, } 172 . \\ \text { " } & \text { mouth of, } 59, \mathbf{2 3 .} . \\ \text { " } & \text { scales of, } \mathbf{2 7 1 , 2 7 2 .}\end{array}$

Candis-fly, 295.

Cæcilia, 318.

Cæcum, 51.

Calcispongia, 246.

Camel, 352.

Cameo-shell, 278, 237.

Canaliculi, 37, 8.

Canine teeth, 69, 34, 35.

Capillaries, 104, 66, 68.

Caprimulgus, 338, 323.

Capybara, 346.

Carapace, 323, 115.

Cardium, 227.

Carinatæ, $32 \mathrm{~S}$.

Carnivora, 353, 90, 92, 106, 108-110, 128, 142, 346, 350.

" brain of, 142.

66 teeth of, 70 .

Cartilage, 36, 5 .

Cassis, 278, 237.

Cassowary, 327.

Castor, 346, 337.

Cat, 355.

" brain of, 142.
Cat, teeth of, 70.

Caterpillar, 301.

: anatomy of, $78, \mathbf{4 0}$.

" circulation in, 105,69

" false legs of, 172.

" head of, 303, 276

" heart of, 105, 69).

" jaws of, $53,276$.

46 Jocomotion of, 162

" muscles of, 156.

" nervous system of, 169,130

“ see Butterfly, Insecta, Lepidoptera.

Catfish, 316, 291

Cebus, 357, 352.

Cell, 31, 1.

Cement, 66, 31 .

Centipede, 291, 259.

Cephalization, 225.

Cephalopoda, 27s, 16, 47, 151, 247-249.

" see Cuttlefish, Squid.

Cephalo-thorax, 282.

Cerebellum, 171.

Cerebrum, 170.

Ceryle, 338, 327.

Cetacea, 348, 30, 341, 342.

" see Whale.

Chalaza, 193, 162.

Chameleon, 322.

" tongue of, 81 .

Cheiroptera, 346, 339, 340.

Chelonia, 322, 115, 301, 302. "6 see Turtle.

Chelydra, 323.

Chilognatha, 291.

Chilopoda, 291, 259.

Chimæra, 314.

Chimpanzee, 357, 354, 356.

"6 skeleton of, 120.

Chitine, 132.

Chiton, 276, 240.

Chlorophyl, 23.

Choroid, 188.

Chrysaora, 213, 178.

Chrysalis, 208, 390, 172.

Chyle, 93, 59.

Chyme, 92.

Cicada, 297, 266.

Cicatricula, 194.

Cidaris, 262, 96, 97.

Cilia, 154, 2.

Ciliata, 248, 188.

Circulation in Arthropoda, 106.

" in Ascidians, 107.

" in Birds, 109.

"، development of, 200.

" in Echinodermata, 105.

"s in Insects, 105.

" in Mammalia, 109.

6 in Mollusca, 106. 
Circulation in Vermes, 105.

"، in Vertebrata, 107, 281.

" see Heart.

Cirripedia, 284, 253, 254.

“ see Baruacle.

Clam, 272.

" adductors of, 46.

" alimentary canal of, $80,44,46$.

" anatomy of, $\mathbf{4 6}$.

" circulation in, 106.

" ear of, 178, 150.

"6 foot of, 161, 46.

" gills of, 113,78 .

" heart of, 106, 46

" hinge of, 270 .

" locomotion of, 161.

66 mouth of, 56 .

" nervous system of, 168,135

" prehension of, 50 .

"، shell of, $133,99$.

" siphons of, 46 .

" see Lamellibranchiata, Oyster.

Clamatores, 33s, 322.

Class, 235.

Classification, 231.

"Table, 239.

" synopsis of, 362 .

Claws, 136,

Cloaca, 85.

Clypeaster, 262.

Coagulation, 98 .

Cochineal, 297.

Cockle, 272, 227.

Cockroach, 297 .

Cod, 316, 292.

" eggs of, 195

Cœlenterata, 246.

$$
\text { " } \quad \text { number of, } 221 \text {. }
$$
Jelly-fish.

Coleoptera, 297, 41, 156, 267, 268.

$$
\text { "s see Beetle. }
$$

Columbae, $323,316$.

Condor, 335.

Cone-shell, 276, 239.

Conjugation, 196.

Connective Tissue, 34, 3, 4.

Coral, 130, 251, 95, 201-208. “ see Actinoid Polyp.

Corallium, 256, 207.

Coral reef, 254.

Cormorant, 330, 309.

Cornea, 183.

Corpuscles, see Blood.

Correlation, 218.

Cowry, 276, 234.

Corydalus, 295.

Crab, 287, 257.

"locomotion of, 162 .

" vocal organs of, 188 .

" see Lobster.
Crane, 332.

Craniota, 309.

Cranium, 141.

Cray-fish, 282, 250.

Cricket, 295, 264.

Crinoidea, 258, 211.

Crocodilia, 323, 303.

" exoskeleton of, 135.

" heart of, 108.

" locomotion of, 163.

" mouth of, $61,26$.

"6 skeleton of, $149,113$.

6 stomach of, 82, 49.

" see Reptilia.

Crow, 339.

Crustacea, 282.

" nauplius of, $211,177$.

"6 see Crab, Lobster.

Cteuactis, 253, 202.

Ctenophora, 257, 209.

Cuckoo, 335.

Cuculi, 335, 321.

Curassow, 333.

Cursores, 327, 305.

Cuticle, $12 \mathrm{~S}$.

Cutis, 128.

Cuttlefish, 280, 248.

" anatomy of, 47.

" alimentary canal of, S0, 47.

" beak of, 52,47 .

"6 brain of, $168,151$.

" circulation in, 107 .

"6 ear of, 151.

"6 eye of, $181,151$.

" heart of, 107.

" ink-bag of, 47.

" mouth of, 57 .

" pancreas of, 123.

" prehension of, 52.

"6 skeleton of, 134.

66 suckers of, 16.

" see Cephalopoda, Squid.

Cyclops, 284, 255.

Cypræa, 276, 234.

Cypris, 284, 255.

Cypseli, 335, 320.

DADDY-LONG-LEGS, 289, 300.

Daphnia, 284, 255.

Dasypus, $344,334$.

Dasyurus, 343.

Decapoda (Crustacea), 286, 70, 248, 250, $256,257$.

Decussation, 184 .

(Dibranchiata), 280.

Deglutition, 72.

Delphinus, 349, 343.

Demodex, 2S7, 258.

Dental Formulæ, 70.

“ Tissue, 38, 31.

Dentiue, 38, 66, 31 . 
Dermis, 128.

Development, 197.

by alternate generation, 211 .

of Bird, 199.

of blastula, 198, 165 .

of embryonic forms, 207.

of gastrula, 193, 166.

of Invertebrates, 204.

by metamorphosis, 207.

by metamorphosis, retrograde, 210.

oviparous, 309.

ovoviviparous, 309 .

segmentation of egg, 197.

of Vertebrates, 205.

viviparous, 309 .

see Metamorphosis, Reproduction.

Diaphragm, 86, 88.

Diastema, 70, 383 .

Dibranchiata, 280, 16, 47, 151, 248, 249.

Differentiation, 31 .

Digestion, chemical, 92.

$\begin{array}{ll}\text { " } & \text { of Invertebrate, } 92 . \\ \text { " } & \text { object of, } 91 . \\ \text { of Vertebrate, } 92 .\end{array}$

Digitigrade, 355, 128.

Diploria, 254, 204.

Dipnoi, 316, 293.

Diptera, 300, 24, 127, 173, 269, 270.

" see Fly, Mosquito.

\section{Discophora, 220.}

Distribution, 371-379.

Divers, 328.

Dog, 354

" brain of, 171 .

“" skull of, 143 .

" teeth of, 68 .

Dolichocephalic, 393.

Dolphin, 349, 343.

" teeth of, 68.

Doris, 274

Dove, 333, 316.

Dragon-fly, 294, 263.

Duck, 331, 311.

flight of, 387 .

Duck-mole, 342, 331.

Dugong, 350 .

$$
\text { " heart of, } 73 .
$$

Duodenum, 90.

Eagle, 334, 319.

Ear, 179, 387, 152.

Ear-shell, 278, 235, 246.

Earth-worm, 269.

$\begin{array}{ll}\text { “ } & \text { alimentary canal of, } 77 . \\ \text { " } & \text { locomotion of, } 162 . \\ \text { " } & \text { nervous system of, } 168 . \\ \text { prehension of, } 52 .\end{array}$

Ecderon, 127.

Echidna, 342.

Echinodermata, 257.

“ number of species of, 221.

Echinoidea, 261, 28, 39, 96, 97, 214.

Echinus, 262, 214.

"s see Sea-urchin.

Edentata, 344, 101, 333, 334.

Egg, fertilization of, 197 .

" form of, 195.

"6 number of, 195.

" segmentation of, 197, 165.

“ structure of, 192, 161, 163.

Elasmobranchii, 314, 287, 288.

“i see Ray, Shark.

Elephant, 350

$\begin{array}{ll}\text { "6 } & \text { brain of, } 170 . \\ \text { "6 } & \text { skeleton of, } \mathbf{1 1 9} . \\ \text { " } & \text { teeth of, } 69, \mathbf{3 6} . \\ \text { " } & \text { trunk of, } 66 . \\ \text { " } & \text { tusks of, } 71, \mathbf{6 6}, 119 . \\ & \text { voice of, } 189 .\end{array}$

Elytra, 297.

Embryology, 197 .

Emu, 327.

Enamel, 66, 31.

Encephalon, 170.

Enderon, 127.

Endoskeleton, 127.

Entomostraca, 284, 255.

Epiblast, 199.

Epidermis, 34.

Epiglottis, 119, 159.

Epithelium, 33, 2.

Equus, see Horse.

Euplectella, 246.

Excretion, 121, 125.

Exoskeleton, 127.

Eye, of Invertebrates, 180.

" of Vertebrates, 181.

" development of, 204 .

Facial Angin, 309.

Falcon, 335.

Family, 235.

Fat, 38, 10.

Feathers, 137, 105.

“ development of, 204.

Felis, 355 .

Fertilization of Egg, 197.

Fibrine, 98.

Fishes, 310 .

" air-bladder of, 117, 48.

" alimentary canal of, 80, 48.

“ blood of, 99, 100, 65 .

“ brain of, 172, 139.

" circulation in, $107,51,75$.

"6 eye of, 184.

، fins of, 158, 123.

"6 gills of, 114, 48 . 
Fishes, heart of, 108, 48 .

" locomotion of, 159, 124.

6 mouth of, 61 .

"6. muscles of, 157, 48.

"6 number of species of, 313 .

66 ovary of, 48.

" pancreas of, 123 .

“6 prehension of, 54 .

" scales of, $135, \mathbf{1 0 2}, \mathbf{2 8 3}$

“ skeleton of, 112.

" skull of, 138, 112.

"6 teeth of, $61,67,32$.

Fish-hawk, 335, 318.

Fission, 191, 160.

Flagella, 154, 187.

Flagellata, 243, 187.

Flamingo, 331.

Flea, 300 .

Flight of Bats, 161 .

"6 of Birds, 160.

" of Iusects, 159 .

Fluke, 265.

Flustra, 267, 220.

Fly, 300 .

"6 buzzing of, $18 s$.

"6 foot of, 127.

" metamorphosis of, 270.

" mode of feeding of, 50 .

" mouth of, $59, \mathbf{2 4}$.

" see Diptera, Mosquito.

Fly-catcher, 338, 322.

Flying Fox, 346 .

Follicle, 123, 90.

Food, 47-49.

Foramen magnum, 172.

Foraminifera, 51, 241, 15, 186.

Forms of animals, 222.

Fox, 355, 349.

Frog, 318, 297.

" alimentary canal of, 82.

“ blood-corpuscles of, $99,63,65$.

" breathing of, 119 .

" circulation in, 10s, 76.

"6 food of, 49 .

"6 heart of, $10 \mathrm{~s}$.

" lungs of, 118, 85 .

"6 lymph-heart of, 96 .

" metamorphosis of, 209.

" respiration in, 117-119.

"6 slieleton of, $119,140,145,87$.

" tongue of, 61 .

" vertebræ of, 140,87 .

Fruit-moth, 303, 275.

Function, 41.

Fungia, 252, 202.

GALI.-BLADDER, 124, 92.

Gall-fly, 303.

Ganglion, 166, 14, 146.

Gannet, 331.

Ganoidei, 315, 289, 290.
Gar-pike, 315, 289.

Gasteropoda, 20, 29, 45, 100, 154, 176, 272. " see Suail.

Gastric glands, 123, 90. " juice, 93.

Gastrula, 198, 166.

Gavial, 324.

Gecko, 322.

Gelatine, 36 .

Genus, 235.

Germinal vesicle, 192.

Gibbon, 357.

Gills, 114, 125, 48.

Giraffe, 353.

Gizzard of Invertebrates, 79 "6 of Vertebrates, 84 .

Gland, 121, 89.

" gastric, 123, 90.

“ liver, 123, 92.

" pancleas, 123, 91.

" salivary, 122.

“6 sweat, 126, 94.

Globigerina, 242.

Glottis, 119.

Glycogen, 23.

Goatsucker, 338, $\mathbf{8 2 3 .}$

Goniaster, 260, 212.

Goose, 331, 310.

Gorgonia, 256, 208.

Gorilla, 357, 357.

Grallatores, 332, 313.

Grasshopper, 297.

$\begin{array}{ll}\text { " } & \text { development of, } 208 . \\ \text { " } & \text { mizzard of, 79. } \\ \text { mouth-parts of, } 58,21 . \\ \text { stridulation, 188. }\end{array}$

Grebe, 329.

Gregarinida, 240, 184.

Grouse, 333, 315.

Growth, 214.

Grubs, 389.

Gryllus, 295, 264.

Guinea-pig, 345.

Gulls, 329.

HamatocrYa, 393.

Hæmatotherma, 393.

Hæmocyanin, 102.

Hæmoglobin, 102.

Hag-fish, 54, 314.

Hair, 136, 94, 104.

Hair-worm, 262.

Haliotis, 278, 235, 246.

Hand, 359.

Hare, 346, 336.

Harvest-man, 289.

Haversian Canals, 37, 7.

Hawk, 335, 318.

Hearing of Invertebrates, 178.

"6 of Vertebrates, 179.

Heart, Arthropoda, 105, 69, 70. 
Heart, development of, 200,168 .

“" of Mollusks, 106.

" of 'Tunicates, 107, 279.

“ of Vertebrates, 107-109, 71-74.

Heat, 121.

Hedgehog, 346 .

Helix, 275, 282.

Hemiptera, 297, 265, 266.

$$
\text { " mouth of, } 59 \text {. }
$$

Heron, 332, 313.

Heterocercal, 159, 123.

Heteromya, 272.

Hippopotamus, 352 .

Histology, 12.

$$
\text { " foot of, } \mathbf{1 2 9} .
$$

Hog, 352 .

" teeth of, 67 .

Holothuroidea, 262, 215.

Homarus, see Lobster.

Homo, see Man.

Homocercal, 159, 287.

Homology, 217.

$$
\text { " serial, } 218 .
$$

Homomorphism, 217.

Hoofs, 136, 103.

Hornera, 267, 220.

Horns, 136.

Horse, brain of, 171, 138.

" hoof of, 136, 164, 103, 129.

" skeleton of, $151,117$.

“" skull of, 144, 111.

" splint-bones of, 207.

" stomach of, Ss, $\mathbf{5 3}$.

Horse-fly, mouth of, 60, 24.

Horseshoe-crab, 284.

$$
\text { “ “ “ } \quad \begin{aligned}
& \text { jaws of, } 53 . \\
& \text { skeleton of, } 131 .
\end{aligned}
$$

Hummer, 335 .

Hyalea, 274, 229.

Hydra, 246, 191.

"6 budding of, 192.

"6 digestive cavity of, 75 .

" nerve-cells of, 168 .

" repair of, 215.

Hydroid, see Hydrozoa.

Hydrozoa, 246, 178, 191-196.

$$
\text { “ } \quad \text { development of, } 205 .
$$

Hyena, 355 .

Hymenoptera, 303, 22, 42, 81, 277.

$$
\text { "6 see Bee. }
$$

Hypoblast, 199.

Ibis, 332.

Ichneumon, 304.

Ich thyopsida, 309.

Ichthyosaurus, 324 .

Idotia, 286, 251.

Iguana, 322 .

Incisors, 68 .
Individual, 220

Infusoria described, 243, 160.

" digestive cavity of, 75

" fission, 191, 160.

“ mode of feeding of, 50 .

“" motion of, 154.

" mouth of, 55 .

"“ respiration of, 112.

" skin of, 127.

Inheritance, 217.

Insectivora, 346.

Insecta, 29.1.

“" absorption of, 94 .

“ alimentary canal of, 79, 41-43

“ auatomy of, $\mathbf{4 3}, \mathbf{8 1}$.

“ antennæ of, 147.

" chrysalis of, $\mathbf{1 7 2}$.

" circulation in, 105, 292.

“ development of, 205 .

“ ear of, 179.

“ eye of, $181, \mathbf{1 5 5}, \mathbf{1 5 6}$.

“ feet and legs of, 162, 127, 131.

“ flight of, 159 .

“ gizzard of, 79 .

" heart of, $105,69$.

“ kidney of, $126,41,42$

“ liver of, 124

“ locomotion of, 159,162

" metamorphosis of, $207,172,173$, 264-267.

" mouth of, 57.

“ mouth-parts of, 53, 21-24.

" muscles of, 156, 131 .

“ nervous system of, 169,43

“ respiration in, $114,-291$.

" salivary glands of, 122 .

" silk glands of, $\mathbf{4 0 .}$

" skeleton of, 132, 292, 98, 262.

“ smell of, 178 .

“ spiracle of, 114, 79

" touch of, $177,147$.

" tracheæ of, 114, 40, 80, 81 .

“ - wings of, 159.

Insessores, 337, 322-328.

Inspiration, modes of, $115,119,120$.

Instinct, 184.

Intelligence, 187 .

Intestine of Amphibian, 82.

" of Bird, 84.

" of Fish, 81 .

" of Mammal, 85 .

"“ of Reptile, 82

“ see Alimentary Canal.

Isomya, 272.

Ivory, 66.

JAws, 51-71.

Jay, 339.

Jelly-fish, 247, 193-197.

"“ blood of, 97 .

“ development of, 212, 178, 195. 
Jelly-fish, eye of, 180.

$\begin{array}{ll}\text { “ } & \text { mode of feeding of, } 51 . \\ \text { " } & \text { nouth of, } 55 . \\ \text { "“ves of, } 168 . & \text { nettle-cells of, } 51 . \\ \text { reproduction of, } 212 .\end{array}$

Joints, 147. reproduction of, 212

Julus, 291.

KANGAROO, 88, 343.

Kidney, 126, 41, 93.

King-crab, see Horseshoe-crab.

Kingfisher, 335, 327.

Kite, 335 .

LabiUm and Labrum, 58, 21.

Labyrinthodontia, 318.

Lacerta, 321, 300.

Lacertilia, 321.

Lachnosterna, 297, 267.

Lacteals, 94, 60.

Lacunæ, 37, 8.

Lamellibranchiata, $270,44,46,78,99$,

$135,150,224-227$.

“6 eye of, 181, 153

" see Clam.

Lamellirostres, 331, 311.

Lamprey, 286.

Lamp-shell, 266, 221.

Lancelet, 310, 282.

Land-suail, 275, 232.

Lark, 340.

Larynx, 189, 159.

Lasso-cells, 51.

Leech, 268.

“" alimentary canal of, 77 .

" jaws of, 64 .

" locomotion of, 161.

" mode of feeding of, 50 .

Lemur, $355,351$.

Lepas, 284, 253.

Lepidoptera, 300, 43, 172.

Lepidosiren, 317 see Butterfly.

Lepidosteus, 315, 289.

Libellula, 294, 263.

Life, distribution of, 372.

"duration of, 226.

" nature of, 28.

“ struggle for, 227.

Lightning-bug, 299.

Ligula, 58, 21.

Likeness, 215.

Limax, 275, 232.

Limbs, development of, 204.

" skeleton of, 146.

Limnæa, 275, 232.

Limpet, 278, 245.

Limulus, 284.

" see Horseshoe-crab.

| Lion, 355.

" foot of, 128.

" skeleton of, 106.

"6 stomach of, 88, 55.

Liver, 123, 92.

Lizard, see Lacertilia.

Lobster, 106, 70, 256.

" alimentary canal of, 78 .

" anatomy of, 282 .

“ circulation in, 106, 70.

، ear of, 179

"6 eggs of, 196.

" gills of, 114

" gizzard of, 64 .

" locomotion of, 158.

"، moulting of, 132 .

" mouth of, 57 .

، prehension of, $53,57$.

، respiration in, 114 .

“ skeleton of, 131.

Lob-worm, 77.

Locomotion of Arthropoda, 162.

" of Birds, 160.

" of Fishes, 158

"، of Insects, 159.

"6 of Mollusks, 161.

" of Starfish, 161.

" of Vertebrates, 163.

"6 of Worms, 161.

Locust, 297.

Loligo, see Squid.

Longipennes, 329, 308.

Loon, 328, 307.

Louse, 297, 50.

Lucernaria, 197.

Lumbricus, see Earth-worm.

Lungs, function of, 125.

"6 of Snail, 116.

" surface of, 385 .

" of Vertebrates, 117.

Lymph, 102.

Lymphatics, 94, 61.

Lymph-heart, 96.

Magtra, 271, 46, 226.

Madrepore, $252, \mathbf{2 0 1}, 206$.

Madreporic plate, 258, 39.

Maggots, 389.

Mammalia, 309.

\begin{tabular}{|c|c|}
\hline & \\
\hline “6 & $\begin{array}{l}\text { alimentary canal of, } 85 \text {. } \\
\text { anatomy of, } 87, \mathbf{5 2} \text {. }\end{array}$ \\
\hline "6 & blood-corpuscles of, 99,65 . \\
\hline “6 & brain of, $171,138,142-145$. \\
\hline 66 & circulation in, $109,76,281$. \\
\hline "6 & digestion of, $92, \mathbf{5 1}$. \\
\hline “6 & drinking of, 50 \\
\hline "6 & ear of, 179,152 . \\
\hline “" & egg of, 198,165 \\
\hline “6 & embryo of, $202,171$. \\
\hline 6: & eye of, $183,157$. \\
\hline 66 & hair of, 136, 104 . \\
\hline
\end{tabular}


Mainmalia, heart of, 109, 73, 74. " locomotion of, 163 . " lungs of, 118, 86 . "6 mouth of, 62 ‘ palate of, $86,27,51$ " placenta of, $196,203,171$ "6 respiration in, 120 . “ skeleton of, 139 "6 smell of, 178, 149. "6 teeth of, 68 . " touch of, 177 “ voice of, 189,159

Man, 359.

" blood-corpuscles of, 99, 62.

" brain of, $170,171,137,144,145$.

" digestive tract of, $\mathbf{5 1}$.

" ear of, $179,152$.

" eye of, 198, 157.

" mouth of, $86,27$.

" muscles of leg of, 165, 130.

" nose of, $178,149$.

Manatee, 350, 848.

Maudibles, 58, 21.

Mantis, 53.

Mantle, 127, 46.

Marsipobranchii, 314, 286.

Marsupialia, 342, 332.

Mastodon, 350.

May-fly, 295.

Meandrina, 252.

Medulla oblongata, 172.

Medusa, see Jelly-fish.

Megatherium, 344.

Melania, 278.

Menobranchus, 317, 294

Mesentery, 83.

Mesoblast, 199

Metamoruhosis, 207.

$\begin{array}{ll}\text { " } & \text { of Crab, } 209 . \\ \text { " } & \text { of Frog, 209. } \\ \text { " } & \text { of Grasshoct, 208. } \\ \text { of Starfish, 208. }\end{array}$

Metazoa, 244.

Millepede, see Myriapoda.

Millepore, 391.

Mimicry, 217.

Minerals and Organisms, 19.

Mite, 287, 258.

Molar Teeth, 69.

Mole, 346.

Mollusca, 269.

$\begin{array}{ll}\text { " } & \text { absorption of, } 94 . \\ \text { "6 } & \text { circulation in, } 106 . \\ \text { " } & \text { development of, } 205 . \\ \text { " } & \text { digestion of, } 92 . \\ \text { " } & \text { distribution of, } 377 . \\ \text { "6rowth of, } 214 . \\ \text { " } & \text { kidney of. } 126,78 . \\ & \text { liver of, } 124 .\end{array}$

Mollusca, locomotion of, 161.

" metamorphosis of, 269.

6. mode of feeding of, 52 .

". mouth of, 56 .

" nervous system of, $168, \mathbf{1 3 4}, 135$

$$
\text { 151, } 157 .
$$

"6 number of species of, 221.

" respiration in, $113,46,47,78$.

" salivary glands of, 122.

" shell of, $133,385,99,100$.

"6 skin of, 127.

" see Clam, Cuttle-fish, Snail, Squid.

Monad, 243, 187.

Monera, 240, 183.

Monkey, 356, 19 , 352. see Primates.

Monomya, 271.

Monotremata, 342, $\mathbf{3 3 1}$

$$
\text { " mouth of, } 62 \text {. }
$$

Mosquito, 300, 173, 26!)

"6 metamorphosis of, 208.

" mode of feeding of, 50 .

Moth, 302, 274-276.

" anatomy of, 79, 43.

" metamorphosis of, 274.

" see Butterfly, Lepidoptera.

Motor Nerves, 167.

Moulting, 128, 209.

Mouse, 346.

Mouth, 55 .

$\begin{array}{ll}\text { " } & \text { of Arthropoda, } 57 . \\ \text { " } & \text { of Ascidia, } 60 . \\ \text { " } & \text { of Colenterata, } 55 . \\ \text { " } & \text { of Echinodermata, } 56 \text {. } \\ \text { " } & \text { of Infuses, } 61 . \\ \text { " } & \text { of Mammals, } 62 . \\ \text { " } & \text { of Mollusks, } 56 . \\ \text { " of Parasites, } 55 . \\ \text { " of Reptilia, } 61 . \\ \text { " of Vermes, } 57 .\end{array}$

Mucous Membrane, 89 .

Mud-fish, 315.

Murex, 278.

Mus, 346.

Musca, see Diptera, Fly.

Muscle, 39, 12, 122.

، development of, 204

"6 of Invertebrates, 156.

" kinds of, 155.

"6 of Vertebrates, 156.

Mushroom-coral, 252, 202.

Mussel, 270, 225.

Myriapoda, 290, 259.

$\begin{array}{ll}6 & \text { alimentary canal of, } 77 . \\ 6 & \text { mouth of, } 57 . \\ \text { 6 } & \text { sespiration in, } 116 . \\ & \text { seentipede. }\end{array}$


Myrmecophaga, 344, 333.

Mytilus, 270, 225.

NAIL, 135.

Narwhal, 223, 68.

Natatores, 328 .

Natica, 278 .

Natural Selection, 227.

Nauplius, 211, 178.

Nautilus, 279, 247.

Nematelminthes, 265, 218.

Nereis, 26s, 17.

Nerve-cells, 40, 132.

" fibres, 40, 13.

"“ kinds of, 167 .

“ velocity of impulse of, 167 .

Nervous System, 16S.

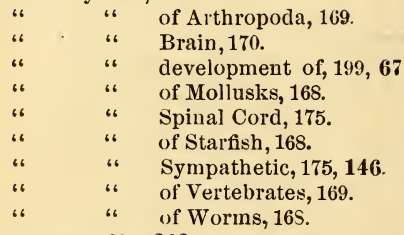

Newroptera, 294, 263.

$$
\text { " see Dragon-fly. }
$$

Neuroskeleton, 141.

Newt, 318, 296.

Nomenclature, Zoological, 236.

Notochord, 200, 167.

Nucleolus, $31,1$.

Nucleus, $31, \mathbf{1}$.

Nummulite, 242.

Nutrition, 45.

Nymph, 377.

Ochr.tr, 1 S1.

Octopus, 280.

Esophagus, 86 .

Olfactory Lobes, 172.

$$
\text { " Nerves, 17s. }
$$

Olive-shell, 278.

Oniscus, 286.

Operculum, 114, 134, 228.

Ophidia, 320.

$$
\text { " see Snake. }
$$

Ophiura, 260.

Opisthobrauchs, 274, 352, 230, 231.

Opisthocœlous, 383.

Opossum, 342, 332.

Optic Lobes, 172.

Orang-utan, 357, 353, 355.

Order, 235.

Organ, 41.

Organization, 30.

Organ-pipe Coral, 251, 200.

Oriole, 339.

Ornithorhynchris, $342,331$.

Orthoceras, 287.
Orthoptera, 217, 295, 21, 264.

\section{Orycteropus, 344 .}

Oscines, 338.

Osseous Tissue, see Bone.

Ossification, 37, 203.

Ostrea, 272. “ see Oyster.

Ostrich, 327, 305.

Otoliths, 178, 156.

Ovipositor, 293.

Owls, 335, 317.

Ox, alimentary canal of, 90.

"foot of, 352, 129.

" teeth of, 352 .

" see Ungulata.

Oyster, anatomy of, 80,44

" I development of, 205 .

"6 eggs of, 195.

"6 heart of, 106, 44.

“ mouth of, 56 .

“ prehension of, 50 .

" respiration in, 113

" see Clam, Lamellibranchiata.

Palate, 61.

Pallial Sinus, 271, 99.

Palpi, 58, 21.

Paludina, 278, 244.

Pancreas, 123, 91.

Pancreatic Juice, 93.

Pangolin, 344.

Paper Nautilus, 2S0, 249.

Papilio, 303.

Papillæ, 12S, 148.

Paramecium, 243, 188.

Parrot, 337, 320. see Infusoria.

$$
\text { " tongue of, } 62 \text {. }
$$

Partridge, 333.

Patella, 278.

Pavement-teeth, 67, 32.

Pearl-oyster, 224.

Pectoral Arch, 146.

Pedicelluriæ, 7т, 97.

Pedipalpi, 288.

Pelias, 320, 298.

see Scorpion.

Pelican, 331.

Penguin, 329, 306.

Penuatula, 256, 208.

Pentacrinus, 258, 211.

Pepsin, 93.

Peptone, 93.

Perch, skeleton of, 112.

Perchers, 337.

Periosteum, 138.

Peristaltic Movement, 89.

Periwinkle, 278.

Petrel, 330.

Petromyzon, 314, 286 
Pharyngobranchii, 310, 282.

Pharynx, 85.

Pheasant, 333.

Phoca, 354 .

Physalia, 246, 194.

Physeter, 348, 341.

Picariæ, 335 . see Whale.

Pici, 335, 320.

Pigeon, 333, 316.

Pinnigrade, 354, 128.

Pisces, 310, 48, 51, 65, 75, 102, 112, 123 , " see Fish.

$$
\text { 124, 139, 283-293. }
$$

Placenta, 196, 171.

Planaria, 264, 217.

Plant, 22.

" food of, 25.

" functions of, 24

Plantigrade, 355, 128.

Plant-louse, 297.

Plasma of blood, 98.

Plastron, 323.

Platyhelminthes, 264, 216, 217.

Platyonychus, 287, 257. see Tape-worm.

Pleurobrachia, 257, 209.

Plover, 332.

Poison-fangs, 68, 33.

Polycistina, 242, 186.

Polyp, 250. "see Actinia.

Polyzoa, 266, 220.

Pund-snail, 275, 282.

Porcupine, 346.

Porites, 252.

Porpoise, 88, 349, 54 .

Poital circulation, 307, 355, 281

Portuguese Man-of-war, 246, 194.

Potato-worm, 303.

Poulpe, 280.

Prairie Chicken, 333, 315.

Primates, 356, 35, 120, 143-145, 352-358. “" brain of, 143-145.

" skeleton of Chimpanzee, $\mathbf{1 2 0}$

" teeth of Chimpanzee, $\mathbf{3 5}$

" see Ape, Man, Monkey.

Proboscidea, 350, 36, 119, 129.

Proboscis of Butterfly, 59, 28. " of Elephant, 62, 119.

Procœlous, 383.

Prognathous, 393.

Prosobranchs, 278, 234-246.

Proteus, 318, 295.

Protista, 21.

“ blood-corpuscle of, $99,65$.

Protoplasm, 31.

Protopterus, 316, 293.

Protozoa, 238.

" number of species of, 221 .

" see Amœba, Infusoria.
Pseudopodia, 51, 15.

Pseudotriton, 318, 296.

Psittaci, 337, 320.

Pteropoda, 274, 229.

6. mouth of, 56

Pulmonates, 274, 232, 233.

Pulse, 385.

Pupil, 183, 158.

Pygopodes, 32S, 306, 307.

QUadrumana, 356.

Raccoon, 355, 346 .

Radiates, 233.

Radiolaria, 241, 186.

Rail, 332, 314.

Rana, see Frog.

Range of Auimals, 373 .

Rauk of Animals, 224 .

Raptores, 334, 116, 317-319.

Rasores, 332, $\mathbf{3 1 5}$.

Rat, 346.

Ratitæ, 327, 305 .

Rattlesuake, 68, 33.

Raven, 339.

Ray, 314, 288.

" teeth of, $67,32$.

Razor-shell, 272.

Redstart, 338, 325.

Repair, 215.

Reproduction, 191.

$\begin{array}{ll}\text { 66 } & \text { asexual, } 191 . \\ \text { 6 } & \text { by budding, } 192 . \\ \text { " } & \text { by division, } 191 . \\ \text { " } & \text { rapidity of, } 226 . \\ \text { " } & \text { sexual, 192. }\end{array}$

Reptilia, 819

6 alimentary canal of, 82 .

، brain of, $172,141$.

" circulation in, 108, 76.

“ corpuscles of, 99,65 .

" distribution of, 378.

" lungs of, 118, 84 .

"6 mouth of, 61 .

" prehension of, 61 .

" scales of, 135 .

"6 teeth of, 67 .

" voice of, 189.

" see Crocodile, Lizard, Suake, Turtle.

Respiration, 111.
"6 in Crustacea, 114.
"6 in Echinoderms, 112.
6. in Fishes, 114.
" in Insects, 114.
" in Mollusks, 113.
" rate of, 120.
" in Vertebrates, 117.
" in Worms, 113.

liete mucosum, 128. 
Retina, 183, 158.

Rhea, 327.

Rhinoceros, 351, $\mathbf{3 4 4 .}$

Rhizopoda, 240, 15, 185, 186.

6. skeleton of, 129 .

Rodentia, 345, 335, 336, 337. " teeth of, $71, \mathbf{3 3 5}$.

Rotifera, 266, 219.

" jaws of, 64.

Rudimentary Organs, 207.

Ruminantia, 351.

$$
\text { "6 stomach of, S8, } \mathbf{5 6} .
$$

Salamani)er, 318, 296.

$$
\text { "6 metamorphosis of, } \mathbf{1 7 4} .
$$

Saliva, function of, 93 .

Salivary Glands, 122.

Salmon, 316, 285.

Sand-flea, 284, 252.

Sandpiper, 332, 312.

Sarcolemma, 39, 204.

Sauropsida, 309.

Saururæ, 394.

Scales of Butterflies, 301, 272.

" of Fishes and Reptiles,135, 102,283.

Scallop, eye of, 181, 153.

" shell of, 272.

Scapnlar Arch, 146.

Scarabæus, 299.

Scarf-skin, 128.

Sclerobase, 129.

scleroderm, 129.

Sclerotic, 183.

Scolopendra, 291, 259.

Scorpion, $288, \mathbf{2 5 9}$.

$$
\text { "6 } \quad \text { respiration in, } 116 .
$$

Sea-anemone, see Polyp.

Sea-blubber, 247.

Sea-butterfly, 273, 229.

Sea-fan, 256, 208.

Sea-hare, $2 \pi 4$.

Seal, 355, 128.

Sea-lemon, 274.

\begin{tabular}{|c|c|}
\hline "6 & absorption by, 94 . \\
\hline "6 & alimentary canal of, 76,39 . \\
\hline 66 & anatomy of, $\mathbf{3 9}$. \\
\hline 66 & circulation in, 105 . \\
\hline 66 & digestion in, 92. \\
\hline "6 & growth of, 214 . \\
\hline "6 & mode of feeding, 52 . \\
\hline ، & month of, 56 . \\
\hline 66 & respiration in, 112. \\
\hline 6 & shell of, 28 . \\
\hline 66 & skeleton of, $130,96$. \\
\hline 66 & spines of, 130,97 . \\
\hline
\end{tabular}

Sea-lily, 25S, 211.

Sea-lion, 355, 350.

Sea-slug, 274.

Sea-urchin, 262, 214.
Sea-urchin, teeth of, $64,28$.

Sea-worm, 268, 17, 223.

Secretion, 121.

$$
\text { " see Gland. }
$$

Segmentation of egg, 197, 165 .

Self-division, 191, 160.

Seusation, 176.

Sense of hearing, 178.

" of sight, 180.

" of smell, 177.

" of taste, 177.

"، of touch, 176.

Sense-organs, see Sense.

Sensibility, 176. development of, 204

Sepia, 280, 248.

Serpent, see Snake.

Sertularia, 247, 192.

Serum, 98.

Setæ, 269.

Setophaga, 340, $\mathbf{3 2 5}$.

Seventeen-year locust, $297, \mathbf{2 6 6}$

Shark, 314, 287.

"، eggs of, 194, 164

"6 gills of, 114, 287

" skeleton of, 137, 145.

Shells of Crustacea, 131.

" of Echinoderms, 130.

" of Mollusks, 133.

Shoulder-girdle, 146.

Shrew, 63, 346, 338.

Shrimp, 286.

Sight, of Arthropods, 181.

"6 of Cœlenterates, 180.

"6 of Mollusks, 181.

"6 of Vertebrates, 182.

Silk-gland, 40.

Silk-worm, 303.

Simia, 358, 353, 355.

Sinuses, 138.

Siphonophora, 24S, 194

Siphuncle, 279, 247.

Siren, 318.

Sirenia, 349, 73, 343.

"6 see Dugong.

Size of Animals, 221

Skeleton, of Arthropoda, 131.

6 of Birds, 116, 144.

6 of Cœlenterates, 130

" of Echinoderms, 130.

" of Fish, 138, 144, 112.

"6 of limbs, 146.

" Lion, 139, 116.

" Mammals, 139, 106, 114, 117120.

"6 Moliusks, 133.

" Reptiles, 11\%, 115.

"6 of skull, 141, 108, 111.

"6 of Vertebrates, 134

"6 of Whale, 114

" see Exoskeleton. 
Skin of Invertebrates, 127.

" of Vertebrates, 128.

Skull, 141.

Slater, 2S4, 251.

Slug, 274, 232.

Smell, 177.

Suail, 272.

" alimentary canal of, S0, 45.

" anatomy of, $\mathbf{4 5}$.

" circulation in, 106, 45.

" eye of, 181, 154.

"6 gills of, 113.

"6 gizzard of, 64.

" heart of, 45.

" jaw of, $56,20$.

"6 larva of, 176.

"locomotion of, 161.

" lnng of, $116,274,45$.

" mode of feeding, 52 .

"6 mouth of, 56.

" nervous system of, $168, \mathbf{1 3 4}, \mathbf{1 5 4}$

66 operculum of, 114, 134, 228.

" respiration in, $116, \mathbf{4 5}, 228$.

“ shell of, 133, 100, 228, 233-246.

، siphon of, 228 .

" smell of, 178.

"6 teeth of, $65, \mathbf{2 9}$.

" tentacles of, $176, \mathbf{1 5 4}, \mathbf{2 2 8}$

" see Gasteropoda.

Silake, 320, 298, 299.

.6 deglutition of, 73 .

" locomotion of, 162.

" lungs of, $119,84$.

" poison apparatus of, 6S, 33

" scales of, 135.

"6 skull of, 37.

" stomach of, 82.

" tongue of, 61.

"6 Vertebræ of, 140.

". voice of, 189 .

“ see Boa, Ophidia, Reptilia.

Snapping-bug, 299.

Snipe, 332.

Solaster, 260.

Somite, 392.

Songsters, 338.

Sorex, 346, 338.

Sow-bug, 285.

Sparrow, 339.

Species, defined, 235.

"6 number of, 221.

sperm-whale, see Whale.

sphinx-moth, 303, 43.

Spider, classification of, $289, \mathbf{2 6 0}$.

“ alimentary canal of, 79 .

“ appendages of, $\mathbf{2 5}$.

" circulation in, 106.

"6 fangs of, $53,18,25$.

"6 mouth of, 60, 25.

"6 respiration in, 116.

“ spinnerets of, $289, \mathbf{2 5}, \mathbf{2 6 1}$.
Spider, web of, $259,260$.

Spinal column, 140.

"6 cord, 175.

Spinneret of Spider, 289, 261.

"6 of Caterpillar, 301, 276.

Spiracle, 114, 79.

Spongida, 244, 189, 190.

“6 alimentary canal of, 76.

"6 anatomy of, 189

"6 egg of, 194, 163.

“ feeding of, 50, 189.

“ respiration in, 112.

"6 skeleton of, 129,190 .

Squash-bug, 297.

Squid, 2 s0.

" locomotion of, 158.

" see Cuttlefish.

Squirrel, 346.

Stag, 352, 345.

Star-fish, alimentary canal of, 76, 126.

" auatomy of, 126.

" circulation in, 105,126

" classification of, 258.

“ development of, 208.

" digestion in, 92 .

" locomotion of, 161,126

" metamorphosis of, 207.

، $\quad$ mode of feeding of, 51 .

" month of, 56 .

“6 nervous system of, $168, \mathbf{1 3 3}$.

" respiration in, 112.

" see Echinodermata.

Stilt, 332.

Stomach, 82-89.

Stork, 532.

"6 digestion in, 93 .

Stridulation, 188.

Strombus, 278, 243.

Struggle for Life, 226.

Struthio, 327, 305.

Sturgeon, 315, 290.

Subkingdom, 233.

Sun-fish, 247.

Suln-star, 260.

Survival of Fittest, 226.

Sutnre, 147.

Swallow, 340, 328.

Swan, 331.

Swift, 335.

Swimmeret, 282.

Symmetry, 222.

Sympathetic nervous system, 175, 146.

Syuovia, 147.

Thenia, see Tape-worm.

Tanager, 339.

Tapetum, 184.

Tape-wol'm, 264, 216.

Tapir, 63, 351

feeding of, 49 .

Taste, 177. 
Teeth, of Amphibia, 67.

“ of Fishes, $61,66,67$.

“ of Invertebrates, 63.

" of Mammals, 68, 70 .

- of Reptiles, 67.

" structure of, $3 S, 66,9,31$.

Teleostei, 315, 284, 290-292.

'I'elson, 282.

Temperature of Animals, 121.

Tendon, 36.

Tentacie, 51

Tent-caterpillar, 303.

Termies, 295.

'Terebra, 278, 238.

Terebratula, 267, 222.

Terebratulina, 267, 221.

Termite, 295.

T'eru, 329, 308.

Testudo, see Turtle.

Tetrabranchs, 279, 247.

Tetradecapods, 285, 251, 252.

Thoracic duct, 95, 61.

Thorax, 119, 88.

Thornback, 315, 288.

Thousand-legged Worm, see Julus.

Thrush, 340 .

Thylacinus, 343.

Thyroid Cartilage, 189, 150.

Ticks, 288.

'Tissue, 33.

Toad, 318.

'T'ongue, of Batrachians, 61 .

" of Birds, 62 .

" of Fishes, 61 .

" of Iusects, 50,58 .

" of Mammals, 63 .

"6 of Mollusks, 52.

" of Spiders, 60 .

Top-shell, 278, 242.

Tortuise, 323, $\mathbf{3 0 2}$.

$$
\text { " see Turtle. }
$$

Totipalmates, $330, \mathbf{3 0 9}$.

Toucan, 335 .

Touch, 176.

Trachea, 119.

Tracheæ, 114, 40, 79, 80, 81 .

Trichina, 265, 218.

Tridacne, 272.

Trilobite, 284.

Trionyx, 322.

Triton, 318, 296.

Tritonian, 274, 230.

Trochosphere, 211, 175.

Trochus, 278.

$$
\text { " embryo of, 211, } 176 .
$$

Trogon, 335, 321.

Tubipora, 252, 200.

Tunicata, 305, 278, 279.

$$
\text { " see Ascidians. }
$$

'Turbn, 278, 242.

T'urkey, 333 .

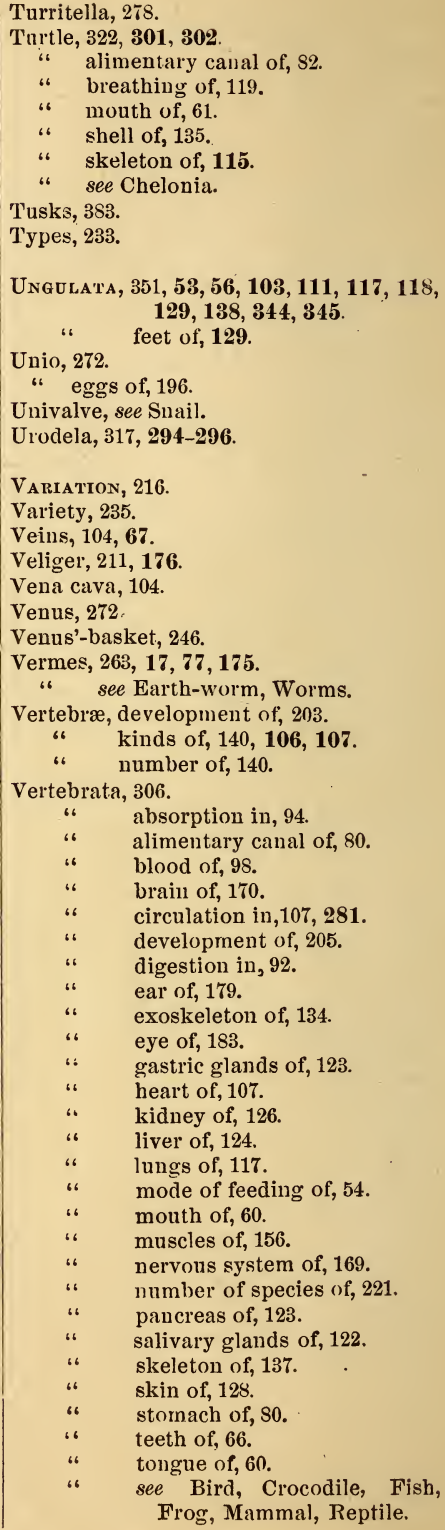


INDEX.

Villi, 90, 58.

Vinegar-eel, 265.

Vireo, 340, 326.

Vitelline Membraıe, 193.

Viviparous, 309.

Vocal Cords, 189.

Voice, of Invertebrates, 188. " of Vertebrates, 189.

Volute, 278, 241.

Vorticella, 243, 160.

Vulture, 335, 116.

WALKING-STICK, 297.

Walrus, 355, 383.

Warbler, 340.

Wasp, 304.

Water-boatman, 297, 265.

Water-fleas, 284, 255.

Wax-wing, 340.

Weasel, 355, 348 .

Weevil, 300.

Whale, 348, 341, 342.

" baleen of, $65, \mathbf{3 0}$.

"6 brain of, 170.

"6 fat of, 39 .

“ mode of feeding of, 50.

" mouth of, 62.

"s swimming of, 159.

" teeth of, 383 .

Whelk, 278, 228.

" see Snail.

White Ant, 295.
Windpipe, 119, 86.

Wings, of Bats, 161, 339, $\mathbf{3 4 0}$.

"6 of Birds, $160, \mathbf{3 0 4}$.

" of Insects, 159, 266.

Wolf, 355, 347.

Wombat, 343.

Woodpecker, 335, $\mathbf{8 2 0}$.

Worms, 263.

" absorption in, 94 .

6 alimentary canai of, $7 \boldsymbol{\tau}$.

"6 blood of, 98 .

"، eye of, 17.

"6 head of, 17.

"6 jaws of, 17.

"، larva of, $\mathbf{1 7 5}$

" locomotion of, 161 .

" mouth of, 57.

" number of species of, 221.

" proboscis of, 17.

"6 reproduction in, 192.

"6 respiration of, $113, \mathbf{7 7}$.

" skin of, 127.

" see Earth-worm.

Wren, 340.

YoLK, 192.

Zoorogicat analysis, 236.

"6 barriers, 375 .

66 history, 18

"6 provinces, 376.

Zoology, 19. 








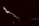




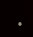


